\title{
EL CENTRO HISTÓRICO COMO PAISAJE URBANO HISTÓRICO
}

\section{EL DESAFÍO DE}

INTERVENIR

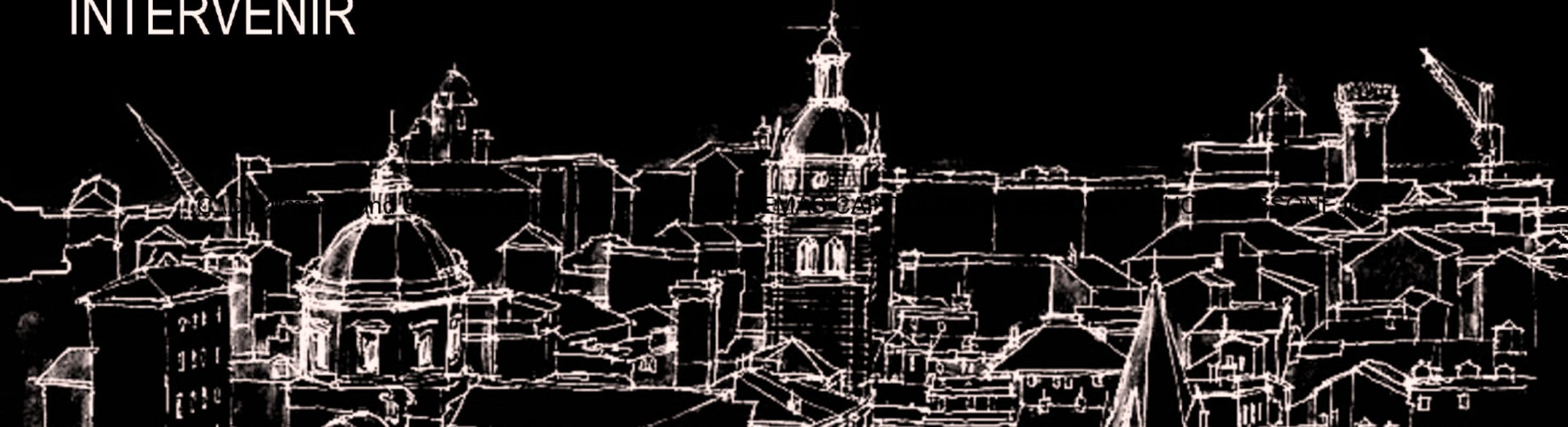




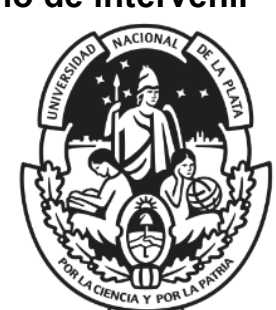

UNIVERSIDAD NACIONAL DE LA PLATA

FACULTAD DE ARQUITECTURA Y URBANISMO DOCTORADO EN ARQUITECTURA Y URBANISMO

EL CENTRO HISTÓRICO COMO PAISAJE URBANO HISTÓRICO:

El desafío de intervenir

Tesis Doctoral presentada por MG. ARQ. ALEJANDRA GONZÁLEZ BIFFIS

ante la Facultad de Arquitectura y Urbanismo de la Universidad Nacional de La Plata

Para acceder al grado académico de: DOCTOR EN ARQUITECTURA Y URBANISMO

Dirección de tesis: Director: Dr. Arq. Juan Carlos Etulain Co-director: Arq. Isabel López 


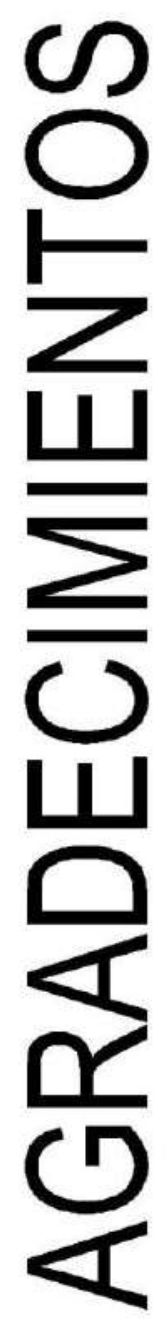

A Juan (Juan Carlos Etulain), por brindarme su acompañamiento y seguimiento constante, por su paciencia con mis tiempos y por su compromiso incesante en todo horario, tanto en dias hábiles, fines de semana como vacaciones. Un placer haberte tenido como director...

A Isa (Isabel López), por abrirme las puertas del CIUT y haberme invitado a ser parte de su equipo, por sus valiosos aportes a esta tesis, y, por su calidez y su interés continuo en lo académico y personal...

A mis compañeros del CIUT y de la Cátedra de Planificación Territorial López-Rocca-Etulain, en especial a mis amigos: Cris (por su complicidad y "madrinazgo" permanente...), Vic y Braian, por su compañerismo y por haberme hecho el aguante en este último tiempo de caos generalizado...hermoso grupo humano!; Lau y Cyn, por la buena energía transmitida en cada charla, por esos buenos momentos que han traspasado lo académico...

A mis amores, mi familia. Mamá, Papá y Juli, por su amor incondicional y por el apoyo constante que me permite seguir desarrollándome en el ámbito académico. Gabi, por caminar juntos desde hace 18 años, por el amor y soporte de cada dia, las incontables lecturas y charlas sobre este trabajo, y por quienes llenan de alegria nuestros dias, Rafi y Joaqui que llegaron en el proceso de esta tesis...

A todos, GRACIAS. 
Introducción

Problema de investigación

Objetivos de la tesis

Interrogantes

ipótesis

Estrategia metodológica y estructura de la tesis

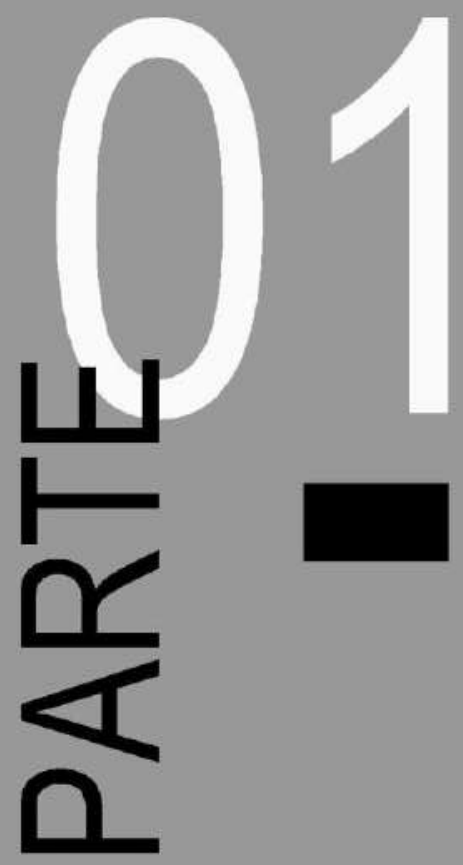

1 Centro Histórico: concepto y componentes

1.1 Introducción. Estructura del marco teórico-conceptual

1.2 Origen y evolución del concepto "Centro Histórico"

1.2.1 El "Paisaje Urbano Histórico"

1.3 El centro histórico como sistema en proceso continuo de transformación

1.4 Componentes claves para un centro histórico vivo

1.4.1 Patrimonio cultural, material e inmaterial

1.4.1.1 Los limites de la intervención: las zonas de amortiguamiento 1.4.2 Espacio público

1.4.3 Multifuncionalidad

1.4.3.1 Residencialidad

1.4.4 Identidad y participación ciudadana

2.2 Cambios de enfoques en las estrategias de intervención y gestión Implementadas

2.3. Los desafios de la intervención y gestión: el desarrollo sostenible y el urbanismo sos tenible 63 2.3.1. Origen y dimensiones del desarrollo sostenible

231.1 Sostenibilidad ficico-ambiental: vaciamiento físico-funcional y articulación nuevo-antiguo

2.3.1.2 Sostenibilidad socio-cultural: Gentrificación

2.3.1.3 Sostenibilidad económica: turismo y comercio callejero

2.3.1.4 Sostenibilidad institucional: gestión 
3.1 Introducción.

3.2 Intervenciones que operan en Centros Históricos

3.2.1. Enfoques en el contexto europeo

3.2.1.1 Intervención y gestión en Italia

3.2.1.2 Intervención y gestión en España

3.2.2. Enfoques en el contexto latinoamericano

3.3 Experiencias de intervención y gestión identificadas y seleccionadas

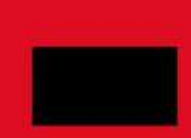

4 Análisis de experiencias

4.1 Introducción. Caracterización y análisis de experiencias seleccionadas

4.2 Una mirada global de las experiencias

4.2.1 Problemáticas e intervenciones

4.2.2 Estrategias e instrumentos de intervención y gestión: casos paradigmáticos / nuevos enfoques

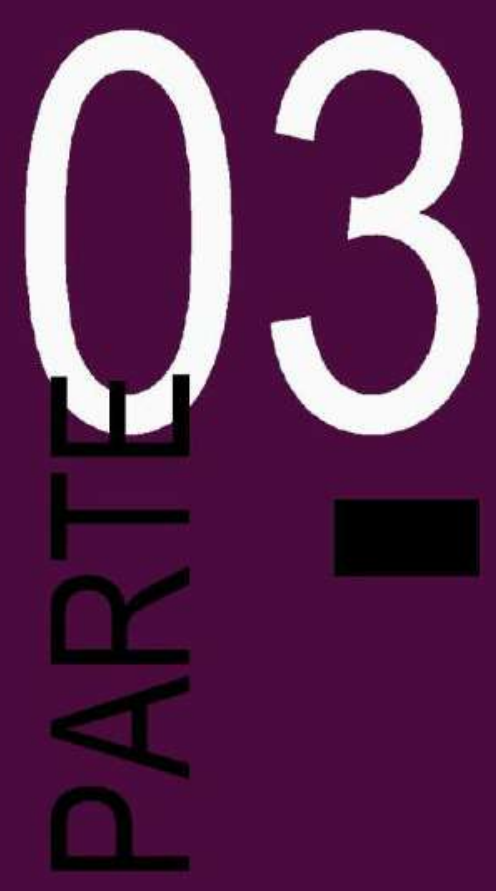

5 Propuesta metodológica para la Valoración, Intervención y Gestión de Paisajes Urbanos Históricos

5.1 Introducción

5.2 Proceso Metodológico Propuesto

5.2.1 Objetivos

5.2.2 Propuesta de Valoración

6 Conclusiones generales: Cierre y apertura

6.1 Sobre los cambios teórico conceptuales del Centro Histórico y los enfoques y desafíos de la intervención y gestión 
A.1. Fichas síntesis de los 40 casos analizados

A.2. Cuadros Sintesis de similitudes y diferencias de los $\mathrm{CH}$ y de las intervenciones 254

A.3. Gráficos de análisis cuantitativo de los 40 casos

\section{Bibliografia}

B.1. Centro histórico: concepto y componentes

B.2. Intervención y gestión de los centros históricos: enfoques y desafíos

B.3. Experiencias de intervención y gestión en $\mathrm{CH}$

B.5. Propuesta metodológica para la valoración, intervención y gestión

B.6. Cierre y apertura

B.7. Enfoque metodológico

\section{ACRÓNIMOS Y SIGLAS}

AECID - Agencia Española de Cooperación Internacional para el Desarrollo

AL - América Latina

BID - Banco Interamericano de Desarrollo

CEPAL - Centro de estudios para América Latina y el Caribe

$\mathrm{CH}$ - Centro/s Histórico/s

PAE - Paisaje de Atención Especial

PEDI - Plan Especial de Desarrollo Integral de La Habana Vieja, Cuba

PEEP - Piano de Edilizia, Economia Popolare, Bologna, Italia

PNUD - Programa de las Naciones unidas para el Desarrollo

PUH - Paisaje/s Urbano/s Histórico/s

UNESCO - Organización de las Naciones Unidas para la Educación, la Ciencia y la Cultura 
La tesis que a continuación se presenta, se centra en colaborar en posibles intervenciones para Centros Históricos (de aquí en adelante $\mathrm{CH}$ ) como Paisajes Urbanos Históricos (PUH) latinoamericanos, enmarcada en el enfoque del urbanismo sostenible. Para ello, se pretende analizar los diversos enfoques del $\mathrm{CH}$ y las estrategias de intervención y gestión aplicadas en $\mathrm{CH}$ de ciudades grandes e intermedias de América Latina (AL), Italia y España en el periodo 1970-2015, e identificar estrategias e instrumentos innovadores de intervención y gestión, factibles de ser aplicados en futuras intervenciones en PUH latinoamericanos como parte de una propuesta metodológica para la valoración, intervención y gestión de PUH latinoamericanos.

Las transformaciones sociales y urbanas, las nuevas demandas funcionales y físicas originadas por el crecimiento demográfico, la expansión de las ciudades producidas por la revolución industrial y las destrucciones provocadas en Europa durante la Primera y Segunda Guerra Mundial, han conllevado a plantear una serie de intervenciones en los $\mathrm{CH}$ de las ciudades. Estas intervenciones han tenido una época de auge en las décadas del 70 y 80 , y se han extendido (con diferentes modalidades de intervención) hasta la actualidad. Pese al vasto desarrollo de intervenciones en el periodo de estudio, en contadas ocasiones logran dar respuesta a las problemáticas que las motivaron o a abordar de un modo integral la complejidad del $\mathrm{CH}$, llegando en algunos casos a transformar las dinámicas del área. Por otra parte, existen actuaciones novedosas tanto desde la intervención como desde la gestión, que han procurado aportar al desarrollo sostenible de los $\mathrm{CH}$, que requieren de una profundización para reconocer si esas operaciones pueden proporcionar estrategias e instrumentos que puedan formar parte de una propuesta de valoración, intervención y gestión para los PUH latinoamericanos.

\section{RESUMEN}


Esta investigación explicativa de tipo cualitativa y cuantitativa, para la elaboración de la propuesta, se fundamenta en el reconocimiento de los distintos enfoques que los $\mathrm{CH}$ han atravesado a lo largo del tiempo, y que han llevado a pensarlos en la actualidad desde la mirada del Paisaje como PUH; y en la identificación de propuestas de intervención y gestión en los paises de estudio. De ellas, se han seleccionado aquellas consideradas interesantes para profundizar, porque han incorporado una perspectiva innovadora en sus procesos de intervención y/o gestión o porque han evidenciado con el tiempo aciertos o desaciertos sobresalientes en la implementación de sus estrategias. Estos casos, analizados desde sus instrumentos de planificación como información primaria y desde fuentes secundarias, han sido sistematizados a partir de la elaboración de fichas sintesis, que han abordado una serie de variables que han permitido determinar cuáles han sido los cambios manifestados en las estrategias de intervención en las últimas décadas, sintetizar su información en relación a las dimensiones físico-ambiental, socio-cultural, económica e institucional (gestión), y reconocer casos paradigmáticos que fueron representativos de las distintos periodos por los que han atravesado los $\mathrm{CH}$. Entendemos como paradigmáticos a aquellas intervenciones que llevadas a cabo en el marco de Planes de Sector, han sido puntos de inflexión, configurando modelos, ejemplos a seguir dado que han planteado nuevas miradas para afrontar la complejidad de los $\mathrm{CH}$, poniendo sobre la mesa nuevos enfoques sobre temáticas recurrentes o presentando propuestas a problemas que permanecian al margen de los análisis urbanos.

Este estudio, además de su valor explicativo, intenta proveer una herramienta que pueda ser relevante para profesionales que deban intervenir sobre el patrimonio material e inmaterial de los PUH latinoamericanos. 
The thesis that is presented below focuses on collaborating on possible interventions for Historic Centers (hereinafter $\mathrm{CH}$ ) as Latin American Historic Urban Landscapes (PUH), framed within the sustainable urbanism approach. For this purpose, it is intended to analyze the different approaches of the $\mathrm{CH}$ and the strategies of intervention and management applied in $\mathrm{CH}$ of large and intermediate cities of Latin America (AL), Italy and Spain in the period 1970-2015, and identify strategies and innovative instruments of intervention and management, feasible to be applied in future interventions in Latin American PUH as part of a methodological proposal for the valuation, intervention and management of Latin American PUH.

The social and urban transformations, the new functional and physical demands originated by the demographic growth, the expansion of the cities produced by the industrial revolution and the destructions caused in Europe during the First and Second World War, have led to a series of interventions. in the $\mathrm{CH}$ of the cities. These interventions have had a boom in the 70 s and 80 s, and have been extended (with different intervention modalities) to the present. Despite the vast development of interventions in the study period, they rarely manage to respond to the problems that motivated them or to comprehensively address the complexity of $\mathrm{CH}$, reaching in some cases to transform the dynamics of the area. On the other hand, there are innovative actions both from the intervention and from the management, which have sought to contribute to the sustainable development of the $\mathrm{CHs}$, which require a deepening to recognize if those operations can provide strategies and instruments that can be part of a proposal for valuation, intervention and management for Latin American PUH.

This explanatory research of qualitative and quantitative type, for the elaboration of the proposal, is based on the recognition of the different approaches that the $\mathrm{CH}$ have crossed over time, and that have led them to think about them nowadays from the perspective of the Landscape as PUH; and in the identification of intervention and management proposals in the ABSTRACT countries of study. Of these, we have selected those considered interesting to deepen, because they have incorporated an innovative perspective in their intervention and / or management processes or because they have shown over time outstanding successes or failures in the implementation of their strategies. 
These cases, analyzed from their planning instruments as primary information and from secondary sources, have been systematized based on the preparation of summary cards, which have addressed a series of variables that have allowed determining the changes manifested in the strategies of intervention in recent decades, synthesize their information in relation to the physical-environmental, socio-cultural, economic and institutional (management), and recognize paradigmatic cases that were representative of the different periods through which the $\mathrm{CH}$ have gone through. We understand as paradigmatic those interventions carried out in the framework of a Sector Plans, have been turning points, setting up models, examples to follow given that they have proposed new approaches to face the complexity of the $\mathrm{CH}$, putting on the table new approaches on recurring themes or presenting proposals to problems that remained outside of urban analyzes.

This study, in addition to its explanatory value, tries to provide a tool that may be relevant for professionals who must intervene in the material and immaterial heritage of the Latin American PUH. 
INTRODUCCIÓN 


\section{Introducción}

La tesis que se expone en este documento, se enmarca en la línea de investigación vinculada con la Planificación Urbana y Territorial llevada adelante en la Facultad de Arquitectura y Urbanismo (FAU) de la Universidad Nacional de La Plata (UNLP). En este contexto, el trabajo tiene como lugar de desarrollo al Centro de Investigaciones Urbanas y Territoriales (CIUT), cuya directora es la Arquitecta Isabel López, en el que he participado como becaria de investigación desde el año 2011, con becas de investigación otorgadas inicialmente por la UNLP y en la actualidad por el CONICET. A su vez, este estudio se vincula con la línea de investigación del Director en CONICET, asociada fundamentalmente al "Proyecto Urbano como Instrumento de Intervención. Su aplicación en territorios vulnerables“. Además, se relaciona con la actividad docente que desarrollo en la materia Planificación Territorial I, de la cátedra López-Rocca-Etulain, en la misma institución, y a la Maestría en Conservación, restauración e intervención del Patrimonio Arquitectónico y Urbano (CRIP) que he llevado adelante en la misma unidad académica.

En este sentido, el tema de la tesis, la intervención en $\mathrm{CH}$, logra vincular dos de mis grandes intereses, por un lado, el patrimonio, y por el otro, la planificación urbana.

\section{Problema de investigación}

La indagación en esta temática, ha permitido reconocer la problemática y el enorme desafío que representa intervenir los $\mathrm{CH}$ de las ciudades. Entre las principales fundamentaciones que expresan la necesidad de desarrollar este tipo de investigaciones, se encuentra el reconocimiento de que a pesar de la gran cantidad de intervenciones que se han llevado a cabo y que se encuentran en desarrollo en las últimas décadas en los $\mathrm{CH}$, muy pocas de ellas logran dar solución a las necesidades que las impulsan, y menos aún abordarlas desde una mirada integral. La mayor parte de ellas se centran en intervenciones fragmentarias que se enfocan principalmente en la resolución de problemas puntuales, generalmente físicos, dejando de lado aspectos vinculados a lo social, cultural, ambiental, económico e institucional, que inevitablemente constituyen parte de un todo, de un sistema complejo que garantiza el funcionamiento de estos sectores de gran valor histórico. Por lo tanto, algunas de ellas no han logrado dar solución a las necesidades que las motivaron y/o han generado cambios en estas áreas, que han profundizado aún más las problemáticas existentes en las ciudades que los contienen. Otras intervenciones, por el contrario, han planteado propuestas originales $\mathrm{o}$ han buscado alternativas intentado contribuir al Desarrollo Sostenible de los $\mathrm{CH}$, (enfoque muy reciente y poco abordado desde la planificación en $\mathrm{CH}$ ) brindando a su vez 
actuaciones interesantes desde la gestión, que invitan a una indagación para reconocer si las mismas facilitan estrategias e instrumentos que puedan formar parte de una propuesta metodológica para la valoración, intervención y gestión de los PUH latinoamericanos.

Frente a esta situación, la incorporación del paisaje en la mirada de los $\mathrm{CH}$ por medio del nuevo concepto de $\mathrm{PUH}$, abre la posibilidad de acercarnos al problema con una visión más integral. No obstante, la cercanía temporal en la definición del concepto, explica la reciente implementación en algunas ciudades europeas y el inicio de su consideración en ciudades de $\mathrm{AL}$, resultando de este modo, una temática interesante, relativamente nueva y poco profundizada.

Al mismo tiempo, existe una necesidad de identificar y analizar cuáles han sido los cambios teórico-conceptuales experimentados en los modos de interpretar los $\mathrm{CH}$, y que han influido en el diseño de estas estrategias de intervención y gestión aplicadas en $\mathrm{CH}$ de ciudades grandes e intermedias de AL, Italia y España en el periodo 1970-2015. En una época de grandes cambios, es importante el análisis de diversas propuestas de intervención que permitan identificar aportes para hacer frente a los nuevos retos que plantean los $\mathrm{CH}$ latinoamericanos.
El recorte de los casos a ciudades de Italia, España y $A L$, se fundamenta en la gran cercanía que los países latinoamericanos han mantenido históricamente con estos países europeos. Los lazos con España comenzaron con el descubrimiento de América, y se potenciaron a lo largo del tiempo con las colonizaciones, y siglos más tarde, con las importantes oleadas migratorias que los países latinoamericanos han recibido de este país, así como ha sucedido también con los inmigrantes italianos debido a las Guerras Mundiales. Esto se verifica en que países como Argentina poseen la segunda comunidad más numerosa de españoles, y lo mismo sucede con la comunidad italiana, por lo que estos territorios comparten muchos aspectos y elementos culturales como la lengua, la religión y diversas costumbres y tradiciones, hechos que hacen que la población sea tan similar y se sienta tan identificada. Indudablemente, estas cuestiones se ven reflejadas en el desarrollo de las ciudades, donde pueden reconocerse muchas características y problemáticas comunes. Al mismo tiempo, Italia ha sido uno de los países con mayor trayectoria en cuanto a la restauración e intervención de áreas y obras históricas, constituyendo un referente indiscutido en la temática. Los vínculos mencionados previamente, son la causa por la que varias fuentes de financiamiento para el desarrollo de intervenciones urbanas en $A L$ provienen de instituciones públicas europeas, como el Programa de Naciones Unidas para el desarrollo (PNUD), la Agencia Española de Cooperación Internacional (AECID), y la Junta de Andalucía, entre 
otras fuentes que colaboran con instituciones internacionales de financiamiento como el Banco Interamericano de Desarrollo (BID).

Dado el impacto social, económico, político, histórico y cultural que tienen los $\mathrm{CH}$ para las comunidades, este trabajo inicia un camino tendiente a mostrar diversas estrategias de intervención y gestión llevadas a cabo en ciudades europeas y latinoamericanas, con el propósito de reconocer aquellas experiencias que logren brindar respuestas a necesidades reconocidas en las dimensiones físicoambiental, socio-cultural, económica e institucional de los $\mathrm{CH}$ y que puedan formar parte de una propuesta integral para $\mathrm{PUH}$, adaptable a la escala y particularidades de cada caso, enmarcada en el enfoque del urbanismo sostenible, en pos de conseguir que las futuras intervenciones conserven, renueven y potencien estos espacios claves de las ciudades.

Los estudios realizados sobre las estrategias aplicadas en los $\mathrm{CH}$ son numerosos, pero generalmente han sido elaborados por profesionales o arquitectos involucrados en la actuación, resultando a la vez análisis tendenciosos. El siguiente trabajo, cuya importancia radica en la posibilidad de colaborar en futuras intervenciones en PUH de $\mathrm{AL}$, plantea a su vez la transferencia de conocimientos a diversos profesionales involucrados en la intervención de los mismos, e intenta esbozar un enfoque integral, porque analiza transversalmente todas las variables consideradas relevantes al analizar las estrategias de valoración, intervención y gestión. Primariamente, este trabajo esta basado en el reconocimiento de los cambios en las distintas perspectivas por los que los $\mathrm{CH}$ han transitado, y en la identificación a través de los casos reconocidos a nivel internacional, de las transformaciones sufridas en las estrategias de intervención y gestión. Las más recientes, surgen como consecuencia de un cambio de enfoque en cuando al abordaje de la ciudad, el urbanismo sostenible que a través del desarrollo sostenible, propone una nueva manera de afrontar las intervenciones en los $\mathrm{CH}$.

No obstante el vasto desarrollo bibliográfico asociado a la temática de estudio, existe aún un vacío en la elaboración y aplicación de metodologías para valorar, intervenir y gestionar los $\mathrm{PUH}$ latinoamericanos, y en la identificación de los cambios sufridos en la conceptualización y diseño de estrategias de intervención aplicadas en $\mathrm{CH}$ en el periodo 1970-2015. También, como se demostrará en el Estado de la Cuestión, se encuentra una ausencia en lo que respecta a detectar cómo las intervenciones llevadas a cabo en ciudades grandes e intermedias de Italia y España han influido y transformado los modos de intervenir en ciudades de $A L$ de similar escala y en el mismo periodo de estudio, o a la inversa. A su vez, no se ha encontrado un análisis que demuestre cómo esos cambios se han manifestado a través de casos paradigmáticos, o que identifique propuestas innovadoras asociadas a dimensiones 


\section{EL CENTRO HISTÓRICO COMO PAISAJE URBANO HISTÓRICO - EI desafío de intervenir}

físico-ambiental, socio-cultural, económica e institucional que puedan ser factibles de aplicar en PUH latinoamericanos con el objetivo de mejorar la calidad de vida en el presente y a futuro, de la enorme población que reside, trabaja y transita en los $\mathrm{CH}$.

El análisis del material bibliográfico recopilado ha dado cuenta del gran desafío que genera intervenir en sectores tan valiosos de las ciudades. La confrontación de los distintos aspectos integrantes de las numerosas intervenciones que se vienen desarrollando en los $\mathrm{CH}$ en las últimas décadas, permite reconocer los diferentes medios existentes para recuperar el valor que concentran estos espacios clave para toda la sociedad. Enfatizándose en que se puede intervenir y adaptar la ciudad a las necesidades de la vida contemporánea sin dejar por ello de lado de trabajar sobre la identidad, y el sentido de pertenencia de sus habitantes. Ya que son ellos quienes le dan sentido a los $\mathrm{CH}$, y hacen que estos sitios continúen siendo centros vivos.

Por los motivos que se acaban de señalar, subsanar el déficit de información y formación sobre los modos para valorar, intervenir y gestionar PUH permitirá colaborar con los gobiernos locales interesados de llevar a cabo este tipo de intervenciones urbanas en $\mathrm{CH}$ de AL.

\section{Objetivos de la tesis}

Objetivo general

Colaborar en posibles intervenciones para los Centros Históricos $(\mathrm{CH})$ latinoamericanos como Paisajes Urbanos Históricos (PUH), en el marco del enfoque del urbanismo sostenible.

\section{Objetivos específicos:}

- Identificar y analizar cuáles han sido los cambios teóricoconceptuales experimentados en los modos de interpretar los $\mathrm{CH}$, que han influido en el diseño de estrategias de intervención y gestión aplicadas en $\mathrm{CH}$.

- Indagar propuestas de intervención y gestión llevadas a cabo en ciudades grandes e intermedias de AL, Italia y España en el periodo 1970-2015. con el propósito de reconocer aquellas experiencias que logren brindar respuestas a las necesidades reconocidas en los $\mathrm{CH}$.

- Construir una propuesta metodológica, como instrumento para la valoración, intervención y gestión de Centros Históricos $(\mathrm{CH})$ latinoamericanos como Paisajes Urbanos Históricos (PUH), enmarcada en el enfoque del Urbanismo Sostenible. 
De lo expuesto previamente surgen algunos interrogantes que la presente Tesis intentará responder a partir del estudio de estrategias de intervención y gestión aplicadas en $\mathrm{CH}$ :

\section{Interrogantes}

\section{Preguntas generales}

¿Qué aporta el paisaje en la mirada de los $\mathrm{CH}$ ?, ¿cómo se puede colaborar en futuras intervencione s para PUH latinoamericanos enmarcadas en el enfoque del urbanismo sostenible?

\section{Preguntas específicas}

- ¿Cuáles han sido los cambios teórico-conceptuales experimentados en los modos de interpretar los $\mathrm{CH}$ ?, ¿han influido en el diseño de estrategias de intervención y gestión aplicadas en $\mathrm{CH}$ ?

- ¿Existen experiencias en ciudades grandes e intermedias de AL, Italia y España en el periodo 19702015 que logren brindar respuestas a necesidades reconocidas en los $\mathrm{CH}$ ?, ¿es factible reconocerlas mediante el estudio de casos?, ¿pueden formar parte de una propuesta integral para $\mathrm{PUH}$ ?
- ¿Es posible construir una propuesta metodológica que pueda constituir un instrumento para futuras intervenciones?, ¿qué aspectos debería incorporar para responder a las demandas actuales?

\section{Hipótesis}

\section{Hipótesis central}

La nueva mirada a los $\mathrm{CH}$ latinoamericanos como PUH permite colaborar en posibles intervenciones enmarcadas en el enfoque del urbanismo sostenible.

\section{Hipótesis secundarias:}

- Los cambios teórico-conceptuales experimentados en los modos de interpretar los $\mathrm{CH}$, han influido en el diseño de estrategias de intervención y gestión aplicadas en $\mathrm{CH}$.

- Existen propuestas de intervención y gestión llevadas a cabo en ciudades grandes e intermedias de AL, Italia y España en el periodo 1970-2015, que logran brindar respuestas a necesidades reconocidas en los $\mathrm{CH}$.

- La construcción de una propuesta metodológica, puede aportar un instrumento para la valoración, intervención y 
gestión de Centros Históricos $(\mathrm{CH})$ latinoamericanos como Paisajes Urbanos Históricos (PUH), enmarcada en el enfoque del urbanismo sostenible.

\section{Estrategia metodológica y estructura de la tesis}

El desarrollo de la tesis Doctoral se presenta en el marco de un proceso continuo de formación que ha constituido el Plan de Doctorado. La metodología propuesta para dicho Plan se ha basado en el desarrollo de una investigación de tipo explicativa, cualitativa y cuantitativa, articulada en tres sucesivas fases y fundamentada en la colaboración en posibles intervenciones en PUH de AL, basada en el conocimiento del marco teóricoconceptual, la identificación de casos y referentes de países europeos como Italia y España, y de países de $A L$, y la construcción de una metodología para la valoración, intervención y gestión. Seguidamente se detallan las actividades correspondientes a cada fase:

- Fase I (Sincrética o Ideatoria): de conceptualización, encuadre del tema. Se presenta en primera instancia el problema (preguntas), las hipótesis y los objetivos en la introducción. A continuación, se expone la construcción del estado de la cuestión en el tema, y la elaboración del marco teórico-conceptual, confeccionado en base a una revisión y sistematización bibliográfica que ha ido verificando y ajustando los resultados obtenidos a lo largo del proceso. Para ello, se reconocen los trabajos y referentes centrales en el campo temático, se profundiza en los conceptos fundamentales que definen el problema, como los conceptos "Centro Histórico" y "Paisaje Urbano Histórico", y se ahonda en los componentes claves para mantener su vitalidad. A su vez, se estudian los cambios de enfoques en las estrategias de intervención y gestión implementadas en $\mathrm{CH}$, y los nuevos desafíos para la intervención, basados en el Desarrollo Sostenible. Esta fase, se desarrolla en los Capítulos I y II.

- Fase II (Analítica): las hipótesis secundarias hacen de fuelle entre esta fase y la anterior, dando pie a una etapa de producción de datos, y diseño de la investigación. En esta segunda instancia, la recopilación bibliográfica realizada, fuentes primarias y secundarias, permite la identificación de experiencias de intervención y gestión en AL, España e Italia en el periodo de estudio, de las cuales se seleccionan aquellas que resultan interesantes para profundizar mediante la confección de fichas síntesis, y de las que además es posible poseer acceso a información. Las fichas, 


\section{EL CENTRO HISTÓRICO COMO PAISAJE URBANO HISTÓRICO - El desafío de intervenir}

permiten volcar de forma sistémica la información más relevante de las intervenciones seleccionadas a nivel nacional e internacional. Para tal fin, se determinan una serie de características relativas al $\mathrm{CH}$ (extensión, características del entorno -área metropolitana, urbana, rural-, especialización funcional -industrial, turístico, agrícola-, dinámica general y urbanística, declaratorias y problemáticas), y características relativas a la intervención (tipo de intervención, objetivos, instrumento de planificación, principales ejes del Plan, Instrumento de gestión, principal aporte de los instrumentos, instancia de implementación). El análisis de las fichas permite determinar los cambios manifestados en las estrategias de intervención y gestión en las últimas décadas, identificar problemas críticos, diferencias y similitudes entre ellas, reconocer casos paradigmáticos (puntos de inflexión en el modo de intervenir los $\mathrm{CH}$, y referentes para posteriores actuaciones), y dilucidar si existen experiencias posibles de replicar. La elaboración de esta información primaria, ha sido resultado no sólo del análisis de material bibliográfico sino producto a su vez, de una estadía en el Centro de Investigación DICEA de la Facultad de Arquitectura, de la Universidad Federico II de Nápoles, y de viajes de estudio por ciudades de Italia, España y $\mathrm{AL}$, que han permitido conocer de cerca las complejas realidades de los $\mathrm{CH}$. Esta fase, se desarrolla en los Capítulos III y IV.

- Fase III (Sintética u Operativa): se elabora la síntesis de la investigación, realizando el tratamiento e interpretación de los datos, y reintegrando lo diferenciado y disociado en las fases Sincrética y Analítica. La constatación empírica posibilita avanzar en esta tercera fase, donde se elabora una propuesta metodológica, como instrumento que colabore en la valoración, intervención y gestión de $\mathrm{CH}$ de $A L$ desde la perspectiva del Paisaje (PUH), con el propósito de maximizar los resultados de las intervenciones. Por último, se presentan las conclusiones finales de la tesis sobre los diferentes aspectos abordadas en las Partes I, II y III. Esta última fase, se expone en los Capítulos V y VI.

A continuación, se exhibe un esquema que sintetiza las tres Partes en que se organiza el proceso de investigación (Ver Figura A) distribuido en seis capítulos que conforman el núcleo central de la tesis y desarrollan los principales contenidos teóricos y analíticos. La Parte 1 de la tesis (Capítulos 1 y 2), que coincide, según lo expresado, con la fase sincrética o ideatoria, presenta el marco teórico medular de esta temática con los conceptos básicos implicados y los cambios que los mismos han experimentado en el periodo de estudio. Posteriormente, la Parte 2 (Capítulos 3 y 4), correspondiente a la fase analítica, intenta reconocer y analizar en 
EL CENTRO HISTÓRICO COMO PAISAJE URBANO HISTÓRICO - EI desafío de intervenir

los casos de estudio los contenidos teóricos identificados en la Parte 1 e integrarlos desde el análisis de las experiencias de intervención y gestión identificadas. Para concluir, la Parte 3 de la tesis (Capítulos 5 y 6), que conforma la fase Sintética u Operativa presenta la propuesta metodológica diseñada para la valoración intervención y gestión de PUH, y las conclusiones finales.

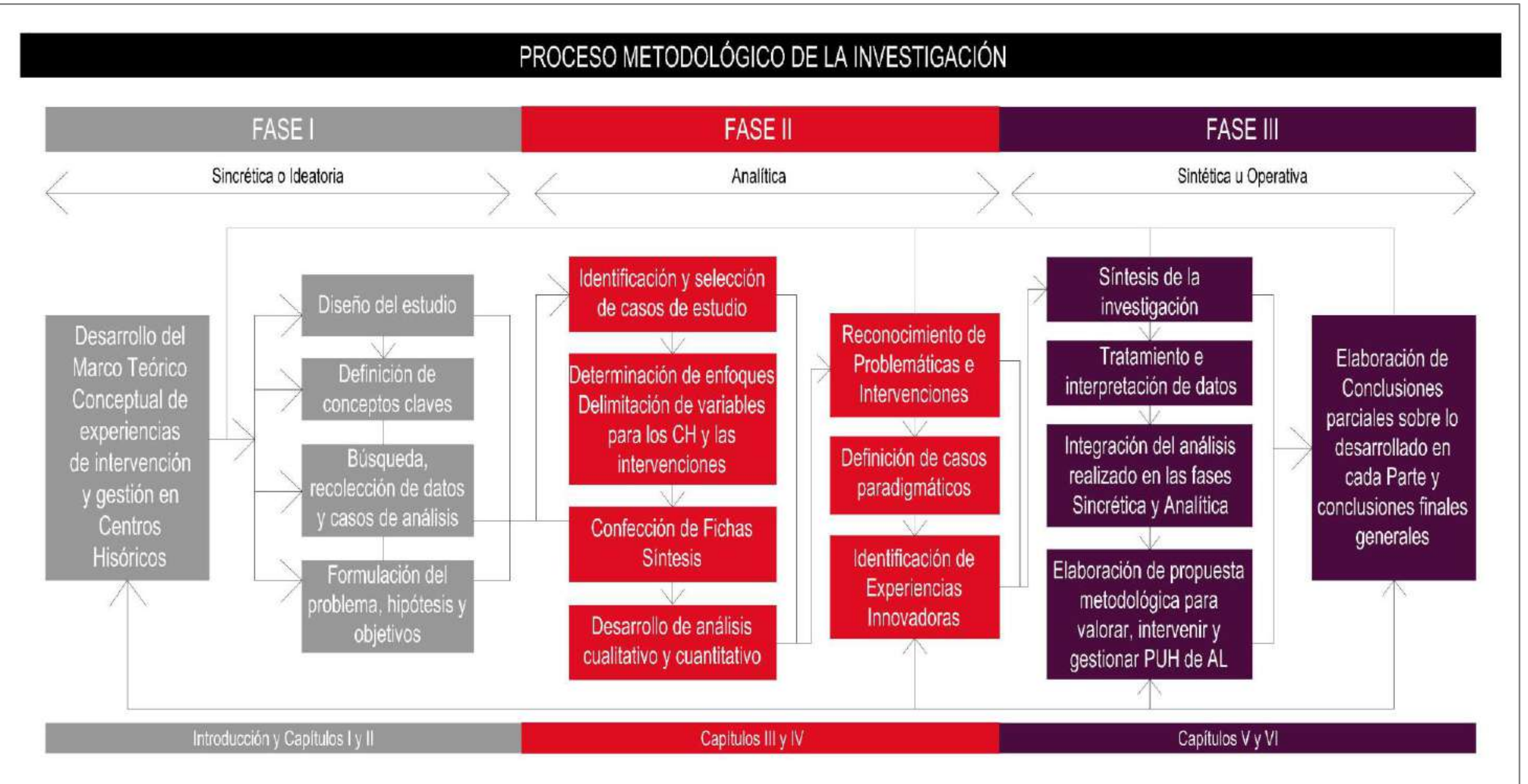

Figura A: Proceso metodológico de la investigación. Elaboración propia 


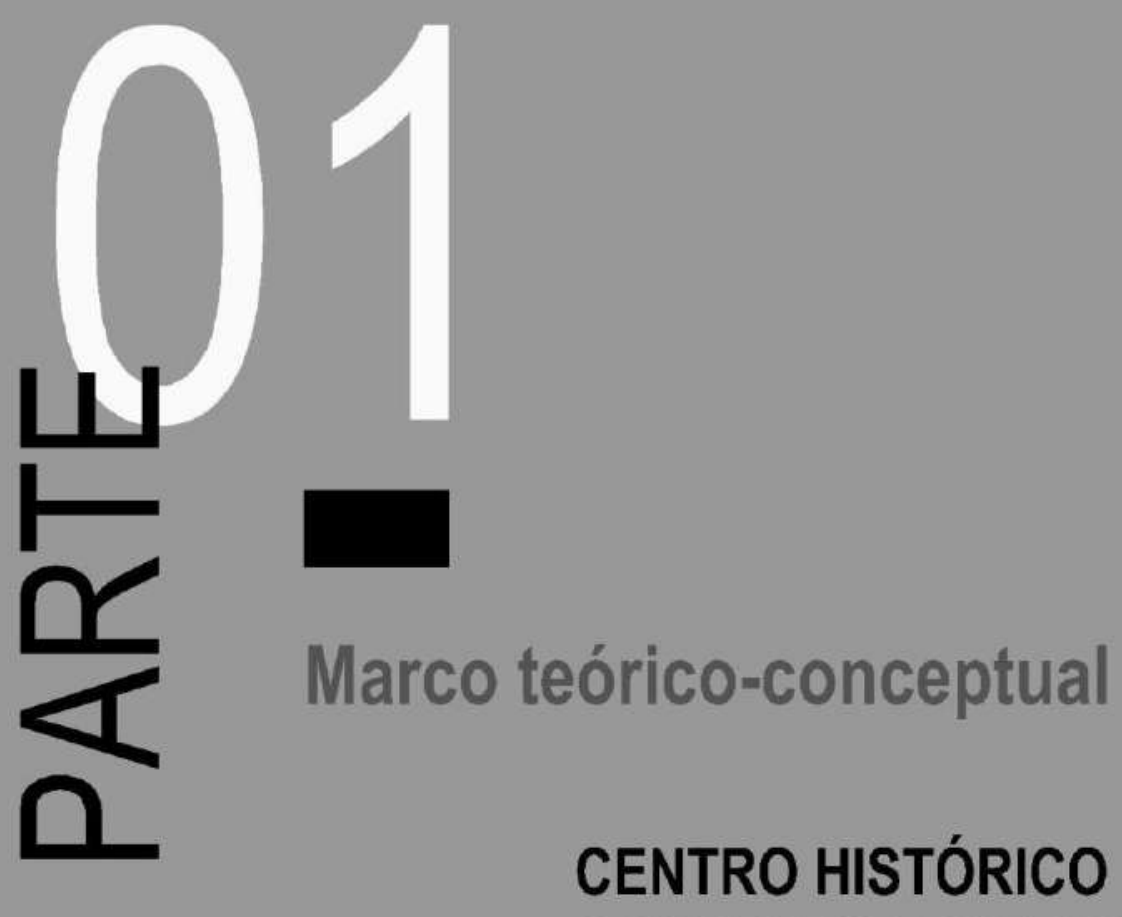

CONCEPTO Y COMPONENTES

INTERVENCIÓN Y GESTIÓN DE LOS CENTROS HISTÓRICOS

ENFOQUES Y DESAFIOOS 


\section{CENTRO HISTÓRICO / CONCEPTO Y COMPONENTES}

Introducción. Estructura del marco teórico-conceptual

Origen y evolución del concepto "Centro Histórico" El "Paisaje Urbano Histórico"

El Centro Histórico como sistema en proceso continuo de transformación

Componentes claves para un centro histórico vivo: Patrimonio cultural, material e inmaterial Los límites de la intervención: las zonas de amortiguamiento

Espacio público Multifuncionalidad

Residencialidad Identidad y participación ciudadana 


\section{EL CENTRO HISTÓRICO COMO PAISAJE URBANO HISTÓRICO - EI desafío de intervenir}

\subsection{Introducción}

El primer apartado de esta primera parte de la tesis, inaugura el abordaje teórico-conceptual de la temática. Se entiende que para el desarrollo de la investigación, ha sido necesario profundizar en algunos conceptos que se desarrollan en este Capítulo, y que resultan esenciales para la concreción de este trabajo, partiendo por comprender cuál es el significado que en la actualidad posee el término "Centro Histórico" y que ha sido producto de sucesivos cambios a lo largo del tiempo que han llevado a mirarlo desde la integralidad el Paisaje como "Paisaje Urbano Histórico". Asociados a este concepto marco, y entendiendo al $\mathrm{CH}$ como un sistema en proceso continuo de transformación, aparecen componentes claves que requieren ser indagados como el "patrimonio cultural, material e inmaterial" (definiendo las zonas de amortiguamiento de los $\mathrm{CH}$ ), el "espacio público", la "multifuncionalidad" (haciendo foco en la "residencialidad") y la "Identidad y participación ciudadana". Para cada uno de ellos se han consultado numerosos autores $y$ documentos, que han tenido un aporte principal en los conceptos en los que se encuadran, aunque muchos de ellos, por su amplio tratamiento del tema de estudio, han generado contribuciones que han enriquecido la mirada global de la temática. A continuación se mencionan los citados en este capítulo:
Origen y evolución del concepto "Centro Histórico"

Alfredo Conti / Françoise Choay / John Ruskin / Camilo Sitte / Gustavo Giovannoni / Fernando Carrión Mena / Fernando Gaja i Díaz / José Luis Lalana Soto

Carta de Atenas / Carta de Venecia / Normas de Quito / Convención de UNESCO, 1972 / Carta de Quito, 1977

\section{El "Centro Histórico" como "Paisaje Urbano Histórico"}

Memorando de Viena, 2005 / Recomendación relativa a los Paisajes Urbanos históricos, 2011 / Convenio Europeo del Paisaje (2000) / Recomendaciones para la aplicación del Convenio (2008) / Alfredo Conti / José Luis Lalana Soto / Milton Santos

El "Centro Histórico" como sistema en proceso continuo de transformación

Fernando Carrión Mena / Marcelo Brito / Gabriel Ruiz Cabrero

Componentes claves para un "Centro Histórico" vivo

Fernando Carrión Mena / Ignacio Casado Galván / Araceli Pereda / Carta de Quito

Patrimonio cultural, material e inmaterial

Víctor Pérez Escolano / Patrice Melé / Fernando Carrión Mena / René Coulomb / Pedro Salmerón 


\section{EL CENTRO HISTÓRICO COMO PAISAJE URBANO HISTÓRICO - El desafío de intervenir}

Zonas de amortiguamiento

Gustavo Garza Merodio / José Luis Lalana Soto / Paloma Guzmán

\section{Espacio Público}

Anna Ortiz Guitart / Gerard Althabe / Llorenç Prats / Marc Augé / Jordi Borja / Zaida Muxí / Fernando Carrión Mena / Milton Santos /

Daniel Sepulveda Voullième / Manuel Herce Vallejo / José Luis Cañavale / Francisco Rubio González / Jan Gehl

\section{Multifuncionalidad}

Víctor Fernández Salinas / Manuel Ferrer Regales / Fernando Carrión Mena / Jordi Borja / Miguel Ángel Troitiño Viñuesa / Juan M. Alonso Velasco / Felix Bayon

\section{Residencialidad}

Fernando Carrión Mena / Jesús Leal Maldonado / Luis González Tamarit / Dora Arizaga Guzmán / José Moreno García / Carlos Hernández Pezzi

\section{Identidad y participación ciudadana}

Paulo Ormindo de Azevedo / Patrice Melé / Edgardo Venturini / René Coulomb / Néstor García Canclini / Heidi Mendoza Barrau / Silvia Bossio / Declaración de Lima, 1997 


\subsection{Origen y evolución del concepto "Centro Histórico"}

En L'allégorie du patrimoine (1992), Françoise Choay ${ }^{1}$ dedica un capítulo a "la invención del patrimonio urbano"; allí ubica el inicio de este proceso hacia mediados del siglo XIX, en correspondencia con los impactos de la industrialización en las ciudades europeas, con los grands travaux desarrollados por Hausmann ${ }^{2}$ en París y con los textos de John Ruskin ${ }^{3}$, que instala por primera vez la idea de conservación de la ciudad haciendo referencia a la ciudad y al tejido urbano como idea de monumento histórico, como objeto de cuidado y estricta conservación, pero con la noción de "congelarlos" (Conti, 2008). Choay propone tres enfoques para interpretar el desarrollo del patrimonio urbano:

- El memorial: donde la ciudad en su conjunto juega el papel de un monumento histórico: un objeto no concebido con la finalidad de rememorar, pero que posee el don de enraizar a sus habitantes en espacio y tiempo. Lo que Ruskin no prevé es el modo en que el proceso histórico incide sobre la ciudad.

- El histórico: representado fundamentalmente por Camillo

1. Françoise Choay: teórica e historiadora francesa sobre urbanismo y arquitectura

2. Georges-Eugène Haussmann, conocido como el Baron Haussmann, fue un funcionario público, diputado y senador francés que dirigió la ambiciosa renovación urbana de Paris.

3. John Ruskin, fue un escritor, crítico de arte, sociólogo, artista y reformador social británico, creador del famoso libro "Las siete lámparas de la arquitectura" (1849).
Sitte. En su obra, la ciudad preindustrial aparece como un objeto del pasado a la vez que la historicidad posee una connotación positiva, la ciudad antigua configura un objeto histórico que sirve de lección para la construcción de la ciudad moderna.

- El historial: representa la síntesis y superación de las dos anteriores. La figura central es Gustavo Giovannoni ${ }^{4}$ (s. XX), quien funda una doctrina de la conservación urbana. En su obra, acuerda simultáneamente valor de uso y valor museal a los conjuntos urbanos antiguos, integrándolos en una concepción general de ordenamiento territorial. Interpreta que la ciudad, los barrios y otros sectores urbanos deben conservarse, y los entiende como "monumentos vivos", considerando que la ciudad es un contenedor de vida, y defendiendo la idea de generar un equilibrio entre aquello a conservar y lo necesario a renovar que la ciudad requiere para integrarse a la vida dinámica, manteniendo el carácter social de la población.

Las ideas de Giovannoni, incluidas en la Carta Italiana del Restauro de $1931^{5}$, anticipan las diversas políticas aplicadas en Europa

4. Gustavo Giovannoni fue un arquitecto, urbanista e ingeniero italiano, discípulo de Camilo Boito, considerado uno de los más importantes teóricos de la restauración.

5. La Carta Italiana del Restauro de 1931, elaborada en Roma, es una de las siete Cartas de Restauro que establecen de común acuerdo, recomendaciones para las intervenciones. Desarrolla el problema del repristino o copia sin elementos básicos que lo amparen, así como la copia como base de la restauración. 


\section{EL CENTRO HISTÓRICO COMO PAISAJE URBANO HISTÓRICO - El desafío de intervenir}

desde la década de 1960. En este marco, son numerosas las teorías de conservación y restauro que se han desarrollado a lo largo del tiempo y que han tenido un gran aporte con la Escuela Italiana de Restauro ${ }^{6}$ del siglo XIX, con debates sobre temas que son trasladables aún a la actualidad, y que ha sido cuna de numerosos intelectuales como Camillo Boito, Luca Beltrami, Cesare Brandi, el citado Gustavo Giovannoni, entre otros que conforman durante fines del siglo XIX y el XX las bases del restauro moderno. Las cartas publicadas en el siglo $\mathrm{XX}$ y las convenciones internacionales sobre Patrimonio Arquitectonico y Urbano también juegan un rol significativo en la intervencion del patrimonio, dado que han generado interesantes debates conceptuales y practicos sobre los modos de ver e intervenir la ciudad.

A partir de la década de 1970, el problema de la integración de los conjuntos históricos se instala en el debate internacional, lo cual queda plasmado en la Recomendación ${ }^{7}$ de Nairobi de 1976, que incorpora la idea de "cohesión" y "homogeneidad", como las bases de los valores arquitectónicos, urbanos y estéticos.

6. La Escuela Italiana de Restauro ha promovido la mínima intervención en obras patrimoniales, la diferenciación de estilos entre lo nuevo y lo viejo, la distinción entre los materiales originales y los incorporados en la intervención, la eliminación de ornamentos en el sector restaurado, la señalización de las nuevas piezas introducidas, y la incorporación de una leyenda en el edificio que indique que ha sido restaurado.

7. En la terminología UNESCO (y de Naciones Unidas en general), una Recomendación es un documento que formula principios directores y normas para reglar internacionalmente una cuestión, que las diversas Administraciones pueden adoptar en sus respectivas legislaciones.
Con estos cambios en la mirada de la conservación del patrimonio urbano, surge en la década del 60 del siglo $\mathrm{XX}$ el concepto de $\mathrm{CH}$. Previamente solo existía la noción de conservar monumentos aislados representativos como se menciona en la Carta de Atenas ${ }^{8}$ de 1931. La misma plantea la necesidad de utilización y conservación de los monumentos como continuidad de su existencia y sostiene que los nuevos edificios deben respetar la fisonomía de la ciudad conservada, sobre todo en cercanías de monumentos, y conservar "perspectivas particularmente pintorescas". Por lo tanto, una verdadera preocupación por la preservación del conjunto urbano se hace notable por primera vez en la Carta de Venecia ${ }^{9}$ de 1964, que determina que la noción de patrimonio histórico no solo comprende la obra aislada sino también el contexto urbano o rural en el que se inserta. Esta evolución "del concepto de monumento aislado a la ciudad como monumento ha permitido el ingreso de la planificación urbana" (Carrión, 2000).

De este modo, se comienza a intervenir en las ciudades europeas, mediante la realización de tareas de conservación y rehabilitación en los $\mathrm{CH}$. Los mismos, eran generalmente definidos como las áreas históricas consolidadas durante la Edad Media, que se diferencian en el s XIX y XX de la extensión de la ciudad.

8. La Carta de Atenas (1931), es un documento que describe la salvaguardia de la arquitectura, es decir, la conservación sin intervención.

9. La Carta de Venecia (1964), distingue la restauración como método de la conservación. 


\section{EL CENTRO HISTÓRICO COMO PAISAJE URBANO HISTÓRICO - El desafío de intervenir}

Este concepto comienza prontamente a ser tratado en $\mathrm{AL}$, durante la reunión en la que se declaran las Normas de Quito ${ }^{10}$ de 1967 , y se traslada en particular, a los centros de ciudades con escasa dinámica en el tiempo, y que por lo tanto conservan sus características originales. Sin embargo, en ciudades donde los procesos de cambio fueron muy intensos la noción de $\mathrm{CH}$ no es fácilmente aplicable, dado que en ellas sólo se conservan algunos componentes arquitectónicos además del trazado (Conti, 2011). No obstante, en la reunión de Quito se planteó la idea de que el espacio es inseparable del monumento y que todo Estado debe tutelar el contexto urbano. También reconocen que muchas ciudades habían perdido importantes obras patrimoniales en pos del progreso urbano y sostienen la necesidad de conciliar las exigencias del progreso urbano con la salvaguarda de los valores ambientales en la formulación de los planes de ordenamiento.

En la Convención de la UNESCO ${ }^{11}$ del año 1972 para la Protección del Patrimonio Mundial, Cultural y Natural, se incluye a los $\mathrm{CH}$ dentro de la categoría de "Grupos o Conjuntos de edificios", y en este contexto, durante la década del 80 , numerosos $\mathrm{CH}$

10. Las Normas de Quito (1967), son el resultado de la reunión celebrada en Quito sobre la conservación y utilización de monumentos y lugares de interés histórico y artístico.

11. UNESCO: Organización de las Naciones Unidas para la Educación, la Ciencia y la Cultura. La Convención sobre la Protección del Patrimonio Mundial, Cultural y Natural de la UNESCO (1972), se centra en la salvaguardia de bienes de patrimonio cultural o natural de valor excepcional que deben conservarse como elementos del Patrimonio de la humanidad. latinoamericanos (Quito -que junto con Cracovia fueron los dos primeros $\mathrm{CH}$ en ingresar en la Lista de UNESCO-, Olinda, Lima, La Habana, Salvador, Zacatecas, Cartagena) fueron declarados Patrimonio de la Humanidad ${ }^{12}$, poniendo el acento en la conservación de sus componentes arquitectónicos sin considerarse las funciones, los usos o la población.

Hasta ese momento, los $\mathrm{CH}$ eran entendidos como conjuntos monumentales, con políticas conservacionistas que los mantenían como museos, como espacios de contemplación para el uso turístico. Con el paso del tiempo este concepto comienza a cuestionarse y se empiezan a ver a los $\mathrm{CH}$ como centros vivos, resultado de la sociedad que lo habita. Ya no se ve a los mismos sólo como un conjunto de edificios monumentales, sino como contenedores de la población. La Carta de Quito de $1977^{13}$, plantea que los protagonistas de los centros son sus habitantes y que uno de los elementos esenciales de su rehabilitación debe ser el uso residencial (Carrión, 2009), y en el año 1978 en esa misma ciudad ecuatoriana, fue determinada por la UNESCO la definición de la expresión "Centro Histórico", El objetivo era dar inicio a la

12. La declaración de Patrimonio de la Humanidad es el título otorgado po UNESCO a todos aquellos sitios que posean una importancia excepcional para la humanidad, con el fin de catalogar, preservar y dar a conocerlos. Para ello, pueden acceder bajo determinadas condiciones, a fondos de financiación para su conservación.

13. La Carta de Quito (1977) resultado del Coloquio sobre la Preservación de los CH ante el crecimiento de las ciudades contemporáneas. 
conservación de las viejas estructuras urbanas de las ciudades latinoamericanas deterioradas a causa de fenómenos naturales, a la indiferencia de las autoridades locales y a la ignorancia de la población civil en su afán de modernización. Este término es por lo tanto muy empleado en AL. Por su parte, en España a los antiguos barrios urbanos suelen denominarlos "cascos antiguos", "centros urbanos" o "ciudades históricas".

Para Gaja Díaz (1992), una "ciudad histórica" debe comprender una trama urbana que haya sido parte de la ciudad antes de la plena consolidación de la revolución industrial, y que conserve en la actualidad características morfológicas básicas que permitan constatar la permanencia de los modos urbanísticos pre-modernos. Sin embargo, encontrar estas características básicas intactas en una ciudad histórica no es una tarea simple. Las crisis políticas, económicas y sociales por las que atraviesan las sociedades se reflejan también en los $\mathrm{CH}$, donde la decadencia y el abandono arquitectónico y urbano pueden hacerse evidentes.

A su vez, como sostiene Conti (2008), "a la ampliación constante del concepto de patrimonio se suman el incremento del público interesado en el tema, incentivado por los medios de difusión y las modernas técnicas de intercambio de información, el avance de las industrias culturales y el desarrollo significativo del turismo. En este esquema, el patrimonio cultural se convierte, muchas veces, en espectáculo, mercancía y objeto de consumo masivo. Por otra parte, las ciudades se han lanzado a una carrera de posicionamiento en un mundo globalizado y competitivo; para ello, la construcción de grandes equipamientos, destinados a la administración, el comercio, la diversión o el turismo, se convierten en estrategias posibles. Contar con edificios o complejos edilicios proyectados por arquitectos de fama internacional y rápidamente difundidos por los medios de comunicación, son considerados oportunidades para que las ciudades sean reconocidas, valoradas y visitadas. A la vez, presiones vinculadas con el desarrollo se traducen en una creciente especulación sobre el suelo urbano".

Esta situación ha llevado a pensar, un nuevo concepto que colabore en la gestión del patrimonio urbano y que contemple las diversas etapas históricas del área con sus valores naturales y culturales, e incluya un contexto urbano más amplio que considere a su vez el patrimonio intangible. De esta manera, es que se incorpora en el Memorando de Viena $^{14}$ (2005) el concepto de "Paisajes Urbanos Históricos" (de aquí en adelante PUH) para referirse a estos sectores de las ciudades que contienen gran parte

14. El Memorando de Viena surge durante la Conferencia Internacional "El Patrimonio Mundial y la Arquitectura Contemporánea. Gestión de los Paisajes Históricos Urbanos", promovido ante la preocupación de reconocer que ante las presiones económicas, sociales y culturales a las que están sometidas las ciudades históricas, particularmente aquellas inscritas en la Lista de Patrimonio Mundial, los documentos doctrinarios como los instrumentos de gestión disponibles, parecian insuficientes para dar una respuesta adecuada (Conti, 2008). 
de la historia de las sociedades y conservan las huellas del pasado, pero que a su vez conjugan la conservación del patrimonio histórico con los nuevos desarrollos. Plantea un enfoque integrado que una la arquitectura contemporánea, el desarrollo urbano sostenible y la integridad del paisaje basándose en los modelos históricos, el estilo de construcción y el contexto. El 10 de noviembre del año 2011 se logró la aprobación por parte de la UNESCO, de una Recomendación relativa a la protección de los $\mathrm{PUH}$.

\subsubsection{El "Centro Histórico" como "Paisaje Urbano Histórico"}

La incorporación del concepto de Paisaje aplicado a los $\mathrm{CH}$ aporta una visión integral, y requiere apelar a documentos marco y autores especialistas en la temática. "Paisaje es cualquier parte del territorio tal como lo percibe la población, cuyo carácter es el resultado de la acción y la interacción de factores naturales y/o humanos" (Convenio Europeo del Paisaje, Florencia 2000), y "expresa el deseo de afrontar de manera global y frontal, la cuestión de la calidad de los lugares donde vive la población, reconocida como condición esencial para el bienestar individual y social (entendido en el sentido físico, fisiológico, psicológico e intelectual), para un desarrollo sostenible y como recurso que favorece la actividad económica" (Recomendaciones para la aplicación del Convenio Europeo de Paisaje, 2008).

Se entiende que "paisaje es lo que llega a los sentidos, la dimensión del paisaje es la dimensión de la percepción. Por eso, el aparato cognitivo tiene crucial importancia en esa aprehensión, por el mero hecho de que toda nuestra educación, formal e informal, se ha llevado a cabo de forma selectiva, y por lo tanto, diferentes personas presentan distintas versiones del mismo hecho. Además, la percepción es siempre un proceso selectivo de aprehensión" (Santos, 1995). En línea con lo expresado, las Recomendaciones afirman que "la percepción sensorial (visual, auditiva, olfativa, táctil y gustativa) y emocional que tiene una población de su entorno, y el conocimiento de sus diversidades y especificidades históricas y culturales son esenciales para el respeto y la salvaguarda de la identidad y para su enriquecimiento individual y social. Ello implica un reconocimiento de los derechos y deberes de la población para jugar un papel activo en los procesos de conocimiento, decisión y gestión de la calidad de los lugares, (...) siendo parte integral de los procesos de gestión, protección y ordenación".

Para su intervención, el Convenio Europeo del Paisaje, brinda un marco normativo para todas las políticas territoriales, y se fundamente en tres acciones principales:

- La "protección de los paisajes", entendida como las 
acciones encaminadas a conservar y mantener los aspectos significativos o característicos de un paisaje, justificados por su valor patrimonial derivado de su configuración natural y/o la acción del hombre;

- La "gestión de los paisajes", que comprende las acciones encaminadas, desde una perspectiva de desarrollo sostenible, a garantizar el mantenimiento regular de un paisaje, con el fin de guiar y armonizar las transformaciones inducidas por los procesos sociales, económicos y medioambientales;

- La "ordenación paisajística", que abarca las acciones que presentan un carácter prospectivo particularmente acentuado con vistas a mejorar, restaurar o crear paisajes.

En este contexto del Paisaje, el Memorandum de Viena (2005) y las Recomendaciones de 2011, plantean a los PUH como el paisaje urbano con significación patrimonial, resultante de una estratificación histórica de valores y atributos culturales y naturales, por lo que la noción de paisaje histórico urbano va más allá de los términos tradicionales "centros históricos", "conjuntos" o "alrededores", para incluir el más amplio contexto territorial y paisajístico, una visión más integral de la ciudad y su entorno. El PUH no sólo incorpora condiciones ambientales y topográficas, sino que también expresa valores económicos y socioculturales propios de las distintas sociedades. Por tanto, la protección y conservación del paisaje histórico urbano comprende las relaciones significativas, ya sean físicas, funcionales, visuales, materiales o asociativas, junto con las tipologías y morfologías históricas. Esta definición, sienta las bases de un planteamiento global e integrado para la determinación, evaluación, conservación y gestión de los PUH como parte de un plan general de desarrollo sostenible. La noción de PUH, que tiene en cuenta las tradiciones y percepciones de las comunidades locales, ofrece herramientas para la gestión de las transformaciones físicas y sociales y procura que las intervenciones contemporáneas se integren armónicamente con el patrimonio en un entorno histórico que considere el contexto regional.

Por lo tanto, la intervención de los $\mathrm{PUH}$ debe comprender las relaciones físicas, funcionales, visuales, materiales o asociativas, junto con las tipológicas y morfológicas históricas, con un planteamiento holístico de la gestión de los PUH que integre objetivos de conservación del patrimonio urbano con los del desarrollo socioeconómico. En este sentido, es necesario que los distintos actores que modelan la ciudad, autoridades públicas que la administran y los promotores y empresarios que operan en ella, trabajen en forma conjunta.

Sobre este nuevo concepto, Lalana Soto (2011) afirma que: "representa un avance teórico en la definición, conservación y gestión de los conjuntos urbanos con valor patrimonial, con un claro 


\section{EL CENTRO HISTÓRICO COMO PAISAJE URBANO HISTÓRICO - El desafío de intervenir}

afán integrador de las diversas escalas y cuestiones relacionadas con estos objetivos, facilitando así la adecuación de la conservación del patrimonio urbano al nuevo paradigma ${ }^{15}$ de la sostenibilidad en todas sus vertientes (ambiental, económica y social). (...) - que se profundizará en el capítulo 2- y que esta nueva perspectiva, y específicamente la del paisaje, tiene también la virtud de la síntesis, al integrar en una sola palabra muchos puntos de vista, desde la concepción dinámica de la ciudad, a la primacía de la idea de relación entre los diversos elementos de la realidad, o la consideración de los bienes patrimoniales dentro de un contexto territorial más amplio. Así, la noción de PUH puede enfatizar la necesidad de una visión global, sobre todo en lo que se refiere a tres aspectos: patrimonial, urbano y sectorial, al resaltar las relaciones entre los diversos componentes de la realidad urbana, desde los ambientales a los sociales, los económicos, los culturales o los paisajísticos". No obstante, el autor plantea que existen limitaciones e indefiniciones para abordar los problemas que originaron el debate y llevaron a la creación de este nuevo concepto, y que continúan quedando en un segundo plano aspectos relacionados al uso residencial y las cuestiones sociales.

Conti (2008) complementa afirmando que: "se admite que todas las ciudades históricas poseen un paisaje histórico implícito en ellas.

15. Paradigma: según la Real Academia Española, teoría o conjunto de teorías cuyo núcleo central se acepta sin cuestionar y que suministra la base y modelo para resolver problemas y avanzar en el conocimiento.
Sin embargo, no siempre es paralelo el valor de una ciudad histórica al de su paisaje histórico. Se refuerza el argumento de que el paisaje histórico es un componente de la ciudad histórica, pero no el único y a veces no el más importante. La ciudad es una entidad y el paisaje uno de sus componentes o elementos. La consideración de los paisajes urbanos históricos ayuda a comprender mejor la categoría de la ciudad histórica pero no puede reemplazarla. Una ciudad histórica, su espacio y su paisaje, no son estáticos; pueden cambiar con prudencia, sensibilidad y mesura; manteniendo siempre su carácter, sus signos distintivos de identidad propia y procurando un desarrollo armónico que evite rupturas de escala, de trama urbana, de tipología, de color, etc. Un desarrollo que permita la integración de las nuevas exigencias de la vida moderna, de la arquitectura contemporánea, pero con absoluto respeto al ambiente, al contexto histórico y cultural. Un desarrollo que permita la cohesión y armonía entre sus elementos construidos, entre las nuevas áreas urbanas e infraestructuras y la ciudad histórica y entre ésta y el paisaje natural circundante".

La idea es que el concepto de PUH brinde una herramienta para valorar, intervenir y gestionar los $\mathrm{CH}$, integrando mediante el Paisaje el patrimonio material e inmaterial, y que desarrolle instrumentos de gestión pensados para y por la comunidad. 
Durante las Partes 1 y 2 de la tesis, se van a continuar mencionando a estas áreas históricas de las ciudades como "centros históricos" (historic center, centro storico, centre historique...), dado que el concepto de PUH no reemplaza este término, sino que aporta una nueva mirada al $\mathrm{CH}$ desde la integralidad del paisaje.

A continuación se expone un esquema síntesis que integra aspectos relevantes expuestos sobre $\mathrm{CH}$, paisaje y $\mathrm{PUH}$, conceptos claves que guiarán el desarrollo de la tesis (Figura I.1). 


\begin{tabular}{|c|c|}
\hline $\begin{array}{l}\text { CENTRO } \\
\text { HISTÓRICO }\end{array}$ & $\begin{array}{l}\text { CARTA DE VENECIA, 1964: PATRIMONIO HISTÓRICO: obra más contexto urbano o rural en que se inserta } \\
\text { NORMAS DE QUITO, 1967: centros históricos latinoamericanos, centros de ciudades con escasa dinámica en el tiempo, que onservan caracteristicas originales. } \\
\text { monumento inseparable del contexto } \\
\text { CONVENCIÓN DEL PATRIMONIO CULTURAL, 1972: centros histórico como "grupos o conjuntos de edificios" (elementos del patrimonio cultural material) } \\
\text { CARTA DE QUITO, 1977: los protagonistas de los Centros Históricos son sus habitantes. El uso residencial debe ser un elemento esencial. Centros vivos. } \\
\text { QUITO, 1978: la UNESCO define la expresión "Centro histórico" } \\
\text { CONVENCION DEL PATRIMONIO INMATERIAL, 2003: se delerminan los elementos que constituyen el patrimonio inmaterial }\end{array}$ \\
\hline PAISAJE & $\begin{array}{l}\text { CONVENIO EUROPEO DEL PAISAJE - FLORENCIA, 2000: Paisaje, cualquier parte del territorio tal como lo percibe la población, cuyo carácter es el resultado de } \\
\text { la acción y la interacción de factores naturales y/o humanos. } \\
\text { Incluye todas las políticas territoriales. Se fundamenta en tres acciones principales: Protección / Gestión / Ordenación } \\
\text { RECOMENDACIONES PARA LA APLICACIÓN DEL CONVENIO EUROPEO DEL PAISAJE, 2008: la percepción sensorial y emocional que tiene una población de } \\
\text { su entorno y el conocimiento de sus especificidades son esenciales parael respeto y salvagurdade la identidad }\end{array}$ \\
\hline
\end{tabular}

PAISAJE URBANO HISTÓRICO
MEMORANDUM DE VIENA, 2005 / RECOMENDACION SOBRE EL PUH, 2011: Paisaje urbano con significación patrimonial , resultante de una estratificación histórica de atributos culturales y naturales. Supera el concepto "Centro Histórico". Incluye el contexto territorial y paisajistico. Visión integral de la ciudad y su entorno. Incorpora condiciones ambientales, topográficas, valores económicos y socioculturales propios de las distintas sociedades. La protección y conservación comprende relaciones significativas, fisicas, funcionales, materiales o asociativas, tipológicas y morfológicas históricas. Fomenta la arquitectura contemporánea que responda a nuevas necesidades y respete el paisaje urbano heredado y su entorno paisajistico y el DesarrolloUrbano Sostenible

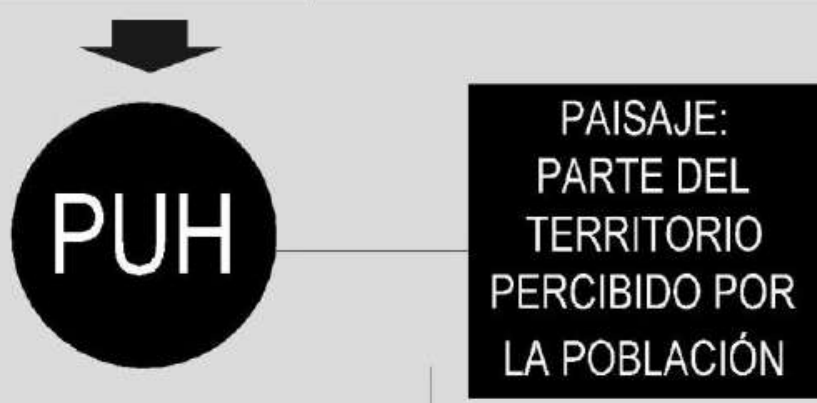

Convenio Europeo del Paisaje (2000) Recomendaciones (2008)

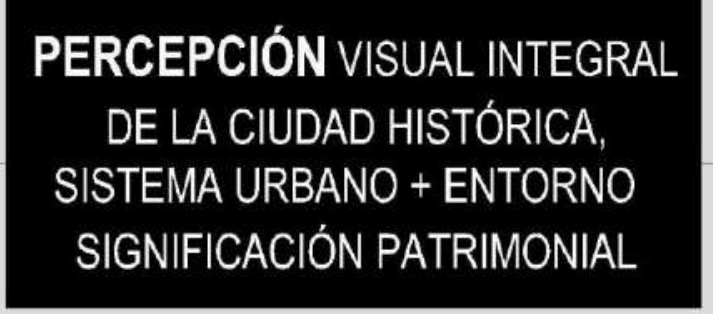

CONDICIONANTES
AMBIENTALES.
TOPOGRÁFICAS,
ECONÓMICASY
SOCIO-CULTURALES

Memorándum de Viena (2005) Recomendación para los PUH (2011)

\section{COMPONENTES \\ MATERIALES \\ COMPONENTES INMATERIALES}

Convención Patrimonio Cultural (1972)

Convención Patrimonio Inmaterial (2003) 


\section{EL CENTRO HISTÓRICO COMO PAISAJE URBANO HISTÓRICO - El desafío de intervenir}

1.3 El Centro Histórico como sistema en proceso continuo de transformación

"Si a partir de la segunda posguerra se implanta una urbanización caracterizada por su desarrollo periférico-expansivo y de modalidad metropolitana con alta primacía urbana -propios del modelo del Estado de bienestar y de la economía de sustitución de importaciones- medio siglo después nos encontramos con un proceso en formación que se expresa en la introspección hacia la ciudad construida y en la formación de ciudades globales. (...) Contrario a la internacionalización, se observa un movimiento hacia el interior de la ciudad. El urbanismo fundado en la 'periferización' y expansión urbana, entra en crisis, avizorándose su salida a partir de la década de los noventa a través de lo que puede definirse como el retorno hacia la ciudad existente. (...) De allí que se observe una mutación en la tradicional tendencia del desarrollo urbano (exógeno y centrífugo), que privilegiaba el urbanismo de la periferia, a uno que produce un cambio de dirección hacia la ciudad existente (endógeno y centrípeta). De esta manera, pasamos de la urbanización de un espacio vacío o plano, a la urbanización de un territorio configurado; esto es, de una urbanización de lo urbano". (Carrión Mena, 2001).
Este retorno al centro, como plantea Brito (2007), entiende a las "ciudades como resultantes de un proceso permanente y continuo de transformaciones cumulativas, donde el patrimonio cultural congrega la sumatoria de las diversas contribuciones de los varios períodos de existencia de las propias ciudades". Son ciudades en permanente construcción, donde la necesidad de adaptación a las fluctuantes necesidades y de integración a las nuevas dinámicas como lugares vivos, han llevado a desarrollar durante las últimas dos décadas del siglo pasado procesos de preservación recuperación y revitalización, ${ }^{16}$ de áreas históricas degradadas, deterioradas físicamente, marginales socialmente y deprimidas económicamente. Se observan nuevas políticas de preservación del patrimonio cultural ${ }^{17}$, como pilar esencial de la rehabilitación urbana y como una forma de desarrollo.

Entendemos al $\mathrm{CH}$ como un "patrimonio vivo porque todos los días cambia, crece y se destruye, se enriquece o se empobrece. Varía en su condición física. Está en perpetua e impredecible transformación. En ocasiones cambia de naturaleza, se metamorfosea. Es también un patrimonio vivo, porque lo que está construido debe ser reinterpretado todos los días. Cada día los arqueólogos hacen nuevos descubrimientos, los historiadores corrigen interpretaciones de antiguos documentos, las ciencias

16. Las estrategias de preservación, recuperación, revitalización y rehabilitación serán profundizadas, junto a otras, en el capítulo 2 .

17. Este término será ampliado en el próximo capítulo 
sociales valoran de forma radicalmente distinta los rasgos urbanos de antiguo conocidos, o les dan un rango diferente. La historia, decimos, se está rescribiendo continuamente". (Ruiz Cabrero, 2007).

En esta marco, resulta necesario comprender el funcionamiento del $\mathrm{CH}$ ahondando en los componentes claves que garanticen su vitalidad.

\subsection{Componentes claves para un Centro Histórico vivo}

Como se ha expresado previamente, la Carta de Quito de 1977 ha planteado una nueva mirada a los $\mathrm{CH}$, que ha dejado atrás la idea de $\mathrm{CH}$ como museo para contemplación turística, para entenderlo como un centro vivo, resultado la sociedad que lo habita, con un uso enfocado en la actividad residencial. Sin embargo, esta función no es la única que garantiza su centralidad. "Cuando el $\mathrm{CH}$ comienza a diferenciarse del centro urbano, se debe a la pérdida de centralidad de esta área histórica, en beneficio de una nueva, en otro lugar de la ciudad, que puede generar dos situaciones: una centralidad compartida, donde el $\mathrm{CH}$ mantiene algunas de las funciones que le dan vida y otras se desplazan al nuevo centro; o la pérdida total de sus funciones, que acarrean su disolución, o a su transformación en un barrio histórico carente de centralidad urbana (...) Por lo tanto, existe la necesidad de que los $\mathrm{CH}$ no pierdan la centralidad urbana" (Carrión Mena, 2003).

Pero para que un $\mathrm{CH}$ constituya a su vez un centro urbano vivo deben darse algunas condiciones. Casado Galván (2010), plantea que "el concepto de centro se refiere a un tipo de ocupación del espacio, a un conjunto de funciones y de grupos sociales localizados sobre un lugar de características más o menos específicas, y al papel predominante que el centro desempeña en el control del crecimiento urbano, es decir, que puede delimitarse como un lugar geográfico con un contenido social específico. No obstante, el centro urbano no requiere centralidad geográfica ni es una entidad espacial inmutable, es una noción principalmente sociológica. En un centro urbano, se identifican espacios ocupados por ciertas actividades y que connotan ciertas funciones: la función de integración de elementos del conjunto de la ciudad, la coordinación de actividades y la función simbólica"

Por lo tanto, para que un $\mathrm{CH}$, recupere, conserve o incorpore funciones que le otorguen vitalidad, es necesario que atienda a ciertos componentes esenciales que responden a medios físicoambientales, socio-culturales y económicos como:

- Patrimonio cultural, material e inmaterial

- Espacio público 


\section{EL CENTRO HISTÓRICO COMO PAISAJE URBANO HISTÓRICO - El desafío de intervenir}

- Multifuncionalidad

- Identidad y participación ciudadana

Dentro del medio físico-ambiental, se consideran características geomorfológicas, geográficas, topográficas, así como las correspondientes al medio construido, infraestructuras de servicios, sistemas de movimientos, usos del suelo, equipamientos (comerciales, educativos, recreativos, de salud, religiosos, administrativos, industriales), trazado, tejido, y características del espacio público.

Por otra parte, con respecto al medio económico acordamos con Brito (2007) en que refiere a los requisitos necesarios para la activación económica. En este sentido, las características determinantes son:

- La centralidad: capacidad que posee una ciudad para generar movimientos comerciales, de servicios, de ideas. El grado de frecuentación que es capaz de generar acorde a los atractivos que posee, otorgan centralidad.

- La multifuncionalidad: diversidad de funciones que se integran y se articulan para permitir la permanencia con vida del área. Define los índices de vigor de un $\mathrm{CH}$, fundamental para evaluar propuestas de iniciativas de activación económica.
- La vialidad: redes de vías de circulación, y su estado general.

- La accesibilidad: intensidad de flujos que se mueven por las arterias viales. Estos flujos se asocian a la mayor o menor posibilidad de reactivación económica.

En cuanto al medio socio-cultural, involucra todos aquellos aspectos socio-demográficos y aquellos culturales, que expresan el modo de cómo la sociedad crea significados y símbolos que dan identidad a determinado lugar y objetos. La materialización de esa identidad se apoya en un proceso selectivo, y aunque son múltiples las manifestaciones que se producen en un lugar, en gran parte los edificios y su distribución urbana son los que más aportan a esa identidad, porque expresan el proceso de ocupación del territorio, resultante de la sumatoria de relaciones sociales, económicas y culturales de una sociedad. Por lo tanto, si no estuvieron articulados a la red de relaciones sociales y simbólicas de ese lugar se constituirían en un conjunto de objetos desprovistos de significado $y$, por lo tanto, no constituirían un patrimonio cultural para mantener y valorizar.

En definitiva, el suelo urbano como soporte material de las ciudades, al tener como "predicado la potencialidad de crear espacio" y de adquirir significados distintos según la actuación de los agentes que en él intervienen, está sometido, conforme la 
definición de su valor atribuido, a la condición de manutención, transformación o sustitución de sus estructuras, no solamente físicas, sino también las sociales que en él se encuentran. Son esos aspectos, por lo tanto, los que en un marco urbanístico, deben orientar las acciones del patrimonio, preservando las ciudades históricas en su contexto sociocultural. Así, comprender hoy por hoy las ciudades históricas como urbs implica considerar sus estructuras físicas, herencia legada por nuestros antepasados, el cuerpo del ser vivo existente, sino también sus estructuras sociales, que les dan significado, vida propia, movimiento". (Brito, 2007)

Lo expresado previamente, denota el gran desafío que representa la intervención en los $\mathrm{CH}$, siendo que "el patrimonio es una realidad compleja, tiene cuerpo (lo que vemos) y espíritu (lo que no vemos pero constituye la esencia de su vida). Ninguna intervención a favor del patrimonio lo será si tiene en cuenta sólo uno de los aspectos y no el de un organismo vivo con sus peculiaridades vitales, sus proporciones, su adaptación al medio, sus necesidades propias; comprendido por quienes les rodean, cuidado de manera preventiva para evitar tener que curar. Unos $\mathrm{CH}$ sin fachadismo, que sólo atiende a las apariencias, sin crecimientos indigestos, sin cirugías plásticas que momifican, unos centros que maduren equilibradamente". (Pereda, 2007)

\subsubsection{Patrimonio cultural, material e inmaterial}

En cuanto al tratamiento del patrimonio, una de las organizaciones más reconocidas a nivel internacional es la UNESCO, que ha sido fundada en el año 1945, y promueve, entre varios temas, el entendimiento intercultural mediante la protección del patrimonio y el apoyo a la diversidad cultural. La UNESCO entiende que en el mundo interconectado en el que vivimos, es fácil constatar que la cultura tiene el poder de transformar las sociedades. Sus diversas manifestaciones, que abarcan desde los más valorados monumentos históricos y museos hasta los ritos tradicionales y el arte contemporáneo, enriquecen nuestro día a día de múltiples maneras. El patrimonio constituye una seña de identidad y favorece la cohesión de las comunidades que no asimilan bien los cambios rápidos o que sufren el impacto de la crisis económica.

Para asegurarse de que los planes y estrategias de desarrollo tengan en cuenta la cultura, la UNESCO ha adoptado una táctica basada en tres ejes: la conservación del patrimonio, el fortalecimiento de las industrias creativas y el fomento del pluralismo cultural. En este marco, establece acuerdos y marcos reglamentarios que puedan guiar a gobiernos y actores locales, y elabora tratados internacionales por medio de convenciones, como la Convención sobre la Protección del Patrimonio Mundial, Cultural 
y Natural, celebrada en París en el año 1972 donde se define como Patrimonio Cultural (material) a:

- Ios monumentos; obras arquitectónicas, de escultura o de pintura monumentales, elementos o estructuras de carácter arqueológico, inscripciones, cavernas y grupos de elementos, que tengan un valor universal excepcional desde el punto de vista de la historia, del arte o de la ciencia,

- Ios conjuntos: grupos de construcciones, aisladas o reunidas, cuya arquitectura, unidad e integración en el paisaje les dé un valor universal excepcional desde el punto de vista de la historia, del arte o de la ciencia,

- Ios lugares: obras del hombre u obras conjuntas del hombre y la naturaleza así como las zonas, incluidos los lugares arqueológicos que tengan un valor universal excepcional desde el punto de vista histórico, estético, etnológico o antropológico.

No obstante, el concepto de patrimonio cultural ha ido cambiando en las últimas décadas y no se limita a monumentos y colecciones de objetos, sino que comprende también tradiciones o expresiones vivas heredadas de nuestros antepasados y transmitidas a nuestros descendientes. Por lo tanto, el patrimonio cultural, conjuga tanto al Patrimonio "Material o Tangible", detallado recientemente, como al "Inmaterial o Intangible". Este último, incluye según la Convención para la salvaguardia del Patrimonio Cultural Inmaterial desarrollada en el año 2003, los usos, representaciones, expresiones, conocimientos y técnicas -junto con los instrumentos, objetos, artefactos y espacios culturales que les son inherentes- que las comunidades, los grupos y en algunos casos los individuos reconozcan como parte integrante de su patrimonio cultural. Este patrimonio es transmitido de generación en generación, recreado constantemente por las comunidades y grupos en función de su entorno, su interacción con la naturaleza y su historia, infundiéndoles un sentimiento de identidad y continuidad y contribuyendo así a promover el respeto de la diversidad cultural y la creatividad humana, y se manifiesta en los siguientes ámbitos:

a) tradiciones y expresiones orales, incluido el idioma como vehículo del patrimonio cultural inmaterial;

b) artes del espectáculo;

c) usos sociales, rituales y actos festivos;

d) conocimientos y usos relacionados con la naturaleza y el universo;

e) técnicas artesanales tradicionales.

Los cambios conceptuales en torno al patrimonio se reflejan en varios documentos, como la Carta de Burra (1979) y en numerosas convenciones. En la actualidad, la UNESCO, fomenta el desarrollo de políticas integrales que sean capaces de responder a la dimensión social, medioambiental y económica del desarrollo sostenible. 
En este contexto, en la Convención de Patrimonio Mundial del año 1992, se difunde el concepto "Paisaje Cultural" promoviéndolo como aquel paisaje construido por la interacción entre naturaleza y la acción humana. Por lo tanto, el mundo está constituido por incontables 'paisajes culturales' como resultado de la relación hombre-entorno natural. Estos paisajes están construidos a partir de la vida diaria de las personas, de sus percepciones y son fundamentales para el sentimiento identitario y el bienestar de la gente. El concepto de paisajes culturales reconoce que las acciones humanas no pueden separarse de aspectos del paisaje, incluyendo su ecología, patrimonio y economía, o las creencias. En el año 2000, la Unión Europea reconoció la importancia de gestionar los paisajes culturales de una forma eficaz, dando lugar a la mencionada Convención Europea de Paisaje (ratificada por Francia, España y el Reino Unido, en 2006), que ha influido en la política de los gobiernos y enfatizado el desarrollo de formas de gestión de estos paisajes en un marco sostenible. Según este concepto, es posible entender, que los $\mathrm{CH}$ configuran infinidad de paisajes culturales.

Con el objetivo de promover la defensa del patrimonio, la UNESCO ha creado el concepto de 'Patrimonio Mundial', para la protección de lugares de un Valor Universal Excepcional (VUE), y los entiende ${ }^{18}$ como aquellos que poseen "una importancia cultural y/o natural tan extraordinaria que trasciende las fronteras nacionales $y$ cobra importancia para las generaciones presentes y venideras de toda la humanidad. Por lo tanto, la protección permanente de este patrimonio es de capital importancia para el conjunto de la comunidad internacional". (WHC 2008).

Para contar con VUE es necesario cumplir con determinados criterios detallados en las Directrices. A su vez, para ser considerado de Valor Universal Excepcional, el bien también debe reunir las condiciones de "integridad" 19 y/o "autenticidad"20" y debe contar con un sistema de protección y gestión adecuado que garantice su salvaguardia ${ }^{21}$. Según el tipo de patrimonio cultural y su contexto cultural, puede estimarse que un bien reúne las condiciones de "autenticidad" si su valor cultural se expresa de forma fehaciente y creíble a través de diversos atributos, como: forma y diseño; materiales y substancia; uso y función; tradiciones, técnicas y sistemas de gestión; localización y entorno; lengua y

18. En el Documento "Directrices Prácticas para la aplicación de la Convención del Patrimonio mundial de UNESCO" (2008)

19. Además de tratarse este concepto en varios documentos, en el año 2012, se ha realizado en Emiratos Árabes Unidos un Encuentro para tratar la Integridad del Patrimonio cultural.

20. La Carta de Nara de Autenticidad y la Declaración de Yamato, ambas del año 2004, ahondan en el concepto de Autenticidad.

21. Se entiende como "salvaguardia" a la aplicación de todas aquellas acciones tendientes a la protección de un bien. 


\section{EL CENTRO HISTÓRICO COMO PAISAJE URBANO HISTÓRICO - El desafío de intervenir}

otras formas de patrimonio inmaterial; espíritu y sensibilidad; y otros factores internos y externos.

Por otra parte, la "integridad" mide el carácter unitario e intacto del patrimonio natural y/o cultural y de sus atributos. Por ello, para examinar las condiciones de integridad es preciso evaluar en qué medida el bien posee todos los elementos necesarios para expresar su VUE; tiene un tamaño adecuado que permita la representación completa de las características y los procesos que transmiten la importancia del bien; y acusa los efectos adversos del desarrollo y/o las negligencias. Por lo tanto, todos aquellos patrimonios que posean VUE, son ingresados en la Lista del Patrimonio Mundial, y deben responder con un modelo de gestión determinado, para que la protección y gestión garanticen la permanencia.

Siguiendo estas premisas, desde el año 1978 a la actualidad, son numerosos los $\mathrm{CH}$ que se han incluido en la Lista de Patrimonio Mundial de la UNESCO. Sin embargo, el hecho de que un sitio no posea declaración de UNESCO, no significa que no albergue un valioso patrimonio urbano, material, inmaterial o ambos, sino que quizás no ha logrado reunir todos los requisitos que la UNESCO demanda. A su vez, no siempre la declaración de un sitio como Patrimonio de la Humanidad resulta tan beneficioso como se espera, en muchos casos, las transformaciones que se generan no logran atender rápidamente a impactos no deseados, y en la valoración bajo mismos criterios a sitios muy diversos a nivel mundial, se terminan homogeneizando áreas que albergaban valores muy heterogéneos, y poblándose de turistas sitios que terminan conformando museos a cielo abierto, que alteran las dinámicas del sitio.

En este marco, Pérez Escolano (2007) afirma que: "el patrimonio vivo debe ser comprendido en una escala urbana y territorial integral, optimizando su conocimiento, desarrollando los instrumentos para una precisa interacción entre planificación e intervención, atendiendo al paisaje cultural como nueva referencia para actuar previsoramente y con rigor contemporáneo. El patrimonio, integrador de lo tangible e intangible, constituye un activo para la gestión y el progreso sostenibles de la ciudad histórica. La vitalidad de los $\mathrm{CH}$ ha de contribuir al reforzamiento de los valores colectivos, estimular la sensibilidad, la educación, los intercambios y la creatividad productiva (la calidad en el diseño, la arquitectura y los oficios). El patrimonio es un bien escaso y frágil por lo que su planificación y gestión deben integrar el principio de sostenibilidad, en particular evitando la sobreexplotación de los $\mathrm{CH}$ sometidos al exceso turístico, el caos circulatorio y la especulación. La concertación, la transversalidad, la participación ciudadana son atributos imprescindibles para alcanzar una planificación y una gestión eficaces. La identidad patrimonial, entendida como registro 


\section{EL CENTRO HISTÓRICO COMO PAISAJE URBANO HISTÓRICO - El desafío de intervenir}

vivo de la memoria, reside en los espacios abiertos de sociabilidad tanto como en los espacios construidos, nunca en las falsas escenografías y el fachadismo, y se sustenta en la diversidad, la contextualización, la autenticidad, la multifuncionalidad y el valor de contemporaneidad".

Melé (2006) agrega que la política patrimonial es la que permite la identificación de un $\mathrm{CH}$, y que aquellas surgidas en los 70 y generalizadas en los 80 , han logrado proteger edificios y al mismo tiempo, crear un freno a transformaciones que propiciaban la destrucción del conjunto de estas áreas históricas. A su vez, sostiene que el interés por preservar la estructura de los $\mathrm{CH}$, ha sido una manera novedosa de pensar el futuro de estas áreas.

La necesidad de intervenir los $\mathrm{CH}$ plantea la aparición de una gran cantidad de "actores o sujetos patrimoniales". De este modo, Carrión (2003) sostiene que esta definición implica que lo patrimonial existe en la medida que uno o varios sujetos lo reconozcan, apropien y protejan como tal. Los mismos pueden identificarse según ámbitos: locales, provinciales, nacionales o internacionales; según a origen público, privado o comunitario: o a funciones comerciales, administrativas o de servicios. Estos sujetos o actores patrimoniales como la cooperación internacional (UNESCO, BID), los vendedores callejeros (cooperativas, asociaciones), los propietarios inmobiliarios (predios, edificios), el capital (comercial, industrial), la iglesia, entre otros tantos, deben ser entendidos de acuerdo a la dimensión que cobran en el proceso de producción-reproducción del $\mathrm{CH}$ en cada momento particular. $\mathrm{El}$ vínculo entre los actores patrimoniales y su responsabilidad en la transmisión generacional de este legado, propone el tratamiento de cuestiones como el derecho a la ciudad ${ }^{22}$, de la dimensión colectiva del patrimonio, del carácter público de esta creación social, y de la necesidad de democratizar el patrimonio para que sea efectiva su renovación.

Coulomb (2009) advierte que muchas veces los $\mathrm{CH}$ corren el riesgo de homogeneización cultural a causa de la globalización. Donde la búsqueda de productos accesibles (informativos, culturales o turísticos) deriva en un reduccionismo cultural de los $\mathrm{CH}$ que incide en la construcción de imaginarios, y donde la conservación se basa en falsos procesos de apropiación colectiva del patrimonio cultural urbano. A su vez, este reduccionismo cultural conlleva también un reduccionismo espacial y funcional.

Por otra parte, muchas intervenciones que se realizan sobre el patrimonio cultural no proponen una relación armónica entre pasado y presente, memoria y futuro. Es necesario debatir sobre las nuevas intervenciones, la incorporación y creación de

22. Término introducido en el año 1968 por el filósofo y sociólogo francés Henr Lefebvre en su libro "El derecho a la ciudad". Este concepto se profundizará en el Capítulo 2. 
arquitectura contemporánea con valores propios que dialogue con el patrimonio cultural existente. En la actualidad, muchas actuaciones son impulsadas con el propósito de reposicionar una ciudad a nivel local o internacional, lo que genera importantes ingresos. Por lo tanto, resulta preciso planificar las funciones atribuidas, la especialización, la llegada de recursos a través de canales diversos, incluidos los de la industria cultural ${ }^{23}$, las nuevas infraestructuras, dado que es necesaria la adaptación del $\mathrm{CH}$ a las nuevas demandas, en el marco de medidas preventivas, compatibles con una situación creativa y de renovación. Interesa pensar el patrimonio cultural, los bienes culturales, como un sistema que involucra tanto al $\mathrm{CH}$ como al resto de la ciudad que es factible de proponer nuevas relaciones acorde a un desarrollo sostenible (Salmerón, 2007).

Por lo expuesto previamente, resulta imprescindible no sólo plantear estrategias y políticas que se circunscriban a los límites del área identificada como $\mathrm{CH}$, sino que es necesario ampliarlas a las zonas circundantes, y que por tanto funcionan como fuelle con el resto de la ciudad y los barrios que se han ido conformando con el crecimiento de la misma.

23. Industria cultural: concepto introducido por los teóricos alemanes Theodor Adorno y Max Horkheimer (1944-1947). Hace referencia al conjunto de sectores destinados a la producción, promoción, difusión y comercialización de bienes, servicios y actividades de contenido cultural, artístico o patrimonial. En la actualidad se habla de Industrias culturales y creativas.
1.4.1.1 Los límites de la intervención: las zonas de amortiguamiento

"En el manejo de las áreas urbanas preservadas, se ha dado prioridad a la conservación de lo que en términos de patrimonio cultural se denomina monumentos, e incluso en algunos casos, sus calles o plazas adyacentes. Sin embargo, tal visión no impulsa ni la articulación del entorno protegido con el paisaje que sustenta a la ciudad, ni con el conjunto urbano al que dio origen el $\mathrm{CH}$ salvaguardado. Estas limitantes han sido superadas en tiempos recientes con la inclusión y definición de áreas de amortiguamiento" (Garza Merodio, 2011).

Las zonas de amortiguamiento, zonas tampón o buffer zone en inglés, han sido definidas en las Directrices Prácticas para la aplicación de la Convención del Patrimonio Mundial de la UNESCO, como "las áreas alrededor del bien cuyo uso y desarrollo están restringidos jurídica y/o consuetudinariamente a fin de reforzar su protección" (WHC, 2009). Es un concepto que como afirma Lalana Soto (2010), proviene de la gestión de las áreas naturales, y en su acepción más común se ha venido entendiendo como un "escudo", un área de protección que actúa separando dos usos considerados incompatibles. Sin embargo y aunque en determinados casos todavía se aplica con este significado, con el tiempo se ha ido imponiendo una visión más vinculada a los conceptos de transición 


\section{EL CENTRO HISTÓRICO COMO PAISAJE URBANO HISTÓRICO - El desafío de intervenir}

y de conexión, y se ha ampliado, en los dos sentidos, al campo del patrimonio cultural. Estas zonas surgen con la finalidad de proteger un Bien inscripto en la Lista del Patrimonio Mundial, de problemas que se originan fuera de sus límites, para preservar y realzar su integridad, y por otro lado, establecer o facilitar relaciones entre el área protegida y la más amplia que la rodea.

Por lo tanto, como sostiene Garza Merodio, resulta importante para un $\mathrm{CH}$ la definición de su zona núcleo, concentradora de monumentos y vías de gran valor cultural, económico y político, y de su zona de amortiguamiento, que aunque puede carecer de patrimonio valiosos a preservar, su incorporación es necesaria para explicar las diversas dinámicas por las que ha atravesado la ciudad. Generalmente, en las zonas de amortiguamiento predomina la función residencial, en consecuencia, se requiere de una gestión participativa que permita la conservación del patrimonio y la inclusión de los habitantes, (que muchas veces por sus condiciones económicas no se sienten incluidos). Para ello, debe estudiarse las características de las propiedades de estas áreas y de sus habitantes. La ampliación de los límites, facilita una mejor interpretación del paisaje que sustenta las continuas transformaciones urbanas, y una mejor vinculación con su entorno.

Estas áreas de amortiguamiento, permiten la protección del valor excepcional del bien, aunque en algunos casos, al no formar parte del bien propuesto $O$ no ser obligatorias, han generado inconvenientes debido a ciertas indefiniciones en cuanto a su terminología, definición de límites o el grado de protección. Así pues, la debilidad o inexistencia de mecanismos legales ha propiciado la localización en estas áreas de amenazas (estructuras fuera de escala y contexto), que afectan a los bienes patrimonio tanto desde las visuales como en la promoción de usos que generan fuertes impactos, como el turismo masivo o grandes desarrollos inmobiliarios y comerciales. (Guzmán, 2011)

Lalana Soto (2011), recuerda también que la preocupación por el tratamiento del concepto "Paisajes Urbanos Históricos" (PUH), surge a partir de un gran proyecto urbanístico localizado en la zona de amortiguamiento de la ciudad de Viena, donde en el año 2001 se recomendaban modificaciones al proyecto y por tal motivo se amenazó con quitar al Bien de la Lista de Patrimonio Mundial. Algo similar sucedió en otras ciudades, destacándose el caso de la Catedral de Colonia, Alemania, donde a raíz de otro proyecto ferroviario en la zona de amortiguamiento, fue incluida en la Lista de Patrimonio Mundial en Peligro del año 2004, paso previo a la eliminación de la Lista de Patrimonio de la Humanidad. Otro caso de gran alcance fue el de Sevilla, donde en el año 2012 se recomendó paralizar una torre del arquitecto Pelli y disminuir su altura por el impacto negativo en el área de amortiguamiento, caso contrario sería incluida dentro de la Lista de Patrimonio en Peligro. 


\section{EL CENTRO HISTÓRICO COMO PAISAJE URBANO HISTÓRICO - El desafío de intervenir}

No obstante, se acuerda con Guzmán, que las zonas de amortiguamiento no deben ser interpretadas como una limitante espacial, sino como una herramienta más que puede facilitar el trabajo de conservación. Dichas áreas pueden presentar potencialidades funcionales y de interacción social, económica y desarrollo, que pueden conjugar el patrimonio cultural y sus beneficios como fomento al desarrollo, y que desde su intervención en el espacio público, integrador por excelencia, pueda ser el medio que promueva la vinculación del $\mathrm{CH}$ con el resto de la ciudad.

\subsubsection{Espacio Público}

Como expresa Ortiz Guitart (2006), "El interés de la geografía por el lugar, el sentido de lugar y el sentido de pertenencia se inicia con la geografía humanística aparecida a principios de los años setenta y será desarrollada, desde otra perspectiva, años más tarde, por la geografía cultural. El enfoque humanista valora por encima de todo las experiencias humanas y declara que "no existe un mundo único y objetivo, sino una pluralidad de mundos, tantos como actitudes e intenciones" del ser humano (García Ramón, 1985). Los lugares, por tanto, están llenos de significados y tienen una dimensión existencial, una vinculación emocional con el ser humano y se relacionan siempre con un espacio concreto y con unos atributos bien definidos (García Ballesteros, 1989). El sentido de lugar, considera el lugar como una construcción social o una subjetivización de los lugares y permite analizar la forma como el espacio, entendido como algo abstracto y genérico, se convierte en lugar gracias a la experiencia y a la acción de los individuos que, viviéndolo cotidianamente, lo humanizan y llenan de contenidos y significados" (Massey, 1995).

En esta misma línea, Gerard Althabe (1999), sostiene que la transformación del centro de las ciudades en patrimonio supone una articulación entre la producción de lugares, la valoración de un pasado urbano y, al mismo tiempo, la producción de una identidad urbana ligada a la centralidad. "iEs imposible separar la noción de centralidad de estas transformaciones del lugar urbano en patrimonioi para construir una imagen de la ciudad como una realidad con su singularidad propia!". De esta forma, identifica una doble producción de patrimonio urbano, "la interna", identificatoria, y que se realiza en el marco de prácticas de producción de identidades colectivas, y "la externa", que posee un sentido comercial: el turista es la mirada exterior que participa en la elaboración de las identidades colectivas. Por lo tanto, la noción patrimonio es esencialmente externa. Es asunto de los poderes y de los intelectuales (arquitectos, sociólogos, entre otros) que aconsejan a estos poderes. En este sentido, toda intervención efectuada sobre el espacio público es generadora de diferentes 


\section{EL CENTRO HISTÓRICO COMO PAISAJE URBANO HISTÓRICO - El desafío de intervenir}

opiniones y discusiones, que tienen distintas miradas y que pretenden diversos "lugares" según el actor al que involucre.

Gerard Althabe (2000), señala que esta vivencia individual, no colectiva de lo urbano, juega una marginalización en relación con el espacio como uso social y lugar de pertenencia; y analizando esta transformación de las prácticas sociales en el espacio, Marc Augé (1992-1998) expresa que la sobremodernidad es productora de "no lugares", es decir, de espacios que no son en sí lugares antropológicos (identificatario, relacional e histórico), y que no integran los lugares antiguos. El espacio del "no lugar" no crea identidad, singularidad, ni relación, sino soledad y similitud. Tampoco le da lugar a la historia. Y "la historia de la ciudad es la de su espacio público. Las relaciones entre los habitantes y entre el poder y la ciudadanía se materializan, se expresan en la conformación de las calles, las plazas, los parques, los lugares de encuentro ciudadano, en los monumentos. La ciudad entendida como sistema, de redes o de conjunto de elementos - tanto si son calles y plazas como si son infraestructuras de comunicación (estaciones de trenes y autobuses), áreas comerciales, equipamientos culturales es decir espacios de uso colectivos debido a la apropiación progresiva de la gente - que permiten el paseo y el encuentro, que ordenan cada zona de la ciudad y le dan sentido, que son el ámbito físico de la expresión colectiva y de la diversidad social y cultural. Es decir que el espacio público es a un tiempo el espacio principal del urbanismo, de la cultura urbana y de la ciudadanía. Es un espacio físico, simbólico y político". (BorjaMuxí, 2000)

El $\mathrm{CH}$ es el área que más cambia de la ciudad, que más se adapta, es el espacio público por excelencia, un ámbito de relación y de encuentro, donde la población se socializa, informa y expresa cívica y colectivamente, gracias a su condición de centralidad y por la heterogeneidad de gente, funciones, tiempos y espacios que contiene. Es reconocido por el todo y no por partes aisladas, es un "espacio de todos" que otorga identidad colectiva y que posee una gran carga simbólica. A su vez, concentra particularidades del marco legal (leyes, ordenanzas, códigos e inventarios particulares) y alberga las múltiples organizaciones públicas que conforman el marco institucional (nacional, local y autónomo). (Carrión Mena, 2008)

El espacio público, no solo es considerado un indicador de calidad urbana, sino que también es un instrumento de la política urbanística para intervenir en la ciudad, recualificar periferias y áreas degradadas, y recuperar el uso ciudadano. El espacio público favorece la mistura social, y debe garantizar la apropiación por parte de diferentes grupos sociales y culturales, de género y de edad. "El derecho al espacio público es el derecho a ejercer como 
ciudadano que tienen todos los que viven y que quieren vivir en las ciudades". (Borja-Muxí, 2000)

Ampliando lo antedicho, Santos (1996), afirma que "el espacio no es ni una cosa ni un sistema de cosas, sino una realidad relacional: cosas y relaciones juntas. (...) El espacio debe considerarse como el conjunto indisociable del que participan, por un lado, cierta disposición de objetos geográficos, objetos naturales y objetos sociales, y por otro, la vida que los llena y anima, la sociedad en movimiento. El contenido (de la sociedad) no es independiente de la forma (los objetos geográficos): cada forma encierra un conjunto de formas, que contienen fracciones de la sociedad en movimiento. Las formas, pues, tienen un papel en la realización social" y es necesario en los procesos de intervención y gestión proponer estrategias que incluyan mecanismos de apoyo a la iniciativa ciudadana, que deben ir acompañadas del mejoramiento del espacio público. Se requiere atender a la diversidad ciudadana, protegiendo la vida diaria de los habitantes que incorpore también a los más vulnerables, para garantizar que este espacio sea un hecho colectivo (Sepúlveda Voulliéme, 2004).

El $\mathrm{CH}$ conjuga una gran cantidad usuarios, (residentes, trabajadores, turistas, estudiantes,...) es un sector de referencia colectivo, cargado de significado histórico y muchas veces carente de valores y significados contemporáneos. En él, la participación ciudadana es clave para la continuidad del espacio público. La mezcla de usos, población, espacios, y actividades es fundamental para su permanencia, y en ello es fundamental la aplicación de políticas urbanas integradas. Transporte, vivienda, cultura, educación, trabajo, salud, comercio... todo ello debe integrarse a través del espacio público en el $\mathrm{CH}$, creando sistemas de espacios que garanticen la continuidad y la apertura. (Muxí, 2004)

En esta misma línea, Herce Vallejo (2001), plantea que entender el espacio público significa valorizarlo, pensarlo para todos y no sólo para ciertas áreas de la ciudad o como remanente del espacio del automóvil, recuperando la calle para el paseo, intercambio y multiplicidad de actividades. Se requiere desde el sector público, fórmulas imaginativas para conseguir recursos, y una administración más preocupada por conseguir de cada gran operación privada un buen entorno para la ciudad, que por discutir trabas a agentes inversores. Las ciudades que han fundamentado sus actuaciones en el espacio público y la ciudadanía, han comprobado el efecto de estas mejoras de urbanización sobre la creación de actividad económica y la propia vida en las calles. Una de las formas más eficaces de recuperación del espacio público y de generación de renta indirecta para la población, es el ordenamiento del transporte público. Limitando y regulando el espacio para vehículo privado. 


\section{EL CENTRO HISTÓRICO COMO PAISAJE URBANO HISTÓRICO - El desafío de intervenir}

Cañavale (2004) coincide con Herce Vallejo en que la introducción del automóvil produce la gran crisis del espacio urbano, y que en la actualidad existe un nuevo espacio urbano, el espacio digital, el ciberespacio público, y que debemos comenzar a concebir este nuevo tipo de fenómeno urbano que articula el espacio real con el virtual, donde el proceso de urbanización del espacio está siendo continuado por un proceso de urbanización del tiempo.

Por lo tanto, es evidente que la velocidad de los flujos, las redes y los nuevos sistemas tecnológicos introducen en los espacios públicos nuevas temporalidades, generando lugares de circulación más que de encuentro, donde la identidad y los significados se modifican en un nuevo contexto espacio-temporal complejo. Para intervenir en esta realidad, es necesario replantear las herramientas de análisis y los mecanismos de actuación que posibiliten que la dinámica de aceleración-degradación pueda ser sustituida por la de conservación-transformación. (Rubio González, 2004)

Bajo esta óptica, el arquitecto danés Gehl (2011) hace hincapié en la humanización del espacio público, es decir, en pensar ciudades a escala humana, para la gente y no para los automóviles, y en ese sentido plantea que el espacio público, la calle, las plazas, el espacio entre edificios debe brindar áreas para el desarrollo de múltiples funciones humanas que permitan la apropiación..."Da igual de donde eres, los fundamentos son muy similares. Los humanos somos previsibles. Si creas buenos espacios acudirán en masa. Si el espacio es malo, lo abandonarán"

\subsubsection{Multifuncionalidad}

Los $\mathrm{CH}$ han experimentado numerosos cambios de funcionalidad a lo largo de su historia que han incidido en su apogeo o abandono, y "de la diversidad de usos y actividades que conviven en ellos, así como en su entorno, deriva una compleja realidad funcional y social que enriquece la vida urbana de estos espacios y les da singularidad" (Fernández Salinas, 1999). La riqueza de la vida urbana los constituye en sectores propicios para las relaciones sociales, y es por ello que en algunos casos las funciones religiosa, administrativa, comercial o residencial han dado lugar a funciones cultural, simbólica y turística.

Como expresa Ferrer Regales (2000), la multifuncionalidad es uno de los rasgos que otorga identidad propia a los $\mathrm{CH}$ de las ciudades, por lo tanto, mantenerla es un reto para su permanencia como realidades sociales vivas; sin embargo, no resulta sencillo poner en marcha políticas integradas de recuperación que, más allá de las dimensiones arquitectónicas, afronten en profundidad cuestiones funcionales y sociales. Para evitar la museificación de los $\mathrm{CH}$, sin descuidar su protección, deben lograr la reutilización funcional de su patrimonio cultural, y en ese sentido, la función residencial juega 


\section{EL CENTRO HISTÓRICO COMO PAISAJE URBANO HISTÓRICO - El desafío de intervenir}

un rol decisivo, porque es quien garantiza la heterogeneidad social. El vaciamiento residencial, que se ahondará en el próximo capítulo, tiene un efecto muy negativo, pero también puede tenerlo la elitización al empobrecer la vida urbana y las relaciones sociales. Una política de recuperación urbana, si no tiene las precauciones oportunas, puede provocar un encarecimiento del precio de suelo y hacer difícil la permanencia o la entrada de familias de rentas medias o bajas, hechos que desencadenan en el fenómeno de gentrificación ${ }^{24}$. El problema funcional deriva, por un lado, de la competencia entre usos residenciales, turísticos, culturales, comerciales o dotacionales, por la ocupación de un suelo escaso, y, por otro, de la crisis de funciones que les llenaron de vida durante siglos, como la residencial, la comercial o la religiosa.

"Se debe tener en cuenta que los $\mathrm{CH}$, para ser tales, deben ser heterogéneos en términos de la pluralidad de las funciones centrales que concentran, deben contar con una importante noción de antigüedad y deben ser un elemento medular de las relaciones interurbanas. Eso significa que todas las centralidades urbanas son históricas. Por eso, cualquier actuación que se realice en este territorio debe potenciar la relación entre las múltiples funciones

24. Gentrificación en un término acuñado en el año 1964 por la socióloga británica Ruth Glass, (proveniente del ingles gentry, alta burguesía) para referirse al reemplazo de los antiguos pobladores de un barrio por habitantes de mayor poder adquisitivo, este fenómeno tiene origen comúnmente como resultado de procesos de intervención. En el capítulo 2, se profundizará en esta problemática de los $\mathrm{CH}$. centrales y fortalecer una saludable concepción intersectorial; esto es, una condición relacional donde lo central debe expresarse históricamente a través de los enlaces sectoriales y territoriales dentro y fuera de la zona considerada como tal- y los vínculos entre los múltiples sujetos patrimoniales que las encarnan. Esta afirmación finalmente se expresa en que los $\mathrm{CH}$ no se definen exclusivamente por los atributos monumentales o por la población residente en ella, sino por las relaciones que determinan la condición y cualidad central: el tiempo (historia) y el espacio (concentración funcional)". (Carrión Mena, 2009).

Con esta misma idea, Borja (2001) amplía que cuando los $\mathrm{CH}$ no se especializan y se homogeneizan resultan todos parecidos, y se inician en ellos procesos de degradación y marginalidad, con desequilibrios funcionales y estigmatizados desde la pobreza y la inseguridad. En la actualidad, hay que intervenir sobre los centros, creando nuevas centralidades y ejes que permitan la continuidad física y simbólica de la ciudad, integrando lo histórico y lo nuevo, y favoreciendo la mixtura social y funcional en todas las áreas.

Por lo tanto, de acuerdo con Troitiño Vinuesa (2003), es necesario que la innovación en la intervención de los $\mathrm{CH}$ se centre en la búsqueda de nuevos equilibrios que, siendo respetuosos con los valores urbanísticos, culturales, sociales y funcionales de la ciudad del pasado, den respuesta a los problemas y necesidades actuales. 
Siendo uno de los retos de futuro la preservación, la multifuncionalidad, la revitalización funcional y la mejora de la calidad de vida de los residentes, que deberían constituir prioridades de la intervención y de la gestión.

Alonso Velasco (2004) agrega que la revitalización ${ }^{25}$ de cualquier espacio urbano degradado está condicionada a la creación de equipamientos urbanos que el mismo sector demande, y el efecto es superador cuando estos espacios se relacionan con otras áreas de la ciudad. En este sentido, sostiene que los equipamientos culturales, en todas sus variantes y tipologías, (centros de enseñanza más o menos especializados, centros culturales, etc.), son siempre focos de atracción de población, y se convierten en integradores del área histórica con el resto de la ciudad. Al mismo tiempo, insiste en que el grado de vitalidad de un espacio histórico, la cantidad de actividades que en él se produzcan, estará en íntima dependencia con sus equipamientos culturales, que poseen una rápida adaptabilidad a los $\mathrm{CH}$, y que entendidos como bienes de interés cultural demandan nuevas funciones.

El mismo autor también aporta que el nivel de vitalidad urbana mantiene una íntima dependencia con su equipamiento comercial. Varios $\mathrm{CH}$ poseen funciones de centralidad comercial en proceso

25. Revitalización: estrategia de intervención urbana que pretende recuperar o dar nueva vida o función a un sector urbano degradado. Esta estrategia se profundizará en el próximo capítulo. de desaparición. Los comercios que aún subsisten constituyen un tipo de actividad privada sobre la cual no es posible actuar directamente desde instancias administrativas. Regenerar un tejido comercial en decadencia en un área urbana que ha perdido su condición de "centralidad económica", es una tarea de muy difícil solución si no se realiza previamente la revitalización del barrio y su reintegración a la vida social de la ciudad.

En relación a este tema, Bayón (2004) asume que los $\mathrm{CH}$ han albergado todo tipo de usos: habitacional, de servicios (comercial, hostelero, burocrático, financiero, sanitario...), artesanal e industrial, de los cuales los dos últimos han ido desapareciendo. En parte, a que los artesanos dejaron de existir, y porque las industrias necesitaron mayores espacios y resultaron incompatibles con la función residencial. En esta transformación, han quedado dentro del tejido edificios industriales abandonados (fábricas, subestaciones eléctricas, antiguos depósitos de agua, instalaciones gasísticas...), que en la última década del siglo $\mathrm{XX}$, han intentado recuperarse para otros usos compatibles con la vida contemporánea.

La reactivación de viejas infraestructuras, sean industriales, residenciales, comerciales, religiosas o culturales, y del valioso espacio público que las vincula, conllevan en la mayoría de los casos el incremento de la actividad turística, (que se abordará en el 
próximo capítulo). Al respecto, Venturini (2006) manifiesta que la transformación del patrimonio construido en atractivo turístico no requiere sólo de infraestructuras viales y equipamientos hoteleros sino, esencialmente, de estrategias urbanas que incorporen las dimensiones sociales, urbanísticas y económicas, con nuevas políticas de recuperación del patrimonio y de planificación estratégica urbana, así como de nuevos mecanismos de cooperación entre actuaciones del sector público y el sector privado, que garanticen la vitalidad de estos centros asegurando su recuperación social y su multifuncionalidad. Esto significa asumir que el $\mathrm{CH}$ es un capital de sus habitantes que comparten con los visitantes, por lo cual no es aceptable excluir a la población local de las operaciones de refuncionalización del patrimonio. Ello implica asumir al patrimonio como capital estratégico de la ciudad capaz de desempeñar un rol de agente dinamizador de los procesos de desarrollo urbano.

Para concluir este tema, interesa insistir en que la multifuncionalidad, tiene lugar siempre que el uso principal que debe albergar un $\mathrm{CH}$, el residencial, continúe siendo el motor que motive la aparición de todas aquellas funciones complementarias. Como afirma Carrión Mena (2000), la mayoría de las construcciones de los $\mathrm{CH}$ son viviendas, y aunque el tratamiento de esta temática es nuevo en los $\mathrm{CH}$, incorpora otra escala de intervención, el pequeño patrimonio, integra el sentido social que supera al edificio, replantea políticas de vivienda ahora con foco en el mejoramiento y rehabilitación de preexistencias, y acarrea con ella infinidad de temas urbanos (suelo, accesibilidad, servicios), económicos (mercado inmobiliario, subsidios, impuestos, producción), sociales (calidad de vida, empleo, sentido comunitario, demográficos) políticos (organización, instituciones, actores), y culturales (identidades, barrios, residentes).

\subsubsection{Residencialidad}

La consideración de la vivienda como elemento patrimonial le otorga una nueva dimensión al concepto y a la intervención en los $\mathrm{CH}$, y por lo tanto, en toda la ciudad. En este marco, el sentido social del patrimonio y de los $\mathrm{CH}$ no está ausente de las políticas de renovación ${ }^{26}$, dado que involucra a un conjunto de sujetos patrimoniales que actúan en defensa de sus intereses: inquilinos, capital inmobiliario, cooperación internacional, tecnócratas, propietarios y comerciantes ambulantes, entre otros. (Carrión Mena, 2009).

Pero este pequeño patrimonio de los $\mathrm{CH}$ suele encontrarse en muchos casos en malas condiciones, en edificios deteriorados, en ruinas, con humedades o falta de ventilación, con carencia de

26. Renovación: estrategia de intervención urbana que pretende recuperar la imagen de un sector urbano. Esta estrategia se ampliará en el capítulo 2. 


\section{EL CENTRO HISTÓRICO COMO PAISAJE URBANO HISTÓRICO - El desafío de intervenir}

servicios básicos, con dimensiones mínimas y con dificultades de accesibilidad. Y como afirma Leal Maldonado (2004), en varias ocasiones la intervención sobre estas viviendas se limita a un lavado de cara exterior, interviniendo sobre las fachadas pero sin mejorar las condiciones interiores de las mismas. Esta actuación parcial no aborda la dificultad de sus moradores propietarios para afrontar los gastos de rehabilitación, ni enfrenta al problema que supone a veces una pérdida del patrimonio construido. Muchos $\mathrm{CH}$ contienen una gran cantidad de viviendas en mal estado donde encuentran lugar de residencia las minorías marginadas.

El mismo autor, plantea que para intervenir sobre la función residencial de un $\mathrm{CH}$, es necesario analizar el impacto que se va a generar sobre los comportamientos residenciales de sus habitantes, y al respecto, aporta una clasificación de estos comportamientos en tres categorías:

- La movilidad residencial en los $\mathrm{CH}$ : que es más elevada que la media de la ciudad, por la existencia de mayor proporción de viviendas en alquiler, que puede producir un cambio más rápido en la composición social que en el resto de la ciudad. Existen algunos procesos que les afectan: la "gentrificación", que en algunas ciudades da origen a una transformación social completa del centro y con ella, a un cambio de imagen. A su vez este fenómeno puede acarrear otros dos procesos: el envejecimiento progresivo de las zonas, con un descenso de la capacidad económica de sus habitantes y una obsolescencia de las viviendas que supone el deterioro de las mismas; y la“ invasión y sucesión" (descrito así por la Escuela de Chicago) que refiere a la capacidad del centro para atraer a las minorías, a inmigrantes extranjeros que buscan una vivienda económica de alquiler y cercana al trabajo. Una vez que el flujo de inmigrantes llega a una dimensión determinada, los antiguos residentes empiezan a abandonar el barrio a causa de razones culturales como dificultades para convivir con otras culturas y otras expresiones (ruidos, olores, etc..), y a razones económicas ante el miedo de la pérdida de valor de la propia vivienda, afectada por una imagen del barrio que supone una pérdida de su valor social.

- El acceso y la tenencia de la vivienda: Los CH poseen una mayor proporción de inquilinos que la media, debido a diversas causas. Una de ellas puede ser la continuidad de casos donde persiste la situación original donde un único propietario posee todo un edificio, y las distintas unidades son ofrecidas en alquiler. Otra, es que en el $\mathrm{CH}$ se registra una mayor demanda de este tipo de viviendas como lugar de residencia por hogares que tienen una situación transitoria, ya sea por motivos laborales, educativos, familiares o económicos.

- El uso de las viviendas y del entorno residencial: existe un aumento de las segundas viviendas en los $\mathrm{CH}$ debido a diversos motivos. Uno de ellos, es la propia atracción de estas áreas como lugar de residencia alternativa a la residencia permanente. Otro, es 


\section{EL CENTRO HISTÓRICO COMO PAISAJE URBANO HISTÓRICO - EI desafío de intervenir}

el mantenimiento de estas viviendas por individuos que teniendo su residencia permanente en otro lugar, tienen que residir durante el tiempo de trabajo en la ciudad. Finalmente, existen situaciones donde ciudadanos que deciden vivir en la periferia de la ciudad mantienen la residencia del $\mathrm{CH}$ como vivienda secundaria por proximidad al trabajo y/o por la oferta cultural que concentran los centros.

Por lo expuesto previamente, las políticas de vivienda, como explica González Tamarit (2001), constituyen un instrumento privilegiado de intervención y de recuperación en la ciudad, que posee influencia directa en aspectos como:

- La regulación de los modos de funcionamiento del mercado del suelo urbano y del mercado inmobiliario (control sobre el crecimiento y ordenación de la ciudad).

- La resolución digna del problema del alojamiento de colectivos sociales desfavorecidos.

- La contribución a la fijación de población en el caso de los $\mathrm{CH}$, y por su capacidad potencial de favorecer la heterogeneidad social.

- La recuperación del patrimonio edificado.

- La creación de una nueva cultura urbana basada en la valoración y el respeto hacia la ciudad heredada.
- La garantía de integración de políticas sectoriales en el marco de la planificación, competencia de la administración pública.

- La posibilidad de poner en marcha políticas de acuerdo y consenso con los principales agentes económicos y sociales que operan en el sector inmobiliario.

- La aplicación de recursos económicos y la integración de otro tipo de recursos en operaciones cuyo atractivo inicial para la iniciativa privada suele ser escaso.

En este sentido, discutir temas de vivienda no solo es importante para validar políticas que orientan a que el destino de muchas de las edificaciones heredadas sean usadas con su uso original, sino porque es necesario reflexionar sobre las múltiples miradas y significados e imaginarios comunitarios de vivir en el centro, y las dificultades de aplicación de políticas de vivienda. En la actualidad, los $\mathrm{CH}$ y su medio construido son vistos y entendidos como una nueva oferta de mercado y oportunidad de negocios, y la vivienda no escapa a ello. Se convierten por lo tanto en un espacio de disputa entre lo público y lo privado, y reactivan la discusión sobre el entendimiento del patrimonio cultural como un "bien común", sus valores y sus símbolos comunitarios que trascienden el tiempo (antiguo-moderno), y el espacio (centro-periferia), y que a través de las diversas intervenciones, unas veces son puestas en peligro, destruyéndolas 0 ignorándolas, 0 en otras, crean nuevas 


\section{EL CENTRO HISTÓRICO COMO PAISAJE URBANO HISTÓRICO - EI desafío de intervenir}

identidades y nuevas herencias. Muchas veces, las inversiones que se realizan en los $\mathrm{CH}$ incrementan las rentas del suelo que inciden en la accesibilidad de la vivienda, generando expulsión de la población de menores recursos económicos, o incrementando la densidad habitacional, con soluciones que se alejan de los parámetros de vivienda digna, o dejando que el mercado defina las mejores opciones (Arizaga Guzmán, 2004).

Con respecto a este tema, Moreno Garcia (2001) enfatiza en la fragilidad de la vivienda como unidad tipológica para su conservación, porque afirma que la demolición de grandes estructuras como iglesias, palacios generan en la población mayor rechazo y movilización que el pequeño patrimonio. Sin embargo, la conservación de monumentos aislados atenta contra el $\mathrm{CH}$ como unidad urbana, como suele suceder en algunos $\mathrm{CH}$ declarados patrimonio mundial. Al respecto, aclara que es muy reciente la aparición de indicadores sobre la función residencial que tienen en cuenta el mantenimiento de la estructura urbana-histórica (alineaciones, parcelas, etc.), la permanencia y estado de las tipologías espaciales, o la presencia de una adecuada política residencial. Explica que en Europa es muy común en los procesos de intervención de los $\mathrm{CH}$ la sustitución funcional de la residencia por usos terciarios, el comercio o la banca, aunque, en general se siguen manteniendo la función representativa y simbólica del poder político y religioso. Existe, dificultad en respetar el derecho de los habitantes a conservar su lugar de residencia en los ámbitos centrales de la ciudad, en sus $\mathrm{CH}$, produciendo transformaciones en el tejido social, al generarse iniciativas inmobiliarias que tienden a la revalorización del suelo. Plantea que estas situaciones ocurren también en otros continentes, y que las excepciones, aparecen por la unión de voluntad política cierta y continua y de una tradición en el control democrático del poder por parte de la sociedad civil.

En el contexto de AL, Carrión Mena (2009) sostiene que se han invertido en los $\mathrm{CH}$ importantes recursos financieros que han provocado significativas transformaciones a nivel económico, urbano, cultural y social, logrando una importante revalorización del patrimonio material: los precios del suelo, los alquileres y la propiedad inmobiliaria. Sin embargo, aclara que este boom de la centralidad conlleva, como en Europa, un proceso contradictorio, el paulatino despoblamiento de habitantes residentes que arrastra el vaciamiento social. Resulta preocupante que la inversión en vivienda no garantiza que los habitantes de menores recursos económicos y residentes históricos se mantengan como sujetos patrimoniales y menos aún que se logre el repoblamiento.

Por último, Hernández Pezzi (2004) sostiene que el objetivo central de las políticas de vivienda es la vida humana como proceso de interrelación de la humanidad con la naturaleza y el medio. Con el fin de dinamizar los $\mathrm{CH}$, se interviene sobre la función residencial, 


\section{EL CENTRO HISTÓRICO COMO PAISAJE URBANO HISTÓRICO - EI desafío de intervenir}

ocupando residencias innovadoras, conectadas, accesibles, tecnológica y ambientalmente eficientes. No obstante, este interés por recuperar viviendas dignas debe incorporar el esfuerzo por vincular poblaciones de diverso origen, grupos etarios e intereses, que puedan compartir otros usos a distintas escalas, llenando de vida los $\mathrm{CH}$. Emplear el recurso vivienda como integrador físico y social, que por sí solo no hace ciudad, pero que tampoco la producen la mejora de entornos, comercios, educación, ocio y servicios en forma aislada, sino solo pensando en todos estos componentes en forma integral. Este desafío requiere de buena arquitectura y urbanismo, estrategias integrales de intervención y gestión, y sociedades que apropien todos los espacios de la ciudad.

\subsubsection{Identidad y participación ciudadana}

Ormindo de Azevedo (2001) sostiene que; "Castells (1999) y otros autores, apuntan al rescate y construcción de nuevas identidades como una trinchera de resistencia a la disolución de los valores de identidad, homogeneización cultural y derrumbe de las fronteras nacionales producida por la globalización. Esta revaloración de la identidad puede ser, en si misma, un deflagrador de cambios socioculturales positivos. Pero como las identidades están marcadas por la estructura de poder, por la historia de cada grupo, creencias religiosas e instituciones vigentes, ni todas ellas son renovadoras. Existe una gran gama de identidades que van desde aquellas que son solamente resistencia a los cambios, hasta identidades forjadoras de proyectos de futuro". Según él, las manifestaciones identitarias actuales pueden clasificarse en:

- Identidad legitimadora: ligada en su origen a las instituciones dominantes, y que sirve de base a muchos movimientos nacionalistas, étnicos y religiosos.

- Identidad de resistencia: generada por actores sociales devaluados y/o estigmatizados por la lógica de la dominación, construyendo de este modo trincheras de resistencia con base en principios que difieren o se oponen a las instituciones de la sociedad.

- Identidad de proyecto: desarrolladas por actores sociales que tornan cualquier tipo de material cultural disponible para construir una nueva identidad capaz de redefinir su posición en la sociedad $y$, de este modo, transformar toda la estructura social.

Por lo tanto, estudiar los $\mathrm{CH}$ significa para Melé (2006) tratar de comprender dos de los elementos constitutivos de la identidad de la ciudad y del hecho urbano en su inscripción espacial:

- La centralidad: las manifestaciones o las huellas de la ocupación espacial de las funciones centrales, así como las funciones simbólicas y las representaciones asociadas a los espacios centrales. 
- La historicidad: las relaciones de la sociedad local con los espacios heredados que expresan las modalidades de la relación de cada ciudad con su historia. Los espacios heredados son testimonios de los distintos estados de la organización urbana en el pasado y de las modalidades de su inscripción en el funcionamiento en la ciudad contemporánea.

En este contexto, Venturini (2004) afirma que "el patrimonio de los $\mathrm{CH}$ ha adquirido una notable importancia en el discurso sobre la ciudad, pero también en las prácticas de producción de lo urbano y en la memoria de las comunidades urbanas. Ello nos permite afirmar que el patrimonio constituye la objetivación de valores simbólicos que están en la base de la construcción social de la identidad de una comunidad, de un lugar. Por otra parte, aquella preocupación también ha conducido a reproponer la cuestión del patrimonio en términos de mayor amplitud, como patrimonio ambiental, entendiendo lo ambiental en el sentido de ambiente humano, producto de la interacción histórica entre sociedad y naturaleza, siendo la ciudad uno de sus más acabados productos y expresión, a la vez. Aquí cabe entender al patrimonio ambiental como el resultado pero también la condición de habitar humanamente (Rainis,1987). El patrimonio recoge las huellas más significativas del habitar humano: "habitar es dejar huellas" (Walter Benjamin); "habitar es construir" (Martin Heidegger). El patrimonio adquiere su pleno sentido de capital simbólico de una sociedad cuando trasciende el valor instrumental de aplicabilidad práctica de los recursos; patrimonio es aquello que, fundamentalmente, tiene valor de significación como base de la construcción de la memoria social. (...) En el plano urbano, se trata de lograr ambiente físico y social vivible, en el cual se asocien espacios públicos y privados al bienestar social, emocional y físico de los individuos y de la comunidad. Aquí el patrimonio constituye un elemento esencial, como base de los universos simbólicos que estructuran el sentido de pertenencia del individuo al lugar, lo que implica nuevos conceptos y procesos en la definición de políticas y en el planeamiento de las transformaciones urbanas".

Desde esta misma óptica, Coulomb (2001) reconoce que los gobiernos locales cada vez están más convencidos de que no es posible revitalizar un $\mathrm{CH}$ si no existe consenso, "participación y concertación ciudadana" (Declaración de Lima, 1997)27, y que resulta una tarea muy compleja porque estas áreas concentran múltiples intereses que generan ciertos interrogantes difíciles de responder, ¿Cómo conciliar el interés de los que viven en un $\mathrm{CH}$ con el de los que lo visitan? ¿A cuáles demandas responder: a las de la población residente o a las de la 'población flotante'?, ¿A quiénes hacer caso: a los vecinos, a los comerciantes establecidos,

27. Declaración de Lima: elaborada durante el Encuentro de Alcaldes de América Latina y el Caribe, de ciudades con Centros Históricos en proceso de recuperación. Lima, 1997. 


\section{EL CENTRO HISTÓRICO COMO PAISAJE URBANO HISTÓRICO - El desafío de intervenir}

a los comerciantes en vía pública, a los peatones, a los automovilistas, a los propietarios y promotores inmobiliarios, a las sociedades de defensa del patrimonio, a la industria turística, al BID...?, ¿De quién es el patrimonio urbano de los $\mathrm{CH}$ ?, ¿cuál es el sujeto patrimonial que actúa en su rescate y conservación?... de estas respuestas depende el futuro de los $\mathrm{CH}$, y de su grado de apropiación como 'patrimonio' colectivo.

La eficiencia de las políticas de preservación y desarrollo del patrimonio dependen de la valoración que los diversos usuarios tengan de él. Es necesario que el patrimonio considere los usos sociales desde una visión más compleja, de cómo la sociedad se apropia de sus historia, incorporando nuevos actores y asumiendo los conflictos que lo acompañan. De este modo, el patrimonio puede ser un conector entre los diversos grupos sociales que lo comparten (García Canclini,1993). Por ello, es importante la existencia de marcos legales que regulen el uso y la construcción del espacio público, y trabajar con los ciudadanos en pos de promover la relación, apropiación y formas de uso. Resulta indispensable lograr el involucramiento del ciudadano para que se apropie de la ciudad; como propone Lefebvre, es necesario que el ciudadano ejerza "el derecho a la ciudad". Para que la política pública de cultura ciudadana sea sostenible se precisa la participación y el compromiso de todos (Mendoza Barrau, 2011).
Es innegable que "la degradación de los contextos históricos o la pérdida de los elementos que los constituyen, privan a las generaciones futuras de la posibilidad de disfrutar de estas riquezas y trae como consecuencia la ausencia del sentido de pertenencia y del reconocimiento del valor testimonial y cultural que poseen. Son espacios con un gran potencial, capaces de dar respuesta a las necesidades de vivienda y de servicios que una ciudad en constante crecimiento y evolución requiere para su desarrollo" (Bossio, 2006).

Bossio sintetiza en este párrafo varias cuestiones profundizados en páginas precedentes, que para su mejor interpretación se han analizado en forma independiente, pero en cada uno de los componentes ha quedado manifiesto los indisolubles vínculos que entre ellos existen, la presencia de todos en cada uno de ellos, y la influencia que cada uno ejerce sobre los restantes. Es el modo en que convive la ciudad, y el $\mathrm{CH}$ como parte de ella, como un sistema de interrelaciones donde el medio físico-ambiental, el socio-cultural, el económico y el institucional conforman un todo, que ha ido mutando en su comprensión a lo largo del tiempo. Estos cambios en la interpretación del $\mathrm{CH}$ y sus componentes esenciales, han dado origen a diversos modos de intervenir y gestionar, que aún presentan varios desafíos por afrontar, y que serán indagados en el próximo capítulo. 
Cambios de enfoques en las estrategias de intervención y gestión Implementadas

Los desafíos de la intervención y gestión: el desarrollo sostenible y el urbanismo sostenible:

Origen y dimensiones del desarrollo sostenible

Sostenibilidad físico-ambiental: vaciamiento físico-funcional y articulación nuevo-antiguo

Sostenibilidad socio-cultural: Gentrificación Sostenibilidad económica: turismo y comercio callejero 


\section{EL CENTRO HISTÓRICO COMO PAISAJE URBANO HISTÓRICO - El desafío de intervenir}

\subsection{Introducción}

Una vez profundizados los conceptos claves que permiten interpretar los cambios en las formas de concebir el $\mathrm{CH}$, el segundo Capítulo que aquí inicia, propone reconocer cómo las nuevas miradas han influido en las formas de intervenir y gestionar estas áreas de gran valor patrimonial. Para ello, se ahondará en los cambios de enfoques que han atravesado las estrategias de intervención y gestión implementadas, y cuáles son los desafíos a afrontar teniendo como objetivo el desarrollo sostenible. Se indagarán las dimensiones del mismo, y los retos para conseguir la sostenibilidad Físico-ambiental, abordando el vaciamiento físicofuncional y la articulación nuevo-antiguo; la sostenibilidad Sociocultural, reflexionando sobre el proceso de gentrificación; la sostenibilidad Económica, profundizando sobre el turismo y el comercio callejero; y finalmente la sostenibilidad Institucional, planteando los obstáculos a sortear desde la gestión. Seguidamente, se indican los autores y documentos citados en este Capítulo de la tesis:
Los cambios de enfoques en las estrategias de intervención y

$$
\text { gestión implementadas }
$$

Fernando Gaja Díaz / Martín Consuegra / Silvia Bossio / María Castrillo / Encajes Urbanos / Horacio Gnemmi / M. Florencia Girola, M. Paula Yacovino y Soledad Laborde

Los desafíos de la intervención y gestión: el Desarrollo Sostenible. Origen y dimensiones del Desarrollo Sostenible

Jan Gehl / Informe Brundtland / Declaración de Río / Juan Carlos Wandemberg Boschetti / Documento Final Cumbre Mundial ONU / Carta de la Tierra / Declaración Universal sobre Diversidad cultural / Agenda 21 de la Cultura / León Restrepo Mejía / Georges Bonan

\section{El desafío de la sostenibilidad físico-ambiental}

Andrea Cerletti / Guillermo Tella-Alejandra Potocko / Reencuentro / León Restrepo Mejía / Luis González Tamarit Teresa Cannarozzo Leone / Horacio Gnemmi / Walter Debenedetti

\section{El desafío de la sostenibilidad socio-cultural}

Ruth Glass / Giorgio Piccinato / Ibán Díaz Parra y Pablo Rabasco Pozuelo / Tom Slater / Lance Freeman / Chris Hamnett / Stuart Cameron / Henri Lefebvre / David Harvey / Jordi Borja / Carta Mundial por el Derecho a la Ciudad / Neil Smith / Ramón Folch / Michael Janoschka, Jorge Sequera y

Luis Salinas / Martín Checa Artasu / Paulo Ormindo de Azevedo / Fernando Carrión Mena / Rod Burgess 
El desafío de la sostenibilidad económica

Lisa Hanley / M. Florencia Girola, M. Paula Yacovino y Soledad Laborde / Llorenc Prats / Edgardo Venturini / Víctor Fernández Salinas / Fernando Carrión Mena

El desafío de la sostenibilidad institucional: gestión

José Luis Moreno García / Giuseppe Campos Venuti / René Coulomb / Declaración de México / Declaración de Lima / Manuel Herce Vallejo /

Patrice Melé Fernando Carrión Mena 


\subsection{Los cambios de enfoques en las Estrategias de intervención y gestión implementadas}

Este primer punto del Capítulo presenta por medio de una clasificación una serie de intervenciones definidas por diversos autores, que han ido tomando variadas particularidades con el paso del tiempo en correspondencia a los cambios de miradas hacia el $\mathrm{CH}$, y que serán adoptadas en esta tesis para la identificación en los casos de estudio.

Gaja Diaz (2001), sostiene que en el siglo XIX comienzan intervenciones urbanísticas planificadas en los $\mathrm{CH}$, con el objetivo de adecuarlos formal y funcionalmente a nuevas demandas sociales. Las mismas se implementan con Estrategias "clásicas o históricas", desarrolladas antes de la decada del 70, y estrategias "contemporáneas", aplicadas por el Estado desde mediados de los años 70 hasta la actualidad. Haciendo foco en estas últimas, surgen dos líneas o tendencias: "conservacionistas" o "transformadoras", que comparten el mismo objetivo, pero difieren en el método. Esta investigación adopta esta taxonomía para clasificar las intervenciones identificadas, entendiendo como "conservacionistas" a aquellas intervenciones dirigidas a conservar o mantener lo tejidos preindustriales, y que mantienen una hipótesis común: que los tejidos preindustriales reúnen condiciones suficientes y adecuadas para permitir su utilización o reutilización, de acuerdo con estándares, exigencias y requisitos contemporáneos. Dentro de esta categoría, se organizan las estrategias de intervención según su grado de transformación de patrimonio urbano:

1. Restauración: mantenimiento y/o recuperación de las características primigenias de forma inalterada.

2. Protección: acciones dirigidas a cuidar el patrimonio evitando daños o perjuicios.

3. Rehabilitación: técnicas para recuperar la o las funciones perdidas luego de un deterioro. Restablecimiento de su antiguo estado.

4. Recuperación: mantenimiento de la trama urbana, con alteración de la edificación.

5. Esponjamiento: alteraciones acotadas de la trama urbana, con alteración de la edificación.

Por otra parte, se comprende a las intervenciones "transformadoras", como aquellas dirigidas a transformar en un sentido moderno, cuya hipótesis común afirma que los $\mathrm{CH}$ no tienen las condiciones mínimas exigibles en nuestra sociedad, ni los pueden tener, a menos que se realicen transformaciones profundas. Dentro de esta clasificación se encuentran las siguientes estrategias: 
1. Reforma Interior: desaparición de los tejidos en su totalidad.

2. Renovación: recuperar, restaurar, modernizar antiguas estructuras en desuso por nuevas.

3. Reestructuración: modificación de la estructura funcional.

4. Recualificación: alteración de la estructura funcional, y propuesta de constitución de un centro terciario o directivo, con mantenimiento de características físicas más aparentes.

5. Tercerización: constitución de un centro terciario o directivo, con mantenimiento de características físicas más aparentes.

A su vez, se identifican otras estrategias más integrales que se suman a la Rehabilitación Integral, que poseen una elevada implementación en actuaciones recientes, e incorporan y combinan dentro de ellas estrategias conservacionistas y transformadoras presentadas en la clasificación anterior:

Regeneración: de acuerdo a Consuegra et al. (2015), el concepto de regeneración urbana, más completo que el de rehabilitación ${ }^{28}$,

28. Rehabilitación: estrategia enunciada anteriormente y definida por Bossio (2006) como aquella destinada a "otorgar competencia, idoneidad y aptitud para un fin determinado. Por consiguiente, en el caso de la rehabilitación edilicia y urbana, entendemos como tal a las acciones arquitectónicas, urbanísticas y sociales que permiten mejorar la calidad de vida de los habitantes y la capacidad de reutilización de esta arquitectura y de estos espacios dentro de niveles de comprende un sistema de cambios importantes en la forma y naturaleza de la ciudad actual con el que se pretende atajar una serie de problemas también complejos, como son:

1. La pérdida del límite de la ciudad, con el aumento del tiempo y energía dedicados a desplazamientos y la erosión de espacios naturales, son consecuencia de la dispersión urbana o crecimiento en mancha de aceite (urban sprawl).

2. La crisis funcional de la ciudad, con espacios de uso especializado que tienden a cerrarse en sí mismos en lugar de generar complejidad urbana, el abandono o la terciarización de los $\mathrm{CH}$, la degradación de zonas periféricas y de las áreas productivas, entre otras problemáticas.

3. El incremento de la población en riesgo de pobreza. Muchas ciudades se enfrentan a un significativo aumento de la exclusión social a los que la ineficiencia de los actuales modelos de gestión de la ciudad no da respuesta, con prevalencia de medidas contra la crisis sustancialmente conservadoras y faltas de originalidad e imaginación.

No obstante, Castrillo et al. (2014) expresa que: "la regeneración urbana se plantea hoy desde las instituciones como una vía para la

habitabilidad, salubridad y confort convenientes. Esto se logra dotándolos de los equipamientos y las infraestructuras suficientes, pero siempre dentro de los parámetros que permiten la identificación de los habitantes con su medio y su patrimonio, es decir respetando su memoria y su identidad". 


\section{EL CENTRO HISTÓRICO COMO PAISAJE URBANO HISTÓRICO - EI desafío de intervenir}

recuperación económica que además garantiza un modelo basado en la sostenibilidad y en la integración de los aspectos sociales, económicos y ambientales. Sin embargo, la intervención en la ciudad existente (donde la "regeneración urbana" se encuadra), conlleva cambios más profundos que los exclusivamente ligados a la transformación física y que son especialmente problemáticos en lo que se refiere a la desposesión urbana de las clases más bajas".

Revitalización: "Acción y efecto de revitalizar, dar más fuerza y vitalidad a algo. Revitalizar un ambiente urbano significa atender a los espacios de relación y a la calidad del espacio público, contemplando la diversidad social y de usos, la percepción de libertad, el sentimiento de comunidad, el carácter y la identidad, la escala de proximidad y las actividades de barrio. Poner en valor, bajo estos conceptos, tanto las condiciones físicas como sociales del entorno. Es importante la identificación entre las personas y el espacio público para apropiarse de los lugares y que éstos se conviertan en espacios con vida. Realizar una acción revitalizante implica generar una transformación sobre el soporte, físico o psíquico, que permita devolverle la vida. Una transformación que puede ir desde una acción efímera a una permanente. La participación colectiva se convierte en la herramienta que pone de manifiesto la enorme capacidad de la ciudadanía para reinventar su entorno físico. Ampliando el imaginario colectivo, surgen nuevas reglas de juego que ofrecen otras maneras de vivir el espacio público. Revitalizar implica, por tanto, rejuvenecer. La mayoría de las veces no es necesario construir nada nuevo, sólo es cuestión de transformar, saber colocar, poner en su sitio, trabajar sobre lo ya "construido" (repensar, reciclar, reactivar, remirar, rehabilitar), para mejorar la vida cotidiana en toda su diversidad y escalas" (Encajes urbanos, 2011). A esta definición, Gnemmi (2013) aporta que "revitalizar una ciudad o un $\mathrm{CH}$ es poner en práctica acciones de diverso tipo y carácter dirigidas a conservar valores, por un lado, y a sumar nuevos en la medida de lo posible, cuando el mismo, el $\mathrm{CH}$, esté en condiciones de recibirlos y de soportarlos", e incorpora que las operaciones de revitalización se pueden concretar desde tres grandes líneas de acción/control: la conservación, la nueva arquitectura, y la tutela del espacio público, este último, considerado como el factor conciliador y vinculante, sobre el cual desde la conservación y desde el diseño es posible concretar su revitalización.

Reconversión: esta estrategia implica todas aquellas acciones que permitan modificar nuevamente algo que con anterioridad ya había sido transformado, o transformar una cosa para que tenga otra utilidad. Generalmente, esta estrategia se aplica en zonas que por diversas circunstancias han quedado obsoletas o abandonadas con el paso del tiempo, como ha sucedido con grandes áreas industriales y ferroviarias, y en el marco de esta tesis, en aquellas cercanas a $\mathrm{CH}$ o con infraestructuras en desuso dentro de los mismos. Para llevar adelante la estrategia de reconversión, es necesario recurrir a una estrategia mencionada anteriormente, la 
recualificación, es decir volver a dar a algo, en este caso a las infraestructuras abandonadas, las cualidades necesarias o adecuadas para su uso. Girola, Yacovino y Laborde (2011), afirman que la recualificación urbana refiere a la reconversión de espacios antiguamente marginalizados, siendo una de las principales tendencias en el presente. Consideran que la propagación de estos procesos han ido de la mano de la consolidación de una modalidad de intervención territorial, el planeamiento estratégico, que en los años 80 en Europa, han designado de este modo a las operaciones de remodelación en áreas centrales o periféricas de las metrópolis. En el primer caso, con la reestructuración de la ciudad existente (recualificación de $\mathrm{CH}$ ), y en el segundo lugar, con la incorporación de nuevas construcciones en áreas vacantes de la perifera. Se interviene en la reestructuración de áreas degradadas a través del reordenamiento de sus espacios, imágenes y población, orientando todos los esfuerzos a la recuperación del espacio público.

En definitiva, a continuación se presenta la clasificación de estrategias a utilizarse dada la lectura de análisis teóricos previos:

\begin{tabular}{|c|c|c|}
\hline \multicolumn{3}{c|}{ ESTRATEGIASTCONTEMPORÁNEAS } \\
\hline CONSERVACIONISTASE & TRANSFORMADORAS & INTEGRALES \\
\hline RESTAURACIÓN & REFORMAIINTERIOR & REGENERACIÓN \\
\hline PROTECCIÓN & RENOVACIÓN & REVITALIZACIÓNIINTEGRAL \\
\hline REHABILITACIÓN & REESTRUCTURACIÓN & RECONVERSIÓN \\
\hline RECUPERACIÓN & RECUALIFICACIÓN & REHABILITACIÓNIINTEGRAL \\
\hline ESPONJAMIENTO & TERCERIZACIÓN & \\
\hline
\end{tabular}

Tabla II. 1: Clasificación de estrategias a adoptar. Elaboración propia.
La identificación de estas estrategias en el fichaje de los casos reconocidos, permite reconocer la mirada de los gestores frente al $\mathrm{CH}$; y el estudio histórico de las transformaciones que han experimentado las estrategias involucradas en esta investigación, facilitan la comprensión de algunos aspectos que se han ido modificando en las propuestas de actuación en estas áreas tan valiosas. 


\section{EL CENTRO HISTÓRICO COMO PAISAJE URBANO HISTÓRICO - El desafío de intervenir}

\subsection{Los desafíos en las estrategias de} intervención y gestión: Desarrollo Sostenible y Urbanismo Sostenible

En el año 1987, se elabora para la ONU el denominado informe Brundtland o "Nuestro futuro común" ${ }^{29}$, donde por primera vez se utiliza el término "Desarrollo Sostenible". Se entiende al mismo como aquel que satisface las necesidades del presente sin comprometer las necesidades de las futuras generaciones. Implica un cambio muy importante en cuanto a la idea de sostenibilidad, principalmente ecológica, y a un marco que da también énfasis al contexto económico y social del desarrollo. Esta definición se adopta en el Principio $3^{\circ}$ de la Declaración de Río (1992), aprobada en la Conferencia de las Naciones Unidas sobre el Medio Ambiente y el Desarrollo. Es a partir de este informe cuando se acata el término inglés sustainable development, y donde nace la confusión entre los términos «desarrollo sostenible» $\mathrm{y}$ «desarrollo sustentable». La diferencia es sustantiva ya que «desarrollo sostenible» implica un proceso en el tiempo y espacio y va de la mano de la eficiencia, lo cual le permite además ser eficaz. Mientras que el «desarrollo sustentable» implica una finalidad (aquí/ahora) y va de la mano de la eficacia más no necesariamente

29. Informe resultado de la Comisión Mundial de Medio Ambiente y Desarrollo de Naciones Unidas, creada durante la Asamblea de las Naciones Unidas en 1983. de la eficiencia. Por tanto, un verdadero Desarrollo Sostenible implica por añadidura sustentabilidad, más la sustentabilidad no implica necesariamente sostenibilidad (Wandemberg Boschetti, 2015).

Por lo expuesto anteriormente, en adelante, la tesis adoptará el término "Desarrollo Sostenible".

La incorporación de las condicionantes ambientales le imponen a las estrategias urbanas demandas específicas a partir del reconocimiento de los aspectos ecológicos, las tecnologías de avanzadas en metabolismo urbano, el paisaje natural y urbanizado, poniendo en valor las preexistencias ambientales del lugar de la intervención junto con la necesaria participación ciudadana. La historia muestra que en la década de 1950 y principios de los 60 ya se planteaba que la naturaleza debía ser contemplada en pos de mejorar la calidad de vida de la sociedad, pero recién en la Cumbre de Río de Janeiro de 1992, se pone en discusión el término de 'sostenibilidad' relacionándolo con la salud de la naturaleza y con el bienestar y la supervivencia de la humanidad.

Esta transformación operada concibe a la intervención en la ciudad, en el marco de un paradigma embrionario caracterizado como "Urbanismo Sostenible" que conjuntamente con el enfoque del 
"Derecho a la Ciudad" ${ }^{30}$, incorporan junto a la revalorización de la lógica social del Urbanismo la razón ecológica, basándose en un modelo social alternativo que se construye sobre la búsqueda de la cohesión social, la integración, la equidad, la sostenibilidad y la cooperación. (Gaja i Diaz, 2006).

En la búsqueda de intervenciones que aspiren a un urbanismo sostenible, las estrategias e instrumentos de intervención y gestión se enfrentan al gran reto del "desarrollo sostenible", que basa su existencia en tres grandes dimensiones: cultural, social y económica, donde cada una de ellas engloba una serie de problemáticas que requieren de un abordaje comprometido en pos de mantener la sostenibilidad de las dimensiones que implica.

“Lo urbano, en su complejidad contemporánea, no puede percibirse sino como un fenómeno multidimensional cuya realidad material, constructiva y técnica refleja la creatividad de los seres humanos, pero igualmente sus conflictos, sus contradicciones y los recursos de los cuales disponen para materializar sus proyectos" (Gehl, 2010).

30. Carta Mundial de Derecho a la Ciudad. Foro Social de las Américas - Quito Julio 2004. Foro Mundial Urbano - Barcelona - Quito - Octubre 2004. Se amplía este enfoque en el punto 2.3.2.2 de este capítulo.

\subsubsection{Dimensiones del Desarrollo Sostenible}

Varios textos de las Naciones Unidas, incluyendo el Documento Final de la Cumbre Mundial en el 2005, se refieren a las tres dimensiones del desarrollo sostenible o "pilares interdependientes que se refuerzan mutuamente", ellas son:

- Dimensión Ambiental: exige un desarrollo compatible con el mantenimiento de los procesos ecológicos, la biodiversidad y un uso responsable de los recursos naturales.

- Dimensión Social: requiere fortalecer la identidad de las comunidades y posee implícito el principio de equidad, clasificada en tres tipos: Equidad Intergeneracional, que supone considerar en los costos del desarrollo económico actual la demanda de futuras generaciones; la Equidad Intrageneracional, que fomenta la inclusión de los grupos sociales más desfavorecidos para que participen en la toma de decisiones que afecten los aspectos ambientales, sociales y económicos; y la Equidad entre países, poniendo énfasis en la relación entre países desarrollados y aquellos en vías de desarrollo.

- Dimensión Económica: demanda un desarrollo eficiente y equitativo para las generaciones presentes y futuras, considera un desarrollo económico a largo plazo que preserve los recursos naturales, considerando a lo económico y lo ecológico 


\section{EL CENTRO HISTÓRICO COMO PAISAJE URBANO HISTÓRICO - El desafío de intervenir}

como mutuamente dependientes. Se debe garantizar un crecimiento continuo e impulso simultáneo, a nivel macroeconómico inversiones y crecimiento, y a nivel microeconómico mejorar la productividad, la competitividad y el agregado de valor.

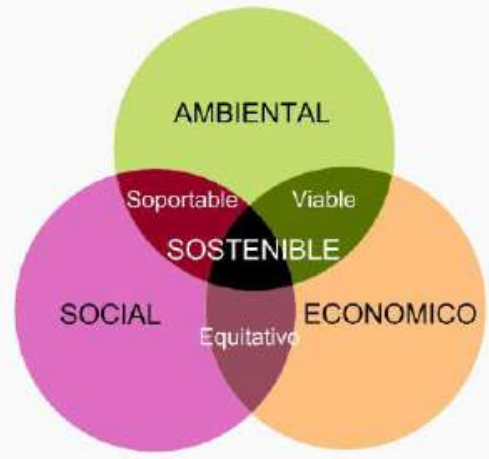

Figura II.1: Las dimensiones del Desarrollo Sostenible según la ONU Elaboración propia

Por otra parte, la Carta de la Tierra (2000) presenta los valores y principios asociados al Desarrollo Sostenible, y La Declaración Universal sobre la Diversidad Cultural (Unesco, 2001), profundiza aún más en el concepto al afirmar que "la diversidad cultural es tan necesaria para el género humano como la diversidad biológica para los organismos vivos". Se convierte en "una de las raíces del desarrollo entendido no solo en términos de crecimiento económico, sino también como un medio para lograr un balance más satisfactorio desde lo intelectual, afectivo, moral y espiritual". Con esta mirada, la diversidad cultural es considerada la cuarta dimensión o pilar del desarrollo sostenible. En la misma línea conceptual se orienta la organización mundial de ciudades (Ciudades y Gobiernos Locales Unidos, CGLU) con la Agenda 21 de la Cultura.

Sin embargo, resulta difícil analizar el aspecto cultural como independiente del social, sería más preciso hablar de una "Dimensión socio-cultural", que fundamentada también en la Equidad, cimente sus bases en el respeto por la autenticidad sociocultural, la tolerancia intercultural, y el desarrollo de un turismo sostenible que vincule necesidades actuales con preocupaciones futuras en pos de preservar recursos para generaciones venideras, mantener y proteger el patrimonio cultural e histórico, mantener la productividad de la base de los recursos, mantener la biodiversidad y evitar cambios ecológicos irreversibles.

Al mismo tiempo, se piensa a la "Dimensión Ambiental" como un conjunto de elementos físicos y naturales en continua interacción, considerándola por lo tanto como "Dimensión Físico-Ambiental". Finalmente, se tendrá en cuenta una cuarta dimensión que resulta clave, dado que engloba a las otras tres, y que posiciona a la gestión como medio para garantizar el funcionamiento y logro de los objetivos, la "Dimensión institucional". 


\section{EL CENTRO HISTÓRICO COMO PAISAJE URBANO HISTÓRICO - El desafío de intervenir}

Por lo expuesto, para el desarrollo de esta tesis, se tendrán en cuenta las siguientes dimensiones:

\section{- Dimensión Físico- Ambiental}

\section{- Dimensión Socio-cultural}

- Dimensión Económica

\section{- Dimensión Institucional}

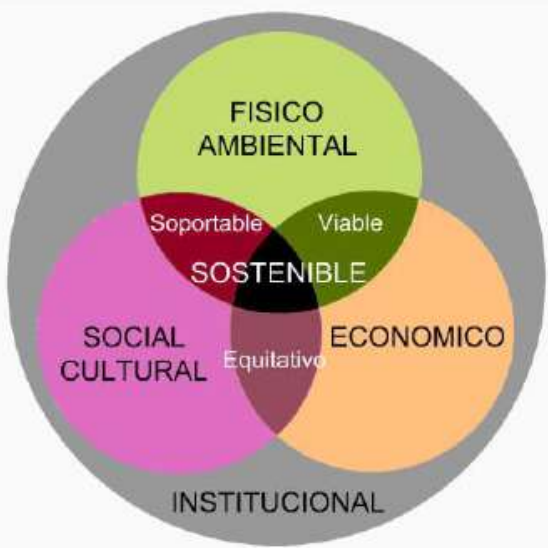

Figura II.2: Dimensiones propuestas, a considerar en la tesis

Elaboración propia

En este contexto, es necesario contar con "los mecanismos que harán posible "sostener" el patrimonio en el tiempo, desde una perspectiva social, cultural, económica y material para garantizar la permanencia de los bienes patrimoniales en la autenticidad de su mensaje como bienes útiles a la sociedad y como edificaciones que ofrecen condiciones de vida adecuadas a las necesidades del momento, insertos en las dinámicas territoriales y urbanas de las poblaciones de las que forman parte” (Restrepo Mejía, 2011) Como reflexiona Bonan (2011), "construir la sostenibilidad de un $\mathrm{CH}$ es buscar la compatibilidad entre la indispensable protección del patrimonio, la necesaria modernización de un $\mathrm{CH}$ para atraer actividades y habitantes (en armonía con el patrimonio existente) y un obligatorio mestizaje social, es decir equilibrio entre diferentes categorías sociales y diferentes generaciones para evitar la constitución de "guetos sociales". Son las condiciones para construir, no solamente la ciudad del día de hoy, sino también la ciudad que responde a las aspiraciones y necesidades del futuro".

\subsubsection{Desafíos del Desarrollo Sostenible}

\subsubsection{Sostenibilidad físico-ambiental: vaciamiento físico- funcional y articulación nuevo-antiguo}

Los $\mathrm{CH}$, por su alto valor patrimonial, se enfrentan a una doble situación, de poseer por un lado un gran potencial a desarrollar, y por el otro las grandes inversiones que ello implica y la alta presión inmobiliaria a la que se ven sometidos por su situación de centralidad. Para preservar las características esenciales de estas áreas, se establecen normas urbanísticas altamente limitantes en relación a la densificación y su preservación, que generan otra dinámica inmobiliaria. Al reducirse la especulación, los propios 


\section{EL CENTRO HISTÓRICO COMO PAISAJE URBANO HISTÓRICO - El desafío de intervenir}

propietarios y hasta el Estado también se encuentran frente a la dificultad de mantener los bienes, y comúnmente, por la falta de intervención, las áreas entran en procesos de degradación que acarrean pérdida de vitalidad, segregación y vaciamiento. Esta condición de deterioro, facilita acciones de demolición en pos de generar nuevas construcciones más rentables económicamente. Estos procesos, ponen en evidencia la complejidad de intervenir en áreas patrimoniales y de lograr el equilibrio entre las necesidades de los diversos actores (Cerletti, 2011)

En línea con Cerletti, Tella-Potocko (2009) afirman que al entrar en crisis el $\mathrm{CH}$ por el surgimiento de nuevas áreas con condición de centralidad, se registran dos procesos de recambio social. Por un lado, la tugurización, donde los inmuebles son ocupados por los grupos sociales más necesitado, dando lugar a pensiones, inquilinatos, y a la ocupación de antiguos edificios, viviendas y predios vacíos, que contribuyen a la estigmatización del área por la degradación general que sufre debido al vaciamiento por el traslado de residentes a otras áreas de la ciudad. Esta "tugurización" por otra parte, ha permitido en muchos casos conservar bienes patrimoniales que han quedado relegados de la presión inmobiliaria. Al mismo tiempo, el $\mathrm{CH}$ se expone a pocesos de "gentrificación", que originan la expulsión de población de menores recursos para la promoción de inversiones y la revalorización del sector, tema que se profundizará en el próximo apartado. E recambio social, pone en peligro -como ya se ha mencionado- la función residencial, frente a usos económicamente más rentables para el mercado.

La intervención sobre el patrimonio siempre ha sido un tema sensible, porque en general la población lo ve como una obligación del Estado, que debe ser el encargado de poner en valor edificios o áreas urbanas porque se considera que cualquier operación sobre el patrimonio genera pérdida. A su vez, generalmente, los propietarios que poseen un bien patrimonial en un área de protección o protegido, lo consideran más una restricción que un privilegio. (Reencuentro, 2011).

Como acuerda Restrepo Mejía (2011), esta idea se funda en que "existe un desequilibrio entre los beneficios, apoyos, y exenciones que reciben los propietarios de las edificaciones comprendidas en cualquier declaratoria patrimonial y las cargas que ella misma impone, en términos de limitaciones al dominio, restricciones en el uso y aprovechamiento y complejización de los trámites de cualquier actuación prevista. Esto requiere poner en marcha propuestas creativas capaces de romper las dificultades que en este tema existen". Estos supuestos han empezado a revertirse, a partir del reconocimiento de que las áreas históricas son valiosas desde el aspecto histórico-simbólico y pueden ser motores y generadores de recursos económicos. Esta situación plantea 
enormes desafíos como sostener los $\mathrm{CH}$ sin que ello implique sólo iniciativas del Estado, encontrar equilibrio entre inversión pública y privada; hallar formas de gestión que respondan a los diversos actores y necesidades; abordar el binomio patrimonio-desarrollo; $y$ encontrar equilibrio en el rol activo del Estado, orientador y regulador de las inversiones privadas. (Reencuentro, 2011).

Por otra parte, González Tamarit (2001) sostiene que "la acción debe saber combinar la rehabilitación o intervención edificatoria destinada a implantar usos (preexistentes o de nueva creación) respetando los valores arquitectónicos esenciales de los edificios, garantizando su funcionalidad, adecuados a los requerimientos actuales, con la sustitución selectiva de inmuebles irrecuperables o la edificación de nueva planta en terrenos vacantes, lo que introduce el debate sobre la presencia de ejemplos de arquitectura contemporánea en la ciudad histórica". El debate sobre la introducción de nueva arquitectura en los $\mathrm{CH}$ agrega otro dilema a la ya existente complejidad del $\mathrm{CH}$, ¿cómo articular lo nuevo y lo antiguo consiguiendo que la arquitectura contemporánea respete, dialogue y revalorice el contexto histórico en el que se inserta?

En esta línea, Cannarozzo y Leone (2013) agregan que el proyecto de intervención debe integrar el contexto físico, económico y social, logrando un diálogo entre la cultura del proyecto y la cultura del lugar. Plantean que debe dejarse de lado las diferencias entre conservadores e innovadores, y poner como eje el rol del $\mathrm{CH}$ dentro de la ciudad contemporánea y el territorio, pensando para ello marcos de planificación coordinados e integrados por políticas eficientes. Los $\mathrm{CH}$ necesitan proyectos de innovación y modernización que no respondan sólo a la sustitución edilicia, sino que involucren al resto de la ciudad, y que le devuelvan vitalidad acorde a su condición histórica conservando multifuncionalidad, y por sobre todo residencialidad. La innovación debe lograr la vinculación entre $\mathrm{CH}$, ciudad contemporánea y áreas de amortiguamiento, respondiendo a su vez a las transformaciones sociales, que originan nuevas demandas tanto a nivel privado como en los espacios públicos.

Por su parte, Gnemmi (2013) coincide en que no se trata de una ciudad o de un $\mathrm{CH}$ hechos sólo de arquitectura y, por lo tanto, no es cuestión de sumar arquitecturas sino de integrar. Para ello, no existe una única receta, porque la integración puede sostenerse desde la nostalgia o desde la novedad. Agrega que la singularidad de las nuevas obras no pasa por la excelencia arquitectónica, sino en su capacidad de integrarse a expresiones de otros tiempos y de reflejar el mundo contemporáneo a través de la propuesta.

Estas propuestas, en la actualidad, también requieren de la búsqueda de una mirada ambiental, que contribuyan con intervenciones a escala arquitectónica y urbana, a la sostenibilidad 


\section{EL CENTRO HISTÓRICO COMO PAISAJE URBANO HISTÓRICO - EI desafío de intervenir}

del medio natural, mediante la reutilización de infraestructuras y redes existentes para responder a demandas actuales, y mediante la adecuada elección e incorporación de técnicas y materiales que favorezcan el ahorro energético. "El patrimonio construido durante siglos, nuestras ciudades, son el rostro visible de nuestra identidad, pero coexiste con ellas una expresión más sutil e intangible, las tradiciones, las costumbres, los modos de hacer y de pensar, la visión del mundo, nuestra cultura. Esto le da sentido al lugar, y más allá de nuestras legítimas preocupaciones por conservar el patrimonio cultural y natural, nos pone en la ineludible responsabilidad de convivir en forma sustentable con el medio ambiente, para que nuestro territorio tenga futuro". (Debenedetti, 2011).

\subsubsection{Sostenibilidad socio-cultural: Gentrificación}

La identidad a la que hace mención Debenedetti, aquella que desde lo intangible, las tradiciones, las costumbres, forja la sostenibilidad social, es puesta en juego en cada decisión, en cada intervención que involucre al patrimonio ...la presión que el mercado inmobiliario y el turismo ejercen sobre estas áreas centrales generan tensiones constantes entre el medio físico y el social que se enfrentan en la difícil búsqueda de equilibrio.
Una de las principales consecuencias de la pérdida del patrimonio tangible en los $\mathrm{CH}$ es la gentrificación, donde los inmuebles deteriorados son desocupados para ser remodelados $\mathrm{y} / \mathrm{o}$ refuncionalizados para luego ser habitados por una población de mayor poder adquisitivo, fenómeno que deriva en el desplazamiento o la expulsión de los residentes antiguos. La socióloga Ruth Glass (1964) acuña el término "gentrificación", que viene de gentry, o clase alta de la Inglaterra Victoriana, queriendo hacer mención a una "elitización" del área, pero cuando describe el fenómeno enfatiza la expulsión de los residentes antiguos. Este proceso o fenómeno de gentrificación, que conlleva un enorme gasto público, se ha manifestado como consecuencia negativa de la intervención en muchas ciudades de todo el mundo. Como sostiene Piccinato (1983), parece ser que "sanear el centro histórico (expulsar a sus habitantes y sustituir a propietarios), es una operación necesaria para insertar dicho patrimonio histórico acumulado en el nuevo gran mercado urbano".

Desde la década de los 60 y 70, este fenómeno se ha registrado en ciudades anglosajonas, y se ha expandido décadas posteriores a ciudades europeas y del resto del mundo. Se evidencia una creciente preocupación por la temática tanto en ciudades mediterráneas como latinoamericanas a partir de los 90. Como expresan Díaz Parra y Rabasco Pozuelo (2013), algunos autores minimizan los efectos negativos y enfatizan en los positivos, y otros 
se centran en el desplazamiento para hacer hincapié en lo negativo de este proceso. La polémica en torno a la gentrificación se incrementa con críticos como Slater (2006, 2009), Freeman (2008), Hamnett (2009) y Cameron (2003) ${ }^{31}$, este último, introduce el término de "gentrificación positiva" aludiendo que en algunos casos este proceso puede ser más positivo que negativo, mientras Slater considera esta visión contradictoria.

De todos modos, un proceso de revitalización urbana, tendiente a la mejora de la calidad de vida de la población no debiera contribuir a la fragmentación y marginalidad social, que entran en contradicción con la idea de Lefebvre (1968) del "Derecho a la Ciudad" de sus habitantes. Este derecho, que "rescata al ciudadano como elemento principal, protagonista de la ciudad que él mismo ha construido", restableciendo la idea de ciudad, como lugar de "encuentro para la construcción de la vida colectiva". Como agrega Harvey (2008), "es el derecho activo a hacer una ciudad diferente a adecuarla un poco más a nuestros anhelos, y a rehacernos también nosotros de acuerdo a una imagen diferente". "El derecho a un

31. Para mayor profundización en este debate Ver Slater (2006), "The eviction of critical perspectives from gentrification research". International Journal of Urban and Regional Research, (30); (2009), "Missing Marcuse. On gentrification and displacement". City, 13 (2-3); Freeman (2008), "Comment on 'The Eviction of Critical Perspectives from Gentrification Research". International Journal of Urban and Regional Research, 32 (1); Hamnett (2008), "The new Mikado? Tom Slater, gentrification and displacement", City. 5; (13); y Cameron (2003), "Gentrification, housing redifferentiation and urban regeneration: going for growth in Newcastle upon Tyne". Urban Studies, 12 (49) lugar, a la movilidad, a la belleza del entorno, a la centralidad, a la calidad ambiental, a la inserción en la ciudad formal, al autogobierno...configuran "el Derecho a la Ciudad" (Borja, 2003). La Carta Mundial por el Derecho a la Ciudad (2004) también direcciona en ese sentido.

Smith (1996), aporta que hubo una transición entre el concepto de gentrificación de los 60 planteado por Glass, asociado a la renovación residencial, y la gentrificación de décadas cercanas, que se ha expandido e integrado a procesos urbanos y globales más amplios. El mismo autor afirma que el deterioro y la desvalorización económica de las zonas deprimidas constituyen el resultado racional del funcionamiento del mercado del suelo y del mercado inmobiliario. La falta de mantenimiento del patrimonio construido acarrea la desinversión, y por lo tanto contribuye al vaciamiento de los $\mathrm{CH}$, que terminan siendo foco de vandalismo, delincuencia, prostitución y narcotráfico. Smith explica técnicamente que esta desvalorización es la que produce las condiciones económicas que hacen que la revalorización del capital (gentrificación) se vuelva una respuesta lógica del mercado. Este proceso se explica con la denominada diferencia potencial de renta (diferencia entre valor actual del suelo y valor potencial), donde una profunda degradación del barrio genera una gran diferencia potencial de renta, hecho que atrae a diferentes actores del mercado inmobiliario y del mercado del suelo por las altas 


\section{EL CENTRO HISTÓRICO COMO PAISAJE URBANO HISTÓRICO - El desafío de intervenir}

ganancias que sus inversiones pueden generar, dando inicio a un proceso de gentrificación. Por lo tanto, el proceso de gentrificación puede presentar aspectos favorables como negativos según la posición del actor en el proceso de intervención. Como bien afirma Folch (2003), en la ciudad..."las cosas son tal cual son, pero se ven según se miran..."

En este sentido, Janoschka, Sequera y Salinas (2014) sostienen que la gentrificación que se registra en España y $A L$, difiere de los procesos que tienen lugar en el mundo anglosajón, tomando "especificidades locales y creando formas simbióticas que integran discursos y prácticas existentes, así como estructuras administrativas, políticas y sociales locales". A su vez, explican que existen muchos modos de contribuir a la gentrificación, y exponen distintos tipos de gentrificación registrados en España, que en sus distintas formas también pueden observarse en ciudades de otros países:

- La gentrificación y migración transnacional: que debido a la expansión económica atrae a inmigrantes.
- La gentrificación turística: impulsada por el Estado, basado en la puesta en valor del patrimonio histórico y cultural.

- La gentrificación productiva y comercial: con la reconversión de antiguas áreas industriales, que producen cambios de imagen y población de estas áreas.

- La gentrificación simbólica vía producción cultural institucionalizada: con la introducción de nuevos estilos de vida basados en prácticas de consumo, mediante incorporación de equipamientos culturales y comerciales.

- Las nuevas geografías de la gentrificación: a nivel rural, con cambios de uso productivos, y gentrificación a nivel provincial.

- La resistencia a la gentrificación: llevada adelante mediante movimientos sociales que se enfrentan a la expansión de este fenómeno, y que han dado lugar a grupos como "Left hand rotation", que ha generado proyectos como "Gentrificación no es un nombre de señora" como medio para difundir y debatir sobre los procesos de gentrificación urbanos.

Figura II.3: Proceso de gentrificación, esquema elaborado en base a imagen publicada en www.contested-cities.net. Elaboración propia.

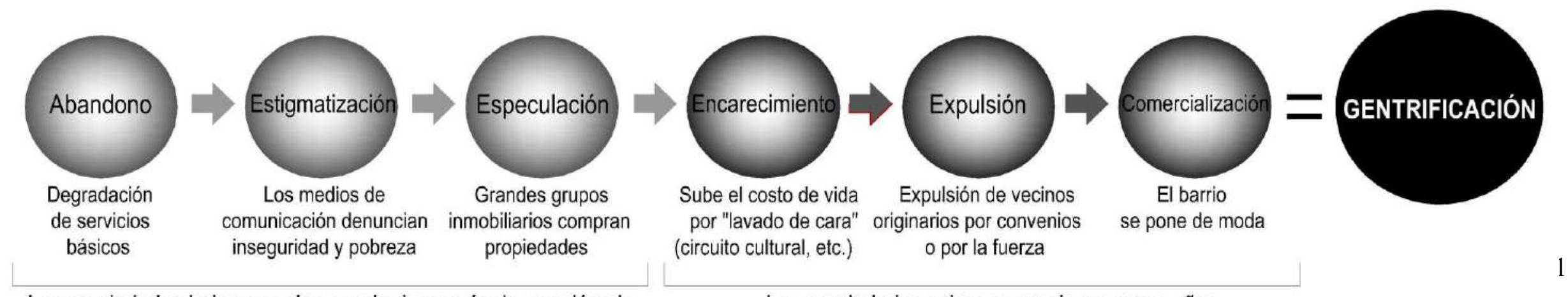

Las propiedades bajan su valor, puede durar más de una década

Las propiedades suben su precio en pocos años 


\section{EL CENTRO HISTÓRICO COMO PAISAJE URBANO HISTÓRICO - El desafío de intervenir}

Por lo tanto, se puede contribuir a la gentrificación desde distintos ámbitos. Checa Artasu (2011), explica que pueden existir numerosos dinamizadores de este proceso, como los gobiernos locales, grupos sociales y la misma cultura, mediante artistas y arte, patrimonio, infraestructuras culturales y ocio.

En España, los $\mathrm{CH}$ de Barcelona y Madrid han sido de los primeros en sufrir gentrificación, y en Italia ciudades como Venecia, Florencia y Roma presentan altos grados de este proceso. En el contexto latinoamericano, Ormindo de Azevedo (2004) asegura que el Pelourinho, $\mathrm{CH}$ de Salvador de Bahía, ha sido uno de los primeros núcleos centrales de AL en ser objeto de trabajos de revitalización urbana con miras a preservar sus valores culturales, y en este caso se ha verificado la puesta en práctica del proceso de gentrificación mencionado, a partir de la expropiación y sustitución de las propiedades, de los edificios y de los usuarios, que ha sido objeto de análisis de numerosos estudios.

Carrión Mena (2009), agrega que en términos de vivienda se genera la siguiente disyuntiva:

- La gentrificación, con reconstrucción de vivienda de alta calidad e infraestructura, que produce recambio poblacional, disminución de densidad y alta movilidad social. Generando beneficios en el mercado inmobiliario con la construcción de nuevos imaginarios.
- La "boutiquización", con la adecuación del patrimonio construido de los $\mathrm{CH}$ con el fin de generar un recambio funcional, que reduce la población residente y popular, y dan lugar a nuevas actividades urbanas más rentables que el uso residencial. Comercios, hoteles, restaurantes son concebidos bajo la lógica boutique. Fomentan el uso turístico con una presencia activa de los sujetos patrimoniales externos.

Por otra parte, en la actualidad ha comenzado a incorporarse un nuevo término "greentrificación", para hacer referencia a la capacidad de contribuir a la gentrificación que poseen los espacios vacantes o antiguas infraestructuras en desuso (vías férreas, autopistas), que mediante la incorporación de espacios verdes públicos como grandes parques lineales o plazas, que actúan como revitalizadores del barrio, acarrean al mismo tiempo, un aumento del valor del suelo con la respectiva especulación inmobiliaria.

En este sentido, para evitar que aspectos económicos atenten contra la sostenibilidad social de un $\mathrm{CH}$, es indispensable que, como reflexiona Burgess (2003), las políticas de desarrollo urbano sostenible se fundamenten en la justicia social, dado que para satisfacer las necesidades sociales, culturales y económicas es necesario una distribución más equitativa de los recursos e ingresos urbanos. La sostenibilidad social requiere de integración y 


\section{EL CENTRO HISTÓRICO COMO PAISAJE URBANO HISTÓRICO - El desafío de intervenir}

estabilidad, y para ello, los grupos con mayores necesidades deben participar activamente en la toma de decisiones y su implementación.

\subsubsection{Sostenibilidad económica: turismo y comercio callejero}

Como se ha manifestado en el apartado anterior, la puesta en valor de las áreas históricas con la recuperación de su patrimonio arquitectónico y urbano, acarrea importantes dinámicas socioproductivas basadas mayoritariamente en la promoción del turismo cultural, por su capacidad de producir un fuerte incentivo e impacto en la estructura económica local.

La importancia que adquieren las intervenciones operadas en $\mathrm{CH}$, se ve reflejada en los beneficios que reciben los diversos actores que participan, entre las que se pueden mencionar:

- La sociedad en su conjunto: puede verse favorecida con la puesta en valor de las propiedades, el mejoramiento de los servicios, calles, veredas, seguridad y el crecimiento de la actividad económica vinculada al turismo;

- El Estado: puede recibir ingresos al incrementarse la actividad turística y por consiguiente la económica, que le permiten obtener recursos para financiar la conservación del $\mathrm{CH}$ y su promoción.

- El Sector Privado: puede encontrar en el $\mathrm{CH}$ la posibilidad de desarrollar emprendimientos, inversiones apoyadas en el turismo y en bienes raíces que le generen altos márgenes de ganancia.

Por otro lado, como se mencionó en el apartado anterior, aún cuando los beneficios pueden ser elevados, también suelen existir efectos colaterales no deseados sobre el patrimonio y la dinámica de las ciudades y su entorno, si no se lo protege correctamente e interviene con una estrategia de gestión integral.

Uno de los principales promotores de intervenciones en sitios con valores culturales y naturales es la UNESCO. Cuando un sitio es declarado patrimonio, la UNESCO junto a otros actores rápidamente comienzan a plantearse estrategias de conservación y restauración, y generalmente aparecen nuevos usos. "Los $\mathrm{CH}$ suelen transformarse de tugurios a enclaves turísticos" (Hanley, 2008). En este contexto, surgen diversas estrategias o procesos como la revitalización, rehabilitación, reconversión o más recientemente regeneración que como sostienen Girola,Yacovino y Laborde (2011), intentan recomponer tanto la materialidad como la imagen de estas áreas devaluadas, para convertirlos en atractivos sitios de entretenimiento, consumo visual y estético. Sin embargo, un exceso en el montaje de estas escenografías urbanas en aras 
de una reactivación turística-económica puede ocasionar la pérdida o transformación del verdadero patrimonio del sector, sea este un patrimonio tangible (arquitectónico, urbano, artístico, social) o intangible (cultura, tradiciones, festividades.

El turismo, es uno de los principales impulsores de las intervenciones y es uno de los valores agregados más destacados, tal como quedó registrado al mencionar los beneficios de los diversos actores que participan en la recuperación de los $\mathrm{CH}$. En la generalidad de los casos, surge en el marco de un enfoque múltiple, en el cual la recuperación del patrimonio arquitectónico y del espacio público permite promocionar el turismo metropolitano, una actividad en creciente desarrollo debido a su capacidad de reactivación económica. En este sentido, la recuperación y puesta en valor del patrimonio histórico permite afianzar la identidad local de la población en su conjunto, reafirmando los valores culturales locales ante la apertura a un sistema globalizado. Sin embargo, se pueden recavar algunas observaciones ya realizadas. El desarrollo del turismo, ligado a la mejora de la calidad de las viviendas y de los servicios e infraestructuras del $\mathrm{CH}$ puede generar un aumento potencial del valor del suelo, donde el mercado inmobiliario encuentra un interesante campo de acción. Al originar un incremento en la demanda de los inmuebles para usufructo del turismo, arrastra una especulación que incide en que muchos $\mathrm{CH}$ puedan quedar anulados o gravemente alterados. Esta situación logra captar a inmobiliarias y constructoras locales 0 internacionales, que generan grandes inversiones para el desarrollo de nuevas intervenciones. Por lo general, conforman asociaciones público - privadas que originan a su vez, un foco de atracción para nuevos inversores.

La ausencia de instrumentos y herramientas necesarios para llevar adelante estas intervenciones, puede acarrear la destrucción del valioso patrimonio arquitectónico. Del mismo modo, también puede alterarse el patrimonio social si consideramos que, por lo general, las intervenciones urbanas conllevan al fenómeno de la gentrificación, desarrollado previamente.

Por otra parte, Llorenc Ptrats (1997) señala que nace un nuevo tipo de "activaciones patrimoniales" cuya motivación ya no es de carácter identitario, sino abiertamente turístico y comercial, enfocada en la imagen externa, y a menudo estereotipada que se tiene de nuestra identidad (de los protagonistas) desde los centros emisores de turismo. Así por ejemplo, el diseño del espacio público exterior (veredas, calles peatonales, plazas y parques urbanos) prioriza la composición (abstracción) y la estética resultante, antes que la calidad de la resolución procurando la apropiación del usuario o habitante de la ciudad. Resolución escenográfica, que se ve reforzada por la iluminación del espacio urbano. De esta forma, se realizan espacios públicos carentes de vegetación y con 
predomino de superficies pavimentadas en climas cálidos, pérgolas que no protegen del sol, bancos incómodos o lámparas que no iluminan a escala del peatón. Lo urbano se transforma en decorado, en artículo de consumo para el turismo, relegándose a un segundo plano el objetivo de elevar la calidad de vida de los habitantes residentes en los $\mathrm{CH}$ degradados.

Asimismo, otras acciones procuran la puesta en valor $y$ refuncionalización de edificios antiguos transformándolos en museos, bares, restaurantes, paseos comerciales, mediante intervenciones que efectúan su vaciamiento interior y la conservación de su cáscara como caparazón externa. Pero no solo edificios y monumentos se han convertido en artículos de consumo, sino también todo lo referente al patrimonio intangible, fiestas y tradiciones, procesos productivos y culturas enteras ya sea para la televisión, ya sea para el turismo cultural (mucho más auténtico), hasta el punto que, para muchas comunidades se ha convertido en el único -o principal- modo de vida.

En este sentido, no obstante el inmenso aporte económico y cultural que la actividad turística puede impulsar en un $\mathrm{CH}$, cada centro o ciudad debería plantearse la necesidad de generar actividades alternativas que le permitan sostener al $\mathrm{CH}$ con relativa independencia de los diferentes contextos por los que pueda atravesar la ciudad y el país. Cuando una sociedad se ve afectada por crisis económicas, una de las primeras actividades que ve perder protagonismo es el turismo. Al mismo tiempo, una de las primeras áreas en ver disminuido su financiamiento por parte de los gobiernos es la destinada a la conservación del patrimonio histórico de las ciudades.

A su vez, según algunos especialistas como el geógrafo Fernández Salinas (2004), las crisis también tienen su lado benéfico para el patrimonio, dado que al acabarse la especulación inmobiliaria también desaparecen las amenazas para el patrimonio, al menos las de reconversión o las más invasivas.

Por otra parte, tampoco podemos olvidar que a pesar de que el turismo puede generar en muchos casos rupturas en la conformación social de los $\mathrm{CH}$, si se aplican las políticas y las medidas necesarias para una correcta intervención, el turismo es una de las herramientas más valiosas para la reactivación y refuncionalización de estas zonas en estado de abandono, y puede ser el elemento que permita al $\mathrm{CH}$ reintegrarse a la ciudad y volver a ser un centro vivo de actividad y de sociedad.

El reconocimiento de los $\mathrm{CH}$ como espacios de valor patrimonial motorizadores y generadores de importantes recursos económicos ha sido clave para el desarrollo de innumerables intervenciones a nivel mundial. Dichas intervenciones, enfrentan el desafío de conservar el patrimonio físico-ambiental, y socio-cultural original de 


\section{EL CENTRO HISTÓRICO COMO PAISAJE URBANO HISTÓRICO - EI desafío de intervenir}

los $\mathrm{CH}$ promoviendo al mismo tiempo la revitalización del área con nuevos usos o potenciando los ya existentes, y brindando respuestas a las principales demandas urbanas y sociales que atañen a la mayoría de estos sectores centrales de las ciudades. Es por ello, que las intervenciones de $\mathrm{CH}$ en la mayoría de los casos, requiere un abordaje desde un enfoque que contemple la salvaguarda del patrimonio arquitectónico de valor histórico promoviendo el turismo metropolitano, conjuntamente con programas de reactivación económica y con planes de salvaguarda e inserción social de sus residentes, (siendo que en muchos casos se encuentran en condiciones de hacinamiento, inseguridad y marginalidad), y atrayendo el interés del sector privado.

Como sostiene Venturini (2006), es necesario "desarrollar estrategias cualitativas consensuadas entre los diversos actores y sectores de intereses, teniendo presente que el patrimonio, cuya presencia es el motivo desencadenante de estas actuaciones, tiene potencialidades pero también limitaciones para su reutilización".

Y en este sentido, otra de las actividades económicas que genera tensiones en los $\mathrm{CH}$, y en donde la búsqueda de consensos no es una tarea sencilla, es el comercio callejero. La gran atracción que generan estas áreas, por la alta concentración de usos, de población y de recursos, invita al desarrollo de la actividad comercial informal. La característica de centralidad de los $\mathrm{CH}$ capta a los sectores populares, que como afirma Carrión Mena (2003) han generado un crecimiento desmesurado del comercio callejero en los $\mathrm{CH}$, sufriendo una verdadera invasión del espacio público, que ha reducido al derecho ciudadano de su uso, y que ha provocado un deterioro importante del patrimonio arquitectónico y urbano. Según la perspectiva de las administraciones frente al tema, han surgido diversas fórmulas y estrategias para abordarlo. "Quienes lo ven como un problema, desde la perspectiva del turismo, del comercio formal, del espacio público, y de la imagen constructora de identidades; y quienes lo ven como solución, como alternativa al desempleo y a la baja de ingresos, de abastecimiento de los sectores populares con precios menores, y servicios de los usuarios no residentes en el CH". (Carrión Mena, 2000).

Acorde a estas miradas, en algunos $\mathrm{CH}$ se ha optado por la erradicación forzosa, en otros casos se ha decidido ignorarlo, y en intervenciones recientes se ha elegido encararlo de forma consensuada, buscando renovar las condiciones de empleo y recuperar las vías, veredas y plazas para el encuentro de la población. 


\section{EL CENTRO HISTÓRICO COMO PAISAJE URBANO HISTÓRICO - El desafío de intervenir}

\subsubsection{Sostenibilidad institucional: gestión}

Sumando a lo expresado anteriormente, Moreno García (2001) manifiesta que existe otro factor de complejidad que caracteriza a los $\mathrm{CH}$ y es la dificultad en la gestión para dar solución de vivienda a los grupos más desfavorecidos. En ese sentido, enfatiza que solo la gestión pública es capaz de resolver los desequilibrios sociales de quienes habitan en los $\mathrm{CH}$, y adhiere con Campos Venuti ${ }^{32}$ (1978) que: "Al Estado, como promotor, le corresponde apoyar cuanto sea posible, al sector de ciudadanos que se encuentran en situación de necesidad (...) La actuación publica en el campo de rehabilitación urbana es la más difícil porque se trata de actuar en el interior del tejido urbano, sin alterar su composición social, de mantener las propiedades familiares atacando solamente las posturas especulativas y absentistas, de primar las intervenciones de acuerdo con una severa selección de los niveles de renta familiar que resultaran beneficiados" e insiste en que una adecuada política de vivienda en el $\mathrm{CH}$ puede resultar beneficiosa tanto para el residente como para el poder público, como se ha pensado en varios casos entre los que se puede mencionar Bolonia, Barcelona, Vitoria Gasteiz, Santiago de Chile, Montevideo, San José de Costa Rica, Recife, entre otros tantos.

32. En su libro Urbanismo y Austeridad, publicado en 1978.
Frente a problemáticas comunes de los $\mathrm{CH}$, se plantea la necesidad de repensar el rol de estas áreas centrales en relación con la expansión de la urbanización y la aparición de nuevas centralidades. Este hecho, trasluce según Coulomb (2001) la carencia de políticas y de la gestión pública en $\mathrm{CH}$, a lo que se suma la ausencia de un enfoque integral. Quienes se enfrentan a esta situación, aspiran a encontrar nuevos modelos de intervención y gestión, que permitan recuperar la vitalidad del sector mediante un nuevo rol y la articulación de los actores públicos y privados, (gobiernos nacionales, autoridades locales, iniciativa privada, habitantes, agencias internacionales de cooperación, entre otros tantos). En general, la mayoría de las actuaciones son conducidas por el Estado, que ha creado incentivos para la inversión privada (gestión compartida), frente a la incapacidad de financiar los procesos completos.

No obstante, a pesar de esta tendencia de gestión mixta, existen importantes ejemplos de intervención en $\mathrm{CH}$ que gracias a una fuerte presencia gubernamental, liderazgo y continuidad política, han creado autoridades específicas autónomas que responden al ámbito de gobiernos municipales, con capacidad de actuación en todas las temáticas que un $\mathrm{CH}$ involucra, con recursos propios que aseguren su sostenibilidad y que tienen a su cargo la elaboración e implementación de un plan para el sector. La creación de estos órganos autosuficientes se presenta como un desafío para la 


\section{EL CENTRO HISTÓRICO COMO PAISAJE URBANO HISTÓRICO - EI desafío de intervenir}

mayoría de los $\mathrm{CH}$, pero que registra algunas excepciones tanto en Europa como en AL.

La elaboración de Planes de Sector, Planes Maestro, de Revitalización, que vinculan la planificación con la gestión de los $\mathrm{CH}$ se explica por un lado, por la exigencia de UNESCO o de las agencias de financiamiento, como el Banco Interamericano de Desarrollo; y por otro, por su capacidad de atracción y de generación de confianza a inversiones de particulares. Estos planes, facilitan la coordinación de los diversos actores y fijan un rumbo concreto con continuidad a largo plazo con miras a una intervención más integral que deje de lado la actuación en monumentos aislados. Sin embargo, en las políticas y gestión pública, la integralidad se manifiesta más como anhelo que como una práctica. Y como afirma Coulomb (2001), la integralidad de la acción pública no solo implica "que la planeación y las políticas de desarrollo económico y social logren articularse con la planeación territorial y las políticas de desarrollo urbano y vivienda", sino que a su vez el $\mathrm{CH}$ se inscriba "dentro de la problemática del desarrollo de la ciudad en su conjunto, tomando en cuenta los niveles superiores de planeación, el Plan General o el Proyecto de Ciudad" (Declaración de México) fomentando una "visión integral que los interprete e inserte como parte del sistema urbano en su conjunto", acorde a lo planteado en la Declaración de Lima.
Para ello, Herce Vallejo (2001), plantea que: "Es preciso comenzar a formular imaginativas formas de organización autónoma de gestión de proyectos urbanos, con gerencias públicas o con sociedades mixtas, que puedan funcionar con autonomía del trabajo cotidiano de las secretarías. Secretarías cuyas competencias precisan de una urgente descentralización, que las aproxime al ciudadano; y en este sentido, las nuevas tecnologías son un excelente instrumento para garantizar su seguimiento y su eficacia en los proyectos de ciudad". Las acciones de los poderes públicos poseen un valor determinante en la producción de la ciudad, y "debido no sólo a sus impactos reales sobre la transformación de los espacios concretos, sino también a la producción de un discurso de la ciudad, de una visión de la organización intraurbana, de la definición de las condiciones de intervención de los actores privados. Las especificidades de la evolución de los espacios centrales de las ciudades (...) no solo resultan del legado histórico, y de ciertas dinámicas económicas, sino también de formas particulares de acción pública, y de reglamentación de la intervención de los actores privados que condicionan las dinámicas de los espacios concretos. El espacio urbano es producto de la actividad humana, de la suma, de la estratificación de proyectos y de acciones, tanto individuales como colectivas". Melé (2006), En este sentido, Carrión Mena (2003) sostiene que se transita una época de transición en que se conforma una nueva modalidad de gestión de los $\mathrm{CH}$, que tiene como 


\section{EL CENTRO HISTÓRICO COMO PAISAJE URBANO HISTÓRICO - El desafío de intervenir}

antecedente a un marco institucional que ha transitado tres momentos:

- Un primer momento en que la sociedad civil representada por ciertas elites cultas (los notables) reivindica ante el Estado la necesidad de preservar los valores histórico-culturales de las ciudades.

- Un segundo, en que el Estado nacional establece un marco institucional a través de institutos especializados o ministerios de cultura y de políticas públicas inscritas en el fortalecimiento de la identidad nacional.

- Un tercer momento, en que los marcos institucionales de gestión de los $\mathrm{CH}$ se encuentran en transición y son aún poco claros.

En la actualidad, el debate sobre los modelos de gestión toma fuerza, dado que los actores patrimoniales han cambiado y se han incrementado. El marco institucional, las modalidades de gestión, y el carácter de las intervenciones se encuentran en un momento de quiebre. Una época de descentralización del Estado, de lo central a lo local-municipal, donde se crean poderes especializados, y de privatización de la gestión pública, con la creación de empresas y fundaciones. De este modo, se genera un cambio en los actores patrimoniales:

- Sujetos patrimoniales más vinculados a la privatización y que comienzan a tener más peso como los organismos no gubernamentales (patronatos, fundaciones), las empresas públicas y privadas, y la banca internacional.
- Sujetos patrimoniales que dan rentabilidad a las inversiones, a través de las distintas fases del ciclo de la producción (consumo, intercambio, gestión); los sectores de altos recursos económicos, las nuevas actividades (comercio, banca), y sobre todo, el turismo.

Con la presencia de estos nuevos actores se produce el desplazamiento de otros como el pequeño comercio (formal, callejero), sectores de bajos ingresos (inquilinos, artesanos), propietarios de pequeño patrimonio (inmuebles, bares), entre otros Para rehabilitar un $\mathrm{CH}$ hoy resulta esencial tratar las modalidades de gestión y las políticas. Es importante buscar soluciones en las relaciones público/privado y Estado/sociedad.

A su vez, la nueva mirada a los $\mathrm{CH}$ desde del paisaje, conduce a considerar la "gestión de los paisajes", entendida por el Convenio Europeo del Paisaje (2000) como las "acciones encaminadas desde una perspectiva de desarrollo sostenible, a garantizar el mantenimiento regular de un paisaje, con el fin de guiar y armonizar las transformaciones inducidas por los procesos sociales, económicos y medioambientales". A esta definición, la Recomendación para la aplicación del Convenio Europeo del Paisaje (2008), agrega que "la gestión del paisaje es una acción continua en el tiempo destinada a influir en cualquier actividad susceptible de modificar el paisaje. Puede verse como una forma de ordenación adaptativa, que evoluciona por si misma a medida 
que las sociedades transforman su modo de vida, su desarrollo y su entorno. Se concibe también como un proyecto de territorio que tiene en cuenta las nuevas aspiraciones sociales, las previsiones de modificación de las características biofísicas y culturales y el acceso a los recursos naturales. La ordenación del paisaje es asimilable a la noción de proyecto de territorio y comprende formas de transformación que tengan la capacidad de anticipar nuevas necesidades sociales mediante la consideración de las evoluciones en curso. Debería ser igualmente consecuente con el desarrollo sostenible y prever los procesos ecológicos y económicos a medio y largo plazo".

En este contexto, la Gestión se presenta como el medio para garantizar el logro de objetivos a corto, mediano y largo plazo para el PUH.

Para intervenir abarcando la temática desde sus diferentes aspectos, se requiere del desarrollo y aplicación de diversas estrategias implementadas a partir de mecanismos e instrumentos específicos acordes a las necesidades de cada $\mathrm{CH}$, como pretende visibilizar esta tesis en la siguiente Parte. 


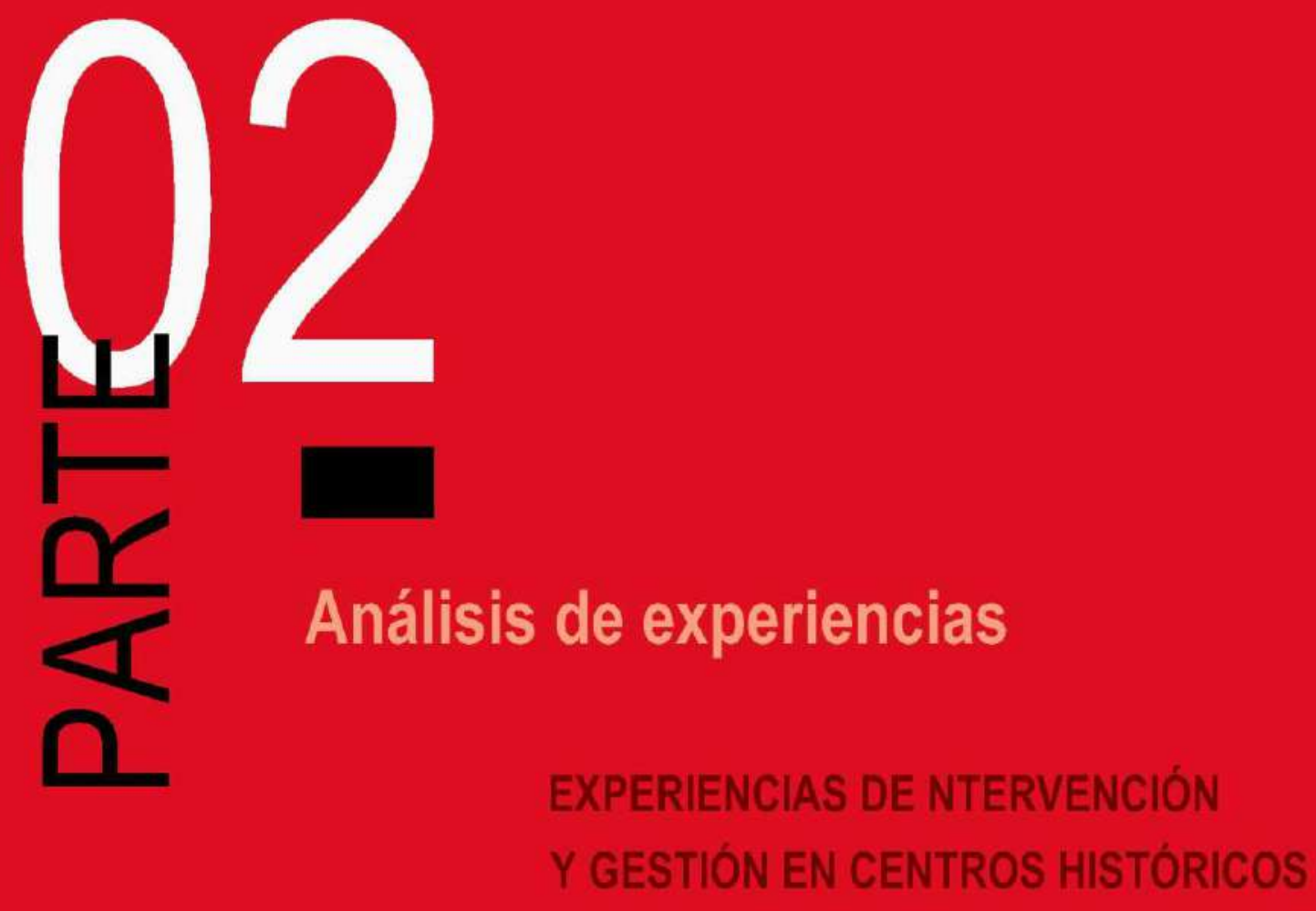

ANÁLISIS DE EXPERIENCIAS 


\section{EXPERIENCIAS DE INTERVENCIÓN Y GESTIÓN EN CENTROS HISTÓRICOS}

Introducción

Intervenciones que operan en Centros Históricos

Enfoques en el contexto europeo

Intervención y gestión en Italia

Intervención y gestión en España

Enfoques en el contexto latinoamericano

Experiencias de intervención y gestión identificadas y seleccionadas 


\subsection{Introducción}

Luego de haber indagado en los cambios acaecidos en las formas de ver e interpretar los $\mathrm{CH}$ de las ciudades, la segunda parte de esta tesis, que se inicia con el presente apartado, propone un recorrido por los enfoques y el análisis de experiencias de intervención y gestión que los han acompañado en el periodo de estudio. Este Capítulo, plantea inicialmente los enfoques que han influenciado el desarrollo de las estrategias de intervención y gestión en el contexto europeo (Italia y España), y en el contexto latinoamericano en el periodo comprendido desde la década del 70 hasta la actualidad. Posteriormente, se presentan las 40 experiencias de intervención y gestión seleccionadas en ambos contextos debido a que formulan propuestas interesantes de indagar, las cuales han sido elegidas dentro de una minuciosa identificación mayor de casos en los países de estudio, que ha permitido la elaboración de un profundo análisis que se presenta en el capítulo siguiente.

A continuación se exponen los autores consultados para la identificación de los enfoques que han guiado a las estrategias desarrolladas en el contexto europeo (Italia y España) y en el contexto latinoamericano:

\section{Enfoques en el contexto europeo}

Intervención y gestión en Italia

Carlo Cesari / Giuseppe Campos Venuti / Mario Ridolfi / José Antonio Blasco / María Franchina Luca / M. Ángel Chaves Martín /

Carta de Gubbio / Carta Europea del Patrimonio

$$
\text { Intervención y gestión en España }
$$

Fernando Gaja Díaz / José Ramón García Antón / Francisco Pol Méndez / Joaquín Santamaría Comallonga / Leticia Tobalina / Miguel Ángel Troitiño

Vinuesa / Manuel Valenzuela Rubio

\section{Enfoques en el contexto latinoamericano}

Patricia Rodríguez Alomá / Emilio Luque Azcona / Harry Smith Coloquio de Quito / Carta de Machu Picchu / Declaratoria de Bogotá /

Declaratoria de México / Carta de Petrópolis / Carta de Veracruz /

Carta de Washington

La bibliografía consultada para la elaboración de las fichas síntesis de cada uno de los casos se encuentra presentada en el punto

\section{B.3.3 del Anexo.}




\subsection{Intervenciones que operan en Centros}

\section{Históricos}

En capítulos precedentes, hemos observado cómo el abandono o degradación de los $\mathrm{CH}$ por motivos bélicos, políticos o por el mismo crecimiento de las ciudades que ha conllevado a la aparición de nuevas centralidades, ha constituido la condición previa para el inicio de procesos de intervención de distinta naturaleza, renovación, rehabilitación, sustitución de usos y puesta en valor de estos espacios centrales, mediante distintas estrategias de conservación y transformación que han acompañado a intervenciones urbanas de gran escala, ubicadas en lugares estratégicos de las ciudades, procurando mejorar el funcionamiento de sectores urbanos, transmisores de significados, memoria e identidad.

En Europa, el interés por la recuperación de la ciudad histórica comienza en el siglo XX, a finales de los 60 , pero con motivo de la crisis del sector de la construcción y la crisis urbana de los años 70 , es recién a partir de los años 80 cuando comienzan a ponerse en practica muchas intervenciones, aunque algunos planes ya habían sido elaborados en la década del 70. Para esa misma época, comienza a intervenirse también en $A L$, y desde ese momento a la actualidad, es posible verificar cómo los cambios por los que han atravesado las sociedades han influido en la forma de ver y actuar sobre la ciudad, hechos que han incidido en los modos de planificar y gestionar.

La intervención y gestión de los $\mathrm{CH}$, como se ha demostrado en la Parte 1 de la tesis, es una compleja tarea considerando la diversidad de actores y situaciones que ellos concentran y a su vez la multiplicidad de realidades de los mismos, teniendo en cuenta los diferentes procesos que han atravesado. Por tal motivo, como sostiene Carrión (2003), no es posible tratarlos como si fueran una realidad única y homogénea. Existe una heterogeneidad de situaciones que generan $\mathrm{CH}$ diferentes: la distinta calidad patrimonial (por ejemplo, entre Medellín y Lima), el tiempo de la intervención (reciente o antigua), la cantidad de población (sea residente, usuaria o turística), los distintos rangos de ciudades (capitales, metropolitanas, intermedias y pequeñas), el tipo de institucionalidad que actúa (nacional o local, pública o privada) o los orígenes históricos. Hay $\mathrm{CH}$ que se inician, por ejemplo, en el medioevo (como muchos $\mathrm{CH}$ de Italia y España), en los períodos prehispánico (Cuzco), colonial (Popayán), republicano (Santiago) o moderno (Brasilia), lo que desemboca en que, por un lado, pueda haber varios $\mathrm{CH}$ con orígenes distintos al interior de una ciudad y, por otro, que los $\mathrm{CH}$ se configuren a lo largo de la historia y no, como se piensa, solo en un período y asociado, generalmente, a la fundación de la ciudad. Este universo altamente diferenciado de los 
$\mathrm{CH}$ es necesario remarcarlo, ya que expresa la riqueza que tienen y porqué exige creatividad analítica a la hora de definir metodologías para captarlos y actuar. Por lo tanto, es muy importante al momento de proponer estrategias de intervención y gestión, no generalizar casos exitosos intentando homogeneizar las realidades, sino buscar aquellas estrategias que logren potenciar al $\mathrm{CH}$ reforzando a su vez sus singularidades.

A continuación se presentan los distintos enfoques que han incidido en el período de estudio en las estrategias desarrolladas en Italia y España, como parte del contexto europeo, y en las estrategias implementadas en el contexto latinoamericano.

\subsubsection{Enfoques que guían las estrategias en el contexto europeo}

\subsubsection{Intervención y gestión en Italia}

Los $\mathrm{CH}$ italianos poseen un alto valor histórico patrimonial, aún conservan vestigios de antiguas civilizaciones (etruscos, griegos, romanos) que han influenciado la cultura, literatura, lengua, arte, arquitectura, derecho y filosofía del mundo y han dejado su impronta en el ámbito urbano-arquitectónico, con desarrollo de arquitectura gótica, renacentista y barroca.. En sus ciudades se reconocen los diversos períodos por los que han atravesado, evidenciados en la estratificación que aún exhiben muchos $\mathrm{CH}$. En la actualidad, la mayoría de ellos se encuentran en muy buen estado de conservación, con elevado número de construcciones originales, pero durante las guerras mundiales muchos de ellos fueron destruidos, y posteriores crisis han contribuido también a su deterioro. Esa situación impulsó el desarrollo de planes urbanos orientados a la recuperación del valioso patrimonio de los $\mathrm{CH}$.

Sin duda alguna, por lo expuesto en el Capítulo 1, Gustavo Giovanonni ha sido una figura clave para la comprensión del patrimonio urbano tanto italiano como del resto del mundo, que teniendo como antecedente a las ideas de Camilo Sitte de protección de ambientes y no de monumentos, ha entendido a la ciudad como contenedor de vida, y ha aportado estas ideas en las Cartas italianas de Restauro. A su vez, renombrados autores italianos han escrito sobre la intervención en los $\mathrm{CH}$ de su país, Carlo Cesari (1989), ha clasificado cinco generaciones en cuanto a planes de intervención en ciudades italianas; Giuseppe Campos Venuti (1993), ha definido tres generaciones de intervenciones urbanísticas que se han desarrollado entre los años 1942 y 1992; y Mario Ridolfi (1952), ha afirmado que: "las ciudades históricas italianas que en el pasado habían tenido la fortuna de ver acrecentar su patrimonio, fruto del nivel cultural de las población de entonces, asisten luego a la transferencia de la promoción a unos anónimos operadores económicos, motivados 
por la mera razón mercantil. Por lo tanto, prevalece el triunfo de la ignorancia que ve a administradores, propietarios, operadores y falsos proyectistas, celebrar banquetes sobre las ruinas de las ciudades dañadas por la mano del hombre a causa de los acontecimientos bélicos, pero todavía más por la reconstrucción".

Luego de las reconstrucciones del 45 al 49, en la década del 50 se experimenta una intervención masiva del Estado tanto para reconstrucción como para creación de nuevas viviendas. Las primeras reacciones ante el incorrecto tratamiento del Patrimonio Histórico y Monumental son las denuncias realizadas por asociaciones como "Italia Nostra"1 y ANCSA $^{2}$ (Chaves Martín (2013). Esta última, con sede en la ciudad de Gubbio, otorga desde el año 1990 el "Premio Gubbio", que promueve los avances en las modalidades de intervención sobre la ciudad y el territorio histórico, reconociendo las experiencias más significativas en el campo de la recualificación urbana y ambiental, así como en la recuperación del patrimonio edilicio histórico. En este marco, diversas experiencias europeas y de AL han sido galardonadas (Bolonia, La Habana, Montevideo, Buenos Aires).

En el año 1958, se plantea en diversos congresos la problemática de la conservación de los $\mathrm{CH}$, los motivos de su deterioro y las

33. Italia Nostra: Asociación Nacional para la tutela del patrimonio Histórico, Artístico y Natural de la Nación, creada en 1955.

34. ANCSA: Asociación Nacional de Centros Históricos y Artísticos, constituida en 1960. posibles formas de intervención, y comienzan investigaciones sobre casos como Gubbio, Siena y Venecia en los 60. La Carta de Gubbio, elaborada en 1960, propuso una declaración de principios sobre la conservación y restauración de los $\mathrm{CH}$, que tuvo vigencia durante el siglo $\mathrm{XX}$, orientando las actuaciones hacia el conjunto de los $\mathrm{CH}$, dejando atrás la idea de intervención sobre el edificio aislado. Ha afirmado la necesidad de considerar las actuaciones de conservación ${ }^{3}$ y restauración ${ }^{4}$ como premisa del desarrollo de la ciudad moderna, y por lo tanto, la importancia de que ellas sean parte de la planificación urbanística, mediante Planes Reguladores Municipales y Generales (PRG), como una de las fases esenciales para la planificación de las intervenciones. Propone también la creación de Planes de Restauración Conservadora (Risanamento Conservativo) como Planes detallados de iniciativa municipal (Piano Particolareggiato), con el fin de fijar la modalidad de intervención sobre el conjunto. Finalmente, sostiene que dentro de estos planes, debe brindarse una atención especial a la identificación de la estructura social que caracteriza a los barrios, protegiendo la vivienda y las actividades comerciales existentes (Carta de Gubbio, 1960). Este documento, ha dado pie para hablar del Patri

35. Conservar: mantener y cuidar para que el elemento no pierda características con el paso del tiempo, para que continúe manteniendo su estado, condición, actitud.

36. Restaurar: Arreglar o reparar un edificio, obra de arte u objeto de los daños que ha sufrido. Regresar el objeto al estado previo al daño.

37. Fuente: apuntes del Seminario "Intervención Arquitectónica I", dictado por el Arq. Fernando Gandolfi en el marco de la Maestría CRIP, FAU, UNLP. 
monio Cultural de los $\mathrm{CH}$, considerado desde la planificación urbanística y entendido también como un bien económico. En este marco, surge según Campos Venuti (1993), una primera generación de planes italianos de reconstrucción urbana, planes de ordenamiento urbano para el $\mathrm{CH}$ (en las décadas de los 40,50-60) como el de Milán (1953), Verona (1954, Marconi), Padua (1954, Piccinato), Siena (1956, Piccinato-Bottoni-Luchini), Asís (1958, Astengo), Urbino (1958), Bolonia (1958), Módena (1958); una segunda generación de planes de expansión urbana (en los 60-70) que ve a la ciudad como sistema y proceso, en ella surgen planes como el de Nápoles (1961), Florencia (1962, Detti), Roma (1962, Piccinato), Ravena (1962), Módena (1965, Campos VenutiPiacentini), Reggio Emilia (1967, Campos Venuti-Piacentini), Bergamo (1969), Imola (1969), Bolonia (1969, CervellatiSacannavini), Ravena (1973), Ferrara (1975), con las variantes de Módena (1975), Bolonia (1978), y Venecia (1979); y una tercera generación (en los 80) de planes de transformación urbana, como Bolonia (1985), Arezzo (1985), Siena (1987) y Ancona (1988).

Sin embargo, Carlo Cesari (1993), sostiene que a finales de los 60 en el $\mathrm{CH}$ predominan las funciones terciarias que han modificado su rol. En la misma década, surge una nueva idea de recuperación de la arquitectura histórica, aunque en muchas construcciones solo se han conservado fachadas y se han vaciado interiores.

Chaves Martín (2013) también afirma que hacia la década del 70 , crece el interés por la conservación de la ciudad, respetando el medio construido, incorporando nuevas viviendas que se ajusten al tejido urbano, y mejorando la calidad de vida, Como contrapartida, esto provoca una disminución en las intervenciones a lo que se suma la crisis económica de 1963-1965, agravándose aún más en la década del 70. La aparición en el año 1964 de la Carta de Venecia y la creación de ICOMOS, ${ }^{5}$ constituyen hitos para la época en el tratamiento de esta temática. El documento de Venecia, fue una síntesis de la situación que presentaba el problema urbano y patrimonial en ese momento, defendiendo el principio de autenticidad sobre los frecuentes "falsos históricos" y la valoración del monumento en su conjunto, no como obra aislada sino como parte de ámbitos urbanos y rurales.

Como expresa José Antonio Blasco (2014), la elaboración del Plan para el CH de Bolonia de 1969 (Variante del Plan Regulador 1958 y su actualización con el PEEP de 1973, Piano di Edilizia Economia e Popolare) realizado por Pier Luigi Cervellati y Roberto Scannavini, presentaba una original idea de conservación integral o estructural (arquitectónica, espacial, y social) de recuperación de la ciudad histórica, denominada "Recupero" en italiano. A su vez, poseía un alto contenido social, rigurosa metodología de análisis morfológico,

38. Consejo Internacional de Monumentos y Sitios. 
determinación de tipos arquitectónicos ${ }^{6}$ exigente política de conservación $^{7}$ y una firme apuesta por la iniciativa pública. Ha conceptualizado términos como "Monumento", "Entorno Monumental" o "Centro Histórico", a favor del concepto global de "Ciudad". Promovía la conservación de la ciudad en su integridad, liberándola de cambios de uso destructivos, de la tercerización de los centros urbanos, a favor de los grupos expulsados (pobres, obreros, ancianos) que debían recuperar los edificios históricos como lugar de residencia y no de servicios. La particularidad política de la ciudad luego de la Segunda Guerra Mundial, hizo de ella un espacio para la puesta en práctica de ideas urbanísticas de izquierda. Figuras urbanísticas relevantes como Giuseppe Campos Venuti, Pierluigi Cervellati o Leonardo Benévolo, contribuyeron a la definición del Plan que tenía como objetivos:

- Preservar el $\mathrm{CH}$ de la destrucción y elaborar catálogos de las edificaciones.

- Integrar el patrimonio, incorporando equipamientos que contribuyan al dinamismo.

- Proveer al $\mathrm{CH}$ de los servicios y aspectos técnicos necesarios.

39. Grandes conjuntos monumentales, edificios complejos con patios, edificios privados de viviendas obreras y artesanas de los siglos XVI al XVIII, y edificios tradicionales con variaciones de escala y tipo,

40. Restauración" con conservación integral, "Repristino" con rehabilitación y saneamiento, y "Reconstrucción”, previa demolición parcial o total.
- Organizar la red viaria y peatonalizar sectores incompatibles con el uso vehicular.

- Tal es el impacto que este Plan generó con sus propuestas, que aún se mantiene un intenso debate en toda Europa, dado que a pesar de algunas ideas utópicas, sigue teniendo vigencia con algunos de sus planteamientos.

La propuesta de Bolonia y la siguiente Carta Europea del Patrimonio ${ }^{8}$, significó un importante cambio: de la ciudad renovada por sustitución de sus elementos a la ciudad recuperada, restaurada y rehabilitada. No solamente en su arquitectura, sino también en sus estructuras sociales deterioradas por el desarrollo industrial. Esta Declaración formuló el principio de "Conservación Total o Integral", poniéndose en evidencia que la conservación rigurosa del espacio físico no es suficiente para mantener un $\mathrm{CH}$ vivo como corazón de la ciudad en expansión. Favorece la reutilización y rehabilitación de edificios y no la nueva construcción de políticas precedentes. Finalmente, en el Simposio Europeo sobre Patrimonio Arquitectónico realizado en Ferrara en el año 1978, Bruno Zevi ha defendido la modernidad como necesario freno a los falsos históricos que se estaban desarrollando con anterioridad.

41. Elaborada en el Congreso sobre Patrimonio Arquitectónico Europeo, realizado en Amsterdam en el año 1975 
En la actualidad, se habla de "conservación" o "rehabilitación integral del centro histórico" con la idea de Carlo Cesari (1982), de que proteger el pasado no significa cristalizar o museificar, sino garantizar el crecimiento progresivo de la cultura actual, a través del conocimiento perfecto y el disfrute de los testimonios que produjeron esta misma civilización.

En pos de conservar el pasado para las generaciones futuras, la UNESCO reconoce sitios con Valor Universal Excepcional (VUE) término desarrollado en el Capítulo 2-, con el fin de incorporarlos en la Lista de Patrimonio de la Humanidad. Estos valores han sido localizados en numerosos $\mathrm{CH}$ de Italia, que han obtenido dicho nombramiento: 1980, Roma; 1982, Firenze; 1987, Venezia; 1990, San Gimignano; 1994, Vicenza; 1995 Siena y Napoli; 1995, Ferrara; 1996, Pienza; 1998, Urbino; 2000, Verona y Assisi; 2006, Génova; 2008, Mantova; 2015, Palermo -conjunto árabe-normando y catedrales-. Con estas declaraciones, Italia se sitúa como el país del mundo con mayor cantidad de $\mathrm{CH}$ declarados Patrimonio de la Humanidad por la UNESCO, sólo cuatro de sus veinte regiones (Valle d'Aosta, Calabria, Abruzzo y Molise) no poseen declaratorias.

En este marco, los Planes de Gestión de UNESCO en Italia han sido establecidos por Ley del año 2006, Núm. 77: "Medidas especiales de protección y uso de los sitios italianos del paisaje cultural y el interés del medio ambiente, incluidas en la Lista del Patrimonio Mundial, situadas bajo la protección de la UNESCO". Este Plan de Gestión se desarrolla en concordancia con el Plan Regulador General Comunal (Piano Regolatore Generale Comunale PRGC) del sistema jurídico italiano, instrumento de planificación que regula la actividad edificatoria dentro de un término municipal, que cada ciudad italiana debe cumplir desde el año 1942 acorde a la ley.

En cuanto a las políticas urbanas y territoriales, en los años 90 se han incrementado, con programas locales e intervenciones integradas tanto a escala urbana como territorial. Como ejemplo de instituciones locales europeas que coordinan los planes y medidas de conservación de $\mathrm{CH}$, se encuentran algunas como 'L'Ufficio speciale per gli intervente sul centro storico' de Roma. En este marco, en la misma década, comenzó el Programa de Iniciativa Comunitaria, creando alrededor de mil iniciativas de transformación urbana en diferentes áreas (programas de reciclaje, programas de renovación urbana, programas integrados y contratos de barrio). Finalmente, los programas URBAN, destinados a desarrollos innovadores para la regeneración de áreas mediante proyectos tendientes a la mejora de las condiciones de habitabilidad de los espacios públicos, del transporte, de la integración social, entre otros, han involucrado 127 actuaciones locales, varias de ellas de gran escala, con problemas con respecto a la planificación global de la 
región (Luca, 2010). Dentro de las ciudades italianas que participan de este programa, se encuentran: Bari, Cagliari, Carrara, Caserta, Catania, Catanzaro, Cosenza, Crotone, Foggia, Génova, Lecce, Milano, Misterbianco, Mola di Bari, Napoli, Palermo, Pescara, Reggio di Calabria, Roma, Salerno, Siracusa-Ortigia, Taranto, Torino, Trieste y Venezia-Porto Marghera.

\subsubsection{Intervención y gestión en España}

Las ciudades españolas poseen un alto valor histórico patrimonial, con $\mathrm{CH}$ medievales que concentran vestigios romanos, árabes, judíos y cristianos, y con exponentes arquitectónicos de diversos períodos. Muchos de los $\mathrm{CH}$ se encuentran en la actualidad en muy buen estado de conservación, con elevado número de construcciones originales, sin embargo, durante el período dictatorial, muchos de ellos sufrieron graves transformaciones y se encontraron expuestos al abandono.

Fernando Gaja Diaz, Jordi Borja, Alberto García Gil, Francisco Pol Méndez, Miguel Ángel Troitiño Vinuesa, Manuel Valenzuela Rubio, y Sergio Tomé Fernández, entre otros autores, analizan la realidad de las intervenciones de los $\mathrm{CH}$ españoles, que según García Antón (2001), recibe los efectos de los movimientos de recuperación de la ciudad histórica que surgen en Europa a fines de los 60 -entre los que destaca el ejemplo de Bolonia- y las teorías arquitectónicas en torno a la historia de la ciudad, y que se unen en España, con un periodo de transición política, a finales de los años 70 con los primeros ayuntamientos democráticos. Con ellos ha surgido la preocupación por la salvaguarda de las ciudades históricas a través de Estudios Piloto de Rehabilitación Urbana, con posturas proteccionistas opuestas al urbanismo desarrollista de años anteriores. No obstante, al igual que en Italia, la crisis de los años 70 , se ha traducido en el abandono de grandes áreas de los núcleos tradicionales, que poseen un correlato social y político.

Desde principios de los 70 hasta fines de los 80 , disminuye el ritmo de crecimiento urbano $y$ ante oportunidades de reutilización de zonas abandonadas y obsoletas, y el uso de vacíos intersticiales, se han planteado estrategias de intervención en los tejidos apoyadas por el sector público. Como sostiene Tobalina (2012), la recuperación de los $\mathrm{CH}$ se convirtió en objetivo prioritario de programas y proyectos políticos y sociales. Para llegar a esa situación debió lograrse una progresiva concientización de la ciudadanía y de los poderes en salvaguardar los $\mathrm{CH}$. Entre los factores que marcaron la recuperación de las ciudades históricas y de la nueva sensibilidad han destacado los nuevos mecanismos de intervención (con un mayor respeto de los Planes Urbanísticos hacia las áreas históricas de las ciudades), la transferencia de competencias a las autonomías (políticas de recuperación de $\mathrm{CH}$ ) y la modernización de los planteamientos en las escuelas de 
Arquitectura. En este contexto, en España, se han elaborado Planes Especiales en el marco de Planes Generales, para la intervención de los $\mathrm{CH}$ que se adaptan a la complejidad y particularidad de cada uno de ellos, donde se estudia la singularidad de cada caso.

En España, según lo expresado por Santamaría Camallonga (2013), para la revitalización de los $\mathrm{CH}$ se han desarrollado políticas de renovación y rehabilitación. Las primeras, han propuesto la adaptación del $\mathrm{CH}$ a nuevas funciones y actividades, con participación simultánea del Estado, las corporaciones locales, los fondos públicos y privados, la intervención del gran y pequeño capital, y la participación de especialistas y particulares movilizados por los medios de comunicación social. Estas políticas, suponían la destrucción de la trama urbana antigua, con la consecuente liberalización del suelo, reunión de parcelas y reordenación de usos del suelo; la edificación de inmuebles nuevos con aumento de alturas y volúmenes; la sustitución de usos poco intensivos allí existentes por otros más intensivos entre los que figuran comercios de calidad y servicios especializados; y el desplazamiento de la población tradicional por otra nueva de mayor categoría social y mayor poder económico, una intervención bastante radical que producía una transformación completa del entorno urbano, con cambios morfológicos, funcionales, estructurales y sociales de las zonas afectadas.
Los impactos de estas transformaciones comenzaron a generar polémica a mediados de los 70 , dando lugar a la aparición de políticas de rehabilitación urbana. Las mismas, también se han enfocado en reforzar el potencial económico del centro y favorecer su reconquista por los grupos dominantes, pero a diferencia de la renovación, intentan frenar el despoblamiento y la segregación residencial, al tiempo que pone énfasis en la conservación del entorno urbano y la recuperación de la residencialidad de los barrios antiguos. La rehabilitación implica una estrecha colaboración entre poderes públicos, vecinos y propietarios para hacer frente al financiamiento de las obras y para conciliar intereses. Por lo tanto, esta política tiene un carácter más social que la política de renovación, ya que tiene más en cuenta la opinión de la población.

Estos cambios de enfoques en las estrategias han sido acompañados por transformaciones en los instrumentos para intervenir en los $\mathrm{CH}$, impulsados por campañas dirigidas desde el Consejo de Europa donde se generalizaron iniciativas rehabilitadoras. Como explica Valenzuela Rubio (1998), para el desarrollo de esta nueva práctica urbana se han creado instrumentos legales de tipo urbanístico primero: Planes Especiales de Reforma interior -PERI- o Planes Especiales de Protección y Reforma Interior -PEPRI-, acorde al artículo 20 de la Ley del Patrimonio Histórico Español, que establece que el municipio debe 
redactar obligatoriamente un Plan Especial de Protección, tras la declaración de un Conjunto Histórico, Sitio Histórico o Zona Arqueológica como Bien de Interés Cultural (BIC), que puede tener pequeñas modificaciones en las diversas regulaciones autonómicas. En estos casos, la planificación física era protagonista pero se había superado el período de conservacionismo extremo para entender al $\mathrm{CH}$ en su totalidad (con población y actividades incluidas). Esta revitalización integral es puesta en práctica en forma generalizada, con especificidades de cada caso, en los distintos $\mathrm{CH}$ españoles. El mismo autor, también sostiene que las estrategias de rehabilitación tienen como debilidades el aspecto social, (no logran mantener y recuperar la población residente), y el aspecto económico, (donde cuesta conseguir la diversificación y destercerización), siendo aún desafíos a afrontar.

Gaja Díaz (2001), reconoce que a principios de los 70, el mítico Plan de Bolonia marcó un método, un modelo y un camino para las operaciones de protección y conservación de los $\mathrm{CH}$, conformando un referente que fue asumido de forma generalizada. Al respecto, Pol Méndez (1993) sostiene que las políticas planteadas y experimentadas en Italia, fueron "Referencias" iniciales de las propuestas en España. Siguiendo las indicaciones de Bolonia, se propusieron operaciones para la mayor parte de los grandes Conjuntos Históricos, aunque los pequeños Cascos Históricos permanecieron en general, ajenos a esta estrategia. Sin embargo, desde hace décadas han empezado a generarse posturas opuestas a la conservacionista, a favor de intervenciones de transformación. Como consecuencia, a finales de los noventa los $\mathrm{CH}$ comenzaron a ser analizados y entendidos desde la diversidad.

Dentro de los Planes para la salvaguarda y la protección de los $\mathrm{CH}$ españoles, el mismo autor afirma que los más significativos se desarrollaron en un "laboratorio" de ciudades medias, como Gijón, Salamanca, Lérida, Tarragona, Pamplona, Vitoria Gasteiz, Segovia, así como en el centro antiguo de Barcelona y en algunas partes de Madrid. Estos planes se caracterizaron por la diversidad de procesos de ordenación e intervención, de adaptación del método de diseño y de la normativa urbanística a partir del conocimiento de cada $\mathrm{CH}$. La especificidad de las ciudades españolas hizo que no fuera aplicable el "modelo italiano" de conservación morfológica y recuperación tipológica. Estos planes expresaron los nuevos planteamientos de la "cultura urbanística" de los 80 , con interés por la forma urbana, el desarrollo de proyectos a escalas intermedias, la construcción del plan a partir de proyectos urbanos, el debate sobre la cualidad de las arquitecturas y el reconocimiento del papel estructurante del espacio público, desarrollado en el Capítulo 1, apartado 1.4.2.

Las experiencias de recuperación de $\mathrm{CH}$ españoles, han sido desarrolladas desde iniciativas públicas que han integrado 
equipamientos y usos públicos en antiguos edificios abandonados, o han incorporado nueva arquitectura en "vacíos intersticiales" o en "bordes" degradados de $\mathrm{CH}$ como Madrid, Valencia, Barcelona o Salamanca. Sin embargo, la intervención pública en programas de viviendas no ha tenido un desarrollo muy amplio. Para la rehabilitación del patrimonio residencial, España cuenta con una disposición estatal del año 1983, que propicia el financiamiento y el otorgamiento de subvenciones para iniciativas de rehabilitación privada, en viviendas de protección pública. A su vez, han ofrecido otros procedimientos para el desarrollo de rehabilitaciones integradas de áreas, innovadores en cuanto a la importancia otorgada a la programación y a la creación de órganos de gestión específicos.

Las intervenciones en las distintas Comunidades Autónomas han sido muy heterogéneas, con marcada desigualdad entre las regiones más dinámicas económica y administrativamente, (como Cataluña, País Vasco, Navarra o Valencia), y las más atrasadas (como Castilla, Extremadura...). La mayoría de las Comunidades que han establecido marcos propios para políticas de recuperación se han centrado en subvenciones para edificios de los $\mathrm{CH}$, pero sin abordar (a excepción del País Vasco, Navarra y alguna otra Comunidad), la construcción de vías "orgánicas" y "articuladas" para planificación, programación y gestión de los procesos. Existiendo una intención general de las Comunidades por crear estructuras de información, asesoramiento y gestión del territorio. (Pol Méndez, 1993).

La atención que recobran los $\mathrm{CH}$ en esta época se hace evidente también en la incorporación de varios $\mathrm{CH}$ españoles en la lista de Patrimonio Universal de UNESCO, a partir de la década de los 80. Los primeros de ellos fueron Ávila, Santiago de Compostela y Segovia (1985), seguidos por Cáceres y Toledo (1986) y a los que sucedieron Salamanca (1988), Mérida (1993), Córdoba (1994), Cuenca (1996), Alcalá de Henares (1998), San Cristóbal de la Laguna e Ibiza (1999), Tarragona (2000), y finalmente Úbeda y Baeza (2003). Estas 15 ciudades integran desde el año 1993 el "Grupo de Ciudades Patrimonio de la Humanidad de España," con la finalidad de actuar de manera conjunta en la defensa del patrimonio histórico y cultural de estas ciudades y en el mantenimiento y potenciación de determinadas formas de vida que estos núcleos históricos necesitan, realizando proyectos y propuestas comunes, estableciendo políticas de intercambios de experiencias y afrontando problemáticas comunes. Estos nombramientos, junto a numerosos más (48 materiales y 16 inmateriales), hacen de España el tercer país con más cantidad de bienes declarados Patrimonio de la Humanidad en el mundo, detrás de Italia y China.

Según Troitiño Vinuesa (1991), en España, con el apoyo financiero de 
la Unión Europea se han desarrollado, al igual que en el caso italiano, Programas URBAN que en relación a los primeros estudios del periodo democrático han mostrado importantes mejoras en la valoración de la dimensión histórico-cultural de la ciudad, en los métodos de análisis de la realidad urbana y también en las técnicas y modelos de intervención urbanística, focalizándose en planteamientos de recuperación y puesta en valor de la ciudad histórica. En esta misma línea, Valenzuela Rubio (1998) reconoce que ante la poca colaboración que los instrumentos urbanísticos (PERIs) o de mejora arquitectónica (ARIs), han logrado la mejora de las condiciones de vida de la población, es que este programa (puesto en ejecución en $\mathrm{CH}$ de Cádiz, Málaga, Sevilla, Salamanca, Valencia, Badajoz, Vigo, Cartagena, Sabadell, Barakaldo, Madrid, Córdoba, Pontevedra, Zaragoza y Palma de Mallorca), asume como fin prioritario "la recuperación social y económica de las áreas afectadas con el fin de conseguir su incorporación a la dinámica social y económica de su entorno", a través de objetivos parciales como: mejorar el aspecto de las zonas urbanas seleccionadas a través de actuaciones encaminadas a mejorar las infraestructuras y el medio ambiente; promover el lanzamiento de nuevas actividades económicas; conseguir la integración social de la población afectada; y mejorar los servicios sociales, sanitarios y de seguridad.

Con objetivos de mejora comunes para los $\mathrm{CH}$ españoles, es que surge en el año $1994 \mathrm{COCAHI}^{9}$, una organización sin fines de lucro, cuyos propósitos son: defender el comercio y las actividades mercantiles de los $\mathrm{CH}$ del Estado español; facilitar información sobre las actuaciones de las Administraciones y organismos públicos y privados en los $\mathrm{CH}$; facilitar la gestión de las actuaciones encaminadas al desarrollo y la promoción de los $\mathrm{CH}$; asesorar sobre actuaciones de las Administraciones y organismos públicos y privados, que afecten a las actividades de los asociados y al desarrollo de los $\mathrm{CH}$; trabajar para la mejora general de los $\mathrm{CH}$, con eje en la conservación de su patrimonio; y otros fines que puedan conseguirse por medio de la Confederación para defender intereses de asociados y sus ciudades.

No obstante, la recuperación integral continúa siendo un desafío, dado que a la falta de recursos y a diversos problemas de gestión, se suma la heterogénea situación de los $\mathrm{CH}$ españoles, en los que Troitiño Vinuesa (1991) reconoce al menos cuatro situaciones:

- $\mathrm{CH}$ que han dejado de ser el centro urbano económico, pero que conservan la centralidad simbólica y cultural (Cuenca, Gerona, Cáceres, Alcoy, Oviedo, Vitoria Gasteiz);

- $\mathrm{CH}$ donde lo histórico y lo funcional mantienen diversos niveles de imbricación, conservando una mayor o menor centralidad (Madrid, Granada, Barcelona, León, Segovia, Sevilla);

42. COCAHI: Confederación Española de Cascos Históricos. 
- $\mathrm{CH}$ que siguen siendo el centro de la ciudad actual (Toledo, Santiago de Compostela, Salamanca, Teruel o Córdoba); y $\mathrm{CH}$ cuya identidad urbana se ha perdido o difuminado en estructuras urbanas transformadas $\circ$ degradadas (Castellón, Albacete, Talavera de la Reina o Badajoz).

\subsubsection{Enfoques que guían las estrategias en el contexto latinoamericano}

Muchos de los $\mathrm{CH}$ latinoamericanos poseen un alto valor patrimonial, con arquitectura que ha tenido origen en las colonias españolas en América desde el descubrimiento de Colón en 1492. Los españoles trasladaron su idioma, cultura, religión y costumbres, que impusieron a la población indígena. Por lo tanto, el arte colonial latinoamericano posee los mismo estilos que se desarrollaban paralelamente en Europa, pero con adaptaciones (renacentista, barroco y rococó). A esta influencia española se ha sumado luego la influencia portuguesa, inglesa, italiana y de colectividades que se han ido asentado en $\mathrm{AL}$ con el paso del tiempo, y que han transmitido su cultura a los distintos ámbitos de la vida latinoamericana otorgando una gran riqueza cultural a sus ciudades.
En el contexto latinoamericano, diversos autores como Jorge Enrique Hardoy, Fernando Carrión, René Coulomb, Sivia Bossio, Victor Delgadillo, Sylvio Mutal, Emilio Luque Azcona, Patricia Rodriguez Alomá, Manuel Delgado, entre otros, analizan la realidad de las intervenciones en los $\mathrm{CH}$. Los mismos, reconocen que en $A L$, el crecimiento de las ciudades impulsó el movimiento de la población desde el centro hacia la periferia, quedando los $\mathrm{CH}$ en estado de abandono y degradación, ocupados por una población de escasos recursos, y con políticas públicas enfocadas en la periferia, que influyeron aún más en su deterioro. Esta situación, fue disparadora de diversas actuaciones en $\mathrm{CH}$ que descubrieron el potencial de los mismos para su intervención. Rodriguez Alomá (2013), reconoce que en $A L$ se elaboraron una serie de documentos que contribuyeron en la mirada y las formas de intervenir en los $\mathrm{CH}$ :

- 1977, Coloquio de Quito: presenta la necesidad de desarrollar una política de conservación integral de los $\mathrm{CH}$, y contar con créditos nacionales e internacionales para la rehabilitación de viviendas, redes de infraestructura, equipamiento urbano y desarrollo comunal. Reconoce la pertenencia de los $\mathrm{CH}$, a quienes lo habitan.

- 1977, Carta de Machu Picchu: plantea identificar problemas y oportunidades, además de reconocer la necesidad de un plan continuo y sistemático, que garantizara una planificación urbana, económica y social a partir de una 
interacción permanente entre técnicos, ciudadanos, políticos y la producción de viviendas sociales con un alto grado de participación ciudadana. A su vez, remarca la importancia de un desarrollo económico y social, el estudio y actuación en los campos jurídico, administrativo y financiero, y la trascendencia del patrimonio intangible en su relación con la identidad.

- 1978, Declaratoria de Bogotá: reconoce la cultura como una dimensión transversal del desarrollo y que la identidad cultural no es estática, sino prospectiva; respalda sistemas de comunicación e información que garanticen soberanía e independencia frente al empuje de patrones culturales ajenos, rechazando el colonialismo, el neocolonialismo y el imperialismo, así como la violencia y la discriminación sexual, racial, ideológica, política y religiosa -, necesidad de establecer un nuevo orden económico mundial más justo.

- 1985, Declaración de México: plantea como fundamental el diálogo entre las instituciones culturales y la población y el desarrollo de las industrias culturales como estrategia del desarrollo económico; plantea además que el ser humano es el objetivo, y la necesidad de incluir en los planes de rehabilitación los intereses de minorías étnicas marginalizadas.

- 1987, Carta de Petrópolis: remarca conceptos de otros documentos, recomienda hacer prevalecer el predominio del valor social de la propiedad urbana sobre su condición de bien mercantil. Pone énfasis en el ámbito social: incluir a la comunidad en la toma de decisiones sobre planificación; fortalecer a los líderes de la sociedad civil; crear conciencia ciudadana acerca de deberes y derechos con el patrimonio cultural; garantizar adecuadas condiciones de vida y de trabajo así como reconocer la recuperación del patrimonio como un beneficio tangible para la comunidad.

- 1992, Carta de Veracruz: establece la necesidad de contar con una voluntad política que reconozca la prioridad requerida por la rehabilitación del $\mathrm{CH}$ en su dimensión socioeconómica, en un marco jurídico especial, de nivel nacional. Necesidad de oficina de gestión del $\mathrm{CH}$ competente. Otorga vital importancia a la redacción de un plan en el marco de un plan urbano, que señale etapas, presupuestos y prioridades, así como el seguimiento del mismo para garantizar su implementación y la correcta aplicación de los recursos, para lo cual se debe contar con adecuados y concretos instrumentos jurídicos y financieros. Además, recalca la importancia de interpretar al $\mathrm{CH}$ como un organismo económicamente activo y socialmente positivo.

Fuera de AL, la Carta de Washington de 1987 fue significativa por sus planteamientos. Aportó una visión de respeto hacia los habitantes del $\mathrm{CH}$, que debían tener una actitud comprometida y 
participativa. También se estableció la obligación de contar con estudios multidisciplinarios que definan principios, orientaciones y acciones para que el plan resultante cuente con su adhesión.

Rodriguez Alomá (2008), expresa que estos documentos orientaron hacia los años 80 actuaciones más concientes urbanísticamente, con una mirada más integral de las ciudades y con cambios conceptuales en la forma de actuar. A su vez, desastres naturales como los terremotos de México (1985) y Quito (1987), impulsaron intervenciones en los $\mathrm{CH}$ que generaron cambios profundos en la forma de actuar en los mismos, para dar respuesta a situaciones de emergencia que requerían respuestas concretas y nuevas. En Ciudad de México, hubo una gran producción de vivienda social, con medidas legales como la expropiación de inmuebles; mientras en Quito se creó el FONSAL, con una asignación de fondos permanentes desde el Estado, para la conservación de grandes monumentos. Pero recién en la década de los 90 , se ha observado un cambio radical en la forma de actuar en los $\mathrm{CH}$ de $\mathrm{AL}$. Tras un largo período de dictaduras militares, la brecha entre las áreas ricas de la ciudad y las más pobres se vio acentuada y repercutieron en los $\mathrm{CH}$, donde los problemas existentes se agravaron con un alto grado de violencia y marginalidad. A pesar de ello, el reconocimiento del $\mathrm{CH}$ como un lugar valioso, concentrador de patrimonio tangible e intangible y con una localización privilegiada dentro de la ciudad, generó un paulatino retorno de intereses hacia el centro incorporando nuevos actores. El binomio crisisoportunidad, planteó la necesidad de nuevos enfoques de acción en los $\mathrm{CH}$, en la búsqueda de una de sostenibilidad socioeconómica. El rico patrimonio urbano y arquitectónico se transformó en un activo económico fundamental para su propia revitalización y en la medida en que sea incorporada la dimensión social más legitimidad tendrá el proceso.

En este marco, se han reconocido algunas iniciativas que vinculan las actuaciones del continente europeo y del latinoamericano. Luque Azcona y Smith (2007), mencionan entre ellas el programa europeo URB-AL, iniciativa de cooperación descentralizada de la Comisión Europea destinada a la mejora de las condiciones socioeconómicas y de calidad de vida de las ciudades de Europa, América Latina y el Caribe. También el Centro Internacional para la Conservación del Patrimonio (CICOP), institución no gubernamental con sede en La Laguna (Canarias, España), cuyos objetivos se orientan a la especialización de técnicos y licenciados en el campo de la preservación y restauración del patrimonio físico en ambos continentes.

Dentro de la cooperación internacional desarrollada en Latinoamérica y el Caribe, destaca la tarea del Banco Interamericano de Desarrollo (BID), organización financiera internacional creada en 1959 con el objetivo de mejorar la calidad 
de vida en $A L$ y el Caribe, con apoyo financiero en salud, educación e infraestructura a países que trabajan en reducir la pobreza y la desigualdad, en la búsqueda de un desarrollo sostenible. También la labor desarrollada por países como España, especialmente a partir de conmemorarse en 1992 los 500 años del llamado "encuentro" entre las culturas europeas y americanas. A partir de ese momento, el gobierno central y algunos autonómicos y locales pusieron en marcha programas de colaboración con instituciones locales y regionales en $\mathrm{AL}$, para la elaboración de Planes Maestros y el establecimiento de Escuelas Taller. Uno de los organismos fue la Agencia Española de Cooperación Internacional para el Desarrollo (AECID), creado en 1988 y vinculado al Ministerio de Asuntos Exteriores y de Cooperación, que ha desarrollado el programa 'Patrimonio para el desarrollo', actualización del 'Programa de Patrimonio Cultural' iniciado a fines de los años ochenta. A este organismo se suma la AACID (Agencia Andaluza de Cooperación Internacional para el Desarrollo), que es el órgano encargado de coordinar y fomentar las políticas de solidaridad internacional de la Junta de Andalucía. Se configura como un Ente de Derecho Público con personalidad jurídica propia, es su misión el contribuir "a la erradicación de la pobreza y a la consolidación de los procesos encaminados a asegurar un desarrollo humano sostenible". Esta cooperación se articula mediante la financiación de proyectos de cooperación para el desarrollo, proyectos de sensibilización y educación para el desarrollo, y la acción humanitaria y de emergencia.

Junto a España, otros países como Francia, Italia, Alemania y Bélgica han desempeñado un importante papel en el desarrollo de medidas orientadas a la recuperación de $\mathrm{CH}$ latinoamericanos y caribeños. Entre las iniciativas desarrolladas por estos países destacan la de SIRCHAL (Sitio Internacional sobre la Rehabilitación de los Centros Históricos de la América Latina y del Caribe), que funciona desde el año 1997 como una asociación compuesta por la Dirección de Arquitectura y Patrimonio de Ministerio de Cultura y Comunicación de Francia, con el Ministerio de Relaciones Exteriores de Francia, la Maison de América Latina, el BID, la UNESCO y el UIA, cuyo objetivo es lograr un desarrollo compartido y sostenible, con una metodología participativa, talleres de concertación y un polo de competencias, ampliando su área de actuación también a centros urbanos.

Al igual que en Europa, el boom de intervenciones de los 80 en los $\mathrm{CH}$, fue acompañado del inicio de inclusión de $\mathrm{CH}$ latinoamericanos en la Lista de Patrimonio de la Humanidad. El primer $\mathrm{CH}$ en recibir este nombramiento, como se ha expresado anteriormente, fue Quito en el año 1978, que junto a Cracovia fueron los dos primeros $\mathrm{CH}$ del mundo en formar parte de esta Lista. A continuación siguieron los CH de Antigua Guatemala (1979), Ouro Preto (1980), 
La Habana y Olinda (1982), Cuzco y San Juan de Puerto Rico (1983), Cartagena (1984), Salvador de Bahía (1985), Potosí, Oaxaca, Puebla, Brasilia y Ciudad de México (1987), Guanajuato, Lima y Trinidad (1988), Santo Domingo (1990), Morelia y Sucre (1991), Zacatecas y Coro (1993), Santa Cruz de Mompox y Colonia del Sacramento (1995), Querétaro (1996), Panamá y Sao Luis (1997), Tlacotalpan (1998), Campeche y Cuenca (1999), Arequipa y Caracas (2000). Estos nombramientos fueron acompañados de la exigencia de elaboración de Planes Maestros para los $\mathrm{CH}$. Algunas de las ciudades han elaborado Planes Maestros (por ejemplo La Habana, Quito, Antigua Guatemala, Panamá, Lima, Cuzco); y otras han elaborado Planes de Revitalización, de Manejo, de Acción o Estratégicos (como Cartagena, Ciudad de México, Querétaro, Santo Domingo, Ouro Preto, Olinda).

Pero no sólo los $\mathrm{CH}$ integrantes de la Lista han desarrollado instrumentos de planificación, sino que otras ciudades de AL se han visto atraídas por el desarrollo de Planes con el fin de orientar las acciones para sus $\mathrm{CH}$. Dentro de todas las experiencias desarrolladas en estas últimas décadas, la intervencion de La Habana Vieja propuso un nuevo escenario de actuacion sobre la ciudad, abordando aspectos integrales a partir de trabajar sobre su espacio público y con un novedoso sistema de gestión. Sin embargo, la gestión de los $\mathrm{CH}$ de $\mathrm{AL}$ no posee las mismas características que en el contexto europeo, los escasos recursos con los que cuentan muchos gobiernos municipales han conllevado a que muchas veces ante la imposibilidad de poder gestionar los $\mathrm{CH}$ hayan recurrido a iniciativas privadas.

En el contexto latinoamericano, a partir del "I Encuentro de Alcaldes y Autoridades Latinoamericas con Ciudades con $\mathrm{CH}$ en Procesos Dinámicos de Recuperación”, celebrado en Lima en el año 1997, representantes de varias ciudades de AL propusiero crear una Red de intercambio y reflexión sobre la gestión de los mismos, a partir de los cuales han surgido diversas Declaraciones. A su vez, con el impulso de Fernando Carrión, se crea en el año 2005 en la ciudad de Quito "OLACCHI", Organización Latinoamericana y del Caribe para la conservación de los $\mathrm{CH}$. Esta organización internacional está dirigida a la adecuada conservación del patrimonio histórico de los centros urbanos de la región, rescatando expresiones culturales propias del territorio Latinoamericano y del Caribe.

Brasil y México son dos de los países de AL con mayor cantidad de $\mathrm{CH}$ declarados Patrimonio de la Humanidad, por tal motivo, han creado agencias nacionales o entidades de financiación para los mismos. En Brasil, en el año 1937, se crea el IPHAN (Instituto de Patrimonio Histórico Artístico Nacional), como una agencia federal dependiente del Ministerio de Cultura responsable de la conservación del patrimonio cultural brasileño. Corresponde a IPHAN, promover y proteger el patrimonio cultural del país, lo que 
garantiza su permanencia y el disfrute de generaciones presentes y futuras. A su vez es responsable de la conservación, protección y tutela de los bienes inscritos en la Lista del Patrimonio Mundial de la UNESCO, y desde el año 2010 desarrolla el Plano de Ação como Cidades Históricas (Plan de Acción para ciudades históricas), puesto en marcha por el IPHAN en 2010, que involucra a instituciones federales y estatales para apoyar el desarrollo, la restauración y revitalización de las ciudades históricas en el país, cuenta para ello con oficinas técnicas localizadas en las ciudades históricas.
Este Capítulo, ha presentado los enfoques que han guiado a las estrategias en Italia, España y $\mathrm{AL}$ en el período de estudio. A continuación se sintetiza en la Figura III.1 los autores, documentos, tipos de planes y estrategias que se han desarrollado en las sucesivas décadas de este periodo, y en la Figura III.2 se vinculan los enfoques identificados en este capítulo con los presentados en los capítulos 1 y 2 , y se asocian con las estrategias empleadas. Estas Figuras, actúan como fuelle a la presentación de las experiencias de intervención y gestión identificadas y seleccionadas para su análisis. 


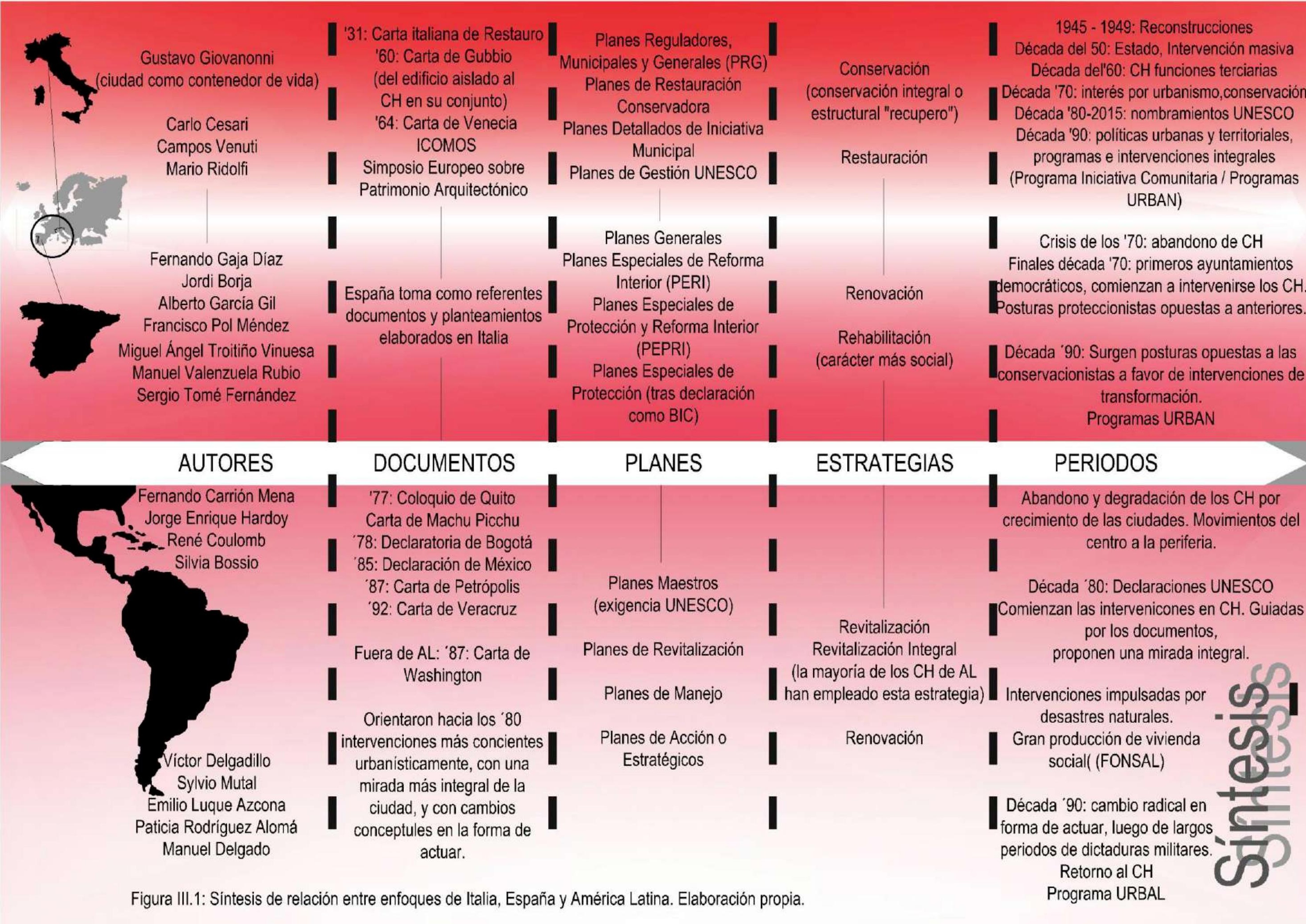




\subsection{Experiencias de intervención y gestión}

\section{identificadas y seleccionadas}

La mirada a los $\mathrm{CH}$ de ciudades grandes e intermedias de $\mathrm{AL}$, España e Italia, ha permitido la identificación de numerosas intervenciones de revitalización, rehabilitación, regeneración, puesta en valor, conservación, entre otras tantas, que han intentado recuperar áreas que por mucho tiempo han permanecido en estado de abandono y degradación. Como se ha mencionado previamente, las intervenciones en $\mathrm{CH}$ se han multiplicado en todo el mundo desde la década del 80 hasta la actualidad, y en las páginas siguientes se exponen algunos de los casos identificados en el contexto europeo (España e Italia) y en el latinoamericano en el período de estudio (Ver Tablas III.2a y III.2b).

Metodológicamente, el criterio de selección utilizado se ha guiado por los siguientes aspectos:

- Que las intervenciones desarrolladas y propuestas para sus $\mathrm{CH}$ se hayan encontrado enmarcadas en un instrumento de planificación.

- Que los casos sean representativos de los cambios en las miradas del $\mathrm{CH}$ a lo largo del tiempo.

- Que se encuentren distribuidos en forma equitativa en la extensión del país o región.
- Que la ciudad registre relevancia política, económica, cultural o histórica a nivel local y/o internacional.

- Que la escala de ciudad y su cantidad de habitantes sea representativa.

- Que la actuación haya tenido un alto impacto, positivo o negativo, a escala local o internacional.

- Que el nivel de información sea suficiente para el análisis. Con este fin, se han escogido casos distribuidos de Norte a Sur y de Este a Oeste, tanto de las regiones italianas, como de las Comunidades Autónomas españolas y de los países latinoamericanos. De las numerosas actuaciones registradas, que superan ampliamente a la cantidad analizada, se han seleccionado 40 para la elaboración de Fichas Síntesis (20 latinoamericanas y 20 europeas - 10 españolas y 10 italianas - Ver Anexo, A1), haciendo principal hincapié en actuaciones enmarcadas en Planes Urbanos, $y$ en aquellas intervenciones desarrolladas en el marco del Urbanismo Sostenible, por las nuevas miradas que aportan a la planificación contemporánea al formar parte de un sistema de planificación o una estrategia general de gestión de la ciudad. No obstante, también se han tomado referentes de intervenciones desarrolladas en períodos anteriores, que por su aporte a la temática no podían obviarse. 
En Europa, para el abordaje del contexto italiano, de las 20 regiones en que se distribuye el territorio, se han escogido 10 casos distribuidos a lo largo y ancho del país (Ver Figura III.3a y Cuadro III.1a). Se han exceptuado casos, como el de la región de Abruzzo que ha sido reemplazado por otro de Toscana, siendo que el $\mathrm{CH}$ de L'Aquila, capital de Abruzzo, ha sido destruido en gran parte por un desastre natural, el terremoto de 2009 y los planes de intervención se encuentran dirigidos a actuaciones más específicas de esa situación (que tendrían lugar en una investigación particular dirigida a esa temática). Por su parte, para el abordaje de la situación española, se tuvo en cuenta la distribución de las 15 Comunidades Autónomas continentales en que se divide el territorio español. Se han seleccionado 10 casos de ciudades distribuidas de Norte a Sur, así como de Este a Oeste del país que han adquirido relevancia sea por la importancia que adoptan en el contexto local e internacional, como por la singularidad de sus actuaciones (Ver Figura III.3b y Cuadro III.1b).

En el contexto latinoamericano, de 66 intervenciones identificadas en los 20 países que integran el extenso territorio, se seleccionaron 20 casos representativos de cada uno de los mismos, con el fin de obtener una mirada lo más integradora posible de la realidad latinoamericana (Ver Figuras III.3.c, III.3d y Cuadro III.1c). No obstante, debido a situaciones particulares, dos casos debieron reemplazarse por exponentes de Brasil y México, dos de los países más poblados, de los más extensos y con mayor cantidad de intervenciones en AL. Uno de los casos reemplazados fue Haití, donde Puerto Príncipe su ciudad Capital, comparte con L'Aquila una situación similar dado que ha sufrido la destrucción de su $\mathrm{CH}$ a causa del terremoto del año 2010; el otro caso es Nicaragua, donde el Plan de intervención para la ciudad de Managua se encuentra aún en elaboración y no se dispone hasta el momento del material bibliográfico necesario para el análisis del $\mathrm{CH}$ de la ciudad capital o de otras intervenciones en $\mathrm{CH}$ nicaragüenses.

Seguramente, en la necesidad de recorte de los casos, han quedado al margen algunas actuaciones interesantes, tanto en Europa como en $\mathrm{AL}$, pero la idea ha sido generar un barrido de la situación general que presentan ambos contextos, y no focalizar solo en situaciones particulares de una región o país.

Las 40 fichas elaboradas han sintetizado en las siguientes variables los principales aspectos del $\mathrm{CH}$ : extensión, población, inserción territorial, dinámica general y urbanística, especialización funcional, declaratorias y problemáticas; así como de la Intervención: tipo de intervención, instrumento de planificación, objetivos, principales ejes del Plan, instrumento de gestión, estado de implementación y nivel de información, lo que ha permitido caracterizar ambos aspectos. (Ver Figura III.4a y III.4b). 


\section{CONTEXTO EUROPEO: CASOS IDENTIFICADOS}

\begin{tabular}{|c|c|c|c|c|c|c|c|}
\hline PAIS & $\overline{N^{0}}$ & CENTRO HISTÓRICO & DECLARACION UNESCO & PAis & $\mathrm{N}^{0}$ & CENTRO HISTÓRICO & DECLARACIÓN UNESCO \\
\hline \multirow{22}{*}{ ITALIA } & 1 & CENTRO HISTORICO DE MILÁN & NO POSEE & \multirow{22}{*}{ ESPANAA } & 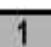 & CENTRO HISTORICO DE GIJÓN & NOPOSEE \\
\hline & 2 & CENTRO HISTORICO DE VERONA & ANO 2000 & & 2 & CENTRO HISTORICO DE ALCOY & NOPOSEE \\
\hline & 3 & CENTRO HISTORICO DE PADUA & NO POSEE & & 3 & CENTRO HISTORICO DE SALAMANCA & ANO 1988 \\
\hline & 4 & CENTRO HISTORICO DE SIENA & AÑO 1995 & & 4 & CENTRO HISTORICO DE SEVILLA & NOPOSEE \\
\hline & 5 & CENTRO HISTORICO DE ASIS & AÑO 2000 & & 5 & CENTRO HISTORICO DE LERIDA & NOPOSEE \\
\hline & 6 & CENTRO HISTORICO DE URBINO & NO POSEE & & 6 & CENTRO HISTORICO DE TARRAGONA & ANO 2000 \\
\hline & 7 & CENTRO HISTORICO DE BOLONIA & NO POSEE & & 7 & CENTRO HISTORICO DE PAMPLONA & NOPOSEE \\
\hline & 8 & CENTRO HISTORICO DE MÓDENA & NO POSEE & & 8 & CENTRO HISTORICO DE VITORIA GASTEIZ & NOPOSEE \\
\hline & 9 & CENTRO HISTORICO DE NAPPOLES & ANO 1995 & & 9 & CENTRO HISTORICO DE SEGOVIA & ANO 1985 \\
\hline & 10 & CENTRO HISTORICO DE FLORENCIA & AÑO 1982 & & 10 & CENTRO HISTORICO DE MADRID & NOPOSEE \\
\hline & 11 & CENTRO HISTORICO DE ROMA & ANO $1980-1990$ & & 11 & CENTRO HISTORICO DE CACERES & ANO 1986 \\
\hline & 12 & CENTRO HISTORICO DE RAVENA & NO POSEE & & 12 & CENTRO HISTORICO DE SANTIAGO DE COMPOSTELA & ANO 1985 \\
\hline & 13 & CENTRO HISTORICO DE RAGGIO EMILIA & NO POSEE & & 13 & CENTRO HISTORICO DE BARCELONA & NO POSEE \\
\hline & 14 & CENTRO HISTORICO DE BERGAMO & NO POSEE & & 14 & CENTRO HISTORICO DE VALENCIA & NOPOSEE \\
\hline & 15 & CENTRO HISTORICO DE IMOLA & NO POSEE & & 15 & CENTRO HISTORICO DE A CORUNA & NOPOSEE \\
\hline & 16 & CENTRO HISTORICO DE FERRARA & ANO 1995 & & 16 & CENTRO HISTORICO DE CUENCA & ANO 1996 \\
\hline & 17 & CENTRO HISTORICO DE AREZZZ & NO POSEE & & 17 & CENTRO HISTORICO DE ZARAGOZA & NOPOSEE \\
\hline & 18 & CENTRO HISTORICO DE ANCONA & NO POSEE & & 18 & CENTRO HISTORICO DE BILBAO & NOPOSEE \\
\hline & 19 & CENTRO HISTORICO DE TORINO & NOPOSEE & & 19 & CENTRO HISTORICO DE LOGRONO & NOPOSEE \\
\hline & 20 & CENTRO HISTORICO DE VENECIA & ANO 1987 & & 20 & CENTRO HISTORICO DE MALAGA & NOPOSEE \\
\hline & 21 & CENTRO HISTORICO DE PALERMO & ANO 2015 & & 21 & CENTRO HISTORICO DE LEONN & NOPOSEE \\
\hline & 22 & CENTRO HISTORICO DE GENOVA & ANO 2006 & & 22 & CENTRO HISTORICO DE VALLADOLID & NOPOSEE \\
\hline
\end{tabular}

Tabla III.1a: Contexto europeo: casos italianos y españoles identificados. Elaboración propia 


\section{CONTEXTO EUROPEO: CASOS ITALIANOS}

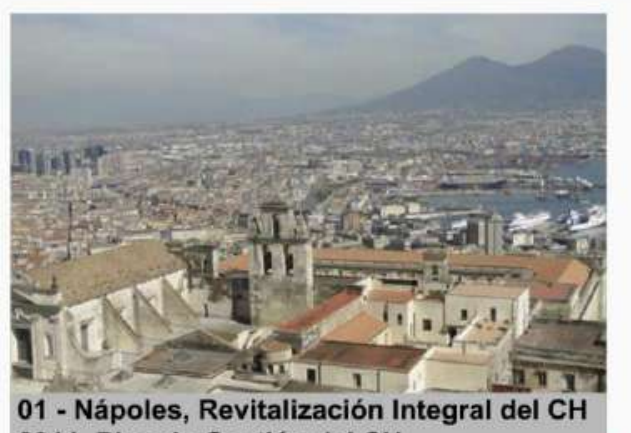

01 - Nápoles, Revitalización Integral del CH

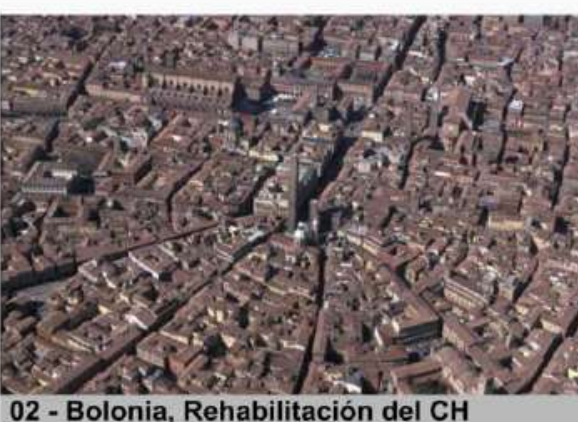
2011, Plan de Gestión del $\mathrm{CH}$.

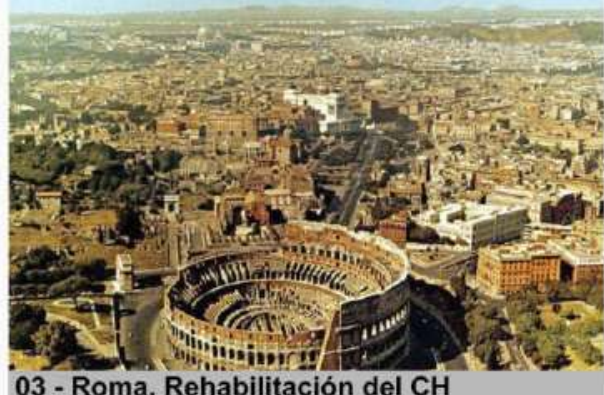

03 - Roma, Rehabilitación del $\mathrm{CH}$ 1973, Piano di Edilizia Economica Popolare

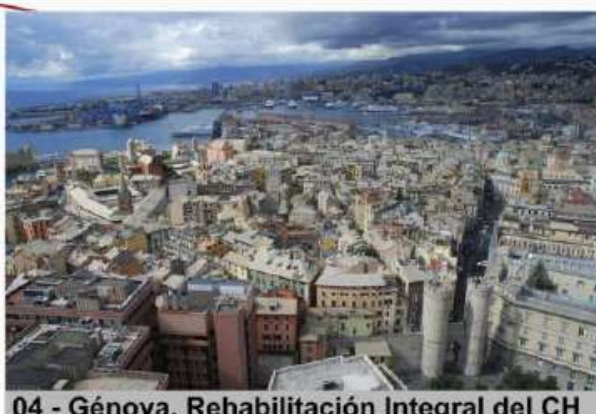
04 - Génova, Rehabilitación Integral del CH 2001, Piano Operativo del $\mathrm{CH}$

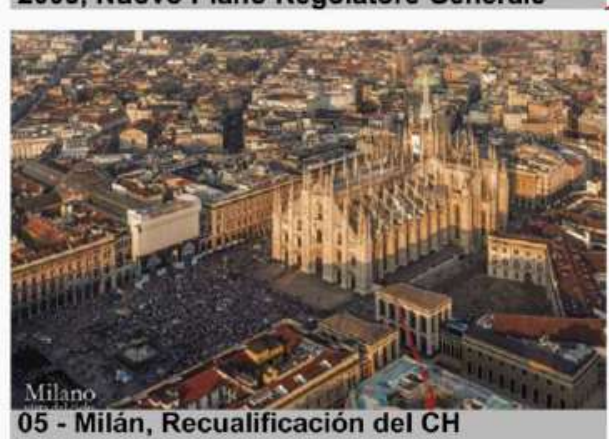

05 - Milán, Recualificación del CH 2012, Piano Urbanistico di Milano

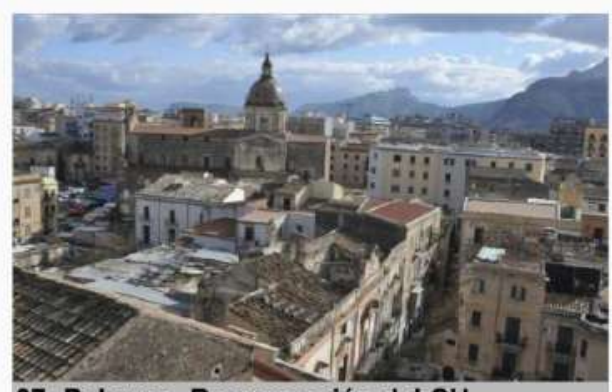

07-Palermo, Recuperación del CH 1993, Piano Particolareggiato Esecutivo $\mathrm{CH}$

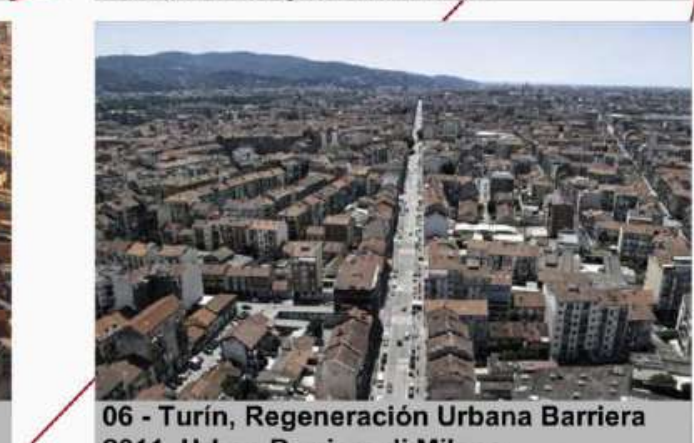
2011. Urban Barriera di Milano

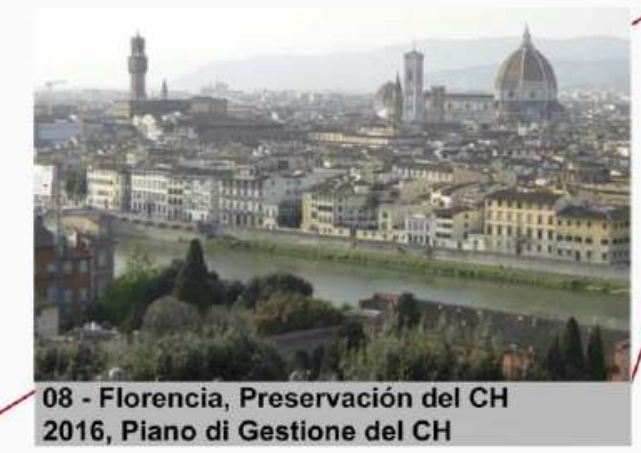

2016, Piano di Gestione del CH

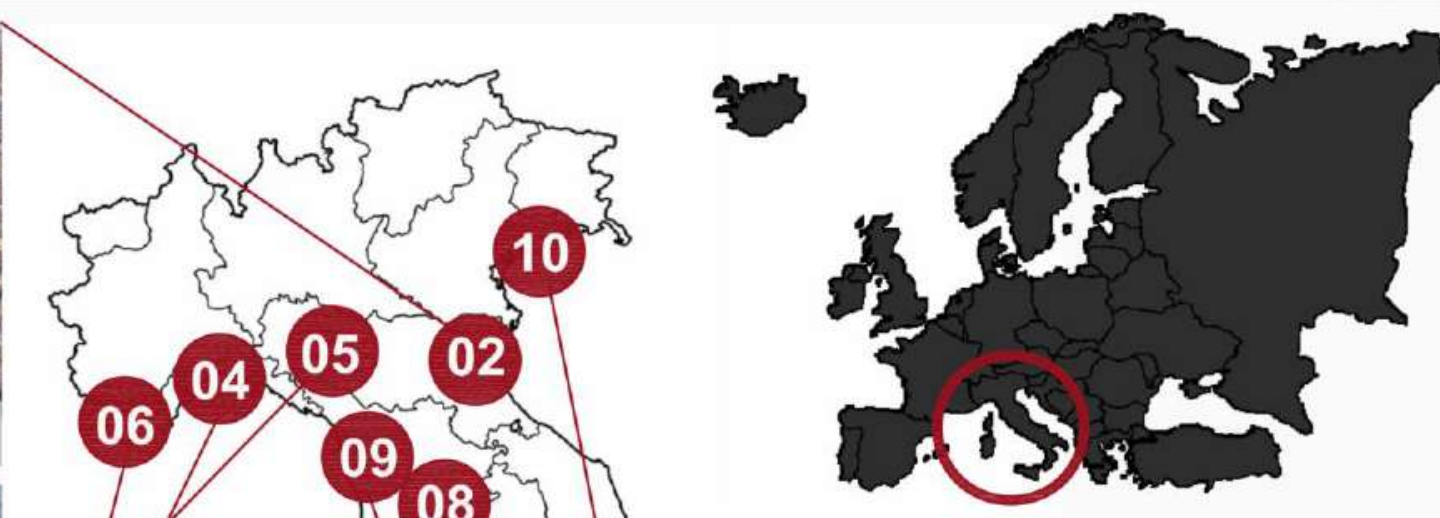

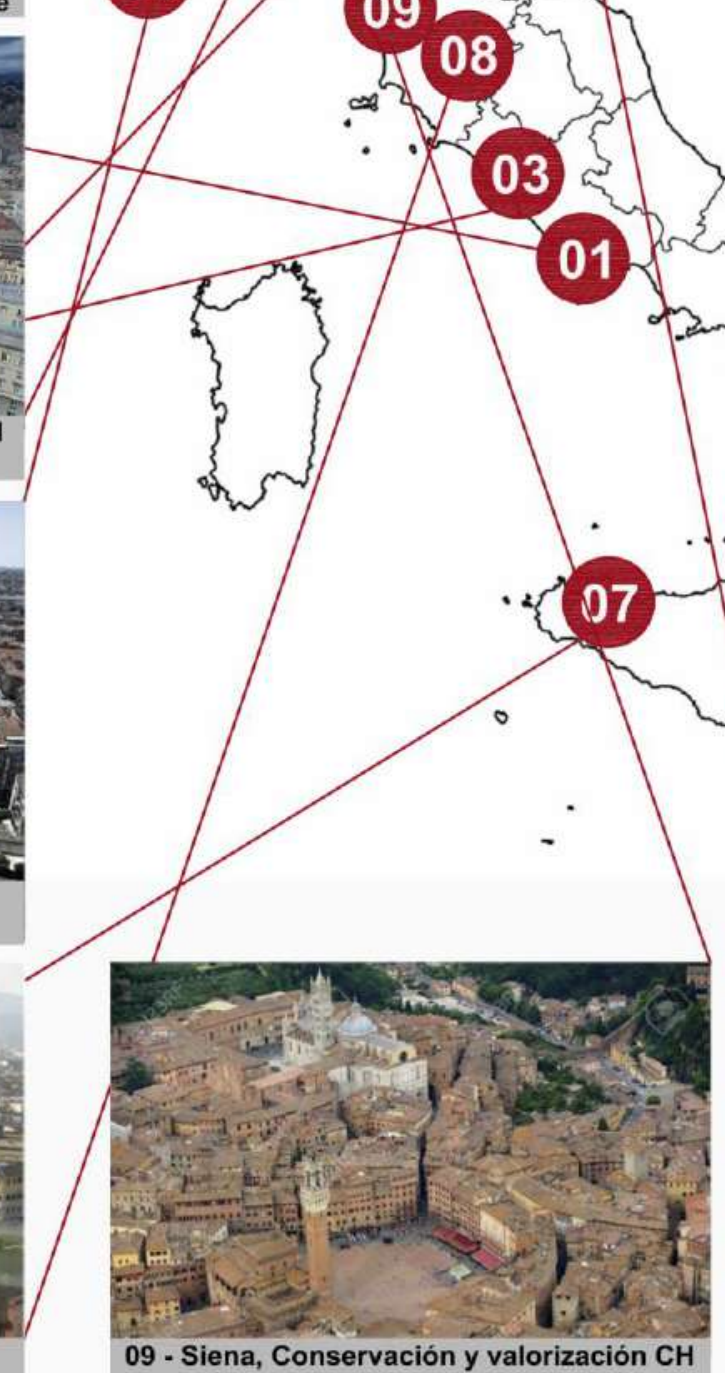

2015, Piano di Gestione del CH

\begin{tabular}{|c|c|c|}
\hline REGIÓN & | CIUDAD & $\mathrm{N}^{\circ}$ \\
\hline Campania & Nápoles & 01 \\
\hline Emilia Romagna & Bolonia & 02 \\
\hline Lazio & Roma & 03 \\
\hline Liguria & Génova & 04 \\
\hline Lombardia & Milán & 05 \\
\hline Piamonte & Turin & 06 \\
\hline Sicilia & Palermo & 07 \\
\hline \multirow[t]{2}{*}{ Toscana } & Florencia & 08 \\
\hline & \begin{tabular}{|l|} 
Siena \\
\end{tabular} & 09 \\
\hline Véneto & Venecia & 10 \\
\hline
\end{tabular}

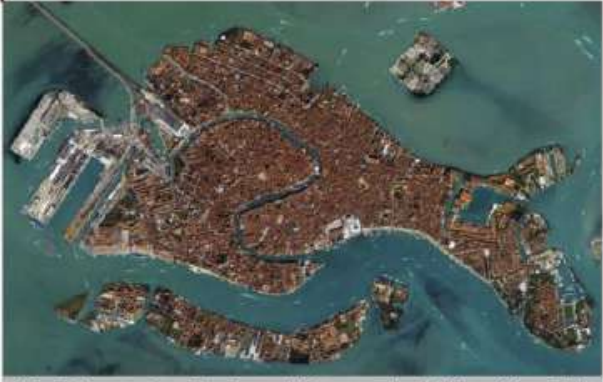

10 - Venecia, Protección y rehabilitación $\mathrm{CH}$ 2012, Piano di Gestione di Venezia e Laguna 

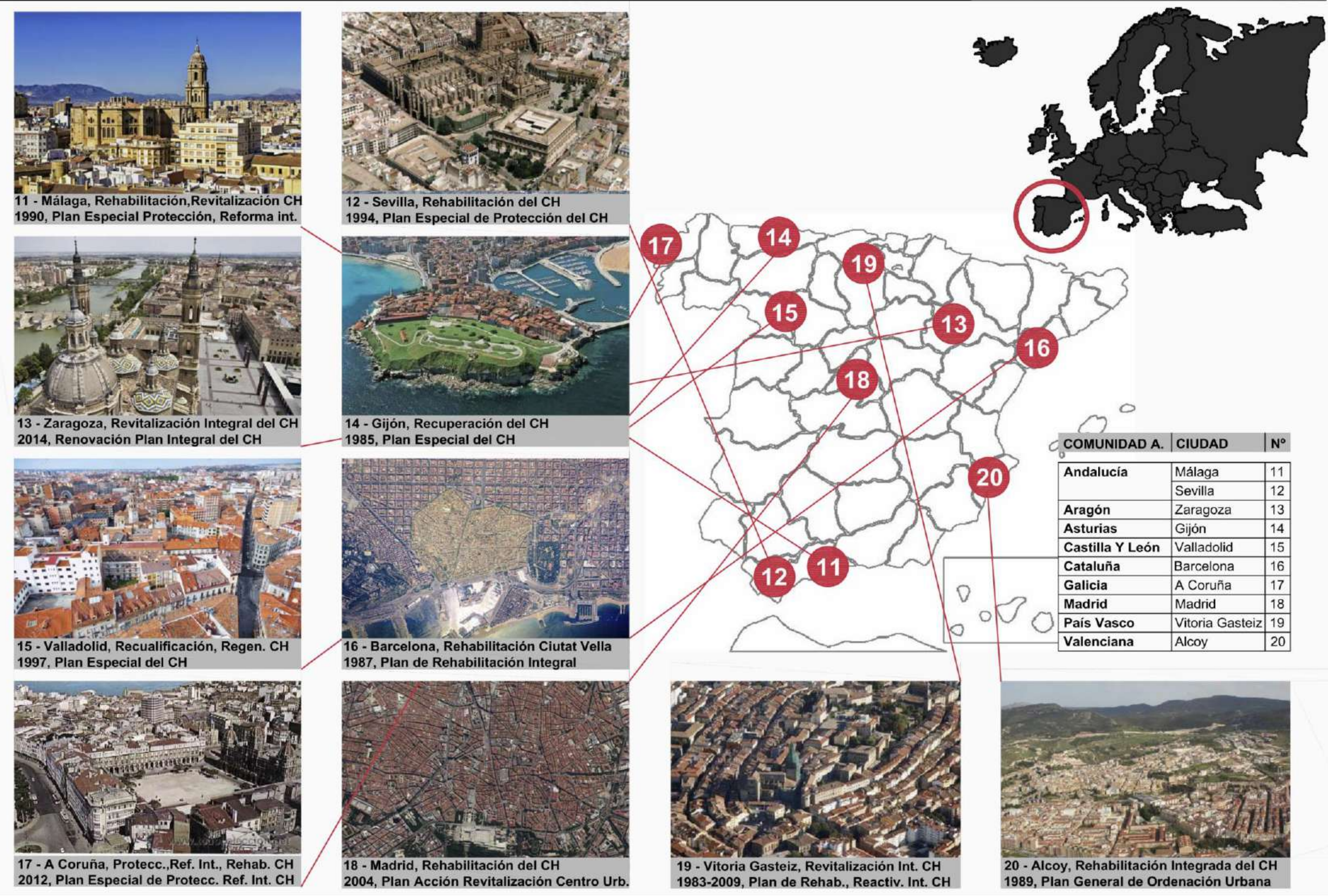
EL CENTRO HISTÓRICO COMO PAISAJE URBANO HISTÓRICO - El desafío de intervenir CONTEXTO EUROPEO: CASOS ITALIANOS SELECCIONADOS

\begin{tabular}{|c|c|c|c|c|c|c|c|}
\hline REGIONN & $\mathrm{N}^{\circ}$ & CIUDAD & INTERVENCION & INSTRUMENTO DE PLANIFICACION & $\begin{array}{l}\text { DECLARACION } \\
\text { UNESCO }\end{array}$ & POBLACION & NIVEL INFO \\
\hline CAMPANIA & 1 & \begin{tabular}{|l|l|l|l} 
NAPOLES & \\
\end{tabular} & REVITALIZACION & $\begin{array}{l}\text { 2011, PLAN DE GESTION DEL CH } \\
\text { PLAN DE ACCION LOCAL (URBAN) } \\
\end{array}$ & $\begin{array}{c}\text { Patrim. Human. } \\
\text { ANO } 1995\end{array}$ & 971.849 hab. & MUY BUENO \\
\hline EMILIA ROMAGNA & 2 & BOLOGNA & REHABILITACIÓN & $\begin{array}{l}\text { 1973. PIANO DI EDILIZIA ECONOMICA POPOLARE } \\
\text { (Cervellati-Sacannavini) }\end{array}$ & 1996. Ciudad Creativa & 371.217 hab. & MUY BUENO \\
\hline LAZIO & 3 & ROMA & RECUALIFICACIÓN & 2003, NUOVO PIANO REGOLATORE GENERALE & AÑo 1980 & 2.872.082 hab. & BUENO \\
\hline LIGURIA & 4 & GÉNOVA & REHABILITACIÓN / REGENERACIÓN & 2001, PIANO OPERATIVO DEL CH & NO POSEE & 594.904 hab. & MUY BUENO \\
\hline LOMBARDIA & 5 & MILAN & RECUALIFICACIÓN / REGENERACIÓN & 2012, PIANO URBANISTICO DI MILANO & NO POSEE & 1.345.890 hab. & BUENO \\
\hline PIEMONTE & 6 & TORINO & REGENERACION & $\begin{array}{l}\text { 2011, URBAN BARRIERA DI MILANO } \\
\text { PROGRAMA INTEGRADO DE DESARROLLO LOCAL } \\
\end{array}$ & NO POSEE & 911.823 hab. & MUY BUENO \\
\hline SICILIA & 7 & PALERMO & RECUPERACIÓN / CONSERVACIÓN & $\begin{array}{l}\text { 1993, PIANO PARTICOLAREGGIATO ESECUTIVO } \\
\text { DEL CH (Cervellati - Benevolo) }\end{array}$ & 2015 (sector) & 860.000 hab. & MUY BUENO \\
\hline \multirow{2}{*}{ TOSCANA } & 8 & FIRENZE & PRESERVACION & 2016, PIANO DI GESTIONE DEL CH & ANO 1982 & 378.236 hab. & MUY BUENO \\
\hline & 9 & \begin{tabular}{l|l} 
SIENA & $T$
\end{tabular} & TUTELA / CONSERVACIÓN / VALORIZACIÓN & 2015. PIANO DI GESTIONE DEL SITO UNESCO CH & AÑo 1995 & 52.774 hab. & MUY BUENO \\
\hline VENETO & 10 & VENEZIA & PROTECCIÓN / REHABILITACIÓN & $\begin{array}{l}\text { 2012, PIANO DI GESTIONE DI VENEZIA E LA SUA } \\
\text { LAGUNA (PIANO REGOLATORE GENERALE 1999) } \\
\end{array}$ & AÑo 1987 & 270.884 hab. & MUY BUENO \\
\hline $\begin{array}{l}\text { COMUNIDAD } \\
\text { AUTONOMA }\end{array}$ & $\mathrm{N}^{\circ}$ & CIUDAD & INTERVENCION & INSTRUMENTO DE PLANIFICACION & $\begin{array}{l}\text { DECLARACION } \\
\text { UNESCO } \\
\end{array}$ & POBLACION & NIVEL INFO \\
\hline \multirow{2}{*}{ ANDALUCIA } & 11 & MALAGA & REHABILITACIÓN / REVITALIZACIÓN & $\begin{array}{l}\text { 1990, PLAN ESPECIAL DE PROTECCIONY } \\
\text { REFORMA INTERIOR (PEPRI) }\end{array}$ & $\begin{array}{l}\text { Ptrim. Human. } \\
\text { NO POSEE }\end{array}$ & 575.322 hab. & MUY BUENO \\
\hline & 12 & SEVILLA & REHABILITACIÓN & $\begin{array}{l}\text { 1994. PLAN ESPECIAL DE PROTECCIÓN DEL } \\
\text { CENTRO HISTÓRICO (PEPCH) }\end{array}$ & NO POSEE & 693.878 hab. & BUENO \\
\hline ARAGÓN & \multicolumn{2}{|c|}{13 ZARAGOZA } & REVITALIZACIÓN & $\begin{array}{l}\text { 1997, PLAN INTEGRAL DEL CASCO HISTORICO } \\
\text { (PICH) }\end{array}$ & NO POSEE & 664.953 hab. & BUENO \\
\hline ASTURIAS & 14 & GIJóN & RECUPERACIÓN & $\begin{array}{l}\text { 1985, PLAN ESPECIAL DEL CASCO HISTÓRICO } \\
\text { (PECH) }\end{array}$ & NO POSEE & 273.422 nab. & ESCASO \\
\hline CASTILLA Y LEÓN & \multicolumn{2}{|c|}{15 ALLADOLII } & RECUALIFICACIÓN / REGENERACIÓN & $\begin{array}{l}\text { 1997, PLAN ESPECIAL DEL CENTRO HISTORICO } \\
\text { (PECH) }\end{array}$ & NO POSEE & 301.876 hab. & BUENO \\
\hline CATALUNIA & \multicolumn{2}{|c|}{16 AARCELONA } & REMABILITACIÓN & 1987. PLAN DE REHABILITACIÓN INTEGRAL & NO POSEE & \begin{tabular}{|l|}
1.608 .746 hab. \\
\end{tabular} & BUENO \\
\hline GALICIA & \multicolumn{2}{|c|}{\begin{tabular}{|l|l|}
17 & A CORUNA \\
\end{tabular}} & PROTECCION / REF. INT. / REHAB. & $\begin{array}{l}\text { 2012, REVISION PLAN ESPECIAL PROTECCIONY } \\
\text { REFORMA INTERIOR DE LA CIUDAD VIEJA } \\
\end{array}$ & NO POSEE & 215.227 hab. & BUENO \\
\hline MADRID & 18 & MADRID & REMABILITACIÓN & $\begin{array}{l}\text { 2004. PLAN DE ACCIÓN PARA LA REVITALIZACIÓN } \\
\text { DEL CENTRO URBANO }\end{array}$ & NO POSEE & \begin{tabular}{|l|}
3.165 .541 hab. \\
\end{tabular} & MUY BUENO \\
\hline PAIS VASCO & \multicolumn{2}{|c|}{19 ORIA GAST } & REHABILITACIÓN & $\begin{array}{l}\text { 1983, PERI / 2009, PLAN DE REACTIVACIÓN } \\
\text { INTEGRALL DEL CENTTRO HISTORICO (URBAN) }\end{array}$ & NO POSEE & 242.223 hab. & MUY BUENO \\
\hline VALENCIANA & 20 & ALcor & REHABILITACION & $\begin{array}{l}\text { 1989. PLAN GRAL. DE ORDENACION URBANA } \\
\text { PLAN ESPECIAL PROTECCION Y REF. INT. }\end{array}$ & NO POSEE & 61.542 hab. & BUENO \\
\hline
\end{tabular}

Cuadros III.1a y III.1b: Casos italianos y españoles seleccionados. Elaboración propia 
CONTEXTO LATINOAMERICANO: CASOS IDENTIFICADOS

\begin{tabular}{|c|c|c|c|}
\hline PAIS & $\mathrm{N}^{\circ}$ & CENTRO HISTORICO & DECLARACIÓN UNESCO \\
\hline \multirow{4}{*}{ ARGENTINA } & 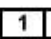 & CASCO HISTORICO DE BUENOS AIRES & NO POSEE \\
\hline & 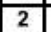 & CENTRO HISTORICO DE SALTA & NO POSEE \\
\hline & 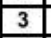 & CENTRO HISTORICO DE CORDOBA & NO POSEE \\
\hline & 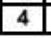 & CENTRO HISTORICO DE CARMEN DE PATAGONES & NO POSEE \\
\hline \multirow{5}{*}{ BOLIVIA } & \begin{tabular}{|l|l|l}
5 & 0 & 0 \\
\end{tabular} & CENTRO HISTORICO DE POTOSI & ANO 1987 \\
\hline & 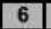 & CENTRO HISTORICO DE LA PAZ & NOPOSEE \\
\hline & \begin{tabular}{|l|l}
7 & 1 \\
\end{tabular} & CENTRO HISTORICO DE SANTA CRUZ DE LA SIERRA & NO POSEE \\
\hline & \begin{tabular}{|l|l|l|l|}
8 & 1 \\
\end{tabular} & CENTRO HISTORICO DE SUCRE & ANO 1991 \\
\hline & 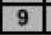 & CENTRO HISTORICO DE COCHABAMBA & NOPOSEE \\
\hline \multirow{11}{*}{ BRASIL } & 10 & CENTRO HISTORICO DE DIAMANTINA & ANO 1999 \\
\hline & 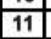 & CENTRO HISTORICO DE GOIAS & ANO 2001 \\
\hline & 12 & CENTRO HISTORICO DE JOAO PESSOA & NO POSEE \\
\hline & 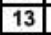 & CENTRO HISTORICO DE OURO PRETO & ANO 1980 \\
\hline & 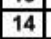 & CENTRO DE RECIFE & NO POSEE \\
\hline & 15 & CENTRO HISTÓRICO DE SALVADOR, PELOURINHO & ANNO 1985 \\
\hline & \begin{tabular}{|l|l|l|l|l}
16 & 0 \\
\end{tabular} & CENTRO HISTORICO DE SAN PABLO & NOPOSEE \\
\hline & 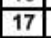 & CENTRO HISTORICO DE RIO DE JANEIRO & NO POSEE \\
\hline & 18 & CENTRO HISTORICO DE PORTO ALEGRE & NO POSEE \\
\hline & \begin{tabular}{|c|c|c|c|c|}
19 \\
\end{tabular} & CENTRO HISTORICO DE PELOTAS & NO POSEE \\
\hline & 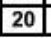 & CENTRO HISTORICO DE SAO LUIS & ANO 1997 \\
\hline \multirow{6}{*}{ COLOMBIA } & 211 & CENTRO HISTORICO DE BOGOTA & NO POSEE \\
\hline & 22 & CENTRO HISTORICO DE CARATGENA DE INDIAS & ANO 1984 \\
\hline & 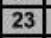 & CENTRO HISTORICO DE MEDELLIN & NOPOSEE \\
\hline & 24 & CENTROS HISTORICOS DE LA REGION DE ANTIOQUIA & NOPOSEE \\
\hline & 25 & CENTRO HISTORICO DE SANTA CRUZ DE MOMPOX & ANO 1995 \\
\hline & 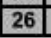 & CENTRO HISTORICO DE SANTA MARTA & NOPOSEE \\
\hline COSTARICA & 27 & CENTRO HISTORICO DE SAN JOSE DE COSTA RICA & NO POSEE \\
\hline \multirow{5}{*}{ CUBA } & 28 & CENTRO HISTORICO DE CAMAGUEY & ANO 2008 \\
\hline & 29 & CENTRO HISTORICO DE CIENFUEGOS & ANO 2005 \\
\hline & 30 & CENTRO HISTORICO DE LA HABANA VIEJA & ANO 1982 \\
\hline & 31 & CENTRO HISTORICO DESAGUA LA GRANDE & NO POSEE \\
\hline & 32 & CENTRO HISTORICO DE TRINIDAD & ANO 1988 \\
\hline \multirow{4}{*}{ CHILE } & 33 & CENTRO HISTORICO DE SANTIAGO & NO POSEE \\
\hline & 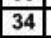 & CENTRO HISTORICO DE VALPARAISO & ANO 2003 \\
\hline & 35 & CENTRO HISTORICO DE IQUIQUE & NO POSEE \\
\hline & 36 & CENTRO HISTORICO DE ARICA & NO POSEE \\
\hline
\end{tabular}

\begin{tabular}{|c|c|c|c|}
\hline PAIS & $\mathrm{N}^{\circ}$ & CENTRO HISTÓRICO & DECLARACIÓN UNESCO \\
\hline \multirow[t]{2}{*}{ ECUADOR } & 37 & CENTRO HISTORICO DE QUITO & ANO 1978 \\
\hline & 38 & CENTRO HISTORICO DE CUENCA & ANO 1999 \\
\hline EL SALVADOR & 39 & CENTRO HISTORICO DE SAN SALVADOR & NO POSEE \\
\hline GUATEMALA & 40 & CENTRO HISTORICO DE ANTIGUA & ANO 1979 \\
\hline HONDURAS & 41 & CENTRO HISTORICO DE COMAYAGUA & NO POSEE \\
\hline \multirow{12}{*}{ MEXICO } & 43 & CENTRO HISTORICO DE CAMPECHE & ANO 1999 \\
\hline & 44 & CENTRO HISTORICO DE LA CIUDAD DE MEXXICO & ANO 1987 \\
\hline & 45 & CENTRO HISTORICO DE GUANAJUATO & ANO 1988 \\
\hline & 46 & CENTRO HISTORICO DE MERIDA & NOPOSEE \\
\hline & 47 & CENTRO HISTORICO DE MORELIA & ANO 1991 \\
\hline & 48 & CENTRO HISTORICO DE OAXACA & ANO 1987 \\
\hline & 49 & CENTRO HISTORICO DE PACHUCA DE SOTO & NOPOSE \\
\hline & 50 & CENTRO HISTORICO DE PUEBLA & ANO 1987 \\
\hline & 51 & CENTRO HISTORICO DE QUERETARO & ANO 1996 \\
\hline & \begin{tabular}{|c|c|c|}
52 \\
\end{tabular} & CENTRO HISTORICO DE SAN MIGUEL DE ALLENDE & ANO 2008 \\
\hline & \begin{tabular}{|c|c|c|c|}
53 \\
\end{tabular} & CENTRO HISTORICO DE TLACOTALPAN & ANO 1999 \\
\hline & 54 & CENTRO HISTORICO DE ZACATECAS & ANO 1993 \\
\hline NICARAGUA & 55 & CASCO HISTORIC DE MANAGUA & NO POSEE \\
\hline PANAMA & 56 & CASCO ANTTIGUO DE PANAMA & Periodo 1997 \\
\hline PARAGUAY & 57 & CENTRO HISTORICO DE ASUNCIÓN & NO POSEE \\
\hline \multirow{3}{*}{ PERU } & 58 & CENTRO HISTORICO DE LIMA & ANO 1988 \\
\hline & 59 & CENTRO HISTORICO DE CUZCO & ANO 1983 \\
\hline & 60 & CENTRO HISTORICO DE AREQUIPA & ANO 2000 \\
\hline REP.DOMINICANA & 61 & CIUDAD COLONIAL DE SANTO DOMINGO & ANO 1990 \\
\hline \multirow[t]{2}{*}{ URUGUAY } & 62 & CENTRO HISTORICO DE MONTEVIDEO & NOPOSEE \\
\hline & 63 & CENTRO HISTORICO DE COLONIA DEL SACRAMENTC & ANO 1995 \\
\hline \multirow{3}{*}{ VENEZUELA } & 64 & CENTRO HISTORICO DE CARACAS & NO POSEE \\
\hline & 65 & CENTRO HISTORICO DE CORO & ANO 1993 \\
\hline & 66 & CENTRO HISTORICO DE MARACAIBO & NO POSEE \\
\hline
\end{tabular}

Cuadros III.1c: Casos latinoamericanos identificados. Elaboración propia 


\section{CONTEXTO LATINOAMERICANO: CASOS}

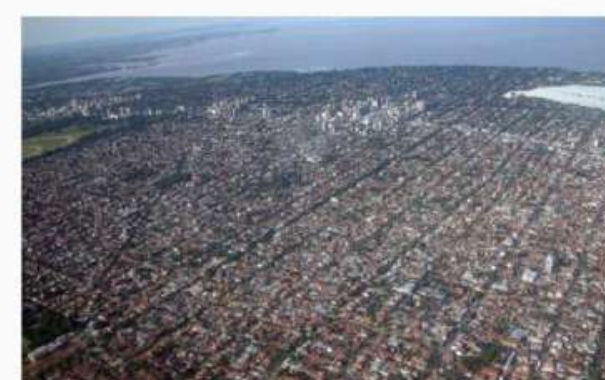

21 - Buenos Aires, Revitalización del CH 2015. Plan de Maneio del $\mathrm{CH}$

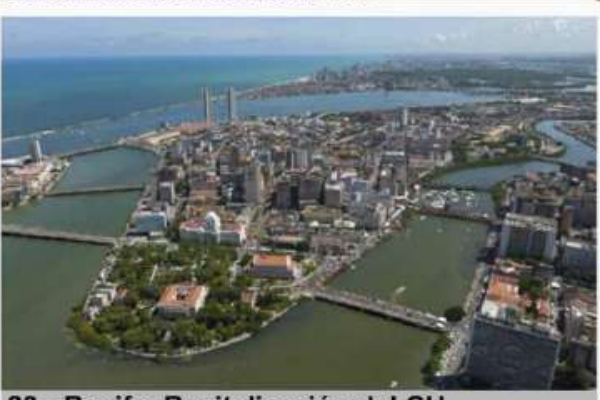

23 - Recife, Revitalización del CH

1980. Plano de Revitalizacao do Centro

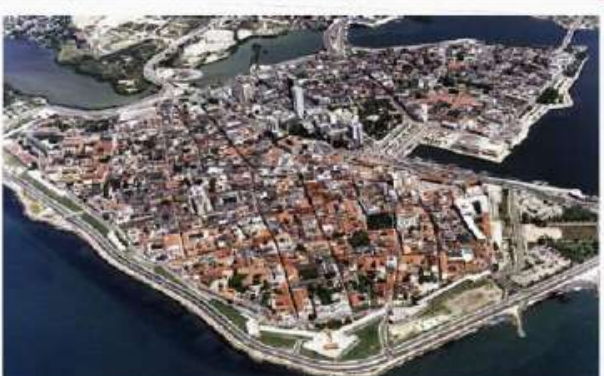

25 - Cartagena de Indias, Revitalización CH 2008, Plan deRevitalización del CH

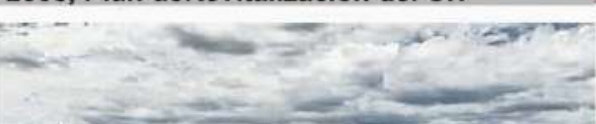

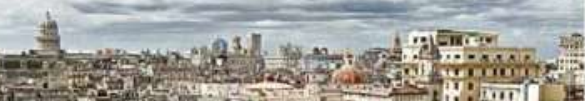
How

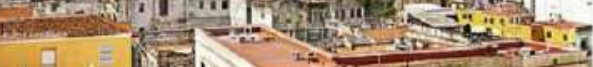

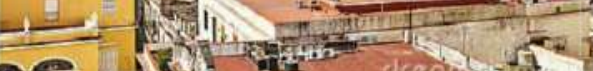
7 - La Habana Vieja, Revitalización del CH 1994, Plan Maestro Revitalización Integral

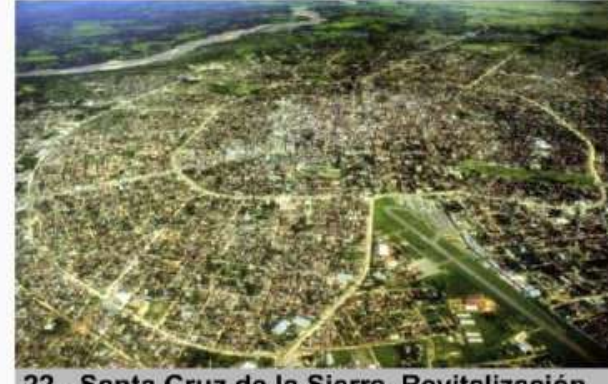

22 - Santa Cruz de la Sierra, Revitalización 2008. Plan de Revitalización Inteqral del $\mathrm{CH}$

24 - Salvador de Bahia, Revitalización del CH 1991. Programa de Recuperacao del CH

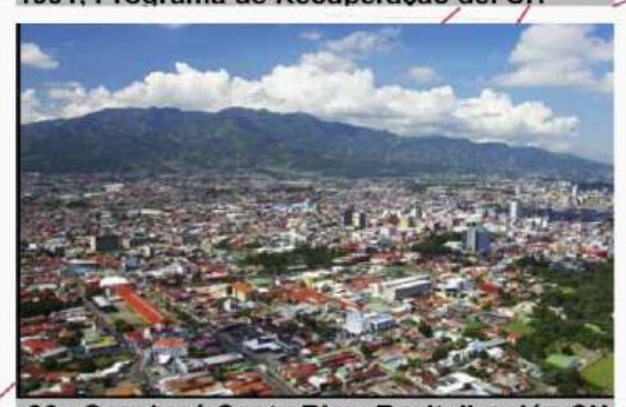

26 - San José Costa Rica, Revitalización CH 2015, Plan de Acción (Revitaliz.) del CH

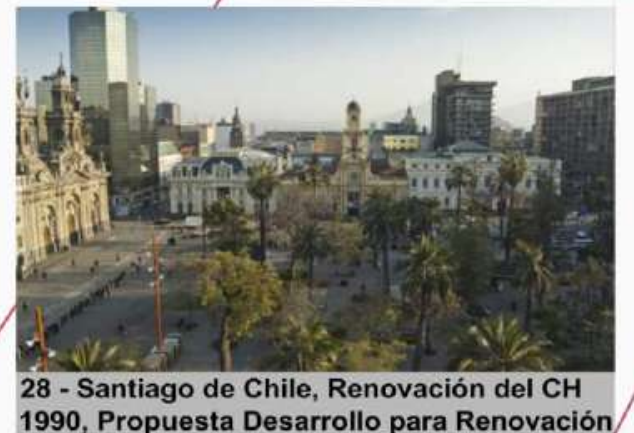

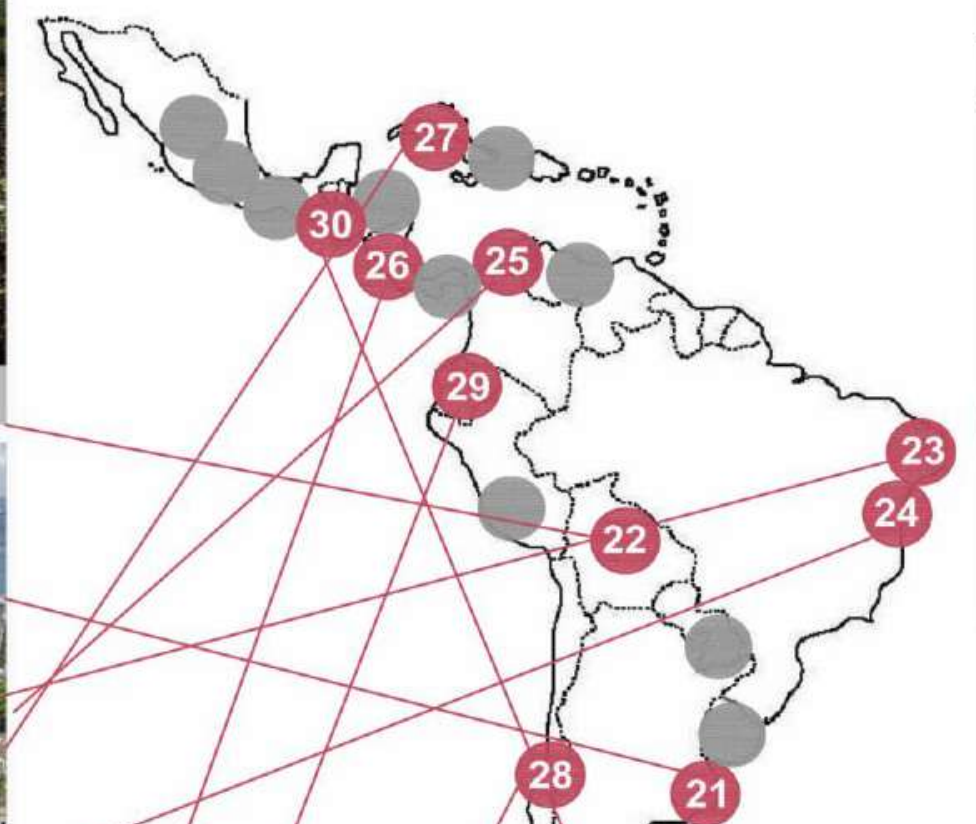

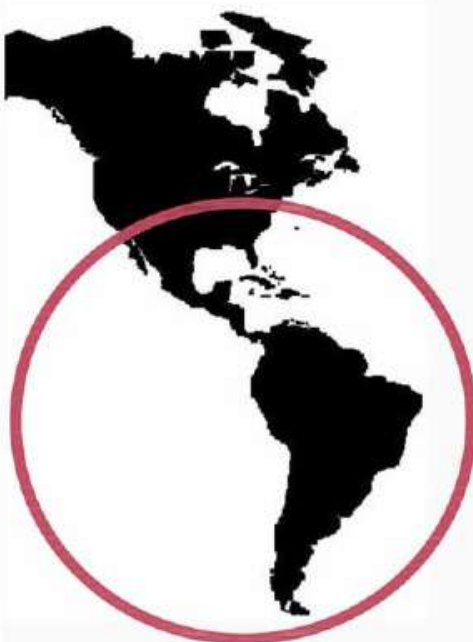

21

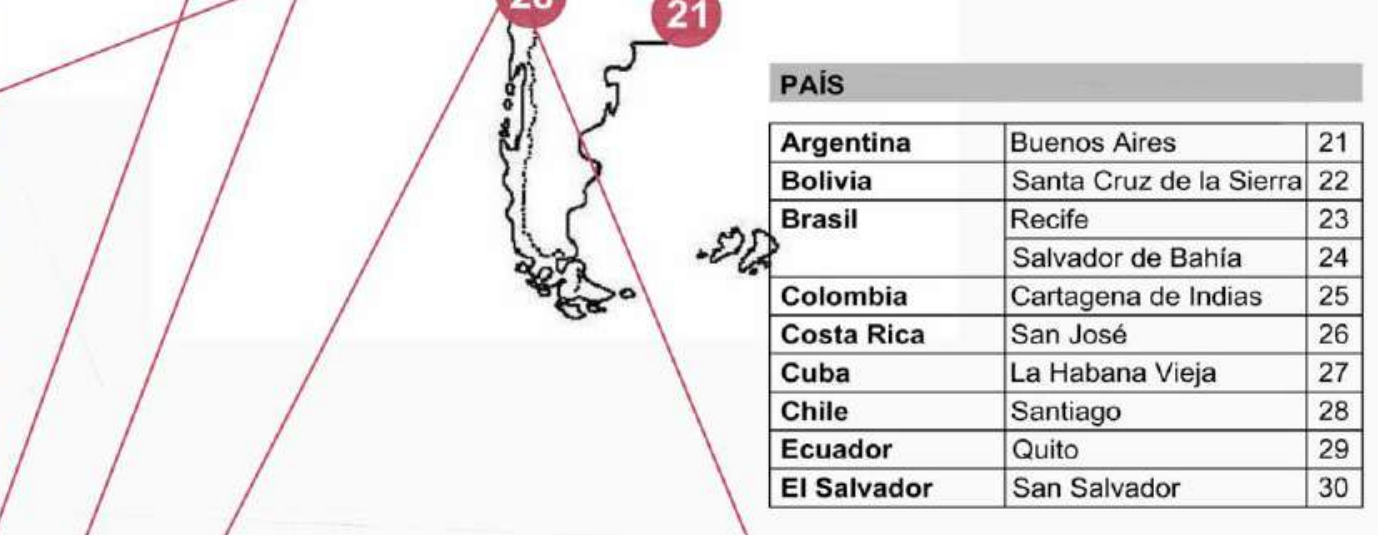

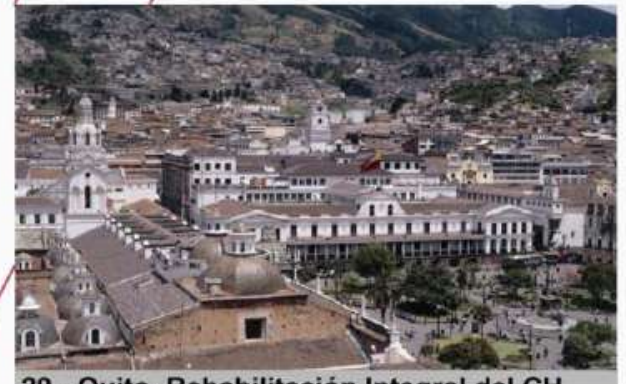

29 - Quito Rehabilitación Integral del $\mathrm{CH}$ 1989, Plan Maestro de Rehabilit, Integral CH

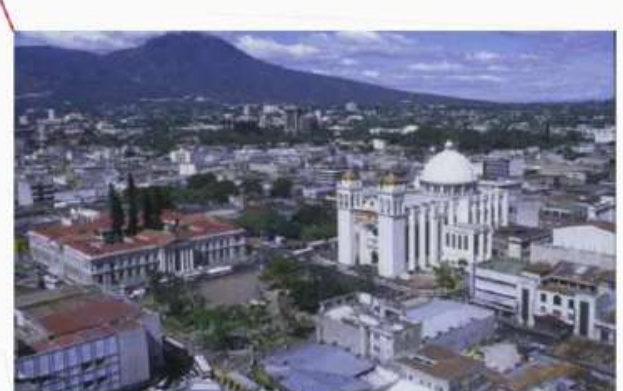

30 - San Salvador, Revitalización del CH 1998, Plan de Rescate del CH 


\section{CONTEXTO LATINOAMERICANO: CASOS}

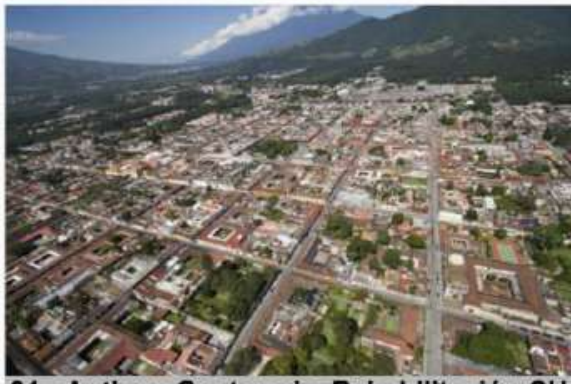

31 - Antigua Guatemala, Rehabilitación CH 2012, Plan Maestro de la Antigua Guatemala

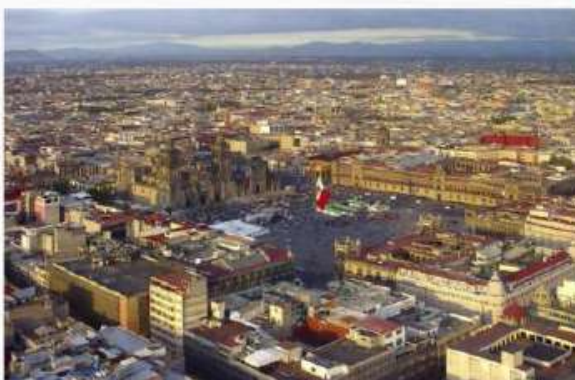

33- Ciudad de México, Revitalización del $\mathrm{CH}$ 2011, Plan de Manejo Integral del CH

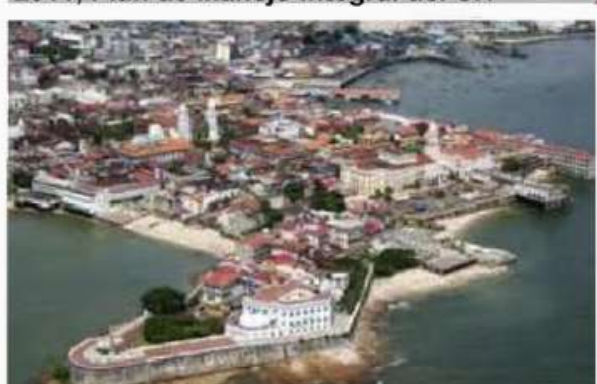

35 - Panamá, Rehabilitación, Restaur. CH 2001, Plan Maestro de Rehab. y restaur. CH

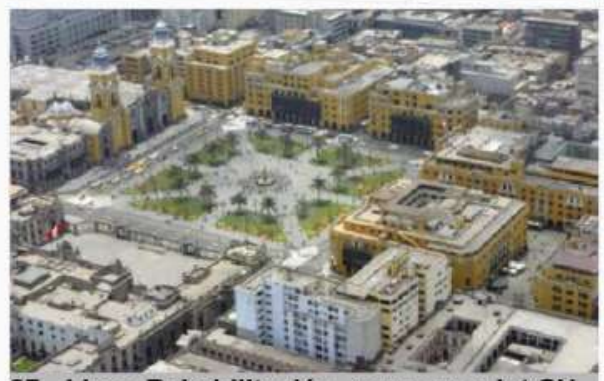

37 - Lima, Rehabilitación, recuperac. Int $\mathrm{CH}$ 2014, Plan Maestro del CH

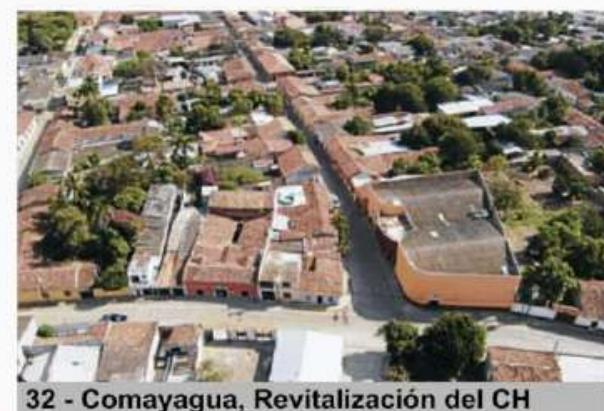

32 - Comayagua, Revitalización del $\mathrm{CH}$

1995, Plan Maestro para Revitalización CH

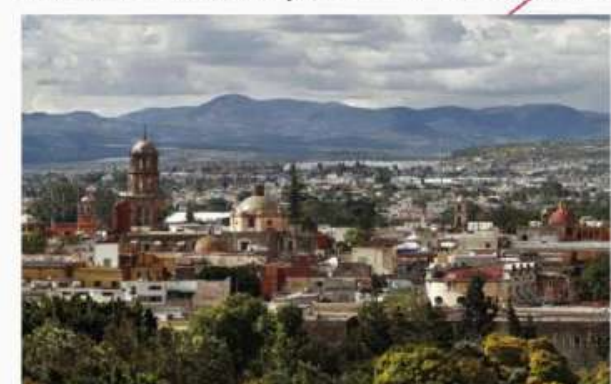

34 - Santiago de Querétaro, Valorización $\mathrm{CH}$ 2008, Plan de Manejo y Conservación CH

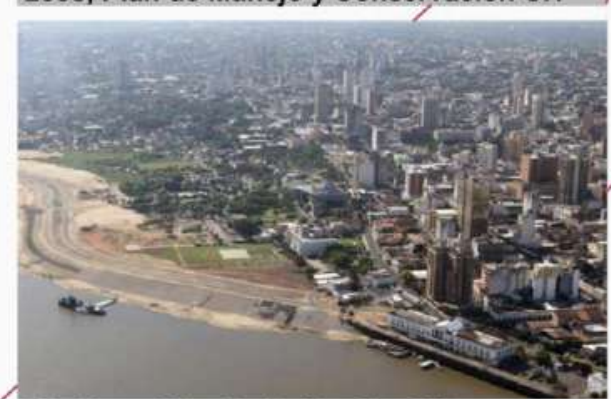

36 - Asunción, Revitalización $\mathrm{CH}$ 2015, Plan Maestro de Revitalización (CHA)

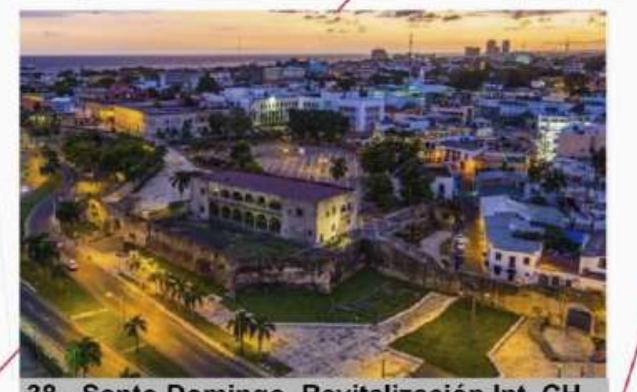

38 - Santo Domingo, Revitalización Int. CH 2006, Plan Estratégico de Revitaliz. Int. CC
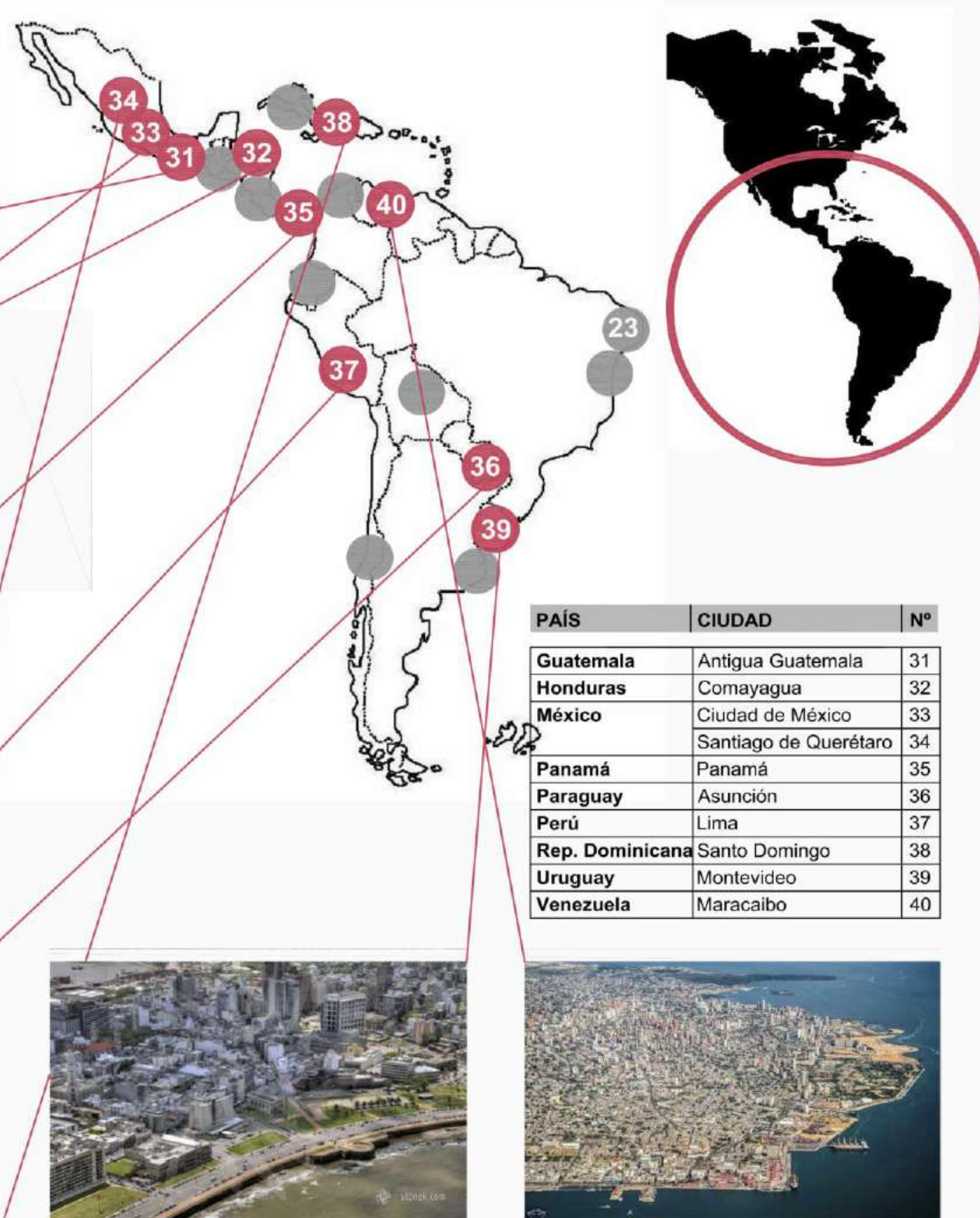

40 - Mracaibo, Renovación del CH

1999, Plan Integral de Renovación Urb. AC
39 - Montevideo, Ordenación Protecc Mejora 2004, Plan Especial Ord., Prot., Mejora CV

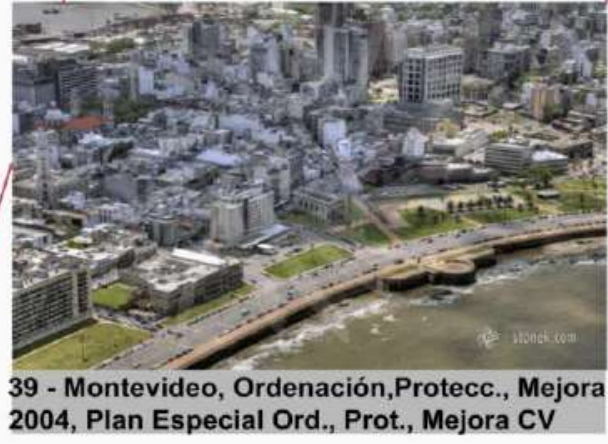


CONTEXTO LATINOAMERICANO: CASOS SELECCIONADOS

\begin{tabular}{|c|c|c|c|c|c|c|c|}
\hline PAis & $\mathrm{N}^{\circ}$ & CIUDAD & INTERVENCION & INSTRUMENTO DE PLANIFICACIÓN & $\begin{array}{l}\text { DECLARACION } \\
\text { UNESCO } \\
\text { Patrim. Human. }\end{array}$ & POBLACIÓN & NIVEL INFO \\
\hline ARGENTINA & 21 & BUENOS AIRES & REVITALIZACION & 2015. PLAN DE MANEJO DEL CASCO HISTORICO & NO POSEE & 2.965 .000 hab. & BUENO \\
\hline BOLIVIA & 22 & SANTA CRUZ DE LA SIERRA & REVITALIZACIÓN & $\begin{array}{l}\text { 2008, PLAN DE REVITALIZACION INTEGRAL } \\
\text { CENTRO HISTORICO }\end{array}$ & NO POSEE & 2.453.549 hab. & BUENO \\
\hline \multirow{2}{*}{ BRASIL } & 23 & RECIFE & REVITALIZACION & $\begin{array}{l}\text { 1980. PLANO DE REVITALIZACACOO DEL CENTRO DE } \\
\text { RECIFE }\end{array}$ & NO POSEE & 1.538.000 hab. & ESCASO \\
\hline & 24 & SALVADOR DE BAHIA & REVITALIZACION & $\begin{array}{l}\text { 1991. PROGRAMA DE RECUPERACAO DEEL CENTRO } \\
\text { HISTORICO DE SALVADOR, PELOURINHO }\end{array}$ & AÑO 1985 & 2.675.000 hab. & BUENO \\
\hline COLOMBIA & 25 & CARTAGENA DE INDIAS & REVITALIZACION & $\begin{array}{l}\text { 2008, PLAN DE REVITALIZACIÓN DEL CENTRO } \\
\text { HISTORICO }\end{array}$ & ANO 1984 & 845.801 hab. & BUENO \\
\hline COSTA RICA & 26 & SAN JOSE DE COSTA RICA & REVITALIZACION & $\begin{array}{l}\text { 2015, PLAN DE ACCION (DE REVITALIZACION) DEL } \\
\text { CENTRO HISTÓRICO }\end{array}$ & NO POSEE & 288.054 hab. & MUY ESCASO \\
\hline CUBA & 27 & LA HABANA & REVITALIZACION & $\begin{array}{l}\text { 1994, PLAN MAESTRO I 2001, PLAN ESPECIAL DE } \\
\text { DESARROLLO INTEGRAL DEL CH } \\
\end{array}$ & AÑ̃ 1982 & 2.105 .000 nab. & MUY BUENO \\
\hline CHILE & 28 & SANTIAGO & RENOVACIÓN & $\begin{array}{l}\text { 1990, PROPUESTA DE DESARROLLO PARA LA } \\
\text { RENOVACION (PLAN DE REPOBLAMIENTO) } \\
\end{array}$ & NO POSEE & 5.128.000 hab. & BUENO \\
\hline ECUADOR & 29 & Quito & REHABILITACION & $\begin{array}{l}\text { 1989, PLAN MAESTRO DE REHABILITACION } \\
\text { INTEGRAL DE LAS AREAS HISTORICAS } \\
\end{array}$ & ANO 1978 & 1.619.000 hab. & MUY BUENO \\
\hline EL SALVADOR & 30 & SAN SALVADOR & REVITALIZACIÓN & $\begin{array}{c}\text { 1998. PLAN DE RESCATE DEL CENTRO HISTORICO } \\
\text { (PRCSS) }\end{array}$ & NO POSEE & 281.870 hab. & BUENO \\
\hline GUATEMALA & 31 & ANTIGUA & REHABILITACIÓN & $\begin{array}{l}\text { 2012, PLAN MAESTRO DE LAANTIGUA } \\
\text { GUAEMALA (PMAG)/PLAN DIRECTOR REHAB. CH } \\
\end{array}$ & ANO 1979 & 45.669 hab. & BUENO \\
\hline HONDURAS & 32 & COMAYAGUA & REVITALIZACION & $\begin{array}{l}\text { 1995, PLAN MAESTRO REVITALIZACION CH/1996, } \\
\text { PROGRAMA COMAYAGUA COLONIAL } \\
\end{array}$ & NO POSEE & 152.051 hab. & BUENO \\
\hline \multirow{2}{*}{ MEXICO } & 33 & CIUDAD DE MÉXICO & REVITALIZACION & $\begin{array}{l}\text { 2011, PLAN DE MANEJO INTEGRAL DEL CENTRO } \\
\text { HISTÓRICO }\end{array}$ & AÑO 1987 & 8.851.000 nab. & MUY BUENO \\
\hline & 34 & QUERETARO & PUESTA EN VALOR / CONSERVACION & $\begin{array}{l}\text { 2008. PLAN DE MANEJOY CONSERVAACON DE LA } \\
\text { ZONA DEMONUMENTOS HISTORICOS } \\
\end{array}$ & AÑO 1996 & 878.931 hab. & MUY BUENO \\
\hline PANAMA & 35 & PANAMA & REHABILITACION / RESTAURACIÓN & $\begin{array}{l}\text { 201, PLAN MAAESTRO DE REEAABLTACACIONY } \\
\text { RESTAURACION / 2004, PLAN REVIVE EL CASCO }\end{array}$ & AÑO 1997 & 880.691 nab. & BUENO \\
\hline PARAGUAY & 36 & ASUNCION & REVITALIZACIÓN & $\begin{array}{l}\text { 2015, PLAN MAESTRO DEREVITALIZACIÓN } \\
\text { CENTRO HISTORICO (CHA) }\end{array}$ & NO POSEE & 525.294 hab. & MUY BUENO \\
\hline PERU & 37 & LIMA & REHABILITACION / RECUPERACION & 2014. PLAN MAESTRO DEL CENTRO HISTORICO & ANO 1991 & 8.473.000 hab. & MUY BUENO \\
\hline REP. DOMINICANA & 38 & SANTO DOMINGO & REVITALIZACION & $\begin{array}{l}\text { 2006. PLAN ESTRATEGICO DE REVITALIZACION) } \\
\text { INTEGRAL DE LA CIUDAD COLONIAL (PRICC) }\end{array}$ & AÑO 1990 & 965.040 hab. & BUENO \\
\hline URUGUAY & 39 & MONTEVIDEO & ORDENACIÓN / PROTECCIÓN / MEJORA & $\begin{array}{l}\text { 2004, PLAN ESPECIAL DE ORDEENACIÓN, } \\
\text { PROTECCION Y MEJORA DE LA CIUDAD VIEJA }\end{array}$ & NO POSEE & 1.305.000 hab. & MUY BUENO \\
\hline VENEZUELA & 40 & MARACAIBO & RENOVACION & $\begin{array}{l}\text { 1999, PLAN INTEGRAL DE RENOVACION URBANA } \\
\text { DEL AREA CENTRAL (PIRU) }\end{array}$ & NO POSEE & 1.339.000 hab. & ESCASO \\
\hline
\end{tabular}

Cuadro III.2: Casos latinoamericanos seleccionados. Elaboración propia 

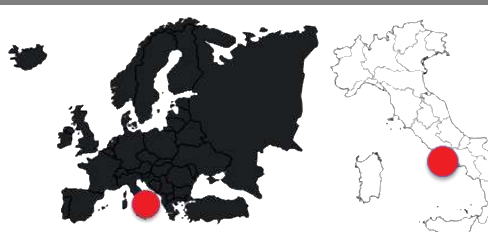

CARACTERISTICAS DEL CENTRO HISTÓRICO

Extensión: 11.727 has. (ciudad) / 1700 has. ( $\mathrm{CH}$ )

Habitantes: 971.849 hab. (2016) / ... hab. (CH)

Inserción territorial: costa del Mar Mediterráneo, centro país

Dinám ica general y urbanistica: es la tercera ciudad más grande de

Italia, y una de las más antiguas de Europa. Su CH c onserva elem entos

de su histórica estratificación que se expresan en sus calles y en las

funciones urbanas y sociales que alberga. La grilla ort ogonal de la antigua fundación griega está aún present e y ha m arcado el desarrollo de la ciudad

Especialización Funcional: ciudad portuaria. $\mathrm{CH}$ : residencial, comercial, administrativa, turistica, cultural.

Declaratorias: 1995, Patrim onio de la Hum anidad, UNESCO

Problemáticas: alta densidad poblacional, desem pleo, bajos niv eles de educación, existencia de edificios públicos y privad os en decadencia, baja calid ad de vivienda, dism inución del com ercio tradicional m inorista por la aparición de grandes centros com erciales precarias condiciones m edioam bientales: alto nivel de contam inación acústica y atmosférica (alto uso del transporte privado -autos y m otos- por falta de transportes alternativos).

CARACTERISTICAS RELATIVAS A LA INTERVENCIÓN

Tipo de intervención: Revitalización integra

Instrum ento de planificación: 2011, Plan de Gestión del Centro Histó-

rico de Nápoles, Plan de Acción Local.

\section{F01}

EXPERIENCIAS DE INTERVENCIÓN Y GESTIÓN EN CENTROS HISTÓRICOS REVITALIZACIÓN INTEGRAL DEL CENTRO HISTÓRICO DE NÁPOLES, CAMPAGNA, ITALIA

Objetivos: Conservar, preservar y revitalizar su patrim onio cultural, y la continuidad de su estratificación histórica; apoyar la producción socioeconóm ica y cultural inter-tradicional de $m$ anufactura, turism o y com ercio; m ejorar el transporte, la infraestructura y proteger el medio am biente, optimizando los recursos de la tierra y fortaleciendo la perspectiva tiendo en producción del conocimiento e investigación. Del Plan de Acción Local: Recualificar la zona m onum ental frente al $m$ ar y la zona urbana histórica cercana; dar nuevas funciones a la ciudad y al patrimonio portuario para la regeneración urbana; apoyar el desarrollo socio-económ ico de Cittá Bassa.

Conservación preservación y revitalización / Manufactura, turism o y com ercio / Transporte, infraestructura y m edio am biente.

Instrumento de gestión: URBACT, Unión Europea

Estado: Por ejecutar

Nivel de inform ación: Muy buen。

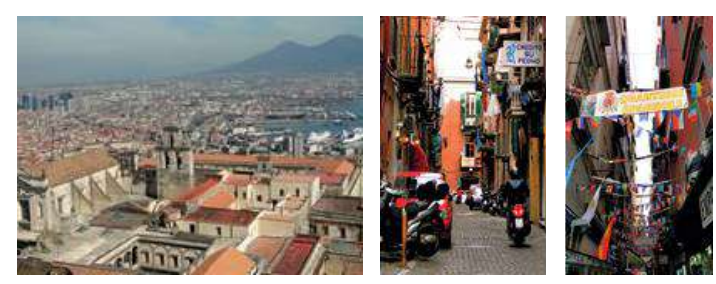

Fuentes: (2011); "Plan de Gestión del Centro His
http ///urbact.eu/sites/default/files/lap naples.pd
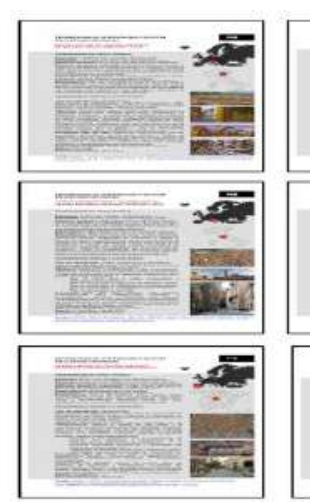

Figuras III.4a: Modelo de Ficha Síntesis de caso de estudio - III.4b: 40

Fichas confeccionadas. Elaboración propia

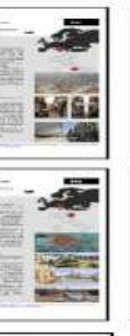

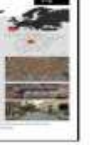
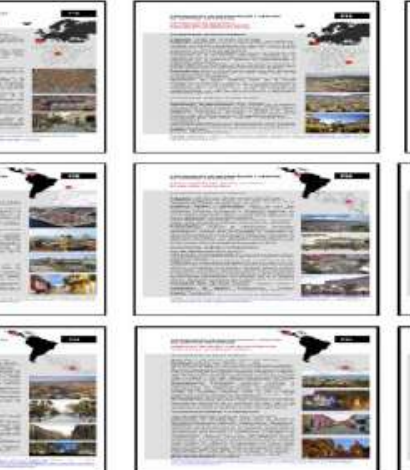

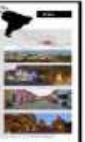
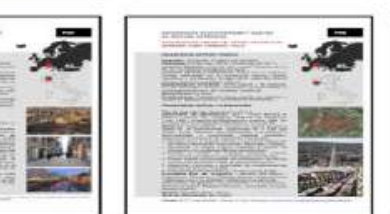

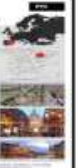
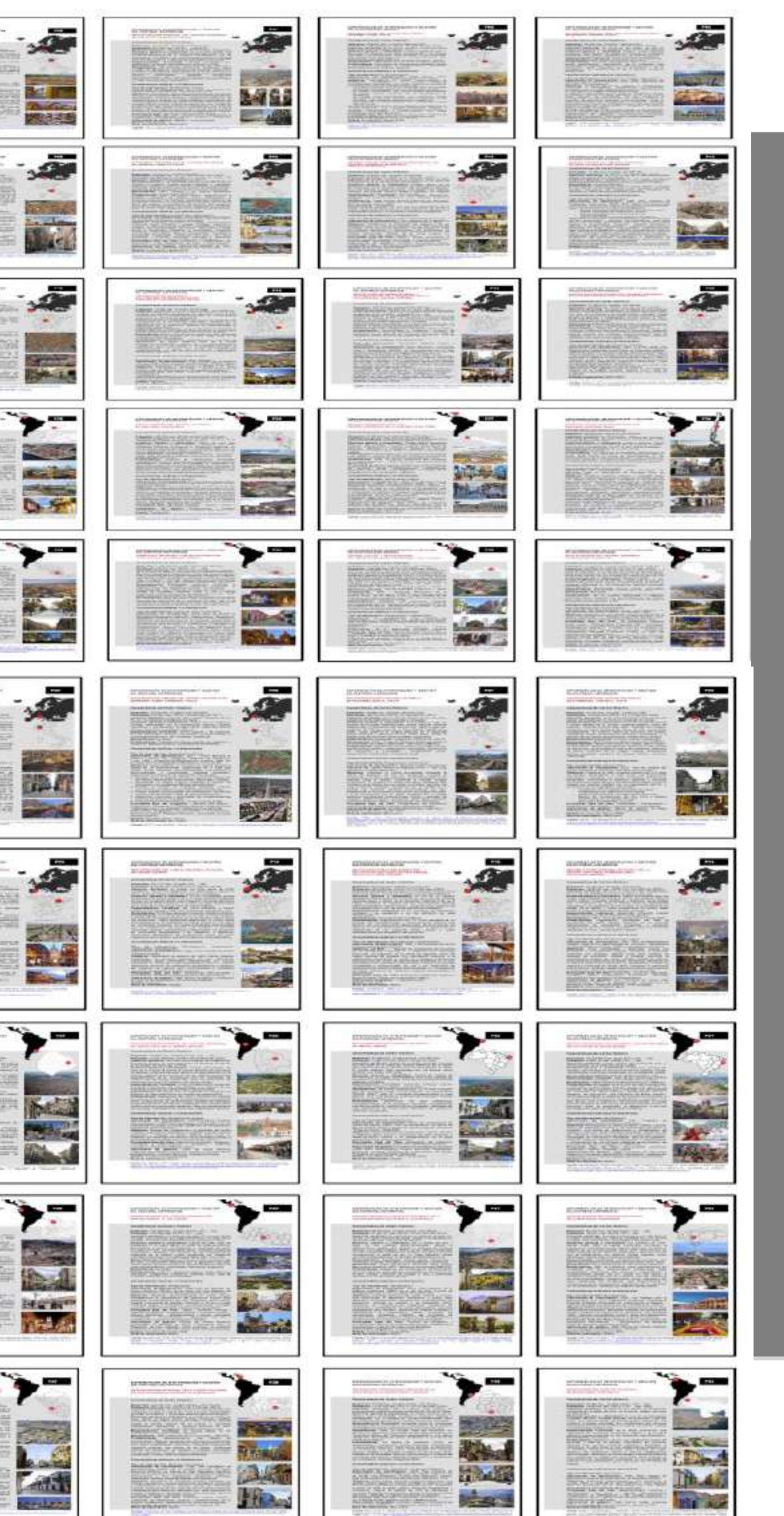

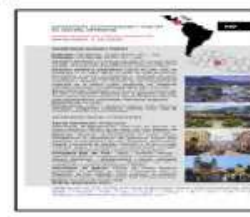

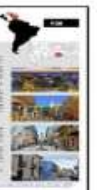
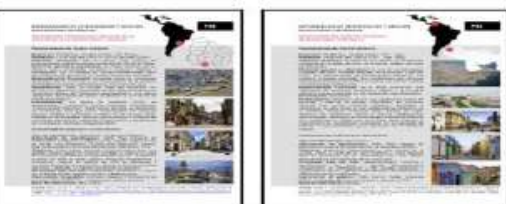


\section{ANÁLISIS DE EXPERIENCIAS}

Introducción. Caracterización y análisis de experiencias seleccionadas

Una mirada global de las experiencias

Problemáticas e intervenciones

Estrategias e instrumentos de intervención y gestión: casos paradigmáticos / nuevos enfoques

Experiencias integrales 


\subsection{Introducción. Caracterización y análisis de experiencias seleccionadas}

La mirada a los $\mathrm{CH}$ de ciudades grandes e intermedias de $\mathrm{AL}$, España e Italia, (cuyo recorte de los países de estudio ha sido fundamentado en la Introducción), ha permitido la identificación de numerosas intervenciones, que enmarcadas dentro de un Plan han intentado recuperar áreas que por mucho tiempo han permanecido en estado de abandono y degradación. En las páginas siguientes se presenta el resultado de un análisis pormenorizado, elaborado a partir de los 40 casos seleccionados en el período investigado, cuya selección ha sido justificada en el capítulo anterior. Se desarrolla una mirada global de los casos analizados, destacando los vínculos e influencias entre ellos, las similitudes y diferencias de los distintos aspectos de los $\mathrm{CH}$, así como de las estrategias e instrumentos de intervención y gestión implementados (Ver Cuadro IV.1: Modelo de Cuadros y en Anexo: Cuadros A.2a a A.2b).

Por otra parte, este estudio también ha permitido identificar casos paradigmáticos, por ser representativos de los distintos períodos por los que han atravesado los $\mathrm{CH}$ y constituir puntos de inflexión al configurar modelos o ejemplos a seguir, planteando nuevas miradas para afrontar la complejidad de los $\mathrm{CH}$.

Se inicia el análisis mediante la Figura IV.1 que distribuye los casos analizados en forma cronológica y posiciona en la parte superior el contexto europeo y en la inferior al latinoamericano. Presenta las relaciones, influencias entre ellos y permite identificar las experiencias enmarcadas en el período del urbanismo sostenible. No obstante, en algunos ejemplos el aspecto temporal no necesariamente los sitúa dentro de una mirada, sino que existen casos que por su postura frente al $\mathrm{CH}$ han mantenido siempre una visión más enfocada en un urbanismo sostenible y otros que a pesar de enmarcarse en ese periodo responden a planteamientos previos del urbanismo. En esta misma figura, se reconocen también los casos paradigmáticos de Italia, España y $\mathrm{AL}$, que han influido con sus propuestas a diversas actuaciones dentro de sus mismas regiones, así como en otros países. Se resaltan como paradigmáticos, Bolonia, Vitoria Gasteiz, Barcelona y Alcoy dentro del contexto europeo y Salvador de Bahía, Quito y La Habana en el contexto latinoamericano. Los motivos por los cuales se los considera de este modo se exponen en el punto 4.1.1.2 de este apartado. 


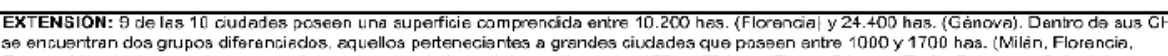

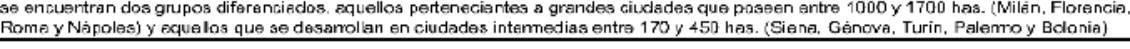

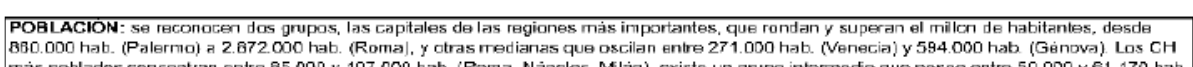

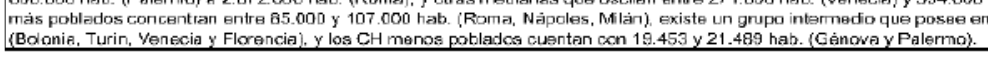

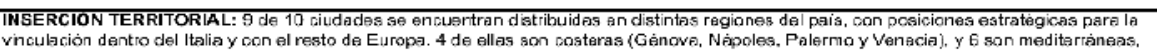

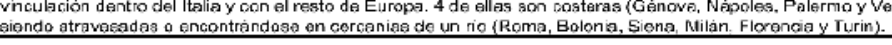

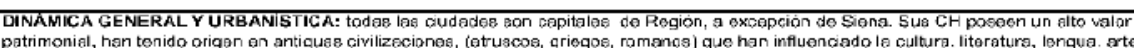

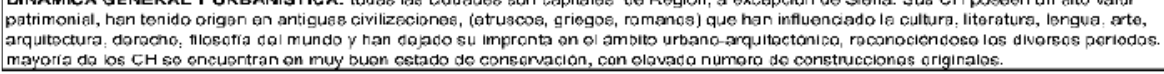

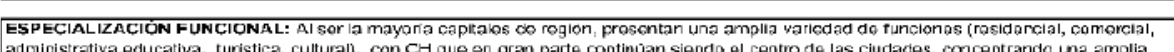
administrativa, duce.
gamia de funcianos.

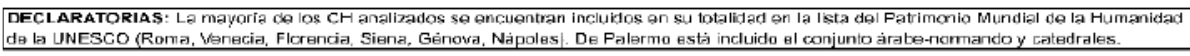

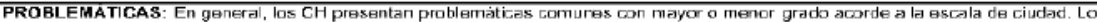

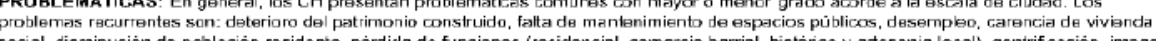

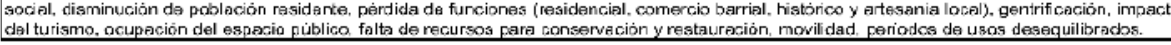

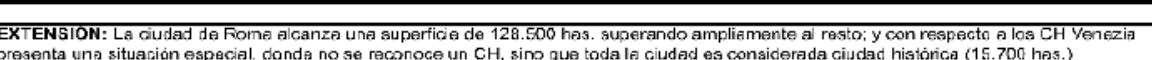

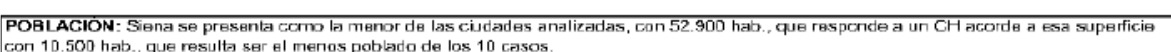

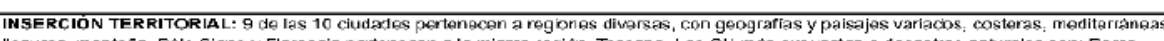

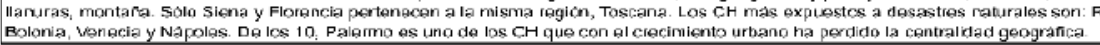

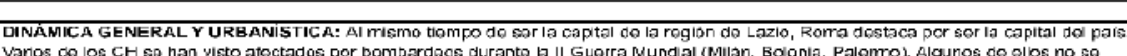

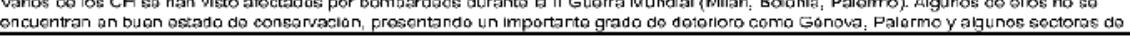

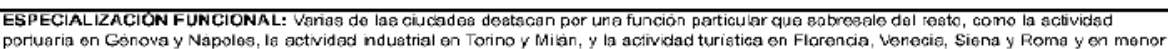

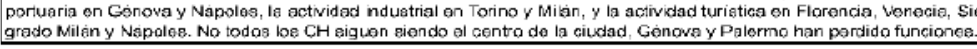

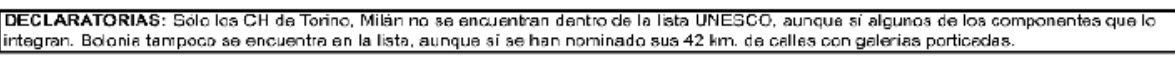

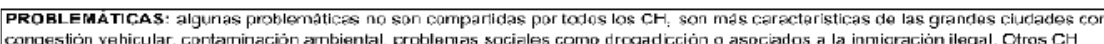

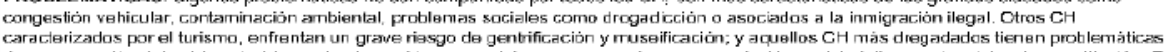

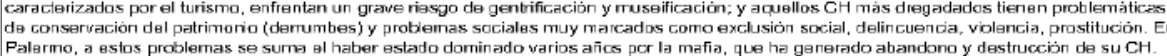
GONTEXTO EUROPEO: TALIA

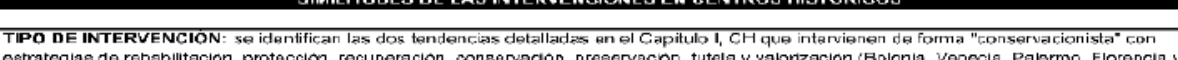

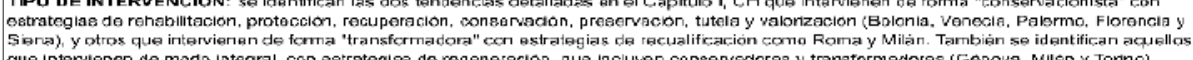

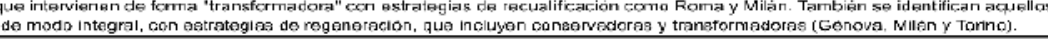

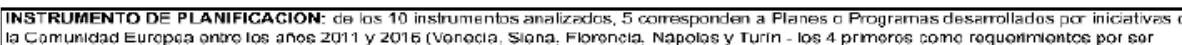

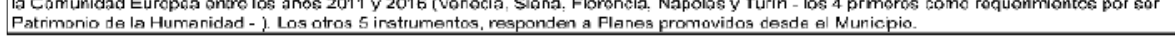

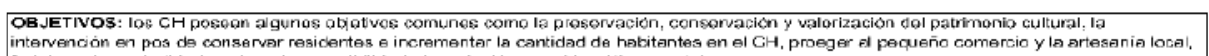

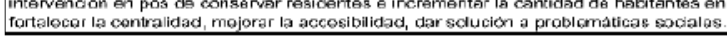

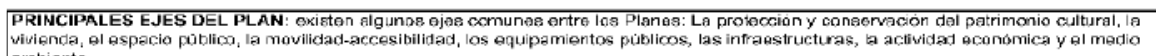

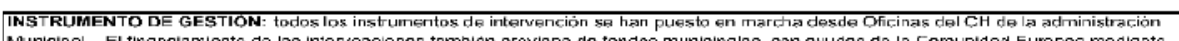
progamas $U R B A N$, URBAGT y fandas FEDER (Napoles, Geinova y Torino)

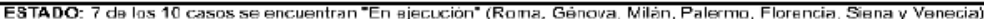

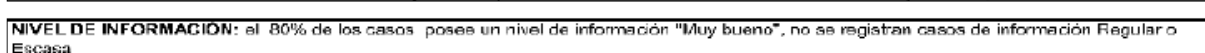

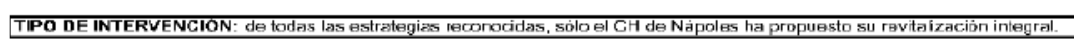

INSTRUMENTO DE PLANIFFCACION: Los instrumantos eleggicos atravicsas poriodos muy civorsos, cosde ol año 1973 (Plan do Bolonia), hasta

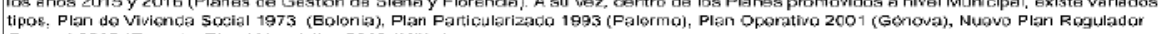

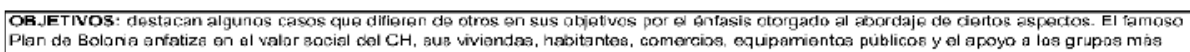

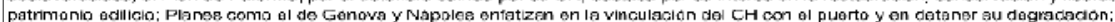

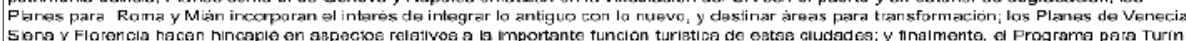

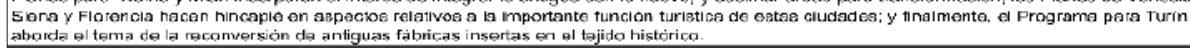

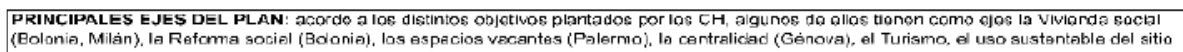

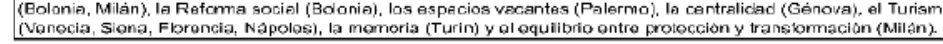

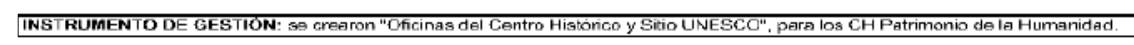

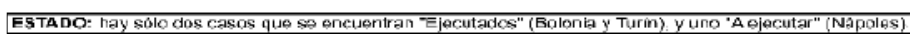

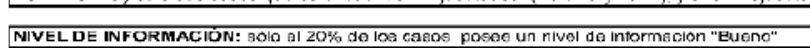

Cuadro IV.1. Modelo de cuadros de similitudes y diferencias de los $\mathrm{CH}$ y de las intervenciones. Fuente: Elaboración Propia 


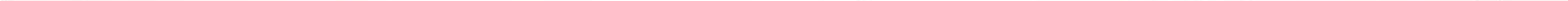




\subsection{Una mirada global de las experiencias}

Los cuadros expuestos, han permitido realizar un primer reconocimiento de características comunes de los $\mathrm{CH}$ desde lo físico-ambiental (extensión, grado de alteración, centralidad urbana y funcional, declaratorias de UNESCO), social (demografía) y económico (turismo, actividad portuaria). De estas características, resulta importante destacar las relaciones que se generan entre las mismas, tanto como las particularidades al interior de cada una de ellas. Existe un vínculo presente que se registra en casi todos los $\mathrm{CH}$ más extensos, que coinciden en que también conservan la centralidad urbana y muchos de ellos al mismo tiempo la centralidad funcional. Por su parte, los $\mathrm{CH}$ menos extensos en general corresponden a los $\mathrm{CH}$ menos poblados. En este sentido, es interesante destacar que los mayores $\mathrm{CH}$ de España, equivalen en superficie a $\mathrm{CH}$ intermedios de Italia y $\mathrm{AL}$, y los menores $\mathrm{CH}$ de Italia coinciden con $\mathrm{CH}$ intermedios de España y $\mathrm{AL}$. Con respecto al grado de alteración, es preciso señalar en el contexto latinoamericano, que en general todas aquellas ciudades que no han atravesado procesos de industrialización importantes, han logrado conservar de forma más intacta el patrimonio material e inmaterial de sus $\mathrm{CH}$. Por tal motivo, es lógico que la mayoría de ellos así como de los $\mathrm{CH}$ europeos que conservan esas condiciones, se encuentren dentro de la Lista UNESCO de $\mathrm{CH}$ o áreas históricas patrimonio de la Humanidad. Al mismo tiempo, estos $\mathrm{CH}$ son los que se encuentran más enfocados en el turismo como actividad económica. En cuanto al aspecto demográfico, el caso de la Ciudad de México resulta un caso particular, siendo que su $\mathrm{CH}$ supera ampliamente -entre cuatro y cinco veces- a los $\mathrm{CH}$ más poblados de Italia y España, y a los siguientes de AL.

Las características descriptas previamente, se encuentran a su vez asociadas a las necesidades que cada uno de ellos presentan y que son impulsoras de las diversas intervenciones (Ver Figura IV.2).

En la actual búsqueda de intervenciones que aspiren a un urbanismo sostenible, las estrategias e instrumentos de intervención y gestión se enfrentan a un gran reto, el "Desarrollo Sostenible". Su existencia se basa en tres grandes dimensiones: ambiental, social y económica. Sin embargo, por lo expuesto en el Capítulo 2, los casos seleccionados han sido organizados para este estudio agrupándolos según problemáticas, intervenciones, estrategias e instrumentos comunes, teniendo en cuenta cuatro dimensiones: "Físico-ambiental", "Socio-cultural", "Económica" e "Institucional". 


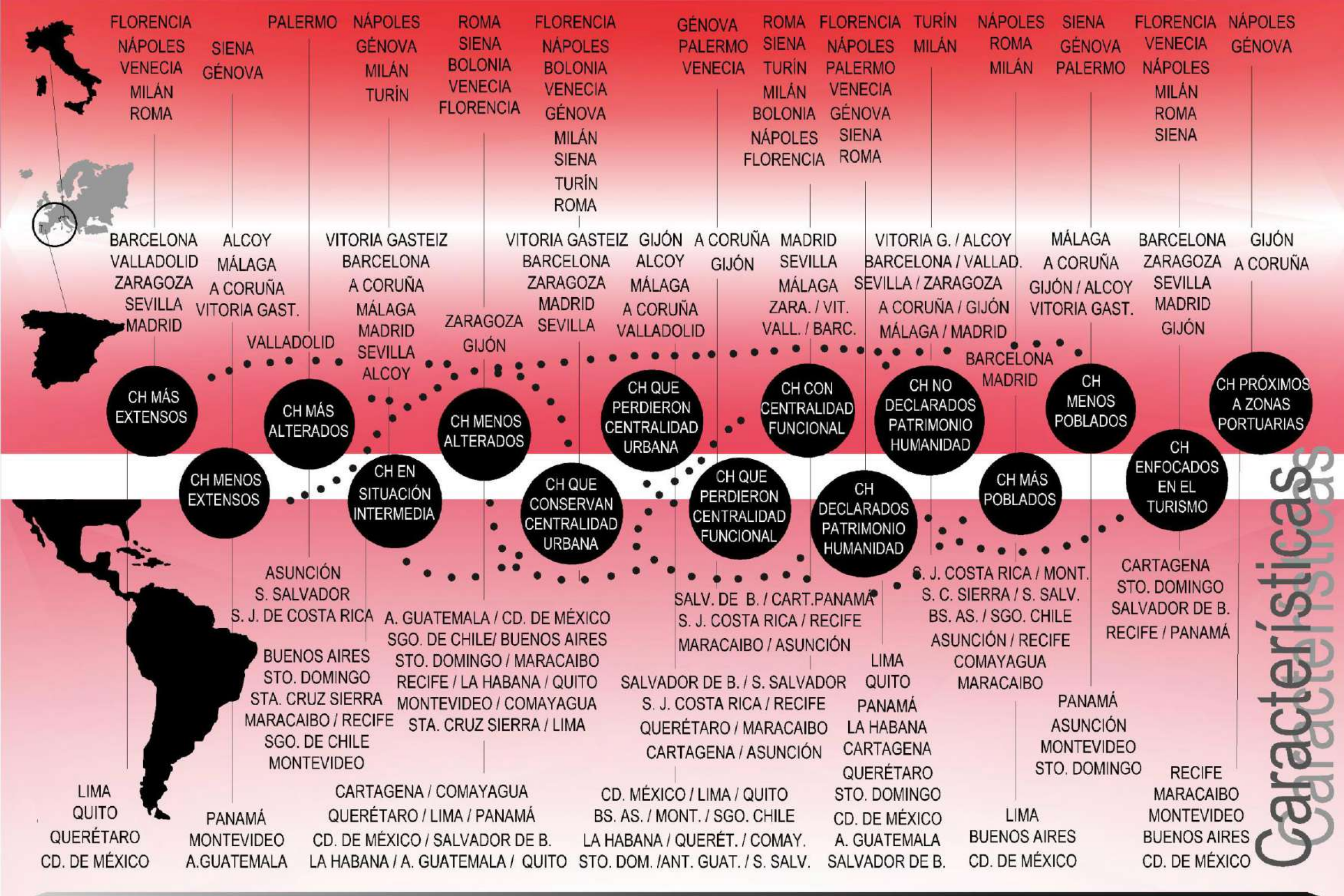




\subsubsection{Problemáticas e Intervenciones}

Como hemos verificado en el estudio de los casos fichados, los $\mathrm{CH}$ de Italia, España y $\mathrm{AL}$ en general comparten las mismas problemáticas, pero difieren en la escala de las mismas, con mayor o menor gravedad acorde a la dimensión o a la situación particular de algunas de las ciudades. Se ha podido realizar una selección de tipologías de problemas, que ha surgido como resultado de una síntesis del análisis de las fichas elaboradas para los 40 casos, donde se ha profundizado en cada uno de los conflictos que han aquejado a cada $\mathrm{CH}$, y se han elegido aquellos que se han reiterado, siendo comunes a varios casos. Se podría afirmar, que las problemáticas recurrentes que aquejan a los $\mathrm{CH}$ son las que se presentan a continuación:

\section{DIMENSIÓN FÍSICO - AMBIENTAL:}

- Deterioro y pérdida del patrimonio construido (por ataques bélicos en Italia, por crecimiento de las ciudades en España y AL, por políticas de gobiernos dictatoriales, y por las crisis de la década de 1980 con reconversiones productivas a nivel mundial).

- Carencia de viviendas sociales

- Edificios abandonados (focos de concentración de problemas sociales)

- Falta de equipamientos y servicios

- Pérdida de centralidad urbana

- Pérdida de centralidad funcional

- Pérdida de funciones (residencial, comercial, y artesanal local)
- Sobre-utilización funcional

- Elevada tugurización

- Deficiencias en la movilidad y accesibilidad

- Débil vinculación con el resto de la ciudad

- Deterioro físico-ambiental por impacto del turismo

- Desequilibrio funcional (diurno-nocturno o estacional)

- Alta exposición a desastres naturales

\section{DIMENSIÓN SOCIO - CULTURAL:}

- Gentrificación

- Disminución de la población residente

- Población envejecida (en CH de España e Italia)

- Escasa población

- Desempleo

- Marginalidad

- Problemáticas sociales (drogadicción, prostitución, delincuencia, violencia)

- Pérdida de valores culturales

- Exaltación o creación de atractivos culturales

- Escasa valoración del espacio público

- Ocupación / invasión del espacio público

- Carencia de espacios verdes

- Exaltación o creación de atractivos culturales
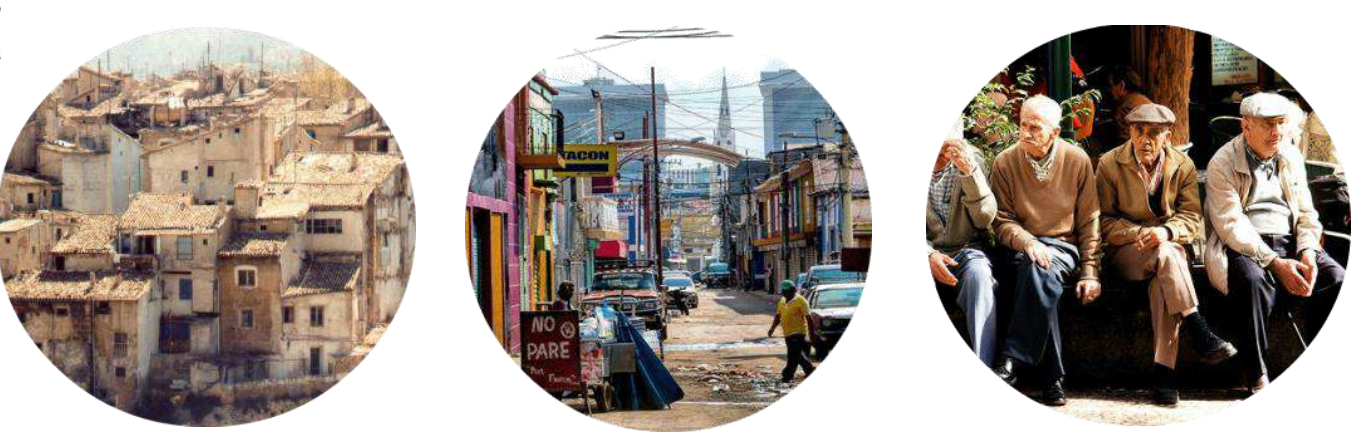


\section{DIMENSIÓN ECONÓMICA:}

- Disminución del comercio barrial y la artesanía local

- Especulación inmobiliaria

- Proliferación / incremento del comercio informal

- Impactos negativos del turismo

\section{DIMENSIÓN INSTITUCIONAL (Gestión):}

- Falta de eficiencia institucional y de instrumentos de planificación y gestión

- Deficiencias en los procesos de seguimiento y control

- Falta de recursos para conservación y restauración
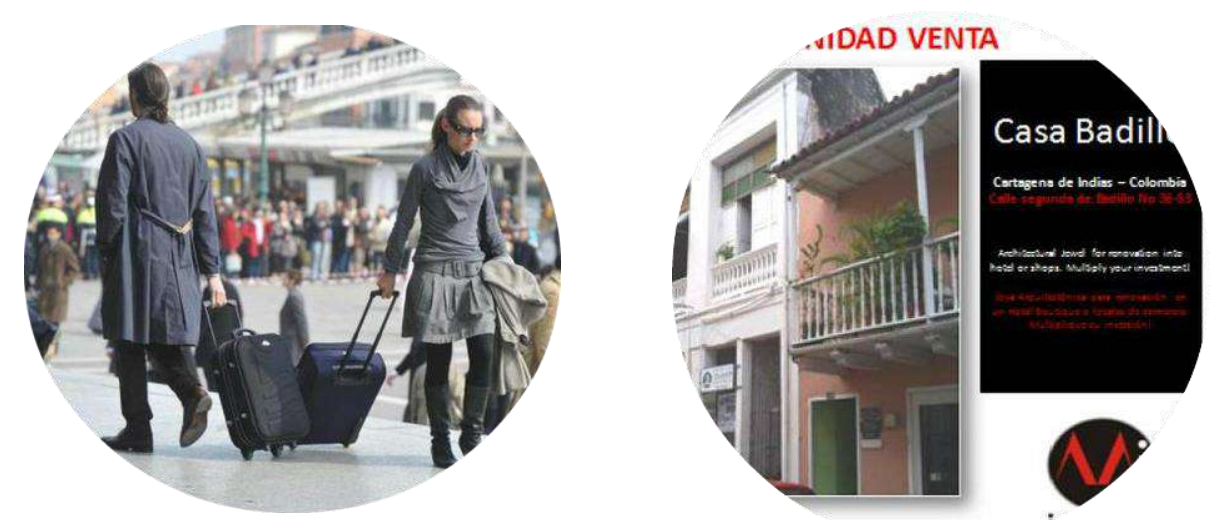

Estas problemáticas se encuentran organizadas en las cuatro dimensiones de análisis, pero es preciso señalar la influencia y el impacto directo de unas sobre otras. Por ejemplo, cómo los conflictos que se manifiestan en la Dimensión Físico-ambiental se reflejan en inconvenientes en la Dimensión Socio-cultural, que a su vez tienen origen en problemáticas económicas y al mismo tiempo, toda esta serie de cuestiones encuentran correspondencia con deficiencias institucionales. La Figura V.3 que se presenta a continuación, identifica las ciudades de ambos contextos en las que se encuentran más presentes cada una de las problemáticas y las relaciones entre las mismas, y se resaltan los problemas que en páginas subsiguientes se reconocen como los más abordados desde las estrategias.
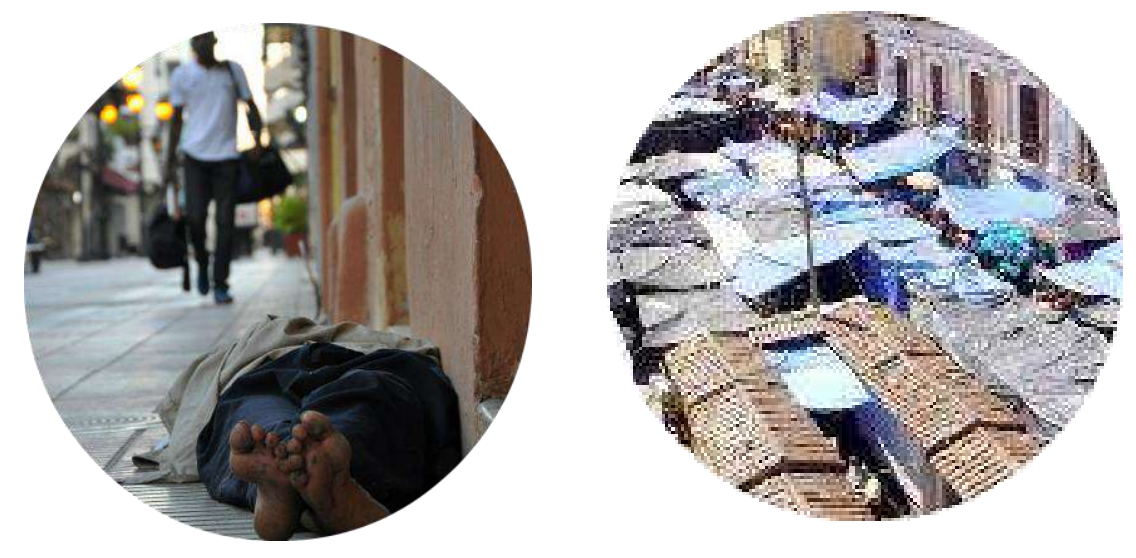
Se reconoce que las ciudades latinoamericanas presentan mayores dificultades en las cuatro dimensiones en relación a las ciudades de Italia y España. Especialmente en el aspecto Socio-cultural, donde existen problemas sociales muy marcados como exclusión social, delincuencia, violencia, drogadicción y prostitución, que si bien se reconocen en ciudades europeas, como Génova, Nápoles y Valladolid, resultan casos más puntuales. En el caso de Palermo en Italia, a la presencia de algunos de estos problemas, se suma que ha estado dominado durante varios años por la mafia, que ha colaborado en generar abandono y destrucción de su $\mathrm{CH}$. En las ciudades de $A L$ estas problemáticas sociales se encuentran más generalizadas y adquieren mayor gravedad llegando a serios problemas de criminalidad. Por otra parte, el problema de la gentrificación afecta a ciudades de ambos contextos, encontrándose asociada principalmente al desarrollo del turismo, que ha llevado a una museificación de los $\mathrm{CH}$, siendo sus casos más significativos en Europa: Venecia, Florencia, Barcelona; o Cartagena y Salvador de Bahía, en AL. En ciudades donde el turismo no representa la actividad central, la gentrificación se produce por recambio poblacional interno producto de fluctuaciones en el mercado inmobiliario. A su vez, problemas sociales relacionados con la inmigración ilegal afectan tanto a países de Europa como de AL.
En las ciudades europeas la degradación física de los $\mathrm{CH}$ se ha encontrado más asociada a períodos dictatoriales, a destrucciones bélicas, a motivos criminales o a reconversiones funcionales. Como los casos del traslado del puerto en Gijón y Génova que afectaron a los $\mathrm{CH}$ perdiendo centralidad, usos y presentando tejidos horadados por instalaciones portuarias abandonadas, que contribuyeron al abandono general. Por su parte en $\mathrm{AL}$, el abandono ha estado más vinculado a constantes o repetidas crisis económicas, a la falta de ingresos, que relacionado a la falta de desarrollo industrial han colaborado en que varios $\mathrm{CH}$ se hayan conservado intactos. Aquellos $\mathrm{CH}$ más degradados tienen problemáticas de conservación del patrimonio. Otros con escasa tradición en la conservación del patrimonio, afrontan el problema de la falta de valoración del $\mathrm{CH}$ por parte de la población residente y usuaria, así como el desinterés por su intervención como en Comayagua, Santo Domingo, Maracaibo y Santa Cruz de la Sierra. Varios $\mathrm{CH}$ poseen una gran presencia de comercio informal, entre ellos Roma, Florencia, Venecia, Madrid, Barcelona, Cartagena, Quito, San Salvador, Comayagua, Ciudad de México, Lima y Maracaibo.

También se verifica una doble situación. Por un lado, de despoblamiento en ciudades intermedias como Vitoria Gasteiz, Alcoy, Santo Domingo, San José de Costa Rica, o de superpoblamiento en ciudades centrales como Nápoles, Roma, La 
Habana, Ciudad de México o Lima, que presentan a su vez tugurización. Estas mismas ciudades registran congestión vehicular y contaminación ambiental. En cuanto a la situación institucional, existen casos en $\mathrm{AL}$ que presentan las condiciones más graves, aunque en general, salvo algunas excepciones el panorama latinoamericano es débil en este aspecto.

Sin duda alguna, todo este conjunto de problemáticas ha contribuido al desarrollo de diversas estrategias e instrumentos de intervención y gestión desde las administraciones públicas para su abordaje. Seguidamente, se sintetizan como hallazgos identificados las estrategias empleadas, tomando como referencia la clasificación de intervenciones contemporáneas propuesta en el Capítulo 2: Estrategias conservacionistas (restauración, protección, rehabilitación, recuperación y esponjamiento); transformadoras (reforma interior, renovación, reestructuración, recualificación y tercerización); e integrales (regeneración, revitalización, reconversión y rehabilitación integral).

\section{ESTRATEGIAS CONSERVACIONISTAS:}

- Conservación I Preservación (Palermo 1993, Venecia 2012, Siena 2015, Florencia 2016)

- Protección, tutela, valorización (Siena 2015, A Coruña 2012, Montevideo 2004)
- Rehabilitación (Bolonia 1973, Gijón 1985, Panamá 2001, Madrid 2004, A Coruña 2012, Antigua Guatemala 2012)

- Recuperación (Palermo 1993, Lima 2014)

- Preservación (Florencia 2016)

\section{ESTRATEGIAS TRANSFORMADORAS:}

- Reforma Interior (A Coruña 2012)

- Renovación (Santiago de Chile 1990, Maracaibo 1999)

- Recualificación (Gijón 1985, Valladolid 1997, Roma 2003, Milán 2012)

\section{ESTRATEGIAS INTEGRALES:}

- Revitalización -Integral- (Recife 1980, Gijón 1985, Málaga 1990, Salvador de Bahía 1991, La Habana 1994, Zaragoza 1997, San Salvador 1998, Ciudad de México 2000, Madrid 2004, Montevideo, 2004 (Ordenación, mejora), Comayagua 2005, Santo Domingo 2006, Santa Cruz de la Sierra 2008, Cartagena 2008, Nápoles 2011, Buenos Aires 2015, Asunción 2015, San José de Costa Rica 2015)

- Rehabilitación -Integral- (Vitoria Gasteiz 1983, Barcelona 1987, Quito 1989, Málaga 1990, Alcoy 1991, Génova 2001, Lima 2014)

- Regeneración (Gijón 1985, Valladolid 1997, Génova 2001, Turín 2011, Milán 2012, Venecia 2012) 
Para la puesta en práctica de estas estrategias, se han identificado como aportes: instrumentos operacionales (legales, de planificación, de participación pública, de gestión -públicos y mixtos- y económico-financieros), las herramientas de planificación, y los organismos de gestión -públicos y mixtos- e instituciones de financiación (públicas y privadas) que se exponen a continuación.

\section{INSTRUMENTOS OPERACIONALES}

1. LEGALES (Normativos: Catalogación / Régimen de Protección)

\subsection{Contexto Europeo:}

- Italia: Áreas homogéneas $(\mathrm{A}, \mathrm{B}, \mathrm{C}, \ldots$..) / Zonas de tutela arqueológica $(1,2,3, \ldots)$

- España: Área de Rehabilitación Integrada (ARI) / Área de Rehabilitación Preferente / Conjunto Histórico Artístico / Bien de Interés Cultural (BIC)

\subsection{Contexto Latinoamericano:}

- Argentina: Área de Protección Histórica (Buenos Aires) / Brasil: Zona Especial de Preservaçao (Recife) / Cuba Guatemala: Monumento Nacional (La Habana Vieja Comayagua - Antigua Guatemala) / México: Zona de Monumentos Históricos / Zonas de conservación
(Querétaro) / Uruguay: "Área testimonial"-"Zona de interés Prioritario" (Montevideo)

\section{DE PLANIFICACIÓN}

\subsection{Urbanos (Generales):}

- Piano di Ediizia Economica Popolare (Bolonia)

- Piano Regolatore Generale (Roma, Turín, Venecia)

- Piano Urbanístico (Milán)

- Plan General de Ordenación Urbanística -PGOU- (Sevilla, Alcoy, A Coruña)

- Plan de Ordenamiento Urbano Territorial (Santa Cruz de la Sierra, Montevideo.

- Plan de Repoblamiento - Propuesta de Desarrollo para la Renovación de Santiago (Santiago de Chile)

\subsection{De Sector:}

- Piano Operativo del Centro Storico (Génova) / Piano Particolareggiato Esecutivo (Palermo)

- Plan de Gestión / Plan de Acción Local (Nápoles, Florencia, Siena, Madrid, San José de Costa Rica)

- Plan Especial (de Protección) y Reforma Interior -PEPRI / PERI - (Málaga, Alcoy, A Coruña, Vitoria Gasteiz) / Plan Especial (de Protección) del Centro Histórico - $\mathrm{PEPCH} /$ PECH- (Sevilla, Gijón, Valladolid) / Plan Especial de 
Ordenación Protección y Mejora (Montevideo) / Plan Especial de Desarrollo Integral (La Habana)

- Plan Integral del Casco Histórico - PICH- (Zaragoza) / Plan Integral de Renovación Urbana del Área Central (Maracaibo)

- Plan de Rehabilitación Integral (Barcelona) / Plan de Reactivación Integral (Vitoria Gasteiz)

- Plan de Revitalización -Integral- (Santa Cruz de la Sierra, Recife, Cartagena, San José de Costa Rica / Plan de Rescate (San Salvador) / Plan Revive el Casco (Panamá)

- Plan de Manejo del CH (Buenos Aires, Ciudad de México)

- Plan Maestro (La Habana, Quito, Antigua Guatemala, Comayagua, Panamá, Asunción, Lima) / Plan Director del $\mathrm{CH}$ (Antigua Guatemala)

- Plan Estratégico (para la recuperación del CH Lima) / (de Revitalización Integral del $\mathrm{CH}$ de Santo Domingo)

- Programa de regeneración urbana - Proyecto del Programa integrado de desarrollo local (Turín) / Programa ARA, Arquitectura y Rehabilitación de Alcoy (Alcoy) / Programa de Recuperaçao do $\mathrm{CH}$ (Salvador de Bahía)

\section{HERRAMIENTAS DE PLANIFICACIÓN}

Manejo - Limitación de alturas / Transferencia de potencial constructivo

\section{INSTRUMENTOS DE PARTICIPACIÓN PÚBLICA}

Asambleas / Talleres / Reuniones / Grupos de trabajo / Encuestas / Audiencias / Consultas.

\section{ORGANISMOS DE GESTIÓN DEL CH}

- De Gestión Pública: Oficina de Gestión de sitios patrimonio de la humanidad (Florencia, Venecia) / Oficina de Rehabilitación del CH (Málaga) / Oficina del Plan Integral del $\mathrm{CH}$ (Zaragoza) / Oficina de Gestión y Proyectos (Gijón) / Promocio de Ciutat Vella S.A., PROCIVESA (Barcelona) / Oficina del Centro (Madrid) / Oficina Plan ARA - Oficina Programa de renovación urbana (PRV) / Empresa Municipal Vivienda, servicios y actividades S.A., (A Coruña) / Departamento del CH S.A. - Agencia para la Revitalización Integral de la Ciudad Histórica, ARICH. S.A. (Vitoria Gasteiz) / Dirección General del CH (Buenos Aires) / Junta del CH (Santa Cruz de la Sierra) / Oficina de Revitalización del CH (Recife) / Oficina del Historiador (La Habana) / Oficina del $\mathrm{CH}$ (San Salvador - Comayagua - Panamá) / Fideicomiso $\mathrm{CH}$ (Ciudad de México) / Organismo de Gestión del $\mathrm{CH}$ (Querétaro) / Programa Municipal para la recuperación del CH -PROLIMA-, Lima / Centro Rafael Urdaneta -CRU-, Maracaibo.

- De Gestión Mixta (Público-privada): Empresa de Desarrollo del CH de Quito / Corporación para e Desarrollo 
de San Salvador / Laboratorio de Desarrollo Urbano ASULAB-, Asunción / Comisión Especial Permanente de la Ciudad Vieja -CEPCV-, Montevideo.

\section{INSTRUMENTOS DE GESTIÓN}

\section{Públicos}

Organismos Autónomos / Programas especiales para el $\mathrm{CH}$ / Fideicomisos

\section{Mixtos (público-privados)}

Empresas / Corporaciones / Patronatos / Fundaciones (privadas) / Laboratorios

\section{INSTITUCIONES DE FINANCIACIÓN}

\section{Públicas:}

- Escala Local: Municipio (Bolonia, Roma, Génova, Milán, Turín, Palermo, Málaga, Zaragoza, Valladolid, Barcelona, Madrid, Alcoy, A Coruña, Vitoria Gasteiz, Buenos Aires, Santa Cruz de la Sierra, Recife, Salvador de Bahía, Cartagena, San José de Costa Rica, Santiago de Chile, San Salvador, Comayagua, Ciudad de México, Lima, Santo Domingo, Maracaibo.

- Escala Regional: Sevilla (Junta de Andalucía) / Madrid, Alcoy, Vitoria Gasteiz,
- Escala Nacional: Gobierno nacional (Madrid, Buenos Aires, Santiago de Chile, Antigua Guatemala,

- Escala Internacional: Unión Europea: URBACT / URBAN / UR-BAL, fondos FEDER (Nápoles, Génova, Turín, Málaga, Barcelona, Madrid, Vitoria Gasteiz) / AECID - Agencia Española de Cooperación Internacional para el DesarrolloComayagua / BID: Santo Domingo.

\section{Privadas:}

Palermo, Madrid, Buenos Aires, Recife, Salvador de Bahía, San José de Costa Rica, Santiago de Chile -CORDESAN-, San Salvador, Ciudad de México -Fundación del $\mathrm{CH}-$, Buenos Aires

\section{INSTRUMENTOS ECONÓMICO-FINANCIEROS}

Incentivos Constructivos para la protección y preservación de bienes patrimoniales / Estímulos fiscales: Exención o reducción de impuestos / Facilidades de financiamiento / Compensacionestransferencias por limitaciones sobre bienes de valor patrimonial / Sanciones al abandono de inmuebles / Cobro de impuestos a empresas o sujetos vinculados al turismo destinados a la recuperación del patrimonio.

Se identifica la implementación de estrategias más conservadoras y transformadoras en ciudades de Italia y España, y el predominio de estrategias más integrales, principalmente de revitalización en AL. 
Las mismas se enmarcan generalmente en Planes de Sector implementados en el ámbito de Planes Urbanos que definen instrumentos legales para su intervención. En gran parte de los casos se llevan adelante mediante organismos de gestión pública del $\mathrm{CH}$, y en algunos casos mediante organismos mixtos. A su vez, existen instituciones financiadoras que contribuyen con los gobiernos municipales como la Unión Europea en el caso de los $\mathrm{CH}$ de España e Italia, AECID y la Junta de Andalucía que intervienen tanto en España como en países de $A L$, así como el BID que subvenciona actuaciones en $\mathrm{CH}$ de $\mathrm{AL}$.
Estas intervenciones han sido organizadas según tipologías o temáticas que las distintas ciudades más han abordado en cada una de las dimensiones, que han surgido -al igual que las problemáticas- del estudio y síntesis de las intervenciones propuestas en los 40 casos, remarcando las influencias que cada una de ellas genera en distintos ámbitos y la relación que las mismas presentan con las problemáticas expuestas anteriormente. La constante búsqueda de soluciones a problemáticas reiteradas ofrece experiencias innovadoras que más allá de enmarcarse para este análisis dentro de dimensiones particulares, repercuten en el entramado de temas que conjuga un $\mathrm{CH}$. (Ver Figura IV.4). 


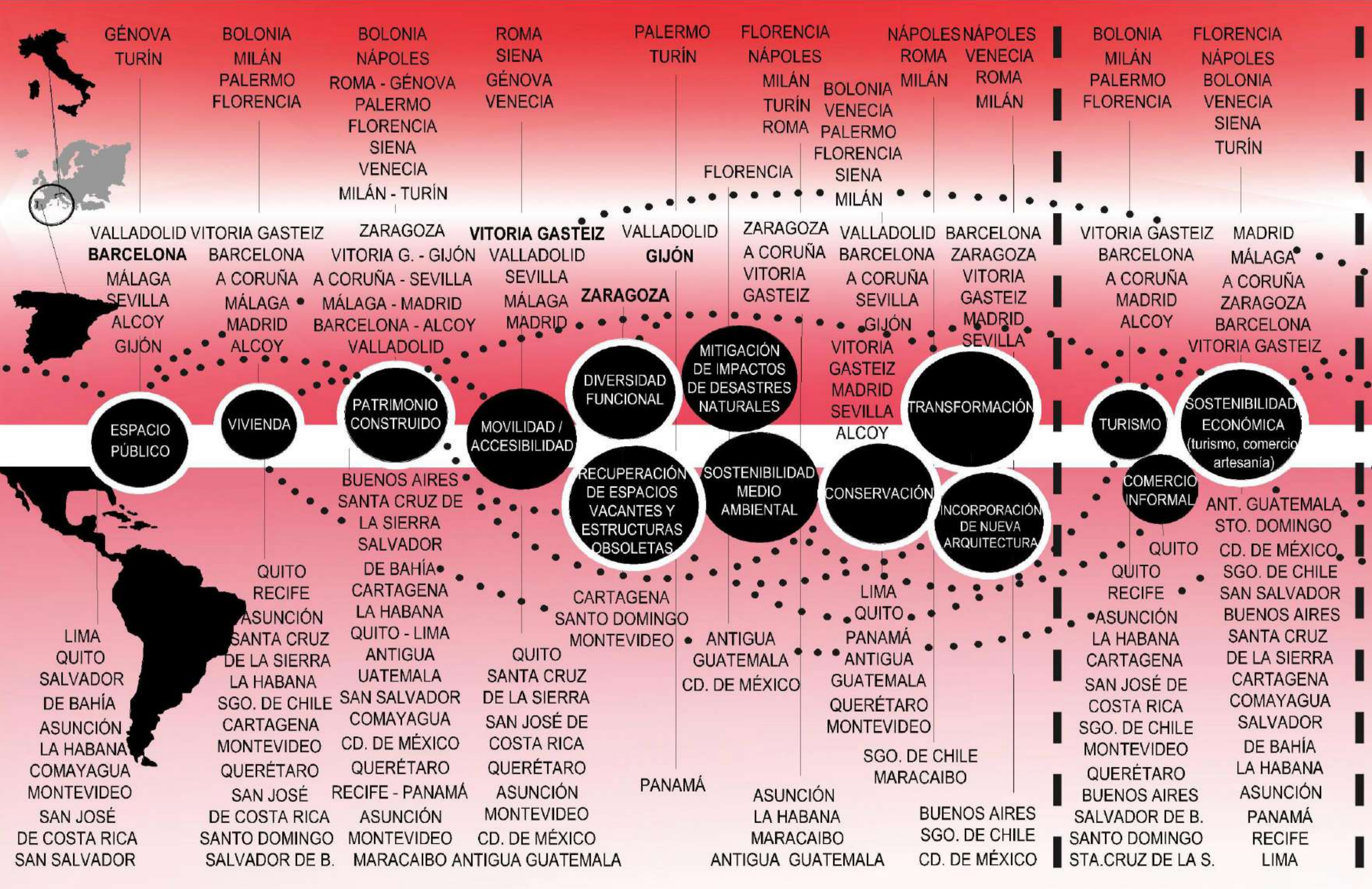


La organización de las problemáticas e intervenciones resultantes por ciudades, ha facilitado la confección de cuadros y gráficos que han permitido cuantificar la cantidad de problemáticas e intervenciones abordadas por dimensiones y tipologías indicadores - (Ver Cuadros IV.2, IV.3 y Anexo A3). Este análisis, resulta muy interesante en cuanto a sus valores, dado que los mismos reflejan el hincapié y la atención que cada administración ha destinado al tratamiento de sus necesidades. Lógicamente, el análisis no logra identificar el nivel de profundidad de los problemas o el abordaje de las intervenciones, aunque sí logra registrarlos y señalarlos en términos cuantitativos. A partir de la información volcada en los cuadros, se han confeccionado los siguientes gráficos:

1) Gráficos de barras que muestran la cantidad de problemáticas e intervenciones observadas por ciudad analizada, organizadas en Italia, España, AL, y en la totalidad.

2) Gráficos de torta que muestran la cantidad de problemáticas e intervenciones observadas en las cuatro dimensiones del US, organizadas en Italia, España, AL.

3) Gráficos de barras y torta que muestran la cantidad de problemáticas e intervenciones observadas en las tipologías -indicadores- contenidas en las cuatro dimensiones del urbanismo sostenible, organizadas en Italia, España, AL, y en la totalidad.

\section{GRÁFICO DE BARRA: PROBLEMÁTICAS POR CIUDAD}

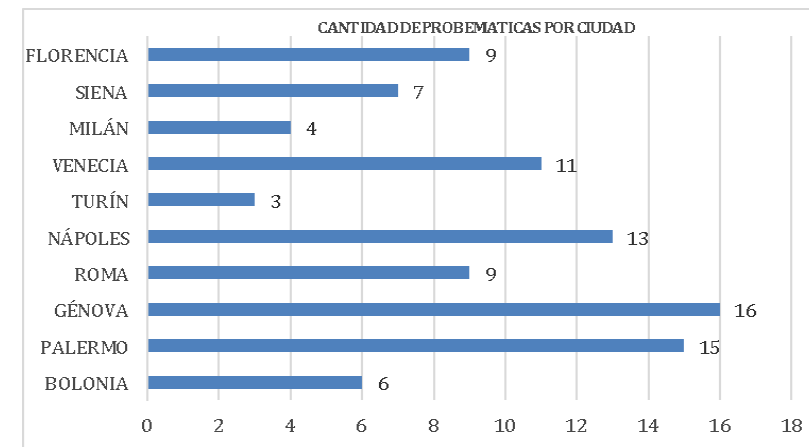

GRÁFICO DE TORTA: PROBLEMÁTICAS POR DIMENSIONES

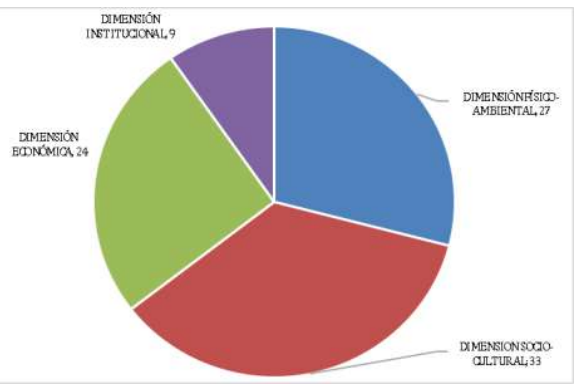

GRÁFICOS (barra y torta) POR TIPOLOGÍA DE PROBLEMAS
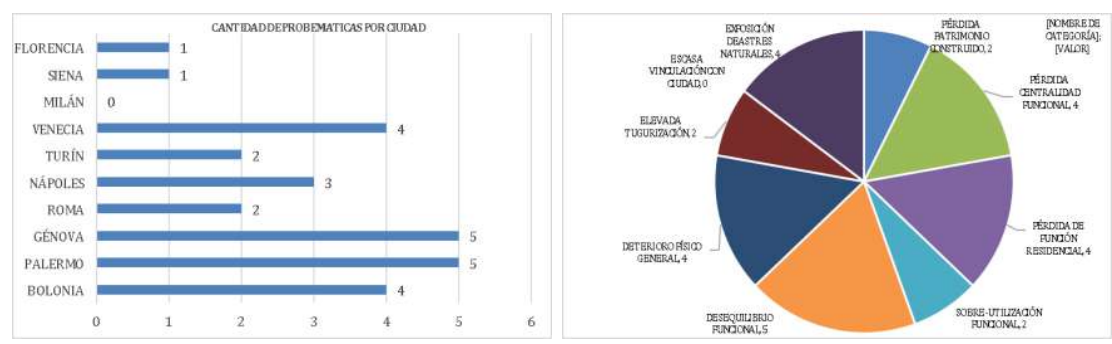

Gráfico IV.1: Ejemplos de gráficos de análisis cuantitativo. 
\begin{tabular}{|l|l|l|l|l|l|l|l|l|l|}
\multicolumn{1}{c}{ TALLLA } \\
\hline BOLONA & PALERMO & GENOVA & ROMA & NÁPOLES & TURiN & VENECIA & MLLÁN & SIENA & FLORENCIA \\
\hline
\end{tabular}

IMENSIONFFISICOAMBBENTAL

PERDDA PATTMMONOCONSTRUDO

PEERDDACENTRALAD UBRANA

PERDDA CENTRALDAD FUNCON-

PERDDDA DE FUNCÓN RESDENCI

SOBRE-UILLACOÓNFUNCONAL

DESEQULLBROFOUNCONGL

DETEROROFISCOGENERA

ELEVADA TUGURZACOON

ESCASA VNCULACOONCON CUDAD

EXPOSCOONDEESATRES NATURALES

CANTDAD DE PROBLEEMATCAS PARCIALES:

DMENSIÓN SOCDOCCULUVRAL

GENTRFCACÓN

DSGMNUCOONPOBBLCOOONRESDENTE

ESCASA POBLACOON

POBBLCCONNENEJJECDA

MARGNALLADNOLEENCA IROGADCC.DELINC.

PÉRDDA DEV VALORES CUIUPALES

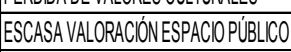

EXLLIACOONCREECLOONATRACTNOS CULTURALES

OCUPACOONNNASOONEESPACOPUBBLLCO

CANTDAD DE PROBLENATCCAS PARCCALES:

DMENSION ECONOOMICA

DSSMNUCOOONCOMERCOOARTESANA

DESEEPPEO

NCREMENTO COMERCONFORMAL

MPACTOS NEGATVOS DEL LURSIMO

ESPECULACOONN NOOBLLARA

CANTIDAD DE PROBLEMATCAS PARCIALES

DMENSOON INSTTUCIONAL

DEFCEECA NSTTUC.FALLA NSTRMUENOS

DEFCEECCA PROCESOS SEGUMI. CONTROL.

ESCASEZDE RECURSOS CONSERVNRESTAUR CANTIDAD DE PROBLEMATCAS PARCILLES

CANTDAD DE PROBEEMATCACAS TOTALES

DMEENSOONFFISCOAMBEENTLL

DIMENSOONSSOCOC.CULTURAL

DMENSOON ECONOOMICA

DIMENSIÓN INSTTTUCIONAL

TOTAL

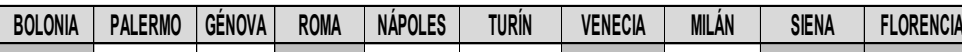

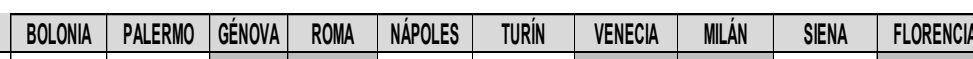
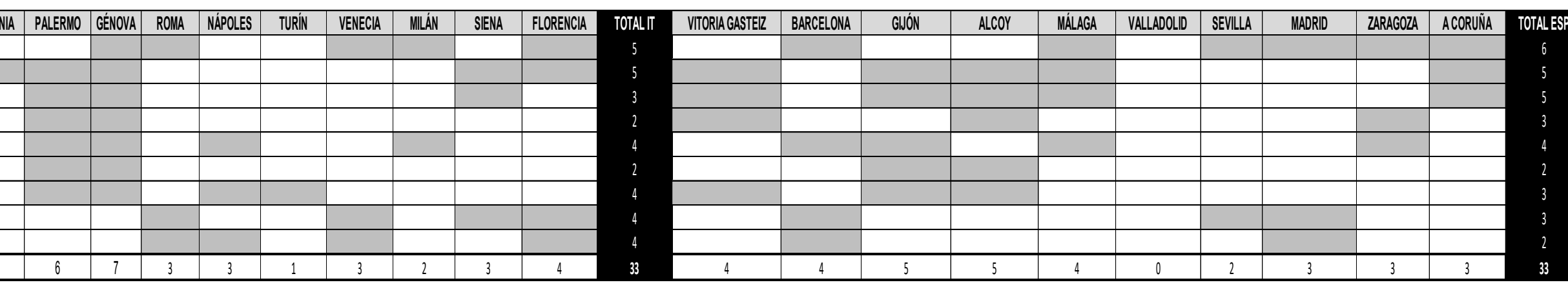

ESPANA

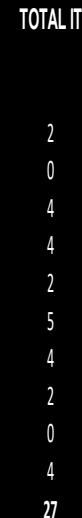

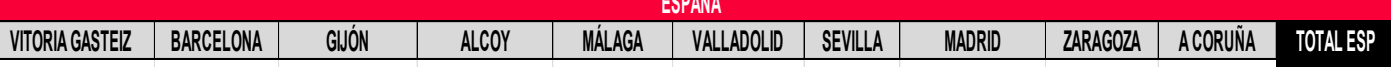

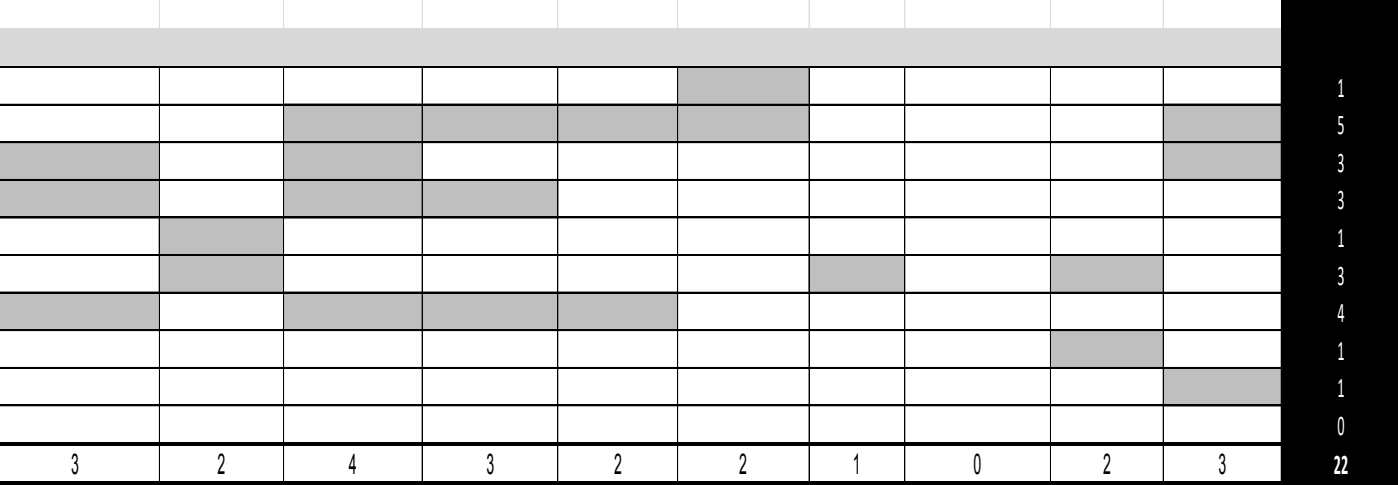



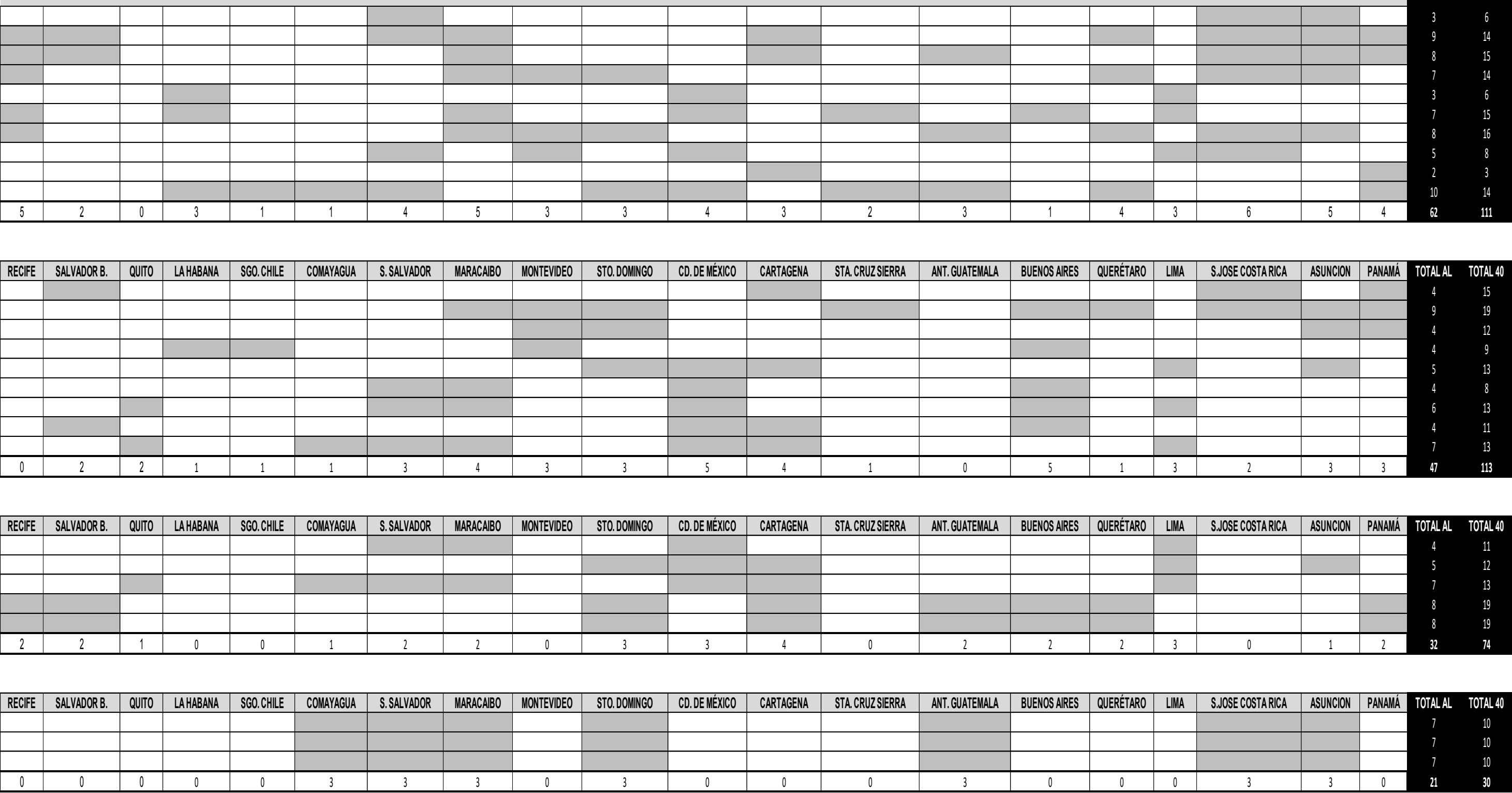

\begin{tabular}{|c|c|c|c|c|c|c|c|c|c|c|c|c|c|c|c|c|c|c|c|c|c|}
\hline RECFEE & SALVADOR B. & QUITO & LAHABANA & SGO.CHLE & COMAYAGUA & S.SALVADOR & MARACABO & MONTEVIDEO & STO. DOMNGO & CD.DE MÉXICO & CARTAGENA & STA.CRUZSIERRA & ANT.GUATEMALA & BUENOS AIRES & QUERÉTARO & LIMA & S.JOSE COSTARICA & ASUNCION & PANAMÁ & TOTALA & TOTAL 40 \\
\hline 5 & 2 & 0 & 3 & 1 & 1 & 4 & 5 & 3 & 3 & 4 & 3 & 2 & 3 & 1 & 4 & 3 & 6 & 5 & 4 & 62 & 111 \\
\hline 0 & 2 & 2 & 1 & 1 & 1 & 3 & 4 & 3 & 3 & 5 & 4 & 1 & 0 & 5 & 1 & 3 & 2 & 3 & 3 & 47 & 113 \\
\hline 2 & 2 & 1 & 0 & 0 & 1 & 2 & 2 & 0 & 3 & 3 & 4 & 0 & 2 & 2 & 2 & 3 & 0 & 1 & 2 & 32 & 74 \\
\hline 0 & 0 & 0 & 0 & 0 & 3 & 3 & 3 & 0 & 3 & 0 & 0 & 0 & 3 & 0 & 0 & 0 & 3 & 3 & 0 & 21 & 30 \\
\hline 7 & 6 & 3 & 4 & 2 & 6 & 12 & 14 & 6 & 12 & 12 & 11 & 3 & 8 & 8 & 7 & 9 & 11 & 12 & 9 & 162 & 328 \\
\hline
\end{tabular}


ITALA

\begin{tabular}{l|l|l|l|l|l|l|l|l|l} 
BOLONIA & PALERMO & GÉNOVA & ROMA & NÁPOLES & TURŔN & VENECCA & MLLÁN & SIENA & FLORENCIA \\
\hline
\end{tabular}
ESPAÑA

TOTALIT

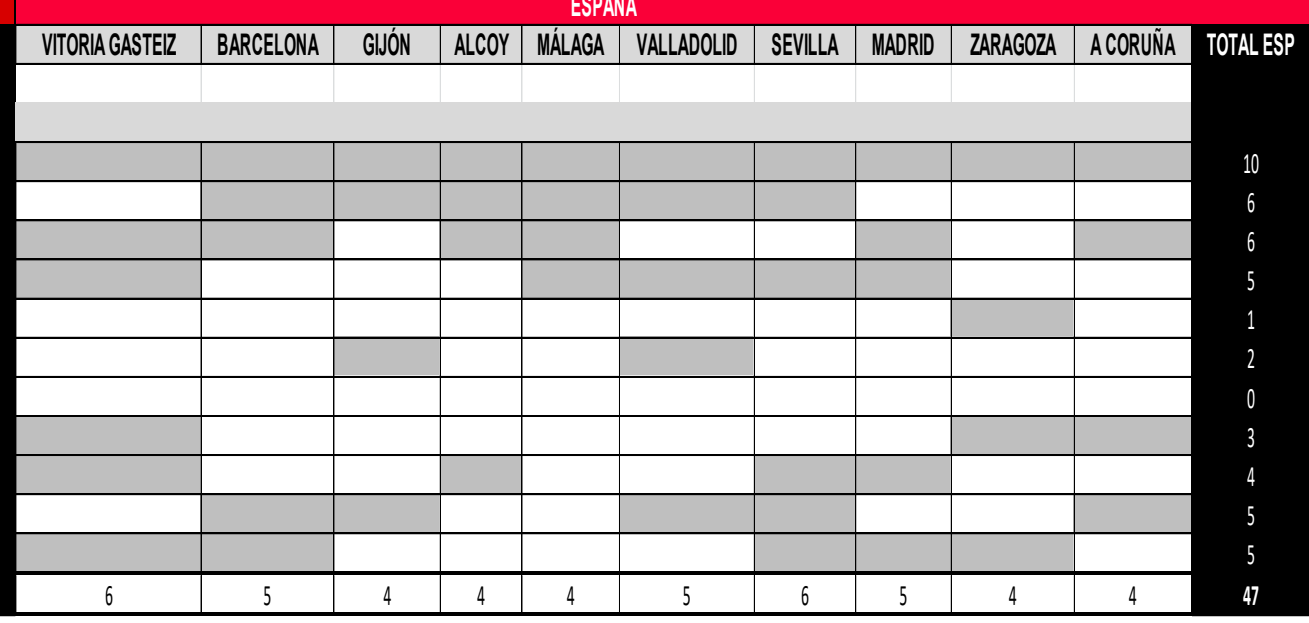

DIMENSION FISICO-AMBEENTAL

PATRMONO CONSTRUDO

ESPACOPÚBLLCO

UWENDA

MOVILDAD/ACCESBLLDAD

DNERSDAD FUNCONAL

ESPACOS VACANTES IESTRUCTURAS OBSOLETAS

MTIGACOÓN MPACTOS DESASTRES NATURALES

SOSTENBLLDAD MEDDOAMBENTAL

CONSERVACOON

TRANSFORMACIÓN

INCORPORACOÓN NUEVA ARQUTECTURA

CANTIDAD DE INTERVENCIONES PARCIALES

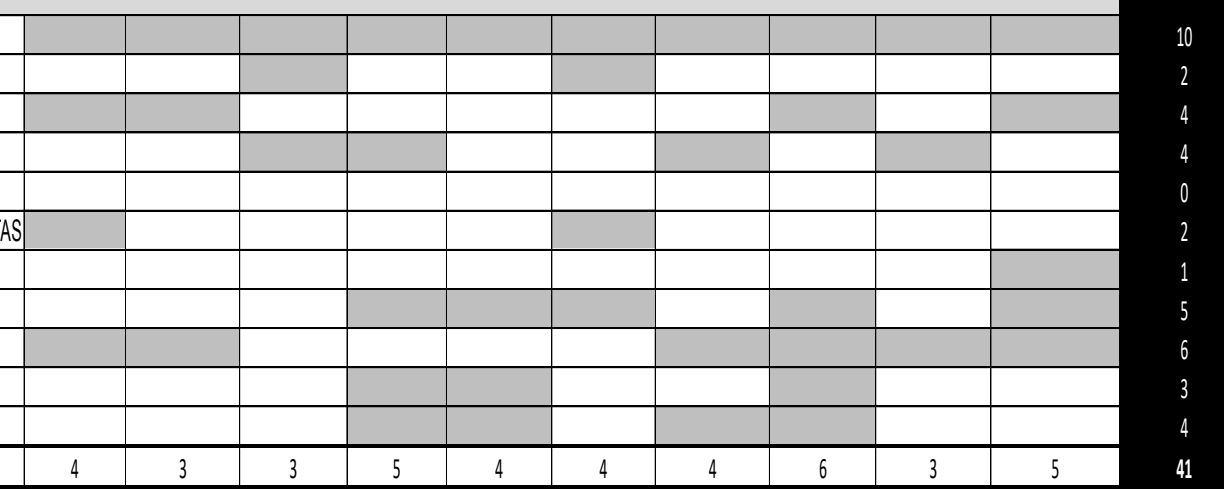

DIMENSIÓN SOCIOCCULTURAL

REPOBLAMENTO

APROPACIÓNDEL ESPACIOPÚBLLCO

MEMORA

IDENTDAD (paricipaccón nividadana)

SOSTENBLLDAD SOCDO-CULTURALI.

CANTIDAD DE ITTERVENCIONES PARCIALE:
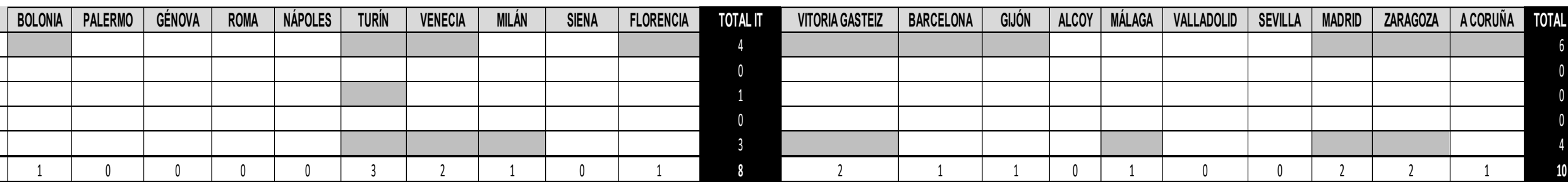

DIMENSION ECONÓMICA

TURSSMO

COMERCONFORMAL

SOSTENBLLDADECONÓNCA

CANTIDAD DE INTERVENCIONES PARCIALES
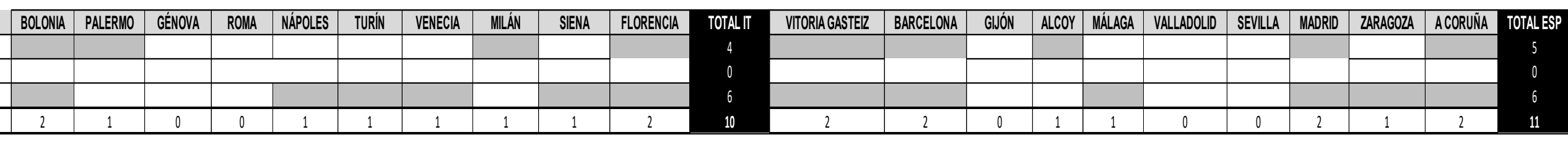

DIMENSIÓN INSTTUUCIONAL

NSTRUMENTOS TRADCONALLES

NSTRUMENTOS INNOVADORES

NSTRUMENTOS REQUERDOS POR UNESCO

NSTRUMENTOS MPLEMENTADOS MENOS 10 AÑOS

NSTRUMENTOS MPLEMENTADOS 10 A 40AÑOS

FNANCAMENTO EXTERNO

CANTIDAD DE ENTERVEECIONES PARCIALES:

\begin{tabular}{l|l|l|l|l|l|l|l|l|l|l}
\hline BOLONIA & PALERMO & GENOONA & ROMA & NÁPOLES & TURIN & VENECIA & MLLÁN & SEENA & FLORENCIA & TOTALIT \\
\hline
\end{tabular}

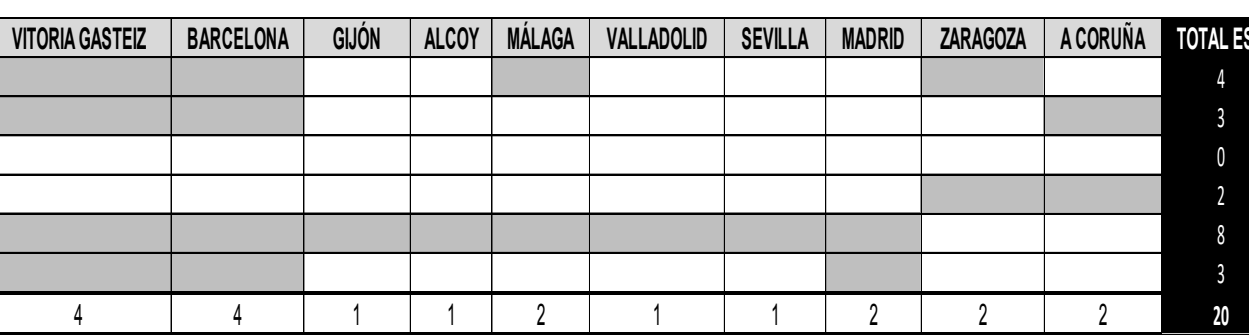

DIMENSION FISICOAMBBENTAL

DIMENSIÓN SOCIO-CULTURA

DIMENSION ECONOMICA

DIMENSOON NSSTTUCIONAL

TOTAL

\begin{tabular}{|c|c|c|c|c|c|c|c|c|c|}
\hline BOLONIA & PALERMO & GÉNOVA & ROMA & N'́POLLES & TURRiN & VENECIA & MLLÁN & SIENA & FLORENCIA \\
\hline 4 & 3 & 3 & 5 & 4 & 4 & 4 & 6 & 3 & 5 \\
\hline 1 & 0 & 0 & 0 & 0 & 3 & 2 & 1 & 0 & 1 \\
\hline 2 & 1 & 0 & 0 & 1 & 1 & 1 & 1 & 1 & 2 \\
\hline 2 & 1 & 3 & 1 & 4 & 2 & 3 & 1 & 3 & 3 \\
\hline
\end{tabular}

\begin{tabular}{|c|c|c|c|c|c|c|c|c|c|c|}
\hline VITORIA GASTEIZ & BARCELONA & GIJON & ALCOY & MÁLAGA & VALLADOLID & SEVILLA & MADRID & ZARAGOZA & ACORUÑA & OTAL \\
\hline 6 & 5 & 4 & 4 & 4 & 5 & 6 & 5 & 4 & $35_{4}$ & 47 \\
\hline 2 & 1 & 1 & 0 & 1 & 0 & 0 & 2 & 2 & 1 & 10 \\
\hline 2 & 2 & 0 & 1 & 1 & 0 & 0 & 2 & 1 & 2 & 11 \\
\hline 4 & 4 & 1 & 1 & 2 & 1 & 1 & 2 & 2 & 2 & 20 \\
\hline 14 & 12 & 6 & 6 & 8 & 6 & 7 & 11 & 9 & 9 & 88 \\
\hline
\end{tabular}




\section{ANÁLISIS CUANTITATIVO PROBLEMÁTICAS CH: GRÁFICOS SÍNTESIS DE LOS 40 CASOS}

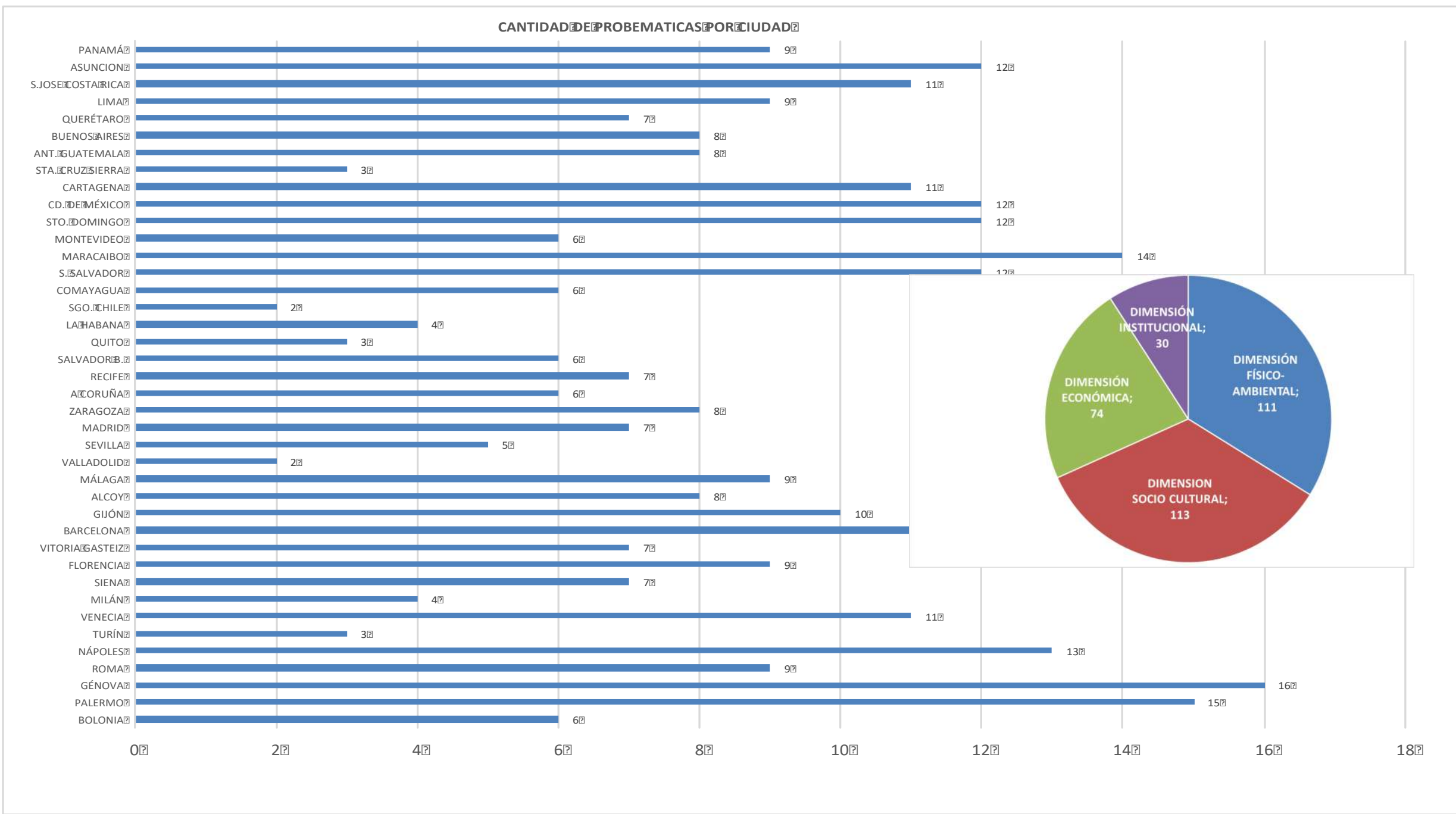

Gráfico IV.2a: Síntesis análisis cuantitativo de las Problemáticas, 40 casos. Elaboración propia 


\section{ANÁLISIS CUANTITATIVO INTERVENCIONES CH: GRÁFICOS SÍNTESIS DE LOS 40 CASOS}

CANTIDADEIDEIINTERVENCIONESITPOREIUDAD?

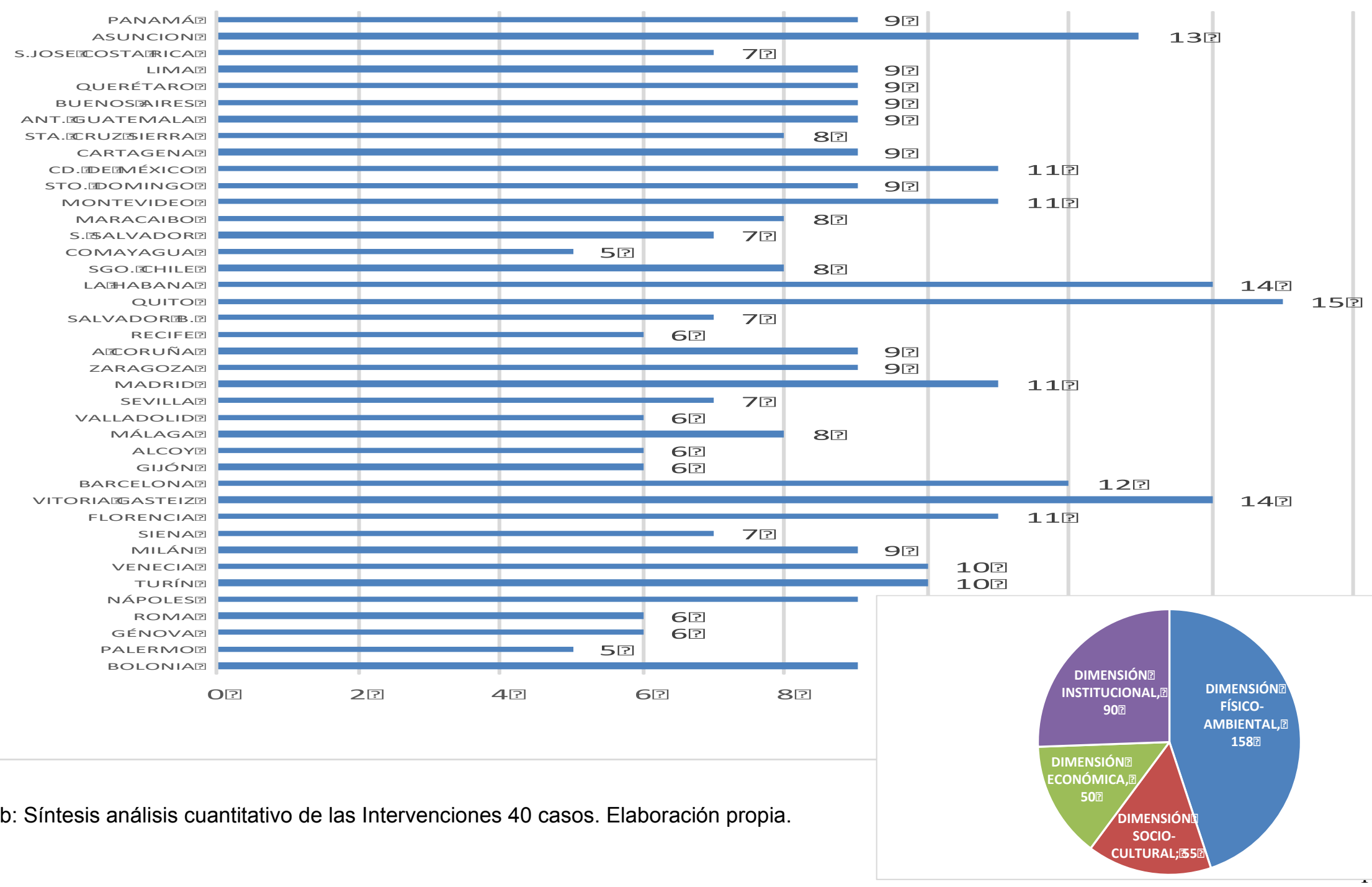

Gráfico IV.2b: Síntesis análisis cuantitativo de las Intervenciones 40 casos. Elaboración propia. 
Este análisis, permite concluir que el mayor porcentaje de problemáticas se concentra en la dimensión Físico-ambiental y Socio-cultural. A su vez, los $\mathrm{CH}$ que reúnen más cantidad de problemáticas en la totalidad de las dimensiones son los italianos Génova, Palermo y Nápoles, y los latinoamericanos Maracaibo, Ciudad de México, Asunción, Santo Domingo y San Salvador. Los $\mathrm{CH}$ con menores conflictos son Valladolid, Turín, Milán en el contexto europeo y Santiago de Chile, Quito y Santa Cruz de la Sierra en el contexto latinoamericano. El resto de los $\mathrm{CH}$ se encuentran en una situación intermedia. De todos modos, un menor valor no significa escasos problemas, sino que el $\mathrm{CH}$ puede presentar una tipología que involucre varias problemáticas de una misma clase. En cuanto a la Dimensión Físico-ambiental: San José de Costa Rica es quien presenta mayores debilidades, seguida por Asunción, Maracaibo, Recife, Génova y Palermo. Con respecto a la Dimensión Socio-cultural: Génova, Palermo, Gijón, Alcoy, Ciudad de México y Buenos Aires son los $\mathrm{CH}$ más afectados. Teniendo en cuenta las problemáticas de la Dimensión Económica: Barcelona, Cartagena, Madrid, Florencia, Venecia, Roma y Nápoles son quienes mayores dificultades presentan con el impacto del turismo; y finalmente, en la Dimensión Institucional: Asunción, San José de Costa Rica, Antigua Guatemala, Santo Domingo, Maracaibo, San Salvador, Comayagua, Nápoles, Génova y Palermo son quienes se encuentran más débiles en ese aspecto.
En Italia, la mayor parte de sus problemáticas se sitúan en la Dimensión Socio-cultural (35\%), seguidas por las presentes en la dimensión Físico-ambiental (29\%) y la Económica (26\%), con menores problemas en la Dimensión institucional (10\%). El mismo orden se registra en España, aunque con mayores valores en las dos primeras (45\% y $30 \%)$, casi el mismo porcentaje en la Dimensión Económica (25\%) y sin denunciar problemas en el aspecto institucional de los casos estudiados. Por su parte, AL difiere con Italia y España en el orden de porcentajes de sus dimensiones. La Dimensión Físico-ambiental presenta el mayor porcentaje de problemáticas (38\%), seguida por la Socio-cultural (29\%), la Económica (20\%) y la Institucional (13\%). En este contexto, es evidente el mayor deterioro Físico-ambiental que presentan los $\mathrm{CH}$ de $\mathrm{AL}$, asociado a problemas institucionales superiores que junto con las problemáticas económicas terminan impactando también la Dimensión Socio-cultural. Mientras que en el contexto europeo, la Dimensión Socio-cultural cobra más relevancia vinculada principalmente a la disminución y envejecimiento de la población residente, y a la gentrificación (Ver Tabla IV.1).

\begin{tabular}{|c|c|c|c|}
\hline \multicolumn{4}{|c|}{ PRDBLEMATICA5 } \\
\hline DINENSION & AL & ITALIA & ESPANA \\
\hline DIMFNSIÓN FISICO-AMRIFNTAI & $38 \%$ & $79 \%$ & $30 \%$ \\
\hline DIMENSIÓN SOCIO-CULTURAL & $29 \%$ & $35 \%$ & $45 \%$ \\
\hline DIMENSIÓN ECONÓMICA & $20 \%$ & $26 \%$ & $25 \%$ \\
\hline DIMENSIÓN INSTITUCIONAL & $13 \%$ & $10 \%$ & $0 \%$ \\
\hline
\end{tabular}

Tabla IV.1: Porcentajes de problemáticas por dimensión. E. Propia. 
De este análisis cuantitativo también se puede deducir cuáles son las tipologías de problemas -indicadores- que dentro de cada dimensión afectan en mayor o menor medida a los $\mathrm{CH}$. Con respecto a la Dimensión Físico-ambiental, el deterioro físico general, la pérdida de centralidad funcional y el desequilibrio funcional, junto con la pérdida de centralidad urbana, la disminución de la función residencial y la alta exposición a desastres naturales, son los conflictos más frecuentes. En la Dimensión Socio-cultural, la disminución de la población residente lidera la lista de problemáticas, seguida por la gentrificación, la marginalidad, violencia, drogadicción y delincuencia, y la invasión y ocupación del espacio público, ligados a la escasa valoración del mismo. Con respecto a la Dimensión Económica, la especulación inmobiliaria y los impactos negativos del turismo se presentan como prioritarias, y en cuanto a la Dimensión Institucional, las tres problemáticas que prevalecen en igualdad de jerarquía son la deficiencia institucional con la falta de instrumentos, la escasez de recursos, y la deficiencia en los procesos de seguimiento y control (Ver Gráficos IV.3a a IV.3d).

\section{DIMENSIÓN FÍSICO-AMBIENTAL - 40 CASOS}

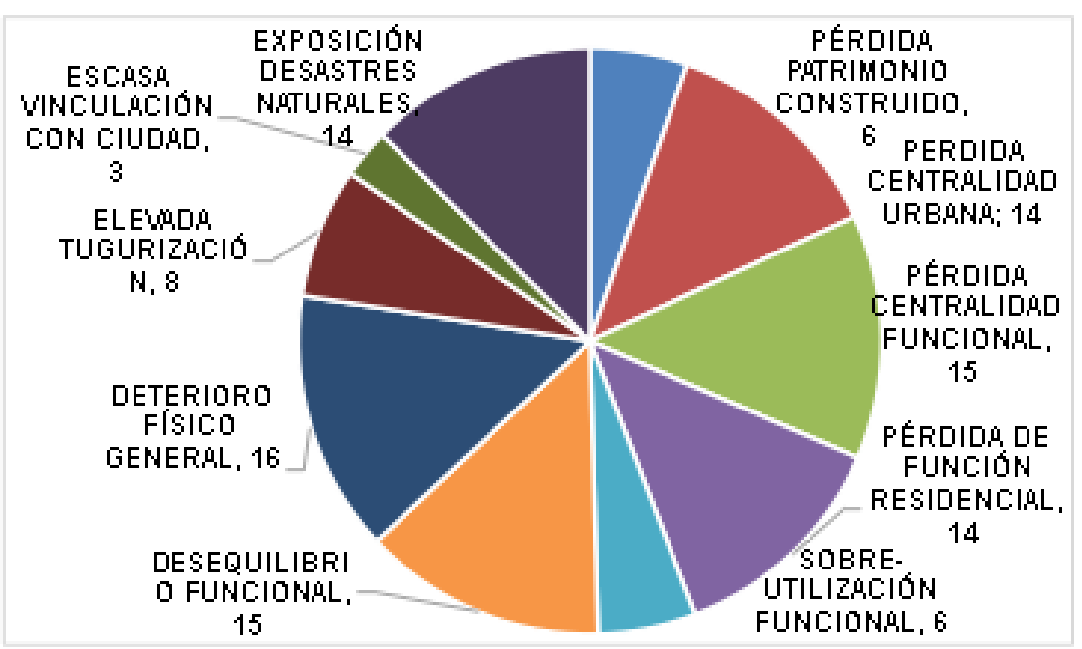

Gráfico IV.3a: Tipologías de problemas-indicadores-, Dimensión Físicoambiental. Elaboración propia

\section{DIMENSIÓN SOCIO-CULTURAL - 40 CASOS}

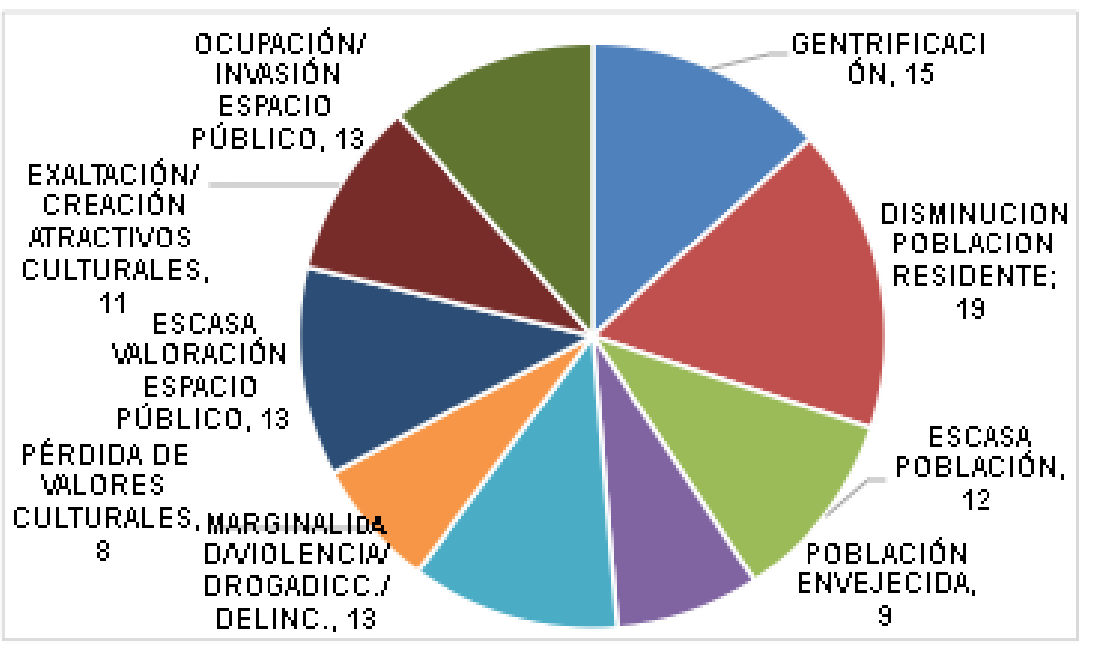

Gráfico IV.3b: Tipologías de problemas, Dimensión Socio-cultural. E.p. 
Con respecto a las intervenciones, el mayor porcentaje se sitúa en la Dimensión Físico-ambiental, seguida por la Institucional. Las ciudades que más actuaciones han registrado son Quito, Vitoria Gasteiz, La Habana, Asunción, Barcelona, Florencia, Ciudad de México, Montevideo, y Madrid. En una situación antagónica se encuentran Comayagua y Palermo. En la Dimensión Físicoambiental: Montevideo, Sevilla, Vitoria Gasteiz y Milán son quienes más actuaciones registran. Por su parte, en la Dimensión Sociocultural: Asunción, Buenos Aires, Maracaibo, San salvador, Quito, La Habana y Turín lideran este aspecto. En la Dimensión Económica: los $\mathrm{CH}$ que han hecho más hincapié son Asunción, Buenos Aires, Santa Cruz de la Sierra, Cartagena, Santo Domingo, Santiago de Chile, La Habana, Quito, Salvador de Bahía, Recife, A Coruña, Madrid, Barcelona, Vitoria Gasteiz, Florencia y Bolonia. Por último, en la Dimensión Institucional: La Habana y Quito guían este ítem acompañados por Lima, Ciudad de México, Barcelona, Vitoria Gasteiz y Nápoles.

\section{DIMENSIÓN ECONÓMICA}

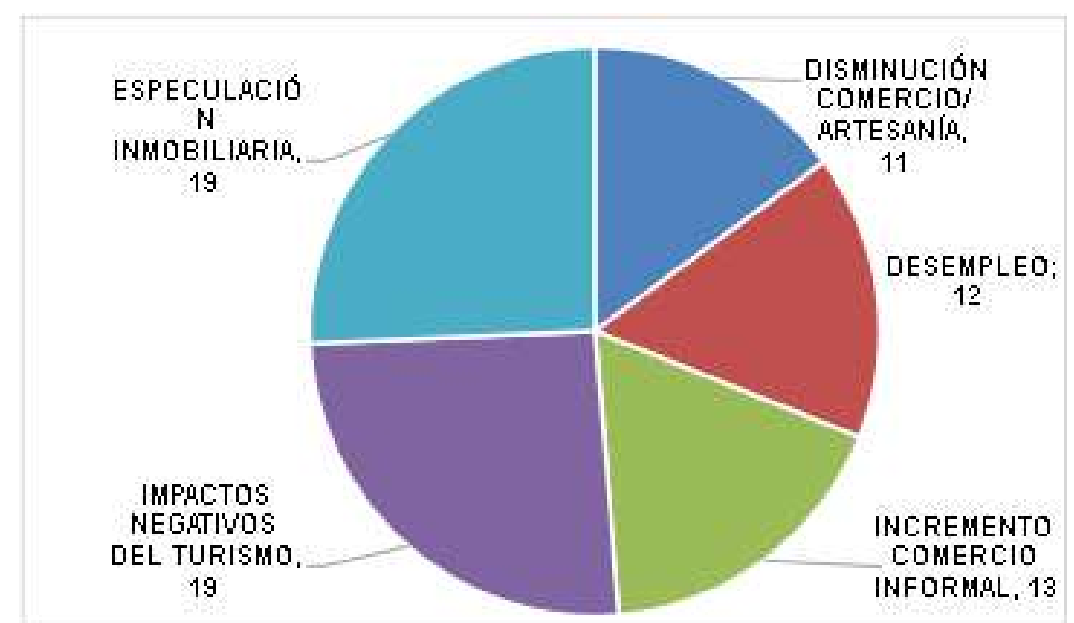

Gráfico IV.3c: Tipologías de problemas, Dimensión Económica Elaboración propia

\section{DIMENSIÓN INSTITUCIONAL}

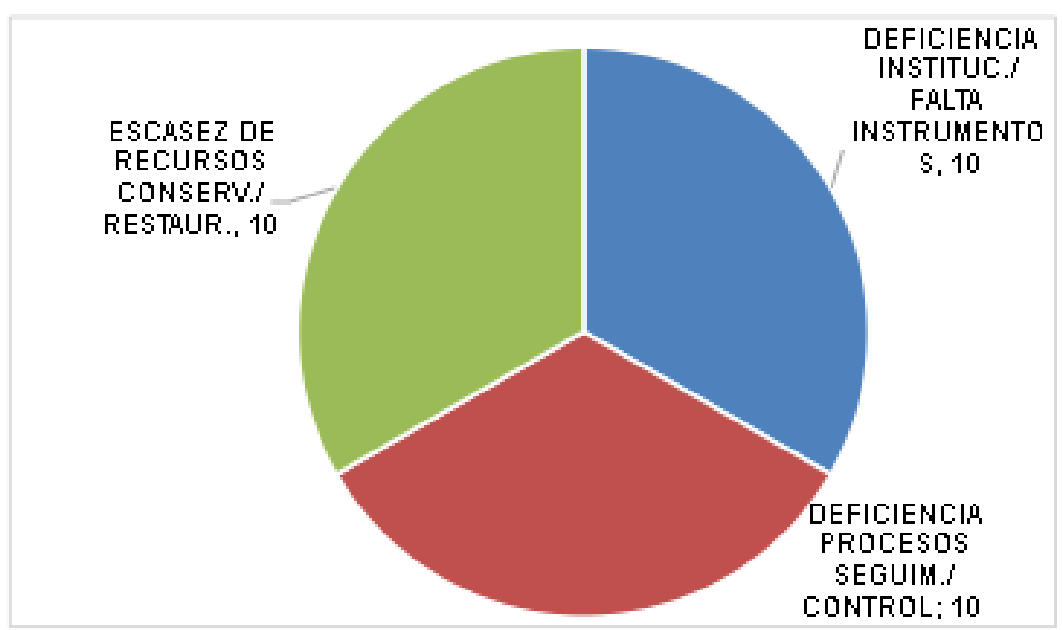

Gráfico IV.3d: Tipologías de problemas, Dimensión Institucional Elaboración propia 
También pueden reconocerse las tipologías de intervenciones indicadores- más usuales al interior de cada dimensión. En la Dimensión Físico-ambiental las intervenciones se focalizan principalmente en la recuperación del patrimonio construido, con actuaciones en la vivienda, el espacio público y la movilidad y accesibilidad. En el ámbito Socio-cultural, la mitad de las intervenciones se centran en el repoblamiento de los $\mathrm{CH}$, con un notable interés en la sostenibilidad socio-cultural. La Dimensión Económica presenta un claro interés con más del $50 \%$ de las intervenciones orientadas a la sostenibilidad en este aspecto, con una fuerte apuesta al turismo; y finalmente la Dimensión Institucional demuestra que aproximadamente la mitad de los casos poseen instrumentos implementados de 10 a 40 años, y la otra mitad con instrumentos de menos de 10 años de aplicación. Mayoritariamente, se desarrollan instrumentos tradicionales con financiamientos externos (Ver Gráficos IV.4a a IV.4d).

\section{DIMENSIÓN FÍSICO-AMBIENTAL}

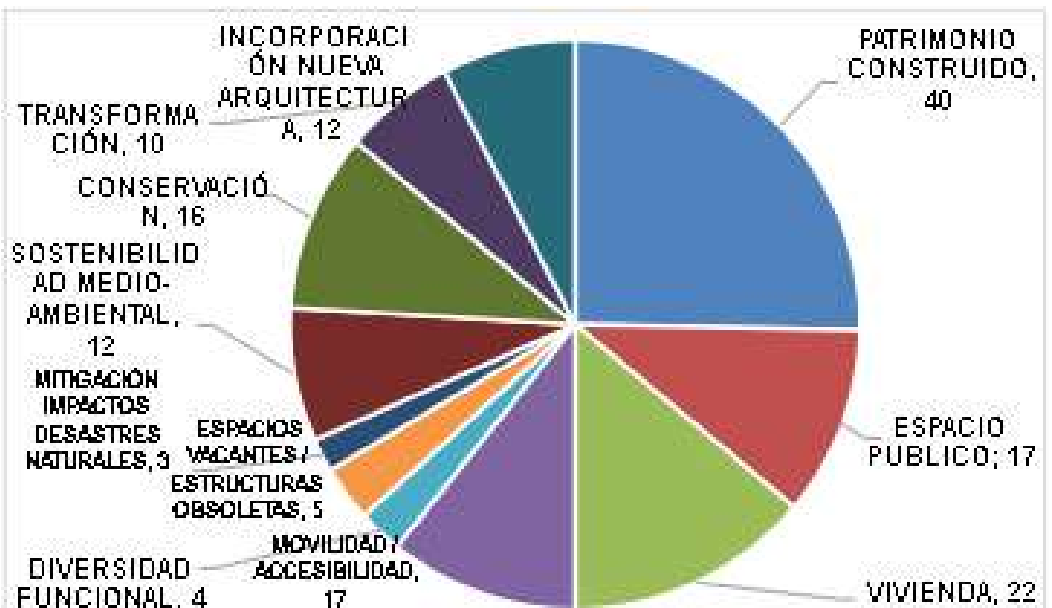

Gráfico IV.4a: Tipologías de intervenciones. Físico-ambiental Elaboración propia

\section{DIMENSIÓN SOCIO-CULTURAL}

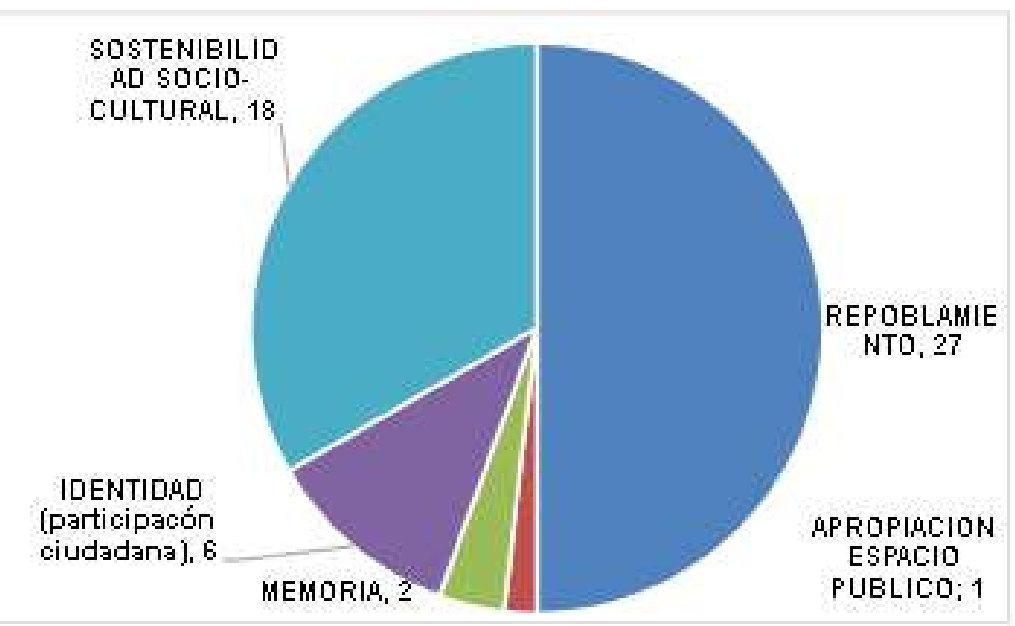

Gráfico IV.4b: Tipologías de intervenciones, Socio-cultural Elaboración propia 
Al analizar la cantidad de intervenciones desarrolladas en cada dimensión, es posible observar que tanto en Italia, España como en $\mathrm{AL}$, la mayoría de las intervenciones se concentran en la Dimensión Físico-ambiental (50\%, 53\% y 38\% respectivamente) acompañada por la Dimensión Institucional (28\%, 23\% y 26\%). En Italia y España las siguen las intervenciones en el ámbito Económico (12\% y 13\%) con menos hincapié en lo Socio-Cultural (10\% y $11 \%)$. Justamente, este hecho podría explicar que se concentren en esta última dimensión las mayores problemáticas en ambos países. AL por su parte, registra más énfasis en aspectos Socio-culturales $(20 \%)$ y menos en lo Económico (16\%), reconociéndose un mayor interés por intervenciones en lo Físico-ambiental y preocupación por la debilidad Institucional (Ver Tabla IV.2).

\begin{tabular}{|c|c|c|c|}
\hline \multicolumn{4}{|c|}{ INTERVENCIONES } \\
\hline DINENSION & AL & ITALIA & ESPAN̄A \\
\hline DIMENSIÓN FISICO-RMBIENTAL & $38 \%$ & $50 \%$ & $53 \%$ \\
\hline DIMENSIÓN SOCIO-CULTURAL & $20 \%$ & $10 \%$ & $11 \%$ \\
\hline DIMENSIÓN ECONÓMICA & $16 \%$ & $12 \%$ & $13 \%$ \\
\hline DIMENSIÓN INSTITUCIONAL & $26 \%$ & $28 \%$ & $23 \%$ \\
\hline
\end{tabular}

Tabla IV.2: Porcentajes de intervenciones por dimensión. E. Propia

\section{DIMENSIÓN ECONÓMICA}

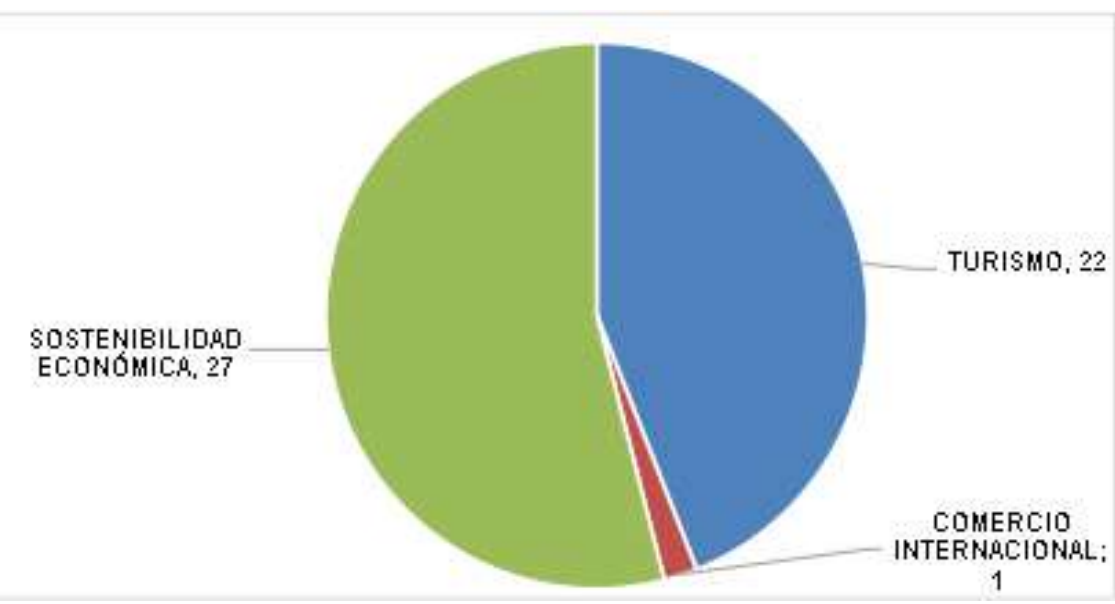

Gráfico IV.4c: Tipologías de intervenciones. Económica Elaboración propia

\section{DIMENSIÓN INSTITUCIONAL}

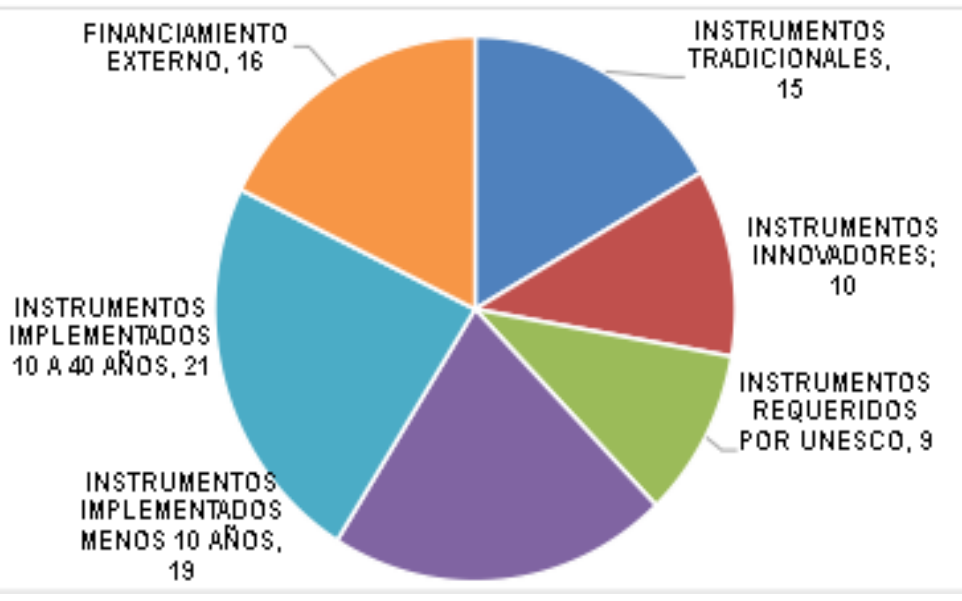

Gráfico IV.4d: Tipologías de intervenciones. Institucional Elaboración propia 
Si se asocian los valores obtenidos en la tabla y gráficos de problemáticas con los reunidos en la tabla y gráficos de intervenciones, puede inferirse que no necesariamente hay coincidencia entre las dimensiones que más problemáticas concentran y las que poseen más intervenciones. La Dimensión Físico-ambiental sí responde a esa lógica, pero por ejemplo, la segunda dimensión más problemática, la Socio-cultural no se corresponde con la segunda que contiene más intervenciones que es la Institucional. Este resultado, puede deberse a que muchos de los $\mathrm{CH}$, especialmente los de $\mathrm{AL}$, presentan graves problemas sociales, y resulta más sencillo intervenir sobre otras dimensiones que abordar esas problemáticas estructurales en profundidad. Considerando los $\mathrm{CH}$ con mayores problemáticas, no existe una correspondencia directa entre los más afectados y los más intervenidos, en general, las mayores actuaciones se registran en $\mathrm{CH}$ con necesidades intermedias. Puede deducirse, que este hecho se manifiesta como consecuencia de que aquellos más conflictivos carecen de la capacidad institucional y económica para llevar adelante acciones que puedan dar respuesta a sus necesidades.

Analizando las dimensiones, la Físico-ambiental no logra correlación entre las mayores problemáticas e intervenciones, las dimensiones Socio-cultural e Institucional sólo alcanzan coincidencia en uno de los casos, y finalmente, la Dimensión Económica es la que logra mejores resultados en cuanto a la relación problema-intervención. Esta situación se podría fundamentar en que uno de los principales problemas de esta dimensión es el impacto de la actividad turística en las áreas históricas, y justamente la mayoría de las intervenciones en $\mathrm{CH}$ se encuentran impulsadas por el interés de las administraciones en potenciar esta función. No obstante estas observaciones, en páginas siguientes se profundiza en experiencias que han intentado dar respuesta a las diversas dimensiones. 


\subsubsection{Estrategias e instrumentos de intervención y gestión: casos paradigmáticos / nuevos enfoques}

En las cuatro dimensiones de análisis, se han reconocido experiencias que han aportado nuevas estrategias e instrumentos de intervención y gestión para el abordaje de las problemáticas y algunas que han logrado abarcarlas de forma integral (Ver Síntesis en Figuras IV.5a, IV.5b y IV.5c). A continuación, se presentan los aportes identificados por dimensión de estudio.

Dentro de la Dimensión Físico-ambiental, se han identificado estrategias que en pos de la recuperación del patrimonio material, han propuesto actuaciones relevantes como la de Bolonia (1973) en Italia. Esta ha sido, como se ha expresado, una de las primeras experiencias iniciada en la década del 70 llevadas a cabo desde la gestión estatal para la reconstrucción y revitalización del $\mathrm{CH}$ pasada la guerra, que más ha influido en sucesivas intervenciones en $\mathrm{CH}$ de ciudades italianas como Ferrara, Brescia, Como, Módena y Vicenza, pero también en ciudades fuera de Italia de variados países del mundo. Su aporte a la mirada del $\mathrm{CH}$ como conjunto urbano (y no como una sumatoria de monumentos aislados) que logra vida a partir de conservar a sus habitantes y a las actividades que le otorgan la dinámica diaria (fuerte apuesta a la Dimensión Socio-cultural), sumado a la rigurosa metodología de análisis morfológico y su exigente política de conservación, lo han constituido como un caso paradigmático, innovador para la época.
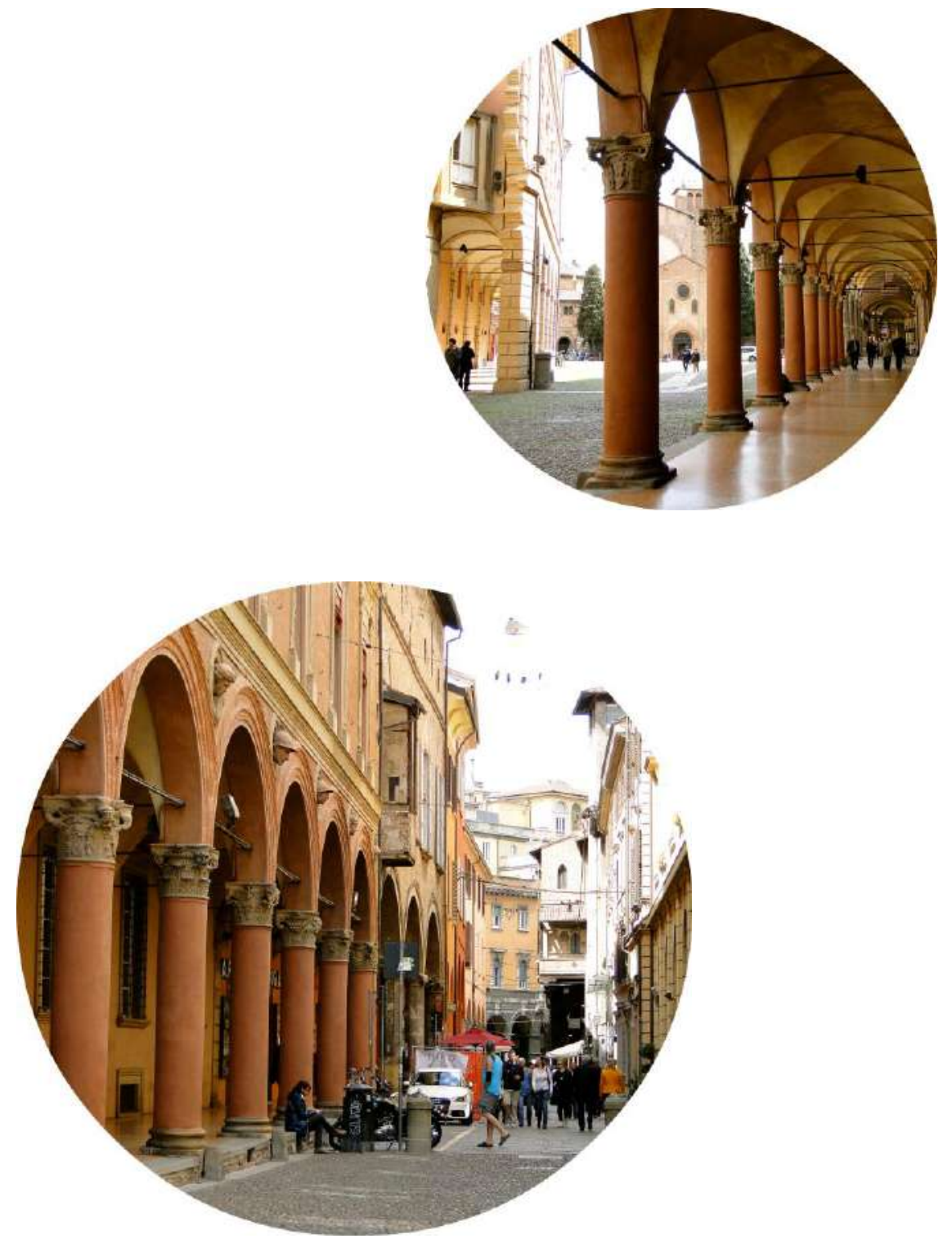
A su vez, se han reconocido destacadas operaciones en el espacio público, como el caso de Barcelona, donde desde la Oficina de Proyectos Urbanos, ha desarrollado dos PERI a principios de los 80 para Ciutat Vella (barrios del Raval y Sector Oriental) y el Plan de Rehabilitación Integral de la Ciutat Vella de Barcelona, a finales de la misma década. Ambos PERI, han estado orientados a la aplicación de intervenciones en el espacio público a escala de la denominada cirugía urbana en el tejido o "acupunturas urbanas" a través de rehabilitación de espacios públicos, equipamientos, infraestructuras y viviendas. En el año 1983 se aprueba el Programa de Actuaciones Integrales (PAI), que actúa a escala global a nivel de distrito. Posteriormente, Ciutat Vella obtiene la clasificación de Área de Rehabilitación Integrada (ARI), requisito necesario para formar parte del PAl, y para obtener el financiamiento desde los gobiernos nacional y regional. Se trabaja en la gestión del suelo, construcción de estacionamientos y equipamientos, promoción de viviendas nuevas y rehabilitadas, renovación de infraestructuras, urbanización de espacios libres y calles, y fomento de la rehabilitación privada. Se crea una Comisión gestora, para la interactuar entre las distintas escalas de gobierno y los vecinos, asegurando la participación ciudadana mediante reuniones. Solo uno de los dos PERI fue puesto en práctica, el desarrollado por los arquitectos Enric Miralles y Benedetta Tagliabue que promueven la rehabilitación de viviendas, espacios públicos y equipamientos (como la remodelación del mercado de
Santa Caterina y el convento de San Agustín). De este modo, la rehabilitación de viviendas y equipamientos, impactan en el espacio público (que incorpora plazas de distinta escala), actuando de conector entre las diversas intervenciones urbanas. A continuación, a finales de la misma década, el Plan de Rehabilitación plantea una intervención integral del $\mathrm{CH}$, con actuaciones sobre el patrimonio edilicio y público, las infraestructuras, el paisaje urbano, la identidad cultural, con fortalecimiento de la cohesión social y de las funciones residenciales, culturales, económicas y de servicios, poniendo hincapié a su vez, en la accesibilidad y movilidad.

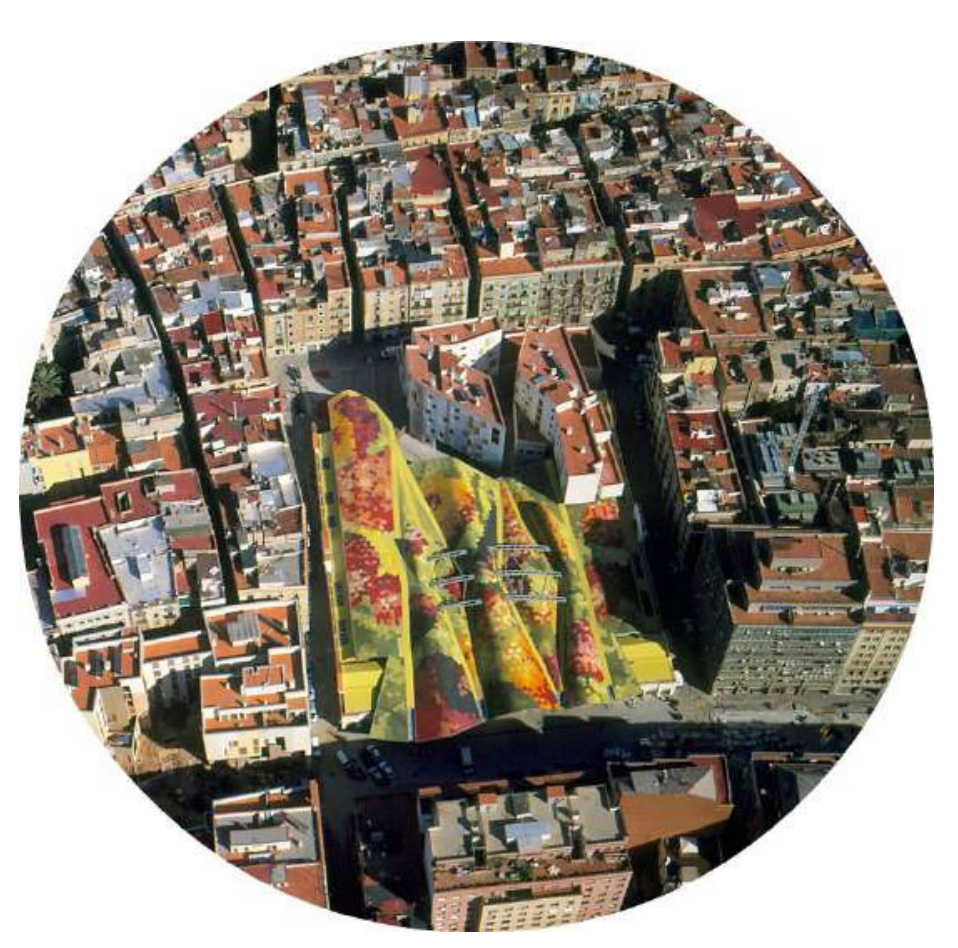


Teniendo a Barcelona como guía para la intervención del espacio público, desde el Ayuntamiento de Alcoy, se crea el Plan ARA. El mismo, posee como objetivo integrar la periferia con una serie de parques urbanos y definir en el $\mathrm{CH}$ cinco áreas de intervención con el propósito de detener la degradación arquitectónica-urbanística y socio-económica e iniciar un proceso de regeneración, rehabilitando y revitalizando el $\mathrm{CH}$ con actuaciones de calidad de mínimo costo de mantenimiento y de carácter pedagógico. Para ello, se convoca a arquitectos de renombre como Álvaro Siza, Francesco Venezia, John Miller y Manuel de Solá Morales, aunque sólo el proyecto del último mencionado llegó a ejecutarse, obteniendo durante el año 1999 un premio FAD, por ser uno de los mejores casos de recuperación integral de áreas centrales de su tiempo. Esta experiencia, ha resultado valiosa y precursora para la época, porque ha logrado concentrar recursos económicos de la Comunidad Autónoma Valenciana para el desarrollo de actuaciones de gran calidad urbana y arquitectónica, en un periodo donde todavía Valencia no había incursionado en intervenciones de esa índole.
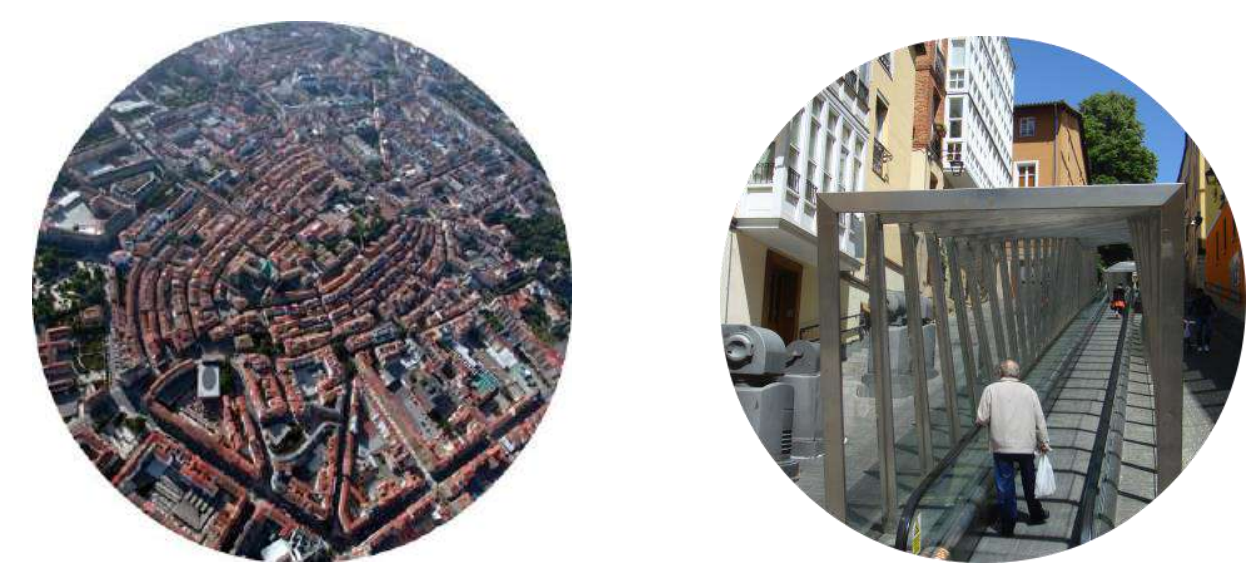

En otra de las Comunidades Autónomas Españolas, en el País Vasco, Vitoria Gasteiz se presenta como un caso de más de treinta años de intervención y gestión en el $\mathrm{CH}$. Mediante el Plan Especial de Rehabilitación Integral iniciado a comienzos de los 80, y el Plan de Reactivación Integral del $\mathrm{CH}$ en funcionamiento desde el año 2009. En este proceso, se destaca la intención integral de renovar infraestructuras urbanas, rehabilitar y adecuar edificios y viviendas, mantener la morfología urbana y las características arquitectónicas existentes, conservar, revalorizar y restaurar el patrimonio histórico artístico, fijar la población residente, mantener y regenerar la composición del tejido social, mejorar los niveles de habitabilidad, y dotar con equipamientos urbanos necesarios, con una fuerte apuesta a la accesibilidad y actuaciones patrimoniales reconocidas.

Asimismo, durante el año 2012, la ciudad ha sido reconocida como Capital Verde Europea por su comportamiento medioambiental.
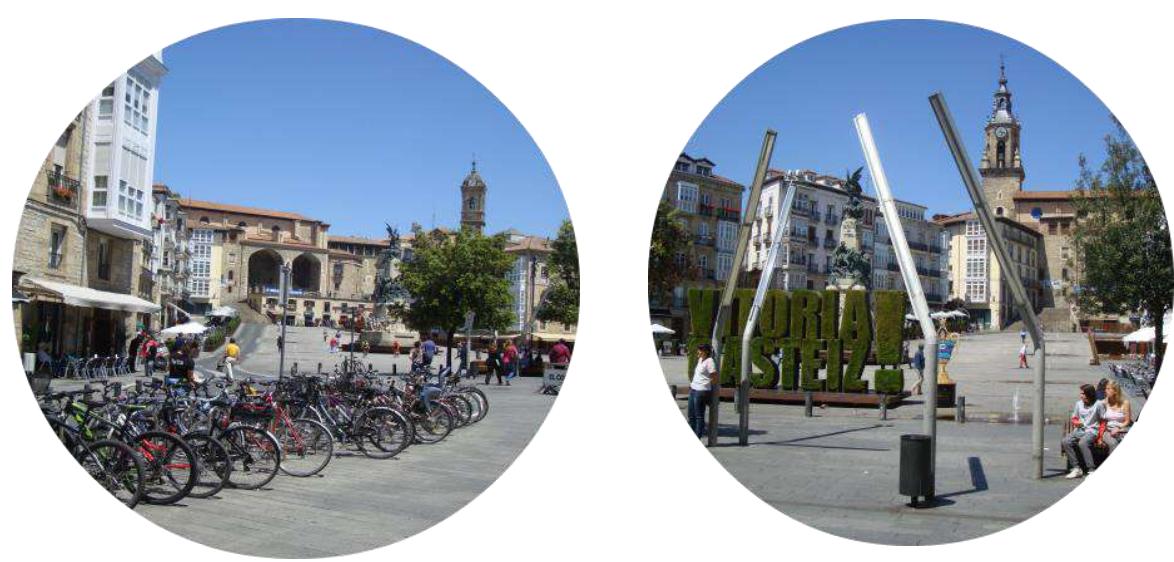
Ha tenido entre sus ejes, la recuperación de espacio público de calidad para funciones de estancia, descanso, juego y relación, en corredores, sendas, ejes, plazas y plazoletas, siendo la presencia del verde una de sus prioridades en el marco del Plan de Movilidad Sostenible y Espacio Público. Su apuesta a la intervención en el espacio público a partir de la conservación patrimonial, ha situado a esta ciudad como otro de los casos referentes.

En el contexto europeo, diversas intervenciones de incorporación de nueva arquitectura en $\mathrm{CH}$ han generado debates entre especialistas, habitantes y usuarios de los $\mathrm{CH}$ sobre cómo debiera ser esa relación nuevo-antiguo. Vitoria Gasteiz, con el interés de dar respuesta a problemas de accesibilidad producto de su geografía irregular, ha instalado ascensores, escaleras y rampas mecánicas para salvar diferencias de alturas. Barcelona, por su parte, ha incorporado en Ciutat Vella, para el Mercado de Santa Caterina, una estructura contemporánea para la cubierta diseñada por Miralles y Tagliabue, que ha modificado la vista aérea del sector y ha impulsado nuevas intervenciones en el espacio urbano. En Sevilla, la inclusión de Metropol Parasol, un mirador de gran escala que une dos plazas del $\mathrm{CH}$, obra del arquitecto berlinés Jurgen Mayer, se ha convertido hoy en día en ícono de la ciudad pero su construcción ha generado tanta polémica como la incorporación del puente de Calatrava sobre el Gran Canal de Venecia. Por su parte, en Nápoles, renombrados arquitectos internacionales se encuentran interviniendo el sistema de estaciones de la red de subte que involucra espacios públicos tanto a nivel subsuelo como en el cero, con intervenciones en plazas y calles que articulan valioso patrimonio arqueológico con nueva arquitectura.
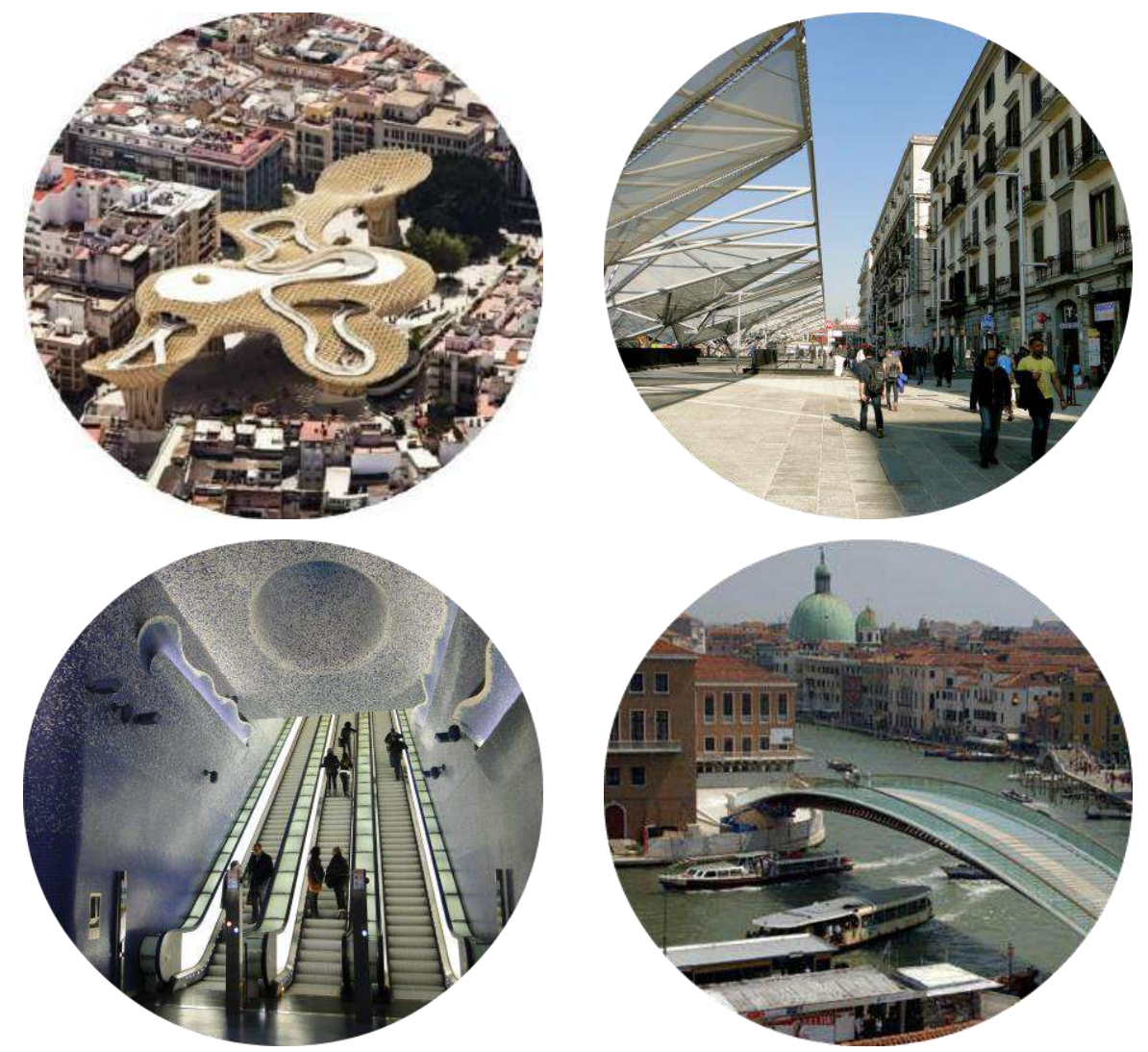

En el contexto latinoamericano, la ciudad de La Habana en el marco de su Plan Maestro de Revitalización Integral de 1994, ha desarrollado el PEDI (Plan Especial de Desarrollo integral del $\mathrm{CH}$, 2001), que presenta una intervención prioritaria en el espacio 
público. Ha iniciado sus actuaciones rehabilitando plazas principales, a las que se han ido incorporando parques y paseos urbanos, ejes, corredores, plazas asociadas a corredores, calles y plazas de principal interés. Este, junto a otros aspectos de su intervención lo posicionan como caso paradigmático dentro del contexto latinoamericano.

Además de esta experiencia destacada y premiada en $\mathrm{AL}$, que ha sido posible a su vez por el importante rol otorgado a la participación ciudadana, existen otras estrategias urbanas en áreas históricas que han logrado ser reconocidas como la intervención en el Mercado Agrícola de Montevideo, que ha recibido el premio Gubbio en el año 2015, por acompañar a las virtudes propias de la restauración edilicia, una operación social y urbana que revitaliza el sector. Este ejemplo, siguiendo la experiencia de "acupuntura urbana" barcelonesa, ha generado una revitalización del antiguo barrio de Goes que por décadas se encontraba sufriendo un proceso de degradación. Se mejoraron equipamientos (guardería infantil y polideportivo), se intervino el espacio público, se renovó el área de estacionamiento del mercado, se incorporó un paseo peatonal y se construyeron viviendas de interés social.
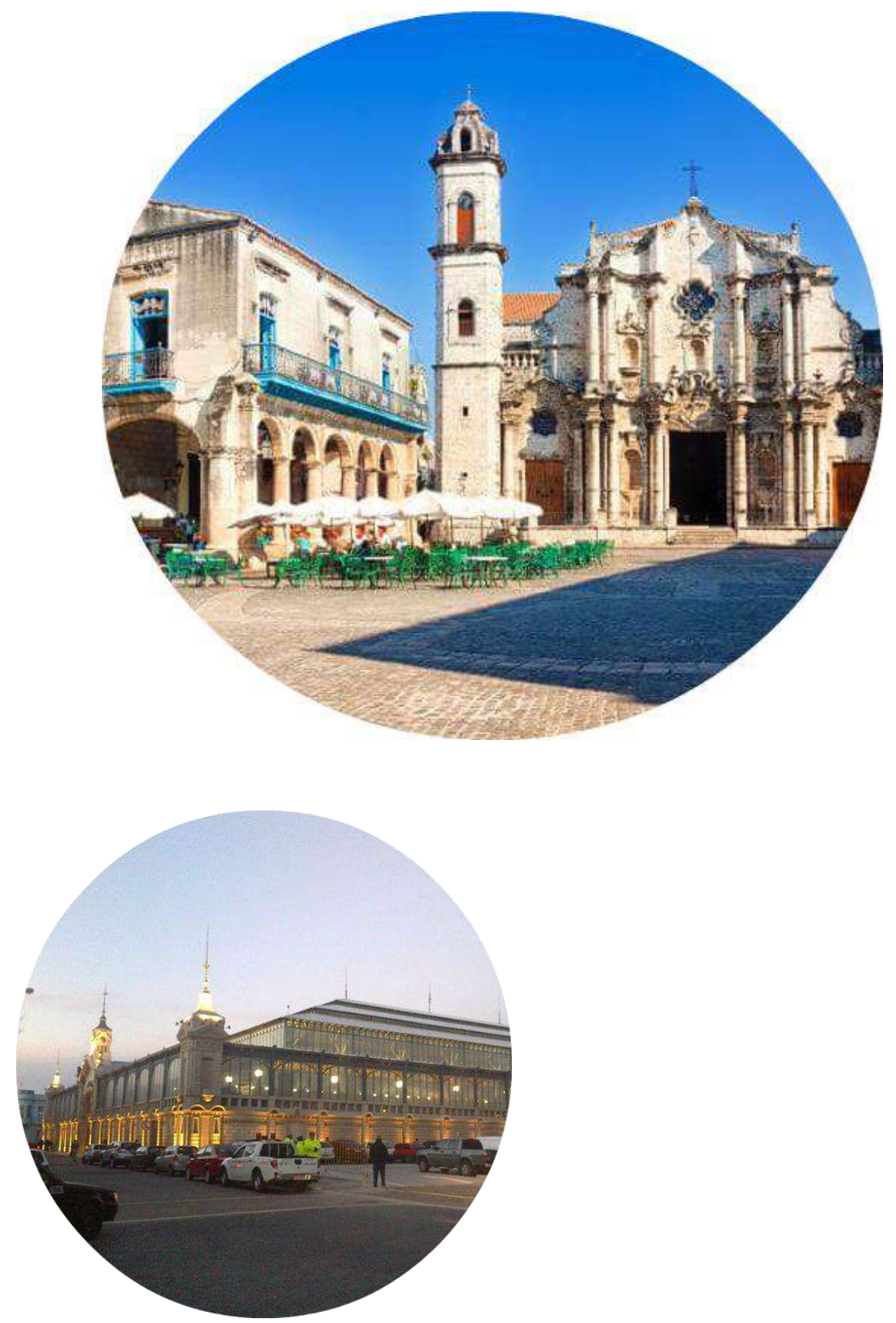
Por su parte, Quito en el año 1989 elabora el Plan Maestro de Rehabilitación Integral de las Áreas Históricas de Quito, que plantea concebir al $\mathrm{CH}$ como espacio urbano representativo e inductor de nuevas y calificadas funciones en otras áreas de la ciudad; y lograr la habitabilidad, accesibilidad y reactivación económica del $\mathrm{CH}$, conciliando la conservación del patrimonio. Una de sus prioridades ha sido la recuperación del espacio público, como eje para la rehabilitación del $\mathrm{CH}$, con un sistema de recorridos peatonales que vinculan los principales puntos. Fomenta el sentido de identidad y pertenencia de sus habitantes, mediante la apropiación social del espacio público asociado a símbolos arquitectónicos o de memoria. Estas acciones han acarreado una intervención previa asociada a la Dimensión Económica, la organización del comercio informal que había proliferado durante décadas en las calles del $\mathrm{CH}$, convirtiéndose en un gran mercado popular al aire libre con todos los inconvenientes que ello conlleva, ocupación indiscriminada del espacio público, suciedad, pérdida de accesibilidad vehicular y peatonal, pérdida de ingresos para los comercios formales, y el surgimiento de mafias para el control de las ventas, entre otros. Para la compleja tarea de gestionar la relocalización del comercio informal, surge el proyecto "Modernización del Comercio Popular", que luego de largas negociaciones con asociaciones de comerciantes que se oponían a la mudanza, traslada a los comerciantes a grandes mercados cerrados denominados "Centros Comerciales del Ahorro".

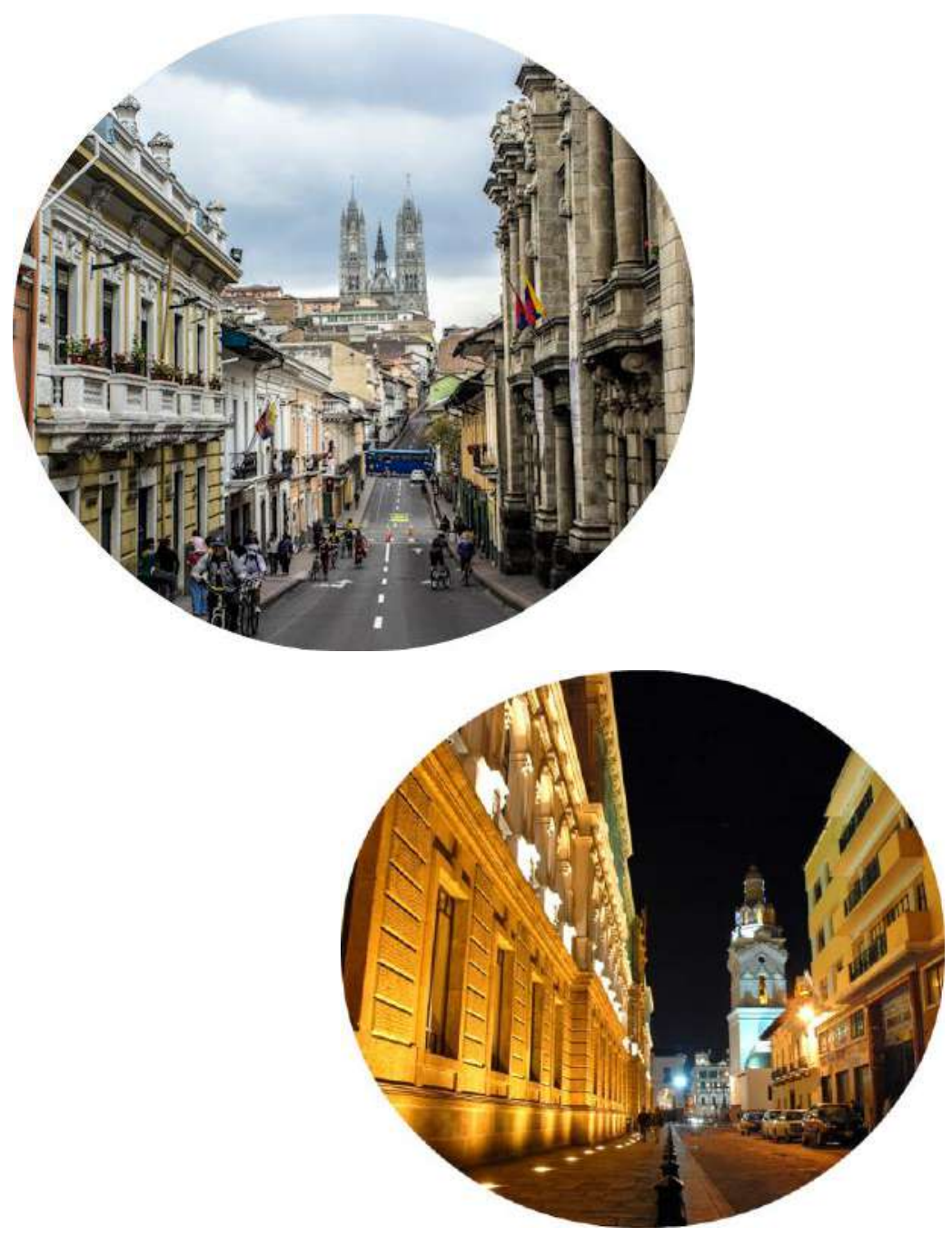

En esta misma dimensión, pero más asociada a la actividad turística, una de las primeras experiencias más comentadas en el contexto latinoamericano, ha sido la intervención del $\mathrm{CH}$ de 
Salvador de Bahía. El reconocimiento de UNESCO en el año 1985 del denominado "Pelourinho", volcó las miradas hacia el $\mathrm{CH}$. De este modo, se ha inicado en el año 1991 el "Programa de Recuperación del Centro Histórico de Salvador", con el objetivo de revitalizar y reestructurar el $\mathrm{CH}$, creando un centro de atracción turística y de actividades recreativas de placer y diversión, con obras de restauración y rehabilitación de edificios históricos, para modificar dinámicas existentes. Ha planteado introducir nuevos usos asociados a la actividad turística y proponer estrategias de intervención enfocadas en la recuperación: obras de restauro, recuperación estructural, y reconstrucción y conservación de los edificios mediante la zonificación de bloques, saneamiento y registro de habitantes. Estas iniciativas basadas en la recuperación e intervención sobre el patrimonio físico y social, han originado nuevas dinámicas en el $\mathrm{CH}$, que transformaron al sector en un enclave principalmente turístico con funciones asociadas a tal fin y con nueva población (gentrificación), que conserva muy pocos residentes originarios previos a la intervención. Estos residentes han creado una asociación llamada AMACH (Asociación de Habitantes -moradores-) del $\mathrm{CH}$.

Como se ha expresado, el incremento del turismo y la dependencia de una actividad económica es una amenaza también en la generación de áreas que funcionen como museos a cielo abierto, lo que se denomina "museificación" de los $\mathrm{CH}$, y que es un riesgo para las áreas históricas de ciudades donde el turismo es una de las actividades que cobra gran relevancia como en Salvador de Bahía, Cartagena, Venecia, Florencia, Siena, Sevilla o Barcelona. El caso del Pelourinho se ha configurado como un interesante ejemplo de análisis para las administraciones, con el fin de evitar ciertos impactos negativos en las intervenciones de los $\mathrm{CH}$ de $\mathrm{AL}$.

Las dos dimensiones, Físico-Ambiental y Económica, presentadas previamente se sintetizan en la Figura IV.5a.

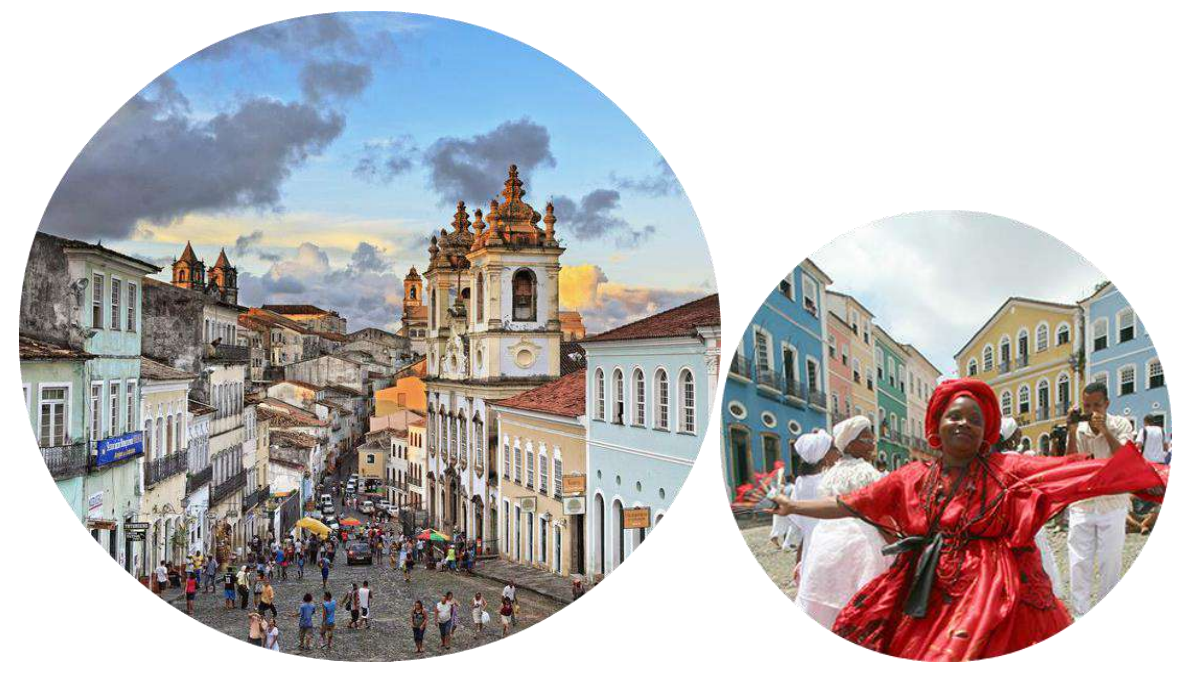

Los complejos procesos de intervención han requerido en la Dimensión Institucional de la creación de instrumentos integrales de gestión (Ver Figura IV.5b). Vitoria Gasteiz, para la aplicación de sus Planes, ha entendido como clave la creación a finales de la década del 80 , de un organismo municipal con un modelo de 
gestión integral como la Agencia de Revitalización Integral de la Ciudad Histórica S.A., que posee un funcionamiento similar al de una empresa privada.

En el contexto latinoamericano, muy tempranamente, en el año 1938, La Habana con una fuerte apuesta al modelo de gestión estatal, sienta sus bases en la constitución de la Oficina del Historiador, organismo municipal autónomo, que desde el año 1981 posee presupuesto para rehabilitación y actúa como entidad líder en la toma de decisiones y financiamiento. Se desempeña bajo un marco legal especial y funciona con un sistema empresarial, con la compañía hotelera Habaguanex S.A. para la explotación turística, la agencia de viajes San Cristóbal y la Inmobiliaria Fénix S.A..

Otro de los ejemplos en gestión pública en $\mathrm{AL}$ es Lima, que ha creado el "Programa Municipal para la Recuperación del $\mathrm{CH}$ PROLIMA", como institución líder en la gestión, recuperación, reactivación y promoción del $\mathrm{DS}$ del $\mathrm{CH}$.

Más recientemente, la Ciudad de México crea el "Fideicomiso $\mathrm{CH}$ de la Ciudad de México", que desde el año 2002 funciona como fideicomiso público dependiente del Gobierno de la Ciudad. En su creación, en el año 1990 fue de carácter privado. Un año antes, en 1989 había sido creada la Secretaría de Turismo para impulsar el desarrollo turístico tanto nacional como internacional (con fondos mixtos de promoción, y mecanismos de participación conjunta del gobierno federal, estatal, y municipal, y de los prestadores de servicios turísticos organizados en la misma Secretaría). De esos Fondos Mixtos ha surgido el "Fondo Mixto Ciudades Coloniales" destinado a la conservación y restauración de ciudades coloniales y sus $\mathrm{CH}$, que incluye 44 ciudades de las más de 100 que se asentaron durante la época colonial. Algunas de las ciudades intervenidas con los Fondos mixtos son: Aguascalientes, Guadalajara, Mérida, Ciudad de México, Pátzcuaro, Puebla, San Miguel de Allende, Taxco, Zacatecas, Campeche, San Cristóbal de las Casas, Durango, Guanajuato, Morelia, Oaxaca, Querétaro, San Luis Potosí, Tlaxcala y Veracruz.

Con respecto a los instrumentos de gestión mixta en el contexto europeo, Barcelona ha desarrollado un instrumento novedoso para la época: la empresa mixta municipal Promocio Ciutat Vella PROCIVESA (luego denominada Foment de Ciutat Vella), que ha servido de inspiración para otras administraciones. En AL, el antecedente previo a este caso es la creación de CORDESAN, Corporación para el desarrollo de Santiago, institución privada sin fines de lucro que fomenta la colaboración entre el Municipio, el sector privado y la comunidad. Una función similar desempeña la "Fundación del $\mathrm{CH}$ de la Ciudad de México (FCHCDM)" o "Fundación Carlos Slim", asociación civil sin fines de lucro, constituida con el apoyo económico de empresas privadas, para 
colaborar con los gobiernos en la revitalización y restauración del $\mathrm{CH}$.

Sin embargo, el primer caso latinoamericano de gestión mixta y funcionamiento semejante al instrumento catalán, es el "Patronato Panamá Viejo", ente administrativo mixto creado en 1995 sin fines de lucro, independiente y con autonomía propia para la toma de decisiones y manejo de fondos para la gestión. Al año siguiente, con el objetivo de la Rehabilitación Integral del $\mathrm{CH}$ se crea en Quito la "Empresa del $\mathrm{CH}$ de Quito $(\mathrm{ECH})$ ", pionera en $\mathrm{AL}$ en este tipo de gestión fomentada desde el Municipio, que recibe sus aportes financieros y del BID. Más recientemente, en el año 2016, se crea en Asunción el "Laboratorio Abierto de Desarrollo Urbano (ASULAB)", que funciona como una "oficina del cambio", interfaz entre la gestión institucional y el impulso ciudadano. Punto de conexión con agentes privados financiadores de proyectos en el $\mathrm{CH}$.
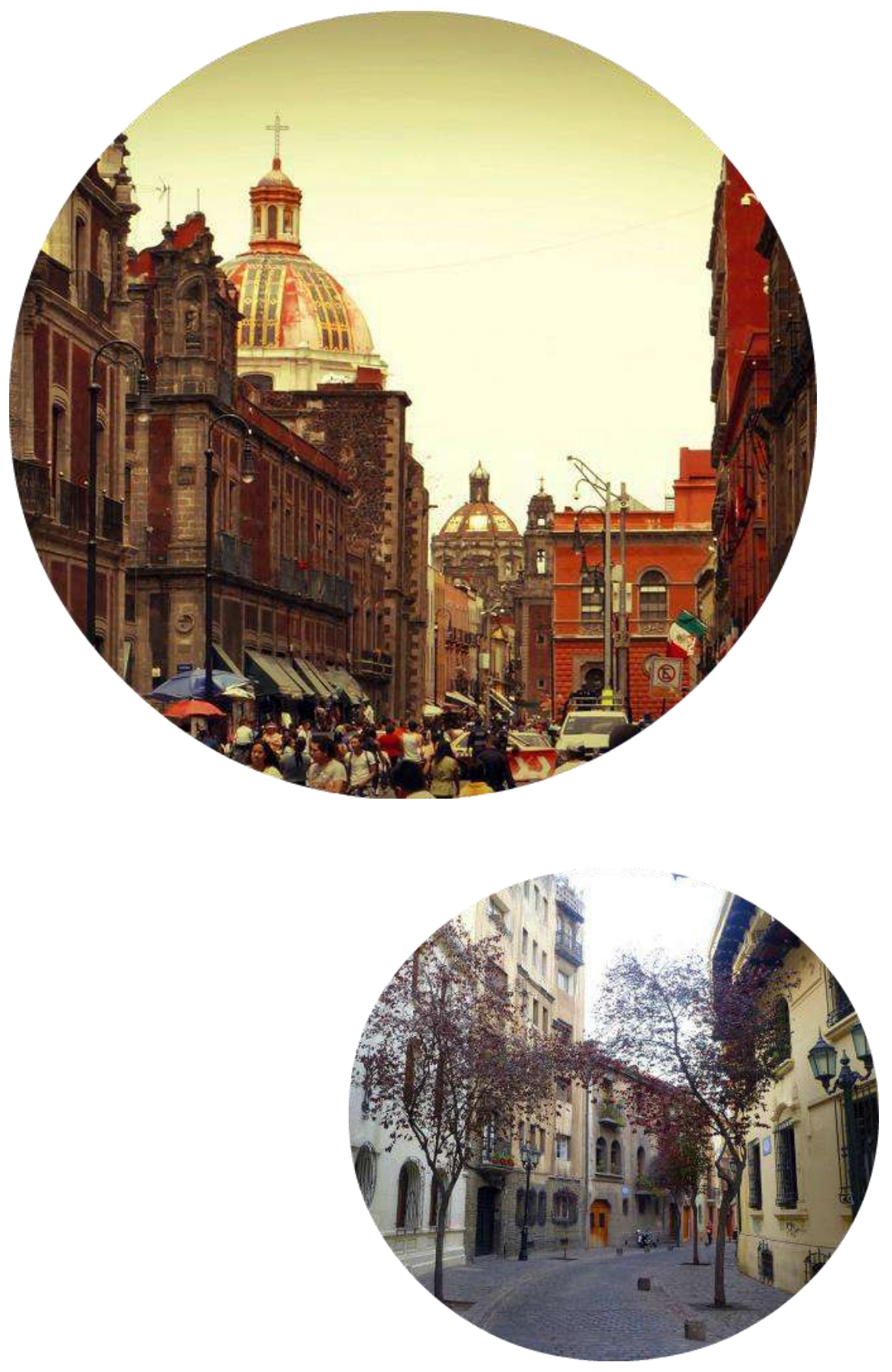
BOLONIA

1973 - Rigurosa metodologia de análisis morfológico, determinación de tipos arquitectónicos (conjuntos monumentales, tipologias de edificios), exigente politica de conservación (restauración. repristino y reconstrucción)

\section{ESPACIO PÚBLICO}

-

$\bullet$

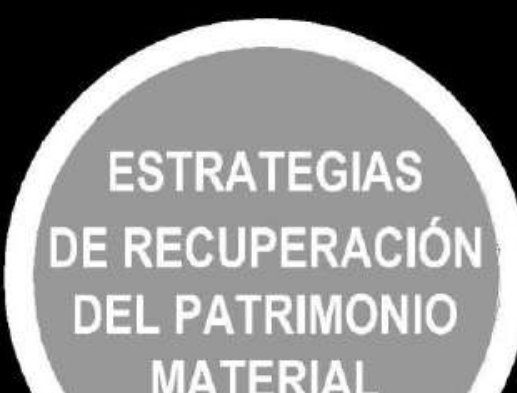

MATERIAL
BARCELONA

1980 - Intervenciones a escala de la denominada cirugia urbana en el tejido o "acupunturas urbanas" a través de rehabilitación de espacios públicos, equipamientos infraestructuras y viviendas

ALCOY

1980 - Define áreas de intervención en el $\mathrm{CH}$. Arquitectos de renombre para realizar intervenciones de calidad, (regenerar, rehabilitar y revitalizar) Experienecia precursora para la época en Valencia. (PERI) QUITO 1989 - Intervenciones para la recuperación del espacio público como eje para la rehabilitación del $\mathrm{CH}$. Propuesta de espacios públicos como sistema de. $\mathrm{CH}$ acompañado de recorridos peatonales que vinculan los

principales puntos. (Plan Maestro)

\section{Acupunturas urbanas / Sistemas de espacios Públicos / Plazas}

en el espacio público, como el primer elemento de percepción del lugar. Rehabilitando plazas principales, parques y paseos urbanos, ejes, corredores, plazas asociadas a corredores, calles y plazas de principal

Reconversión de usos / Recuperación de infraestructuras obsoletas /

\section{VALLADOLID}

\section{7 - Propuesta de} operaciones estructurantes en "areas de oportunidad

$\bullet$

$\bullet$ infraestructuras obsoletas nfrautilizadas o vacios intersticiales

industriales 0 institucionales)

\section{ESTRUCTURAS ABANDONADAS O INFRAUTILIZADAS}

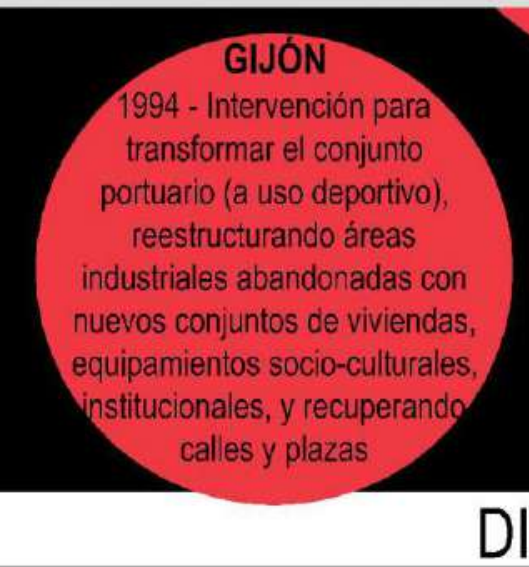

\section{GENOVA}

Te11 - Recualificar ofrecer nuevos espacios de integración como antiguas fábricas abandonadas, que brinde nuevos usos generando nuevas oportunidades económicas, culturales, de socialización y de participación activa
Áreas de oportunidad

\section{QUITO}

1989 - Con el fin de gestionar la compleja tarea de relocalización del comercio informal surge el proyecto "Modernización del

comercio popular" para el traslado de los comerciantes a grandes mercados cerrados denominados

"Centros comerciales de

Ahorro". (Plan Maestro)

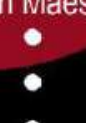

$\bullet$

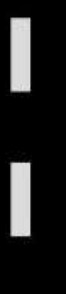

I

\section{ESTRATEGIAS} E INSTRUMENTOS PARA EL TURISMO $Y$ EL COMERCIO INFORMAL $\bullet$

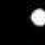

\section{- SA} DE BAHÍA 1991 - Revitalizar, y reestructurar creando un centro de atracción turistica y de actividades de placer y diversión con obras de restauración y rehabilitación de edificios históricos para modificar dinámicas existentes (Programa

de recuperación del $\mathrm{CH}$ ) conexiön fisica y funcional rea entre el $\mathrm{CH}$ y el Puerto Viejo. públicos. Reconversión funcional, ocio, turismo, cultura y

actividades post-industriales 
VITORIA GASTEIZ

977 Creación del Organismo Municipal "Departamento del CH, DCH", caso único en gestión de $\mathrm{CH}$ de la época. A partir de 1982 se constiftuye como sociedad anónima.

\section{PÚBLICA}

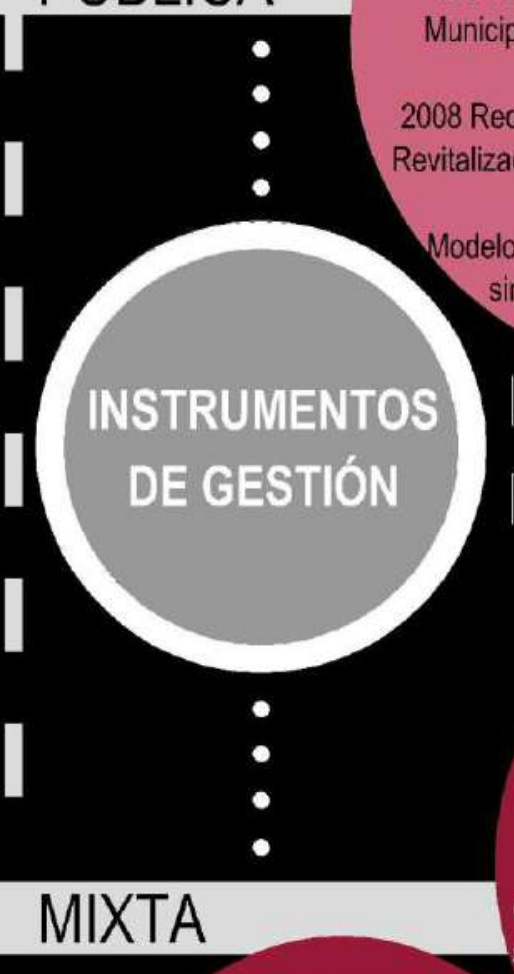

SANTIAGO DE CHILE

1985 - Creación de

"Corporación para el Desarrollo de Santiago (CORDESAN)" Institución privada sin fines de lucro que fomenta la colaboración entre el municipio, el sector privado y la comunidad.

1994 Transformación del DCH en"Agencia

unicipal de Renovación Urbana y Vivienda S.A.(ARU)"

Ae ARU en "Agencia para (A.R.I.C.H,S.A)"

elo de gestión Integral. Funcionamient

similar al de una empresa privada

\section{BARCELONA}

1988 Creación de la "Empresa Mixta Municipal Promoció Ciutat Vella S.A. (PROCIVESA), luego denominada Foment de Ciutat Vella. Constituida en un $51 \%$ por capital municipal, y el $49 \%$ restante distribuido entre empresas urbanizadoras, de uministros y entidades financieras (Caixa de Pensions, BBV, BEX) y una pequeña proporción entre comerciantes y empresarios del $\mathrm{CH}$.

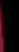

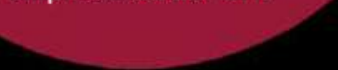

Departamento del CH / Oficina del Historiadr / Programa Municipal / Fideicomiso

Empresas / Corporaciones / Patronatos / Fundaciones / Laboratorios

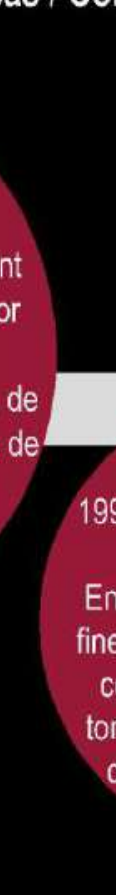

1938 Creación de un organismo municpal con del Historiador" (desde 1981, Entidad lider en la toma de decisiones y financiamiento, que se desempeña bajo un marco legal especial.

Funciona con un sistema empresarial, con la compañia Hotelera Habaguanex S.A. para la explotación turistica, la agencia de viajes San Cristóbal, y la inmobiliaria Fénix S.A

Fue galardonado en varias ocasiones por sus actuaciones en el $\mathrm{CH}$

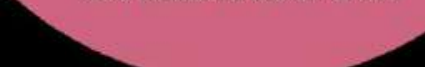

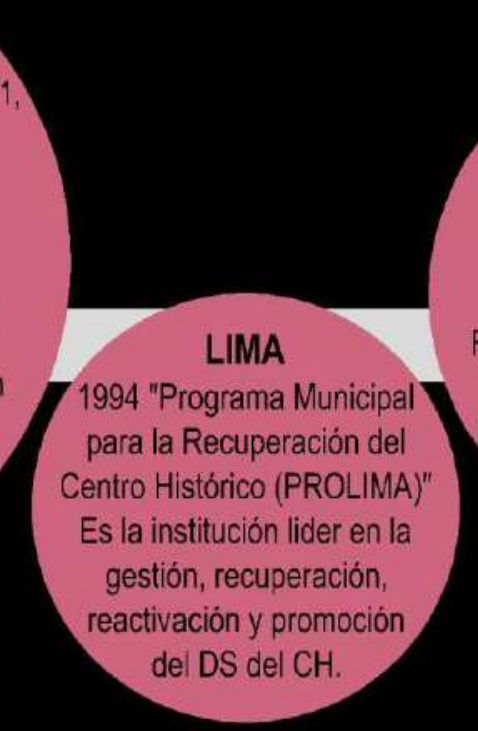

CIUDAD DE MÉXICO 2002 "Fideicomiso Centro Histórico de la Ciudad de México". Desde este año el organismo funciona como

Fideicomiso Público dependiente del Gobierno de la Ciudad.

En su creación, en el año 1990

fue de carácter privado.
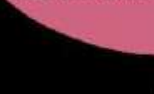

$\bullet$

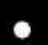

-

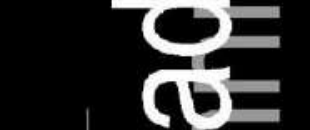

\section{PANAMÁ \\ 1995 - Creación de "Patronato} Panamá Viejo"

Ente administrativo mixto, sin fines de lucro, independiente y

con autonomia propia para

toma de decisiones y manejo

de fondos para la gestión.
QUITO

1996 - Creación de "Empresa del Centro Histórico de Quito (ECH)"

Pionera en este tipo de gestión fomentada desde el Municipio en América Latina

Recibe aportes financieros del Municipio y del BID

\section{CIUDAD DE MÉXICO}

\section{2 - Creación de}

"Fundación del Centro Historico de Ciudad de México (FCHCDM) o

Fundación Carlos Slim"

Asociación civil sin fines de lucro constituida con el apoyo económico

de empresas privadas para colaborar con los gobiernos en la

revitalización y restauración del $\mathrm{CH}$. 
El desarrollo de estos instrumentos, ha permitido la creación en la

Dimensión Socio-cultural de políticas de vivienda enfocadas en el repoblamiento de los $\mathrm{CH}$ (Ver Figura IV.5c). Resulta interesante destacar en Europa la citada experiencia de Bolonia, que ha promovido políticas de vivienda social con alto porcentaje de viviendas de promoción pública con el fin de mantener en el $\mathrm{CH}$ a las clases sociales más desfavorecidas y crear casas para obreros para frenar el despoblamiento. En este ámbito, Barcelona ha desarrollado intervenciones denominadas "acupunturas urbanas con esencia en la vivienda", que han acarreado la recuperación de equipamientos y la renovación de infraestructuras para el sector. También en España en el mismo periodo Vitoria Gasteiz, ha fomentado la aplicación de intervenciones para fijar la población residente, mantener y regenerar el tejido social. En la actualidad, se está pensando en la creación de un Plan de Vivienda Social y Oficina Municipal de vivienda para incentivar el alquiler de jóvenes en el $\mathrm{CH}$.

Por su parte, en AL las experiencias implementadas en Santiago de Chile, Montevideo, Recife y San José de Costa Rica, merecen particular atención. Una de las primeras iniciativas por recuperar y fomentar la residencialidad en el $\mathrm{CH}$ ha sido la de Santiago de Chile, que ha creado el Plan de Repoblamiento de Santiago (1990). Con el objetivo de densificar sectores urbanos y consolidar áreas centrales con pérdida de población para mejorar la calidad de vida y el hábitat urbano. Se ha propuesto recuperar y fortalecer el rol residencial para generar beneficios sociales, económicos y ambientales, beneficiando a personas sin vivienda con interés de vivir en el centro.

Para esa fecha, en Montevideo con el fin de fomentar el repoblamiento defendiendo un hábitat policlasista e integrado, se desarrolla un sistema de cooperativas de viviendas para la recuperación de edificios históricos de la Ciudad Vieja o la construcción de obra nueva, y el incremento de la población residente. La Intendencia de Montevideo facilita el acceso a la tierra a través de licitaciones para la adquisición de terrenos. Las cooperativas permiten que un mismo inmueble genere varias unidades habitacionales, exoneradas de contribución inmobiliaria. Las tierras (con edificaciones a remodelar o demoler), son vendidas a las cooperativas con subsidios altos y largos plazos, sin intereses para facilitar el acceso. Con este sistema se han creado numerosas cooperativas como Covicivi1, 2 y 3, Fecovi, Puerto Fabini, y Mujefa ("Mujeres Jefas de familia"), muchas de ellas agrupadas a FUCVAM (Federación Uruguaya de Cooperativas de Vivienda por Ayuda Mutua) o a FECOVI (Federación Cooperativa de Viviendas de Usuarios por Ahorro Previo).

Otra de las propuestas singulares ha sido el Programa "Morar no centro" en Recife (2002-2005). Este programa, promovido desde la 
Dirección de Programas Especiales del Ayuntamiento, en asociación con el Programa de Recualificación de Áreas Centrales de la Caixa Económica Federal, tenía como objetivos mejorar las condiciones habitacionales de los habitantes del $\mathrm{CH}$, atraer nuevos residentes, estimular la diversidad de usos y la conservación del patrimonio construido en áreas de valor histórico. Con respecto al mejoramiento de las condiciones habitacionales, se propuso un equipo técnico para la realización de reformas, con otorgamiento de créditos y subsidios, y la atracción de nuevos habitantes para el $\mathrm{CH}$. Los habitantes se mostraron interesados en la mejora de sus viviendas, pero por el grado de informalidad laboral, la mayoría no lograba cumplir con los requisitos solicitados por las instituciones bancarias para la financiación. Por otra parte, para atraer nuevos residentes, la Caixa Economica Federal promovía un "Programa de Alquiler Residencial" (PAR), otorgado a quienes poseían un ingreso familiar de 3 a 6 salarios mínimos. Se realizaron simulaciones financieras en 60 edificios del $\mathrm{CH}$, pero sólo uno llegó a concretarse, por la incompatibilidad entre los costos de reforma para adaptación del edificio al uso residencial y los ingresos por financimiento. La única experiencia concreta fue la adecuación del Edificio San José.

Finalmente, el gran despoblamiento y pérdida de vitalidad que paulatinamente está sufriendo el $\mathrm{CH}$ de San José de Costa Rica, ha llevado a incentivar medidas como la rehabilitación de edificios abandonados que sólo ocupan con usos la planta baja. Se promueven viviendas para funcionarios públicos que trabajan en el centro y que en la actualidad viajan por trabajo diariamente desde barrios periféricos, junto al desarrollo de otras actividades complementarias permanentes que aseguren un uso constante del espacio público.

Por otra parte, para fomentar la inserción socio-laboral, se han instituido principalmente en España y AL, Escuelas Taller de los CH. En España, en 1985 se ha creado el "Programa de Escuelas Taller y Casas de Oficios", que ha sido trasladado a AL a través de AECID por medio del Programa "Aprender Haciendo" (1991-2014), que ha alcanzado a numerosos $\mathrm{CH}$ latinoamericanos, fundándose en el año 2013 la "Red de Escuelas Taller de AL".

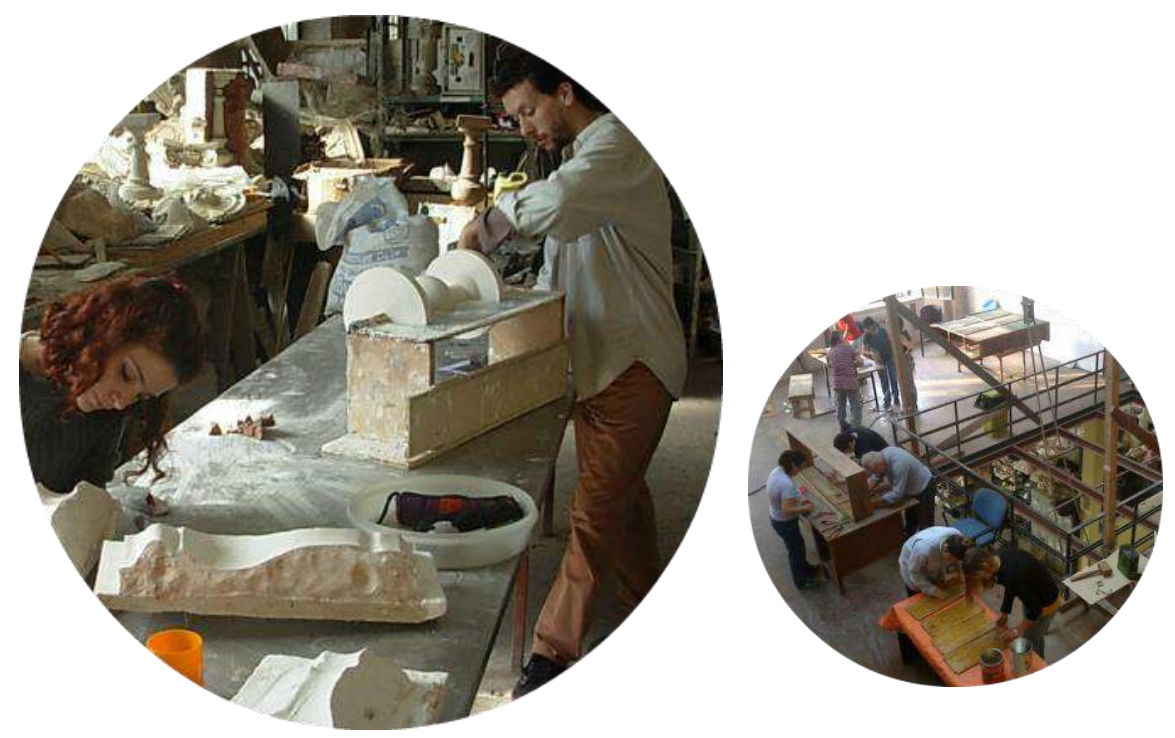


BOLONIA

1973 - Politica de vivienda social con alto porcentaje de vivienda de promoción pública, con el fin de mantener las clases sociales más desfavorecidas y desarrollar casas para obreros para frenar el despoblamiento REPOBLAMIENTO ESTRA
EINSTRU
PARA PR
EL PAT

\section{DESARROLLO SOCIO - CULTURAL}

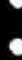

SANTIAGO DE CHILE 1990 - Plan de Repoblamiento de Santiago. Objetivo: densificar sectores urbanos y consolidar áreas centrales con pérdida de población. Recuperar y fortalecer el rol residencial beneficiando a personas sin vivienda con

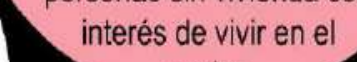

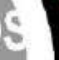

政

\section{A} ámbito residencial, denominadas XS urbanas, acarrean equipamientos infraestructuras para el sector

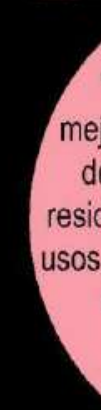
"Morar no centro". Obja mejorar condiciones habita de los habitantes del $\mathrm{CH}$, atraer residentes, estimular la diversidad de usos, y la conservación del patrimonio construido en áreas de valor histórico. Otorgamiento de créditos y subsidios.
EN ESPAÑA: 1985 - Programa de

Barcelona, Sevilla, Madrid, Gijón, Zaragoza

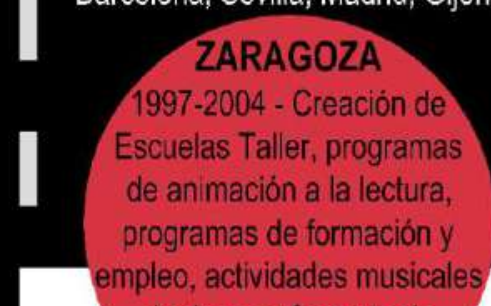

EN AL: Red AECID (1991-2014) Programa de Escuelas Taller "Aprender Haciendo":

La Habana, Cartagena, Antigua Guatemala Quito, Panamá, Ciudad de México, Santo Domingo, Salvador de Bahía, Asunción Lima, Santiago de Chile, Comayagua Red de Escuelas Taller de AL (2013) Otras en AL: Buenos Aires
VITORIA GASTEIZ̄ 1980 - Intervenciones para fijar la población residente y mantener y regenerar la composición del tejido social (PERI 1983-1988 / URBAN 2009-2014).

Propuesta de Plan de Vivienda Social y Oficina Municipal de vivienda para fomentar el alquiler de jóvenes
BOLONIA 973 - Conservación integra, o estructural (arquitectónica, espacial y social). Mantener clases sociales desfavorecidas, frenar despoblamiento, conservar artesania y comercios tipicos, incorporar equipamientos barriales promover el turismo (Piano de Edilizia Economica VITORIA GASTEIZ 1980 - Renovación de Popolare) infraestructuras urbanas, rehabilitación
y adecuación de edificios y viviendas manteniendo la morfologia urbana y 990 - Sistema de Cooperativas Viviendas para la recuperación bjetivo: fomentar el repoblamiento endiendo un hábitat policlasista integrado. La Intendencia facilita ceso a la tierra por me de licitaciones

\section{SAN JOSÉ DE} COSTA RICA

2015 - Rehabilitación de edificios abandonados con usos sólo en planta baja. Objetivos: promover viviendas para funcionarios públicos que trabajan en el $\mathrm{CH}$ y viven en la periferia, y desarrollar actividades complementarias permanentes que garanticen el uso espacio público.

\section{CARTAGENA}

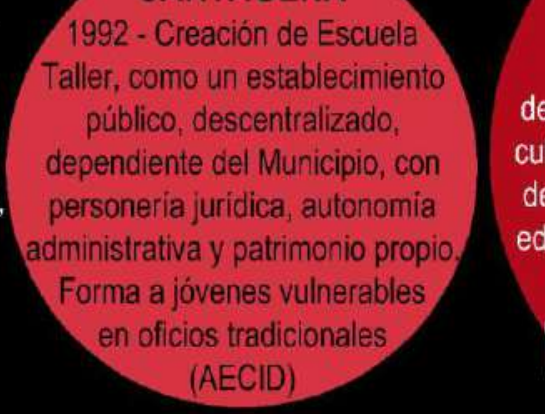

\section{DIMENSIÓN SOCIO - CULTURAL}




\subsection{Experiencias Integrales}

Un primer aspecto a mencionar, es que el análisis cuantitativo de las diversas problemáticas y las intervenciones realizadas en cada una de las dimensiones en los $\mathrm{CH}$, ha posibilitado el reconocimiento de Experiencias Integrales tanto en el contexto europeo como en el latinoamericano (Ver Figura IV.5c), porque han buscado más soluciones a las problemáticas que las han motivado.

Bolonia, ha pesar de adolecer para la mirada actual del abordaje de varios aspectos, para la época en que fue implementada resultó una propuesta mucho más integral e innovadora en relación a intervenciones coetáneas. Ha propuesto una conservación integral o estructural, mantener a las clases sociales más débiles, frenar el despoblamiento, conservar la artesanía y comercios típicos, incorporar equipamientos barriales y promover el turismo. En España, Vitoria Gasteiz destaca por la intención integral de intervenir su patrimonio construido (espacio público, viviendas, equipamientos, infraestructuras y accesibilidad), conservar y revalorizar el patrimonio histórico artístico, fijar la población residente, y mantener y regenerar la composición del tejido social. Barcelona por su parte, se constituye como otro de los casos integrales, con intervenciones sobre el espacio público y privado, las infraestructuras, el paisaje urbano y la identidad cultural, fortaleciendo la cohesión social, y las funciones residenciales, económicas, servicios, accesibilidad y movilidad. Las tres propuestas, se cimentan sobre una sólida base institucional de gestión pública y mixta.

En el contexto latinoamericano, las actuaciones en Quito y La Habana se presentan como casos significativos tanto desde su intervención como desde el desarrollo de instrumentos de gestión. Quito ha desarrollado intervenciones con el objetivo de concebir al $\mathrm{CH}$ como espacio urbano representativo e inductor de nuevas y calificadas funciones en otras áreas de la ciudad, y lograr la habitabilidad, accesibilidad y reactivación económica del $\mathrm{CH}$.

En el caso de La Habana, se han propuesto como objetivos renovar y revitalizar el $\mathrm{CH}$ y lograr la sostenibilidad cultural, medioambiental, social y económica. Para ello plantean mejorar las condiciones de vida de los más necesitados a través de programas de revitalización social y la restauración de edificios, desarrollar programas sociales y patrimoniales, favorecer la apertura económica y el desarrollo turístico. Con ejes en el suelo urbano y la economía local, la vivienda (edificios con altos niveles de hacinamiento y degradación), el equipamiento comunitario, el espacio público y las redes de infraestructura y medioambiente, pero principalmente en la cultura, la identidad y la justicia social. 
Un segundo aspecto a señalar es que el período de análisis ha sido contenedor de un gran número de intervenciones que han recibido constantes influencias entre Europa y AL, y que han encontrado en Bolonia nuevamente un referente para las actuaciones desarrolladas durante las décadas del 70 y 80 . España ha seguido a Bolonia en las primeras intervenciones del 80 , pero luego ha dado paso a intervenciones menos conservacionistas, con un enfoque más transformador que han llevado a desarrollar Planes significativos como el de Gijón, Vitoria Gasteiz, Alcoy, Málaga, Barcelona y Madrid. Dentro de ellos, el caso de Vitoria Gasteiz destaca también por ser precursor en la propuesta de rehabilitación integrada y por el proceso de gestión implementado. Estas experiencias europeas sin duda han influido en los modos de intervenir en $\mathrm{AL}$, que en las últimas décadas ha desarrollado numerosos Planes para los $\mathrm{CH}$, con casos singulares como: Panamá, Quito, La Habana, México, Lima y Montevideo, que seguramente también son objeto de análisis para las ciudades europeas.

Un tercer aspecto es que a excepción de algunos casos, la sostenibilidad integral continúa siendo un desafío. Dado que algunas problemáticas o fenómenos permanecen como retos por abordar o evitar, como la conservación de la población residente y las actividades económicas tradicionales, el repoblamiento, la gentrificación, la museificación derivada del turismo, el comercio informal, el deterioro del patrimonio construido con la siguiente ocupación de grupos sociales desfavorecidos y la proliferación de la drogadicción, la inseguridad y la violencia.

Por último, algunas estrategias siguen siendo eje de debates como el diálogo entre la nueva arquitectura y el patrimonio histórico construido. En el ámbito institucional, la gestión integral sigue requiriendo en muchos casos de la creación de instrumentos competentes y de convicción y continuidad política para alcanzar los objetivos propuestos. A su vez, las metas perseguidas en los Planes generalmente se enfrentan durante el proceso de implementación a situaciones o impactos no esperados, que modifican los resultados deseados.

Por ello, resulta conveniente repensar los modos de valorar, intervenir y gestionar estos valiosos sectores urbanos latinoamericanos, acorde a los más recientes planteamientos expresados tanto en el Memorándum de Viena (2005) como en las posteriores Recomendaciones elaboradas en 2011. En este sentido, la Parte 3 de la tesis que se desarrollará en las próximas páginas, presenta una propuesta que intenta responder a estas nuevas miradas. 


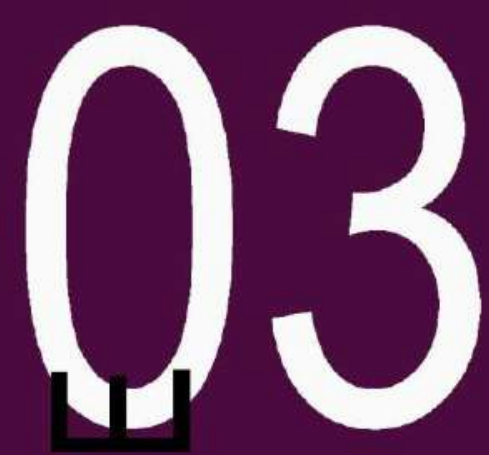

\section{Propuesta}

PROPUESTA METODOLÓGICA PARA LA VALORACIÓN, INTERVENCIÓN Y GESTIÓN DE PAISAJES URBANOS HISTÓRICOS

CONCLUSIONES GENERALES CIERRE Y APERTURA 


\section{PROPUESTA METODOLÓGICA}

Introducción

Proceso Metodológico Propuesto para la Valoración, Intervención y Gestión de Paisajes Urbanos Históricos Latinoamericanos

Objetivos

Propuesta de Valoración

Propuesta de Intervención

Propuesta de Gestión 


\subsection{Introducción}

Esta Parte 3, expone una propuesta metodológica diseñada como cierre de la tesis para contribuir en futuras posibles intervenciones en $\mathrm{CH}$ de $\mathrm{AL}$ como $\mathrm{PUH}$. El camino transitado a lo largo de las Partes 1 y 2 de este trabajo, ha permitido reunir todas las herramientas necesarias para esta elaboración.

Ha sido preciso retomar lo desarrollado hasta aquí para sintetizar lo teórico-conceptual bajo la perspectiva de los Paisajes Urbanos Históricos (PUH) y aportar en la construcción de la metodología para la valoración, intervención y gestión que incorpore aspectos físico-ambientales, socio-culturales, económicos e institucionales. Para que la ciudad pueda ser pensada como un todo y no como fragmentos, donde la identificación de paisajes degradados y con mayores necesidades en sus diversas dimensiones permita desarrollar propuestas de intervención y gestión que incorporen estrategias e instrumentos ya identificados, que aborden la multidimensionalidad de estas valiosas áreas históricas. Las mismas, se expresan a través del patrimonio, las funciones, el espacio público, junto a nuevas ideas que respondan a las especificidades del sitio y que contribuyan, promuevan y refuercen el sentido de pertenencia, identidad y participación ciudadana.
En este sentido, recuperando lo expuesto en los Capítulos 1 y 2 , este quinto capítulo pretende integrar, en el marco del Patrimonio Cultural Material e Inmaterial (Convención sobre la Protección del Patrimonio Mundial Cultural y Natural, 1972 - Convención para la salvaguarda del Patrimonio Cultural Inmaterial, 2003) con base en las dimensiones Institucional, Socio-cultural, Económica y Físicoambiental del desarrollo sostenible, los cuatro componentes claves para mantener la vitalidad del $\mathrm{CH}$ : la identidad y participación ciudadana, la multifuncionalidad con base en la residencialidad, y el espacio público. Ellos se asocian a las principales problemáticas a las que deben hacer frente, como grandes desafíos para alcanzar una intervención integral por medio de estrategias de intervención (Ver Figura V.1).

La integralidad de la propuesta, se basa en el abordaje del $\mathrm{CH}$ desde las cuatro dimensiones del desarrollo sostenible, al que el paisaje aporta la metodología para su mirada, en el marco de lo expuesto en el Convenio Europeo del Paisaje (2000), la Recomendación para la aplicación del Convenio (2008), el Memorándum de Viena (2005), y las Recomendación sobre el Paisaje Urbano Histórico, PUH (2011).

Estos aspectos, son los que guían el proceso metodológico propuesto para el tratamiento de la totalidad del PUH como una Unidad de Paisaje que constituye a su vez un Paisaje de Atención 
Especial (PAE). A modo operativo ha sido necesario recurrir a las definiciones brindadas por el Observatorio de Paisaje de Cataluña, que entiende a la "unidad de paisaje" como un "área del territorio con un carácter similar (de sus elementos naturales, culturales y visuales que propone configuran el paisaje), así como los más perceptivos y simbólicos"; y al "Paisaje de Atención Especial" (PAE), como "aquel espacio que tiene un carácter significativo en la región por su singularidad y/o complejidad territorial así como por estar sometido a dinámicas de transformación relevantes".

Para su abordaje, el proceso ha sido organizado en tres etapas consecutivas e interrelacionadas: Etapa de Gestión (A), Etapa de Valoración (B) y Etapa de Intervención (C) (Ver Figura V.2).

Por lo expuesto en el Capítulo 2, la Etapa de Gestión (A), resulta la más importante al momento de asegurar el alcance de las metas, por lo tanto, funciona como soporte de las otras dos Etapas. Considerando la definición de "gestión de paisajes" desarrollada en el punto 2.3.2.4 del Capítulo 2, esta etapa, se presenta acompañando y movilizando las distintas instancias del proceso metodológico, siendo necesaria su participación al inicio, en el transcurso y al final del proceso. Propone algunos instrumentos, herramientas y aspectos necesarios para llevar adelante las etapas B y C. La siguiente instancia del proceso, la Etapa B, propone valorar el $\mathrm{PUH}$, es decir, conocerlo en profundidad, diagnosticarlo, reconocer sus componentes, sus características, sus especificidades, evaluar e identificar sus conflictos, potencialidades y tendencias, siempre teniendo como meta su intervención, valorar para la acción. El conocimiento del territorio aportado en esta Etapa, sienta las bases para la tercera instancia correspondiente a la Etapa de Intervención (C). que propone brindar respuestas a las problemáticas reconocidas en el $\mathrm{PUH}$, mediante la redacción de objetivos de calidad paisajística, lineamientos y estrategias que puedan implementarse por medio de programas y proyectos, acorde a lo enfatizado en la Recomendación para la aplicación del Convenio Europeo de. Paisaje (2008). La misma, sostiene que "cada nivel administrativo (nacional, regional y local) está llamado a formular estrategias para el paisaje, específicas y/o sectoriales, dentro del marco de sus competencias. Éstas se apoyan en los medios e instituciones que, coordinados en el tiempo y en el espacio, permiten programar la puesta en práctica de la política. Las diferentes estrategias deberían estar vinculadas entre ellas por los objetivos de calidad paisajística".

Como fin de este proceso continuo, se retoma la Etapa de Gestión (A) que permite mediante la creación de instrumentos viabilizar las estrategias, y seguir el funcionamiento global del proceso. 


\section{LOS DESAFIOOS DE LA INTERVENCIÓN INTEGRAL DE LOS PUH}

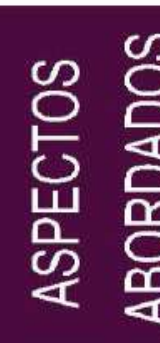

\section{DIMENSIONES \\ DEL \\ DESARROLLO \\ URBANO \\ SOSTENIBLE}

COMPONENTES

CLAVES PARA UN

CENTRO

HISTÓRICO VIVO
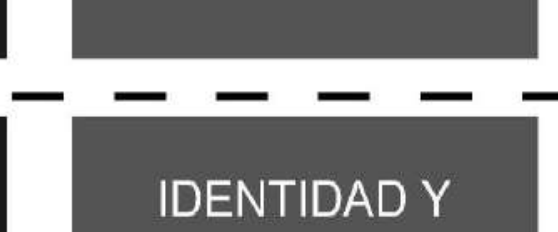

DIMENSIÓN INSTITUCIONAL

PARTICIPACIÓN
CIUDADANA

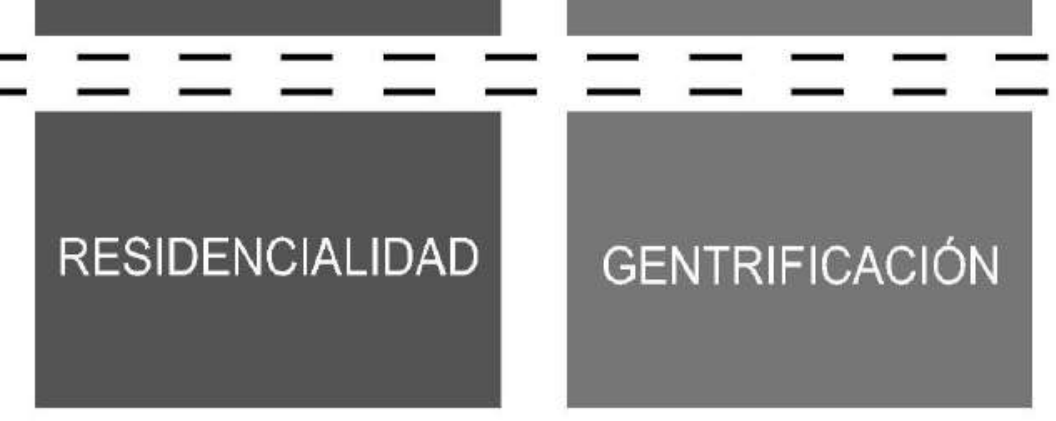

MULTIFUNCIONALIDAD
ECONÓMICA

DIMENSIÓN FÍSICO-AMBIENTAL
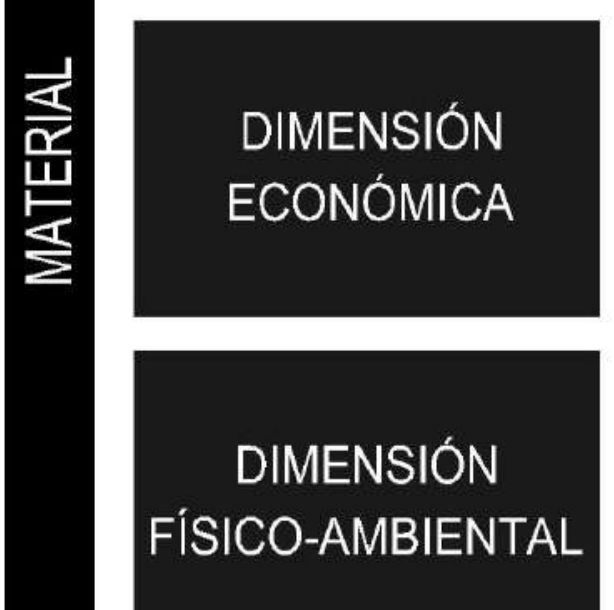
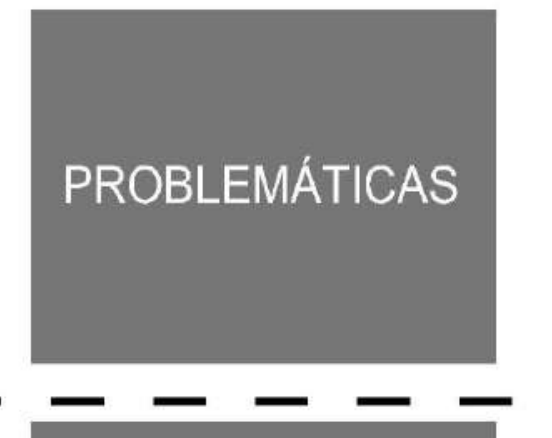

GESTIÓN

TURISMO /

COMERCIO

CALLEJERO

VACIAMIENTO

ESPACIO

PÚBLICO
FISICO-FUNCIONAL

/ ARTICULACIÓN NUEVO-ANTIGUO

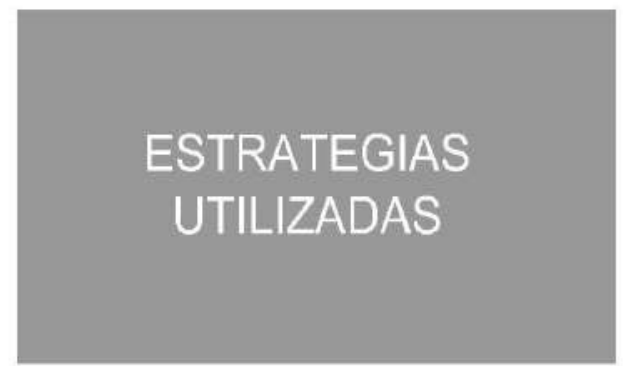

$-----1$

PARTICIPACIÓN

CIUDADANA EN LAS DECISIONES

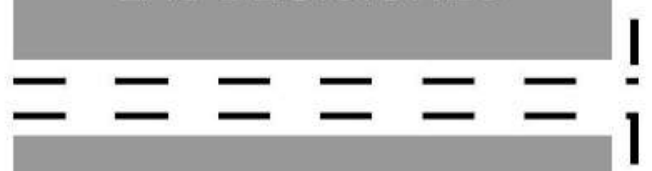

REHABILITACIÓN

DE VIVIENDAS /

FINANCIACIÓN

REFUNCIONALIZACIÓN

I EMPLEO PARA

LA POBLACIÓN

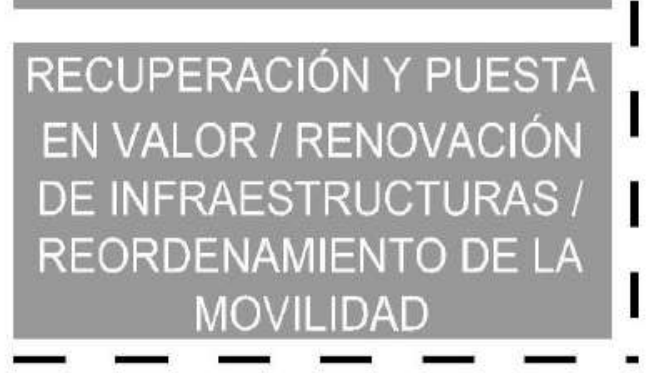




\subsection{Proceso metodológico propuesto para los} PUH latinoamericanos

\subsubsection{Objetivos}

La metodología que se presenta a continuación, intenta proveer un instrumento que permita valorar, intervenir y gestionar los $\mathrm{CH}$ de las ciudades latinoamericanas desde la perspectiva integral que brinda el Paisaje y puede oficializarse por los Municipios como Protocolo, con los ajustes acorde a cada $\mathrm{CH}$ El proceso propuesto, es aplicable a diversos $\mathrm{PUH}$ latinoamericanos que posean $\mathrm{O}$ no declaraciones de UNESCO, dado que se considera que toda ciudad posee $\mathrm{CH}$ de valor material y/o inmaterial para su población. Para ello, se ha pensado en un proceso continuo compuesto de ocho pasos sucesivos organizados en las tres instancias previamente mencionadas, A, B y C (Ver Figura V.2).

En este sentido, la metodología planteada aspira a alcanzar los siguientes objetivos:

1. Crear un organismo de gestión del PUH

2. Definir y analizar Componentes Primarios y Secundarios

3. Valorar el paisaje del PUH (Objetiva y Subjetivamente)

4. Elaborar una propuesta de intervención construida con la participación ciudadana
5. Crear los instrumentos de gestión necesarios para la implementación de la propuesta.

\subsubsection{Propuesta para la Gestión de PUH}

La gestión de un PUH requiere, en primer lugar, de la creación de un organismo específico para su manejo, que será el encargado de aplicar políticas de paisaje mediante la implementación de un Plan Especial para el $\mathrm{PUH}$, instrumento de planificación que deberá estar enmarcado dentro del Plan Urbano y Territorial para la ciudad.

Seguidamente, se detalla el paso 1 de la Instancia A de Gestión, que inicia el proceso metodológico (Ver Figura V.3):

\section{PASO 1: Creación de un organismo específico para el PUH}

La gestión de un PUH, con toda la particularidad que conlleva, resulta una tarea sumamente compleja que requiere de la creación de un instrumento de gestión, un ente especial, que pueda llevar adelante las instancias de valoración e intervención contenidas en el Plan Especial para el PUH. Para la propuesta de este organismo, han sido referentes entidades de gestión desarrolladas en $\mathrm{CH}$ de La Habana, Quito, México, Asunción, Montevideo, Turín y Vitoria. 


\section{PROCESO METODOLÓGICO PARA LOS PAISAJES URBANOS HISTÓRICOS (PUH) LATINOAMERICANOS}

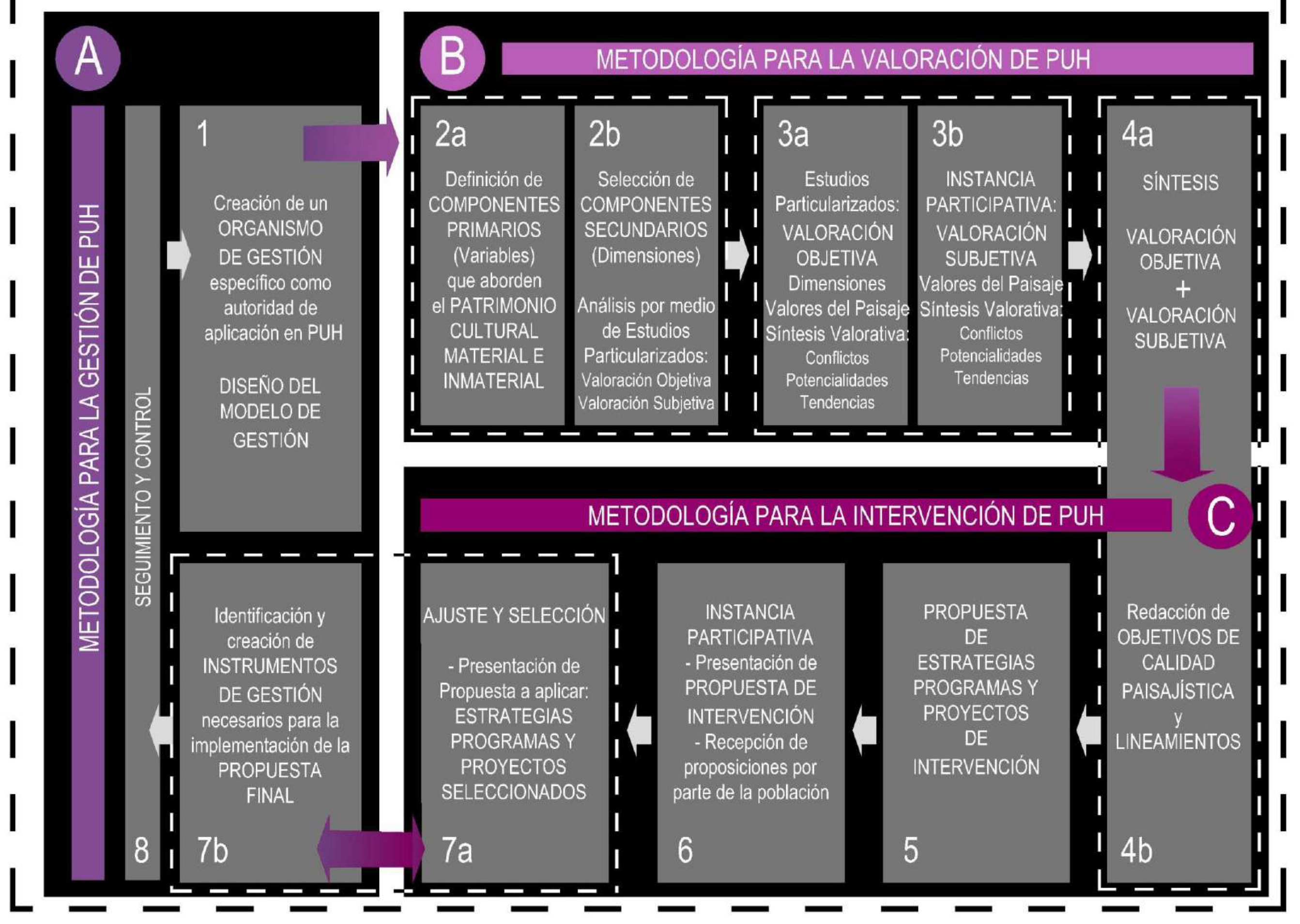


DE GESTIÓN autárquico, con

independencia

para tomar decisiones sobre el PUH

Mediador

entre actores

públicos y

privados que

intervienen

en el PUH

Diseñador e implementador del Plan Especial como instrumento de Planificación abierto, adaptable a las transformaciones del PUH, y receptor e impulsor de iniciativas ciudadanas.

Promotor de actualizaciones permanentes que garanticen su vigencia

Diseñar e implementar el Plan Especial y actuar como intermediario entre la gestión institucional y la ciudadanía

\section{REQUISITOS}

Marco Jurídico: Ordenanza (que le otorgue autarquia, en el marco de la estructura Municipal)
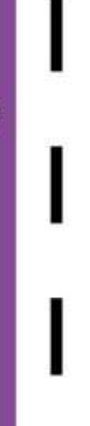

PÚBLICOS (del sector público / del organismo / actor

actores externos) / PRIVADOS (Residentes, empresas, comerciantes, profesonales)

PARTICIPACIÓN CIUDADANA

Uno de los pilares del organismo. Apertura de diversos canales de comunicación para que la población sea participe

\section{FINANCIAMIENTO}

Independencia financiera del Municipio. Instrumento: Fideicomiso. Fuentes de financiamiento: ingresos propios y préstamos
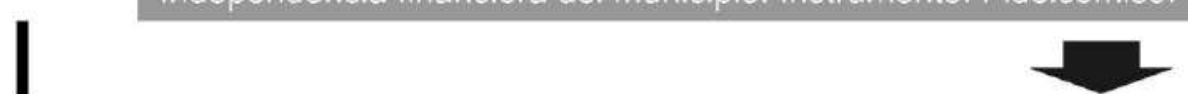

I
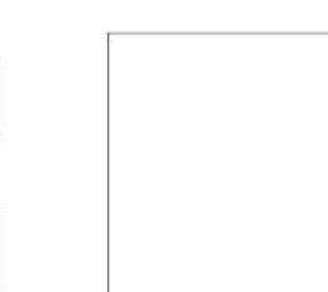

ORGANIGRAMA TENTATIVO DEL ORGANISMO DE GESTIÓN DEL PUH
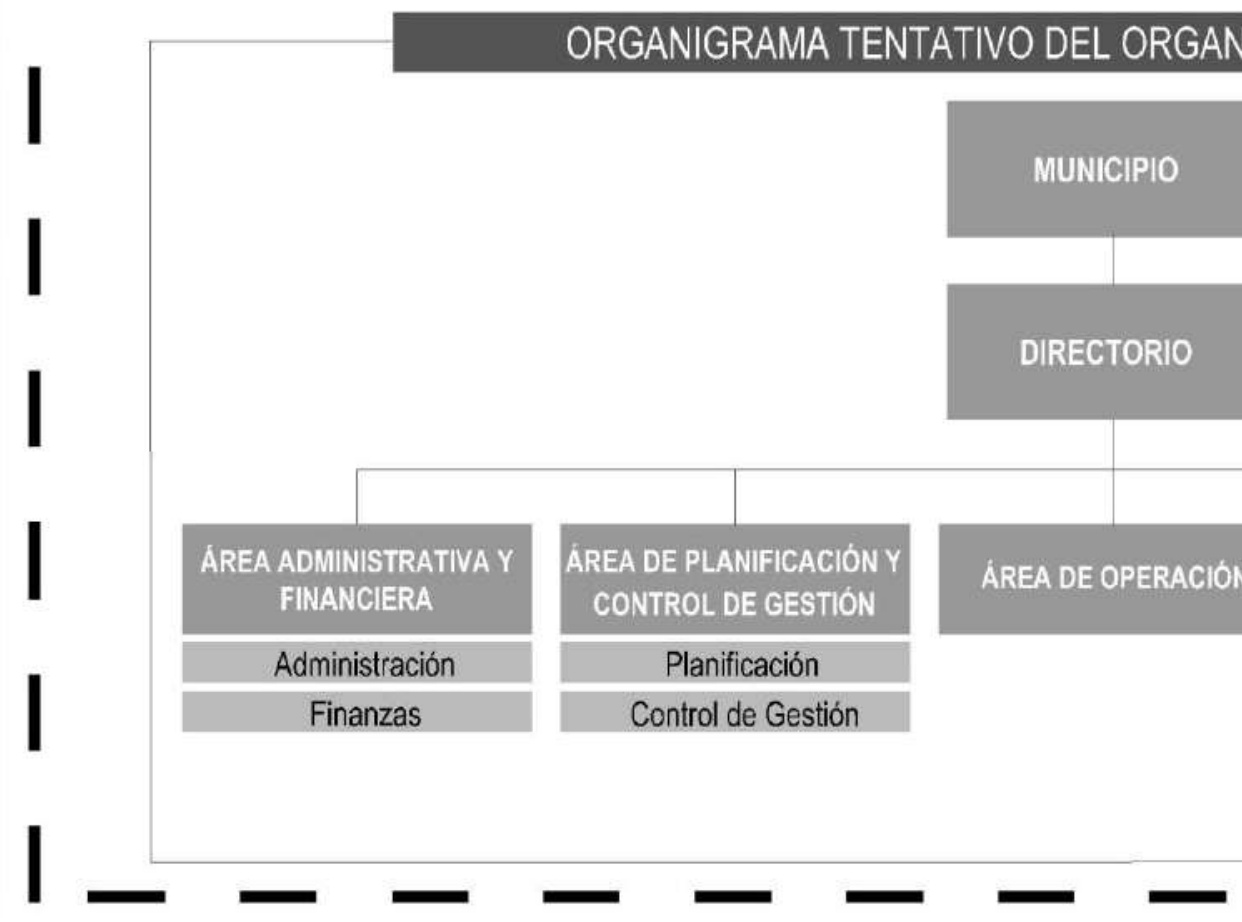
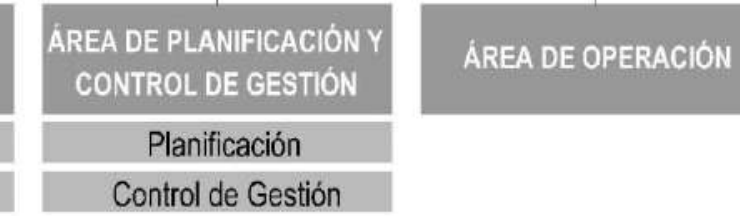

Administración

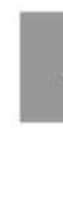

AREA DE OPERACION
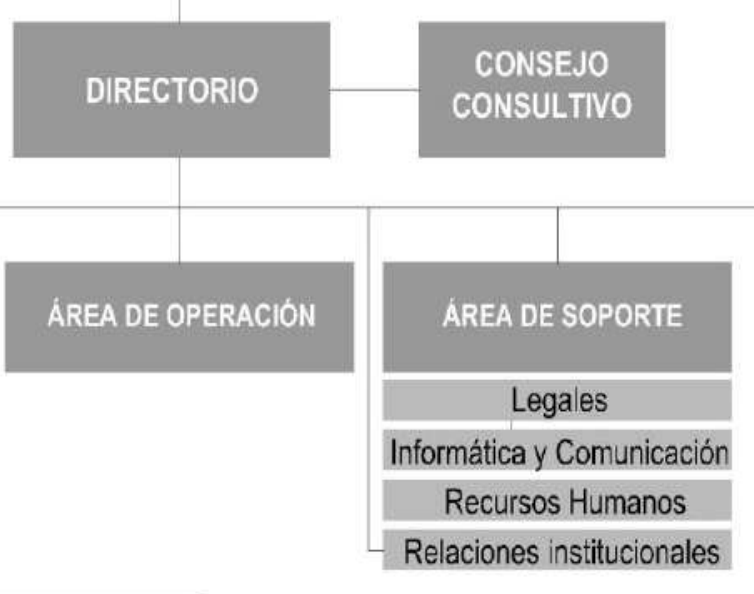

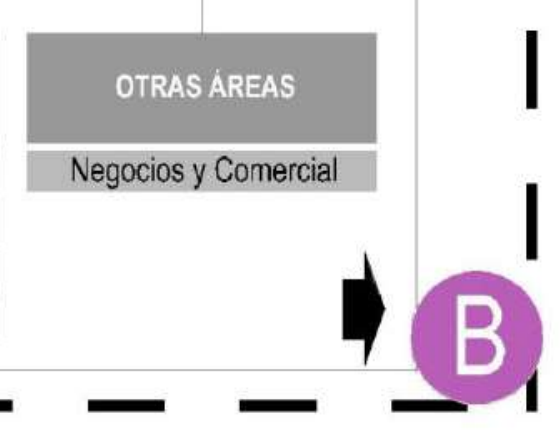




\section{¿Cuál es el objetivo principal de este organismo?}

Este organismo, es el encargado de diseñar e implementar el Plan Especial, que perseguirá la intervención del PUH, y actuar como intermediario entre la gestión institucional y la ciudadanía. Esta ultima resulta un elemento indispensable para la efectividad del organismo. El organismo de gestión, funciona a su vez, como mediador fundamental entre los distintos actores públicos y privados que intervienen en el PUH.

El Plan representa un instrumento abierto, adaptable a las transformaciones que se originen en el PUH como resultado de su dinámica habitual, o influidos por la implementación de acciones promovidas desde el Plan, y receptor e impulsor de iniciativas ciudadanas. Se pretende que este organismo logre la ejecución del Plan, llevando a cabo las acciones previstas con los resultados esperados y consiga continuidad y sostenibilidad política y económica, realizando ajustes y actualizaciones permanentes al instrumento, que garanticen su vigencia.

\section{¿Cuáles son los requisitos para su creación?}

Este organismo, que funciona como administrador específico que ejecuta acciones en el contexto de la estructura Municipal, demanda la existencia de un marco jurídico. Una ordenanza que le otorgue autarquía, para poder tomar decisiones independientemente sobre el PUH. Esta ordenanza debe:

- Delimitar el Área del PUH sobre la que deberá actuar el organismo, considerada Paisaje de Atención especial (PAE).

- Crear el organismo de Gestión del PUH

- Definir sus instrucciones y alcances

- Otorgarle autonomía financiera

- Establecer el marco de las asociaciones público-privadas

\section{¿Cuáles son los instrumentos necesarios?}

Para el funcionamiento del organismo, se prevé la creación de una serie de instrumentos operacionales:

- Legales (Paisaje Urbano Histórico-PUH, Paisaje de Atención Especial-PAE)

- de Planificación (Plan Especial)

- de Participación (Consulta Pública)

\section{¿Qué actores intervienen?}

El organismo de gestión es el responsable de desarrollar la compleja tarea de articular y generar alianzas entre los distintos actores que participan del PUH, que como se ha visto previamente, en varias ocasiones presentan intereses encontrados:

ACTORES PÚBLICOS:

Desde el Sector Público: municipio, gobierno provincial y nacional 
(con sus ministerios de competencia), legislatura y parlamento, empresas y entes públicos.

Al interior del organismo: especialistas en planificación, ejecución, finanzas, administración, comunicación, legal e informática, con equipos multidisciplinarios que abarcan profesionales desde el área del urbanismo, la arquitectura, ingeniería, economía, sociología, política, abogacía, ciencias de la comunicación y tecnología.

Como actores externos: equipos técnicos del área de investigación y docencia de las Universidades; profesionales de Colegios de arquitectos, ingenieros, abogados; ONGs de patrimonio, ecologistas; organismos internacionales de crédito; y población general interesada en participar del proceso.

ACTORES PRIVADOS:

Residentes actuales y potenciales: tanto propietarios como inquilinos.

Empresas: interesadas en desarrollar proyectos en el PUH,

Comerciantes: que desarrollen actividades en el PUH

Profesionales: que desempeñen su actividad en forma independiente en el PUH

Empleados de Empresas y Comercios: que desarrollan su actividad laboral dentro del PUH

\section{¿Qué rol juega la participación ciudadana?}

La participación ciudadana constituye uno de los pilares de este organismo, ofreciéndose para ello la apertura de diversos canales de comunicación con la sociedad que podrá acercarse para ser parte de la transformación del PUH mediante su participación a través de plataformas interactivas y virtuales (Facebook, instagram, página WEB, aplicativo para teléfonos móviles), desarrolladas por el Área de informática; de comunicación, por medio de whatsapp o vía e-mail; o físicamente en el edificio institucional que funcione en alguna estructura en desuso del PUH También podría implementarse una especie de oficina móvil que recorra distintas áreas del PUH para un mayor acercamiento con la población.

A su vez, en la implementación del Plan, se brindará la posibilidad de contribución mediante la apertura de instancias participativas en las diferentes etapas del proceso, como encuestas públicas, Talleres de intercambio de Paisaje, Talleres infantiles de Paisaje, y reuniones a desarrollarse durante el periodo de Consulta Pública que se detallará más adelante en las Etapas de Valoración e Intervención.

\section{¿Cómo se piensa su financiamiento?}

Para obtener la independencia financiera del Municipio, un instrumento a emplear podría ser un fideicomiso que podría recibir como fuentes de financiamiento, ingresos propios recaudados mediante el cobro de tasas a agentes económicos que participan en el PUH (actores comerciales gastronómicos, hoteleros, textiles, 
de electrodomésticos, entre otros) o de servicios que se brinden. $\mathrm{A}$ su vez, podría recibir aportes por medio de préstamos internacionales (por ejemplo del BID, CAF, Banco Mundial, AECID, Junta de Andalucía), o nacionales (Estado Nacional, Provincial, Municipal, bancos privados y públicos). Siendo el mismo organismo de gestión del PUH el encargado de generar los ingresos para la devolución de los préstamos.

Podría considerarse a su vez, la opción de un sistema de cooperación público-privada, donde este organismo estatal permita la participación de diversos actores privados, que acepten las condiciones establecidas por el organismo, para el desarrollo de proyectos, que en el caso latinoamericano resultan muy difíciles de llevar adelante por los escasos recursos con que cuentan los Estados, dado que son países de ingresos y riqueza económica media o baja.

En el largo plazo, los ingresos propios, debieran permitir la gestión autosostenible, llegando a un superávit económico o en su defecto a la ausencia de déficit.

\section{¿Cómo sería la estructura de este organismo?}

El organismo requiere para su implementación de una estructura organizacional clara que determine las funciones principales que deben llevar adelante cada una de las distintas áreas que conforman el organigrama y como mínimo se recomienda que debiera tener:

\section{Directorio y Consejo Consultivo}

Los objetivos que guían la estructura de gestión son seguidos bajo la responsabilidad de una Dirección General que imparte las directivas a seguir, y evalúa los resultados, bajo la presidencia política del gobierno local.

El Consejo Consultivo debe tener representantes del PUH. Entre ellos, se recomienda residentes, tanto propietarios como inquilinos, ya que poseen necesidades distintas, comerciantes, ONGs de Patrimonio y ONGs ecologistas. Su función sería emitir dictámenes vinculantes al Directorio General a los proyectos que desee desarrollar el Directorio del organismo.

\section{Área de Planificación y Control de Gestión}

La sub-área de Planificación, es la encargada de desarrollar el Plan especial, llevando adelante las estrategias mediante programas y proyectos. Así como desarrollar normas, procesos, procedimientos y cronogramas de trabajo (con la participación del Área de Operación) que serán elevados al Directorio para su aprobación y la del Consejo Consultivo.

La sub-área de Control de Gestión, es la encargada de verificar el avance de los proyectos que se ejecuten de acuerdo a los objetivos 
planteados, y de controlar los impactos de los mismos.

\section{Área de Operación}

Esta área es la encargada de llevar a cabo la ejecución del Plan, sus estrategias, programas y proyectos de acuerdo a la planificación, realizando al unísono un seguimiento de su avance para dar cumplimiento a las instrucciones dada por el Directorio.

\section{Área Administrativa y Financiera}

La sub-área de Administración debe estar encargada de la recaudación de ingresos, pago de sueldos, a proveedores, y de los procesos de compras, impuestos y administración del organismo

La sub-área Financiera debe conseguir las fuentes de financiamiento para el funcionamiento del organismo en caso de que los ingresos genuinos del organismo no alcancen a cubrir el funcionamiento del mismo.

\section{Área de Soporte}

Para el funcionamiento de esta estructura, es necesario también la implementación de sub-áreas de soporte. La Sub-Área de Legales, destinada a la elaboración de instrumentos de gestión particularesque se detallan al final del proceso- y normativa específica para llevar adelante las estrategias de intervención. La Sub-Área de Informática y Comunicación, dedicada a la creación de una plataforma interactiva del PUH para la difusión y participación de la población en las actividades del mismo; al funcionamiento de una revista digital que realice publicaciones resultado de investigaciones de especialistas del $\mathrm{PUH}$; y colabore en otras tareas técnicas inherentes al funcionamiento del organismo. La Sub-Área de Recursos Humanos para la administración del personal; y la Sub-Área de Relaciones Institucionales, que desempeña un papel muy importante dentro de la estructura, dada la alta interacción entre las distintas partes que plantea este organismo. Esta ultima, incluso podría depender directamente del Directorio.

\section{Otras Áreas}

Por último, es posible que para algunos PUH resulte necesaria un Área o Sub Área de Negocios y Comercial, en caso de que el organismo tenga la capacidad o facultad de ofrecer servicios y deba comercializarlos. Por ejemplo, ofrecer créditos hipotecarios para inquilinos residentes del $\mathrm{PUH}$, asesoramiento y/o dirección de cooperativas de trabajo, agencias de turismo o inmobiliarias. Pueden ser servicios que se brinden paralelamente a la ejecución de los planes, programas y proyectos y que necesitan una estructura independiente al Área de Operación

Una vez creado el organismo de gestión que brinda el marco para intervenir el PUH, es posible avanzar hacia la Etapa de Valoración del PUH que se desarrolla en el siguiente apartado. 


\subsubsection{Propuesta para la Valoración de PUH}

La instancia B del proceso metodológico (Ver Figura V.4), se asocia con el desarrollo del Capitulo 1, que ha permitido reconocer que esta Unidad de Paisaje (PUH), está compuesta por un Patrimonio Material e Inmaterial, cuyos elementos constitutivos han sido citados previamente en el punto 1.4.1 del mismo capítulo. De este Patrimonio, ha sido posible identificar Componentes Primarios (Variables), como el Espacio Público, la Multifuncionalidad y la Identidad y Participación ciudadana (profundizados también en el Capítulo 1) y Componentes Secundarios (Dimensiones) que se definirán y ahondarán en este Capítulo, en base a lo indagado anteriormente. Estos componentes serán analizados por medio de estudios particularizados que posibilitarán obtener una Valoración Integral del objeto de estudio (PUH), compuesta por una valoración Objetiva y Subjetiva. La valoración Objetiva se entiende como la mirada del paisaje desde el análisis de sus componentes, desarrollado por un equipo técnico-científico multidisciplinario. Por su parte, la valoración Subjetiva representa la mirada del paisaje desde la perspectiva de observadores frecuentes. Ambas valoraciones atravesarán cuatro momentos de análisis de cada componente con miras a la búsqueda del Desarrollo Urbano Sostenible. Estos momentos corresponden a las dimensiones planteadas en el Capítulo 2: Dimensión Físico-ambiental, Dimensión Socio-cultural, Dimensión Económica y Dimensión Institucional. Este análisis por dimensiones se plasmará y articulará en cartografía síntesis por componente secundario, primario e integral de todo el PUH.

De cada Componente Secundario se reconocerán también los Valores del Paisaje, que permitirán identificar áreas de valor excepcional, ordinario o degradado (Convenio Europeo del Paisaje, 2000). Posteriormente, se procederá a la síntesis valorativa, mediante la identificación de conflictos, potencialidades y tendencias que guiarán la futura intervención.

En las siguientes páginas se presentan un esquema síntesis de la metodología de valoración, y la etapa detallada paso a paso $\begin{array}{llll}\text { (Figuras } & \text { V.4 } & \text { y } & \text { V.5). }\end{array}$ 


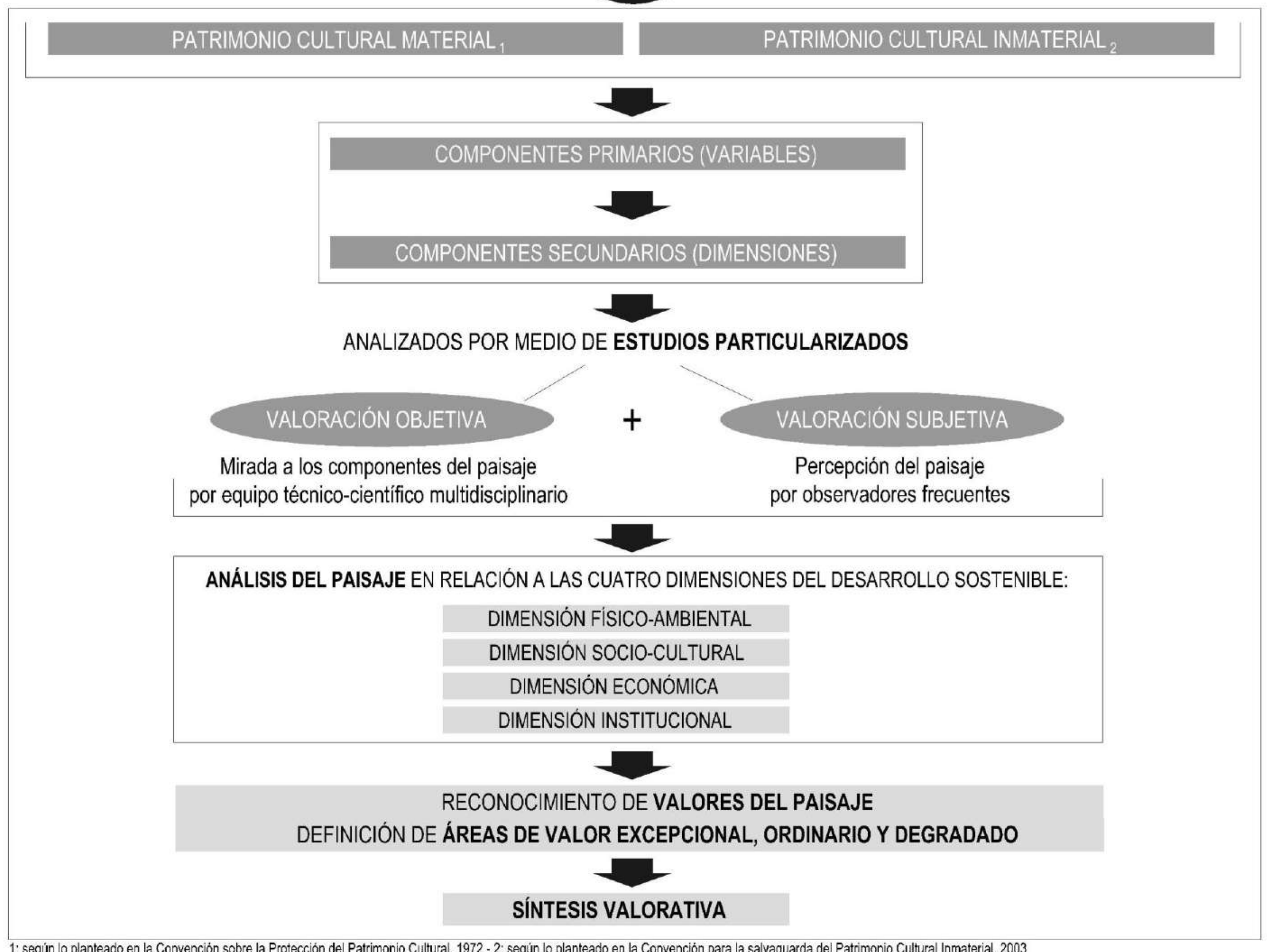



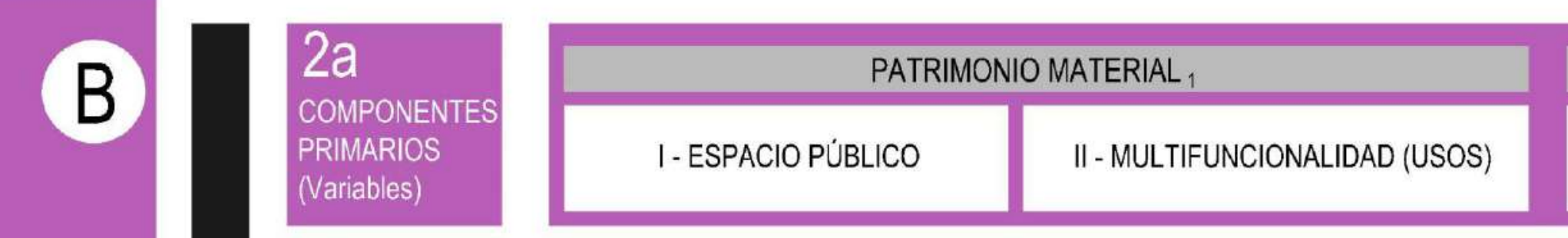

PATRIMONIO INMATERIAL 2
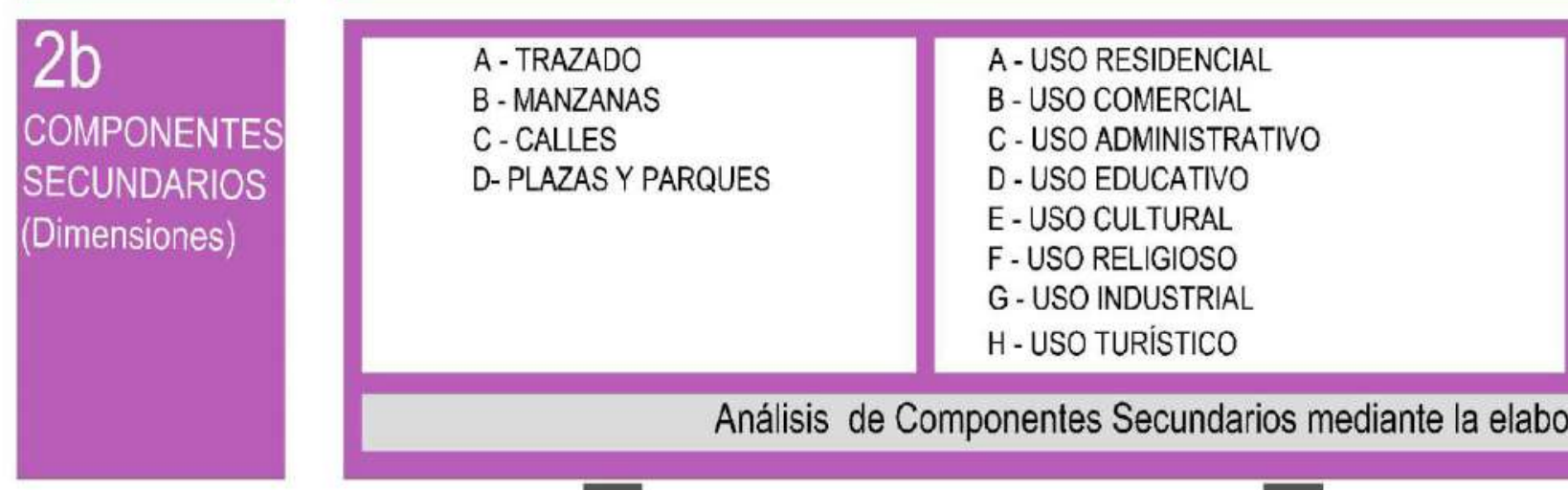

III- IDENTIDAD Y PARTICIPACIÓN CIUDADANA
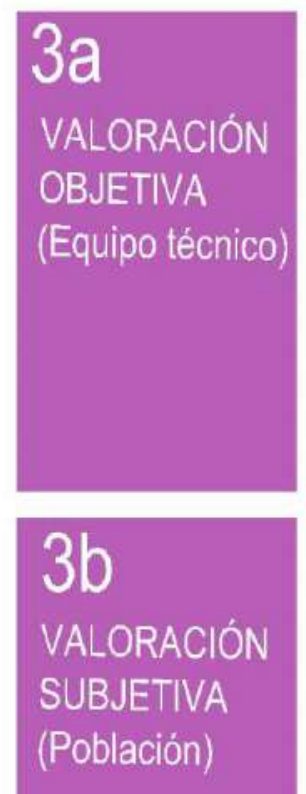

Análisis de Componentes Secundario
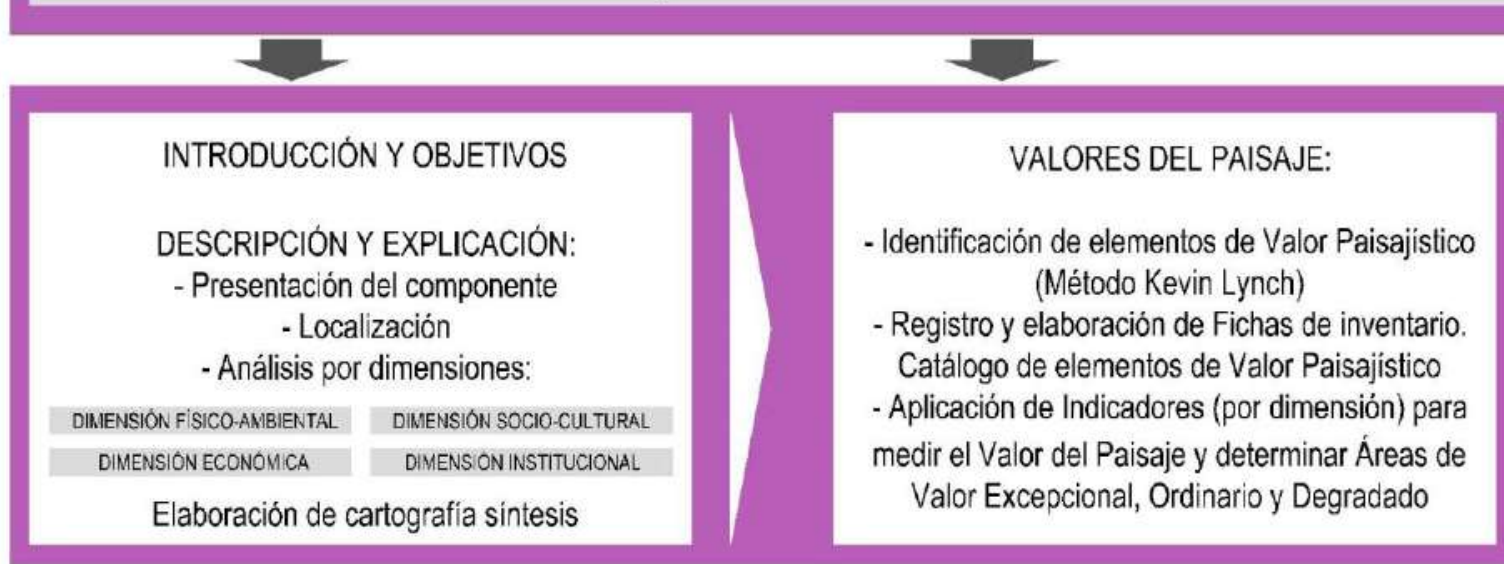
A - MANIFESTACIONES SOCIO-CULTURALES
B - MEMORIA

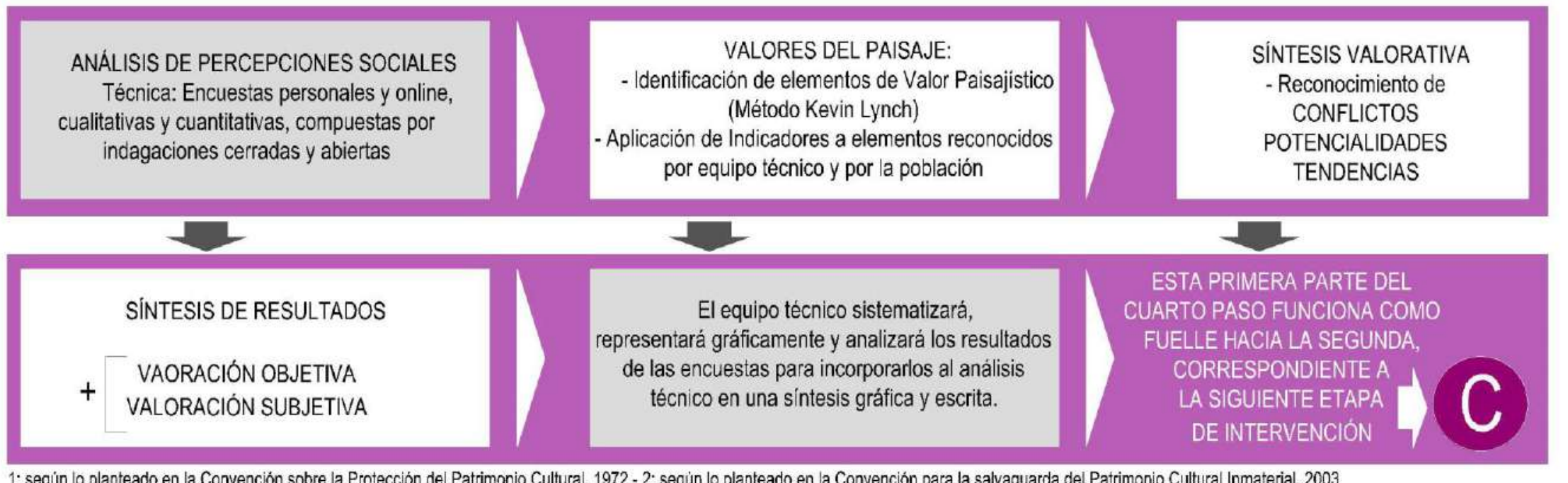


La metodología de valoración propuesta, como se ha expresado previamente y como se ha expuesto en la Figura V.5, se organiza en tres pasos sucesivos ( 2 a 4 ) que se profundizan a continuación.

\section{PASO 2a: Definición de Componentes Primarios (Variables)}

Considerando la constitución de los PUH por un importante Patrimonio Material e Inmaterial, y recuperando lo analizado en el Capítulo 2, se ha podido establecer, (para facilitar el estudio del $\mathrm{PUH}$ ), como Componentes Primarios del Patrimonio Material al Espacio Público y la Multifuncionalidad, y como Componente Primario del Patrimonio Inmaterial a la Identidad y Participación Ciudadana. Estos tres componentes primarios se encuentran en constante interacción, pero para simplificar el diagnóstico, se presentan por separado brindando una mirada del paisaje más enfocada en los aspectos materiales del espacio público y la multifuncionalidad para valorar el Patrimonio Material, y una mirada al paisaje centrada desde la apropiación de esos espacios y actividades, para valorar el Patrimonio Inmaterial.

EI ESPACIO PÚBLICO ha sido el primero de los Componentes Primarios en ser definido por constituir el espacio integrador por excelencia. En él confluyen todas las actividades del $\mathrm{CH}$, por lo tanto vincula toda la estructura material que les da soporte con la componente social que aporta la vitalidad.

En este complejo sistema urbano, la MULTIFUNCIONALIDAD es clave para la subsistencia de estas áreas, y en ese sentido este
Componente se desagrega en todas aquellas funciones, usos fundamentales de un $\mathrm{PUH}$, con miras a valorar el patrimonio material indispensable para los mismos, que se especifican en el siguiente Paso.

Por su parte, el Componente Primario del Patrimonio Inmaterial, la IDENTIDAD Y PARTICIPACIÓN CIUDADANA, resulta un Componente esencial. Sin la presencia de la población que reside, trabaja, transita, estudia, recorre y genera relaciones en los PUH, estos sectores pierden jerarquía dentro de las ciudades y lejos de valorizarse se configuran como áreas degradadas.

Para profundizar el estudio, cada Componente Primario ha sido desagregado en Componentes Secundarios. La síntesis de resultados obtenidos en cada uno de estos componentes brindará una mirada integral del PUH (Ver Figura V.6).

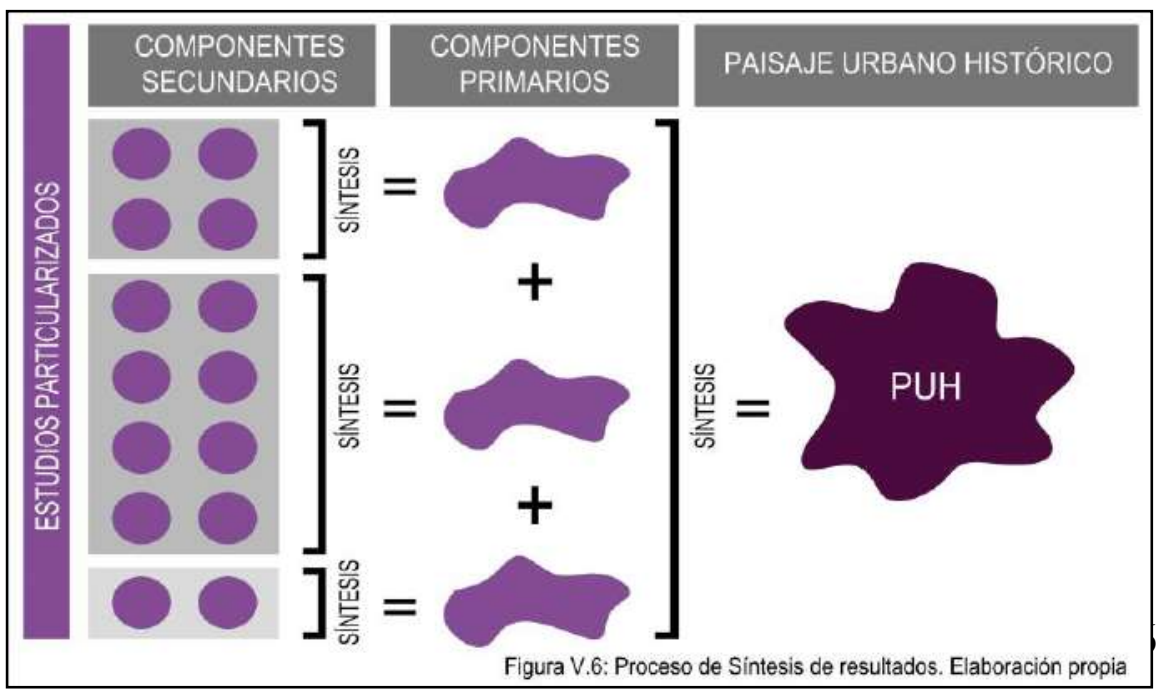


PASO 2b: Selección de Componentes Secundarios (Dimensiones)

Los Componentes Secundarios a analizar, gestores de diversos paisajes, han sido seleccionados teniendo como base lo profundizado en el Capítulo 1 sobre los componentes claves para un $\mathrm{CH}$ vivo. Partiendo de allí, se han elegido a los siguientes:

\section{DEL ESPACIO PÚBLICO:}

- Trazado: disposición de los diferentes elementos urbanos, y la delimitación de lo público y privado. Trama vial, manzanas, bloques, hitos urbanos, espacios verdes.

- Manzanas: diferentes tipologías, el tejido-que caracteriza la edificación, implantación, estado, tipología, valor patrimonial y económico-; la subdivisión-cómo se divide el territorio-; y la ocupación-apropiación del espacio para el desarrollo de actividades (ocupado o vacante).

- Calles: características de las vías, jerarquías, intensidades y tipos de uso, accesibilidad y transporte.

- Plazas y Parques: características, funciones que ofrece, áreas verdes y secas, y apropiación ciudadana.

\section{DE LA MULTIFUNCIONALIDAD:}

Se analizarán los espacios físicos destinados al desarrollo de las actividades. Las características edilicias, arquitectónicas, arqueológicas, históricas-patrimoniales, la intensidad funcional, y la calidad de cada uno de los usos del PUH:

- Uso Residencial

- Uso Comercial

- Uso Administrativo

- Uso Educativo

- Uso Cultural

- Uso Religioso

- Uso Industrial

- Uso Turístico

\section{DE LA IDENTIDAD Y PARTICIPACIÓN CIUDADANA:}

- Manifestaciones socio-culturales: Se hará hincapié en el estudio de todos aquellos aspectos que contribuyan a la identidad de una comunidad y propicien la participación ciudadana incidiendo sobre el paisaje: tradiciones populares (musicales, deportivas, de la vestimenta, rituales); costumbres populares (gastronómicas, lingüísticas, históricas, religiosas, etnográficas, folclóricas), ceremonias y festividades religiosas, manifestaciones artísticas (artesanía, arte urbano, efímero) y festividades populares (laicas y paganas).

- Memoria: Se reconocerán los acontecimientos y los espacios físicos destinados al fortalecimiento de la memoria 
ciudadana, como las conmemoraciones, los mausoleos, y los sitios de memoria.

Para la descripción y explicación de cada uno de estos Componentes Secundarios, se propone la elaboración de Estudios Particularizados tomando la idea de los estudios sugeridos para la gestión del PUH en Ciudades Patrimonio Mundial ${ }^{1}$. Los estudios propuestos, como se ha mencionado en páginas previas, están compuestos de dos pasos complementarios: un primero de Valoración Objetiva (Paso 3a) y un segundo de Valoración Subjetiva (Paso 3b) explicados a continuación y sintetizados en la Figura V.9: Diseño de estructura para la elaboración de Estudio Particularizado.

\section{PASO 3a: Valoración Objetiva de Componentes Secundarios}

La Valoración Objetiva, que estrictamente nunca llega a ser completamente objetiva porque resulta imposible separar cierta subjetividad del observador, se denomina de este modo porque es la elaborada por un equipo técnico-científico multidisciplinario (arquitectos, sociólogos, geógrafos, economistas, arqueólogos,

\footnotetext{
${ }^{1}$ FERNÁNDEZ BACCA-CASARES, Román et al. (2011); "La gestión del paisaje histórico urbano en Ciudades Patrimonio Mundial. Metodología de análisis, seguimiento y evaluación". En El paisaje histórico urbano en las ciudades Patrimonio mundial. Indicadores para su conservación y gestión II. Criterios, metodologías y estudios aplicados.
}

ecólogos, entre otros). La misma, se estructura en el estudio que contiene:

1- Introducción y Objetivos: donde se expone el componente de análisis, y el objetivo general y específicos del estudio.

2- Descripción y explicación: que cuenta con un apartado donde se presenta el Componente Secundario de estudio, se realiza una delimitación conceptual, y se plantea la relación con el Componente Primario. Luego se enseña su localización y se inicia la parte central del estudio que corresponde a la Descripción y Análisis del Componente. Este análisis se desagrega en cuatro dimensiones del Desarrollo Sostenible que ahondan en aspectos centrales del PUH identificados en los Capítulos 1 y 2 :

- Físico-ambiental: esta dimensión profundiza en los aspectos naturales y ecológicos presentes en el paisaje de cada componente, y en los aspectos materiales del mismo. El estado de conservación del paisaje, su ocupación, apropiación, relevancia, singularidad, diversidad, estética, y capacidad de transmitir procesos de transformación a los que han sido sometidos.

- Socio cultural: se enfatiza en los aspectos socioculturales del componente, en los paisajes apropiados por la población para el desarrollo de actividades recreativas, culturales o asociadas a la memoria. 
- Económica: se reconocen los aspectos económicos del componente, recursos paisajísticos, que permiten generan beneficios económicos.

- Institucional: se destacan las tareas de gestión llevadas a cabo desde organismos públicos o privados, para el financiamiento e intervención con miras al mantenimiento y desarrollo del componente, así como la existencia de ordenanzas y normas.

Para cada una de estas Dimensiones se elabora cartografía que luego se integra en un esquema síntesis por Componente Secundario, que al superponerse con los otros Componentes, permite obtener la cartografía síntesis del Componente Primario e Integral del PUH.

\section{Valores del Paisaje}

El siguiente punto de la Valoración Objetiva, consiste en el reconocimiento de los Valores del Paisaje, que adquieren considerable importancia al momento de planificar un PUH. De cada uno de los Componentes se identificarán y valorarán aquellos elementos del paisaje que destaquen por alguna característica particular que le asigne un determinado valor que facilite o dificulte su sostenibilidad dentro del PUH. Para su reconocimiento se aplica la metodología de Kevin Lynch, de percibir el paisaje desde sus elementos, como sendas bordes, barrios, nodos y mojones Estos elementos, serán registrados mediante "fichas de inventario", instrumento del patrimonio, que formará luego parte de un catálogo.

\section{Delimitación de Áreas de Valor Excepcional, Ordinario y Degradado}

Posteriormente, a los elementos identificados como Valores del Paisaje, se le aplicarán indicadores. Los mismos, han surgido del análisis previo realizado, y permitirán evaluar aspectos de las cuatro dimensiones. Esto facilitará la delimitación de Áreas de Valor Excepcional, Ordinario o Degradado (Ver Figura V.7), según la clasificación brindada por el Convenio Europeo del Paisaje (2000).

A continuación se exhibe la Tabla V.1 donde se enumeran los doce indicadores propuestos para la delimitación de las Áreas:

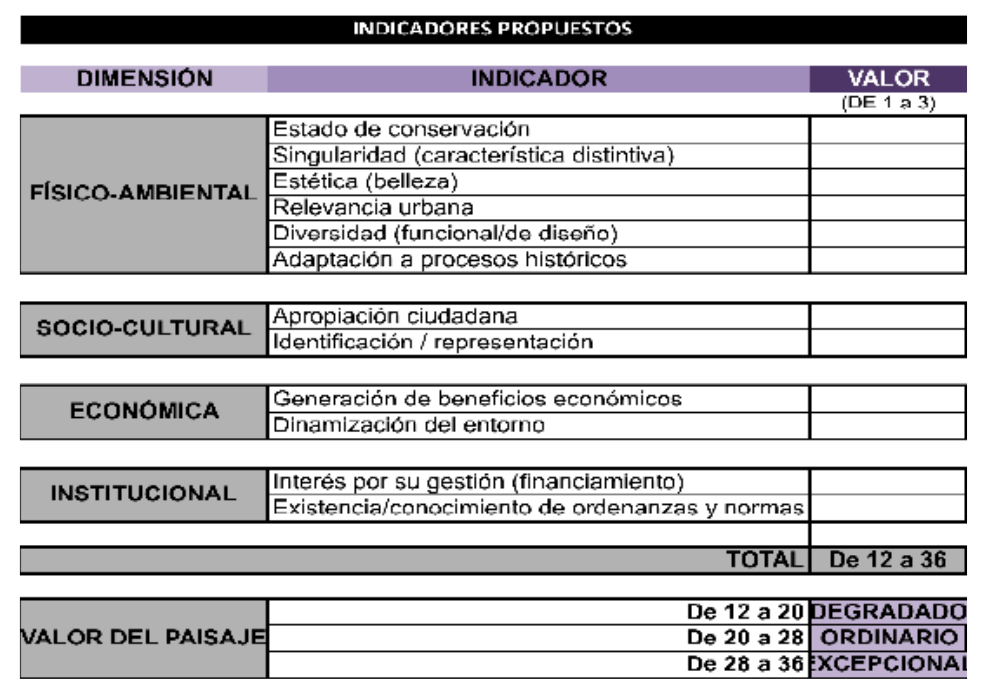

Tabla V.1: Indicadores propuestos para medir el valor del paisaje 
A cada indicador se le asignará un valor de 1 a 3 , siendo 1 el valor mínimo y 3 el puntaje máximo para evaluar el Valor del Paisaje. La sumatoria de los puntos obtenidos en cada indicador dará un valor

total que oscilará entre 12 y 36 , y la integración de los resultados de los distintos componentes del PUH permitirá definir Áreas de Valor:

Degradado: De 12 a 20 puntos

Ordinario: De 21 a 28 puntos

Excepcional: De 29 a 36 puntos

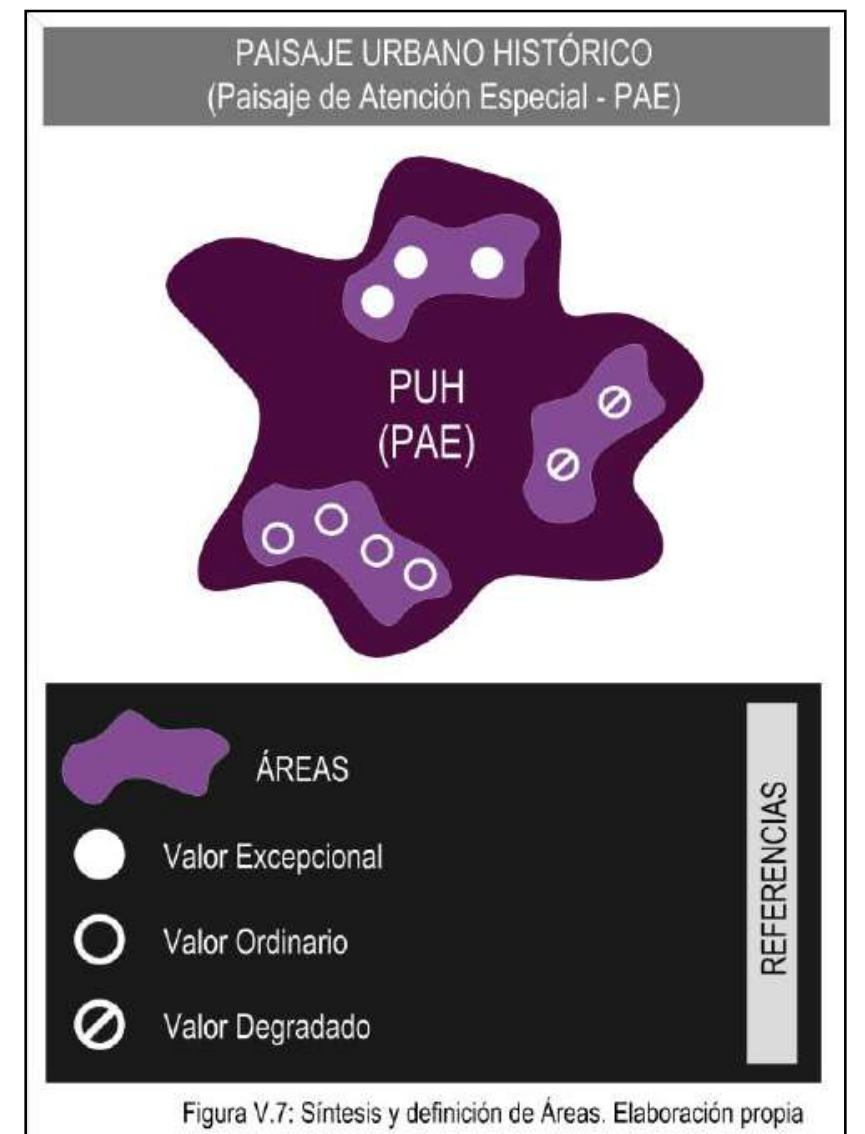

\section{Síntesis Valorativa. Identificación de Conflictos,} Potencialidades y Tendencias

La Valoración Objetiva finaliza con el reconocimiento de Conflictos, Potencialidades y Tendencias del PUH. Los mismos, se identifican por Componente Secundario en cada una de las dimensiones de análisis (físico-ambiental, socio-cultural, económica e institucional).

Se entiende por Conflicto, a aquellas situaciones problemáticas que afectan un $\mathrm{PUH}$, que pueden tener origen en una dimensión pero que impactan en otras, y que inciden negativamente en la calidad y por ende, en la valoración del paisaje. En contraposición, se reconoce como potencialidad a aquellos elementos valorados positivamente porque aportan calidad al paisaje, pero que por motivos diversos aún no han logrado expresar todo su potencial. Por último, se identificarán las Tendencias existentes en los PUH, es decir, los procesos (positivos o negativos), que se encuentran transformando el territorio, y que de no tomarse medidas continuarán su curso (Ver Figura V.8).

El registro de todos estos aspectos plasmados en forma escrita y en cartografía síntesis de Valoración Objetiva, sumado a la Valoración Subjetiva que se explica seguidamente, y que completa el Estudio Particularizado, brindará los insumos necesarios para iniciar la siguiente Etapa de Intervención. 


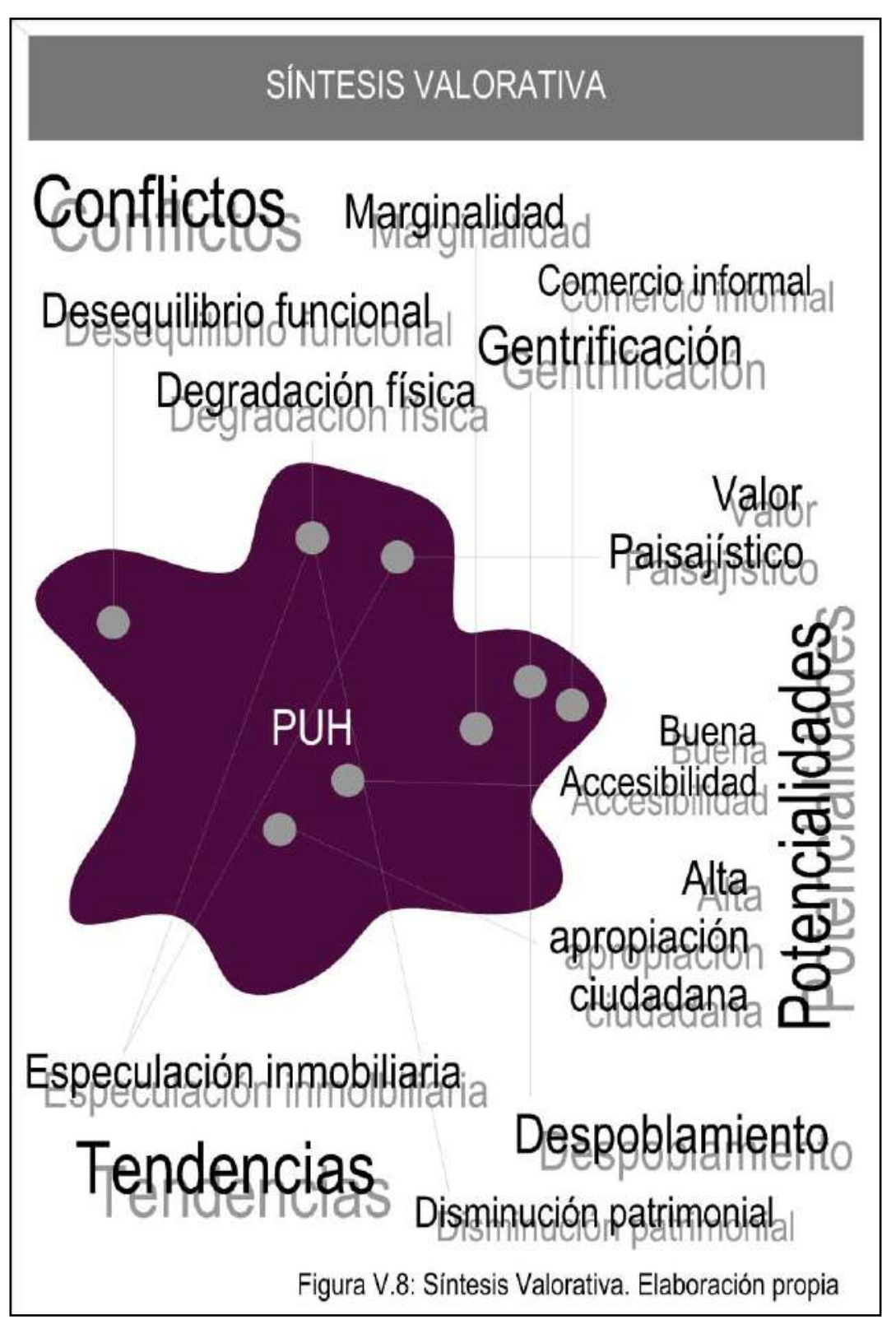

PASO 3b: Valoración Subjetiva de Componentes Secundarios

En este momento del Estudio Particularizado, se incorpora la instancia de Valoración Subjetiva, acorde a lo promovido en las Recomendaciones para la aplicación del Convenio Europeo del Paisaje (2008), donde se sugiere que "todas las acciones emprendidas para la definición, realización y seguimiento de políticas de paisaje deberían estar precedidas y acompañadas por procedimientos de participación de la población y los agentes afectados, con el objetivo de permitirles jugar un papel activo en la formulación de los objetivos de calidad paisajística, su puesta en práctica y su seguimiento".

En esta búsqueda, la Valoración Subjetiva comprende el análisis de las percepciones sociales del paisaje, construida con el aporte de la población, con un perfil de informantes conformado por una gran diversidad de actores (integrantes de asociación o entidad que organice/participe del objeto de estudio, integrantes de asociaciones de defensa del patrimonio, integrantes de asociaciones ecologistas, integrantes de asociaciones vecinales, vecinos residentes, comerciantes, trabajadores, estudiantes y turistas). La población contribuirá con el reconocimiento de percepciones de los elementos de Valor del paisaje, y con la identificación de conflictos, potencialidades y tendencias, que serán transmitidas por medio de encuestas personales y online, cualitativas y cuantitativas, compuestas por indagaciones cerradas 
y abiertas (Ver Diseño de estructura para la confección de Encuestas, Figura V.9), y sintetizadas en cartografía.

\section{PASO 4a: Síntesis: Valoración Objetiva + Valoración Subjetiva}

Este último paso de la Etapa Valorativa, pretende funcionar como fuelle hacia la Etapa de Intervención. El mismo, se desagrega en dos partes, $4 a$ y $4 b$, correspondiendo el primero al cierre de la etapa de valoración y el segundo al inicio de la siguiente etapa. Como finalización de la Etapa Valorativa, el paso 4a consiste en la integración de los resultados. El equipo técnico será el responsable de sistematizar, representar gráficamente y analizar los resultados de las encuestas producto de las percepciones sociales. La sumatoria de la Valoración Objetiva con la Valoración Subjetiva aportará una síntesis gráfica y escrita. Esta Síntesis, posibilita avanzar hacia el Paso 4b de la Etapa de intervención. 


\section{VALORACIÓN OBJETIVA}

Elaborada por equipo técnico multidisciplinario (arquitectos, sociólogos, geógrafos, economistas....)

\section{INTRODUCCIÓN Y OBJETIVOS}

1.1. Objetivo General y Especificos

\section{DESCRIPCIÓN Y EXPLICACIÓN}

2.1. Presentación del Componente Secundario.

Delimitación conceptual del objeto de estudio:

Relación Componente Primario (Variable) - Componente Secundaria (Dimensión):

2.2. Localización

2.3. Descripción y Análisis del Componente en relación a las Dimensiones:

Fisico-ambiental

Aspectos naturales, ecológicos, y materiales. Estado de conservación del paisaje, ocupación, apropiación, relevancia, singularidad, diversidad, estética y capacidad de transmitir al paisaje los procesos de transformación

Socio-cultura Aspectos socio-culturales, paisajes apropiados por la población para el desarrollo de actividades recreativas, culturales, 0 asociadas a la memoria. Transformaciones

Económica Aspectos económicos, recursos paisajisticos que permiten generar beneficios económicos. Cambios e incidencias

Tareas de gestión llevadas a cabo desde organismos públicos y privados, para el financiamiento e intervención con miras al mantenimiento y desarrollo. Cambios

La información escrita será acompañada de documentación gráfica.

\section{VALORES DEL PAISAJE}

3.1 Identificación de elementos de Valor Paisaíistico del Componente Secundario: Elemento 1 / Elemento 2 / Elemento 3 / Elemento 4 / Elemento 5 / Elemento 6 ... Anälisis según método de Kevin Lynch: sendas, bordes, barrios, nodos y mojones 3.2 Registro y elaboración de Fichas de inventario. Catálogo de elementos de valor. 3.2 Aplicación de INDICADORES por dimensión para evaluar el Valor del Paisaje de cada Elemento, y definir Áreas de Valor Excepcional,Ordinario y Degradado

\section{SINTESIS VALORATIVA}

4.1 Reconocimiento de Conflictos, Potencialidades y Tendencias por Dimensión 4.2 Elaboración de cartografía síntesis

\section{INTEGRACIÓN DE VALORACIÓN OBJETIVA Y SUBJETIVA}

5.1 Sintesis de resultados, escrita y gráfica
VALORACIÓN SUBJETIVA

\section{ANÁLISIS DE LAS PERCEPCIONES SOCIALES}

Construida con el aporte de la población

PERFIL DE INFORMANTES:

- Integrante de asociación o entidad que organice / participe en el objeto de estudio - Integrante de asociación de defensa del patrimonio

- Integrante de asociación ecologista

- Integrante de asociación vecinal

- Vecinos residentes / comerciantes / trabajadores / estudiantes

- Turistas

DISEÑO DE ESTRUCTURA PARA LA CONFECCIÓN DE ENCUESTAS

\section{VALORES DEL PAISAJE}

a - Califique de 1 a 3 los siguientes elementos de valor paisajistico.

Incorpore otro/s elemento/s que considere que deban ser tenidos en cuenta por su alto valor, por la falta de él o por su valor corriente (Método Kevin Lynch). Califiquelo.

VALORES Dimensión Fisico-Ambiental Socio-Cultural Económica Institucional TOTAL Indic. Indic. Indic. Indic. Indic. Indic. Indic. Indic. Indic. Indic. Indic. Indic. (AREAS)

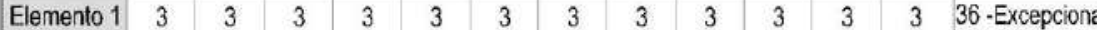
\begin{tabular}{|l|l|l|l|l|l|l|l|l|l|l|l|l|l|}
\hline Elemento 2 & 2 & 2 & 2 & 2 & 2 & 2 & 2 & 2 & 2 & 2 & 2 & 2 & 24 -Ordinario \\
\hline
\end{tabular} \begin{tabular}{|l|l|l|l|l|l|l|l|l|l|l|l|l|l|}
$\overline{\mathrm{u}}$ Elemento 3 & 1 & 1 & 1 & 1 & 1 & 1 & 1 & 1 & 1 & 1 & 1 & 1 & 12 -Degradado
\end{tabular} Elemento 4

Èำento 5 Otro Otro

(La tabla expuesta previamente ejemplifica la metodología de valoración social de los elementos del paisaje de cada componente secundario, según los indicadores propuestos por dimensión de análisis, que permiten la delimitación de Áreas)

\section{SINTESIS VALORATIVA}

b - Una con lineas cada elemento con los Conflictos / Potencialidades / Tendencias que reconoce en ellos. Incorpore otros/as y una al elemento correspondiente.

\begin{tabular}{|c|c|c|c|c|c|}
\hline VALORES & ONFLICTOS & VALORES & POTENCIALIDADES & VALORES & TENDENCIAS \\
\hline Elemento 1 & Conflicto 1 & Elemento 1 & Potenc. 1 & Elemento 1 . & Tendencia 1 \\
\hline Elemento 2 & Conflicto 2 & Elemento 2 & Potenc. 2 & Elemento 2 & Tendencia 2 \\
\hline Elemento 3 & Conflicto 3 & Elemento 3 & Potenc. 3 & Elemento 3 & Tendencia 3 \\
\hline Elemento 4 & Conflicto 4 & Elemento 4 & Potenc 4 & Elemento 4 & Tendencia 4 \\
\hline Elemento 5 & Conflicto 5 & Elemento 5 & Potenc 5 & Elemento 5 & Tendencia 5 \\
\hline Otro & Otro & Otro & Otra & Otro & Otra \\
\hline Otro & Otro & Otro & Otra & Otro & Otra \\
\hline
\end{tabular}


CALIDAD

PAISAJISTICA

LINEAMIENTOS

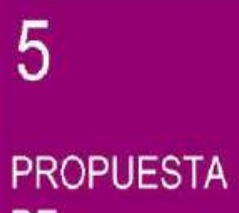

DE

ESTRATEGIAS$$
\text { ESTATEGIAS }
$$

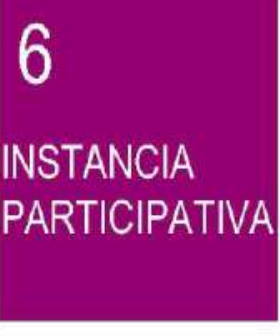

\section{$7 a$}

AJUSTEY

SELECCIÓN

DE

ESTRATEGIAS
PROCESAMIENTO DE LA INFORMACIÓNY PROPUESTAS RECIBIDA POR PARTE DE LA POBLACIÓN DURANTE LOS TALLERES DE INTERCAMBIO E INFANTILES DE PAISAJE
REDACCIÓN DE OBJETIVOS DE

CALIDAD PAISAJISTICA PARA LAS ÁREAS DE VALOR

EXCEPCIONAL, ORDINARIO Y DEGRADADO

¿Qué Paisaje queremos?

REDACCIÓN DE LINEAMIENTOS

PARA LAS ÁREAS DE VALOR

EXCEPCIONAL, ORDINARIO Y DEGRADADO

¿Cómo lograremos ese Paisaje?

Formulación por parte de autoridades públicas competentes,

de las aspiraciones de la población en relación a las caracterisiticas paisajisticas de su entorno
Principios guía o ideas generales para lograr los objetivos,

criterios para la transformación del Paisaje.

Fuelle hacia la ideación de estrategias de intervención
Abordaje de

Dimensiones:

FISICO-AMBIENTAL

SOCIO-CULTURAL

ECONÓMICA

INSTITUCIONAL

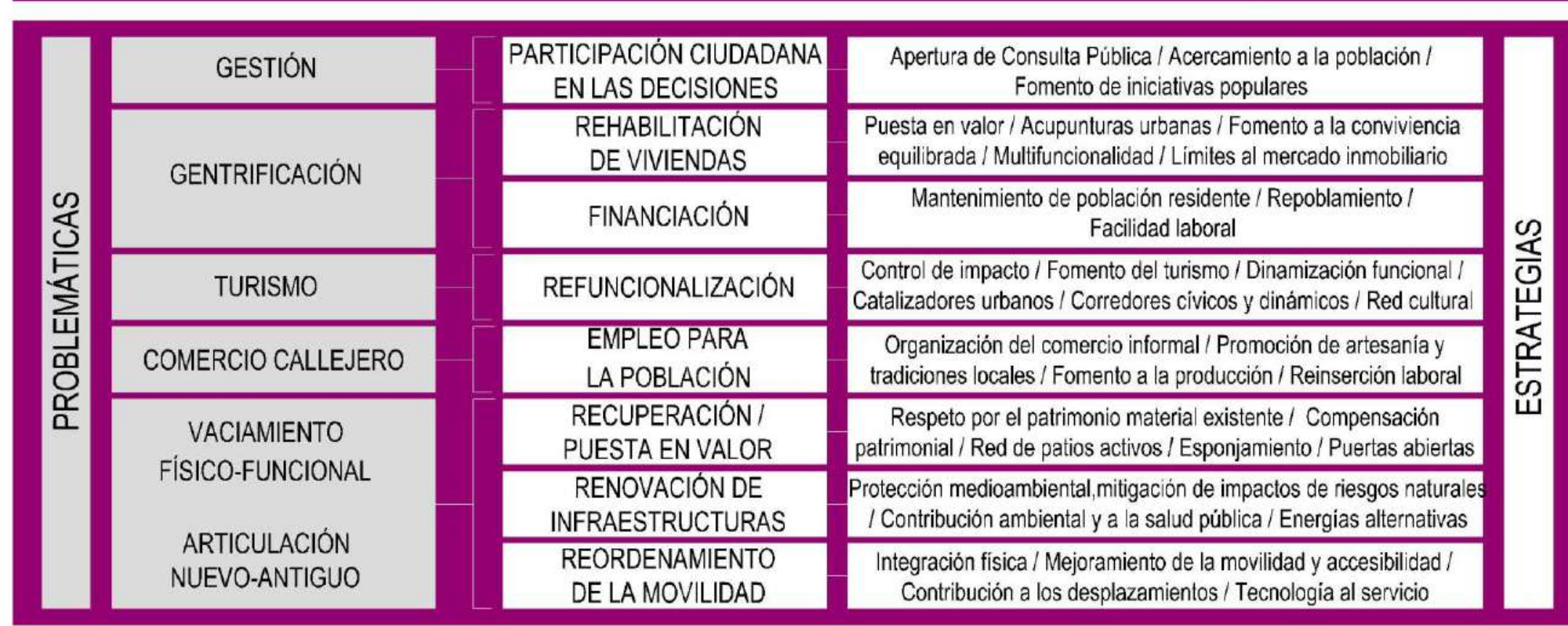

\section{TALLERES DE INTERCAMBIO - Presentación a la comunidad de Estrategias \\ PERIODO DE CONSULTA PÚBLICA DE PAISAJE Propuestas para el PUH - Recepción de sugerencias, observaciones, ideas \\ TALLERES INFANTILES DE PAISAJE $\quad$-Recepción de sugerencias, observaciones, ideas \\ -Presentación a los niños de propuestas infantiles} Talleres presenciales $u$ online, mediante una plataforma virtual

REALIZACIÓN DE AJUSTESE INCORPORACIONES NECESARIAS PARA ADAPTAR LAS PROPUESTAS A LOS REQUERIMIENTOS DE LA POBLACIÓN
CONVOCATORIAA

REUNIÓN PÚBLICA para la preesentación de Estrategias de intervención seleccionadas para aplicar en el PUH 


\subsubsection{Propuesta para la Intervención de PUH}

La instancia B, de Valoración, sintetizada en el Paso 4a, genera los recursos necesarios para dar inicio a la sucesiva instancia $\mathrm{C}$, la Etapa de Intervención. La misma, como una parte del Proceso metodológico propuesto, plantea al igual que la etapa anterior, una serie de cuatro pasos concatenados, 4b a $7 a$ (Ver Figura V.10). A continuación se exponen sus contenidos:

\section{PASO 4b: Redacción de Objetivos de Calidad Paisajística y} Lineamientos para las Áreas

Se entiende por objetivos de calidad paisajística para un paisaje específico, a lo definido por el Convenio Europeo del Paisaje (2000) como la "formulación por parte de las autoridades públicas competentes, de las aspiraciones de las poblaciones en lo que concierne a las características paisajísticas de su entorno", es decir, que como bien afirma el Observatorio de Paisaje de Cataluña, responden a la pregunta ¿qué paisaje queremos?, introducen una mirada más sensible paisajísticamente y buscan incrementar la conciencia ciudadana en relación al paisaje, tanto para quienes intervienen como en la sociedad en general.

"Cada intervención o proyecto de ordenación debería respetar los objetivos de calidad paisajística. Deberían, en particular, mejorar la calidad paisajística o como mínimo, no provocar un deterioro de la misma. En consecuencia, será necesario evaluar los efectos de los proyectos, sea cual sea su escala, sobre los paisajes y definir reglas e instrumentos para responder a esos efectos. Cada intervención o proyecto de ordenación debería ser no sólo compatible, sino también apropiada para las características de los lugares" (Recomendaciones para la aplicación del Convenio Europeo de. Paisaje, 2008).

Una vez redactados estos objetivos, se procederá a la elaboración de Lineamientos de intervención, que responden a la pregunta ¿cómo lograremos ese paisaje?, y constituyen principios guía o ideas generales para lograr los objetivos, criterios para la transformación del paisaje. Estos lineamientos abordarán las cuatro dimensiones que se han ido desarrollando en el proceso, y establecen un fuelle hacia la ideación de estrategias de intervención.

\section{PASO 5: Propuesta de Estrategias, programas y proyectos de Intervención}

En este punto, se retoman las problemáticas principales identificadas en $\mathrm{CH}$ de $\mathrm{AL}$ en el Capítulo 2, asociadas a los componentes claves para un $\mathrm{CH}$ vivo, vinculados a las dimensiones del desarrollo sostenible. A estas problemáticas, se buscará brindar soluciones mediante estrategias analizadas en el Capítulo 4 de esta tesis, a las que se suman otras interesantes a tener en cuenta, de 
las cuales se identificarán aquellas de posible implementación en diversos contextos latinoamericanos. De este modo, acorde a los resultados obtenidos en la instancia de valoración, los responsables de decidir sobre los PUH podrán seleccionar en concordancia también con los objetivos de calidad paisajística esgrimidos, las estrategias que más se ajusten a la situación y escala del $\mathrm{CH}$ a intervenir. Estas estrategias, serán aplicables mediante la creación de programas y proyectos de intervención.

Enseguida se presentan a modo de guía algunas estrategias de intervención de posible implementación en PUH para dar respuesta a los principales desafíos de la intervención integral: la gestión, la gentrificación, el vaciamiento físico-funcional, la articulación nuevoantiguo, el turismo y el comercio callejero. La multiplicidad de problemáticas que presenta un PUH han sido desagregadas en el Capítulo 4, en este caso, como capítulo síntesis, se retoman las principales para ejemplificar con algunas estrategias de posible aplicación en AL. Gran parte de ellas, se apoyan en la revalorización de las potencialidades del sitio en la búsqueda de soluciones a conflictos y tendencias existentes.
COMPONENTE IDENTIDAD Y PARTICIPACIÓN CIUDADANA I DIMENSIÓN INSTITUCIONAL / PATRIMONIO INMATERIAL

PROBLEMÁTICA: Gestión

¿CÓMO MEJORAR LOS RESULTADOS DE LAS INTERVENCIONES?

\section{ESTRATEGIAS}

Participación ciudadana en las decisiones:

- Apertura de Consulta Pública: mediante la creación de talleres y reuniones que permitan la asistencia y participación de la población en etapas de decisión sobre el $\mathrm{PUH}$, así como también por medio de encuestas.

- Acercamiento a la población: mediante oficinas abiertas a la población del organismo encargado de la gestión, instaladas en edificios del PUH, y mediante oficinas móviles, que permanezcan en distintos puntos del PUH.

- Fomento de iniciativas populares: mediante colaboración (técnica y económica) para el desarrollo de iniciativas populares que contribuyan a la apropiación ciudadana del PUH. 
COMPONENTE RESIDENCIALIDAD / DIMENSIÓN SOCIO-

\section{CULTURAL / PATRIMONIO MATERIAL}

PROBLEMÁTICA: Gentrificación

¿CÓMO CONSERVAR LA POBLACIÓN RESIDENTE?

\section{ESTRATEGIAS}

Rehabilitación de la vivienda:

- Puesta en valor de edificios residenciales: mediante el reacondicionamiento de las unidades funcionales con redistribución de superficies e incorporación de ventilaciones y condiciones necesarias para la habitabilidad.

- Acupunturas urbanas: mediante la adaptación de estructuras degradadas al uso residencial.

- Fomento a la convivencia equilibrada: mediante el establecimiento de una densidad urbanística acorde al área.

- Multifuncionalidad: mediante la incorporación de otros usos permanentes que complementen al uso residencial como principal motor para la conservación de la vitalidad del área.

- Límites en el mercado inmobiliario: mediante el control del costo del suelo en usos residenciales que permitan la permanencia de la población residente.

\section{Financiación:}

- Mantenimiento de población residente: mediante el otorgamiento de préstamos hipotecarios a inquilinos residentes con antigüedad en el $\mathrm{CH}$, con créditos a tasa por debajo del mercado para que puedan adquirir su propia vivienda. Los mismos pueden ser facilitados por el organismo de gestión del PUH.

- Repoblamiento: mediante el fomento de cooperativas, beneficios en créditos y subsidios, exenciones $\mathrm{o}$ disminuciones en impuestos y servicios, facilidades de alquiler para familias jóvenes y empleados públicos que trabajen en el $\mathrm{CH}$.

- Facilidad laboral: mediante la creación de una bolsa de trabajo, donde se otorgue concesión preferencial de puestos laborales para residentes, nacidos y/o criados en el $\mathrm{CH}$. El organismo de gestión del PUH también sería el encargado de esta bolsa.

\section{COMPONENTE MULTIFUNCIONALIDAD / DIMENSIÓN ECONÓMICA / PATRIMONIO MATERIAL}

\section{PROBLEMÁTICA: Turismo}

¿CÓMO DISMINUIR EL IMPACTO DEL TURISMO? ¿CÓMO FOMENTAR LA MULTIFUNCIONALIDAD?

\section{ESTRATEGIAS}

Refuncionalización:

- Control de impacto: mediante la disposición de valores límites de visitantes diarios en puntos de atracción

- Fomento del turismo: mediante la oferta de servicios y 
equipamientos necesarios para el visitante.

- Dinamización funcional: mediante la refuncionalización de estructuras en desuso o creación en edificios abandonados o en áreas en desuso de equipamiento para guarderías, jardines de infantes, colegios primarios y secundarios, instalaciones para estudios terciarios y universitarios, y bibliotecas que garanticen la asistencia poblacional diurnanocturna, fomente usos complementarios y estructurales (residenciales) y eviten la monofuncionalidad del PUH.

- Catalizadores urbanos: mediante inclusión de usos mixtos en construcciones históricas degradadas 0 en construcciones de nueva arquitectura en lotes vacantes, con gran capacidad para reactivar el entorno (uso residencial, cultural, administrativo, educativo).

- Corredores dinámicos: mediante el impulso al dinamismo comercial, con una sectorización de usos del suelo que propicie la concentración de comercios en alineamientos que se conecten con catalizadores urbanos.

- Corredores Cívicos: mediante la vinculación de edificios históricos y gubernamentales con intervenciones permanentes y efímeras en las calles de carácter más institucional.

- Áreas de oportunidad: mediante la reconversión de usos industriales en desuso y la recuperación de infraestructuras obsoletas que aporten nueva vida a sectores desactivados del PUH

- Articulación PUH- Industria - Puerto Vivo: mediante la incorporación de equipamientos vivos, con mix de usos, que se articulen con corredores del PUH

- Red cultural: mediante la presencia de elementos en el paisaje que articulen equipamientos culturales del $\mathrm{PUH}$

PROBLEMÁTICA: Comercio callejero ¿CÓMO ORGANIZAR EL COMERCIO CALLEJERO?

\section{ESTRATEGIAS}

\section{Empleo para la población:}

- Organización del comercio informal: mediante la relocalización de comercio callejero en grandes mercados y ferias permanentes e itinerantes.

- Promoción de artesanía y tradiciones locales: mediante facilidades de alquiler de comercios $u$ ofreciendo canales de venta como mercados especializados y ferias.

- Fomento a la producción local: mediante beneficios para la etapa de producción y comercialización en locales, mercados y ferias.

- Reinserción laboral: mediante la creación de escuelastaller y centros de capacitación y formación laboral en oficios, tecnología, gastronomía y turismo 


\section{COMPONENTE ESPACIO PÚBLICO I DIMENSIÓ FÍSCO- AMBIENTAL / PATRIMONIO MATERIAL}

PROBLEMÁTICA: Vaciamiento Físico-funcional ¿CÓMO DETENER EL VACIAMIENTO FÍSICO-FUNCIONAL?

\section{ESTRATEGIAS}

Recuperación y puesta en valor:

- Respeto por el patrimonio material existente: mediante la conservación y restauración de estructuras físicas.

- Compensación a propietarios de bienes de valor patrimonial: mediante transferencias por limitaciones

- Red de patios activos: mediante la creación de nuevos usos en patios y corazones de manzanas

- Esponjamiento: mediante la liberación de edificaciones discordantes para creación de espacio público

- Fomento de la valorización histórica: mediante la conservación de trazados originales y elementos históricos

- Descubrimiento del legado histórico: mediante el impulso de Itinerarios arqueológicos por antiguos trazados

- Concientización social: mediante recorridos abiertos a la población para la enseñanza y conocimiento de los valores del PUH.

- Fomento de situaciones de descanso y apropiación: mediante la Incorporación de mobiliario urbano flexible (lluminación, bancos, bicicleteros, contenedores de residuos diferenciados)

- Puertas abiertas: mediante la apertura a la comunidad de edificios educativos, culturales, gubernamentales y religiosos durante fines de semana $o$ en horarios alternativos con el fin de brindar actividades gratuitas de interés general.

- Red religiosa: mediante la creación de circuitos religiosos que contribuyan a contar la historia del PUH

- Apropiación del espacio público: mediante el impulso de movimientos artísticos, culturales y deportivos e instalaciones permanentes y temporarias (musicales, literarios, de arte urbano, gastronómicos)

- Oferta de actividades nocturnas: mediante la incorporación en edificios institucionales de actividades que otorguen dinamismo durante la noche, como clases, charlas, jornadas, exposiciones.

- Promoción del equilibrio funcional: mediante incentivos a comercios que funcionen en horarios diurnos y nocturnos.

\section{Renovación de infraestructuras:}

- Protección medioambiental y mitigación de impactos de riesgos naturales: mediante la incorporación de infraestructura verde (sistemas de drenaje en veredas, ramblas, plazoletas)

- Contribución ambiental y a la salud pública: mediante el mejoramiento de condiciones de la infraestructura gris (red 
de alcantarillado, plantas de tratamiento de aguas servidas)

- Promoción de utilización de energías alternativas y reducción de consumo energético:

mediante el uso de paneles solares, techos y fachadas verdes, huertas urbanas y nuevos materiales

\section{Reordenamiento de la movilidad:}

- integración física: mediante el tratamiento de barreras materiales (vías de ferrocarril, autopistas en áreas de amortiguación, bienes desafectados) y naturales (cerros, arroyos, ríos), en su totalidad o en las márgenes.

- Mejoramiento de la movilidad y accesibilidad: mediante nuevos sistemas de transportes públicos (subte, colectivo, tranvía, bicicleta, rampas, escaleras mecánicas, ascensores, funiculares).

- Contribución a los desplazamientos: mediante la incorporación de mobiliario urbano flexible (lluminación, bancos, bicicleteros, contenedores de residuos diferenciados)

- Tecnología al servicio de la accesibilidad y movilidad: mediante la instalación de equipamiento técnico para la información de la situación de calles y áreas públicas que incluya a población con capacidad reducida (Smart cities).
PROBLEMÁTICA: Articulación nuevo-antiguo ¿CÓMO INTEGRAR LO NUEVO Y ANTIGUO?

\section{ESTRATEGIAS}

- Fortalecimiento del vínculo con el pasado: mediante Integración de ruinas arqueológicas en espacios públicos (plazas, museos, estaciones de subte, estacionamientos subterráneos)

- Adaptación a demandas funcionales contemporáneas: mediante la fusión de espacios históricos con equipamientos de nueva arquitectura (en plazas, parques, superficies vacantes).

- Acupunturas urbanas: mediante la adaptación de estructuras degradadas al uso residencial que responda a demandas actuales, con empleo de nueva arquitectura y ambientalmente consciente.

- Impulso al conocimiento y la difusión del patrimonio heredado: mediante la inclusión de sitios arqueológicos con centros de interpretación en espacios de concurrencia pública (museos, bibliotecas, bares y restaurantes, hoteles, iglesias y conventos, estaciones de transporte)

La aplicación de cada una de estas estrategias, seguramente demandará por parte de los equipos responsables, de la creación de diversos instrumentos específicos. 
Dentro de los instrumentos operacionales más generales, a continuación se recomienda el establecimiento de los siguientes:

1. LEGALES (Normativos: Régimen de Protección / Catalogación)

- Unidad de Paisaje: Paisaje Urbano Histórico (PUH)

- Paisaje de Atención Especial (PAE)

2. DE PLANIFICACIÓN

2.1 Urbano: Plan de Ordenamiento Urbano Territorial

2.2 De Sector: Plan Especial

3. DE PARTICIPACIÓN PÚBLICA:

Consulta Pública:

Talleres de intercambio de Paisaje / Talleres infantiles /

Reuniones de Paisaje

\section{PASO 6: Apertura de Instancia Participativa}

En este paso del proceso, con el fin de poner en práctica la participación pública en la etapa de intervención, se plantea la apertura de una instancia participativa por medio de la aplicación de diversos instrumentos. En principio, se establecen Talleres de intercambio de Paisaje, durante los mismos, se presentará a la comunidad las Estrategias de Intervención esbozadas para el PUH con el propósito de generar un ida y vuelta. Dentro de estos Talleres, se buscará una participación con una alta representatividad de los distintos rangos etarios y situaciones educativas y laborales. También funcionarán Talleres infantiles, para que los niños también puedan ser partícipes de las propuestas para su PUH. Podrá participarse de estos Talleres en forma presencial como online, mediante una plataforma virtual. Estos Talleres, se llevarán a cabo durante un periodo determinado de Consulta Pública.

\section{PASO 7a: Ajuste y Selección de Estrategias de intervención a aplicar}

Una vez finalizada la instancia de Talleres, y procesada toda la información y propuestas recibidas por parte de la población, se procede a realizar los ajustes e incorporaciones necesarias a las estrategias, programas y proyectos presentados. Posteriormente, se convoca a una reunión pública para realizar la presentación a la población de las Estrategias, programas y proyectos de Intervención seleccionados para la aplicación en el PUH.

Para llegar a concretar los pasos expuestos en las Etapas de Valoración e Intervención profundizadas previamente, resulta necesario articularlos con pasos complementarios de la Etapa de Gestión. La misma, completa el proceso metodológico diseñado para los $\mathrm{PUH}$ latinoamericanos, con los últimos pasos consecutivos 7 b y 8 , que se detallan por paso en las páginas sucesivas. 


\subsubsection{Propuesta para la Gestión de PUH}

Los dos últimos pasos del proceso metodológico, pasos $7 \mathrm{~b}$ y 8 , retoman acciones relativas a la Etapa de Gestión del PUH, que se amplían a continuación.

\section{PASO 7b: Propuesta de Instrumentos de Gestión para la aplicación de las estrategias seleccionadas}

Una vez definidas las estrategias a implementarse mediante programas y proyectos, el Área de Legales será la responsable de crear todos aquellos instrumentos necesarios para la ejecución. A continuación se proponen algunos instrumentos de posible aplicación. Los profesionales encargados de la intervención en el PUH deberán dilucidar aquellos que mejor se adapten a cada caso en particular.

\section{INSTRUMENTOS ECONÓMICO-FINANCIEROS:}

Incentivos Constructivos para la protección y preservación de bienes patrimoniales / Estímulos fiscales: Exención o reducción de impuestos / Facilidades de financiamiento / Compensacionestransferencias por limitaciones sobre bienes de valor patrimonial / Sanciones al abandono de inmuebles / Cobro de impuestos a empresas o sujetos vinculados al turismo destinados a la recuperación del patrimonio / Incentivos a comercios que generen equilibrio funcional diurno-nocturno / Control de costo del suelo / Límites diarios de visitantes para puntos de atracción turística.
Por otra parte, existen estrategias que pueden ser implementadas a partir de la autogestión ciudadana, con el fin de fomentar la apropiación y el sentido de pertenencia de los habitantes hacia el $\mathrm{PUH}$.

\section{PASO 8: Seguimiento y control}

Una vez ejecutados los proyectos que conforman las estrategias, el último paso del proceso metodológico consistirá en realizar un seguimiento continuo del desempeño del organismo de Gestión del PUH, y una evaluación del cumplimiento de objetivos a corto, mediano y largo plazo, valorando a su vez, su capacidad de autosostenibilidad en el tiempo.

El paso 8, concluye el proceso metodológico propuesto para los PUH latinoamericanos, y posibilita iniciar un momento de reflexión acerca del desarrollo de esta investigación, que ha iniciado brindando un marco teórico-conceptual de los $\mathrm{CH}$, pasando por el reconocimiento empírico de actuaciones en los mismos, para finalizar con una metodología que permita valorar, intervenir y gestionar los $\mathrm{CH}$ como $\mathrm{PUH}$. El siguiente y último apartado, expone las conclusiones alcanzadas como cierre de esta instancia doctoral. 


\section{CONCLUSIONES GENERALES: CIERRE Y APERTURA}

Sobre los cambios teórico-conceptuales del Centro Histórico, los enfoques y desafios para la intervención y gestión

Sobre las estrategias e instrumentos de intervención y gestión

Sobre la propuesta metodológica

Sintesis y continuidades 


\subsection{Sobre los cambios teórico-conceptuales del \\ Centro Histórico, los enfoques y desafíos para la intervención y gestión}

Como inicio de este apartado de conclusiones, es preciso retomar la primera hipótesis secundaria de esta tesis planteada en la Introducción: "Los cambios teórico-conceptuales experimentados en los modos de interpretar los $\mathrm{CH}$, han influido en el diseño de estrategias de intervención y gestión aplicadas".

Para testear esta hipótesis, en el transcurso de los Capítulos 1 y 2 de la primera parte de esta investigación, se ha propuesto la profundización en los cambios de enfoques por los que han atravesado los $\mathrm{CH}$ y sus formas de intervenirlos y gestionarlos en el periodo de estudio. En este marco, resulta valioso destacar la evolución en la mirada del monumento aislado al conjunto urbano que basa su existencia en función de un entorno mayor y sus relaciones. Este cambio conceptual nos permite en la actualidad como sostiene Lerner (2010), asimilar su funcionamiento con el de una tortuga un organismo que fusiona vivienda, trabajo y transporte, donde su caparazón asemeja a un tejido urbano, y bajo él se desarrollan todas las funciones. Si se separan estas funciones la tortuga muere, e interpretar a un $\mathrm{CH}$ sin un enfoque integral implica una intervención urbana fragmentada. En este sentido, la intervención de los $\mathrm{CH}$ se presenta como un gran desafío para la planificación urbana considerando la complejidad de la misma.

Los cambios experimentados han generado puntos de inflexión, que han influenciado el abandono de la idea del $\mathrm{CH}$ como una serie de edificios aislados, para pasar a pensarlo en capas temáticas (patrimonio material e inmaterial: espacio público, multifuncionalidad, identidad y participación ciudadana), que conforman una única pieza, un sistema integral de interrelaciones, que en la actualidad resultan inimaginables de abordar en forma aislada.

De esta manera, el $\mathrm{CH}$ como parte de un organismo vivo mayor que es la ciudad, pasa a comprender que existen ciertos aspectos que no pueden dejarse de lado, como el patrimonio intangible, la arquitectura contemporánea, y el desarrollo urbano sostenible, y encuentra en el paisaje el medio para obtener una mirada integradora de todos los elementos, dando lugar a la aparición del concepto de PUH.

En los países de estudio, para afrontar los desafíos que supone el desarrollo sostenible, se han registrado algunos casos donde las estrategias de intervención se han basado en la recuperación de los $\mathrm{CH}$ como una manera de fortalecer la identidad local y el sentido de pertenencia de sus habitantes. 
Al mismo tiempo, se ha apostado a la recuperación de las áreas centrales y sus edificios de valor patrimonial de manera de reactivar el mercado del turismo cultural, como una fuente importante de recursos. A su vez, el Estado ha brindado asistencia a sus residentes mediante programas de educación y reinserción laboral; implementando programas que permiten una reactivación económica, atrayendo la inversión y la demanda del sector privado sobre estos sectores que durante largo tiempo se mantuvieron al margen. En estos casos, el Estado se ha ocupado de la recuperación de los $\mathrm{CH}$ bajo esta lógica, sin perder de vista que éste, es en última instancia un objetivo operacional y que cuyo fin último, es el mejoramiento de la calidad de vida de la población residente.

Esto ha llevado a que el Estado, en varias intervenciones haya encauzado su accionar dentro de esta doble lógica, promoviendo por una parte la recuperación de los espacios públicos y edificios patrimoniales mediante su recualificación o la creación de museos, centros culturales, y demás actividades recreativas; conjuntamente con la recuperación de las edificaciones privadas, la provisión de infraestructuras, equipamiento, servicios que han permitido solucionar los déficits habitacionales presentes.

En ocasiones, las principales estrategias, generalmente derivan de transformaciones operadas en búsqueda del cambio de imagen de estos sectores degradados, que no emergen del campo social (producto del sentido colectivo), sino que entran en una lógica económica. No obstante, existen prioridades sociales en relación a las cuales se han centrado las políticas de actuación del Estado, en algunos proyectos de recualificación urbana. La gran desigualdad económica y social, ha conseguido que el Estado en cada una de sus intervenciones haya dirigido los escasos recursos públicos prioritariamente en relación a estas principales problemáticas, más que en la promoción e incentivos a las grandes empresas privadas para lograr el embellecimiento de un fragmento urbano. $O$ en todo caso, ha utilizado el embellecimiento y recuperación de sectores urbanos, como un instrumento para arribar a la solución de problemas económicos y sociales de sus residentes, mediante la convocatoria de la iniciativa privada.

Es por ello, que las intervenciones en los $\mathrm{CH}$ latinoamericanos en la mayoría de los casos, ha requerido un abordaje desde un enfoque que considere la habilitación mediante la salvaguarda del patrimonio arquitectónico de valor histórico promoviendo el turismo metropolitano, conjuntamente con programas de reactivación económica y con planes de salvaguarda e inserción social de sus residentes, (siendo que en muchos casos se encuentran en condiciones de hacinamiento, inseguridad y marginalidad).

En este marco, debe mencionarse el rol destacado que han jugado las políticas territoriales en la protección del patrimonio histórico. Dado que han tenido entre sus objetivos la reintegración 
procurando un equilibrio social y económico. Desde esta perspectiva, la gestión urbanística de las ciudades ha contado con estrategias y herramientas de intervención y gestión que han permitido poner en valor sectores urbanos degradados en los aspectos físico-ambientales, socio-culturales y económicos.

La historia y el patrimonio ocupan un rol preponderante en la recualificación urbana de los $\mathrm{PUH}$. Los mismos, no son sólo áreas para preservar y poner en valor con miras al desarrollo turístico e inmobiliario, sino que son potenciales generadores de iniciativas de desarrollo local, y en ese sentido asume una función indispensable la gestión de las intervenciones de revitalización o recualificación urbana.

La ausencia de industrias culturales tiene como consecuencia en muchos casos el mecanismo de la gentrificación. Por ello es necesario pensar en un PUH con capacidad de autofinanciación, lo que garantizará su sostenibilidad en el tiempo. Una intervención puede resultar sustentable en determinado momento debido a circunstancias coyunturales, pero al variar estas circunstancias deja de serlo, por lo tanto si una intervención no es estructural, no es sostenible en el tiempo. Como afirma Rodríguez Alomá (2009), elementos indispensables en la efectividad de dichas intervenciones son la autofinanciación (recursos), la coordinación, la formación, la promoción y el mantenimiento y control, que junto a un buen planteo de usos mixtos del área y la participación ciudadana, permitirían alcanzar objetivos de una gestión integral.

Lo expuesto anteriormente, permite afirmar que la primera hipótesis secundaria se verifica, siendo que los cambios teórico-conceptuales experimentados en los modos de interpretar los $\mathrm{CH}$, han influido en el diseño de estrategias de intervención y gestión aplicadas en $\mathrm{CH}$ de ciudades de AL, Italia y España en el periodo de estudio. 


\subsection{Sobre las estrategias e instrumentos de intervención y gestión}

La segunda parte de la tesis, se ha centrado principalmente en la verificación de la segunda hipótesis secundaria: "Existen propuestas de intervención y gestión llevadas a cabo en ciudades grandes e intermedias de AL, Italia y España en el periodo 19702015, que logran brindar respuestas a necesidades reconocidas en los CH".

Para ello, se ha propuesto revisar numerosos casos de intervención y gestión desarrollados en el periodo de estudio, con el fin de detectar cuáles han sido las problemáticas que las han motivado, y en qué medida las intervenciones han logrado dar respuesta a las necesidades preexistentes. Al mismo tiempo, reconocer en ellas los casos paradigmáticos o experiencias que han logrado buenos resultados.

En virtud de ello, se ha observado que el período de análisis ha sido contenedor de un gran número de intervenciones que han recibido constantes influencias entre Europa y $A L$, y que han encontrado en Bolonia un referente para las actuaciones desarrolladas durante las décadas del 70 y 80 . El Plan de Bolonia ha constituido uno de los primeros casos paradigmáticos por su aporte en la rigurosa metodología, por su mirada integral del $\mathrm{CH}, \mathrm{y}$ por el rol central otorgado a las cuestiones sociales, siendo modelo para ciudades europeas y latinoamericanas. España ha seguido a Bolonia en las primeras intervenciones del 80 , pero luego ha dado paso a intervenciones menos conservacionistas, con un enfoque más transformador que han llevado a desarrollar Planes significativos como el de Gijón, Vitoria Gasteiz, Alcoy, Málaga, Barcelona y Madrid. Dentro de ellos, el caso de Vitoria Gasteiz destaca también por ser precursor en la propuesta de rehabilitación integrada y por el proceso de gestión implementado. Estas experiencias europeas sin duda han influido en los modos de intervenir en $\mathrm{AL}$, que en las últimas décadas ha desarrollado numerosos Planes para los $\mathrm{CH}$, con casos singulares como Panamá, Quito, La Habana, México, Lima, Montevideo y Asunción, que han destacado por sus estrategias de intervención y/o sus instrumentos de gestión.

Los ejemplos estudiados son representativos de las constantes búsquedas desde las administraciones públicas por brindar nuevas soluciones a la complejidad de los $\mathrm{CH}$ como sectores urbanos esenciales de las ciudades. Las mismas, atraviesan continuos procesos de transformación que impactan en los $\mathrm{CH}$, acarreando cambios en las dimensiones: físico-ambiental, socio-cultural, económica e institucional, con dinámicos problemas urbanos que van acompañando a las nuevas demandas de las sociedades. Partiendo de estas necesidades, los municipios han planteado 
propuestas cada vez más integrales tanto desde la intervención como desde la gestión.

No obstante este anhelo de superación, a excepción de algunos casos, la mirada desde el paisaje aún no ha logrado incorporarse y expandirse, y la sostenibilidad integral continúa siendo un desafío. Dado que algunas problemáticas o fenómenos permanecen como retos por abordar o evitar, como la conservación de la población residente y las actividades económicas tradicionales, el repoblamiento, la gentrificación, la museificación derivada del turismo, el comercio informal, el deterioro del patrimonio construido con la siguiente ocupación de grupos sociales desfavorecidos y la proliferación de la drogadicción, la inseguridad y la violencia. Por otra parte, algunas estrategias siguen siendo eje de debates como el diálogo entre la nueva arquitectura y el patrimonio histórico construido de los $\mathrm{CH}$.

En el ámbito institucional, la gestión integral sigue requiriendo en muchos casos de la creación de instrumentos competentes y de convicción y continuidad política para alcanzar los objetivos propuestos en los instrumentos de planificación. A su vez, las metas perseguidas en los Planes generalmente se enfrentan durante el proceso de implementación a situaciones o impactos no esperados, que modifican los resultados deseados.
Sin embargo, proponer intervenciones que permitan abrir infinidad de soluciones que garanticen la sostenibilidad integral, no resulta tan simple de implementar, de hecho hasta el momento, muy pocos $\mathrm{CH}$ se encuentran en ese camino. No obstante, la planificación urbana debe continuar avanzando, proponiendo soluciones a las numerosas problemáticas recurrentes de los $\mathrm{CH}$, que mediante un verdadero interés político pueda construir ciudades más accesibles, equitativas y justas.

En conclusión, la segunda hipótesis secundaria se verifica, dado que se han registrado casos que han logrado presentar innovadoras soluciones para responder a las problemáticas presentes en las diferentes dimensiones, aún cuando existen varios casos para los que la sostenibilidad integral permanece como un reto. 


\subsection{Sobre el proceso metodológico propuesto}

Frente al enorme desafío que significa intervenir los $\mathrm{CH}$ como $\mathrm{PUH}$, la tercera parte de la tesis se compromete a testear la tercera hipótesis secundaria: "La construcción de una propuesta metodológica, puede aportar un instrumento para la valoración, intervención y gestión de Centros Históricos $(\mathrm{CH})$ latinoamericanos como Paisajes Urbanos Históricos (PUH), enmarcada en el enfoque del urbanismo sostenible".

La metodología propuesta ha sido pensada como un instrumento abierto, como una guía, un camino a seguir basado en la flexibilidad y adaptabilidad a contextos diversos. Tiene como objetivo orientar, contribuir en posibles intervenciones en $\mathrm{CH}$ posicionada desde la mirada del Paisaje.

La diversidad existente en los $\mathrm{CH}$ latinoamericanos requiere de un instrumento que se adapte a las distintas escalas, características, problemáticas, que se ajuste a sus especificidades para rescatar lo mejor de él. En este sentido este instrumento prevé la incorporación de diversos elementos (componentes secundarios, indicadores, estrategias e instrumentos) en las tres etapas encadenadas en que se estructura el proceso propuesto (Valoración, Intervención y Gestión) con el fin de responder a las necesidades de cada $\mathrm{CH}$.
En el desarrollo del trabajo, ha sido posible, el reconocimiento de estrategias que han dado buenos resultados tanto desde la intervención como desde la gestión. En este sentido, resulta preciso reflexionar sobre la posible aplicabilidad de las mismas en contextos diversos. Es evidente que no existen soluciones que puedan generar los mismos impactos en PUH con realidades tan heterogéneas como las italianas, españolas o latinoamericanas, y al interior de cada país o región. Por lo tanto, es fundamental ante la necesidad de intervención la elaboración de un completo diagnóstico confeccionado desde una mirada interdisciplinaria, que pueda acercarse a las particularidades de cada sociedad. Para ello, la propuesta plantea el desarrollo de una Etapa de Valoración, haciendo hincapié en varios pasos en el reconocimiento y análisis de las particularidades de cada Paisaje orientado en las cuatro dimensiones propuestas del urbanismo sostenible, y resaltando las percepciones sociales del mismo.

La misma estrategia puede resultar eficaz o inapropiada de acuerdo a la situación específica de cada PUH, y es competencia de los profesionales el poder reconocer esas características en el lugar de actuación. Este hecho, no inhabilita la posibilidad de aplicación de estrategias que han dado buenos resultados. Por el contrario, requiere del reconocimiento de las mismas para avanzar en nuevas búsquedas y no reincidir en intrincados caminos ya desandados. La Etapa de Intervención planteada en el proceso, recupera varias de 
las estrategias identificadas en diversos casos analizados, a las que se incorporan otras pensadas particularmente para el $\mathrm{PUH}, \mathrm{y}$ las presenta a la población, con el objeto de fomentar en las distintas instancias la participación ciudadana.

Las dos Etapas mencionadas previamente, de Valoración e Intervención, son contenidas por una tercera Etapa de Gestión que inicia, acompaña y finaliza el proceso, y será la responsable de la transformación del Paisaje. Siendo a su vez esta Etapa la más complicada a la hora de reunir las condiciones necesarias para llevar adelante la actuación.

La propuesta, producto de la preocupación por conseguir mejores resultados en la intervención de los $\mathrm{CH}$, intenta englobar en este proceso los temas principales que se han ido profundizando a lo largo del trabajo, tanto los referentes al funcionamiento del $\mathrm{CH}$ en sí mismo, como los relativos a las estrategias de intervención y gestión implementadas. Como aporte, incorpora la nueva mirada del Paisaje como medio para integrar la complejidad del $\mathrm{CH}$, que pasa a ser entendido como $\mathrm{PUH}$.

Como síntesis, puede afirmarse que acorde a lo expuesto en este apartado la tercera hipótesis secundaria se verifica. 


\subsection{Síntesis y continuidades}

El testeo de las tres hipótesis secundarias permite avanzar hacia la hipótesis central: "La nueva mirada a los $\mathrm{CH}$ latinoamericanos como PUH permite colaborar en posibles intervenciones enmarcadas en el enfoque del urbanismo sostenible".

Para ponerla a prueba, ha sido necesario realizar un profundo estudio bibliográfico para identificar los cambios teóricoconceptuales en torno al $\mathrm{CH}$ que han influenciado el diseño de estrategias en distintos periodos llegando a la búsqueda actual de un urbanismo sostenible que encuentra en el Paisaje la mirada integral para entender a los $\mathrm{CH}$ como $\mathrm{PUH}$. Se ha reconocido, que en este proceso, han sido numerosas las estrategias de intervención y gestión que se han puesto en practica en $\mathrm{CH}$ italianos, españoles y latinoamericanos en el marco de planes de sector. Se rescata la importancia del análisis empírico realizado, basado en información primaria, secundaria y en trabajo de campo, que ha dado cuenta de las problemáticas de los $\mathrm{CH}$ que han conllevado a definir las estrategias de intervención y gestión a implementar. En este aspecto, se reconoce que en muchos casos la cantidad de estrategias propuestas no se condicen con la cantidad de problemáticas ni llegan a otorgarles una solución definitiva. No obstante esta situación, el reconocimiento de casos que han encontrado el camino para abordar el $\mathrm{CH}$ de forma integral resulta un incentivo para seguir trabajando en la búsqueda de mejores intervenciones. Para tal fin, la tesis ha construido una propuesta metodológica que fundamentada en la mirada integral que brinda el desarrollo sostenible y el Paisaje, aporte un instrumento para valorar, intervenir y gestionar $\mathrm{PUH}$ latinoamericanos. De este modo, es posible afirmar que el proceso de investigación ha permitido verificar la hipótesis central planteada para la tesis.

Como apartado de cierre, y acorde a lo indagado a lo largo de los capítulos, la tesis también permite reflexionar acerca de qué $\mathrm{CH}$ queremos y cómo colaborar en su transformación. Es preciso comprender que no tiene sentido la búsqueda de la vitalidad y sostenibilidad por sí mismas si no se las piensa en el sentido de conservar la esencia de los $\mathrm{CH}$, en el contexto de la ciudad que los contiene. El desafío no se encuentra sólo en buscar nuevas funciones que le otorguen vida, sino en conservar y recuperar todo aquello que le otorga identidad, que lo hace genuino. El gran valor de los $\mathrm{CH}$ como áreas patrimoniales requieren de estrategias que permitan el mejoramiento del área sin perder de lado situaciones tradicionales de la vida cotidiana como observar la ropa tendida en las calles, los niños jugando a la pelota, percibir el olor de la comida típica, escuchar las peleas de los vecinos, o alguien tarareando una canción autóctona... es decir sin perder todo aquello que los hace invaluables. 
En este contexto, adquiere real importancia el conocimiento, la concientización y sensibilización de la población con miras a reconocer y valorar la importancia del patrimonio de los $\mathrm{CH}$. El sentido de identidad y pertenencia es quien puede lograr movilizar la participación ciudadana con miras a protegerlo y gestionarlo.

Ninguna investigación se cierra en sí misma, y esta no es la excepción, por el contrario, es el punto de inflexión, de cierre y apertura. Esta tesis doctoral marca el fin de una etapa de reconocimiento del marco teórico-conceptual, de análisis empírico y de propuesta del tema abordado, y sienta las bases para la continuación en la etapa post-doctoral. La propuesta metodológica para valorar, intervenir y gestionar $\mathrm{PUH}$, presentada en la Parte 3 , permite integrar los conocimientos en los que se ha ahondado en las Partes 1 y 2, y generar un cierre, aportando un instrumento para la planificación urbana como proceso continuo compuesto por sucesivas fases para atender la totalidad de un hecho complejo. En este caso, el $\mathrm{CH}$ mirado desde la integralidad del paisaje como $\mathrm{PUH}$, nos enfrenta día a día con el desafío de intervenir y gestionar la complejidad de realidades cambiantes. Desde esta postura, la tesis propone una introspección en esas realidades con miras a contribuir en mejores realidades presentes y futuras.

El cierre de la Parte 3 de la tesis, abre una etapa para la elaboración de la última instancia de la investigación, la Parte 4, a desarrollarse en los próximos dos años de duración de la beca postdoctoral asignada por Conicet.

En esta Parte, se plantea poner a prueba el proceso metodológico propuesto para la valoración, intervención y gestión de PUH latinoamericanos, haciendo una simulación de aplicación en el PUH de la ciudad de Buenos Aires. Se considera una simulación, dado que como se ha expresado a lo largo de la tesis, este tipo de procesos requiere de un abordaje multidisciplinario, y por el alcance de la investigación se estaría realizando de forma individual y desde la mirada de una única disciplina.

La bajada metodológica de un componente primario a un PUH concreto permitirá identificar aciertos y falencias de la propuesta, y realizar los ajustes necesarios requeridos para que cumpliendo y verificando la hipótesis central ideada, la metodología pueda ser aplicada en otros PUH latinoamericanos, colaborando de este modo, en el desafío que representa la intervención de los mismos.

Como observación final, si bien es cierto que la ciudad perfecta no existe, y que aún queda mucho por avanzar, las utopías y los sueños de las personas y las sociedades inspiran y permiten dirigir las grandes transformaciones de la humanidad. Son parte de la esencia humana y por supuesto, la arquitectura y el urbanismo son partícipes de esa esencia. 


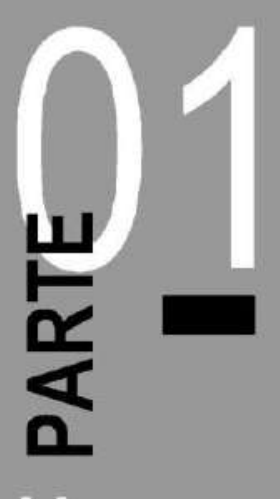

Marco

teórico -

conceptual

Fase Sincrética

o ldeatoria

Conceptos

fundamentales

que definen

el problema $\mathrm{CH}$

Cambios de

enfoques en

estrategias

de intervención

y gestión
Análisis de experiencias

Fase Analítica

Enfoques que guian las actuaciones

Análisis de casos de estudio

C

T

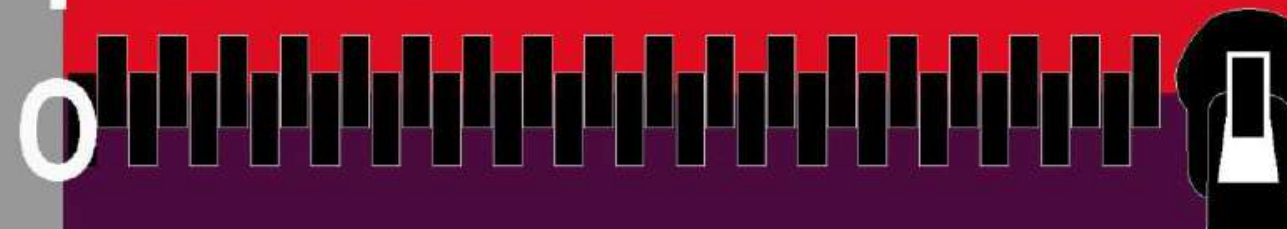

R

A

Propuesta

Fase Sintética u Operativa

Metodología para la valoración, intervención y gestión de PUH

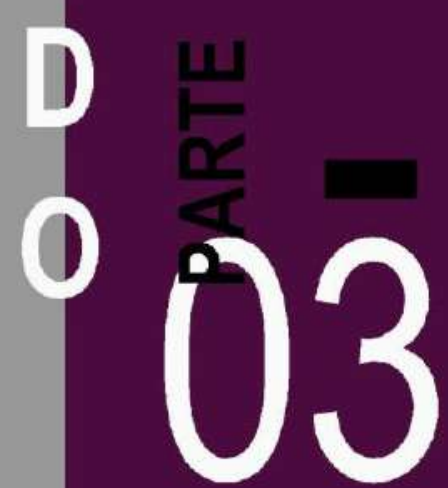
que integre los diversos aspectos claves abordados en las Partes 01 y 02 de la tesis

Conclusiones Finales
POST

\section{DOCTORADO}

Aplicación

Aplicación de la

Metodología

a un caso de estudio

Realización de ajustes a la propuesta metodológica

Conclusiones Finales del proceso completo de investigación

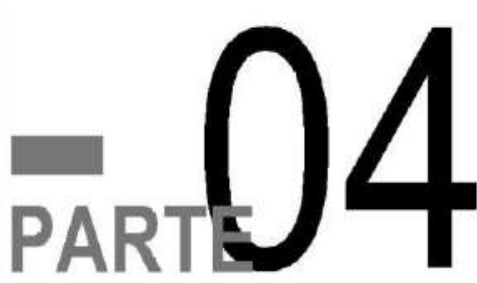




\section{ÍNDICE DE CUADROS, FIGURAS, GRÁFICOS Y TABLAS}

CUADROS (Elaboración propia)

\section{CAPITULO 3}

Cuadro III.1a: Contexto europeo: Casos italianos seleccionados.

Cuadro III.1b: Contexto europeo: Casos españoles seleccionados.

Cuadro III.2: Contexto latinoamericano: Casos seleccionados.

\section{CAPITULO 4}

Cuadro IV.1: Modelo de cuadro de similitudes y diferencias del $\mathrm{CH}$ y las intervenciones (ejemplo Italia.

Cuadro IV.2: Análisis cuantitativo de las problemáticas en Italia, España y AL.

Cuadro IV.3: Análisis cuantitativo de las intervenciones en Italia, España y AL.

\section{FIGURAS (Elaboración propia)}

\section{INTRODUCCIÓN}

Figura A: Proceso metodológico de la investigación.

Figura B: Estructura de la tesis

\section{CAPITULO 1}

Figura I.1: Las dimensiones del Desarrollo Sostenible.

Figura I.2: Dimensiones a considerar en la tesis.

\section{CAPITULO 2}

Figura II.1: Dimensiones del Desarrollo Sostenible según la ONU

Figura II.2: Dimensiones propuestas, a considerar en la tesis

Figura II.3: Proceso de Gentrificación. Elaboración propia en base a gráfico fuente: www.contestedcities.net

\section{CAPITULO 3}

Figura III.1: Síntesis de relación entre enfoques de Italia, España y América Latina

Figura III.2: Relación entre enfoques y estrategias.

Figura III.3a: Contexto europeo: Casos italianos seleccionados 
Figura III. 3b: Contexto europeo: Casos españoles seleccionados

Figura III.3c: Contexto europeo: Casos latinoamericanos seleccionados

Figura III.3d: Contexto europeo: Casos latinoamericanos seleccionados

Figura III.4a: Modelo de Fichas Síntesis

Figura III.4b: Fichas síntesis de los 40 casos

\section{CAPITULO 4}

Figura IV.1: Casos seleccionados. Casos paradigmáticos, enfoques y relaciones.

Figura IV.2: Características de los $\mathrm{CH}$.

Figura IV.3: Síntesis de problemáticas de los $\mathrm{CH}$ por dimensiones.

Figura IV.4: Síntesis de intervenciones en los $\mathrm{CH}$ por dimensiones.

Figura IV.5a, V.5b y V.5c: Experiencias innovadoras: por dimensiones e integrales.

\section{CAPITULO 5}

Figura V.1: Los desafíos de la intervención integral de los PUH

Figura V.2: Proceso metodológico para los $\mathrm{PUH}$ latinoamericanos

Figura V.3: Paso 1 - Organismo de gestión propuesto para PUH

Figura V.4: Esquema síntesis de la metodología para la valoración de PUH

Figura V.5: Pasos de la metodología para la valoración de PUH

Figura V.6: Proceso de síntesis de resultados

Figura V.7: Síntesis y definición de Áreas

Figura V.8: Síntesis valorativa

Figura V.9: Diseño de estructura para la elaboración de Estudio Particularizado por componente secundario

Figura V.10: Pasos de la metodología para la intervención de PUH

CAPITULO 6

Figura VI.4: Esquema de cierre y apertura. 


\section{GRÁFICOS (Elaboración propia)}

\section{CAPITULO 4}

Gráfico IV.1: Ejemplo de gráficos de análisis cuantitativo.

Gráfico IV.2a y V.2b: Síntesis análisis cuantitativo problemáticas e intervenciones para los 40 casos.

Gráficos IV.3a a V.3d: Porcentajes de tipologías de problemáticas -indicadores- en las cuatro dimensiones de análisis.

Gráficos IV.4a a V.4d: Porcentajes de tipologías de intervenciones -indicadores- en las cuatro dimensiones de análisis.

\section{TABLAS (Elaboración propia)}

\section{CAPITULO 2}

Tabla II.1: Clasificación de estrategias a adoptar.

\section{CAPITULO 3}

Tabla III.1a: Casos Identificados contexto europeo (Italia y España)

Tabla III.1b: Casos Identificados contexto latinoamericano

\section{CAPITULO 4}

Tabla IV.1: Porcentajes de problemáticas por dimensión para AL, Italia y España.

Tabla IV.2: Porcentajes de intervenciones por dimensión para AL, Italia y España.

CAPITULO 5

Tabla V.1: Indicadores propuestos para medir el valor del paisaje. 


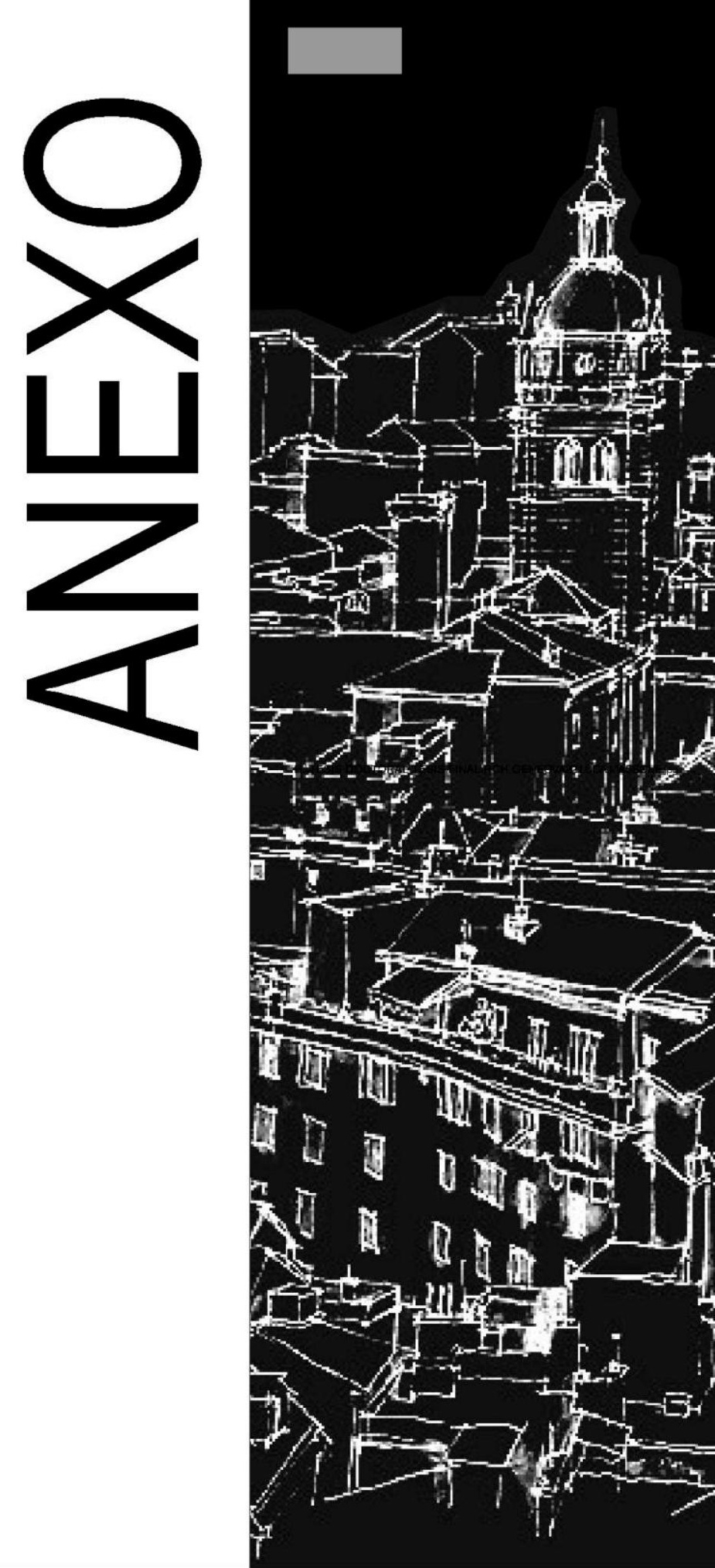


A1:

\section{Fichas de elaboración propia}

Fichas de análisis de casos europeos (italianos y españoles) y latinoamericanos.

A2:

\section{Cuadros de elaboración propia}

Cuadro A.2a: Contexto europeo: Italia. Similitudes de los $\mathrm{CH}$ y sus ciudades.

Cuadro A.2b: Contexto europeo: Italia. Diferencias de los $\mathrm{CH}$ y sus ciudades.

Cuadro A.2c: Contexto europeo: Italia. Similitudes de las intervenciones.

Cuadro A.2d: Contexto europeo: Italia. Diferencias de las intervenciones.

Cuadro A.2e: Contexto europeo: España. Similitudes de los $\mathrm{CH}$ y sus ciudades.

Cuadro A.2f: Contexto europeo: España. Diferencias de los $\mathrm{CH}$ y sus ciudades.

Cuadro A.2g: Contexto europeo: España. Similitudes de las intervenciones.

Cuadro A.2h: Contexto europeo: España. Diferencias de las intervenciones.

Cuadro A.2i: Contexto latinoamericano. Similitudes de los $\mathrm{CH}$ y sus ciudades.

Cuadro A.2j: Contexto latinoamericano. Diferencias de los $\mathrm{CH}$ y sus ciudades.

Cuadro A.2k: Contexto latinoamericano. Similitudes de las intervenciones.

Cuadro A.2l: Contexto latinoamericano. Diferencias de las intervenciones.

A3:

Análisis cuantitativo de problemáticas e Intervenciones: Gráficos de barras y de torta. Elaboración propia.

Gráfico A.3a: Problemáticas $\mathrm{CH}$. Dimensión Físico - Ambiental.

Gráfico A.3b: Problemáticas $\mathrm{CH}$. Dimensión Socio - Cultural.

Gráfico A.3c: Problemáticas CH. Dimensión Económica. 
Gráfico A.3d: Problemáticas CH. Dimensión Institucional. Gráfico A.3e: Problemáticas $\mathrm{CH}$. Todas las dimensiones.

Gráfico A.3f: Intervenciones CH. Dimensión Físico - Ambiental.

Gráfico A.3g: Intervenciones CH. Dimensión Socio - Cultural.

Gráfico A.3h: Intervenciones CH. Dimensión Económica.

Gráfico A.3i: Intervenciones CH. Dimensión Institucional.

Gráfico A.3j: Intervenciones $\mathrm{CH}$. Todas las dimensiones.

\section{BIBLIOGRAFÍA}




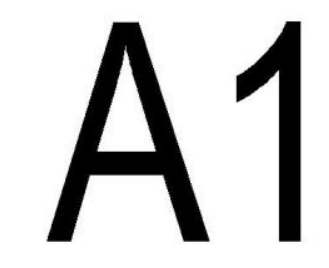

FICHAS DE LAS EXPERIENCIAS DE INTERVENCIÓN Y GESTIÓN SELECCIONADAS 
EXPERIENCIAS DE INTERVENCIÓN Y GESTIÓN EN CENTROS HISTÓRICOS

CONTEXTO EUROPEO I ITALIA

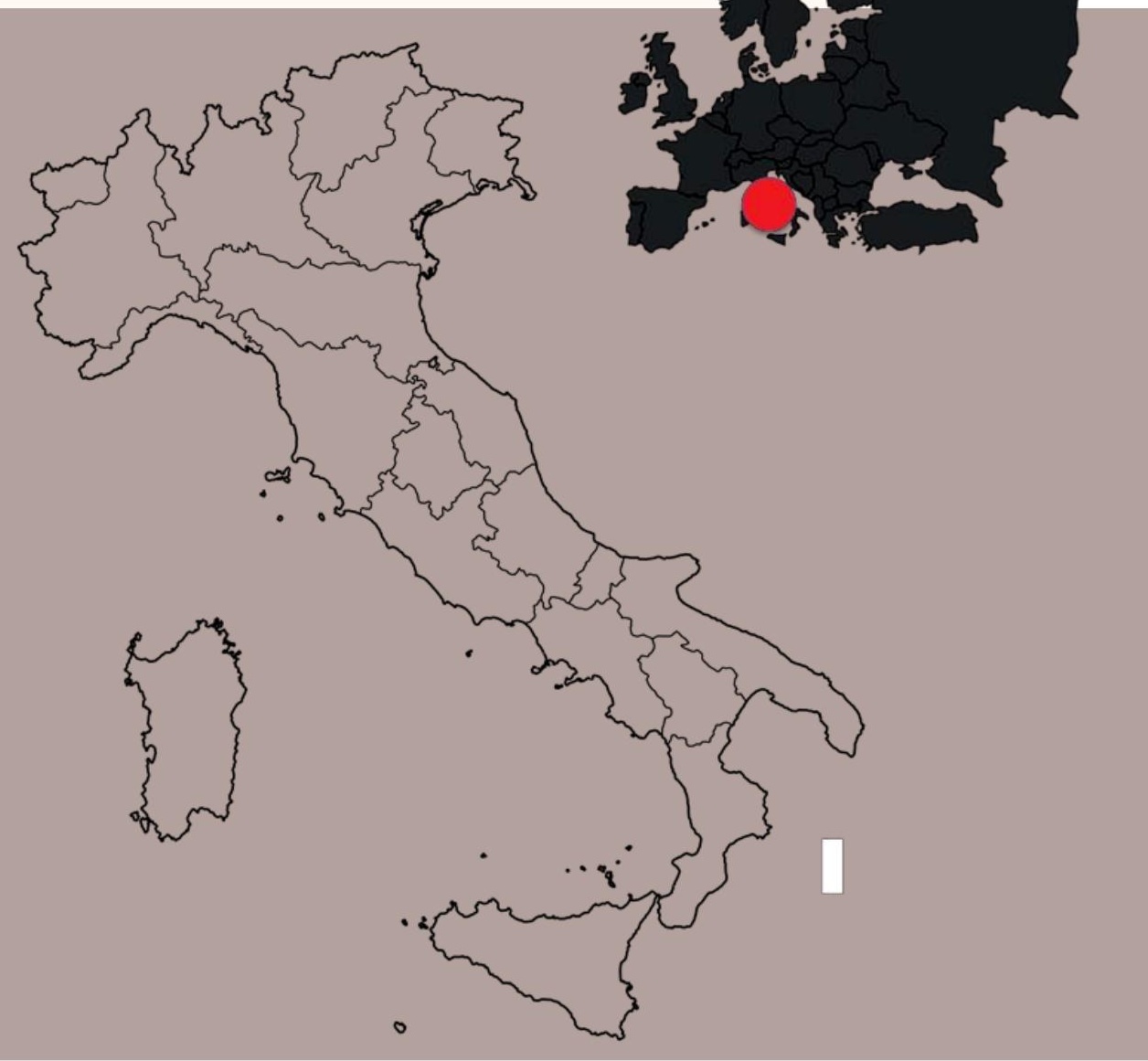




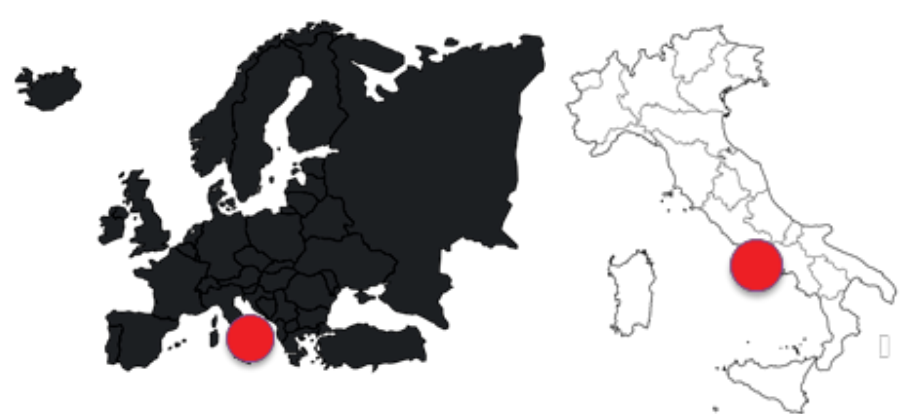

CARACTERÍSTICAS DEL CENTRO HISTÓRICO

Extensión: 11.727 has. (ciudad) / 1700 has.( $\mathrm{CH})$

Habitantes: 971.849 hab. (2016) / ...hab.(CH)

Inserción territorial: costa del Mar Medit erráneo, centro país

Dinám ica general y urbanística: es la tercera ciudad más grande de Italia, y una de las m ás antiguas de Europa. Su CH c onserva elem entos de su histórica estratificación que se expresan en sus calles y en las funciones urbanas y sociales que alberga. La grilla ort ogonal de la antigua fundación griega está aún present e y ha m arcado el desarrollo de la ciudad.

Especialización Funcional: ciudad portuaria. $\mathrm{CH}$ : residencial, comercial, adm in istrativa, turística, cultural.

Declaratorias: 1995, Patrim onio de la Hum anidad, UNESC O

Problem áticas: alta densidad poblacional, desem pleo, bajos niv eles de educación, existencia de ed ificios públicos y privados en decad encia, baja calidad de vivienda, dism inución del c om ercio tradicional m inorista por la aparición de grandes centros com erciales, precarias condiciones m edioam bientales: alto nivel de contam inación acústica y atm osférica (alto uso del transporte privado -autos y m otos- por falta de transportes alternativos).

\section{CARACTERÍSTICAS RELATIVAS A LA INTERVENCIÓN}

Tipo de intervención: Revitalización integral

Instrum ento de planificación: 2011, Plan de Gestión del Centro Histórico de Nápoles, Plan de Acción Local.

\section{F01}

EXPERIENCIAS DE INTERVENCIÓN Y GESTIÓN EN CENTROS HISTÓRICOS

REVITALIZACIÓN INTEGRAL DEL CENTRO HISTÓRICO DE NÁPOLES, CAMPAGNA, ITALIA

Objetivos: Conservar, preservar y revitalizar su patrim onio cultural, y la continuidad de su estratificación histórica; apoyar la producción socioeconóm ica y cultural inter-tradicional de m anufactura, turism o y com ercio; m ejorar el transporte, la infraestructura y proteger el medio am bien te, optimizando los recursos de la tierra y fortaleciendo la perspectiva regional del paisaje hist órico urbano; mejorar la calidad de vida, invirtiendo en producción del conocimiento e investigación. Del Plan de Acción Local: Recualificar la zona m onum ental frente al $\mathrm{m}$ ar y la zona urbana histórica cercana; dar nuevas funciones a la ciudad y al patri monio portuario para la regeneración urbana; apoyar el desarrollo socio-económ ico de Cittá Bassa.

Principales Ejes del Plan: Conservación, preservación y revitalización / Manufactura, turism o y com ercio / Transporte, infraestructura y m edio am biente.

Instrum ento de gestión: URBACT, Unión Europea

Estado: Por ejecutar

Nivel de inform ación: Muy bueno
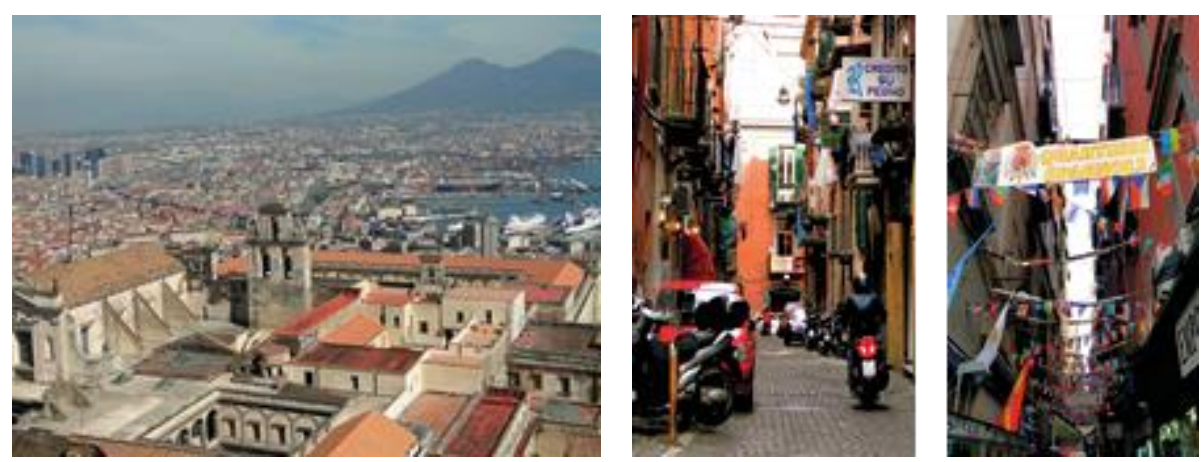

212

Fuentes: (2011); “Plan de Gestión del Centro Histórico de Nápoles Patrim onio de la Hum anidad”, Plan de A cción Local, URBACT, Unión Europea. 7 http $/ /$ urbact.eu/sit es/d efault/files/lap_naples.pdf 

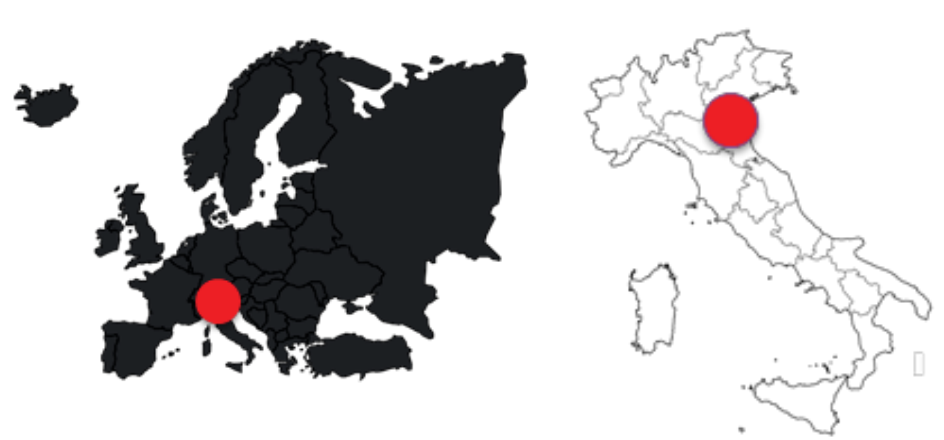

CARACTERISTICAS DEL CENTRO HISTÓRICO

Extensión: 1.408 .600 has. (ciudad) / 450 has. ( $\mathrm{CH}$ )

Habitantes: 371.217 hab. (2001)/ 50.000 hab.( $\mathrm{CH} 2014)$

Inserción territorial: en el norte del país, cercana a Apeninos

Dinám ica general y urbanística: $\mathrm{Su} \mathrm{CH}$ etrusco y rom ano, el segundo más grande de Europa después de Venezia, concentra gran riqueza urbana y arquitectónica. Sus características calles porticadas, $42 \mathrm{~km}$., han sido propuestos a la UNESCO en 2006 como Patrimonio de la Hum anidad.

Especialización Funcional: residencial, universitaria, cultural, com ercial, turística. Capital Europea de la Cultura.

Declaratorias: 2006, Ciudad Creativa de la Música, UNESCO

Problem áticas: $\mathrm{CH}$ m uy castigado durante la Segunda Guerra Mundial lo que conllevó num erosos problem as hacia la década del 60. Entre ellos, el principal era el abandono de gran parte de las viviendas, pero tam bién la falta de higiene, el peligro de derrum bam ient o de edificios aún deshabitados.

\section{CARACTERÍSTICAS RELATIVAS A LA INTERVENCIÓN}

Tipo de intervención: Rehabilitación

Instrum ento de planificación: 1958, Piano Regolatore; 1969, Piano per il Centro Storico; 1973, Piano di Edilizia Econom ica Popolare, Pier Luigi Cervellati - Roberto Scannavini.

Objetivos: Mantener las clases sociales m ás desfavorecidas y desarrollar casas para obreros para evitar dism inución de población; Conservar y desarrollar actividades de art esanía tradicional, comercio y servicios; Crear equipam ientos públicos de barrio (bibliotecas, escuelas, guarderías, centros de salud, et c.) y crear equipam ient os regionales. $\mathrm{CH}$ condensador social; Rehabilitar edificios prestigiosos para usos terciarios, con ayuda privada; Poner en m archa "Consejeros de barrios"; Desarrollar la actividad turística para la puesta e valor de monumentos históricos y tejido urbano; Prom over el "crecim iento cero".

Principales Ejes del Plan: Política de vivienda social, con alto porcentaje de vivienda de prom oción pública / Política de Reform as Urbanas, para obtener el máximo control público del suelo / Política de Servicios Públicos, para increm entar los equipamient os existentes / Política de Reform as Sociales, buscando la dem ocratización de las instituciones. Instrum ento de gestión: desde el Municipio de Bolonia Estado: Ejecutado

Nivel de inform ación: Muy bueno
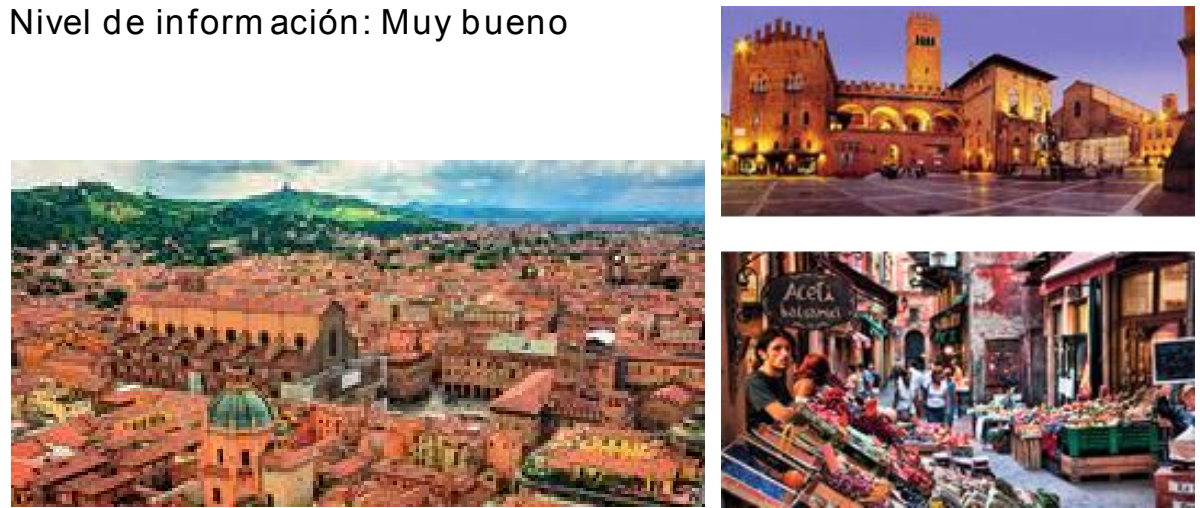

Fuentes: (2014); “Cuando el Plan de Bolonia er a una referencia urbanística (y de izquierdas para la intervención de los centros históricos de las ciudades (2.Ẻ Plan). En: http $/ /$ urban-netw orks.blogspot.com .ar/2014/08/cuando-el-plan-de-bolonia-era-una.htm I 


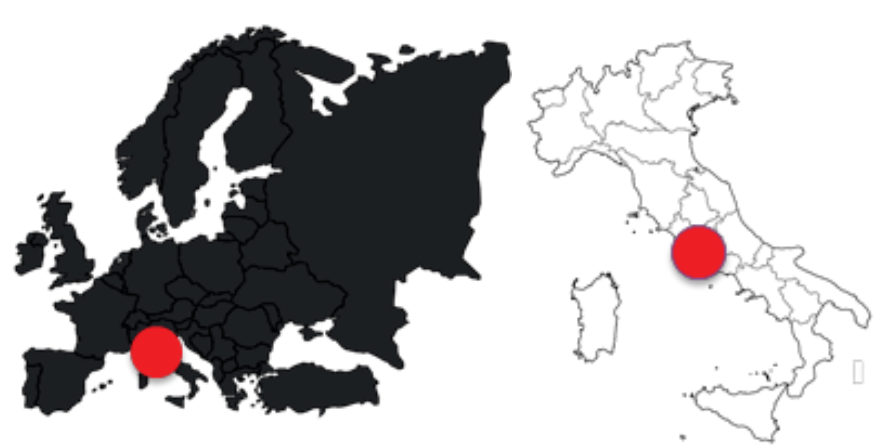

CARACTERÍSTICAS DEL CENTRO HISTÓRICO

Extensión: 128.500 has. (ciudad) 1500 has.( $\mathrm{CH})$

Habitantes: 2.872.082 hab. (2016) / 85.000 hab.( $\mathrm{CH} 2016)$

Inserción territorial: En el centro del país, construida sobre siet e colinas, en las riberas del Río Tiber.

Dinám ica general y urbanística: Ciudad capital del país, y del imperio rom ano con alta concentración de bienes hist óricos y arquitectónicos. Gran metrópoli de la hum anidad que influenció la sociedad, cultur a, lengua, literatura, arte, arquitectura, filosofía y derecho.

Especialización Funcional: $\mathrm{CH}$ es centro funcional, turism o

Declaratorias: 1980 , Patrim onio de la Hum anidad, UNESC O

Problem áticas: $m$ al estado de m onum entos históricos debido a la erosión, abandono y contam inación, desem pleo, deficientes servicios públicos, suciedad.

\section{CARACTERÍSTICAS RELATIVAS A LA INTERVENCIÓN}

Tipo de intervención: Recualificación

Instrum ento de planificación: 2003, Nuovo Piano Regolatore Generale PRG (actualización del PRG 1962).

Objetivos: Recualificar la ciudad, reem plazando la zonificación funcionalista, por nuevas categorías m orfológicas/program áticas, con m ayor atención a valores de los tejidos. Los nuevos grandes ám bitos son:

- La Ciudad Histórica, que se ha am pliado para com prender los tejidos realizad os entre las dos Guerras Mundiales.
EXPERIENCIAS DE INTERVENCIÓN Y GESTIÓN EN CENTROS HISTÓRICOS

REHABILITACIÓN DEL CENTRO HISTÓRICO DE ROMA, LAZIO, ITALIA

- La Ciudad consolidada, que incluye tejidos consolidados de form a estable, producto de la planificación de posguerra.

- La ciudad para reestructurar, que incorpora tejidos principalm ente ilegales, parcialmente configurados y mal definidos, que requieren saneam iento y adaptación.

- La ciudad de la transform ación, que com prende nuevas intervenciones. Se reem plazan lím ites del centro histórico (murallas) por la "Ciudad Histórica", que incorpora arquitectura moderna y contem poránea y lugares simbólicos, conciliando historia y proyecto, conservación y transform ación, con áreas estratégicas para transform ación.

Principales Ejes del Plan: Sist em a am biental / Sist em a de Movilidad / Sistem a de Solución / La ciudad construida Instrum ento de gestión: Com una di Roma, Estado: En ejecución (desde 2003)

Nivel de inform ación: Buena
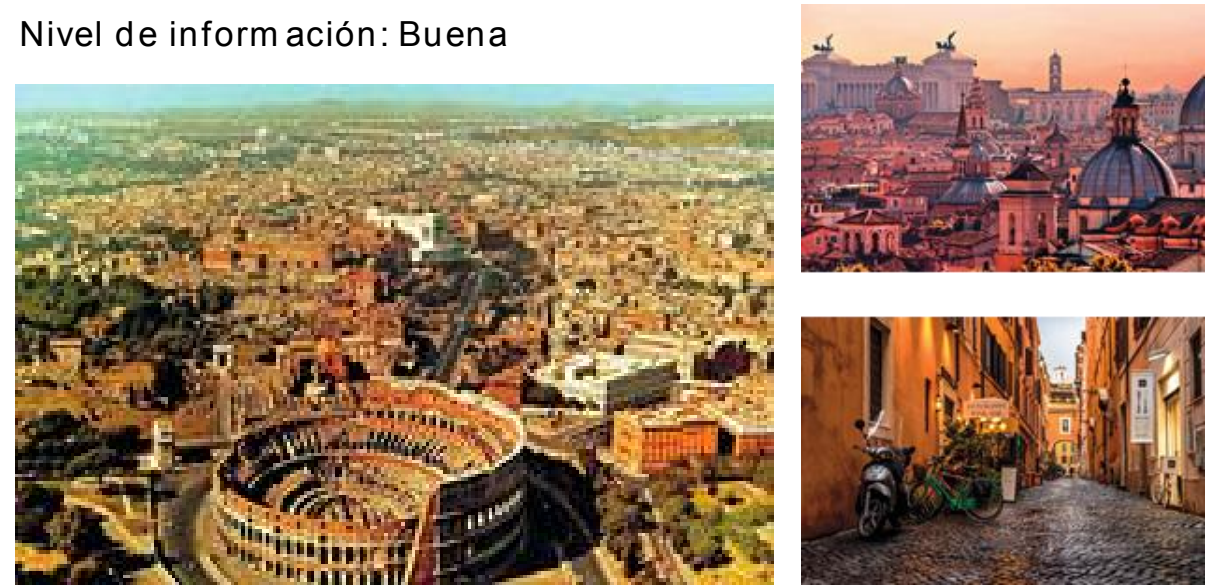

214

Fuentes: (2003); "Piano Regolat ore Generale di Rom a”, Com une di Rom a: www .urbanistica.com une.rom a.it/prg.htm I http $/ /$ www .u rbanistica.com une.rom a.it/prg-racconto/prg-racconto-cittastorica.htm I 

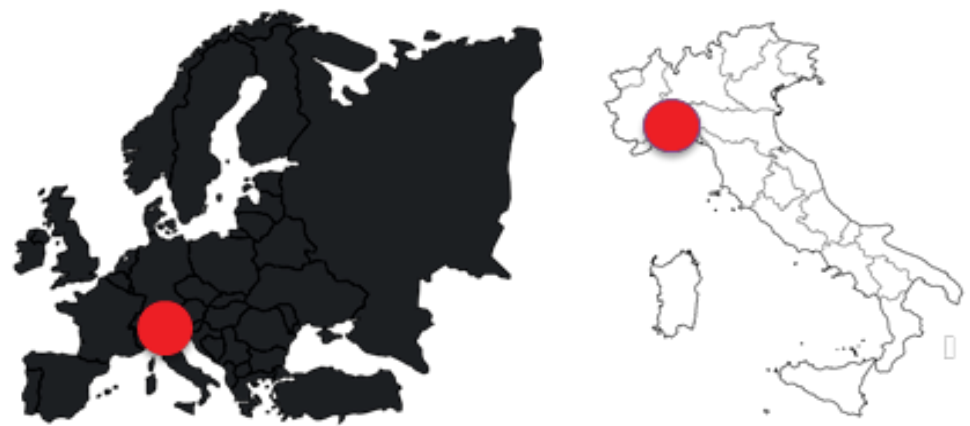

CARACTERÍSTICAS DEL CENTRO HISTÓRICO

Extensión: 24.400 has. (ciudad) / 198 has. $(\mathrm{CH})$

Habitantes: 594.904 hab. (2014)/ 19.453 hab.( CH 2007)

Inserción territorial: se ubica en las costas del mar de Liguria, junt o a colinas y m ontañas de gran altura. NO del país

Dinámica general y urbanística: antigua ciudad medieval europea, unida desde sus orígenes al puerto y actividad es m arineras, que fueron referencia en su historia política y cultural. Fue ocupada por rom anos, bizantinos y lom bardos.

Especialización Funcional: industrial a ocio. $\mathrm{CH}$ residencial

Declaratorias: 2004, Capital europea de la Cultura

Problem áticas: profunda degradación física, económ ica y social; gen trificación, dism inución de la población, alt o porcentaje de población anciana, problem as a causa de las inm igración ilegal; expansión de la prostitución y de la drogadicción en diversas áreas de la ciudad, suciedad, inseguridad.

\section{CARACTERÍSTICAS RELATIVAS A LA INTERVENCIÓN}

Tipo de intervención: Rehabilitación Int egral / regeneración Instrum ento de planificación: 2001, Plan Operativo del Centro Histórico (en el marco del Plan Urbano Municipal del año 2000, Plan estr atégico). Objetivos: Elim inar de form a gradual la degradación, m ejorando la habitabilidad, diversificando equipam ient os sociales y para las actividad es econó$\mathrm{m}$ icas, en pos de que el $\mathrm{CH}$ represent e la im agen cultural de la ciudad.
Fortalecer la centralidad del $\mathrm{CH}$; logar la int egración urbana, la conexión física y funcional real entre el $\mathrm{CH}$ y el Puert o Viejo; $\mathrm{m}$ ejorar las condiciones de vida mediante la remodelación de espacios públicos que pueden influir en la inversión del patrimonio edificado de las viviendas; crear un adecuado sist em a de accesibilidad; incorporar servicios especializad os; invertir en infraestructuras y servicios básicos (servicios públicos subterráneos, carreteras, alum brado público, lim pieza de calles). Principales Ejes del Plan: Fortalecim iento de la centralidad del $\mathrm{CH} /$ creación de un adecuado sist em a de accesibilidad / creación de servicios especializados / apoyo a la recuperación

Instrum ento de gestión: Adm inistración Municipal, program as y proyectos-Com unidad Europea (URBAN).

Estado: En ejecución (desde 2002)

Nivel de inform ación: Muy bueno
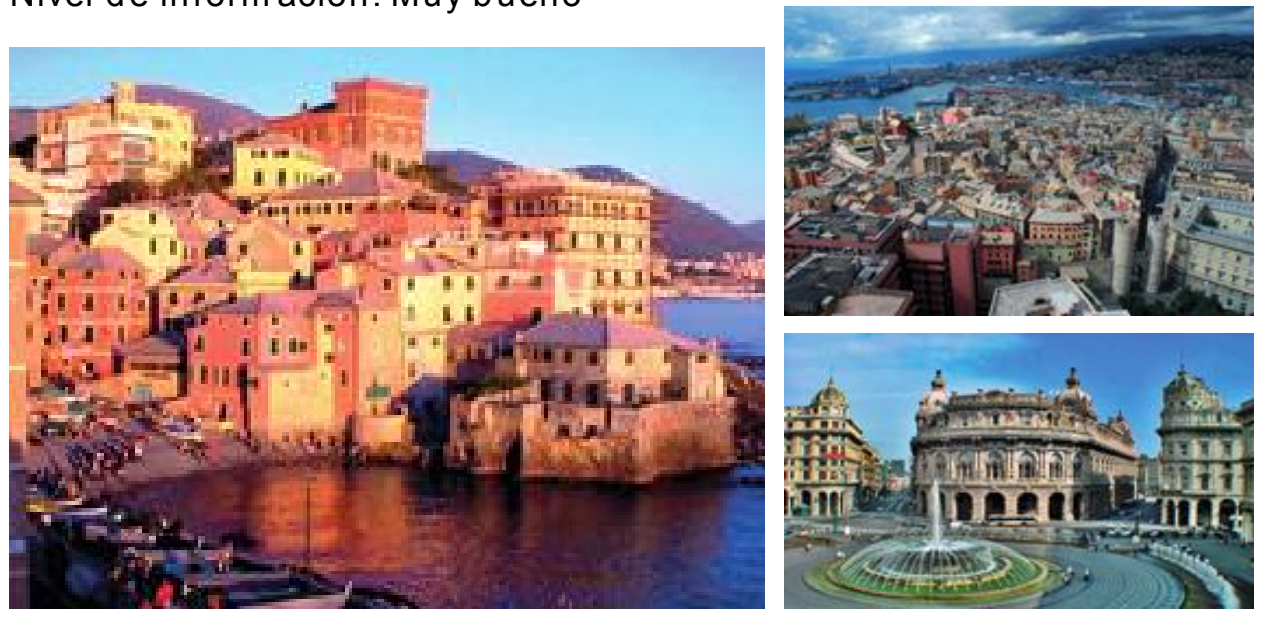

215

Fuentes: “ll Piano Operativo per il Centro Storico" -Com une di genova: http //civis.com une.genova.it/piano_operativo/ / (2014);

"Il recupero del Centro Storico" - Urban Center -Com une di Genova: http://www urbancenter.com une.genova.it/node/73 


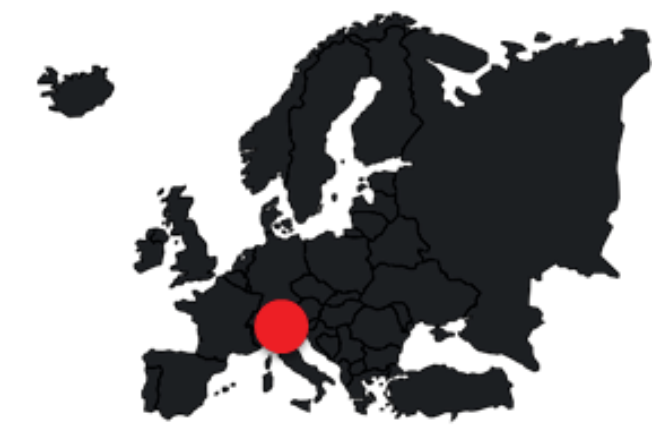

CARACTERÍSTICAS DEL CENTRO HISTÓRICO

Extensión: 18.167 has. (ciudad) / 967 has.( $\mathrm{CH}$ ).

Habitantes: 1.345.890 hab. (2012)/ 107.087 hab.( CH 2006)

Inserción territorial: Al Noroeste del país, buena localización para la vinculación con el resto de Europa.

Dinám ica general y urbanística: El CH contiene num erosos edificios, m onum entos y sitios de im portante valor histórico arquitectónico y artístico. Los bom bard eos de la Segunda Guerra Mundial dejaron varios espacios vacantes donde se construyeron edificaciones m odernas.

Especialización Funcional: Milán, es la capital económ ica, com ercial y financiera de Italia, una de las regiones $m$ ás desarrolladas del país. El $\mathrm{CH}$ concentra diversidad de usos.

Declaratorias: No posee

Problem áticas: gentrificación en el $\mathrm{CH}$, falta de vivienda social, congestión vehicular, contaminación am biental, problem as sociales como drogadicción, prostitución, delin cuencia.

\section{CARACTERÍSTICAS RELATIVAS A LA INTERVENCIÓN}

Tipo de intervención: Recualificación, regeneración

Instrum ento de planificación: 2012, Piano urbanístico di milano (PGT) Objetivos: Hacer frente a los cam bios del m ercado inm obiliario y de la sociedad civil, mediante la búsqueda de un nuevo equilibrio entre protección, intervenciones de transform ación y el cuidad o y la regeneración de la ciudad existente, a través de la aplicación de reglas claras;

\section{UAIAS DEINTERVENCION Y GESTION EN CENTROS HISTORICOS}

RECUALIFICACIÓN DEL CENTRO HISTÓRICO DE MILÁN, LOMBARDIA, ITALIA

satisfacer los tejidos físicos y sociales y poner en orden situaciones com plejas heredadas integrando políticas de infraestructura y medio am biente; fom entar la vivienda social luego de déc adas de apoyo al crecim iento inm obiliario y financiero; fortalecer los servicios públicos; construir un nuevo modelo de desarrollo de recursos ambientales y energéticos. CH: Asegurar la recualificación del tejido histórico, promover la protección, conservación, uso y desarrollo del patrim onio cultu ral de la ciudad, estableciendo tipos de intervención según niveles de interés y valor histórico del m edio construido.

Principales Ejes del Plan: Búsqueda de equilibrio entre protección y transform ación / Recualificación del tejido histórico / Vivienda social / Protección, conservación y uso del patrimonio cultural / Servicios Públicos / Recursos am b .-enérg

Instrum ento de gestión: Com una de Milán

Estado: En ejecución (desde 2012)

Nivel de inform ación: Buena
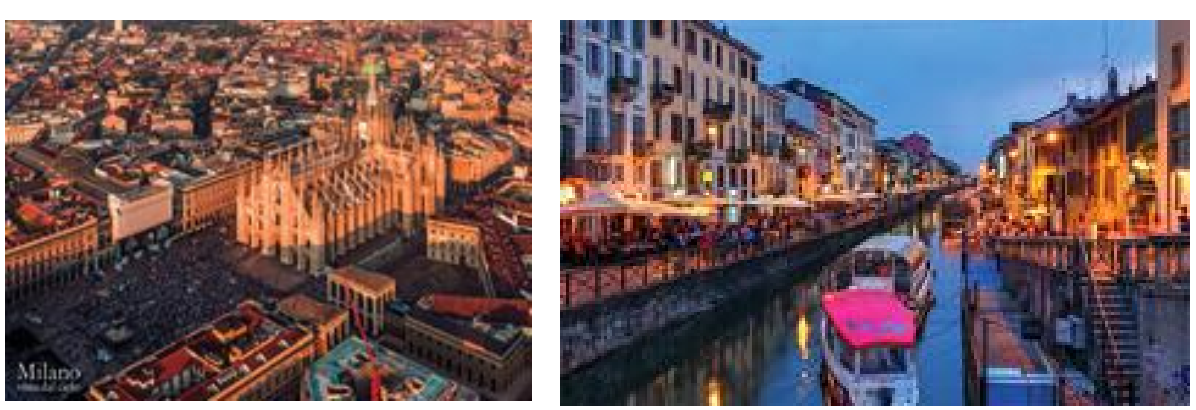

Fuentes: Arcidiacono A., Galuzzi P., Pogliano L., Rota G., Solero E., Vitillo E. (2013); "Il piano Urbanístic o di Milano (PGT 2012)”, TeknoeBook, Wolters Kluwełlkglia s.r.l, Milano. Com une di Milano. 

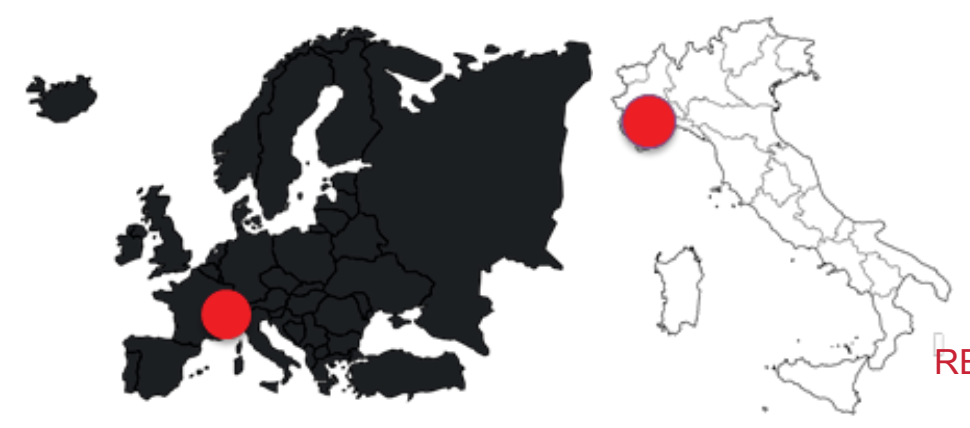

CARACTERISTICAS DEL CENTRO HISTÓRICO

Extensión: 13.020 has. (ciudad) / 230 has.(BH)

Habitantes: 911.823 hab. (2012) / 53.500 hab.(BH 2011)

Inserción territorial: norte del país, margen izquierda del río Po, en una planicie rodeada por los Alpes.

Dinám ica general y urbanística: ciudad rica en cultura e historia, reconocida por su arquitectura barroca, rococó, neoclásica y Art Nouveau. Antiguo centro celta, fue colonia rom ana, bizantina, longobardo y franco. Especialización Funcional: centro cultural y de negocios, de los principales centros industriales (automovilística) y comerciales de Europa. $\mathrm{BH}$ : ind ustrial, residencial

Declaratorias: No posee

Problem áticas: Degradación física; pérdida de identidad y función en espacios público; necesidad de reconversión.

\section{CARACTERÍSTICAS RELATIVAS A LA INTERVENCIÓN}

Tipo de intervención: Regeneración Urbana

Instrum ento de planificación: 2011, “Urban Barriera di Milano”, proyecto del Program a Integrado de Desarrrollo Local, PISU - Program a de Regeneración Urbana, 1990. (en el m arco del Piano Regolat ore Generale di Torino, 2014).

Objetivos: Desencadenar un proceso de mejora integral a través de 34 intervenciones organizadas en 6 Ejes que operan sobre aspect os físicoam bientales, económ icos y socio-culturales e interviniendo m ediante prom oción, cooperación e interacción de los actores involucrados.

1. Trabajar sobre el espacio público y lugares de integración del barrio y devolverles funcionalidad, seguridad, y belleza.

2. Recualificar y ofrecer nuevos espacios y lugares de int egración com o antiguas fáb ricas ab and onadas.

3. Abordar el trabajo en múltiples aspect os, creando condiciones para atraer nueva actividades económ icas.

4. Ofrecer nuevas oportunidades de socialización, de disfrute cultural y de servicios a través de participación activa.

5. Relacionar, com unicar y acom pañar las transform aciones urbanas del entorno inm ediato.

6. Fom entar la m em oria hist órica y el valor por el pasado.

Principales Ejes del Program a: 1.Barriera que Mejora / 2.Barriera se Transform a / 3.Barriera Trabaja / 4.Barriera Vive / 5.Barriera m ira a su alrededor / 6.Barriera que recuerda.

Instrum ento de gestión: Com ité URBAN / Financiam ient o: Com une di Torino, Regione Piem ont e, Com unidad Europea (fond os FEDER).

Estado: Ejecutado (2011-2015)

Nivel de inform ación: Muy bueno

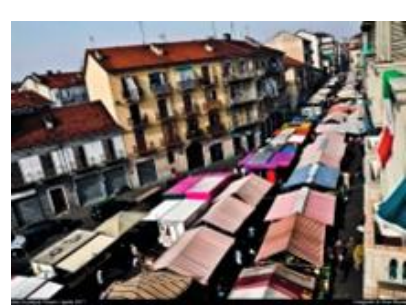

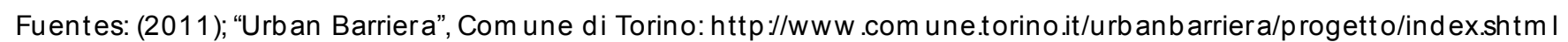

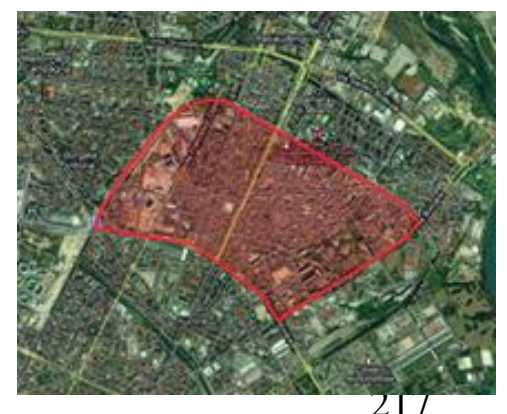

211 


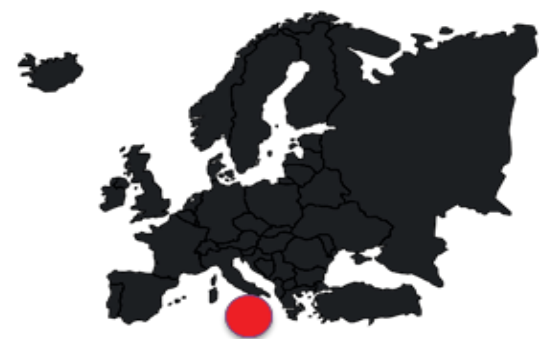

CARACTERÍSTICAS DEL CENTRO HISTÓRICO

Extensión: 15.890 has. (ciudad)/ 250 has. $(\mathrm{CH})$

Habitantes: 860.00 hab. (2016) / 21.489 hab.( $\mathrm{CH} 2001)$

Inserción territorial: En la isla de Sicilia, al sur de Italia, paisaje único de elem entos naturales y culturales.

Dinámica general y urbanística: Encrucijada y lugar de reunión de m uchas dom inaciones, grupos étnicos, culturas $m$ ajestuosas y populares que duraron por siglos y que aún perduran. $\mathrm{Su} \mathrm{CH}$ fue sede de la Cosa Nostra, capital de la m afia, quien gobernó la ciudad después de la Segunda Guerra Mundial y destruyó el CH, hasta 1992, donde el Estado em pezó a luchar contra el crim en organizado.

Especialización Funcional: residencial, institucional, cultur al

Declaratorias: 2015, Conjunto "Palermo árabe-normando y las catedrales de Cefalú y Monreale" Patrim onio UNESCO

Problem áticas: degradación por la Guerra y la m afia, escaso m antenim iento edilicio y restauración, derrumbes, disminución de habitant es y activid ad es, problem átic a social: $m$ arginalid ad, crim inalid ad, inm igración ilegal.

CARACTERÍSTICAS RELATIVAS A LA INTERVENCIÓN

Tipo de intervención: Recuperación, conservación

Instrum ento de planificación: 1993, Piano Particolareggiato Esecutivo del Centro Storico di Palerm o (PPE) - Pier Luigi Cervellati / Leonardo Benevolo. Objetivos: Intervenir la ciudad am urallada, anulando la "t eoría de destri-
EXPERIENCIAS DE INTERVENCIÓN Y GESTIÓN EN CENTROS HISTÓRICOS

RECUPERACIÓN DEL CENTRO HISTÓRICO DE PALERMO, SICILIA, ITALIA

par", en pos de "conservar". Estudiar la hist oria de la ciudad y sus procesos de transform ación com o m atrices para el diseño; Conservar la Ciudad Antigua (incluyendo los aportes de todas sus fases históricas que incidieron en el diseño de sus calles, manzanas, edificios, los usos y hábitos sociales), corrigiendo, en la medida de lo posible, los recient es cam bios incom patibles con ella, adaptándose a condiciones y requisitos funcionales actuales, y a la convivencia con el medio am biente de la ciudad moderna; Im plem entar int ervenciones totales o parciales de restauro, reestructuración, dem olición, obra nueva, ripristino sobre el patrim onio edilicio; Conservar del uso residencial.

Principales Ejes del Plan: Conservación del patrim onio edilicio (particu larm ente Vivienda) y Espacios vacantes.

Instrum ento de gestión: Ayuntam iento (Financ. Públ.-Priv.)

Estado: En ejecución (desde 1993)

Nivel de inform ación: Muy bueno
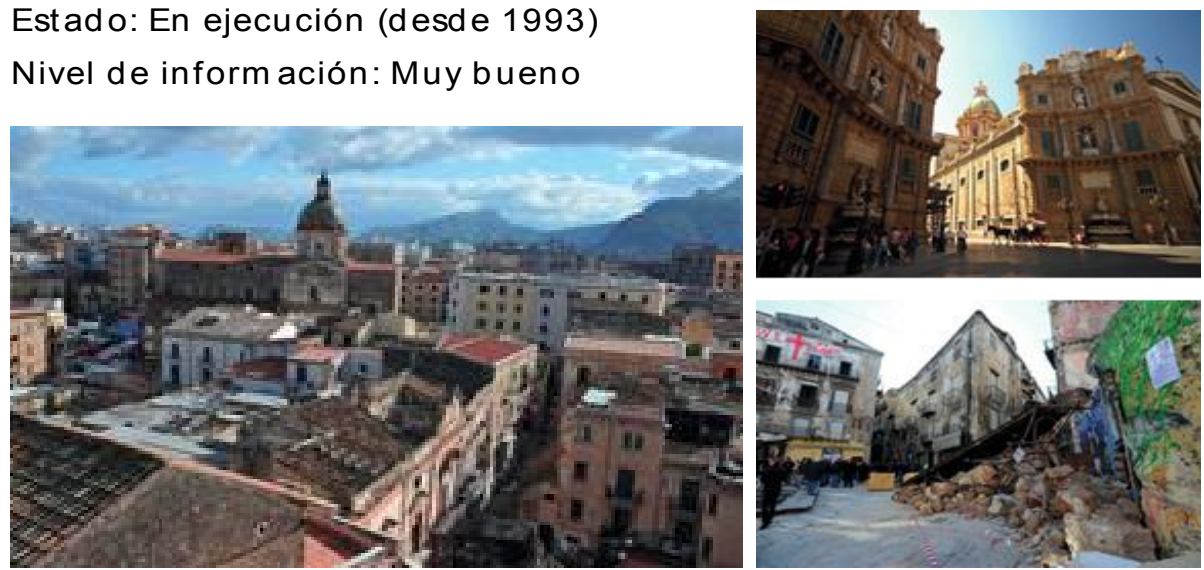

Fuentes: (1993); “Piano Particolareggiato Esecutivo del Centro Storico di Palerm o”, Com une di Palerm o:

http //ideam .alt ervista.org/files_da_pubblicare/Norm e\%20Tecniche\%20Attuazione\%20Centro\%20Storico\%20di\%20Palerm o\%20-\%20P.P.E..pdf / Cannarozzo T. Manfredi L. (2011); “Palerm o: el proceso de recuperación del centro histórico". En Reencuentro2, Libro de las $V$ Jornadas Int ernacionales de Experiencias de Re vitalización de Cascos Históricos, Buenos Aires, Argentina. 


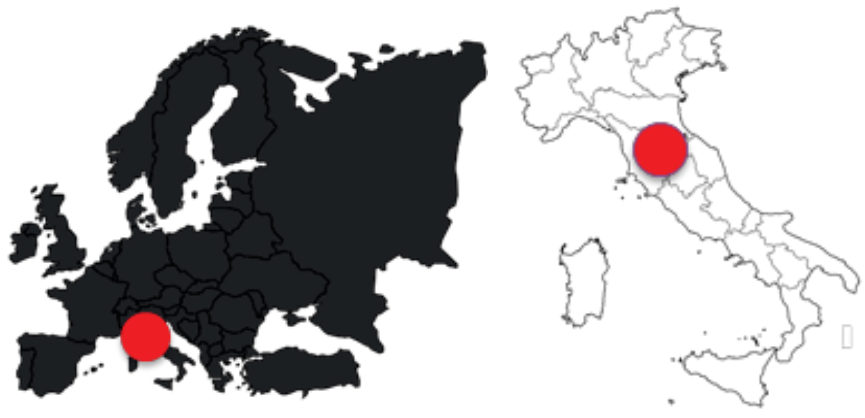

CARACTERÍSTICAS DEL CENTRO HISTÓRICO

Extensión: 10.200 has. (ciudad)/ 1.139 has. $(\mathrm{CH})$

Habitantes: 378.236 hab. (2012) / 67.170 hab.( $\mathrm{CH} 2006)$

Inserción territorial: zona norte-centro del país, sobre una llanura atravesada por el río Arno y rodeada de colinas.

Dinám ica general y urbanística: El CH es em blem a del arte y cultura italiana en el m undo, conjunto artístico único, de creación continua durante seis siglo. Adem ás de museos, concentra la mayor cantidad de obras de arte reconocidas m undialm ente. Su entorno urbano se mantiene casi intacto, respetando raíces m edievales e identidad renacentista, y el paisaje natural aporta características propias de la Toscana.

Especialización Funcional: turística, cultural, residencial

Declaratorias: 1982, Patrim onio de la Hum anidad, UNESC O

Problem áticas: im pacto del turism o de m asas, tráfico urbano, contam inación del aire, gentrific ación, dism inución del núm ero de residen tes, de la art esanía local y de com ercios históricos de barrio, desorden de la im agen urbana, señalización caótica, ocupación excesiva del espacio público, com ercio inapropiado.

\section{CARACTERÍSTICAS RELATIVAS A LA INTERVENCIÓN}

Tipo de int ervención: Preservación

Instrum ento de planificación: 2016, Plan de Gestión del Centro Histórico de Florencia, UNESCO (previo 2006).

Objetivos: Preservar el valor universal excepcional a lo largo del tiem po,
RIENCIAS DE INTERVENCIÓN Y GESTIÓN EN CENTROS HISTÓRICOS

PRESERVACIÓN DEL CENTRO HISTÓRICO DE FLORENCIA, TOSCANA, ITALIA

entendiendo al Plan como una herramienta estratégica y operativa que reúne num erosas dim ensiones territoriales involucradas e identifica objetivos y acciones concretas para hacer frente a las am enazas; Mitigar los cinco riesgos que podrían interferir con la preservación del $\mathrm{CH}$, y por lo tanto de su integridad y autenticidad:

- Congestión del $\mathrm{CH}$ debido al turismo de masas

- Conservación del patrim onio monum ental

- Sistem a de transporte y contam inación am biental

- Peligro de inundaciones del Río Arno y riesgos relacionados c on el cam bio clim ático

- Reducción de resident es en el $\mathrm{CH}$

Principales Ejes del Plan: Credibilidad / Conservación / Desarrollo de capacidades / Com unicación / Com unidades

Instrum ento de gestión: Oficina de Gestión de Sitios Patrimonio de la Hum anidad, Com una de Florencia

Estado: En ejecución (desde 2006)

Nivel de inform ación: Muy bueno
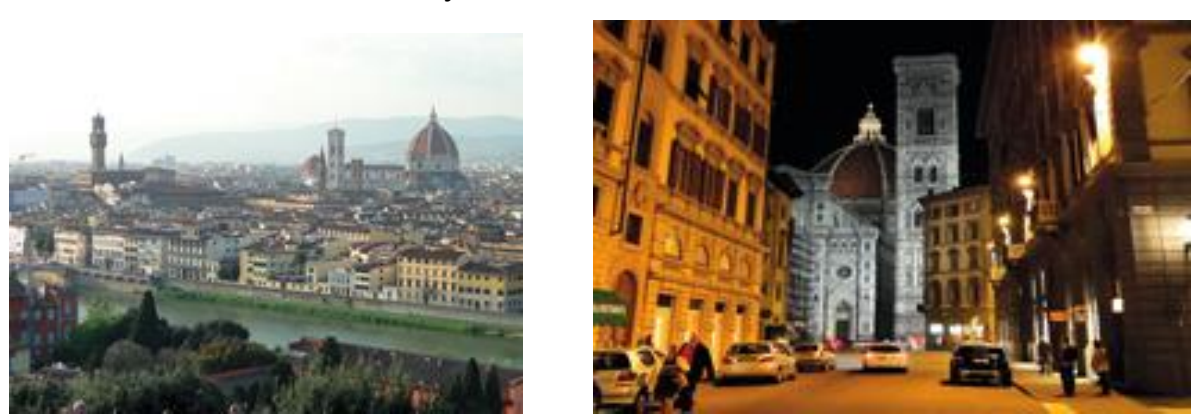

219

Fuentes: (2016); "The Managem ente Plan of the Historic Centre of Florence -UNESCO World Heritage", Com une di Firen ze:

http $/ /$ www firenzepatrim oniom on diale.it/en/piano-di-gestione/ http $/ / w w w$ firenzepatrim oniom ondiale.it/wp -content/uploads/2015/12/nuovo-Piano-di-GestioneFirenze.pdf 


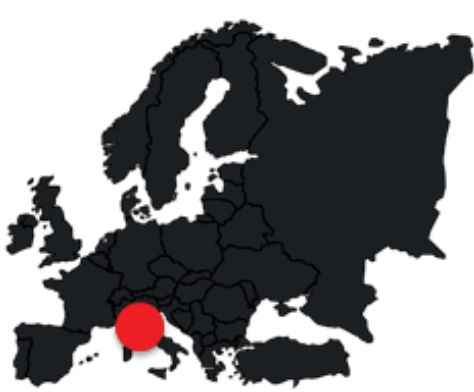

CARACTERÍSTICAS DEL CENTRO HISTÓRICO

Extensión: 11.800 has. (ciudad) / 170 has.( $\mathrm{CH}$ )

Habitantes: 52.774 hab. (2012) / 10.500 hab.( CH 2015)

Inserción territorial: sobre tres colinas, en NOE-centro país

Dinám ica general y urbanística: $\mathrm{El} \mathrm{CH}$, de origen etrusco, es la encarnación de una ciudad medieval. Entre los s. XII y XV adquirió apariencia de ciudad gótica. Es un centro vivo, que concentra todas las actividades urbanas.

Especialización Funcional: residencial, com ercial, cultural

Declaratorias: 1995, Patrim onio de la Hum anidad, UNESC O

Problem áticas: estadías turísticas cortas, contam inación del patrimonio cultural, incapacidad de com unicar y valorar el patrim onio históricoartístico, fuerte oscilación entre el flujo de turistas en alta y baja t em porada, hecho que incide en la estabilidad y c alidad del trabajo turístico. Posibilidad de fenóm enos degenerativos (reem plazo de com ercio barrial por turísticos), riesgo de museificación del patrimonio cultural, riesgo de pérdida de actividad art esanal y com ercial hist órica, carencia de recursos para obras de conservación del $\mathrm{CH}$.

\section{CARACTERÍSTICAS RELATIVAS A LA INTERVENCIÓN}

Tipo de intervención: Tutela, conservación y valorización

Instrum ento de planificación: 2015-2018, Piano di gestione del Sito UNESCO Centro Storico di Siena.

Objetivos: Garantizar la identificación, tutela, conservación, valorización y

Fuentes: (2015); "Piano di Gestione del Sit o UNESCO Centro Storico di Siena", Com une di Siena: http $/ /$ www .com une.siena.it/La-Citta/Territorio/Direzione- 220

Territorio-Sport ello-Unico-e-Attivita-Econom iche/U cio-Centro-Storico-e-Sito-Unesco/Il-nuovo-Piano-di-Gestione-2015-2018

transm isión a las generaciones futuras del Sitio y crear las condiciones para su desarrollo; Desarrollar cinco Planes de Acción sectoriales:

- Plan de Acción para la tutela, conservación y valorización del patrim onio - Plan de Acción para la seguridad del am bient e urbano

- Plan de Acción para la investigación y el conocim iento

- Plan de Acción para la valorización cultural (turismo)

- Plan de Acción para la movilidad

Principales Ejes del Plan: Territorio (que sint etiza consideraciones sobre infraestructura, m ovilidad y accesibilidad)/ Sociedad y Econom ía (que sintetiza consideraciones sobre la actividad económica, la composición de los habitant es y el m ercado inm obiliario) / Turismo (zoom dedicad o com o tem a clave) / Patrim onio (que sintetiza los argum entos relativos al estado del Sitio.

Instrum ento de gestión: Com una de Siena

Estado: En ejecución (desde 2011)

Nivel de información: Muy bueno
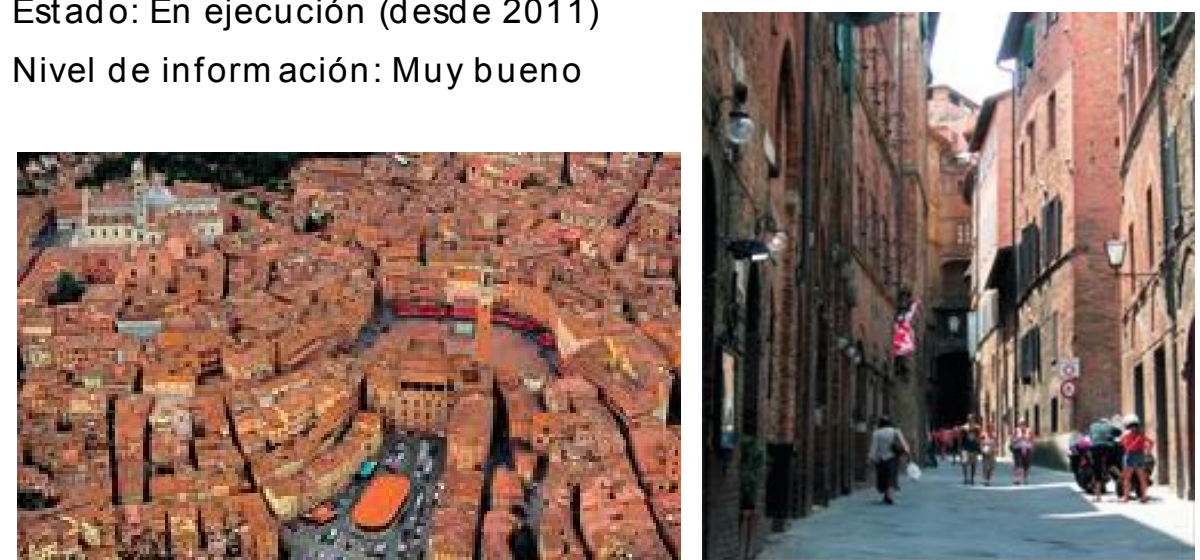


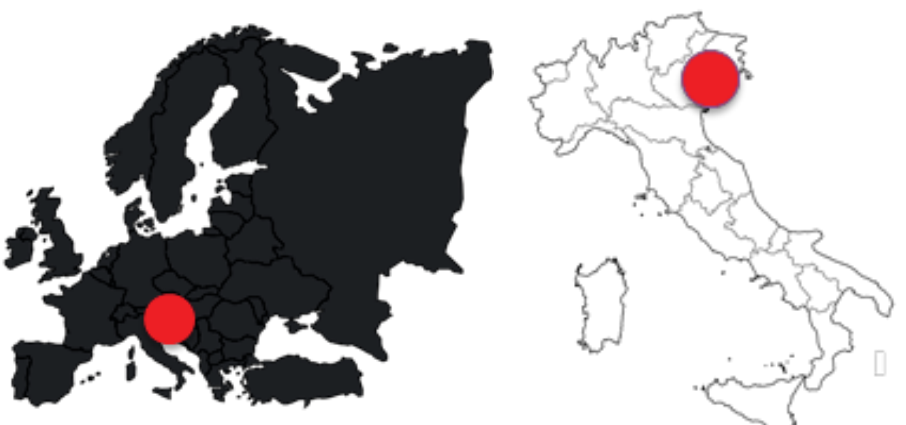

CARACTERÍSTICAS DEL CENTRO HISTÓRICO

Extensión: 15.700 has. (ciudad hist órica)

Habitantes: 270.884 hab. (2011) / 60.020 hab. ( $\mathrm{CH} 2009)$

Inserción territorial: la ciudad fue construida sobre 118 pequeñas islas y parece flotar sobre la laguna,

Dinám ica general y urbanística: Venecia y su laguna es un ecosistem a unitario, de valor universal excepcional desde lo histórico y artístico, integra valores naturales y culturales. Gran complejidad, patrim onio histórico-artístico, arqueológico, am biental, asentamient os urbanos, turism o e infraestructuras.

Especialización Funcional: turística, com ercial, residencial

Declaratorias: 1987, Venecia y su Laguna declaradas Patrim onio de la Hum anidad, UNESCO

Problem áticas: frágil patrim onio urbano, arquit ectónico y artístico; escasez de fondos para restauración y $\mathrm{m}$ antenim iento urbano; reducción de la población residente en la ciudad histórica y en los otros asentam ientos históricos de la laguna; reducción de actividades y servicios de la $\mathrm{CH}$ a favor del turism o; concentración de turism o, uso excesivo; insuficiente accesibilidad y movilidad; agotam iento y deterioro físico de la $\mathrm{CH} ; \mathrm{m}$ ala int egración entre sist em as de transporte.

\section{CARACTERÍSTICAS RELATIVAS A LA INTERVENCIÓN}

Tipo de intervención: Conservación, regeneración

Instrum ento de planificación: 2012-2018, Plan de Gestión de Venecia
EXPERIENCIAS DE INTERVENCIÓN Y GESTIÓN EN CENTROS HISTÓRICOS

PROTEGER Y REHABILITAR EL CENTRO HISTÓRICO DE VENECIA, VÉNETO, ITALIA

y su laguna. (Piano Regolatore Generale per il Centro Storico di Venezia, Cittá Antica,1999)

Objetivos: Proteger, rehabilitar y mejorar asentamientos humanos, m edio am biente y paisaje; Proteger, restaurar y $m$ ejorar el patrim onio arquitectónico, arqueológico, histórico-artístico, etno-antropológico, de archivo; Reconstruir el tejido social y económico históricos e incrementar población resident e; Racionalizar flujos turísticos; Preservar y apoyar actividades productivas; Mejorar accesibilidad, m ovilidad y transporte; Desarrollar conciencia del valor del Sitio; Coordinar y prom over iniciativas culturales y m arketing; Desarrollar recursos hum anos; Difund ir la in vestigación. Principales Ejes del Plan: Protección y Conservación del Patrim onio / Uso sustentable del Sitio / Com unicación, prom oción y entrenam ien to / Conocim iento y difusión (4 PA).

Instrum ento de gestión: Oficina de Gestión de Sitios Patrim onio de la Hum anidad, Municipalidad de Venecia.

Estado: En ejecución (desde 2012)

Nivel de inform ación: Muy bueno

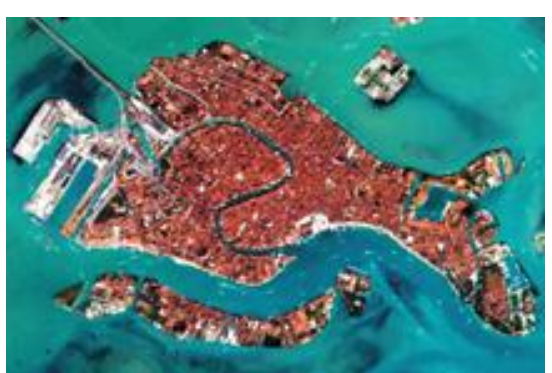

Fuentes: (2002); "Variante Piano Regolatore generale per il Centro Storico di Venezia, Cittá Antica”, Com uni de Venezia: https//www.com une.venezia.it/archivio/48035/http $/ /$ www .veniceandlagoon.net/web/wp-content/uploads/2014/12/MP_volum e_low_eng.pdf 


\section{$F 11-F 20$}

EXPERIENCIAS DE INTERVENCIÓN Y GESTIÓN EN CENTROS HISTÓRICOS

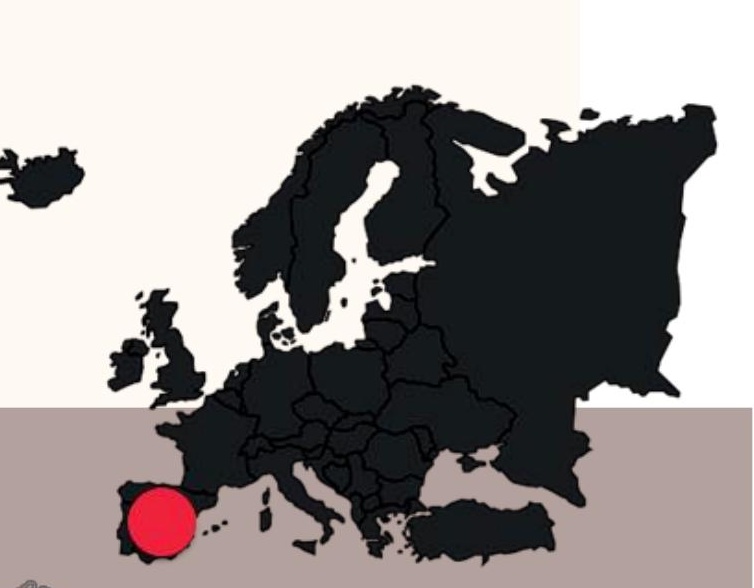

CONTEXTO EUROPEO I ESPAÑA

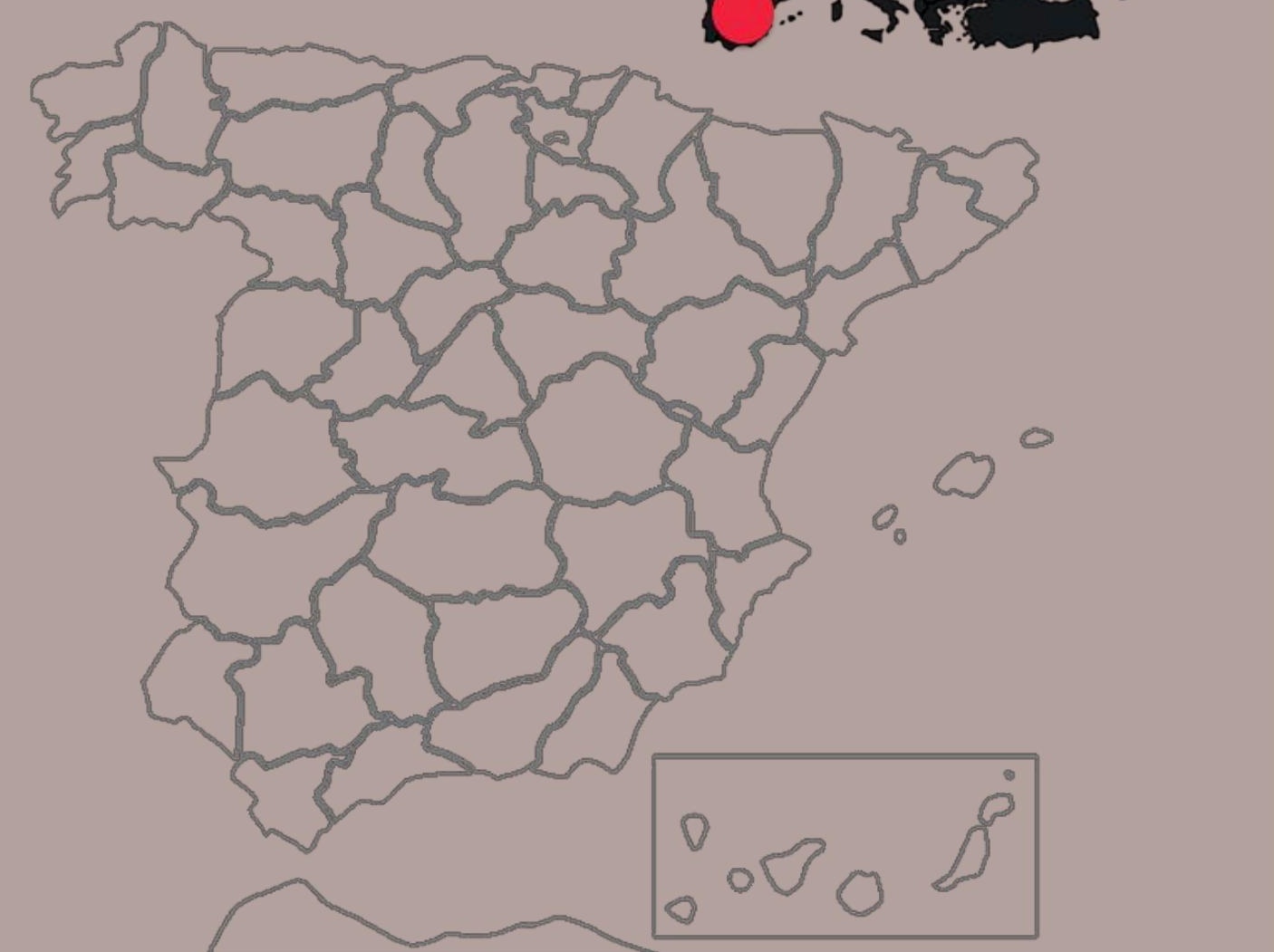




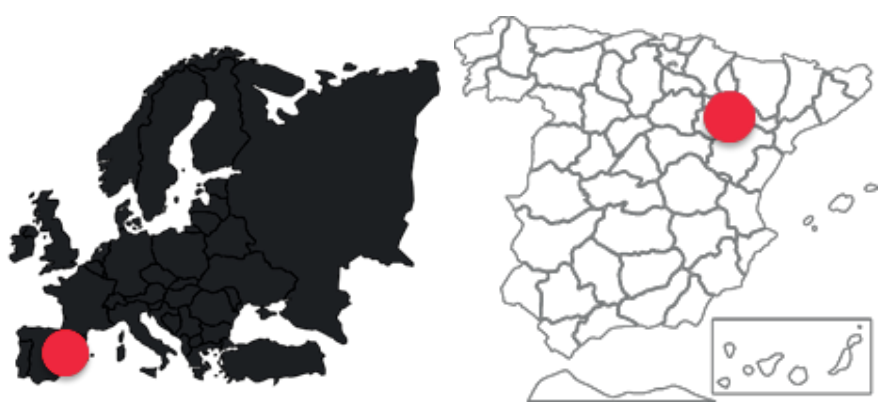

CARACTERÍSTICAS DEL CENTRO HISTÓRICO

Extensión: 97.378 has. (ciudad) / CH 198 has.

Población: 664.953 hab. (2015) / CH 46.821 hab. (2015)

Inserción territorial: a orillas del río Ebro, Huerva y Gallego en el centro de un am plio valle. Situación estratégica.

Dinám ica general y urbanística: Es el segundo $\mathrm{CH}$ más extenso de España, e incluye el área delimitada por las murallas romanas, (s.III) que encerraron toda la ciudad hasta el s. XIII. Concentra los p rincipales m onum entos de la ciudad, rest os rom anos, $m$ edievales, valiosa riqueza patrim onial mudéjar o judía y palacios renac entistas.

Especialización Funcional: ciudad de gran actividad económica. El $\mathrm{CH}$ concentra usos mixtos.

Declaratorias: Conjunto Histórico de Interés Cultural

Problem áticas: disminución de habitantes por población envejecida; infravivienda; vivien das vacías abandonadas como resultado de la expulsión de población autóctona (gentrificación y especulación). Muchas de estas viviendas se encontraban junto a predios abandonados, generando focos de problem as sociales como drogadicción y prostitución; falta de espacios verdes; contam inación acústica,

\section{CARACTERÍSTICAS RELATIVAS A LA INTERVENCIÓN}

Tipo de intervención: Revitalización

Instrum ento de planificación: 1997-2004 Plan Int egral del Casco Histó- rico, PICH; 2005-2012, Reno vación PICH; 2007-2014, Reno vación PICH. Objetivos: Recuperación funcional de las áreas degradadas del CascoHistórico mediante su revitalización socioeconómica y patrimonial; generar em pleo y bienestar y transform ar la im agen e la ciudad; pot enciar el valor histórico-turístico del $\mathrm{CH}$ m ediante la m ejora de la escena urbana; promover el desarrollo social y cultural a través de escuelas Taller, program as de anim ación a la lectura, program as de form ación y em pleo, actividades m usicales de danza y fom ento de guarderías infantiles. Sost enibilidad Social, cultural, económ ica y medioam biental. Principales Ejes del Plan: por m edio de Program as de: Revitalización / Puesta en valor del Casco Histórico / Sociocultural / Medioam biente y paisajístico.

Instrum ento de gestión: Oficina del Plan Int egral del CH

Estado: En ejecución (desde 1997)

Nivel de inform ación: Bueno
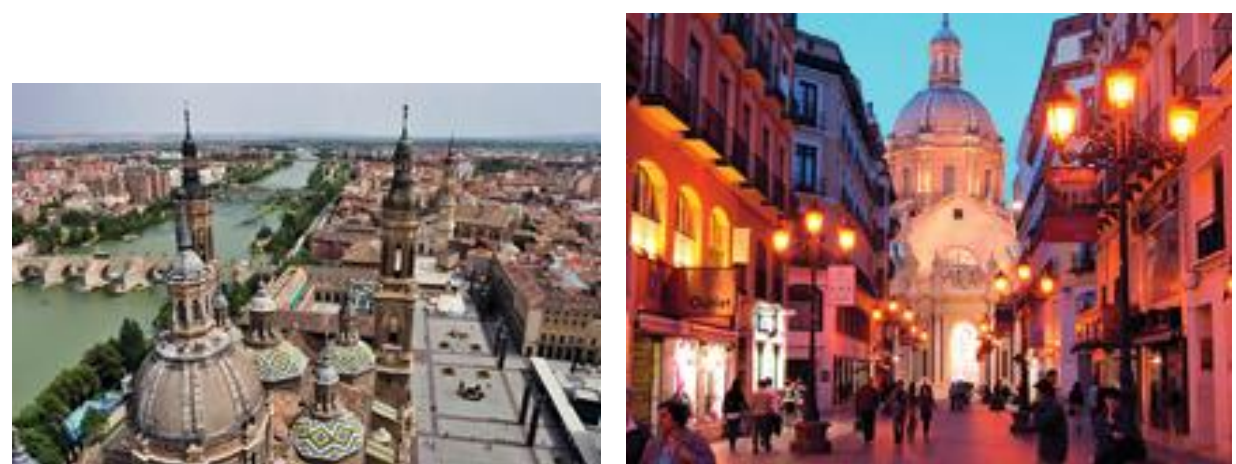

Fuentes: (2013); Evaluación del Plan Integral del Casco Histórico 2005-2012. Diagnóstico del Barrio y Propuestas de futuro. Zaragoza, España. En: $\mathrm{http} \cdot / \mathrm{www}$ zaragoza.es/contenid os/sectores/pich/evaluacion pich.pdf / http $/ / \mathrm{www}$.aragond igital.es/noticia.asp . notid $=25066 \&$ secid $=9$ https:/wearethecityheroes.w ord press.com/2013/01/31/zaragoza-plan-integral-del-casco-historico_-estonoesunsolar/ 

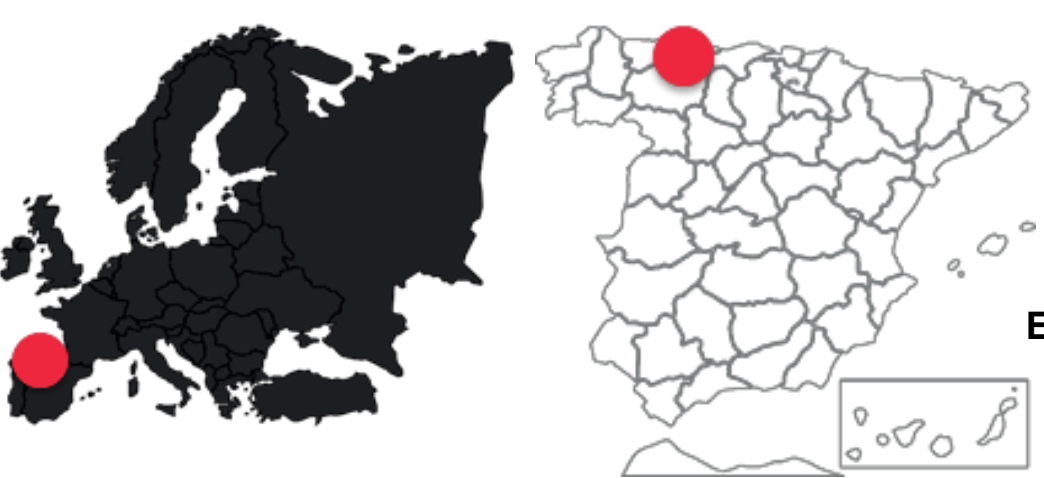

CARACTERÍSTICAS DEL CENTRO HISTÓRICO

Extensión: 181.700 has. (ciudad)/ CH ...has.

Población: 273.422 hab. (2016) / CH 2.714 hab. (2016)

Inserción territorial: la ciudad se sitúa sobre la costa cantábrica. Su CH se asienta en una península, y desde un istmo asciende hasta c ortarse en elevados acantilados.

Dinám ica general y urbanística: El $\mathrm{CH}$, Cim adevilla, posee tres part es: el casco antiguo, con un tejido orgánico medieval (si bien su fundación rem ite a los rom anos); el puerto, elem ento determ inante de la historia de la ciudad; y un gran espacio libre en la cim a de la penínsu la, cerro de Santa Catalina.

Especialización Funcional: de zona industrial a centro turístico, univ., financ. y serv. $\mathrm{CH}$ : residencial, com ercial y ocio.

Declaratorias: El CH fue declarado Conjunto Histórico-Artístico

Problem áticas: A fines de los 80 , el $\mathrm{CH}$ era un área marginal, product o de del desplazam iento de la centralidad urbana hacia los Ensanches. Tejido residencial deteriorado, el puerto había sido abandonado al trasladarse al puert o m oderno, y el tejido se encontraba horadado por áreas industriales abandonadas por la dec adencia del puerto. Los palacios y casonas señoriales estaban abandonados y degr adados. La población se encontraba empobrecida y en regresión, y aparecían fenóm enos degradantes de marginación social. El único organismo adm inistrativo que funcionaba era el Ayuntam iento.

\section{CARACTERÍSTICAS RELATIVAS A LA INTERVENCIÓN}

Tipo de intervención: Revitalización, rehabilitación, regeneración, recualificación. Instrum ento de planificación: 1985, Plan Especial del Casco Histórico de Gijón

Objetivos: Reconvertir el espacio del Cerro Santa Catalina, transform ar el conjunto portuario (a uso deportivo), reestructurar áreas industriales abandonadas con nuevos conjuntos de viviendas, crear equipam ient o social y cultural, desarrollar proyecto de cualificación arquitectónica y urbana y de inserción de nue vos usos institucionales y culturales, recuperar espacios libres (calles y plazas).

Principales Ejes del Plan: Actuaciones estructurantes / recuperación del tejido residencial y de los Espacios libres.

Instrum ento de gestión: 1985, Oficina de gestión y Proyectos (Program a de rehabilitación de prom oción públic a)

Estado: Ejecutado

Nivel de inform ación: Escaso
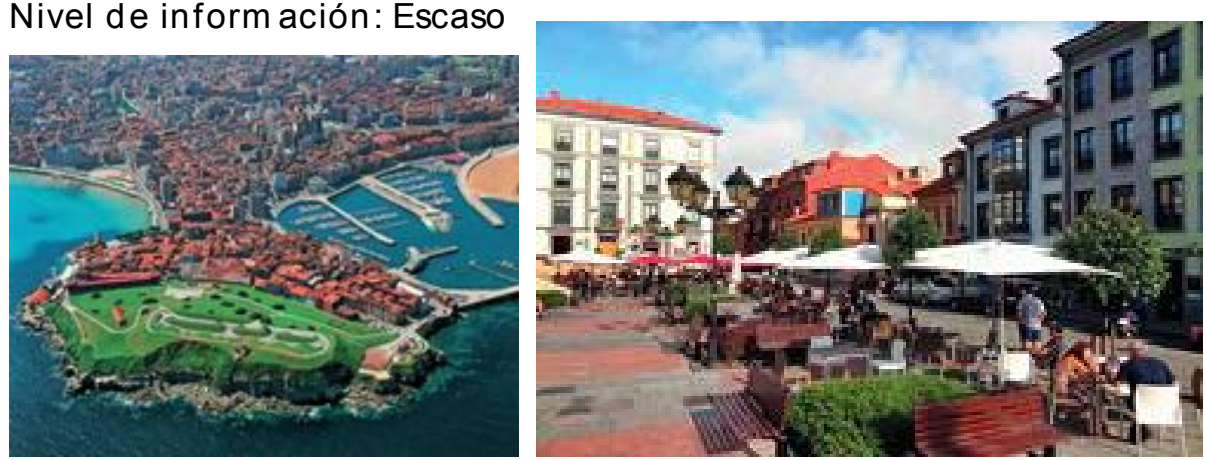

Fuentes: Pol Méndez F. (1993); “La recuperación de los centros históricos en España”, En: https:/dialnet.unirioja.es/d esc arga/articulo/2151411 .pdf 


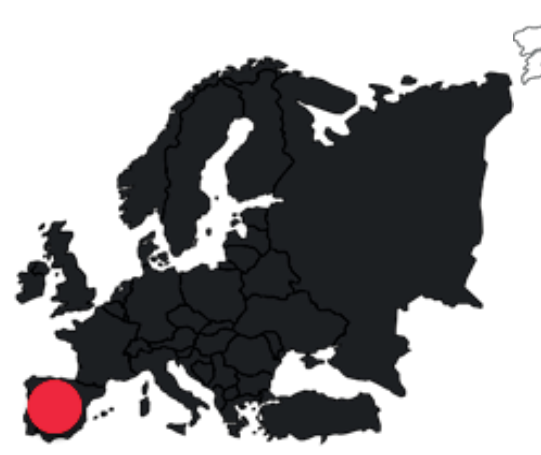

CARACTERÍSTICAS DEL CENTRO HISTÓRICO

Extensión: 197.910 has. (ciudad) / CH 191 has.

Población: 301.876 hab. (2016) / CH 37.000 hab. (2001)

Inserción territorial: se localiza en el cuadrante noroeste de la península ibérica, constituye un nodo en el corredor Atlántico.

Dinámica general y urbanística: El $\mathrm{CH}$ es un espacio estratificado producto de su crecimiento, en el que se rastrean diversas capas y restos de su evolución histórica ( $\mathrm{m}$ ás de $\mathrm{X}$ siglos. Conserva la $\mathrm{m}$ ayoría de los monum entos, edificios públicos históricos, casas nobles, casas de renta, edificios de la burguesía del s. XIX, así como patrimonio museístico.

Especialización Funcional: El CH conserva las actividades centrales y se $\mathrm{m}$ antienen y se han reforzado los usos residenciales.

Declaratorias: Conjunto Histórico-Artístico

Problem áticas: fragm entación del $\mathrm{CH}$ com o resultado de un proceso de malformaciones y deformaciones urbanas que terminó con una destrucción especulativa de la ciudad en los años 60 y 70 que erosio naron y rompieron el tejido histórico; deficiencias en los espacios libres, plazas y calles desvalorizadas por la agresión del aut om óvil.

\section{CARACTERISSTICAS RELATIVAS A LA INTERVENCIÓN}

Tipo de intervención: Recualificación y regeneración Instrum ento de planificación: 1997, Plan Especial del centro Histórico de Valladolid $(\mathrm{PECH})$.

227 Casco Histórico de Valladolid: www itcvalladolid .es/..JPLAN\%20ESPECIAL\%20CASCO\%20HISTORICO\%20VAL....

Objetivos del Plan:

1 - Regular las condiciones de actuación en la edificación histórica;

2 -Elaborar una am biciosa propuesta de actuación en la tr am a de espacios libres del casco capaces de generar una contribución esencial a la cualificación general de la ciudad;

3 - Plantear operaciones estructurantes en "áreas de oportunidad" existentes en el caso (infraestructuras obsoletas, infrautilizadas o vacíos intersticiales ind ustriales o institucionales, sin uso y $\sin$ tr atam iento de espacios libres públicos, áreas desarticuladas);

4 - Reorganizar el tráfico pensando en sistem as evitando fragm entación o desconexión.

Principales Ejes del Plan: Edificación residencial histórica / Espacios libres / Áreas de oportunidad / Tráfico.

Instrum ento de gestión: ...(Ayuntam iento)

Estado: Ejecutado

Nivel de inform ación: Bueno
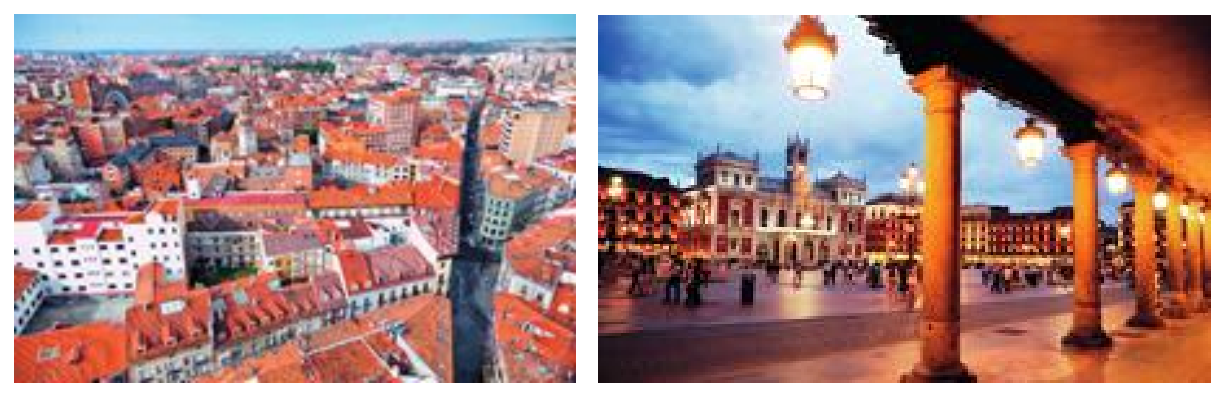


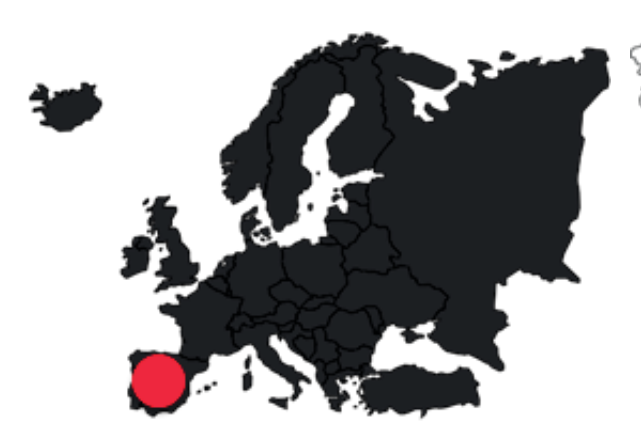

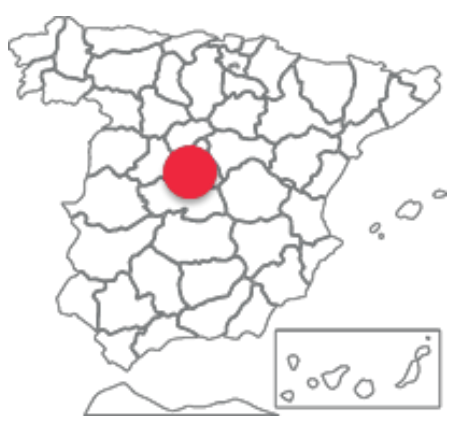

\section{CARACTERISTICAS DEL CENTRO HISTÓRICO}

Extensión: 60.577 has. (ciudad) / CH 523 has. (Centro) Población: 3.165.541 hab. (2016)/ CH 134.271 hab. (2014)

Inserción territorial: en el centro del país, posición estratégica

Dinám ica general y urbanística: ciudad capital del país y la más pobla-

da, una de las m ás im portant es de Europa.

Especialización Funcional: de ciudad capital

Declaratorias: Áreas de Rehabilitación Int egrada

Problem áticas: avance del deterioro urbano general, zonas con elevado nivel de deterioro arquitectónico, urbanístico, social y medioam biental, existiendo barrios con gran m arginalidad que son re fugio de la población inmigrante.

\section{CARACTERÍSTICAS RELATIVAS A LA INTERVENCIÓN}

Tipo de intervención: Rehabilitación

Instrum ento de planificación: 2004, Plan de Acción para la Revitalización del Centro Urbano, (m ediante la intervención en Áreas de Rehabilitación Preferente, centradas en plazas y calles principales de cada barrio). Objetivos: Regenerar la tram a urbana; renovación de las infraestructuras; mejorar el diseño de sus calles y la accesibilidad; mejorar el medio ambiente; rehabilitar inmuebles para mejorar la calidad de vida de sus habitantes; potenciar accesos para actividades culturales; apoyar la industria art esanal y los pequeños com ercios; desarrollar program as sociales y m ejorar la actividad económ ica.
- Promover el uso residencial, con la incorporación de jóvenes como residentes, la desaparición de la infr avivienda y la creación de nuevos modelos.

- Prom over actividades económ icas y com erciales que colaboren en fijar residencia.

- Desarrollar el bienestar social (con integración social, centralidad cultural, espacios públicos y equipam ientos)

Principales Ejes del Plan: A través de program as de: Rehabilitación privada / Urbanización e infraestructuras / Adecuación arquit ectónica / Sociales / Actuaciones m onum entales.

Instrumento de gestión: Oficina del Centro. (Área de Gobierno de Econom ía y Participación Ciudadana del Ayuntamiento de Madrid). Financiamiento mixto: administración estatal, regional y local y Unión Europea (Fond os de Cohesión y proyectos URBAN-fond os FEDER) unido a iniciativa privada.

Estado: En ejecución

Nivel de inform ación: Muy bueno
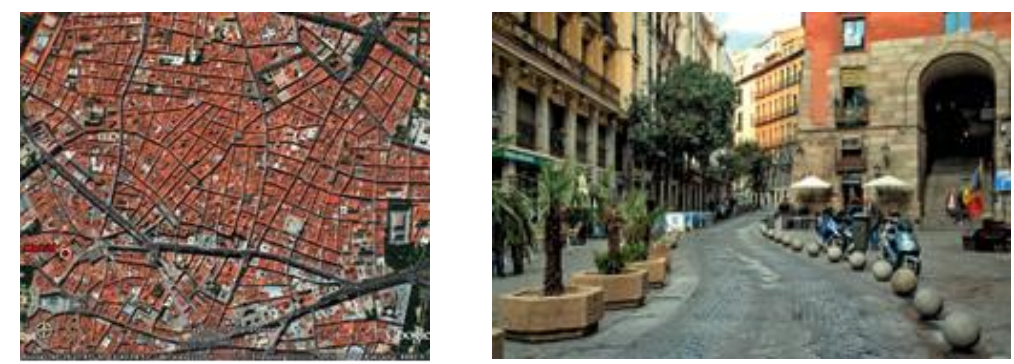

Fuentes: Herráez S. (2000); "La Rehabilitación del centro Histórico de Madrid”. En Inform es de la Construcción Vol. 51 Núm . $465 . /$ Plan para la Revitalización del centro urbano: www .m ad rid .es/Unid ad esDescentralizad as/Urb anism oyVivienda/..J/C02.pdf 

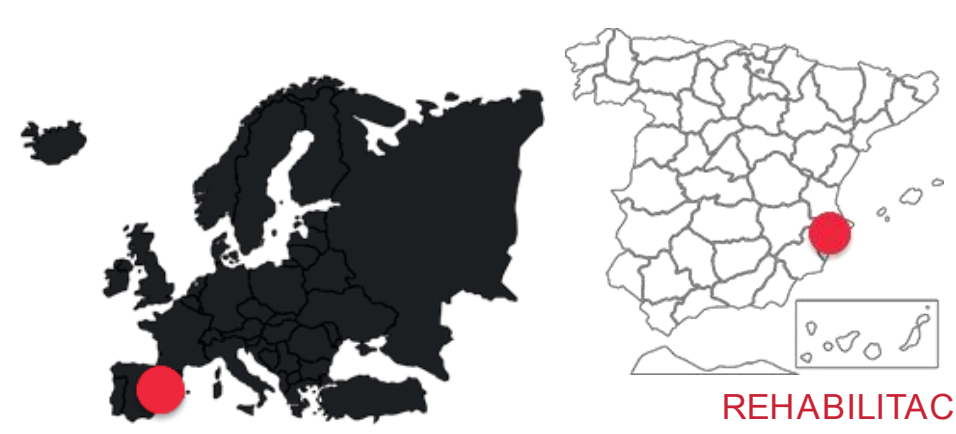

REHABILITACIÓN INTEGRADA DEL CENTRO HISTÓRICO DE ALCOY, COMUNIDAD VALENCIANA, ESPAÑA

\section{CARACTERÍSTICAS DEL CENTRO HISTÓRICO}

Extensión: 12.986 has. (ciudad) / CH 62 has.

Población: 61.542 hab., ciudad int erm ., 2016. / CH 4.836 hab.

Inserción territorial: se sitúa al sureste del país, en un valle rodeado por sierras y atravesado por tres ríos, hecho que ha condicionado su crecim iento. Pertenece a la Com unidad valenciana, en la Provincia de Alicante.

Dinám ica general y urbanística: es una de las ciudades más importantes de la Com unidad valenciana. Destaca por su actividad industrial, y con la mejora en las comunicaciones y la intervención en el patrim onio hist órico ha experim entado un increm ent o del turismo.

Especialización Funcional: Tras la Revolución Industrial en España esta ciudad ha cobrado im portancia en el sect or textil, aunque tam bién en el m etalúrgico y la industria papelera.

Declaratorias: Pese a que el casco antiguo ha sido declarado Conjunto histórico artístico en el año 1982, todo él es considerado Área Degradada. Problemáticas: Preocupante despoblamiento. Proceso de degradación del centro histórico tanto en el ám bito arquitectónico-urbanístico como en el socio-económico. Proceso en el que ha influido la reconversión industrial, la em igración hacia otras zonas y la obsolescencia de sus infraestructuras. A esto, se sum a la problem ática m edioam biental, con falta de espacios públicos y degradación de paisajes naturales.

\section{CARACTERÍSTICAS RELATIVAS A LA INTERVENCIÓN}

Tipo de intervención: Rehabilitación Int egrada

Instrum ento de planificación: Plan General de Ordenación Urbana (1989), Plan Especial de Protección (PEPRI), Planes Especiales de Re forma Interior (PERI), Program a ARA (1991)

Objetivos: Rehabilitar y revitalizar la ciudad y su centro histórico con actuaciones de calidad / Aplicar soluciones de m ínim o costo de m antenim iento y de carácter pedagógico.

Principales Ejes del Plan: Vivienda / Espacio público / Infraestructura Instrum ento de gestión: Área de Renovación Integrada (ARI), Oficina Plan ARA (Arquitectura, Rehabilitación Alcoy, 5 Planes-Proyectos, Oficina Program a de Renovación Urbana (PRV).

Estado: Ejecutado

Nivel de inform ación: Bueno
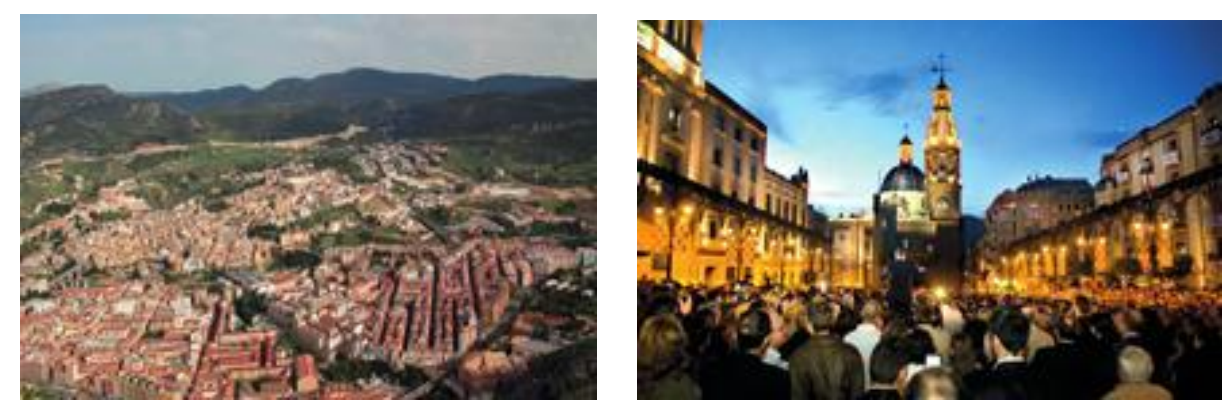

Fuentes: Gaja Díaz, F. (2001); "Intervenciones en centros históricos de la Com unidad Valenciana”, Consejo de Obras Públicas, Urbanism o y Transporte, Dirección Genreal de Arquit ectura y vivienda, Universidad Politécnica de Valencia, Departam ento de Urbanismo. 

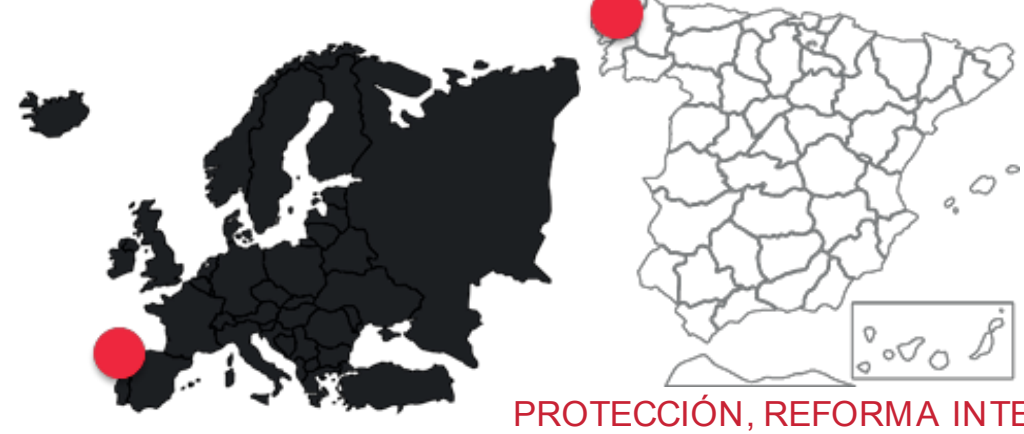

CARACTERÍSTICAS DEL CENTRO HISTÓRICO

Extensión: 378.300 has. (ciudad)/ $\mathrm{CH} 79.8$ has.

Población: 215.227 hab. (2016)/ CH 5.000 hab. (200)

Inserción territorial: Se sitúa en la costa noroeste de España, en las Rías Altas, su centro se desarrolla sobre una península unida a tierr a por un istmo, rodeada de río y mar.

Dinám ica general y urbanística: Es el núcleo urbano m ás poblado de Galicia. El CH, con estrechas y sinuosas calles de piedra y bellas plazas, es la zona más monum ental, presenta un entram ado urbano het erogéneo y com plejo.

Especialización Funcional: la ciudad se centra en los servicios (ind ustria) y com o actividad secundaria el puert o y la refinería, el $\mathrm{CH}$ es principalm ente residencial.

Declaratorias: 1984, Ciudad Vieja "Conjunto histórico Artístico"

Problem áticas: Accesibilidad y visibilidad, procesos de gentrificación, pérdida de población antigua y aum ent o de población nueva, pérdida de pequeños com ercios, falta de integración funcional con el resto de la ciudad

\section{CARACTERÍSTICAS RELATIVAS A LA INTERVENCIÓN}

Tipo de int ervención: Protección, Reform a Interior y Rehabilitación Instrum ento de planificación: 2012, Revisión y adaptación del Plan Especial de Protección y Reform a Interior de la Ciudad Vieja y Pesca- dería (PEPRI), en concordancia con el Plan General de Ordenación m unicipal (PGOM) y con el Plan de Movilidad Urbana Sostenible (PMUS) y "Coruña Futura".

Objetivos: Triple carácter del Plan. Como Plan de Protección: salvaguardar el patrim onio arquit ectónico y cultural; Como Plan de Reforma Interior: prever actuaciones de remodelación urbana que contribuyan a la conservación general del carácter de conjunto; como Plan de Rehabilitación: recuperar e im pulsar los valores sociales, culturales, económ icos, am bientales, edificatorias y funcionales de conjunto.

Principales Ejes del Plan: Salvaguarda del patrim onio / recuperación del uso residencial y la actividad ec onóm ica / m ejora de condiciones de vida evitando el deterioro / integración del sector en el contexto funcional de la ciudad.

Instrumento de gestión: Empresa Municipal Vivienda, servicios y actividades S.A., Consejo de A Coruña., Ofic. Plan.

Estado: En ejecución (desde 1998)

Nivel de información: Bueno
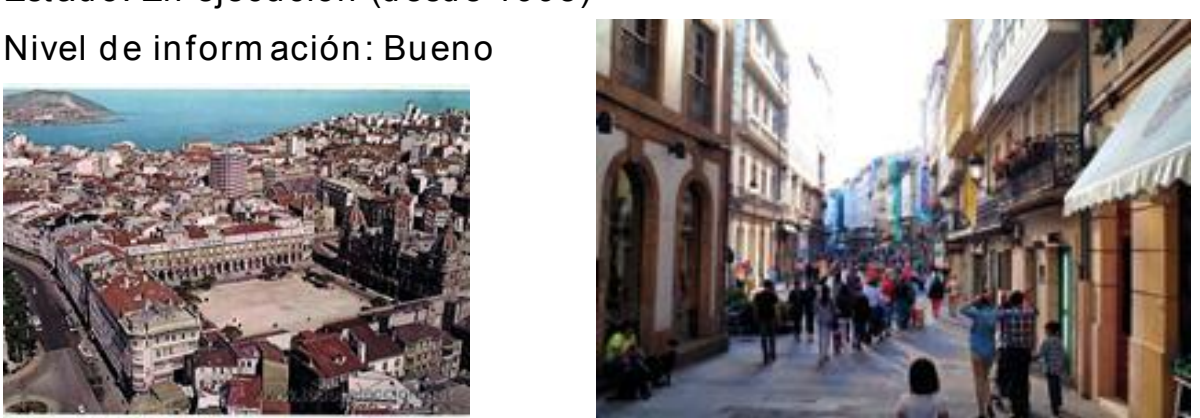

231

Fuentes: Revisión y adaptación del Plan Especial de Prot ección y Reform a Interior de la Ciudad Vieja de A Coruña (PEPRI) $\mathrm{http} \cdot / \mathrm{www}$.coruna.es/urbanism o/es/m od ific acion-pep ri/ap robacion-inicial 

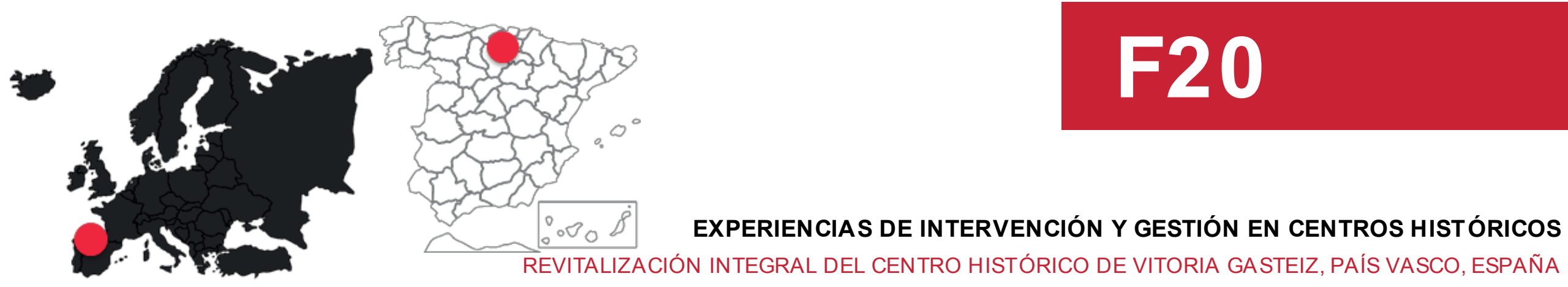

\section{CARACTERÍSTICAS DEL CENTRO HISTÓRICO}

Extensión: 27.680 has. (ciudad) / $\mathrm{CH} 26$ has.

Población: 242.223 hab. (2012) / CH 10.114 hab. (2002)

Inserción territorial: la ciudad se emplaza en una zona de tránsito entre la costa cantábrica y el interior de la península. Situación estratégica que explica la función com ercial y militar que tuvo en su historia y su actual función industrial. Posee uno de los cascos m edievales m ejor conservados de España.

Dinámica general y urbanística: Ciudad capital de Álava, sede oficial del Parlam ento y el Gobierno de la Com unidad Autónom a del País Vasco. Especialización Funcional: Residencial, de ocio, económ ica

Declaratorias: 1983 -Se declara al Casco Medieval Área de Rehabilitación Integrada (ARI) / 2012 Ciudad Verde

Problem áticas: Deterioro generalizad o de ed ificios de viviendas (viviendas anti-higiénicas e insalubres), población en vejecida, abandono, malas condiciones de infraestructuras básicas, pérdida de población, em po brecim iento, falta de equipam ient os cívicos y áreas verd es, poca población calificada, abundancia de hogares unific ados.

\section{CARACTERÍSTICAS RELATIVAS A LA INTERVENCIÓN}

Tipo de intervención: Rehabilitación Int egral Instrum ento de planificación: 1983 -1988: PERI Plan Especial de Rehabilitación Integrada / 2009 -2014: Plan de Reactivación integral del
Centro Histórico, Program a URBAN.

Objetivos: Renovar infraestructuras urbanas / Rehabilitar y adecuar edificios y viviendas / Mant ener la m orfología urbana y las características arquitectónicas existentes / Conserservar, revalorizar y restaurar el patrim onio histórico artístico / Fijar la población residente y m antener y regenerar la composición del tejido social / Mejorar los niveles de habitabilidad / Dotar con equipam ientos urbanos necesarios.

Principales Ejes del Plan: Eje Urban ístico y de vivienda / Eje Patrim oniocultura / Eje social / Eje económ ico.

Instrumento de gestión: Agencia para la Revitalización Integral de la Ciudad Histórica (ARICH SA.). 1982 Se constituye el Departam ento del $\mathrm{CH}$ com o SA., caso único en la gestión.

Estado: En ejecución (desde 2009)

Nivel de inform ación: Muy bueno
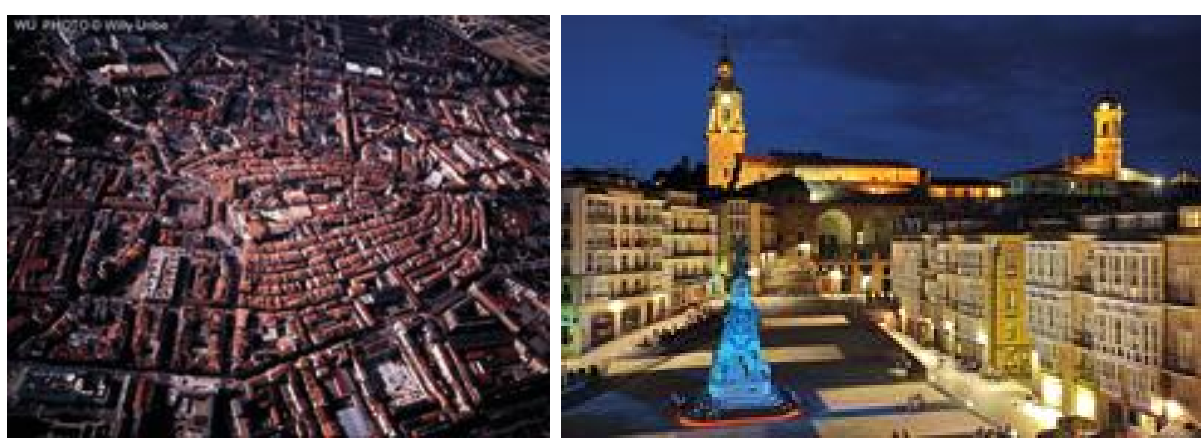

Fuentes: Arroita, G. (2011); "Los centros históricos que se quedaron atrás: La reactivación Integral en Vitoria Gasteiz”, IV Jornadas Int ernacionales “Experiencias de re vitalización de cascos históricos", Buenos Aires, Argentina. / Villapún Ansot egui, E; Vitoria Gasteiz, Geografía Urbana. 


\section{$F 21-F 40$}

EXPERIENCIAS DE INTERVENCIÓN Y GESTIÓN EN CENTROS HISTÓRICOS

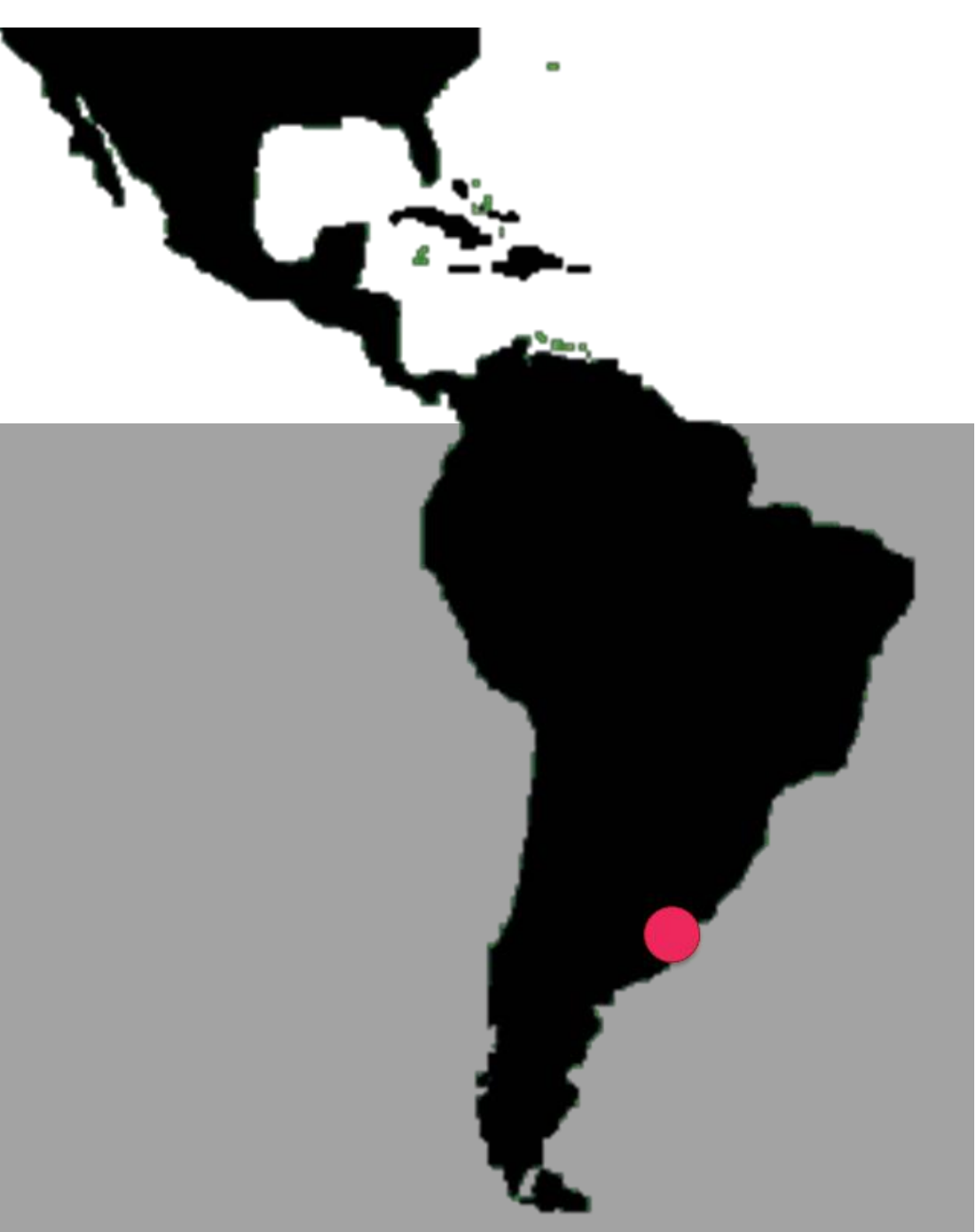

CONTEXTO LATINOAMERICANO 


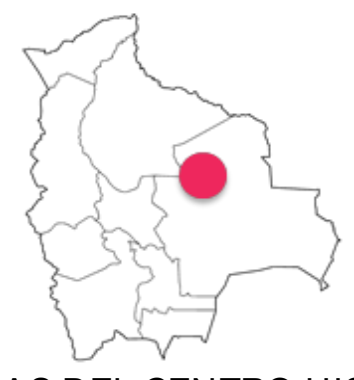

CARACTERÍSTICAS DEL CENTRO HISTÓRICO

Extensión: 32.560 has., Ciudad central. / $\mathrm{CH}$...has.

Población: 2.453.549 hab. (2016)/ CH 77.000 hab. 2001)

Inserción territorial: Se sitúa en el corazón de Sudam érica, al este de Bolivia, en una zona plana de divisoria de aguas, en la margen de recha del río Piraí.

Dinámica general y urbanística: Ciudad más poblada del país, es la puerta de Bolivia al mundo. Posee una estructur a de dam ero y edificios de valor patrimonial que destacan en la relación espacial que perm ite el uso de galerías peat onales. Característicos de su arquitectura son los corredores de madera con elem entos típicos del centro cruceño com o los horcones, los m uros de adobe, y los t echos de teja. Especialización Funcional: Es el principal centro com ercial, industrial y financiero del país, alberga a la mayoría de las em presas y franquicias nacionales e int ernacionales.

Declaratorias: No posee. Se ha realizado un Catálogo de edificios de valor patrim onial con niveles de preservación.

Problem áticas: Destrucción del centro histórico con pérdida de patrimonio construido y de actividades que lo caracterizan como consecuencia de la renovación, pérdida de identidad; congestionamiento de tránsito; problem as de accesibilidad y dism inución de la población residente. Falta de mantenim iento de viviendas, reem plazo por otros usos. Degradación general.

\section{CARACTERÍSTICAS RELATIVAS A LA INTERVENCIÓN}

Tipo de intervención: Revitalización Integral

\section{F22}

EXPERIENCIAS DE INTERVENCIÓN Y GESTIÓN EN CENTROS HISTÓRICOS
Instrum ento de planificación: 1989-PROCEHI Proyecto Centro Histórico / 2002-Plan Estratégico / 2005-PLOT Plan de Ordenamiento urbano Territorial / 2008-Plan de Revitalización Integral del Centro Histórico. Objetivos: Mejorar las condiciones y la atracción del centro histórico, para fijar a la población residente y atraer nuevos ocupantes. / Vitalizar el centro histórico para evitar su deterioro, convirtiéndolo en símbolo de la identidad cultural, y com ponente fundam ental de la com petitividad urbana.

Principales Ejes del Plan: Patrim onio construido - Vivienda / Transporte y peatonalización / Com ercio / Sistem as educativos y religiosos / Paisaje urbano.

Instrumento de gestión: Junta del centro Histórico (Dirección del Centro y Patrim onio Hist órico, Oficialía Mayor de Planificación, Consejo Municipal, Alcalde Municipal).

Estado: En ejecución (desde 2008)

Nivel de inform ación: Bueno
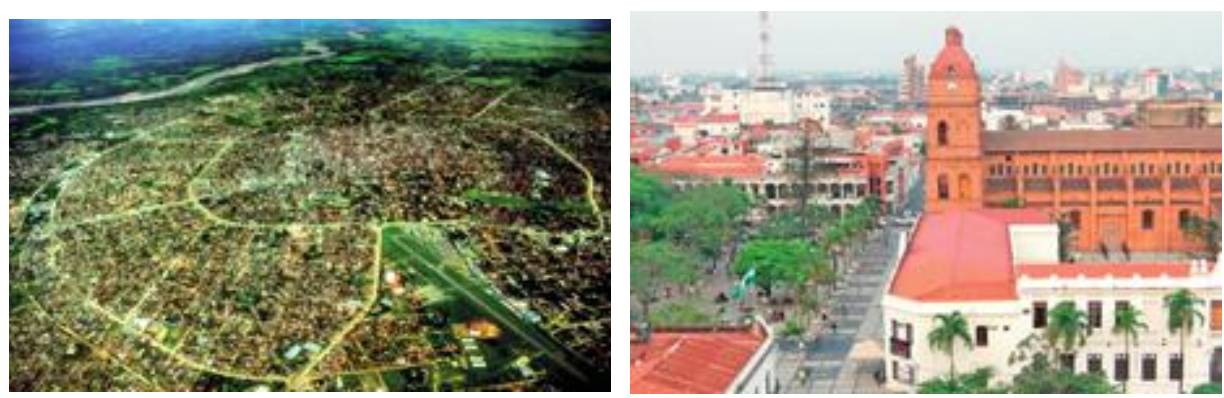

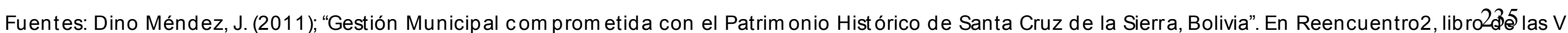

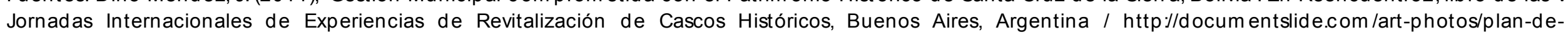
revitalizacion-integral-d el-centro-historico-santa-cruz-d e-la-sierra.htm I / http //arqa.com /arquitectura/el-centro-historico-santa-cruz-d e-la-sierra.htm I 


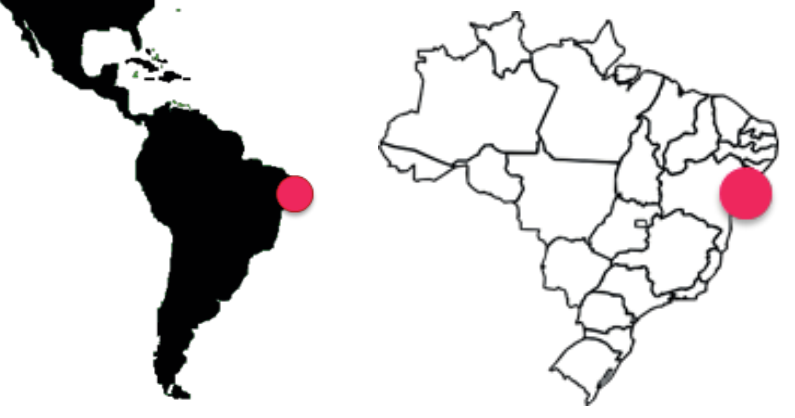

CARACTERÍSTICAS DEL CENTRO HISTÓRICO

Extensión: 70.679 .900 has., área urbana / $\mathrm{CH}$...has.

Población: 2.948.733 hab. (2008) / CH ...hab.

Inserción territorial: ciudad costera del noreste del país, el $\mathrm{CH}$ se localiza en la parte alta de la ciudad.

Dinám ica general y urbanística: ciudad más poblada del norest e. Las prim eras construcciones del $\mathrm{CH}$ (iglesias, plazas, m onum ent os y ed ificios) construidas por propietarios rurales, son de valiosa arquitectura barroca am ericana del s. XVII.

Especialización Funcional: pasó de uso residencial informal con actividades vinculad as, a uso residencial y turístic 0 .

Declaratorias: 1985, Patrim onio de la Hum anidad, UNESCO.

Problem áticas: el traslado en el s. XIX del centro económ ico y financiero a San Pablo, im pactó en la vida del CH. La población de alt os ingresos que lo habitaba fue reemplazada por población de bajos ingresos, descendientes de ex - esclavos, sin educación, que habitaron de form a precaria, hecho que contribuyó al deterioro del patrimonio construido, a la proliferación de prostíbulos, drogadic ción e incendios, a la falta de luz, aire e higiene en las construcciones. El poder público se apartó del $\mathrm{CH}$ que se caracterizó por la pobreza, la exclusión social, la inseguridad, el desem pleo y por las estrategias de supervivencia de sus m oradores.

\section{CARACTERÍSTICAS RELATIVAS A LA INTERVENCIÓN}

Tipo de intervención: Revitalización
Instrum ento de planificación: 1991, Program a de Recuperaçao do Centro Histórico de Salvador.

Objetivos: Revitalización y reestructuración urbana, creando centro de atracción turística y de actividades de placer y diversión, con obras de restauración y rehabilitación de edificios hist óricos, para modificar dinámicas anteriores del $\mathrm{CH}$. Introducir nuevos usos asociados a la actividad turística. Estrategias de intervención adoptadas para la recuperación: obras de restauro, recuperación estructural, y reconstrucción y conservación de los edificios mediant e la zonificación de bloques, saneam iento y registro de habitant es.

Principales Ejes del Plan: Recuperación patrim onio construido / Turismo / Vivienda / Cultura

Instrumento de gestión: 1969, Fundaçao do Patrimonio Artistico e Cultural da Bahía (IPAC). Adquisición, restauración y explotación de inm uebles (estatal, asociado a otros ent es).

Estado: Ejecutado

Nivel de inform ación: Bueno
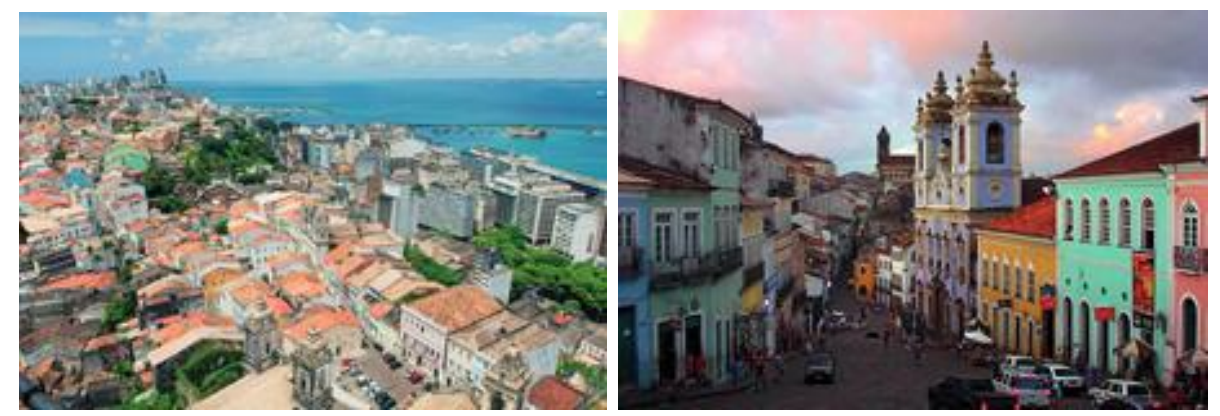

Fuentes: Marques Braga P., Ribeiro dos Santos, W.J. (2009); "Program a de Recuperaçao do Centro Histórico de Salvad or: políticas públucas e participaçao sǫßła”. En Revista Risco, Revista de pesquisa en arquit ectura e urbanism o. http $/ / w w w$ revistas.usp.br/risco/article/viewFile/44777/48408 / Luque Azcona E., Sm ith H. (2010); “Transform aciones, conflictos e identidades en el centro histórico de Salvador de Bahía". En Revista Com plutense de Historia de Am érica. 


\section{C.}

EXPERIENCIAS DE INTERVENCIÓN Y GESTIÓN EN CENTROS HISTÓRICOS

REVITALIZACION DEL CENTRO HISTÓRICO DE CARTAGENA, COLOMBIA

CARACTERÍSTICAS DEL CENTRO HISTÓRICO

Extensión: 70.910 has. / CH ...has.

Población: 983.629 hab. (2017)/ CH ...hab.

Inserción territorial: Ciudad de la zona norte del Caribe colom biano, fue fundada en 1533 siendo uno de los puert os más im portant es de Am érica. Dinámica general y urbanística: $\mathrm{El} \mathrm{CH}$ es el espacio primordial de la ciudad, la historia, la cultura, el desarrollo y la sociedad cartagenera. Cum plió un rol fundam ental en la hist oria del Caribe y el país, y sostie ne con la ciudad una compleja red de relaciones sociales, laborales, económ icas, históricas y culturales.

Especialización Funcional: institucional, com ercial, político-adm inistrativa, cultural, artística, recreativa, religiosa, educativa, residencial perm anent e y turística.

Declaratorias: 1984, Patrim onio Histórico de la Humanidad por la UNESCO (gran patrim onio artístico y cultural).

Problem áticas: Actuales: Dism inución de la vivienda perm anente, usos inadecuados de los inm uebles, desbordam ient o incontrolado del com ercio inform al, inadecuada norm ativa de accesibilidad y movilidad, falta de program as sociales que eviten la mendicidad, la prostitución y la drogadicción, inundaciones, inseguridad ciudadana, surgim ient o de áreas de invasión generadoras de contam inación am biental, invasión del espacio público, actividades delictivas, muchos de ellos product o de la obsolescencia de la norm ativa del $\mathrm{CH}$.

\section{CARACTERÍSTICAS RELATIVAS A LA INTERVENCIÓN}

Tipo de int ervención: Revitalización

Fuentes: Ruz Rojas, G. (2011); "Revitalización del Centro Histórico de Cartagena: Por una ciudad para soñar”. En Reencuentro, libro de las IV Jornadas Int ernąizßßales de Experiencias de Revitalización de Cascos Históricos, Buenos Aires, Argentina / Plan de Re vitalización del Centro Histórico de Cartagena https $/ / w w w$.youtube.com /watch ? =eMb0p veOgtk
Instrum ento de planificación: 2008 - 2011 Plan de Desarrollo Por una sola Cartagena / 2008, Plan de Revitalización del Centro Histórico de Cartagena.

Objetivos: Integrar el $\mathrm{CH}$ con el resto de la ciudad, contribuir al aum ento de com petitividad urbana, proteger la función residencial, mejorar las relaciones internas al centro, fortalecer el mix funcional y el intercam bio cultural con la periferia, definir ejes peat onales.

Principales Ejes del Plan: Desarrollo social, habitabilidad humana, $\mathrm{m}$ em oria histórica, proyecto cultural y económ ico.

Instrum ento de gestión: El Plan es un Program a de la Alcaldía Mayor de Cartagena de Indias. Cám ar a de Com ercio.

Estado: En ejecución (desde 2008)

Nivel de inform ación: Bueno
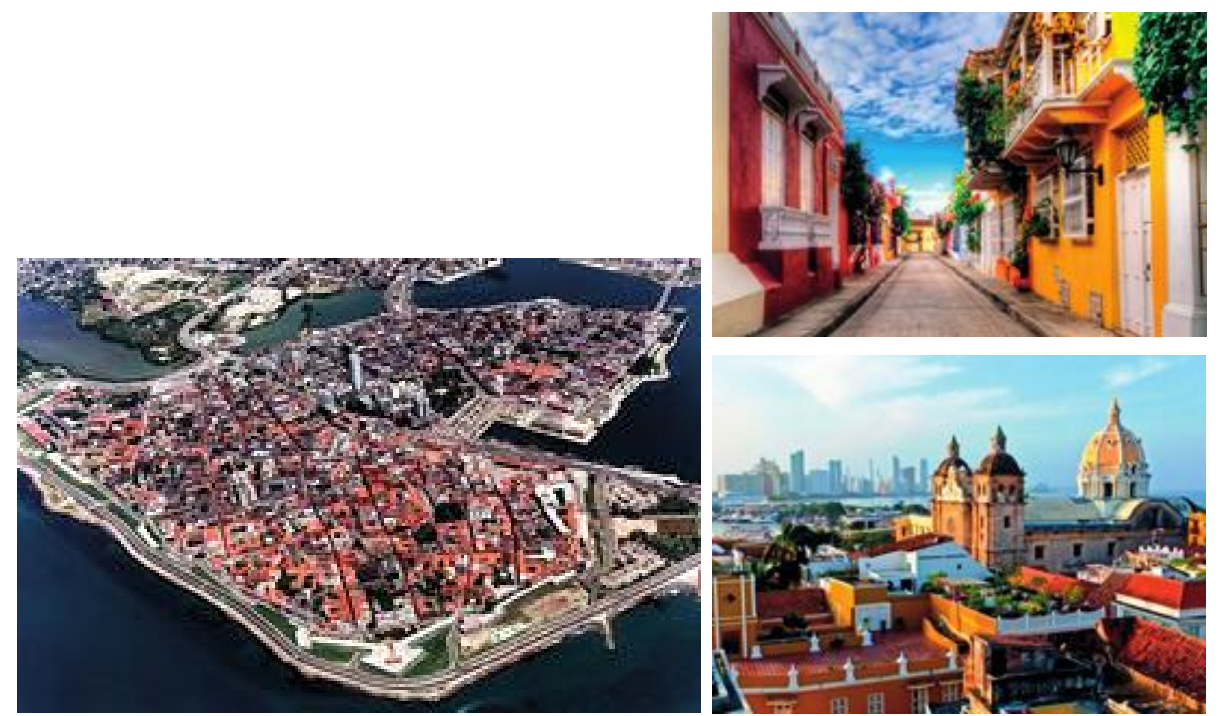


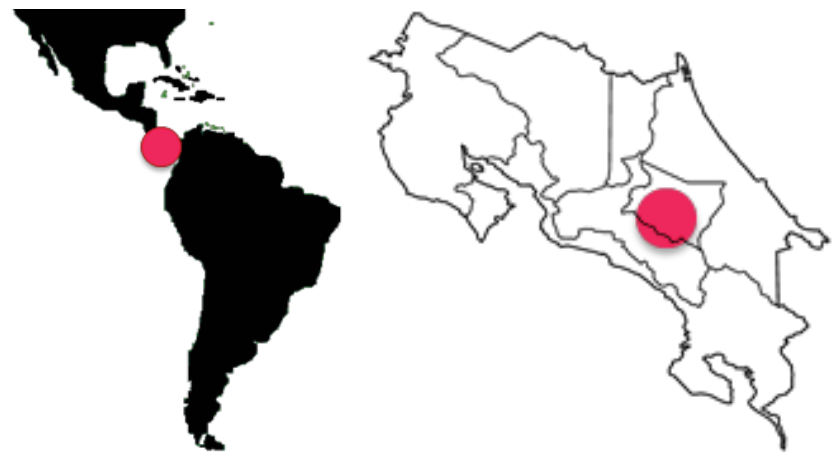

CARACTERÍSTICAS DEL CENTRO HISTÓRICO

Población: 288.054 hab. (2011) / CH 47.000 hab. (2011)

Inserción territorial: se inserta en el centro del país, en la m eseta intervolcánica llam ada Valle Central.

Dinám ica general y urbanística: capital del país, fue descubierto por Cristóbal Colón y fundada en 1848 , recibiendo influencia europea de la inm igración española. La ciudad posee m ezcla de historia y modernidad dado que su $\mathrm{CH}$ no logró conservarse intacto, muchas de sus edificaciones fueron derribad as o gravem ente alteradas .

Especialización Funcional: centro político, económico, social, nodo transporte y telecom unicaciones. $\mathrm{CH}$ : com ercial.

Declaratorias: No posee

Problem áticas: deterioro de edificaciones declarad as patrim onio histórico arquitectónico, despoblamiento del $\mathrm{CH}$, gentrificación, turismo que ha acarreado el incremento de actividades negativas como la prostitución y la dism inución de otras actividades como educativas y religiosas, reem plazo y demolición de edificios que albergaban uso residencial y de pequeño comercio por usos asociados al turismo, dism inución en los últim os años de turistas que se alojan en el $\mathrm{CH}$.

\section{CARACTERÍSTICAS RELATIVAS A LA INTERVENCIÓN}

Tipo de intervención: Revitalización

Instrum ento de planificación: En elaboración desde 2015: Plan de Acción
Extensión: 446.200 has., Ciudad central. / $\mathrm{CH} 100$ has.

(de Revitalización) del Centro Histórico de San José de Costa Rica.

Objetivos: Insertar usos habitacionales y vivienda en el $\mathrm{CH}$ (rehabilitando edificios abandonados que sólo ocupan con uso la planta baja y promoviendo las viviendas para funcionarios públicos que trabajan en el centro); rediseñar espacio público para lograr movilidad sostenible (generando condiciones am igables priorizando el transporte público, la peatonalización y movilidad no motorizada); activar la ciudad con la promoción de actividad es perm anent es que generen uso en el espacio público (dirigiendo acciones para increm entar la actividad públi ca, que haya más vida en las calles).

Principales Ejes del Plan: Vivienda / espacio público / promoción de activid ad es perm anent es.

Instrum ento de gestión: Municipalidad / Institut o Tecnológico de Costa Rica (TEC) - Gestión m ixta: publ. - priv .

Estado: Por ejecutar

Nivel de inform ación: Muy escaso (Plan en elaboración)
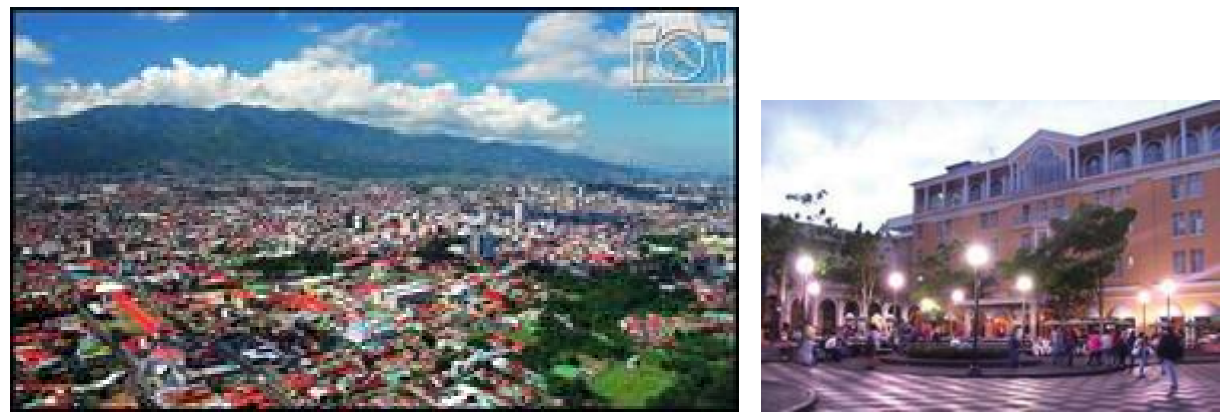

Fuentes: https:/www laprensalibre.cr/Noticias/detalle/73431/m unicipalidad-apo ya-dar-nueva-cara-a-san-jose / Despoblam iento y repoblam iento de Sañ Jose centro". En Revista Am bientico, Revista m ensual sobre la actualidad am biental, C osta Rica, 2013.. En: http :/www .am bientico.una.ac.cr/pdfs/am bientico/234.pd 


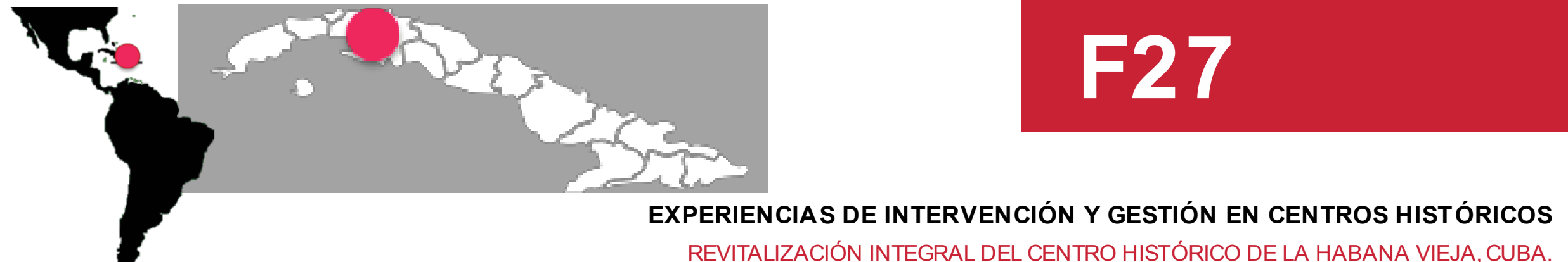

REVITALIZACIÓN INTEGRAL DEL CENTRO HISTÓRICO DE LA HABANA VIEJA, CUBA.

CARACTERÍSTICAS DEL CENTRO HISTÓRICO

Extensión: 72.830 has., Ciudad central. / CH 214 has.

Población: 2.105.000 hab. (2012) / CH 66.752 hab.

Inserción territorial: ubicación privilegiada. Fundada en 1514 por la Corona Española, im portant e centro com ercial.

Dinám ica general y urbanística: Ciudad central, capital del país, la más poblada del Caribe. Im portante patrim onio histórico, arquitectónico y cultural producto de la fusión de europeos, africanos e indígenas, atractivo al turismo. Régim en com unista desde 1959, triunfo de la Revolución cubana.

Especialización Funcional: sede de organismos del Estado y del gobierno cubano, de todas las em presas, asociaciones nacionales y de entidad es extranjeras radicadas en Cuba.

Declaratorias: 1978 , la ciudad intram uros fue declarada Monum ento Nacional - 1982, declarada Patrim onio Mundial de la UNESCO.

Problem áticas: grave situación habitacional, alt os niveles de insalubridad, pérdida de tipicidad de los barrios, desaparición de espacios verdes, superpoblación, contam inación am biental, det erioro de sitios históricos, $\mathrm{m}$ al estado de la infraestructura vial, canalización hidráulica.

\section{CARACTERÍSTICAS RELATIVAS A LA INTERVENCIÓN}

Tipo de intervención: Revitalización Integral

Instrumento de planificación: 1994, Plan Maestro para la Revitalización Integral de la Habana Vieja. 2001, Plan Especial de Desarrollo Int egral
Integral de la Habana Vieja. 2001, Plan Especial de Desarrollo Int egral del centro histórico (PEDI).

Objetivos: Renovación y revitalización urbana. Mejorar las condiciones de vida de los sectores de la población más necesitados a través de program as de revitalización social y la restauración de edificios / Favorecer la apertura económ ica y el desarrollo turístico. Lograr la sost enibilidad cultural, medioam biental, social y económ ica del $\mathrm{CH}$.

Principales Ejes del Plan: Suelo urbano y economía local / Vivienda / Equipam iento com unitario / Espacio Público / Redes de infraestructura y Medioam biente.

Instrum ento de gestión: 1993, Oficina del Historiador (OHCH) que funciona con sistema empresarial, con la compañía Habaguanex S.A.(para la explotación turística), la agencia de viajes San Cristóbal, y la Inm obiliaria Fénix S.A.

Estado: En ejecución (desde 1993)

Nivel de inform ación: Muy bueno
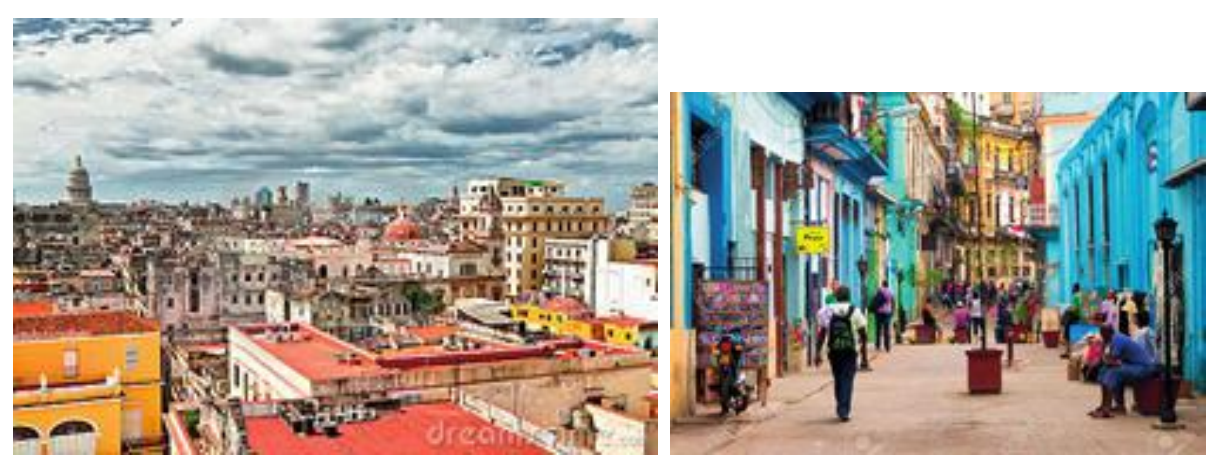

Fuentes: Avance PEDI Plan Especial de Desarrollo Int egral, Plan Maestro para la Revitalización Integral de La Habana, Oficina del Hist oriad or de la ciudad de La Habana, Cuba, 2011. 


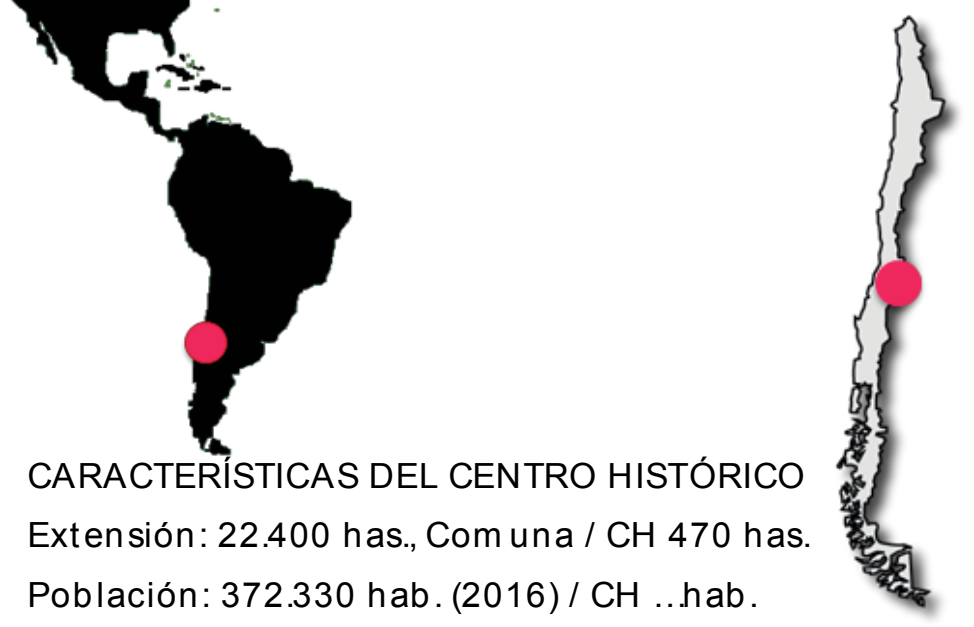

Inserción territorial: en una llanura, Cuenca de Santiago, atravesada por el Río Mapocho. Cercana a la Cordillera d los Andes y al Océano Pacífico.

Dinám ica general y urbanística: capital y principal núcleo urbano del país. Ciudad líder de AL, en factores sociales, económ icos y am bientales. Su $\mathrm{CH}$ ha sido bastant e alterado

Especialización Funcional: de ciudad capital..

Declaratorias: No posee

Problem áticas: Los sectores acomodadas abandonaron el $\mathrm{CH}$ en busca de "la ciudad jardín" nuevos residentes llegaron desde áreas rurales en busca de oportunidades. El $m$ al $m$ antenim iento, los sucesivos terrem otos y las políticas de expulsión, generaron una disminución de población en el $\mathrm{CH}$, su em pobrecimiento, y el deterioro del patrim onio construido.

\section{CARACTERÍSTICAS RELATIVAS A LA INTERVENCIÓN}

Tipo de intervención: Renovación

Instrumento de planificación: 1990, Propuesta de Desarrollo para la Renovación de Santiago (Plan de Repoblamiento).

Objetivos: Densificar sectores urb anos y con solidar áreas centrales con despoblam iento para mejorar la calidad de vida y el hábitat urbano. Recuperar y fortalecer el rol residencial para producir beneficios socia-
EXPERIENCIAS DE INTERVENCIÓN Y GESTIÓN EN CENTROS HISTÓRICOS

RENOVACIÓN DEL CENTRO HISTÓRICO DE SANTIAGO DE CHILE, CHILE

les, económ icos y am bientales. Objetivos SRU: beneficiar a personas sin vivienda que quisieran vivir en el centro; Objetivos CORDESAN: organizar, prom over, planificar, coordinar y ejecutar proyectos para el desarrollo, urbanístico, económico y social con acciones de diseño, rem odelación, renovación, rehabilitación, reconstrucción, edificación, arborización, descontaminación, prevención del deterioro urbano y conservación del patrim onio

Principales Ejes de la Propuesta: Rol residencial de la Com una / Actividades de servicio, com ercio e industria / calidad de vida de la población. Instrum ento de gestión: sector privado, gobierno Nacional y munici pio. 1990, Subsidio de Renovación urbana (SRU), Ministerio de vivienda y Urbanism o; Corporación de Desarrollo de Santiago (CORDESAN), institución privada sin fines de lucro, para gestionar el plan de Repoblam iento.

Estado: Ejecutado

Nivel de inform ación: Bueno
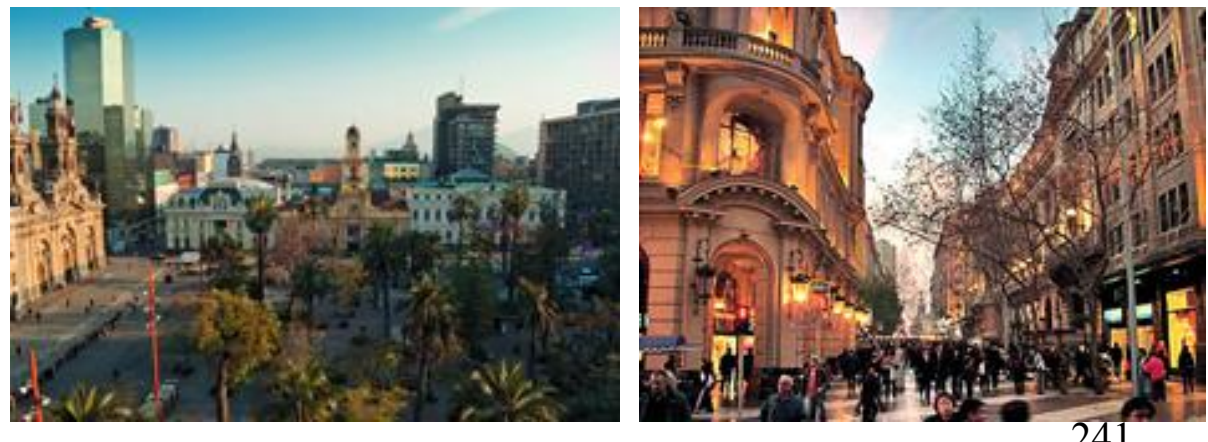

Fuentes: Greene M., Mora R., Berrios E. (2009); "Los instrum entos de repoblam iento del centro de Santiago: SRU y SIT entre 1999 y 2005 ”. En Ciudades para un futuro sostenible, Sim posio Int ernacional Desarrollo, Ciudad y Sost enibilidad, La Serena. Chile. http //habitat .aq .upm .es/boletin/n42/ ab-rm or.htm I 


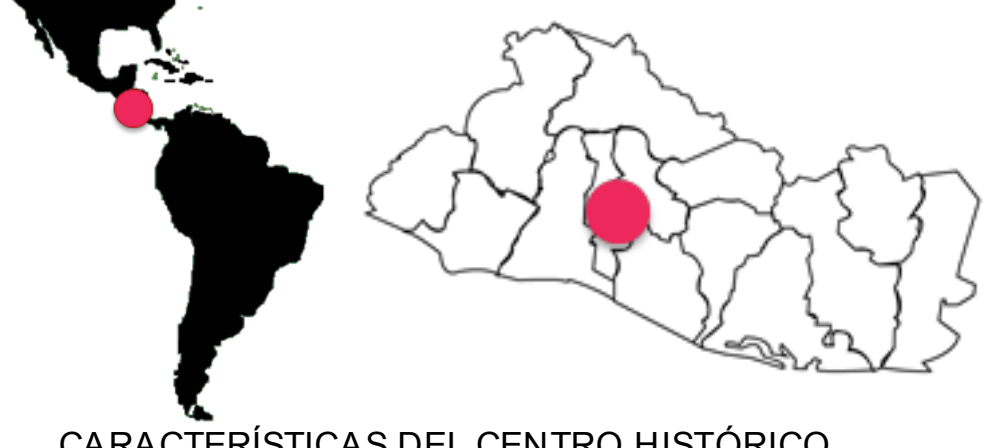

CARACTERÍSTICAS DEL CENTRO HISTÓRICO

Extensión: 722.500 has., Ciudad central. / CH ...has.

Población: 316.090 hab. (2015) / CH ...hab.

Inserción territorial: Ubicada en un valle de la zona central del país, (zona sísm ica que sufrió terrem otos a lo largo de su hist oria), la ciudad está dom inada por un volcán y un cerro.

Dinám ica general y urbanística: Capital del país, sede de Gobiernos, y la m ayor desde el punto de vista económ ico, dem ográfico y asiento de industrias y empresas del país. Fundada en 1525, fue importante centro com ercial durante la colonización española. La mayoría de las construcciones originales de la colonia fueron destruidas por desastres naturales, sobreviven inm uebles que datan del s. XIX y XX.

Especialización Funcional: a fines del s.XIX y principios del XX tuvo un importante desarrollo con la agricultura del café. Como capital del país cuenta con equipamientos de todos los usos (administrativos, com erciales, financieros, religiosos)

Declaratorias: No posee

Problem áticas: Tráfico y transporte $m$ asivo, venta inform al y m ercados, inseguridad ciudadana, deterioro físico, falta de inversión, abandono y poca visibilidad.

\section{CARACTERÍSTICAS RELATIVAS A LA INTERVENCIÓN}

Tipo de intervención: Revitalización

Instrum ento de planificación: 1998, Plan de Rescate del Centro Histórico PRCSS (en el marco del Plan Maestro de Desarrollo Urbano del
WE

REVITALIZACIÓN DEL CENTRO HISTÓRICO DE SAN SALVADOR, EL SALVADOR

Área Metropolitana de San Salvador).

Objetivos: Reactivar económ icam ente el núcleo urbano acom pañando la recuperación del patrim onio cultural para garantizar la recalificación del CH / Presentar visión nueva, integral y coherente de rescate / Convertir el $\mathrm{CH}$ en un lugar ordenado, seguro y com petitivo / Iconcertar entre m unicipio, usuarios, em presas privadas e instituciones de gobierno. Principales Ejes del Plan: Tráfico / com ercio inform al / seguridad ciudadana / espacios públicos y mobiliario urbano / rescate patrimonial / infraestructuras / fuentes tributarias innovadoras / financiam iento / repoblación del $\mathrm{CH}$ / participación ciudadana / Zonific ación / Gestión. Instrum ento de gestión: Oficina del Centro Histórico (encargada de ejecutar el Plan); Corporación para el Desarrollo de San Salvador (para incentivar la inversión privada en el Centro). Oficina Planific. Área Metropolitana S.S.

Estado: En ejecución (desde 1998)

Nivel de inform ación: Bueno
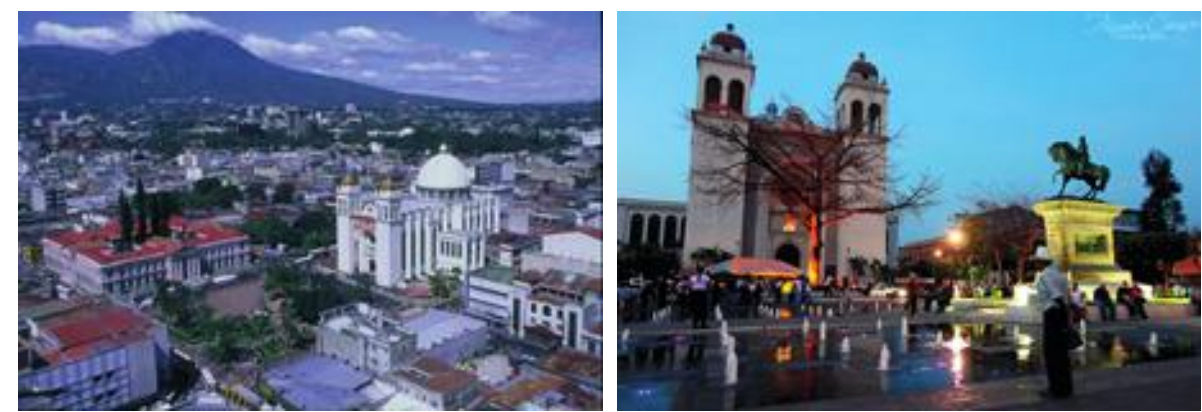

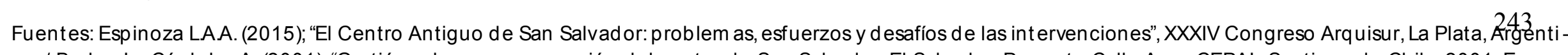
na. / Barba J. -Córd oba A. (2001); "Gestión urbana: recuperación del centro de San Salvador, El Salvador. Proyecto Calle Arce. CEPAL, Santiago de Chile, 2001. En: http $\cdot / /$ repositorio.cepal.org/bitstream/handle/11362/5719/1/S01050371_es.pdf 


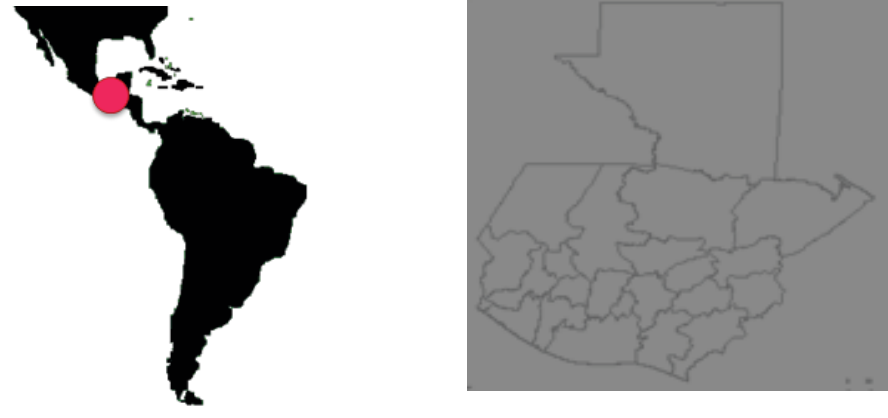

CARACTERÍSTICAS DEL CENTRO HISTÓRICO

Extensión: 69.200 has., Ciudad central. / $\mathrm{CH} 49$ has.

Población: 2.149.107 hab. (2012) / CH 52.700 hab. (2012)

Inserción territorial: se sitúa sobre un valle, en el área sur-centro, con gran cantidad de áreas verdes. Fue afectada por desastres naturales, sobretodo terrem otos.

Dinámica general y urbanística: Es la capital del país y sede de los poderes gubernam entales, siendo la aglom eración urbana más poblada y extensa de América Central. La Ciudad Antigua (1543), es un ejem plo destacado de las fundaciones hispanas en Am éric a, no es un conjunto convencional, a pesar de ser un lugar habitado, posee c arácter arqueológico por la cantidad de edificios en ruina.

Especialización Funcional: ciudad capital (residencial / comercial / cultural / educativo). $\mathrm{CH}$ : residencial y com ercial

Declaratorias: 1944, Monum ento Nacional; 1965, Ciudad Monum ent o Am érica; 1979, Patrim onio Hum anidad UNESCO.

Problem áticas: problem as de conservación, transform ación de usos, factores am enazantes vinculados al crecim iento del turismo (recibe 1.000 .000 de turistas al año) y problem as asociad os al rol de c apital del país,

\section{CARACTERISTIICAS RELATIVAS A LA INTERVENCIÓN}

Tipo de intervención: Rehabilitación

Instrum ento de planificación: 2012, Plan Maestro de la Antigua Gua tem ala PMAG (es el eje del Plan Direct or de Rehabilitación del CH de la Ciudad de Guatem ala).
Objetivos: coordinar acciones del sect or público y privado, que contribuyan al desarrollo económ ico y social, para garantizar la conservación, recuperación y revitalización del patrimonio. Normar la vialidad y el transporte, definir proyectos de infraestructura, establecer proyectos de renovación y rehabilitación de zonas deterioradas, exam inar propiedades para rescate y restauración, realizar inventario y catalogación de propiedades, definir proyectos de saneam iento am biental, creación de proyectos de equipam iento urbano, realizar proyectos de reorganización y modernización m unicipal y prom over valores intangibles.

Principales Ejes del Plan: Políticas de protección y conservación / control del impacto del turismo / medidas para la prevención y gestión del riesgo ante desastres.

Instrum ento de gestión: Consejo Nacional

Estado: En ejecución (desde 2012)

Nivel de inform ación: Bueno

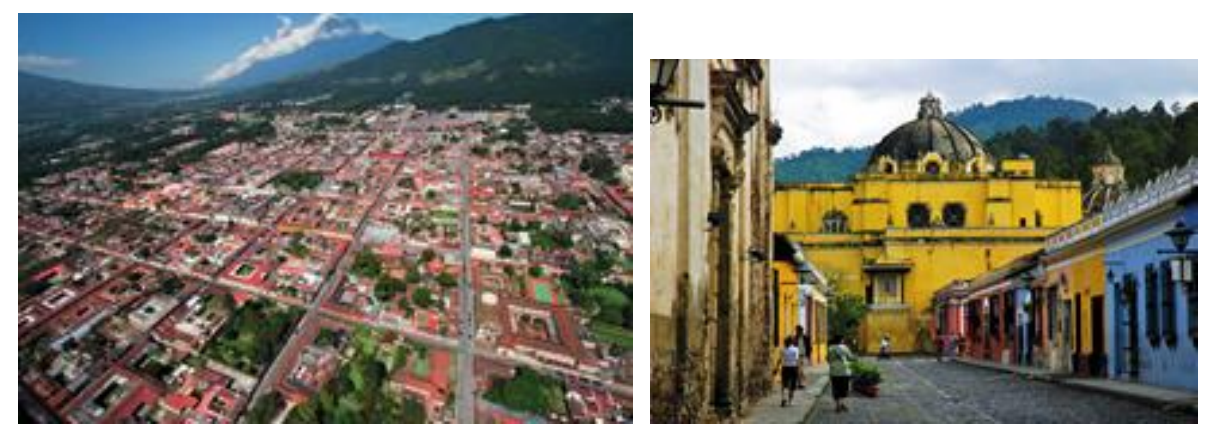

244

López J.S. (2009); ..'La Antigua Guat em ala: Plan Maestro para su centro Histórico". En Manejo y gestión de centros históricos, selección de conferencias de encuentros

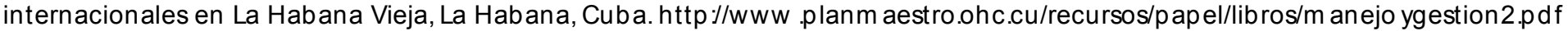




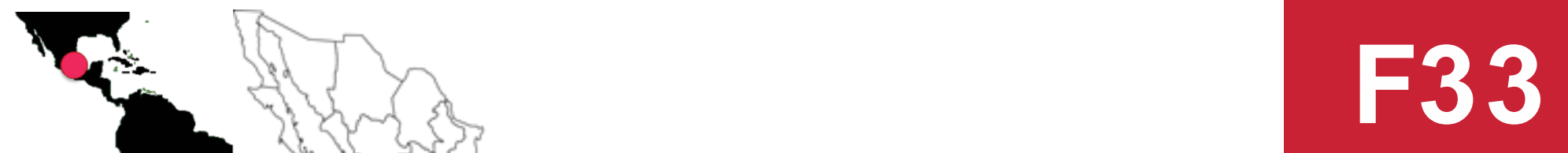

EXPERIENCIAS DE INTERVENCIÓN Y GESTIÓN EN CENTROS HISTÓRICOS

REVITALIZACIÓN DEL CENTRO HISTÓRICO DE LA CIUDAD DE MEXICO

CARACTERÍSTICAS DEL CENTRO HISTÓRICO

Extensión: 149.500 has., Ciudad central. / $\mathrm{CH} 3244$ has.

Población: 8.918.653 hab. (2015) / CH 521.348 hab. (2015)

Inserción territorial: Ciudad mediterránea, asentada sobre el Valle de

México, rodeada por sierras y volcanes apagados.

Dinám ica general y urbanística: Es la capital del país, la más poblada de Am érica Latina y de las más pobladas del mundo. Considerada "ciudad global", es de los centros financieros y culturales más im portantes del mundo. El centro histórico evidencia la transform ación de una ciudad con más de 700 años de historia, fundada en 1325 por indígenas m exicas. Ha sido y es punto de encuentro entre culturas, destacan de él su autenticidad e integridad.

Especialización Funcional: centro político, académ ico, económico, de moda, financiero, em presarial y cultur al.

Declaratorias: 1987, Patrim onio Mundial de la Hum anidad por la UNESC O. Problem áticas: Deterioro edilicio, invasión de la vía pública; problem as de movilidad, comercio ambulante, mal estado de las calles, falta de limpieza, sobre-explotación de los acuíferos, indigencia, prostitución y delincuencia.

\section{CARACTERÍSTICAS RELATIVAS A LA INTERVENCIÓN}

Tipo de int ervención: Revitalización

Instrum ento de planificación: 2000-2014, Proyecto de Revitalización del $\mathrm{CH}$ de la Ciudad de México; 2011-2016, Plan de Manejo Int egral del CH de la Ciudad de México,

Objetivos: Propiciar la recuperación del equilibrio urbano, social y ec onó$\mathrm{m}$ ico; Asegurar perm anencia de valores del sitio y eficiencia del siste$\mathrm{m}$ a urbano; Generar m ecanism os que coordinen diversos agentes del desarrollo; Generar oportunidades para preservación y acrecenta$m$ iento de valores culturales; Conducir mejoram iento progresivo del sitio con acciones inm ediatas y futuras; Construir herram ientas para el seguim iento y evaluación del manejo del sitio.

Principales Ejes del Plan: Revitalización urbana y económ ica / habitabilidad / patrim onio / m o vilidad / prevención de riesgos / vida ciudadana. Instrum ento de gestión: Autoridad del Centro Histórico, Fideicom iso: Centro Histórico de la Ciudad de México, Program as operativos / Fundación CH Ciudad de México.

Estado: En ejecución (desde 2011)

Nivel de inform ación: Muy bueno

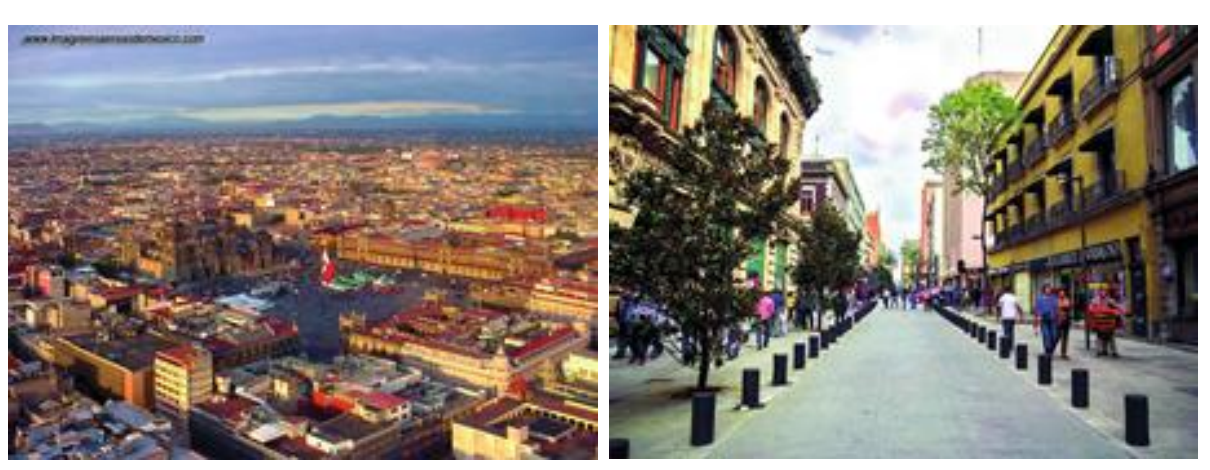

Fuentes: Plan de Manejo Integral del Centro Histórico de la Ciudad de México, 2011 -2016.

http //www autoridad centrohistorico.df.gob.m x/noticias/Plan_int egral_de_m anejo_espanol.pdf.

Tellez Contreras L.F. (2014); "La revitalización del Centro Histórico de la Ciudad de México: entre la voluntad de la élite y la realidad del pueblo". En:

http $/ /$ www pacarinad elsur.com /hom e/m ascaras-e-

id entid ad es/949-la-revitalizacion-d el-centro-historico-de-la-ciudad-d e-m exico-entre-la-voluntad-d e-la-elit e-y-la-realid ad-d el-pueb lo
246 


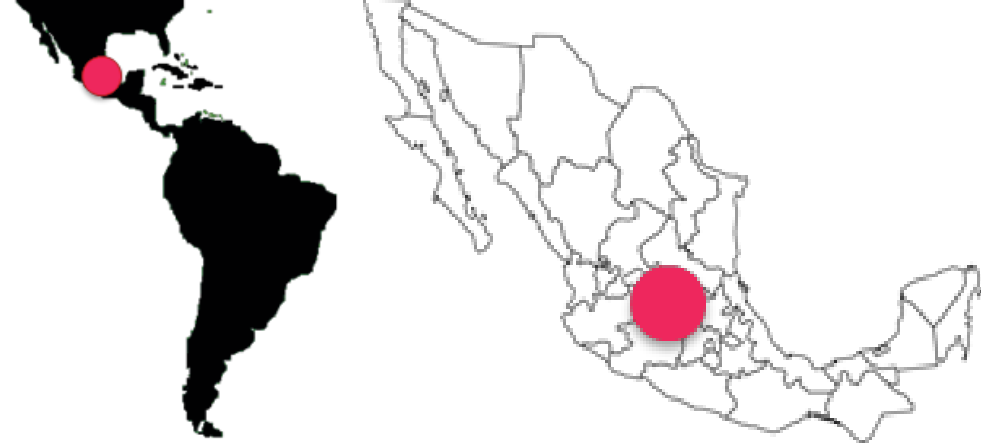

CARACTERÍSTICAS DEL CENTRO HISTÓRICO

Extensión: 1.169 .900 has., Área urbana / CH 932 has.

Población: 878.931 hab. (2015) / CH ...hab.

Inserción territorial: se ubica en el centro del país, a $200 \mathrm{~km}$. de la

Ciudad de México y con buenas conexiones nacionales.

Dinámica general y urbanística: centenaria herencia de una rica y única mezcla de culturas m exicana, española y mestiza, que alberga $m$ iles de edificios construid os entre los s. XVI y XIX de diversas funciones. Reconocido por su excepcional valor universal y por ser ejem plo excepcional de ciudad colonial, su traza sim boliza la m ultietnicidad de su población.

Especialización Funcional: desarrollo industrial, y em presarial con grandes inversiones nacionales e int ernacionales. $\mathrm{CH}$ : residencial, turístic o, act. terciarias.

Declaratorias: 1981, Zona de Monum entos Históricos de la ciudad de Querétaro (ZMHQ); 1995, el CH y barrios tradicionales fueron declarados Zonas de conservación; 1996, Patrim onio de la hum anidad por la UNESCO.

Problem áticas: reducción de población residente; increm ento de nuevas funciones terciarias, que aumentan la afluencia vehicular en detrimento de la movilidad del sitio; baja en la in versión inmobiliaria, norm atividad deficiente que han llevado al abandono y det erioro de áreas de gran valor patrim onial.
EXPERIENCIAS DE INTERVENCIÓN Y GESTIÓN EN CENTROS HISTÓRICOS

PUESTA EN VALOR DEL CENTRO HISTÓRICO DE SANTIAGO DE QUERÉTARO, MÉXICO

\section{CARACTERÍSTICAS RELATIVAS A LA INTERVENCIÓN}

Tipo de intervención: Puesta en valor, conservación

Instrum ento de planificación: 2008, Plan de Manejo y Conservación de la zona de Monum entos Históricos de Santiago de Querétaro (IMPLAN, Instituto Munic. Planeación).

Objetivos: localizar al $\mathrm{CH}$ com o núcleo cívico, histórico y patrim onial de la ciudad para su consecuente conservación y desarrollo económ ico; poner en práctica un Program a de re densificación para fom entar la habitabilidad, y orientado a la revalorización del suelo, al aprovechamiento de infraestructura instalada, promoción del desarrollo urbano, preservación y conservación del patrim onio cultural y freno a la expansión de la m ancha urbana. Prom oción de la vivienda para impedir su deterioro o reem plazo por otros usos; implementar un Sist ema de transferencia de potencialidad es para inm uebles patrim oniales; evitar la terciarización del $\mathrm{CH}$;

Principales Ejes del Plan: conservación del patrim onio cultural histórico / Vivienda / Red de movilidad y Transporte Instrum ento de gestión: Organism o de Gestión del CH.

Nivel de inform ación: Muy bueno

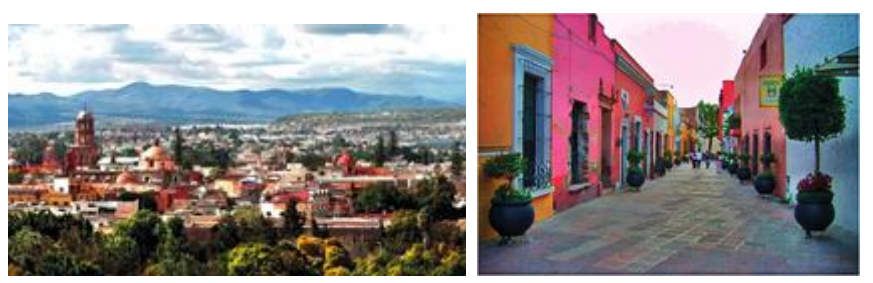

Fuentes: Plan Maestro de la Antigua Guat em ala (2014); https//issuu.com/biblioteca-ulpgc/docs/plan_m aestro_de_la_antigua_guat em al López J.S. (2009); ..'La Antigua Guat em ala: Plan Maestro para su centro Histórico". En Manejo y gestión de centros históricos, selección de conferencias de encuéritros internacionales en La Habana Vieja, La Habana, Cuba. http $/ /$ www .planm aestro.ohc.cu/recursos/pap el/libros/m anejo ygestion2.pdf 


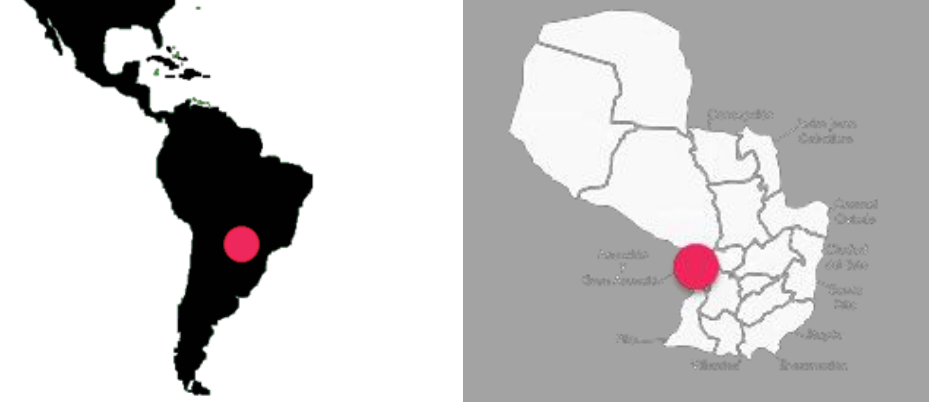

CARACTERISTIICAS DEL CENTRO HISTÓRICO

Extensión: 11.700 has., Ciudad central. / CH $180+38$ has.

Población: 525.294 hab. (2016) / CH 22.017 hab. (2012)

Inserción territorial: ciudad m editerránea, ubicada junto a la bahía de Asunción, en la m argen izquierda del Río Paraguay, frente a la confluencia con el Pilcom ayo. La ciudad se inserta entre siet e colinas, en una de ellas se inserta el $\mathrm{CH}$. Es una de las ciudades más antiguas de Sudam érica (1537),

Dinám ica general y urbanística: Ciudad Capital y la más poblada del país. Sede de los tres poderes de la Nación y c entro cultural del país. Posee el plano característico de las ciudades coloniales. El CH alberga los edificios coloniales m ás antiguos.

Especialización Funcional: Ciudad capital. Actividades políticas, económ icas, sociales, recreativas y culturales.

Declaratorias: No posee.

Problem áticas: vaciam iento poblacional y económ ico del $\mathrm{CH}$, desvalorización de la riqueza patrim onial y deterioro am biental. Baja capacidad de las instituciones del Estado para im plem entar, evaluar y gestionar proyectos, recursos e iniciativas ciudad anas para el $\mathrm{CH}$.

\section{CARACTERÍSTICAS RELATIVAS A LA INTERVENCIÓN}

Tipo de intervención: Revitalización

Instrumento de planificación: 2015, Plan Maestro de Revitalización del Centro Histórico de Asunción ( $\mathrm{CHA}$ ).

Objetivos: Resolver (en un proceso de 23 a 25 años) el vaciamiento

poblacional y económ ico, la desvalorización de la riqueza patrim onial y el deterioro ambiental del $\mathrm{CH}$, como consecuencia de los cambios dem ográficos y territoriales.

Principales Ejes del Plan: 10 Estrategias (Reserva biodiversidad/Frente fluvial / Parque Bicentenario / Costero Verde Activo / Revitalización Chacarita Alta / Corredores ecológicos / Corredores ecológicos, cívicos y dinám icos / Catalizadores urbanos / y Puerto Vivo. 27 Proyectos (de Institucionalización, Movilidad, Prom oción Residencial, Participación, identidad y cultural, Puesta en valor del patrim onio, Parque Caballero). Instrumento de gestión: AsuLab, Laboratorio de Desarrollo Urbano. (2016). Im pulso del Gobierno Municipal y poder legislativo. Alianza privada de organizaciones civiles (Asociación Ciudadela, Asociación par a la movida del centro histórico de Asunción y Colegio de Arquitectos de Paraguay).

Estado: En ejecución (desde 2015)

Nivel de inform ación: Muy bueno
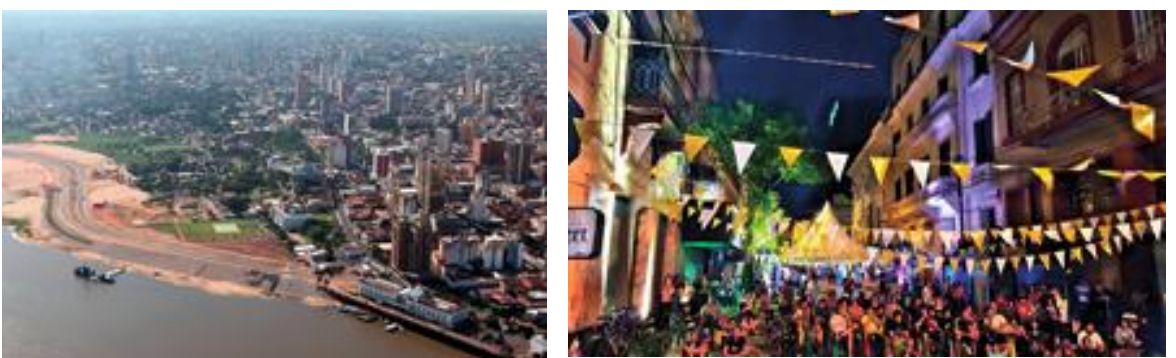


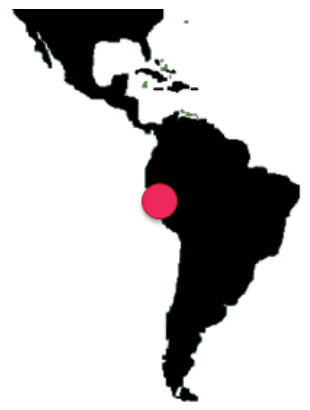

CARACTERÍSTICAS DEL CENTRO HISTÓRICO

Extensión: 267.200 has., Ciudad central. / $\mathrm{CH} 1022$ has.

Población: 8.473.000 hab. (2007)/ CH 146.126 hab. (2014)

Inserción territorial: Se sitúa en la costa central del país, a orillas del Océano Pacífico, flanqueada por el desiert o costero y extendido en los valles de tres ríos.

Dinámica general y urbanística: Capital de Perú y de la provincia hom ónima, es la más poblada del país, Fue fundada en 1535 , siendo Capital del Virreinat o del Perú, y la ciudad más grande e im portante de Am érica del Sur. Su centro histórico es un espacio hum ano, un lugar con vida, reconocible, rep resentativo e íntegro, condicionado por una estruc tura física proveniente del pasado, y caracterizado por la evolución de la ciudad. A lo largo de sus hist oria ha acum ulado monum ent os de gran valor artístico, histórico y cultural, así como espacios urbanos con elem entos a conservar com o am bientes urbanos m onum entales.

Especialización Funcional: centro político, cultural, económ ico y financiero del país.

Declaratorias: 1991, Patrim onio Cultural de la Hum anidad por la UNESCO. Problemáticas: ocupación precaria de las viviendas, el $90 \%$ de las casonas históricas están tugurizadas, degradación del patrimonio construido, inseguridad, comercio informal, sobre-congestión y uso exagerado, prostitución.

\section{CARACTERÍSTICAS RELATIVAS A LA INTERVENCIÓN}

Tipo de intervención: Rehabilitación - recuperación Integral
EXPERIENCIAS DE INTERVENCIÓN Y GESTIÓN EN CENTROS HISTÓRICOS de Lim a al 2035. (1987, Plan del Centro de Lim a; 1994, Reglam ent o de la Adm inistración del CH de Lima; 1999, Plan Maestro Centro de Lima; 2006, Plan Estratégico para la recuperación del CH de Lim a 2006-2035) Objetivos: Conservar, recuperar y realzar los valores form ales, hist óricos y culturales del $\mathrm{CH}$; propiciar la recuperación del equilibrio urbano, social y económ ico; contribuir a la desconcentración funcional; descongestionar y regenerar el tejid o urbano en zonas tugurizadas; regular el uso del suelo; elevar la densidad urbana; preservar y m ejorar los espacios públicos; $m$ ejorar los servicios públicos.

Principales Ejes del Plan: Centralidad / Habitabilidad / Sust entabilidad / Gestión Integral.

Instrumento de gestión: Programa PROLIMA, Programa Municipal para la recuperación del Centro Histórico de Lima.

Nivel de inform ación: Muy bueno
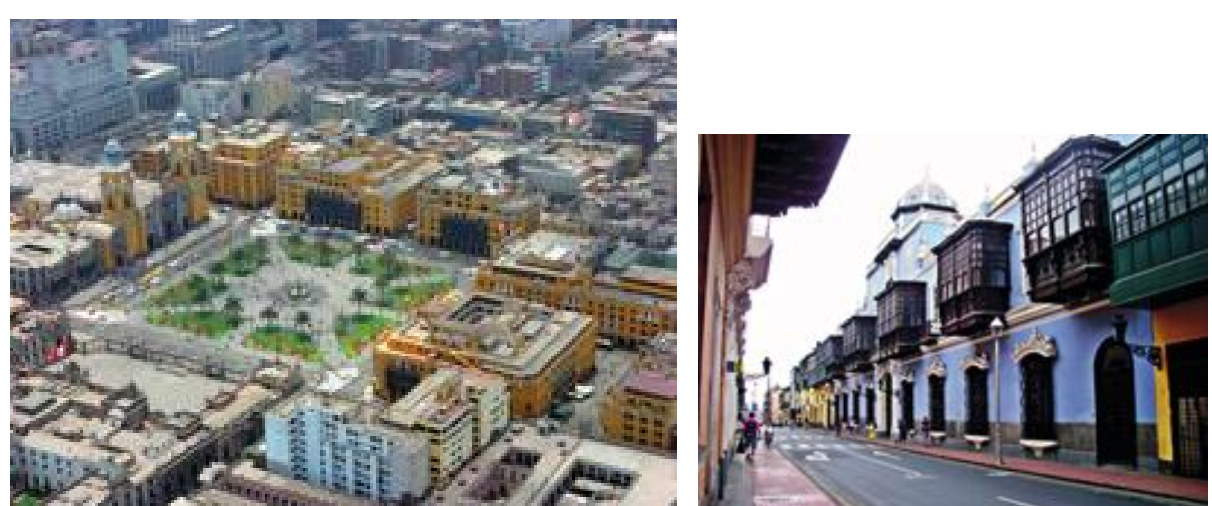

250

Fuentes: Plan Maestro del Centro Histórico de Lim a (2014). En: http //es.slid eshare.net/PatriciaDias VElard e/plan-m aestro-centro-histrico-de-lim a-al-2035/ http $/ / w w w$.m unlim a.gob.pe/prolim a 


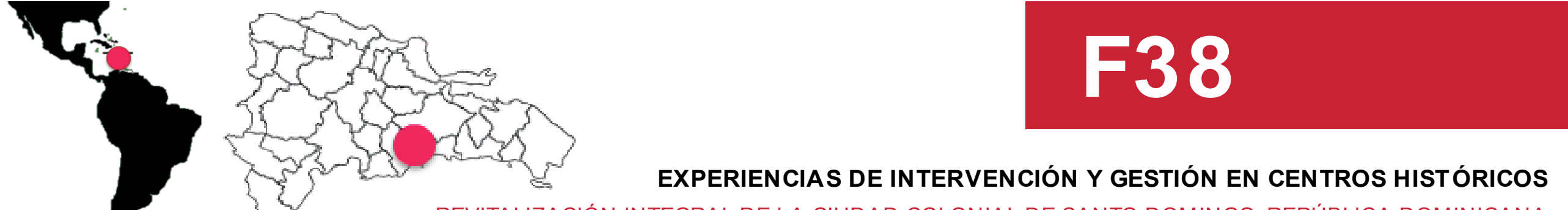

REVITALIZACIÓN INTEGRAL DE LA CIUDAD COLONIAL DE SANTO DOMINGO, REPÚBLICA DOMINICANA

CARACTERÍSTICAS DEL CENTRO HISTÓRICO

Extensión: 130.200 has., Ciudad central. / $\mathrm{CH} 100$ has.

Población: 965.040 hab. (2016) / CH 7.750 hab. (2015)

Inserción territorial: la ciudad se sitúa en las costas del Mar Caribe en la parte sur de la isla. Fue el prim er asentam ient o europeo en Am érica, y la prim era sede del gobierno español.

Dinám ica general y urbanística: la ciudad es la capital del país, siendo el $\mathrm{m}$ ayor centro cultural, financiero, político, com ercial e industrial y el principal puerto. La Zona Colonial posee el diseño original de la ciudad, y concentra edificaciones, estructuras y espacios públicos de valor patrim onial, unidad urbana con identidad e im agen propia.

Especialización Funcional: de ciudad capital, el CH residencial, comercial, turística, religiosa.

Declaratorias: 1990, Patrim onio de la Hum anidad, UNESCO

Problem áticas: despoblam iento, $m$ al estado de conservación, falta de valoración del $\mathrm{CH}$ por sus habitantes, poco turismo, creación de barrios en otras áreas de la ciudad con m ejor accesibilidad y servicios, ocupación indebida de espacios públicos, mal estado de las calles, insuficiente servicio de recolección de residuos y lim pieza, dificultad es con el transporte, drenaje pluvial insuficiente, inseguridad, prostitu ción, ruidos y falta de estacionam ient os.

\section{CARACTERÍSTICAS RELATIVAS A LA INTERVENCIÓN}

Tipo de int ervención: Revitalización Integral

Instrum ento de planificación: 2006, Plan Estratégico de Revitalización integral de la Ciudad Colonial de Santo Dom ingo (PRICC), se articula en Plan Regulador (identifica áreas de conservación y transform ación y establece reglas de intervención) y Plan Estratégico (establece estrategia funcional e identifica áreas de intervención prioritaria).

Objetivos: Prom over la identidad cultural, valorando su historia y patrim onio cultural (patrimonio tangible e intangible) y pot enciando el turismo cultural; valorar las diferencias urbanas potenciando el uso mixto del $\mathrm{CH}$; fortalecer la función habitacional para evitar su reemplazo por usos asociados al turismo; fortalecer y recalificar otros usos actuales com o el com ercial, terciario y del sect or turístico.

Principales Ejes del Plan: Identidad cultural urbana / valoración de diferencias urbanas / fortalecim iento de la función habitacional / recalificación de funciones existentes.

Instrum ento de gestión: Ayuntam iento, Program a BID.

Nivel de inform ación: Bueno
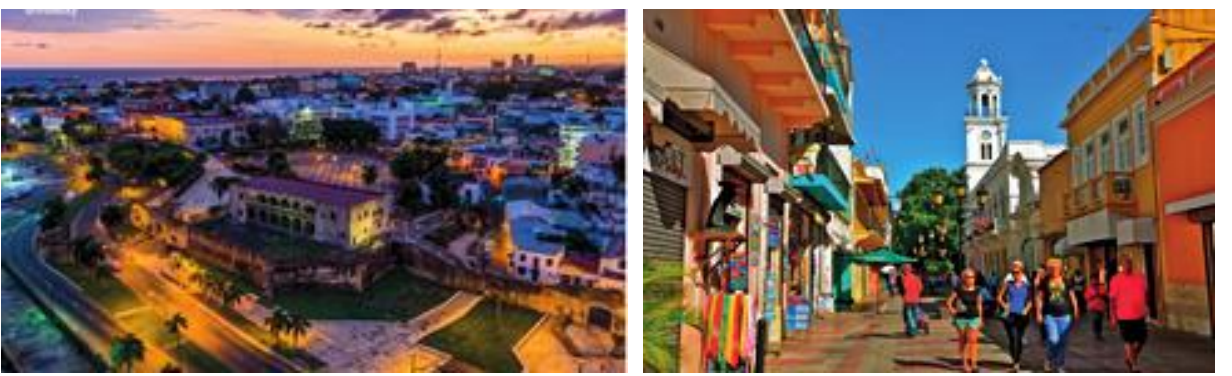

251

Fuentes: Ordenanza del Plan Estratégico de Revitalización Integral de la Ciudad Colonial de Santo Dom ingo (2006) /

$\mathrm{http} / / \mathrm{www}$.diariolib re.com/noticias/ciudad/realizan-investigacion-en-la-ciudad-colonial-en-busca-d el-d esarrollo-de-esta-zona-IJ17482 


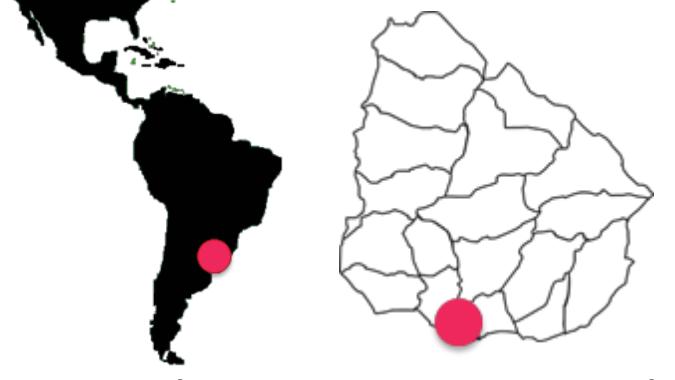

CARACTERÍSTICAS DEL CENTRO HISTÓRICO

Extensión: 73.000 has., Ciudad central. / CH 70 has.

Población: 1.319.108 hab. (2011) / CH 13.000 hab. (2004)

Inserción territorial: Es la capital más austral de Latinoam érica, sobre la margen izquierda del Rio de La Plata.

Dinámica general y urbanística: Su origen colonial, con un antiguo casco am urallado, se debió a razones militares y estratégicas, con un modelo de "ciudad mediterránea", pero con el tiem po se transform ó en ciudad com ercial y portuaria.

Especialización Funcional: Com pleja tram a de actividades asociadas con la vivienda, y con la presencia de la principal centralidad com ercial, adm inistrativa y financiera del país.

Declaratorias: 1982, la Ciudad Vieja fue declarada por decreto en 1982 com o "Área testim onial", luego se elaboró un "In ventario Básico del Patrim onio Arquit ectónico" que definió categorías de protección. 2000 , se declaro al CH "Zona de int erés propietario".

Problem áticas: En época de dictadura (1979), se desclasificaron num erosos bienes culturales considerados "monum entos históricos". Este hecho permitió la dem olición de muchos de ellos que fueron reem plazados por obras de escasa calidad o generaron baldíos en la Ciudad Vieja. Liberación de alquileres, falta de mantenim iento e invasión de inm uebles por fam ilias indigentes. Tugurización y m arginación de la población afincada. Despoblam iento.

\section{CARACTERÍSTICAS RELATIVAS A LA INTERVENCIÓN}

Tipo de int ervención: Ordenación, Prot ección y Mejora

Fuentes: Arana, M. (2011); "Manejo del Casco Histórico de Montevideo". En Reencuentro2, libro de las V Jornadas Int ernacionales de Experiencias de Revitalizzación de Cascos Históricos, Buenos Aires, Argentina / Plan Especial de Ordenación, Prot ección y Mejora de la Ciudad Vieja - 18 de Julio.

http $/ /$ www .m ontevid eo.gub.uy/institucional/politic as/ord enam iento-territorial/plan-especial-d e-ord enacion-p rot eccion-y-m ejora-d e-ciudad-vieja-18-d e-julio

Instrumento de planificación: 2004, Plan Especial de Ordenación, Protección y Mejora de la Ciudad Vieja y el Eje de 18 de Julio; Progr ama "Ciudad Vieja Renueva". (marco: Plan Ordenamiento Territorial Montevideo 1998-2005, POT)

Objetivos: Crear bases técnicas e institucionales para una gestión urbana capaz de ordenar, proteger y m ejorar su área de actuación, perm itiendo la regeneración del $\mathrm{CH}$. / Preservar y poner en valor el tejido urbano; Asegurar accesibilidad y circulación, m ejor ar la calidad de vida de habitantes y usuarios; fom entar la repoblación; alentar la polif uncionalidad del área; y defender un hábitat policlasista e int egrado.

Principales Ejes del Plan: Ordenación, protección y m ejora de: Vivienda social / espacio público / infraestructura.

Instrum ento de gestión: Comisión Especial Permanente de la ciudad Vieja (CEPCV)-colaboración público-privada.

Nivel de inform ación: Muy bueno

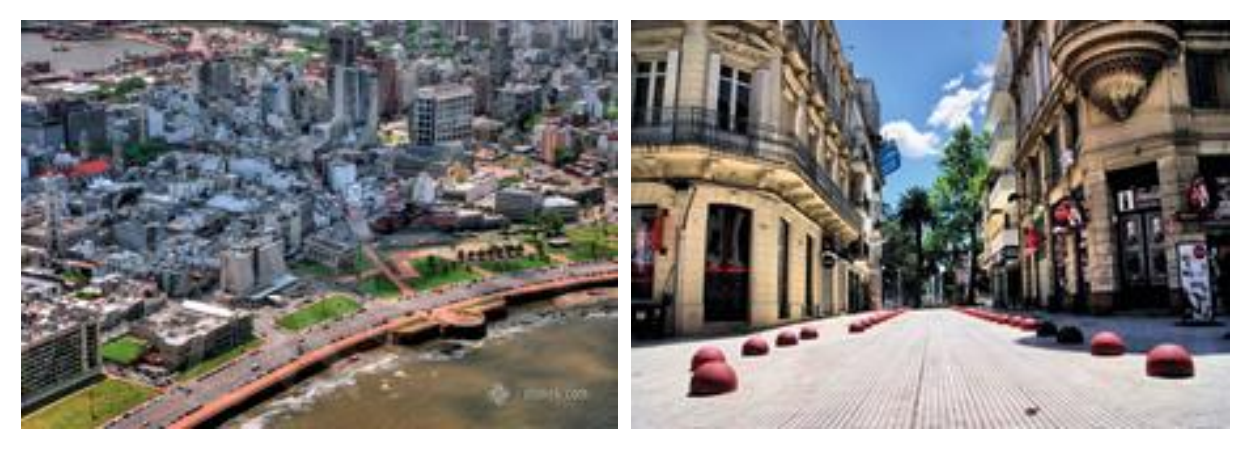
lio 


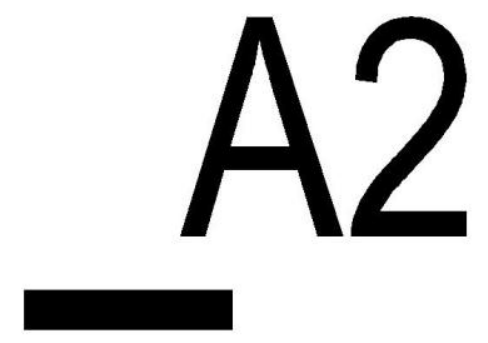

CUADROS SÍNTESIS DE SIMILITUDES Y DIFERENCIAS 


\section{SIMILITUDES DE LOS CENTROS HITÓRICOS Y SUS CIUDADES}

EXTENSIÓN: 9 de las 10 ciudades poseen una superficie comprendida entre 10.200 has. (Florencia) y 24.400 has. (Génova). Dentro de sus CH se encuentran dos grupos diferenciados, aquellos pertenecientes a grandes ciudades que poseen entre 1000 y 1700 has. (Milán, Florencia, Roma y Nápoles) y aquellos que se desarrollan en ciudades intermedias entre 170 y 450 has. (Siena, Génova, Turín, Palermo y Bolonia)

POBLACIÓN: se reconocen dos grupos, las capitales de las regiones más importantes, que rondan y superan el millon de habitantes, desde 860.000 hab. (Palermo) a 2.872.000 hab. (Roma), y otras medianas que oscilan entre 271.000 hab. (Venecia) y 594.000 hab. (Génova). Los CH más poblados concentran entre 85.000 y 107.000 hab. (Roma, Nápoles, Milán), existe un grupo intermedio que posee entre 50.000 y 61.170 hab. (Bolonia, Turín, Venecia y Florencia), y los CH menos poblados cuentan con 19.453 y 21.489 hab. (Génova y Palermo).

INSERCIÓN TERRITORIAL: 9 de 10 ciudades se encuentran distribuidas en distintas regiones del país, con posiciones estratégicas para la vinculación dentro del Italia y con el resto de Europa. 4 de ellas son costeras (Génova, Nápoles, Palermo y Venecia), y 6 son mediterráneas, siendo atravesadas o encontrándose en cercanías de un río (Roma, Bolonia, Siena, Milán, Florencia y Turin).

DINÁMICA GENERAL Y URBANISTICA: todas las ciudades son capitales de Región, a excepción de Siena. Sus CH poseen un alto valor patrimonial, han tenido origen en antiguas civilizaciones, (etruscos, griegos, romanos) que han influenciado la cultura, literatura, lengua, arte, arquitectura, derecho, filosofía del mundo y han dejado su impronta en el ámbito urbano-arquitectónico, reconociéndose los diversos períodos. La mayoría de los $\mathrm{CH}$ se encuentran en muy buen estado de conservación, con elevado número de construcciones originales.

ESPECIALIZACIÓN FUNCIONAL: Al ser la mayoría capitales de región, presentan una amplia variedad de funciones (residencial, comercial, administrativa,educativa, turística, cultural), con $\mathrm{CH}$ que en gran parte continúan siendo el centro de las ciudades, concentrando una amplia gama de funciones.

DECLARATORIAS: La mayoría de los $\mathrm{CH}$ analizados se encuentran incluidos en su totalidad en la lista del Patrimonio Mundial de la Humanidad de la UNESCO (Roma, Venecia, Florencia, Siena, Génova, Nápoles). De Palermo está incluido el conjunto árabe-normando y catedrales.

PROBLEMÁTICAS: En general, los CH presentan problemáticas comunes con mayor o menor grado acorde a la escala de ciudad. Los problemas recurrentes son: deterioro del patrimonio construido, falta de mantenimiento de espacios públicos, desempleo, carencia de vivienda social, disminución de población residente, pérdida de funciones (residencial, comercio barrial, histórico y artesanía local), gentrificación, impacto del turismo, ocupación del espacio público, falta de recursos para conservación y restauración, movilidad, períodos de usos desequilibrados.

A.2a: Contexto europeo: Italia, similitudes de los $\mathrm{CH}$ y sus ciudades. 


\section{DIFERENCIAS DE LOS CENTROS HISTÓRICOS Y SUS CIUDADES}

EXTENSIÓN: La ciudad de Roma alcanza una superficie de 128.500 has. superando ampliamente al resto; y con respecto a los $\mathrm{CH}$ Venezia presenta una situación especial, donde no se reconoce un $\mathrm{CH}$, sino que toda la ciudad es considerada ciudad histórica (15.700 has.)

POBLACIÓN: Siena se presenta como la menor de las ciudades analizadas, con 52.900 hab., que responde a un CH acorde a esa superficie con 10.500 hab., que resulta ser el menos poblado de los 10 casos.

INSERCIÓN TERRITORIAL: 9 de las 10 ciudades pertenecen a regiones diversas, con geografías y paisajes variados, costeras, mediterráneas, Ilanuras, montaña. Sólo Siena y Florencia pertenecen a la misma región, Toscana. Los CH más expuestos a desastres naturales son: Roma, Bolonia, Venecia y Nápoles. De los 10, Palermo es uno de los $\mathrm{CH}$ que con el crecimiento urbano ha perdido la centralidad geográfica.

DINÁMICA GENERAL Y URBANISTICA: Al mismo tiempo de ser la capital de la región de Lazio, Roma destaca por ser la capital del país. Varios de los $\mathrm{CH}$ se han visto afectados por bombardeos durante la II Guerra Mundial (Milán, Bolonia, Palermo). Algunos de ellos no se encuentran en buen estado de conservación, presentando un importante grado de deterioro como Génova, Palermo y algunos sectores de

ESPECIALIZACIÓN FUNCIONAL: Varias de las ciudades destacan por una función particular que sobresale del resto, como la actividad portuaria en Génova y Nápoles, la actividad industrial en Torino y Milán, y la actividad turística en Florencia, Venecia, Siena y Roma y en menor grado Milán y Nápoles. No todos los $\mathrm{CH}$ siguen siendo el centro de la ciudad, Génova y Palermo han perdido funciones.

DECLARATORIAS: Sólo los CH de Torino, Milán no se encuentran dentro de la lista UNESCO, aunque sí algunos de los componentes que lo integran. Bolonia tampoco se encuentra en la lista, aunque sí se han nominado sus $42 \mathrm{~km}$. de calles con galerías porticadas.

PROBLEMÁTICAS: algunas problemáticas no son compartidas por todos los $\mathrm{CH}$, son más características de las grandes ciudades como congestión vehicular, contaminación ambiental, problemas sociales como drogadicción o asociados a la inmigración ilegal. Otros $\mathrm{CH}$ caracterizados por el turismo, enfrentan un grave riesgo de gentrificación y museificación; y aquellos $\mathrm{CH}$ más dregadados tienen problemáticas de conservación del patrimonio (derrumbes) y problemas sociales muy marcados como exclusión social, delincuencia, violencia, prostitución. En Palermo, a estos problemas se suma el haber estado dominado varios años por la mafia, que ha generado abandono y destrucción de su $\mathrm{CH}$.

A.2b: Contexto europeo: Italia, diferencias de los $\mathrm{CH}$ y sus ciudades. 


\section{SIMILITUDES DE LAS INTERVENCIONES EN CENTROS HISTÓRICOS}

TIPO DE INTERVENCIÓN: se identifican las dos tendencias detalladas en el Capítulo I, CH que intervienen de forma "conservacionista" con estrategias de rehabilitación, protección, recuperación, conservación, preservación, tutela y valorización (Bolonia, Venecia, Palermo, Florencia y Siena), y otros que intervienen de forma "transformadora" con estrategias de recualificación como Roma y Milán. También se identifican aquellos que intervienen de modo integral, con estrategias de regeneración, que incluyen conservadoras y transformadoras (Génova, Milán y Torino).

INSTRUMENTO DE PLANIFICACIÓN: de los 10 instrumentos analizados, 5 corresponden a Planes o Programas desarrollados por iniciativas de la Comunidad Europea entre los años 2011 y 2016 (Venecia, Siena, Florencia, Nápoles y Turín - los 4 primeros como requerimientos por ser Patrimonio de la Humanidad - ). Los otros 5 instrumentos, responden a Planes promovidos desde el Municipio.

OBJETIVOS: los $\mathrm{CH}$ poseen algunos objetivos comunes como la preservación, conservación y valorización del patrimonio cultural, la intervención en pos de conservar residentes e incrementar la cantidad de habitantes en el $\mathrm{CH}$, proeger al pequeño comercio y la artesanía local, fortalecer la centralidad, mejorar la accesibilidad, dar solución a problemáticas sociales.

PRINCIPALES EJES DEL PLAN: existen algunos ejes comunes entre los Planes: La protección y conservación del patrimonio cultural, la vivienda, el espacio público, la movilidad-accesibilidad, los equipamientos públicos, las infraestructuras, la actividad económica y el medio ambiente,

INSTRUMENTO DE GESTIÓN: todos los instrumentos de intervención se han puesto en marcha desde Oficinas del CH de la administración Municipal, El financiamiento de las intervenciones también proviene de fondos municipales, con ayudas de la Comunidad Europea mediante programas URBAN, URBACT y fondos FEDER (Nápoles, Génova y Torino).

ESTADO: 7 de los 10 casos se encuentran "En ejecución" (Roma, Génova, Milán, Palermo, Florencia, Siena y Venecia).

NIVEL DE INFORMACIÓN: el $80 \%$ de los casos posee un nivel de información "Muy bueno", no se registran casos de información Regular o Escasa

A.2c: Contexto europeo: Italia, similitudes de las intervenciones y sus ciudades. 


\section{DIFERENCIAS DE LAS INTERVENCIONES EN CENTROS HISTÓRICOS}

TIPO DE INTERVENCIÓN: de todas las estrategias reconocidas, sólo el CH de Nápoles ha propuesto su revitalización integral.

INSTRUMENTO DE PLANIFICACIÓN: los instrumentos elegidos atraviesas períodos muy diversos, desde el año 1973 (Plan de Bolonia), hasta los años 2015 y 2016 (Planes de Gestión de Siena y Florencia). A su vez, dentro de los Planes promovidos a nivel Municipal, existe variados tipos, Plan de Vivienda Social 1973 (Bolonia), Plan Particularizado 1993 (Palermo), Plan Operativo 2001 (Génova), Nuevo Plan Regulador General 2003 (Roma) y Plan Urbanístico 2012 (Milán).

OBJETIVOS: destacan algunos casos que difieren de otros en sus objetivos por el énfasis otorgado al abordaje de ciertos aspectos. El famoso Plan de Bolonia enfatiza en el valor social del $\mathrm{CH}$, sus viviendas, habitantes, comercios, equipamientos públicos y el apoyo a los grupos más desfavorecidos; el Plan de Palermo, por el deterioro sufrido por su $\mathrm{CH}$, destaca por su interés en la restauración, conservación y liberación del patrimonio edilicio; Planes como el de Génova y Nápoles enfatizan en la vinculación del $\mathrm{CH}$ con el puerto y en detener su degradación; los Planes para Roma y Mián incorporan el interés de integrar lo antiguo con lo nuevo, y destinar áreas para transformación; los Planes de Venecia, Siena y Florencia hacen hincapié en aspectos relativos a la importante función turística de estas ciudades; y finalmente, el Programa para Turín aborda el tema de la reconversión de antiguas fábricas insertas en el tejido histórico.

PRINCIPALES EJES DEL PLAN: acorde a los distintos objetivos plantados por los $\mathrm{CH}$, algunos de ellos tienen como ejes la Vivienda social (Bolonia, Milán), la Reforma social (Bolonia), los espacios vacantes (Palermo), la centralidad (Génova), el Turismo, el uso sustentable del sitio (Venecia, Siena, Florencia, Nápoles), la memoria (Turín) y el equilibrio entre protección y transformación (Milán).

INSTRUMENTO DE GESTIÓN: se crearon "Oficinas del Centro Histórico y Sitio UNESCO", para los CH Patrimonio de la Humanidad.

ESTADO: hay sólo dos casos que se encuentran "Ejecutados" (Bolonia y Turín), y uno "A ejecutar" (Nápoles).

NIVEL DE INFORMACIÓN: sólo el 20\% de los casos posee un nivel de información "Bueno"

A.2d: Contexto europeo: Italia, diferencias de las intervenciones y sus ciudades. 


\section{SIMILITUDES DE LOS CENTROS HITÓRICOS Y SUS CIUDADES}

EXTENSIÓN: 6 de las 10 ciudades poseen una superficie comprendida entre 10.190 has. (Barcelona) y 27.680 has. (Vitoria Gasteiz), y otras 3 mayores que poseen entre 40.000 y 97.000 has. (Málaga, Madrid y Zaragoza). Dentro de sus $\mathrm{CH}$ se encuentran dos grupos diferenciados, aquellos que poseen una superficie entre 191 y 523 has. (Valladolid, Zaragoza, Sevilla, Barcelona y Madrid) y aquellos menores que se desarrollan entre 26 y 80 has. (Vitoria Gasteiz, Málaga, Alcoy y A Coruña).

POBLACIÓN: se reconocen tres grupos, las capitales de las comunidades autónomas más importantes, que superan el millon de habitantes, 1.608.746 hab. (Barcelona) a 3.165.541 hab. (Madrid), otras intermedias que oscilan entre 575.322 hab. y 693.878 hab. (Málaga, Sevilla y Zaragoza), y otras que poseen entre 200.000 y 300.000 hab. (A Coruña, Votoira Gasteiz, Gijón y Valladolid). Los CH más poblados concentran entre 100.000 y 130.000 hab. (Barcelona y Madrid), existe un grupo intermedio que posee entre 37.000 y 59.000 hab. (Valladolid, Zaragoza y Sevilla), y los $\mathrm{CH}$ menos poblados poseen entre 2.700 y 10.100 hab. (Gijón, Alcoy, A Coruña, Málaga y Vitoria Gasteiz).

INSERCIÓN TERRITORIAL: 9 de 10 ciudades se encuentran distribuidas en distintas comunidades autónomas del país, con posiciones estratégicas para la vinculación dentro del España y con el resto de Europa. 4 de ellas son costeras (Máaga, Gijón, Barcelona y A Coruña), y 6 son mediterráneas, siendo atravesadas o encontrándose en cercanías de un río (Sevilla, Zaragoza, Valladolid, Madrid, Vitoria Gasteiz y Alcoy).

DINÁMICA GENERAL Y URBANISTICA: 5 de las 10 ciudades son capitales de Comunidades Autónomas (Sevilla, Zaragoza, Barcelona, Madrid y Votoria Gasteiz). Los $\mathrm{CH}$ de los 10 casos poseen un alto valor patrimonial, ciudades medievales con vestigios romanos, árabes, judíos y cristianos, y con exponentes arquitectónicos de diversos períodos. La mayoría de los $\mathrm{CH}$ se encuentran en muy buen estado de conservación, con elevado número de construcciones originales.

ESPECIALIZACIÓN FUNCIONAL: La mayoría de las ciudades presentan una amplia variedad de funciones (residencial, comercial, administrativa, educativa, cultural), con $\mathrm{CH}$ que en gran parte continúan siendo el centro funcional de las ciudades, concentrando una amplia gama de funciones.

DECLARATORIAS: Ninguno de los $\mathrm{CH}$ analizados se encuentran incluidos en la lista del Patrimonio Mundial de la Humanidad de la UNESCO.

PROBLEMÁTICAS: En general, los CH presentan problemáticas comunes con mayor o menor grado acorde a la escala de ciudad. Los problemas recurrentes son: degradación del patrimonio construido (por crecimiento de la ciudades y crisis de los 80 con reconversiones productivas), desempleo marginalidad, disminución de la población residente, población envejecida, edificios abandonados (focos de problemas sociales como drogadicción y prostitución), comercios en decadencia, falta de equipamientos y servicios, falta de espacios verdes, especulación inmpbiliaria, débil vinculación con el resto de la ciudad.

A.2e: Contexto europeo: España, similitudes de los $\mathrm{CH}$ y sus ciudades. 
EXTENSIÓN: La ciudad más pequeña es A Coruña, con una superficie de 3.783 has.; y con respecto a los $\mathrm{CH}$ el de menor superficieo es el de Vitoria Gasteiz, con 26 has., y el más grande es el de Madrid con 523 has.

POBLACIÓN: Alcoy se presenta como la ciudad menos poblada de las ciudades analizadas, con 61.542 hab., y su CH de 4.836 hab. es el segundo $\mathrm{CH}$ menos poblado, dado que Gijón alberga la menor población contando con 2.714 hab.

INSERCIÓN TERRITORIAL: 9 de las 10 ciudades pertenecen a regiones diversas, con geografías y paisajes variados, costeras, mediterráneas, Ilanuras, montaña. Sólo Málaga y Sevilla pertenecen a la misma región, Andalucía. De los $10 \mathrm{CH}$, Gijón, A Coruña,Valladolid, Alcoy y Málaga han perdido la centralidad urbana.

DINÁMICA GENERAL Y URBANISTICA: Al mismo tiempo de ser la capital de la Comunidad de Madrid, la ciudad destaca por ser la capital del país, con una gran actividad económica, seguida por Barcelona. Las ciudades de Gijón y Valladolid, a pesar de no ser capitales de comunidad, son las más pobladas de las entidades administrativas a las que perteneceen. Algunos de los $\mathrm{CH}$ más abandodos son Gijón y Alcoy, teniendo Vitoria Gasteiz el Casco Medieval mejor conservado.

ESPECIALIZACIÓN FUNCIONAL: Algunas ciudades poseen una función que sobresale del resto, como la actividad industrial en A Coruña, Vitoria Gasteiz y Alcoy, y la actividad turística en los $\mathrm{CH}$ de Madrid, Barcelona y Sevilla a nivel local e internacional. Otras ciudades como Málaga, Zaragoza y Gijón también intentan posicionarse en esta actividad. No todos los $\mathrm{CH}$ siguen siendo el centro de la ciudad, Gijón ha perdido ese rol y la ciudad ha intentado reconvertir su uso de industrial a turístico, de puerto tradicional a puerto deportivo.

DECLARATORIAS: En España, para facilitar la gestión de los $\mathrm{CH}$, la mayoría de los mismos están declarados como ARI, Áreas de Rehabilitación Integrada, o como Conjuntos Histórico Artísticos y/o de Interés Cultural.

PROBLEMÁTICAS: algunas problemáticas no son compartidas por todos los $\mathrm{CH}$, son más características de las grandes ciudades como congestión vehicular, contaminación ambiental, problemas sociales como drogadicción o asociados a la inmigración ilegal. Otros $\mathrm{CH}$ caracterizados por el turismo, enfrentan un grave riesgo de gentrificación y museificación; y aquellos $\mathrm{CH}$ más dregadados tienen problemáticas de conservación del patrimonio y problemas sociales muy marcados como exclusión social, delincuencia, violencia, prostitución. En Gijón, el traslado del puerto afectó al $\mathrm{CH}$ que perdió su centralidad, sus usos, y presentó un tejido horadado por instalaciones portuarias abandonadas que contribuyeron al abandono gral.

A.2f: Contexto europeo: España, diferencias de los $\mathrm{CH}$ y sus ciudades. 


\section{SIMILITUDES DE LAS INTERVENCIONES EN CENTROS HISTÓRICOS}

TIPO DE INTERVENCIÓN: se identifican las dos tendencias detalladas en el Capítulo I, CH que intervienen de forma "conservacionista" en 5 casos con estrategias de rehabilitación y protección (Sevilla, Barcelona, Madrid, Vitoria Gasteiz y Alcoy), y otros que intervienen de forma "transformadora" con estrategias de recualificación y reforma interior como Sevilla, Gijón, Valladolid y A Coruña. También se identifican aquellos que intervienen de modo integral, con estrategias de regeneración conservadoras y transformadoras (Gijón, Valladolid y A Coruña).

INSTRUMENTO DE PLANIFICACIÓN: Ninguno de los Planes o Programas han sido requerimientoss de la Comunidad Europea al no encontrarse estos $\mathrm{CH}$ en la lista de Patrimonio de la Humanidad. Los Planes de Reforma Interior (PERI), los Planes Especiales de Protección y Reforma Interior (PEPRI), los Planes Especiales para el Centro histórico $(\mathrm{PECH})$ y los Planes Integrales para el Centro Histórico (PICH) han sido promovidos desde los Municipios habiéndose desarrollado la mayoría entre los años 1983 y 1997 en el marco de Planes Generales de Ordenación Urbana (PGOU).

OBJETIVOS: los $\mathrm{CH}$ poseen algunos objetivos comunes como la rehabilitar, revitalizar y regenerar el patrimonio cultural, intervenir en pos de la recuperación funcional, la revitalización y sostenibilidad socio-económica y medio-ambiental, fomentar la formación y la generación de empleo, conservar residentes e incrementar la cantidad de habitantes en el $\mathrm{CH}$,proponer políticas de vivienda, incentivar la cultura, proteger al pequeño comercio y la artesanía local, fortalecer la centralidad, y mejorar la accesibilidad interna y con la ciudad, dar solución a problemáticas sociales.

PRINCIPALES EJES DEL PLAN: existen algunos ejes comunes entre los Planes: La revitalización, puesta en valor y rehabilitación del patrimonio cultural, el urbanismo y la vivienda, el espacio público, la movilidad-accesibilidad, los equipamientos públicos, las infraestructuras, la actividad económica y el medio ambiente, las actividades socio-culturales, la seguridad y el bienestar social y la recuperación del uso residencial.

INSTRUMENTO DE GESTIÓN: todos los instrumentos de intervención se han puesto en marcha desde la administración Municipal con la creación de Oficinas del Centro Histórico (denominadas Oficinas de Rehabilitación, de Planes, de Gestión y Proyectos...), El financiamiento de las intervenciones también proviene de fondos municipales, con ayudas de la Comunidad Europea mediante programas UR-BAL, URBAN y fondos FEDER (Barcelona, Madrid y Vitoria Gasteiz). El financiamiento de las intervenciones es mixto, con fondos públicos y privados.

ESTADO: 6 de los 10 casos se encuentran "En ejecución" (Málaga, Zaragoza, Barcelona, A Coruña, Madrid y Vitoria Gasteiz) y 4 "Ejecutados" (Sevilla, Gijón, Valladolid y Alcoy).

NIVEL DE INFORMACIÓN: el 60\% de los casos posee un nivel de información "Bueno" y un 30 \% con nivel "Muy bueno".

A.2g: Contexto europeo: España, similitudes de las intervenciones. 
DIFERENCIAS DE LAS INTERVENCIONES EN CENTROS HISTÓRICOS

TIPO DE INTERVENCIÓN: de todas las estrategias reconocidas, sólo en 3 CH se ha propuesto la revitalización integral, Málaga, Zaragoza y Gijón.

INSTRUMENTO DE PLANIFICACIÓN: de los instrumentos analizados, tres Planes corresponden a iniciativas de la Comunidad Europea mediante Programas UR-BAL, URBAN con financiación de fondos FEDER, el Plan de Rehabilitación Integral de Ciudad Vieja, Barcelona (1987), el Plan de Acción para la Revitalización del Centro Urbano de Madrid (2004), y el Plan de Reactivación Integral del Centro Histórico de Vitoria Gasteiz (2009),

OBJETIVOS: destacan algunos casos que a la vez de compartir objetivos con otros $\mathrm{CH}$ difieren en algunos de sus objetivos por el énfasis otorgado al abordaje de ciertos aspectos. Planes como el de Gijón proponen la reconversión de usos, de puerto tradicional a puerto deportivo, y comparte con Valladolid la intención de reestructurar áreas industriales abandonadas con viviendas y equipamientos. Valladolid considera "Áreas de oportunidad" a las infraestructuras obsoletas, infrautilizadas a vacíos intersticiales industriales o edificios institucionales sin uso. Por sus estrategias habitacionales destacan Barcelona, Gijón, Madrid y Votoria Gasteiz, y por su hincapié en el despoblamiento Vitoria Gasteiz, Barcelona y Zaragoza. Algunos planes como el de A Coruña han propuesto la remodelación urbana como estrategia de reforma interior.

PRINCIPALES EJES DEL PLAN: acorde a los distintos objetivos plantados Gijón, tiene como uno de sus ejes las "Actuaciones estructurantes" asociadas a la recuperación del tejido residencial, y Valladolid propone como eje la intervención en "Areas de Oportunidad".

INSTRUMENTO DE GESTIÓN: en el año 1982 se creó en Vitoria Gasteiz la Oficina del Centro Histórico como S.A., caso único de gestión para la época, y luego se crearía la Agencia de Revitalización Integral de la Ciudad Histórica (ARICH S.A.). Posteriormente, en la década del 90, se crea en Barcelona PROCIVESA S.A. para la Promoción de la Ciudad Vieja desde la Oficina de Rehabilitación del Ayuntamiento, y en A Coruña la Empresa Municipal Vivienda, servicios y actividades S.A. desde el Consejo de la ciudad, Oficina de Planeamiento.

ESTADO: hay sólo dos casos que se encuentran "En ejecución" desde los años 2004 y 2009 , los otros son anteriores entre 1987 y 1998.

NIVEL DE INFORMACIÓN: sólo el 10\% de los casos (Gijón) posee un nivel de información "Escaso"

A.2H: Contexto europeo: España, diferencias de las intervenciones. 
EXTENSIÓN: 9 de las 20 ciudades poseen una superficie comprendida entre 11.700 has. (Asunción) y 39.300 has. (Maracaibo), otras 5 rondan las 70.000 has. (Salvador de Bahía, Cartagena, La Habana, Querétaro y Montevideo). Dentro de sus $\mathrm{CH}$, existen 5 de los que no se tiene la superficie y 8 que se encuentran en un rango intermedio comprendido entre 100 y 583 has. (Santo Domingo, San José de Costa Rica, La Habana, Asunción, Quito, Santiago de Chile, Buenos Aires y Recife).

POBLACIÓN: la mitad de las ciudades (10) superan el millon de habitantes. 8 de ellas oscilan entre 1.300.000 y 2.965.000 (Montevideo,

Maracaibo, Recife, Quito, La Habana, Santa Cruz de la Sierra, Salvador de Bahía y Buenos Aires), otras están muy cercanas como Cartagena,

Santo Domingo y Querétaro, y otras 6 medianas oscilan entre 150.000 hab. (Comayagua) y 525.000 hab. (Asunción). De los $5 \mathrm{CH}$ de los que no se tenía la superficie, tampoco se ha accedido al dato de su número de habitantes. Los $12 \mathrm{CH}$ de los que se tiene datos poseen cantidades diversas de habitantes, dos cuentan entre 112.000 y 146.000 hab. (Buenos Aires y Lima), 4 entre 40.000 y 77.000 hab. (Quito, San José de Costa Rica, La Habana y Santa Cruz de la Sierra), y 3 poseen entre 13.000 y 23.700 hab. (Montevideo, Asunción y Recife).

INSERCIÓN TERRITORIAL: 18 de las 20 ciudades se encuentran distribuidas en distintos países, con posiciones muy diversas dentro del América Latina y con diferentes vinculaciones con el resto del mundo. 10 de ellas son costeras, con costas sobre los océanos Atlántico y Pacífico, y el Mar Caribe, (Buenos Aires, Montevideo, Recife, Salvador de Bahía, Maracaibo, Cartagena, Panamá, Santo Domingo, La Habana y Lima), y 10 son mediterráneas, siendo atravesadas o encontrándose en cercanías de un río (San José de Costa Rica, Antigua Guatemala, San Salvador, Comayagua, Ciudad de México, Querétaro, Quito, Santa Cruz de la Sierra, Asunción y Santiago de Chile).

DINÁMICA GENERAL Y URBANISTICA: 13 de las 20 ciudades son capitales de país. Muchos de sus CH poseen un alto valor patrimonial, con arquitectura que ha tenido origen en las colonias españolas en América desde el descubrimiento de Colón en 1492. Los españoles trasladaron su idioma, cultura, religión y costumbres, que impusieron a la población indigena. Por lo tanto, el arte colonial latinoamericano posee los mismo estilos que se desarrollaban paralelamente en Europa pero con adaptaciones (renacentista, barroco y rococó). A esta influencia española se ha sumado luego la influencia portuguesa, inglesa, italiana, y de colectividades que se han ido asentado en AL. Los CH latinoamericanos que conservan más ejemplos de este patrimonio son Querétaro, Quito, La Habana, Panamá, Cartagena, Ciudad de México, Lima, Comayagua y Antigua Guatemala; y los $\mathrm{CH}$ que más han perdido estos exponentes son: San José de Costa Rica y San Salvador. Un grupo en una situación intermedia, está conformado por Recife, Buenos Aires, Asunción, Santa Cruz de la Sierra, Santo Domingo y Montevideo.

ESPECIALIZACIÓN FUNCIONAL: Las 13 ciudades capitales de país, presentan una amplia variedad de funciones (residencial, comercial, administrativa,educativa, turística, cultural), con $\mathrm{CH}$ que en gran parte continúan siendo el centro de las ciudades o siguen desempeñando un rol importante en la ciudad, concentrando una amplia gama de funciones funciones específicas en particular.

DECLARATORIAS: De los $20 \mathrm{CH}$ analizados, 10 se encuentran incluidos en la lista del Patrimonio Mundial de la Humanidad de la UNESCO (Salvador de Bahía, Cartagena, La Habana, Quito, Antigua Guatemala, Ciudad de México, Querétaro, Panamá, Lima y Santo Domingo), y los 10 restantes no poseen declaración de UNESCO.

PROBLEMÁTICAS: En general, los CH presentan problemáticas comunes con mayor o menor grado acorde a la escala de ciudad. Los problemas recurrentes son: deterioro y pérdida del patrimonio construido por destrucción, carencia de vivienda social, disminución de población residente, pérdida de funciones (residencial, comercio barrial, histórico y artesanía local), comercio informal, gentrificación, impacto del turismo, ocupación del espacio público, escasez de mantenimiento de espacios públicos, falta de recursos para conservación y restauración, falta de eficiencia

institucional, movilidad, falta de espacios verdes, desequilibrio entre el uso diurno y nocturno, desempleo, problemas sociales como inseguridad, exclusión, pobreza, mendicidad, prostitución, drogadicción.

A.2i: Contexto latinoamericano: similitudes de los $\mathrm{CH}$ y sus ciudades. 
EXTENSIÓN: La ciudad de México y Lima alcanzan las mayores superficies, con 149.500 y 267.200 has. superando ampliamente al resto, y hay 4 casos que se presentan como las menores, con menos de 10.000 has, entre 4400 y 7225 (San José de costa Rica, Comayagua, Antigua Guatemala y San Salvador); con respecto a los CH destacan 3 mayores, con 932, 1022 y 3244 has. (Querétaro, Ciudad de México y LIma), y 3 menores, con menos de 100 has., 44, 49 y 70 has. (Panamá, Antigua Guatemala y Montevideo). Aclaración: los datos obtenidos de superficie de los $\mathrm{CH}$ son relativos, porque no todos consideran los mismos límites.

POBLACIÓN: Antigua Guatemala se presenta como la menor de las ciudades analizadas, con 45.669 hab., y Ciudad de México y Lima se separan del resto, con 8.918 .653 y 8.473 .000 hab. respectivamente. El CH más poblado es el de la ciudad de México con 521.348 hab., y los menos poblados son los de Panamá y Santo Domingo, con 3262 y 7750 hab. respectivamente. Asunción es uno de los $\mathrm{CH}$ que más pobación ha perdido.

INSERCIÓN TERRITORIAL: Las 10 ciudades pertenecen a regiones diversas, con geografías y paisajes variados, costeras, mediterráneas, llanuras, montaña. Sólo Ciudad de México y Querétaro pertenecen al mismo país, México, y Recife y Salvador de Bahía a Brasil. Por su localización, algunos $\mathrm{CH}$ se encuentran más expuestos a desastres naturales como huracanes, terremotos o tsunamis (San Salvador, Antigua Guatemala, Santo Domingo, Comayagua, Panamá, Ciudad de México, Querétaro, La Habana, Santa Cruz de la Sierra, Santiago de Chile.). De los $20 \mathrm{CH}$, Salvador de Bahía, Recife, Cartagena, Maracaibo, San Salvador, Panamá, San José de Costa Rica, Querétaro y Asunción han perdido la centralidad urbana.

DINÁMICA GENERAL Y URBANISTICA: Las 7 ciudades que no son capitales de país, adquieren diversa relevancia en su contexto local. Los CH de las ciudades latinoamericanas analizadas poseen estados de conservación muy dispares, desde $\mathrm{CH}$ que se han conservado intactos o con muy pocas modificaciones sobre su patrimonio original, (Querétaro, Quito, La Habana, Panamá, Cartagena, Ciudad de México, Lima, Comayagua, Guatemala, Salvador de Bahía), hasta aquellos que han sido muy alterados y apenas conservan algunos elementos originales aislados como San José de Costa Rica Y San Salvador. También se reconoce un grupo intermedio en el que se encuentran los CH de Recife, Buenos Aires, Asunción, Santa Cruz de la Sierra, Santo Domingo, Comayagua y Montevideo).

ESPECIALIZACIÓN FUNCIONAL: Las funciones de las 7 ciudades que no son capitales son variadas, industrial, comercial, turística. De los 20 casos analizados, los $\mathrm{CH}$ de Cartagena y Salvador de Bahía destacan por un uso principalmente turístico y el desarrollo de actividades y servicios asociados al mismo. El CH de San José de Costa Rica es uno de los casos de mayor gravedad en cuanto a la pérdida de la función residencial el $\mathrm{CH}$ de Maracaibo ha perdido la centralidad física y funcional.

DECLARATORIAS: Las fechas de las Declaraciones oscilan entre los años 1978 y 1997, siendo Quito junto con Cracovia (Polonia), los primeros $\mathrm{CH}$ en ser declarados patrimonio de la Humanidada en el año 1978. El último $\mathrm{CH}$ declarado de América Latina fue Panamá, en el año 1997.

PROBLEMÁTICAS: los CH más enfocados en el turismo enfrentan un grave riesgo de gentrificación y museificación; otros, con escasa tradición en la conservación del patrimonio afrontan el problema de la falta de valoración del $\mathrm{CH}$ por parte de la población residente y usuaria y el desinterés por su intervención (Comayagua, Santo Domingo, Maracaibo, Santa Cruz de la Sierra). En consecuencia, Comayagua comparte con Querétaro un deficiente normativa que regule la intervención sobre el patrimonio edificado. Varios $\mathrm{CH}$ poseen una gran presencia de comercio informal (Cartagena, Quito, San Salvador, Comayagua, Ciudad de México, Lima y Maracaibo), y algunos de ellos se encuentran tugurizados (Lima, Montevideo y La Habana).

A.2j: Contexto latinoamericano: diferencias de los $\mathrm{CH}$ y sus ciudades. 


\section{SIMILITUDES DE LAS INTERVENCIONES EN CENTROS HISTÓRICOS}

TIPO DE INTERVENCIÓN: 12 de los $20 \mathrm{CH}$ analizados proponen estrategias de Revitalización (Buenos Aires, Santa cruz de la Sierra, Recife, Salvador de Bahía, Cartagena, San José de Costa Rica, La Habana, San Salvador, Comayagua, Ciudad de México, Asunción y Santo Domingo), otros 6 intervienen de forma "conservacionista" con estrategias de rehabilitación, puesta en valor, restauración, protección, recuperación, conservación y mejora.

INSTRUMENTO DE PLANIFICACIÓN: se han reconocido 7 Planes Maestros (La Habana, Quito, Antigua Guatemala, Comayagua, Panamá, Asunción y Lima), 13 Planes de diversos tipos (Buenos Aires, Santa Cruz de la Sierra, Recife, Cartagena, San José de Costa Rica, La Habana, San Salvador, Ciudad de México, Querétaro, Panamá, Santo Domingo, Montevideo y Maracaibo), y 3 Programas para el CH (Recife, Salvador de Bahía y Comayagua) desarrollados por iniciativas municipales.

OBJETIVOS: los $\mathrm{CH}$ poseen algunos objetivos comunes como la preservación, conservación y valorización del patrimonio cultural, la promoción de la identidad, la intervención en pos de abordar el despoblamiento con búsqueda de estrategias para incrementar la cantidad de habitantes, fomentar actividades permanentes, el uso residencial y la diversidad funcional, promover actividades económicas, fortalecer la centralidad, mejorar la accesibilidad, solucionar graves problemáticas sociales, optimizar la vinculación del $\mathrm{CH}$ con el resto de la ciudad y crear instrumentos y herramientas para la gestión.

PRINCIPALES EJES DEL PLAN: existen algunos ejes comunes entre los instrumentos: La protección y conservación del patrimonio cultural, la vivienda, el repoblamiento, la inclusión social, la identidad, el espacio público, la movilidad-accesibilidad, los equipamientos públicos, las infraestructuras, la actividad económica, la gestión y el medio ambiente,

INSTRUMENTO DE GESTIÓN: todos los instrumentos de intervención se han puesto en marcha desde oficinas del CH que funcionan desde la administración Municipal con financiamiento de fondos municipales. En algunos casos hay colaboración desde el gobierno Nacional para la elaboración de los instrumentos de planificación y el financiamiento, y en CH Patrimonio de la Humanidad coolaboran organismos internacionales como AECID (Agencia española de cooperación internacional para el desarrollo), BID (Banco Interamericano de Desarrollo) y la Junta de Andalucía: Salvador de Bahía, Cartagena, La Habana, Quito, Antigua Guatemala, Ciudad de México, Querétaro, Panamá, Lima y Santo Domingo.

ESTADO: 16 de los 20 casos se encuentran "En ejecución".

NIVEL DE INFORMACIÓN: el 50\% de los casos posee un nivel de información "Bueno", y el 35\% posee un nivel "Muy bueno".

A.2k: Contexto latinoamericano: similitudes de las intervenciones. 
TIPO DE INTERVENCIÓN: de todas las estrategias reconocidas, tan sólo 2 proponen estrategias "transformadoras" de Renovación (Santiago de Chile y Maracaibo). El $\mathrm{CH}$ de Montevideo es el único que propone como estrategia la ordenación.

INSTRUMENTO DE PLANIFICACIÓN: los instrumentos elegidos atraviesas períodos muy diversos, desde el año 1989 (Plan Maestro del CH de Quito), hasta el años 2015 (Plan Plan Maestro del CH de Asunción, Plan de Manejo del CH de Buenos Aires y Plan de Acción del CH de San José de Costa Rica). A su vez, dentro de la variedad de Planes se encuentran Planes de Manejo, Planes de Revitalización, Planes de Acción, Planes Especiales, Planes estratégicos y Planes Integrales.

OBJETIVOS: destacan algunos casos que difieren de otros en sus objetivos por el énfasis otorgado al abordaje de ciertos aspectos. El Plan de La Habana enfatiza en la revitalización social del $\mathrm{CH}$ y la sostenibilidad cultural, medioambiental, social y económica; Panamá y Montevideo también hacen hincapié en la inclusión social, en fomentar al $\mathrm{CH}$ como un ámbito policlasista; otros $\mathrm{CH}$ potencian el reconocimiento del $\mathrm{CH}$ como espacio representativo, de identidad y encuentro con las raíces, como en Quito, Antigua Guatemala, Santo Domingo yMaracaibo; en transformar la base económica aumentando el turismo en Salvador de Bahía y Recife; en la inserción socio-laboral juvenil en Comayagua con desarrollo de Escuela Taller; generar mecanismos que coordinen los agentes de desarrollo en Ciudad de México; e implmentar un sistema de transferencia para bienes patrimoniales en Querétaro. Algunos $\mathrm{CH}$ con sobre-utilización y tugurización como Lima y Ciudad de México proponen desconcentar funcionalmente y regenerar tejidos tugurizados.

PRINCIPALES EJES DEL PLAN: acorde a los distintos objetivos plantados por los $\mathrm{CH}$, algunos de ellos tienen como ejes la Vivienda social (Montevideo), el Suelo urbano y la economía local (La Habana), el desarrollo social y la memoria histórica (Cartagena); la centralidad (Lima); el fomento a la inversión privada (Quito); el comercio informal, la participación ciudadana (San Salvador); prevención y gestión del riesgo (Antigua Guatemala y Ciudad de México).

INSTRUMENTO DE GESTIÓN: se destaca en la gestión la creación de algunos instrumentos como la "Empresa de desarrollo del CH de Quito", de economía mixta; la "Oficina del Historiador de La Habana Vieja", con un sistema empresarial -compañía HABAGUANEX S.A. para la explotación turística, la Agencia de viajes San Cristóbal y la inmobiliaria FÉNIX S.A.-; la corporación de economía mixta "CORDESAN", para el desarrollo de Santiago de Chile; la "Empresa privada de urbanismo de Recife"; el Programa Municipal "PROLIMA" en Lima; la "Comisión Especial Permanente de la Ciudad Vieja de Montevideo" de economía mixta; el "Fideicomiso del CH" de la Ciudad de México, y "ASULAB, Laboratorio de Desarrollo Urbano" de Asunción creado desde el Municipio, con alianzas privadas de organismos civiles.

ESTADO: hay 3 casos "Ejecutados" (Recife, Salvador de Bahía y Santiago de Chile), y uno "A ejecutar" (San José de Costa Rica). Las fechas de los casos "En ejecución" varían entre elaño 1989 al 2015.

NIVEL DE INFORMACIÓN: sólo el 10\% de los casos posee un nivel de información "Escaso" (Maracaibo y Recife) y un $5 \%$ "Muy escaso" (San José de Costa Rica).

A.2l: Contexto latinoamericano: diferencias de las intervenciones. 


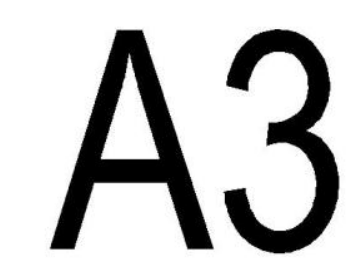

GRÁFICOS DE ANÁLISIS 


\section{ANÁLISIS CUANTITATIVO. PROBLEMÁTICAS: DIMENSIÓN FÍSICO-AMBIENTAL}
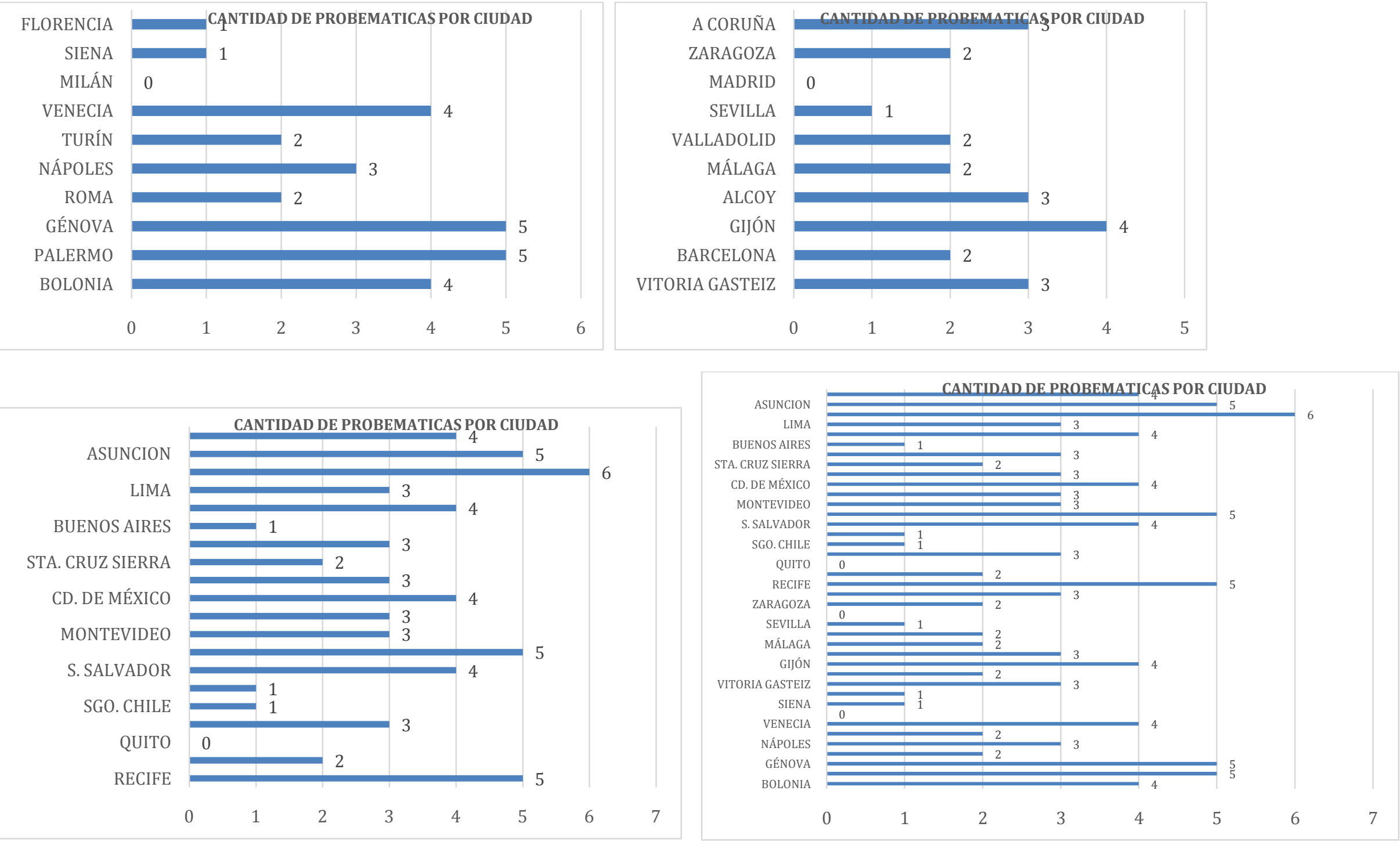


\section{ANÁLISIS CUANTITATIVO. PROBLEMÁTICAS: DIMENSIÓN FÍSICO-AMBIENTAL}
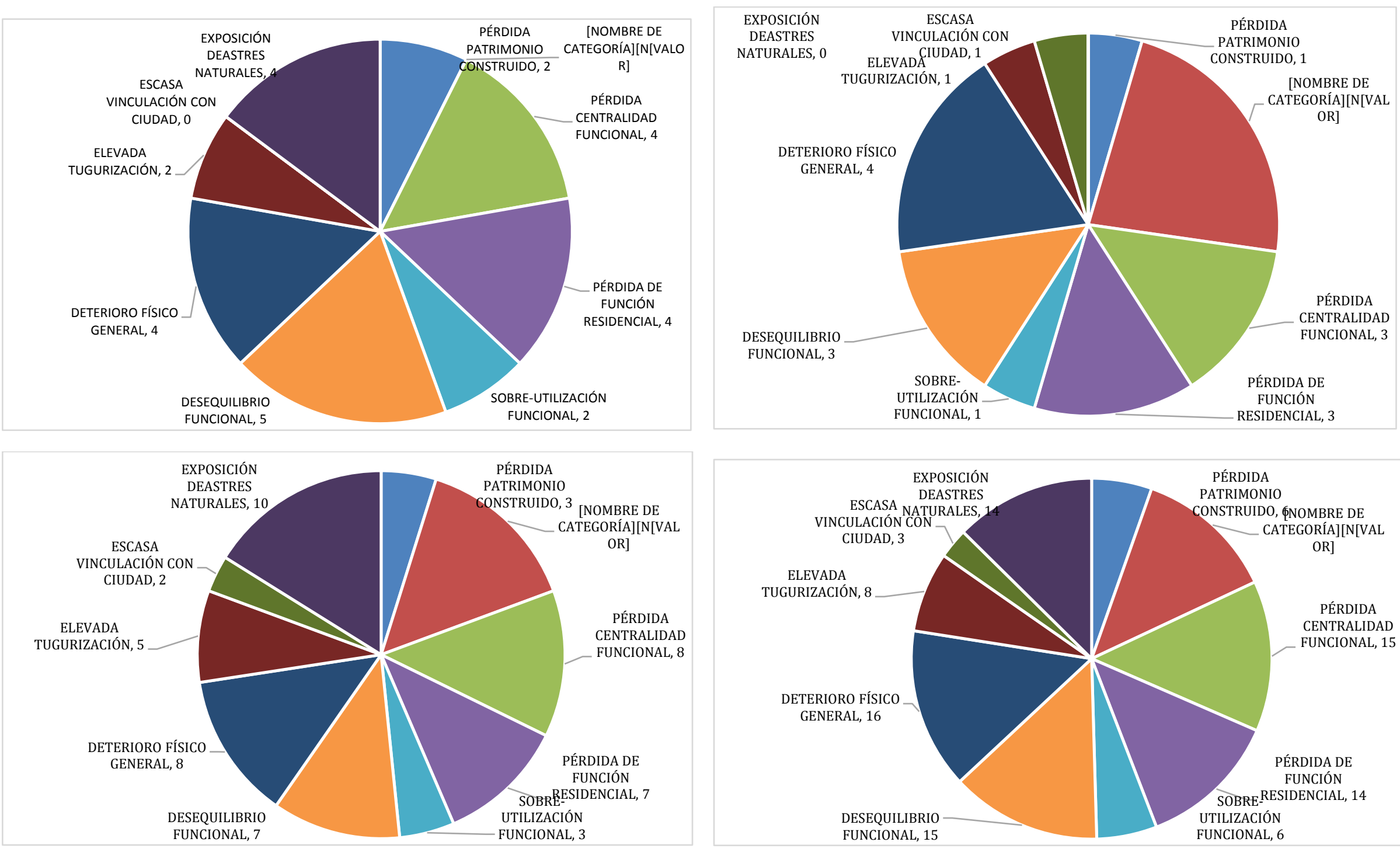


\section{ANÁLISIS CUANTITATIVO. PROBLEMÁTICAS: DIMENSIÓN SOCIO-CULTURAL}
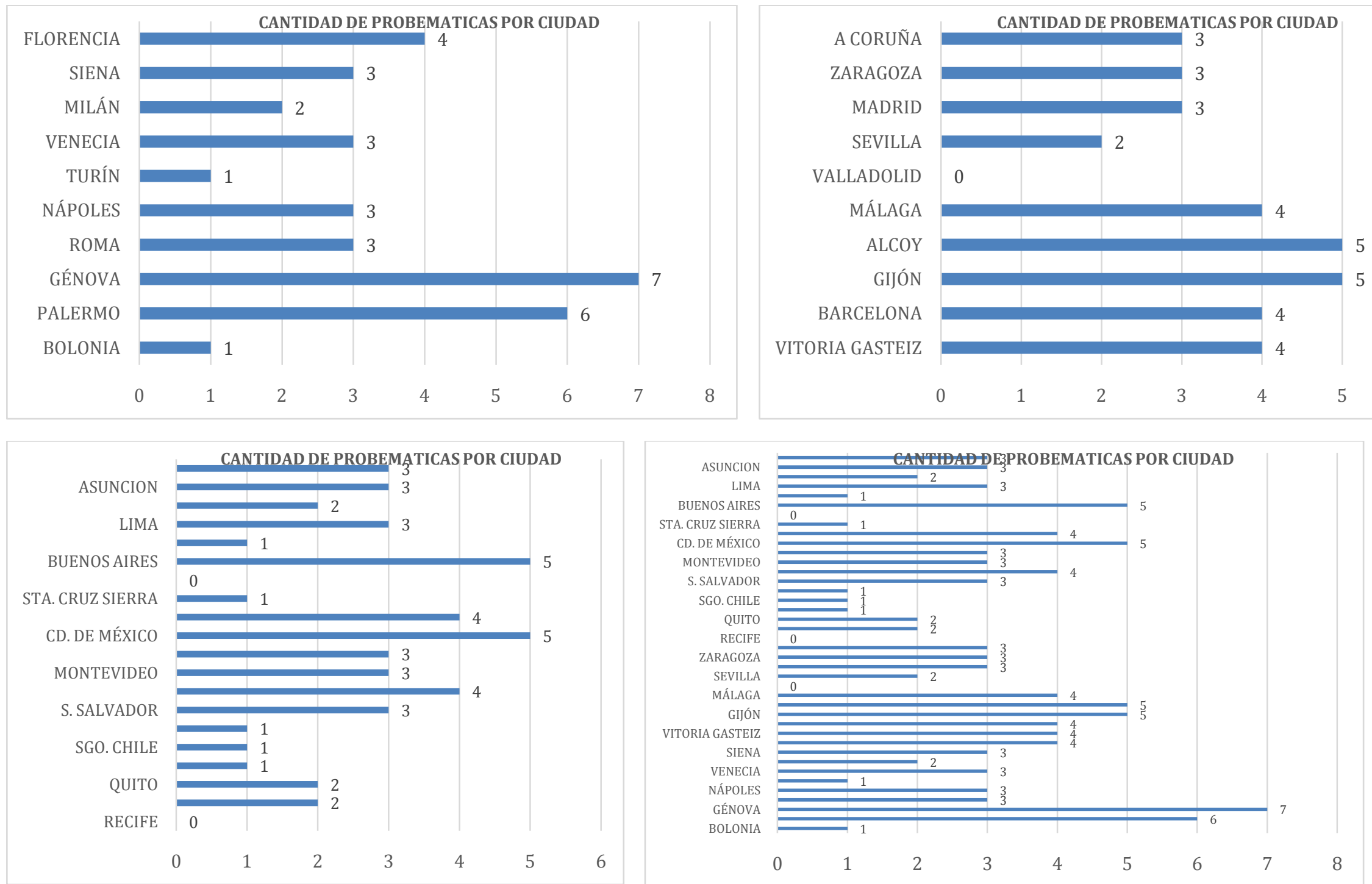


\section{ANÁLISIS CUANTITATIVO. PROBLEMÁTICAS: DIMENSIÓN SOCIO-CULTURAL}
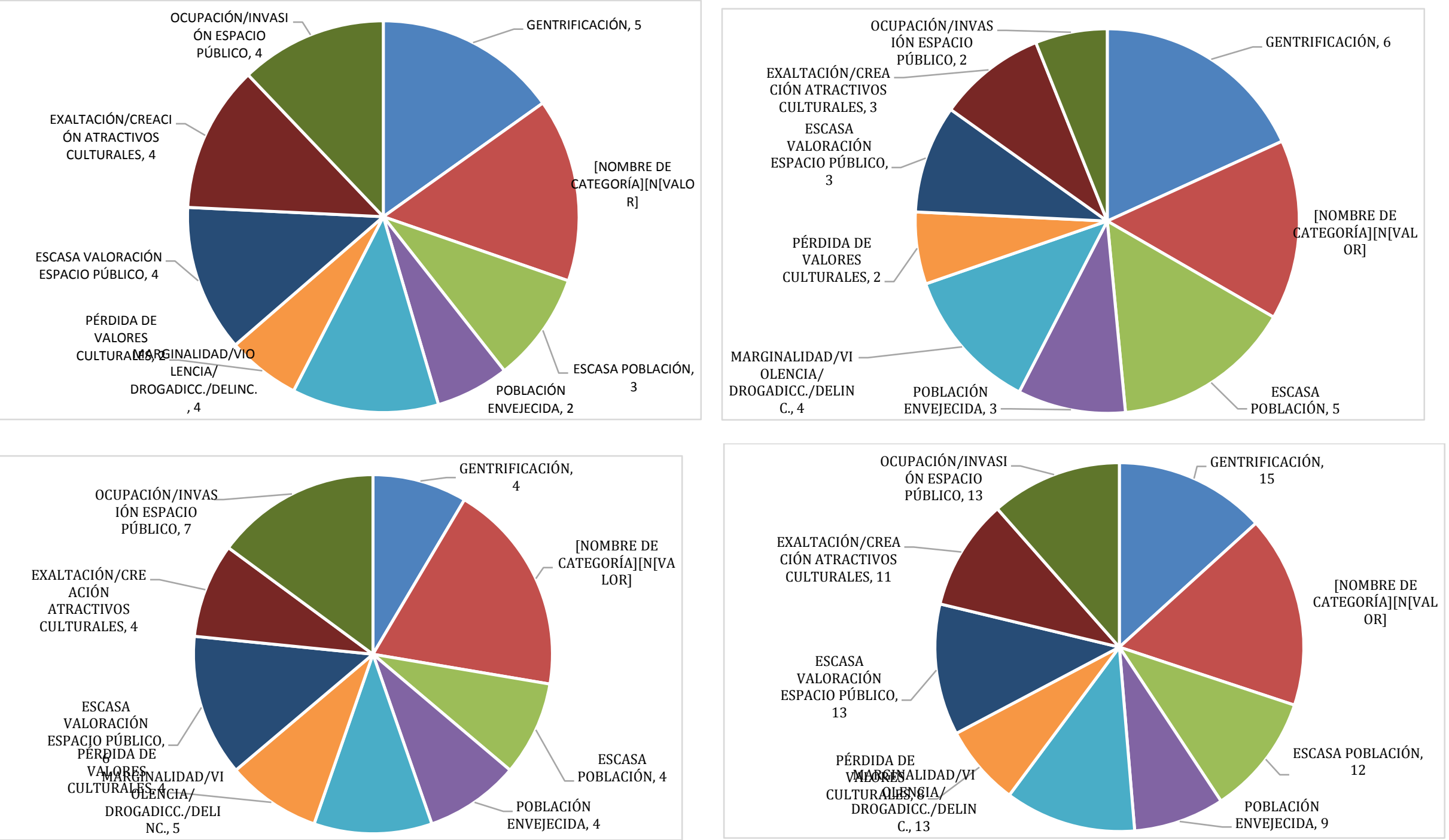


\section{ANÁLISIS CUANTITATIVO. PROBLEMÁTICAS: DIMENSIÓN ECONÓMICA}
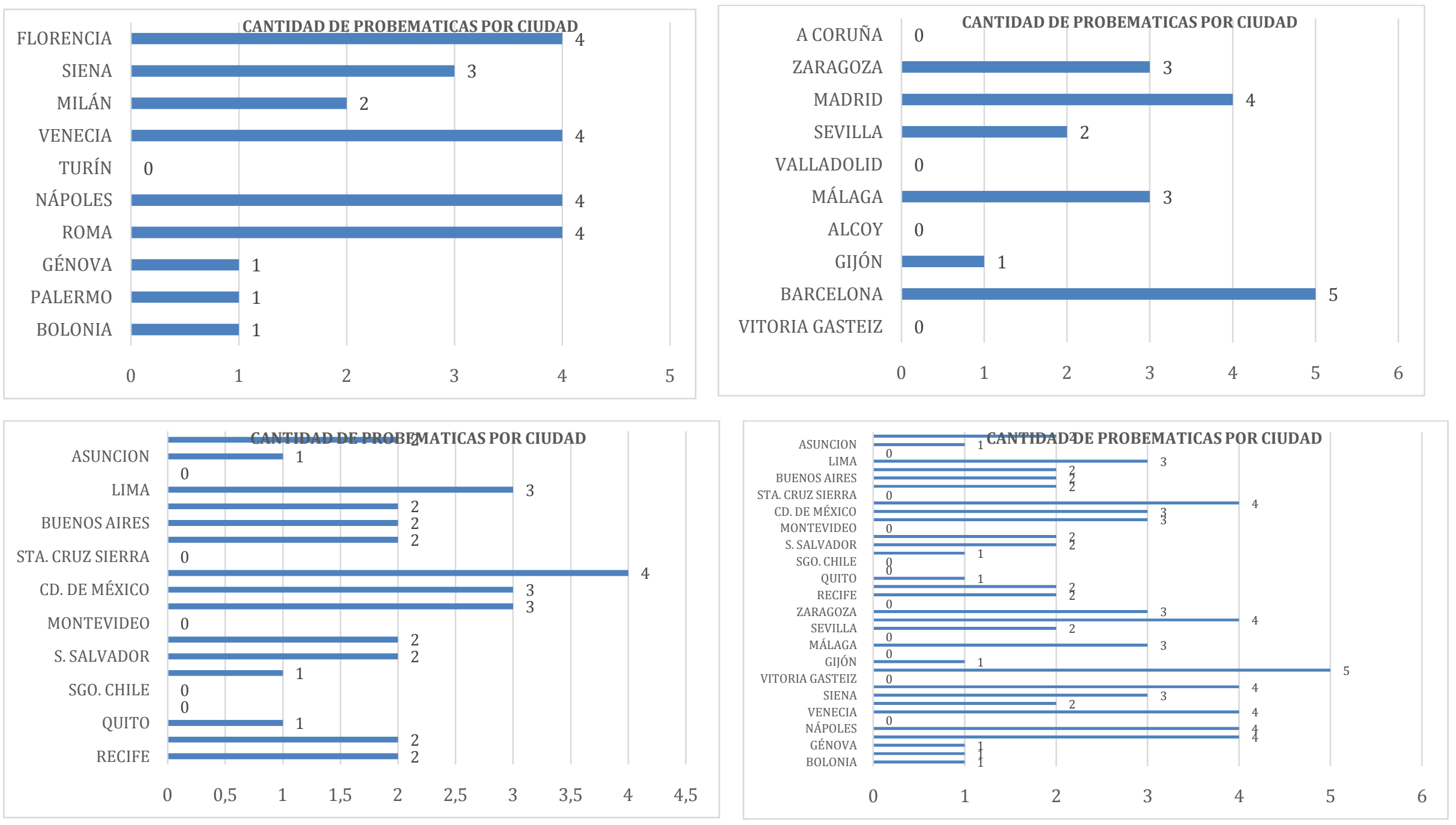
ANÁLISIS CUANTITATIVO. PROBLEMÁTICAS: DIMENSIÓN ECONÓMICA
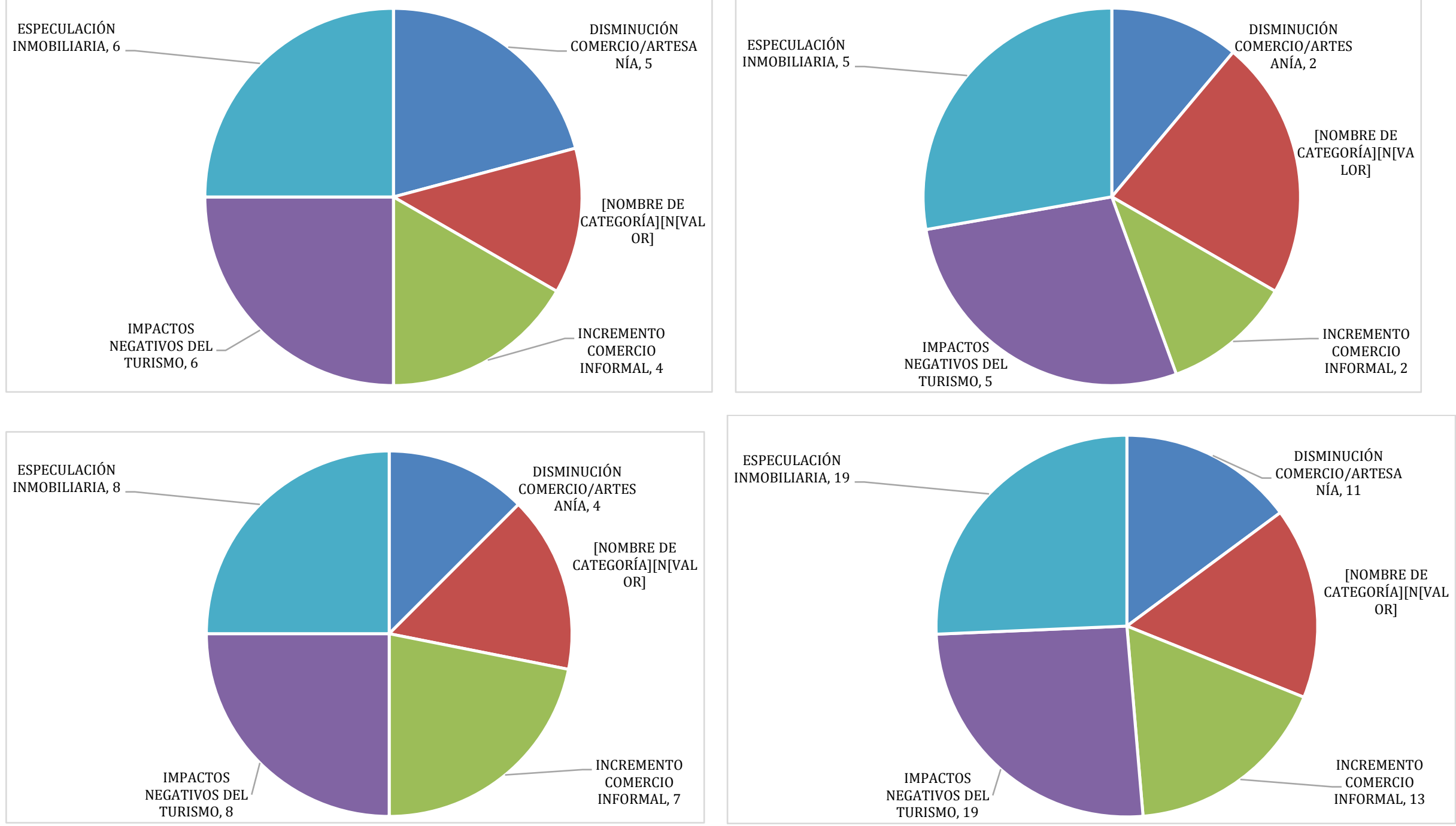


\section{ANÁLISIS CUANTITATIVO. PROBLEMÁTICAS: DIMENSIÓN INSTITUCIONAL}
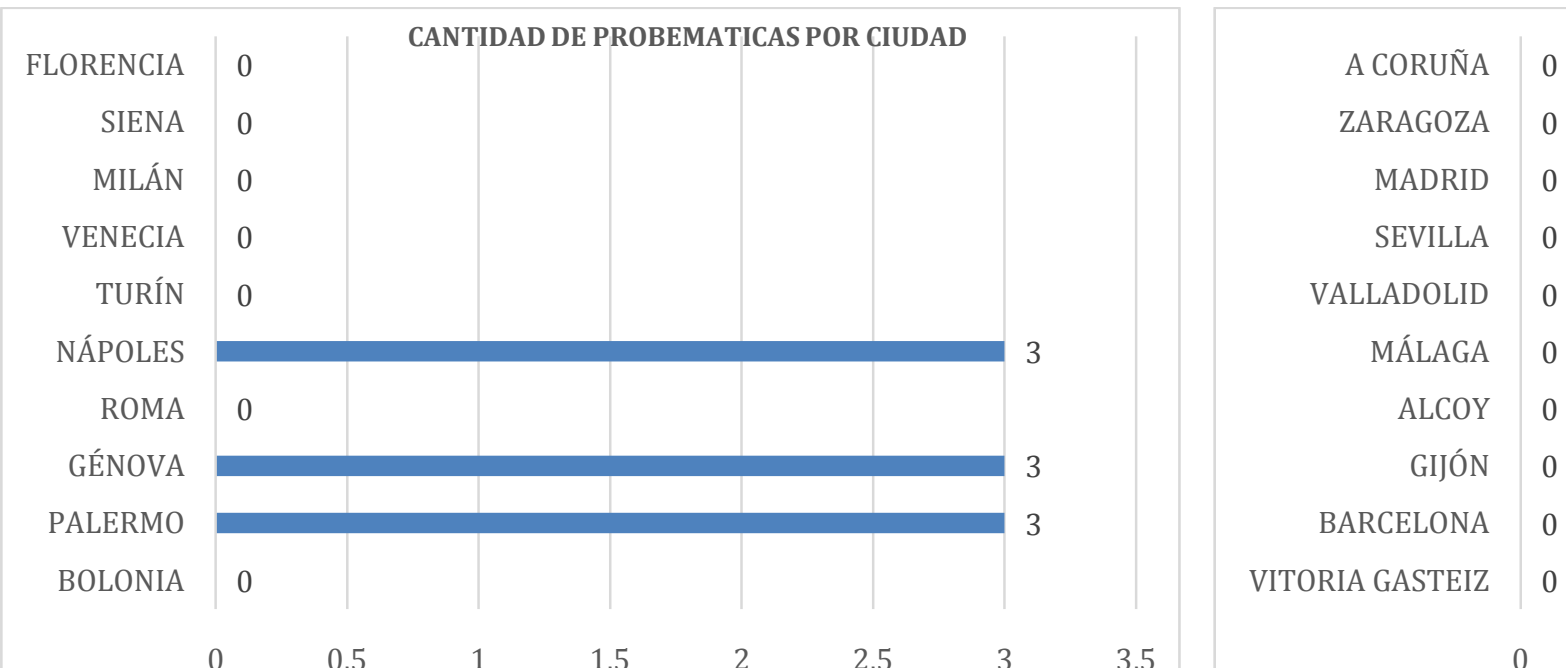

CANTIDAD DE PROBEMATICAS POR CIUDAD
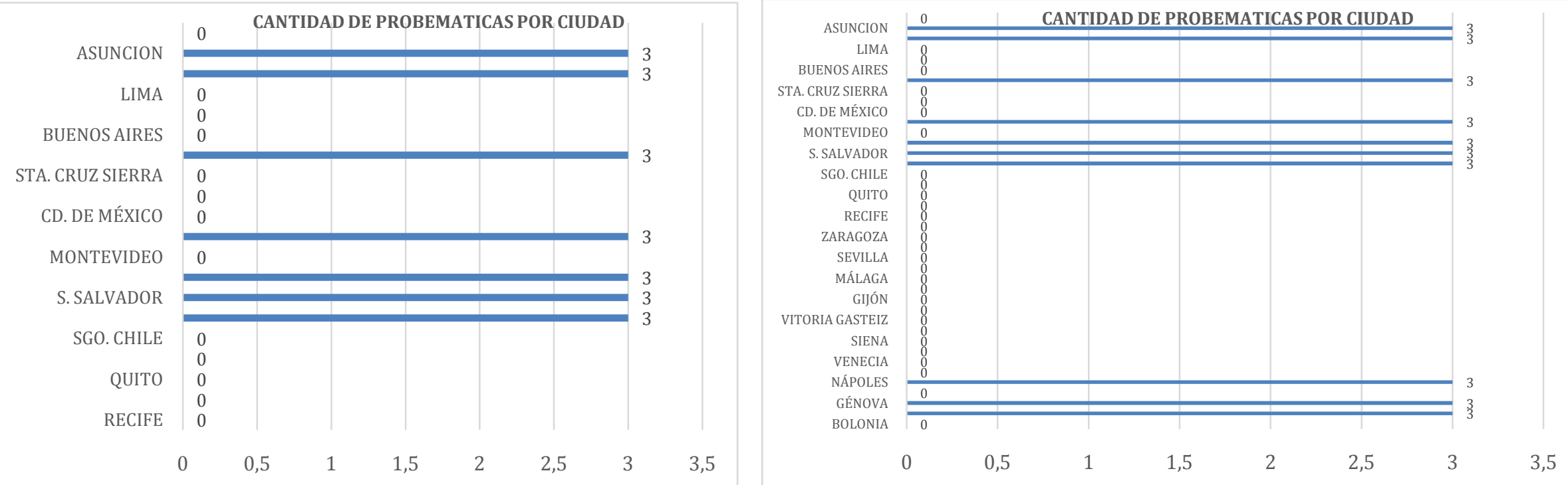
ANÁLISIS CUANTITATIVO. PROBLEMÁTICAS: DIMENSIÓN INSTITUCIONAL

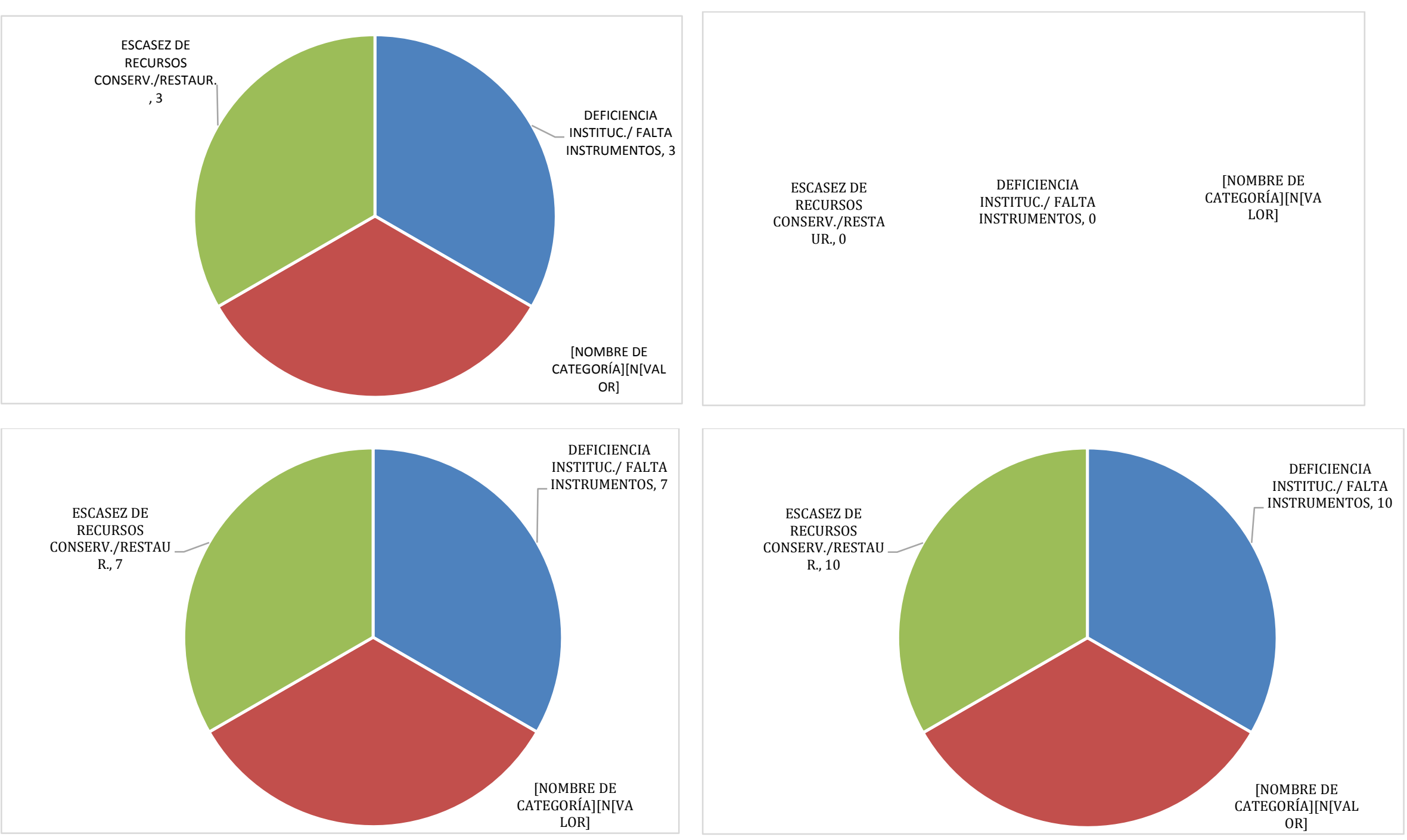




\section{ANÁLISIS CUANTITATIVO. PROBLEMÁTICAS DE TODAS LAS DIMENSIONES}
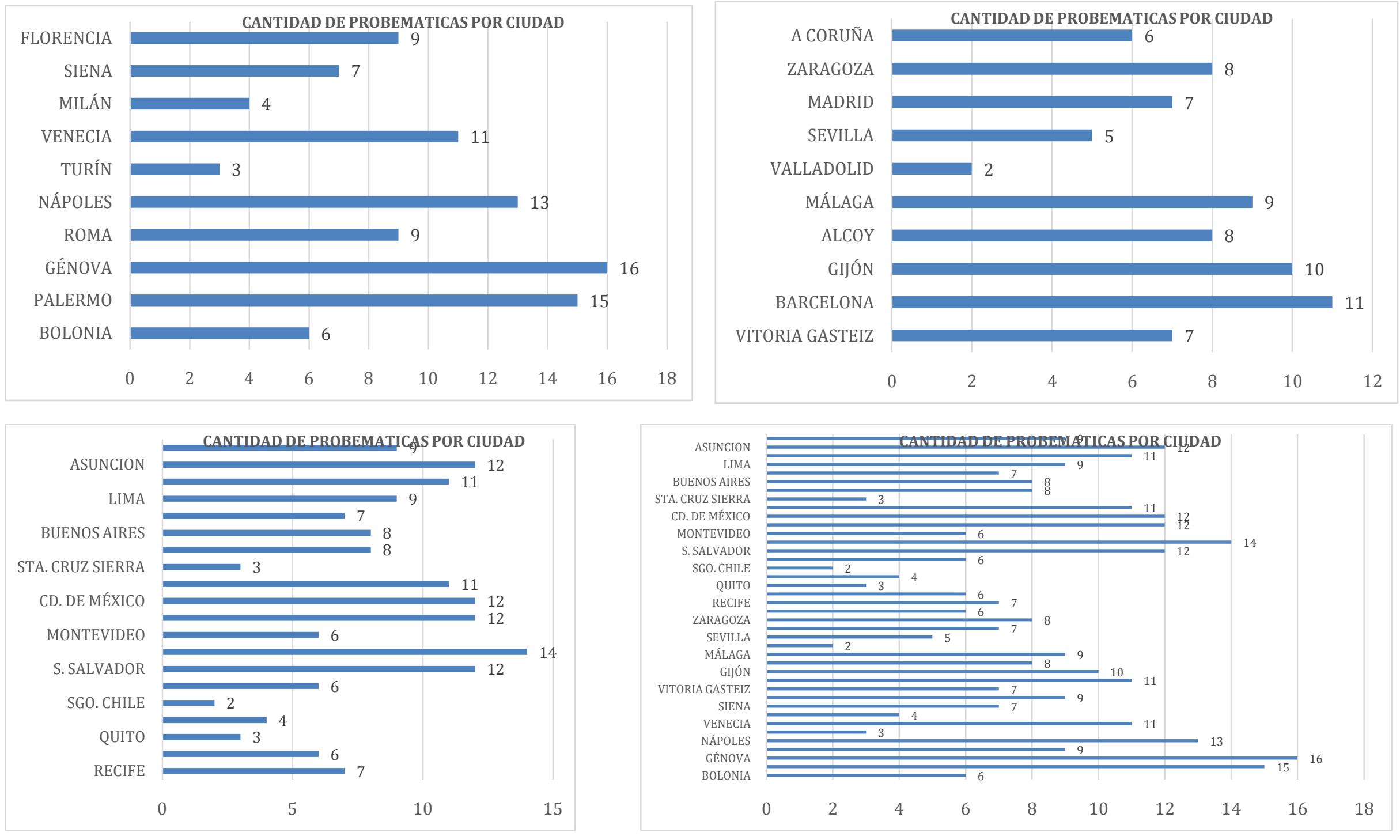


\section{ANÁLISIS CUANTITATIVO. PROBLEMÁTICAS DE TODAS LAS DIMENSIONES}
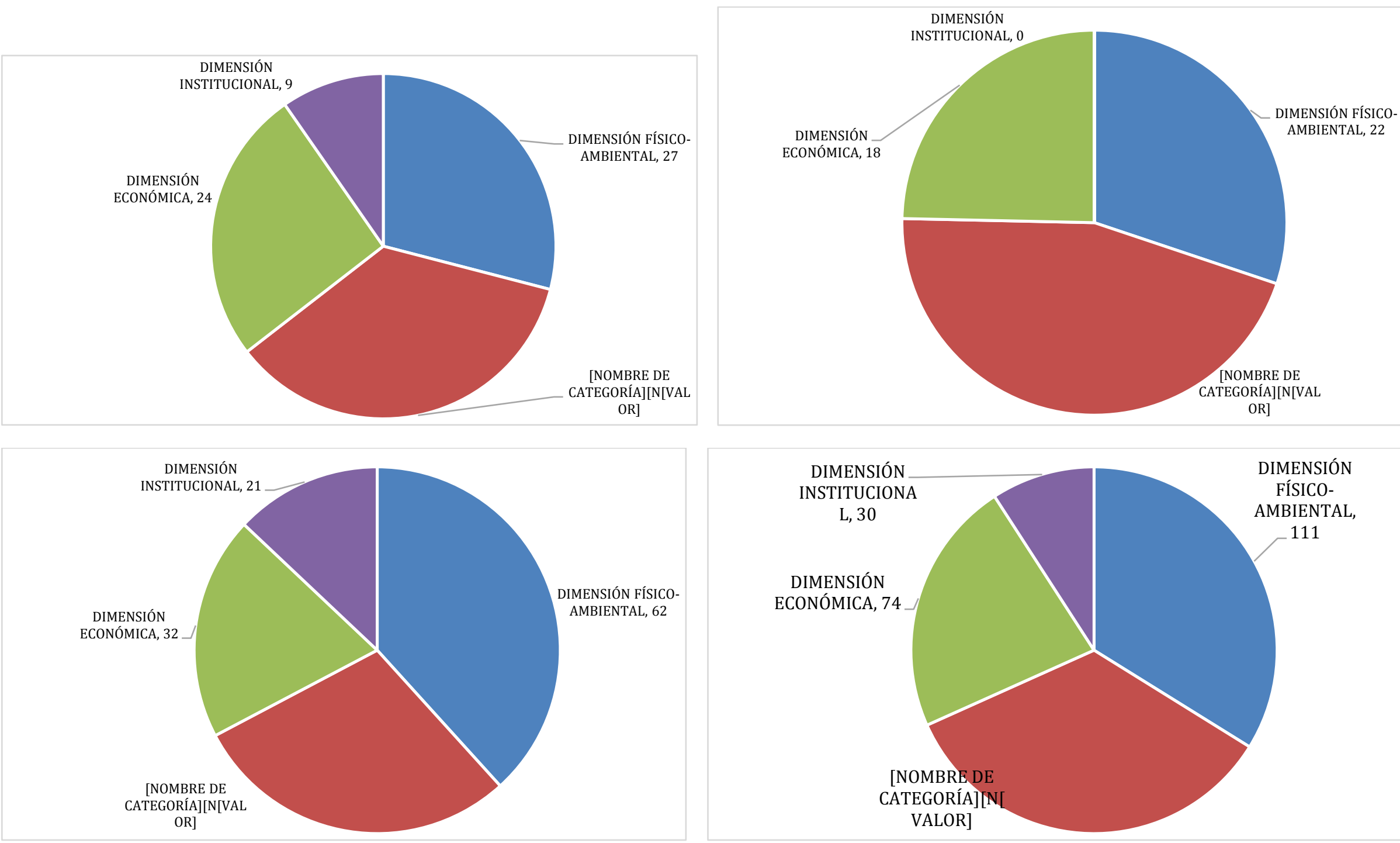


\section{ANÁLISIS CUANTITATIVO. INTERVENCIONES: DIMENSIÓN FÍSICO-AMBIENTAL}
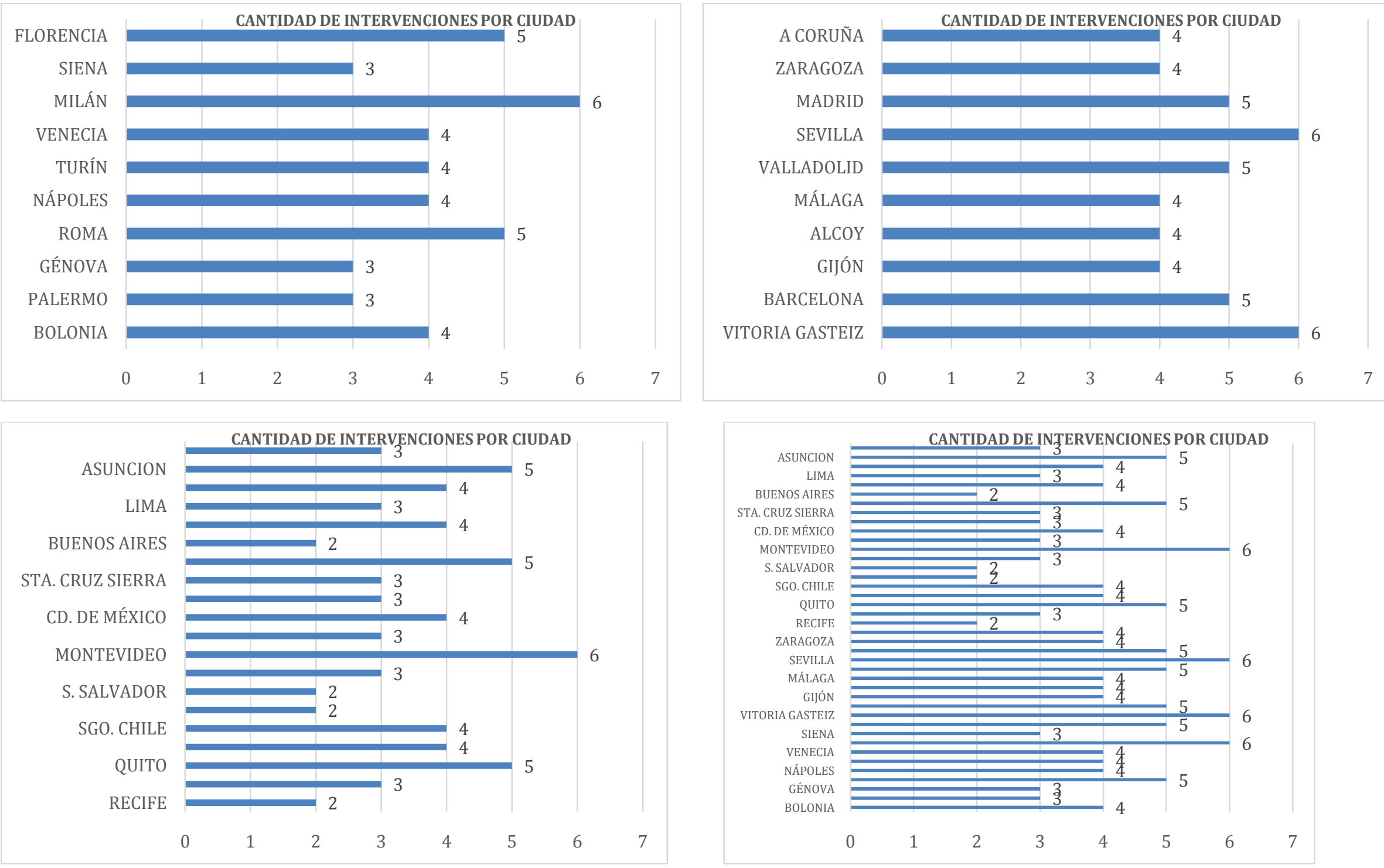


\section{ANÁLISIS CUANTITATIVO. INTERVENCIONES: DIMENSIÓN FÍSICO-AMBIENTAL}
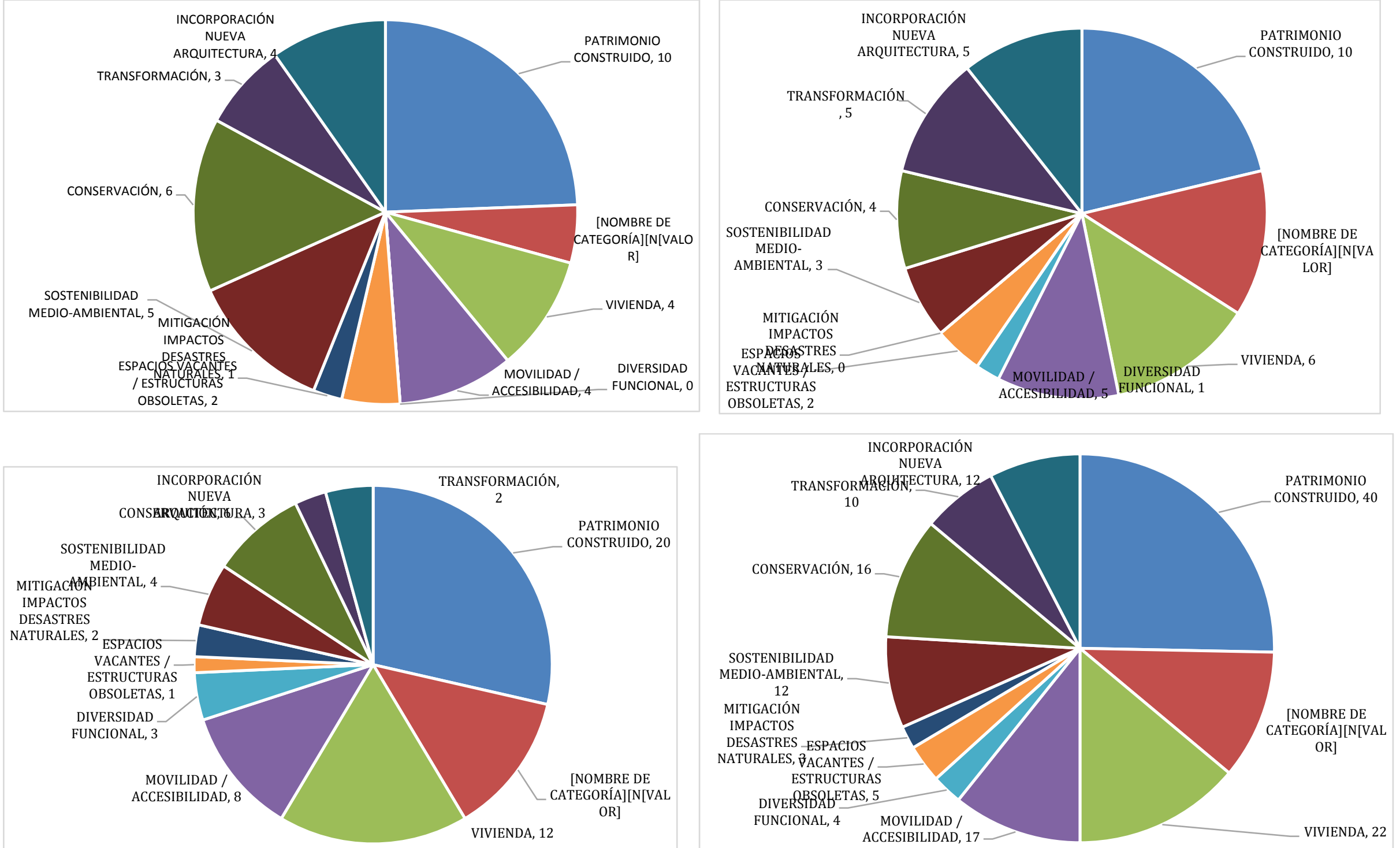


\section{ANÁLISIS CUANTITATIVO. INTERVENCIONES: DIMENSIÓN SOCIO-CULTURAL}
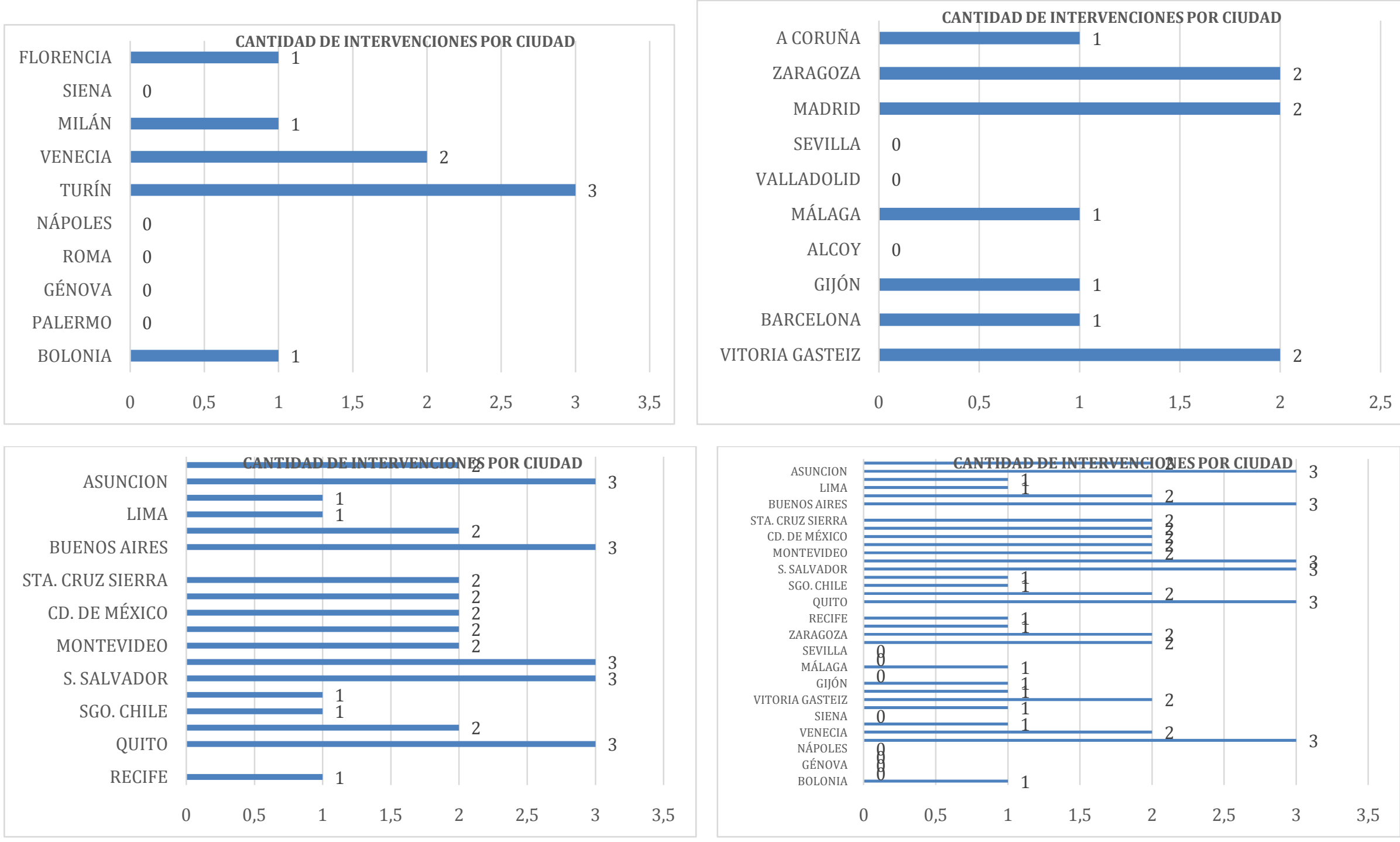
ANÁLISIS CUANTITATIVO. INTERVENCIONES: DIMENSIÓN SOCIO-CULTURAL
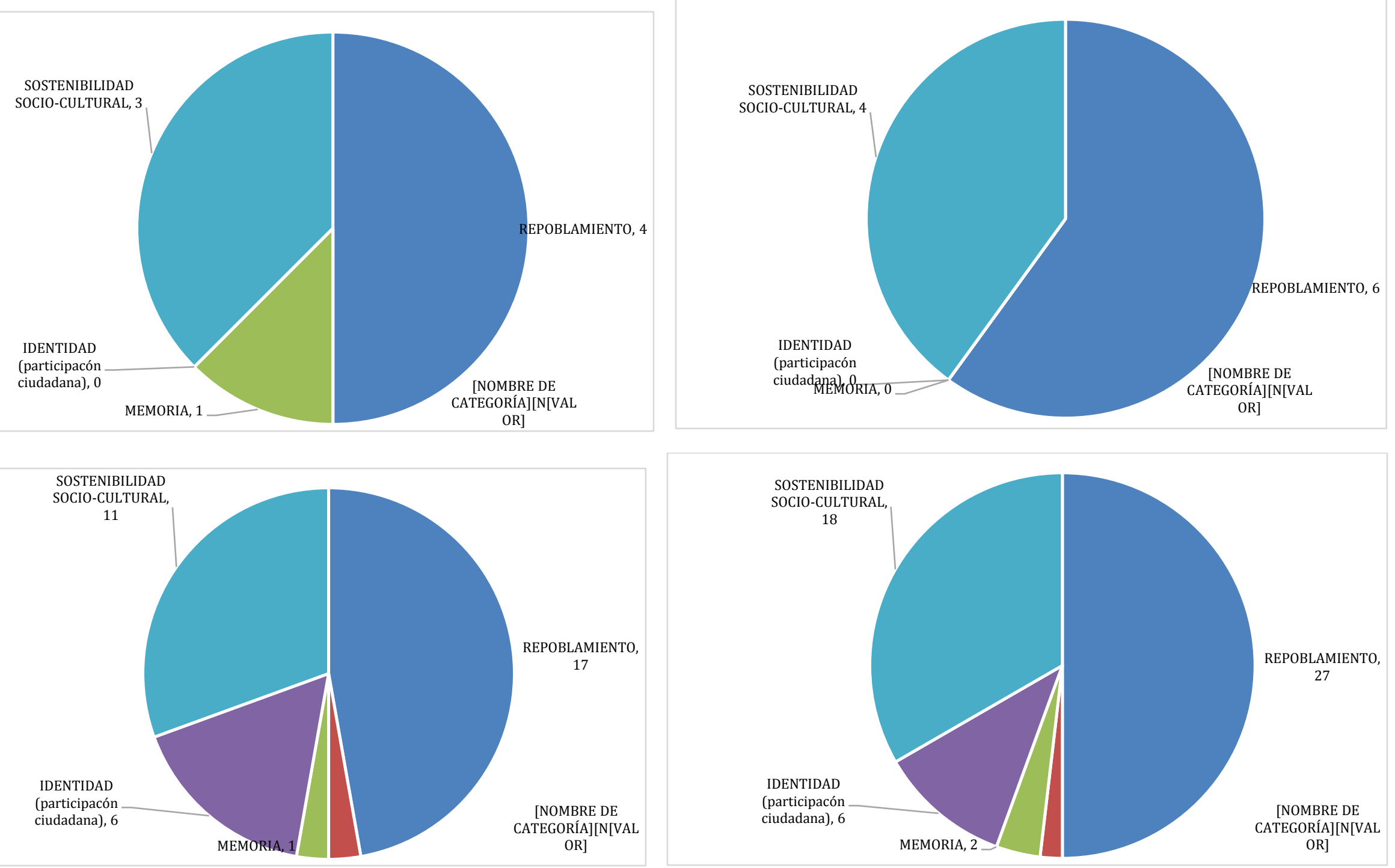


\section{ANÁLISIS CUANTITATIVO. INTERVENCIONES: DIMENSIÓN ECONÓMICA}
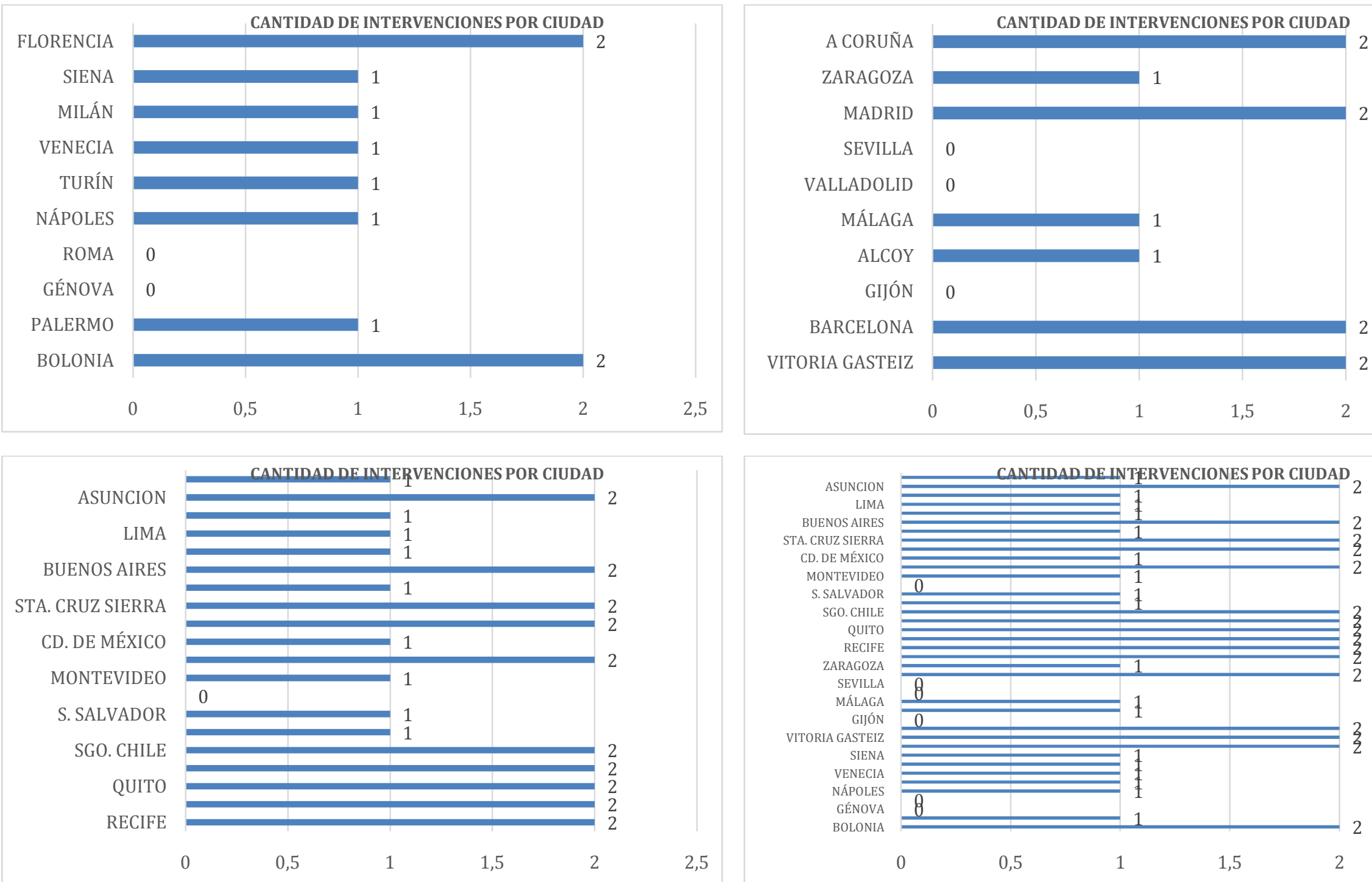
ANÁLISIS CUANTITATIVO. INTERVENCIONES: DIMENSIÓN ECONÓMICA
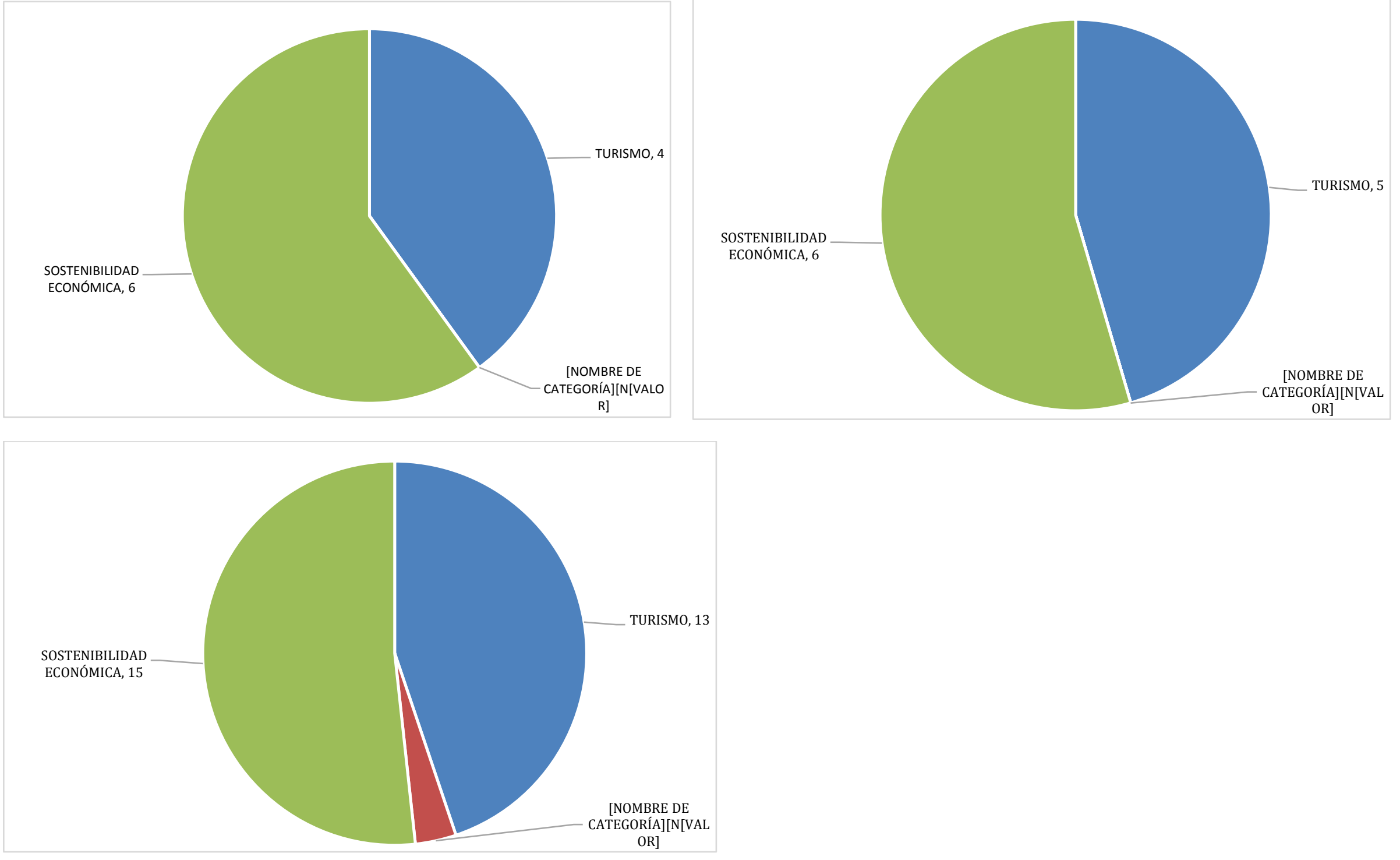


\section{ANÁLISIS CUANTITATIVO. INTERVENCIONES: DIMENSIÓN INSTITUCIONAL}
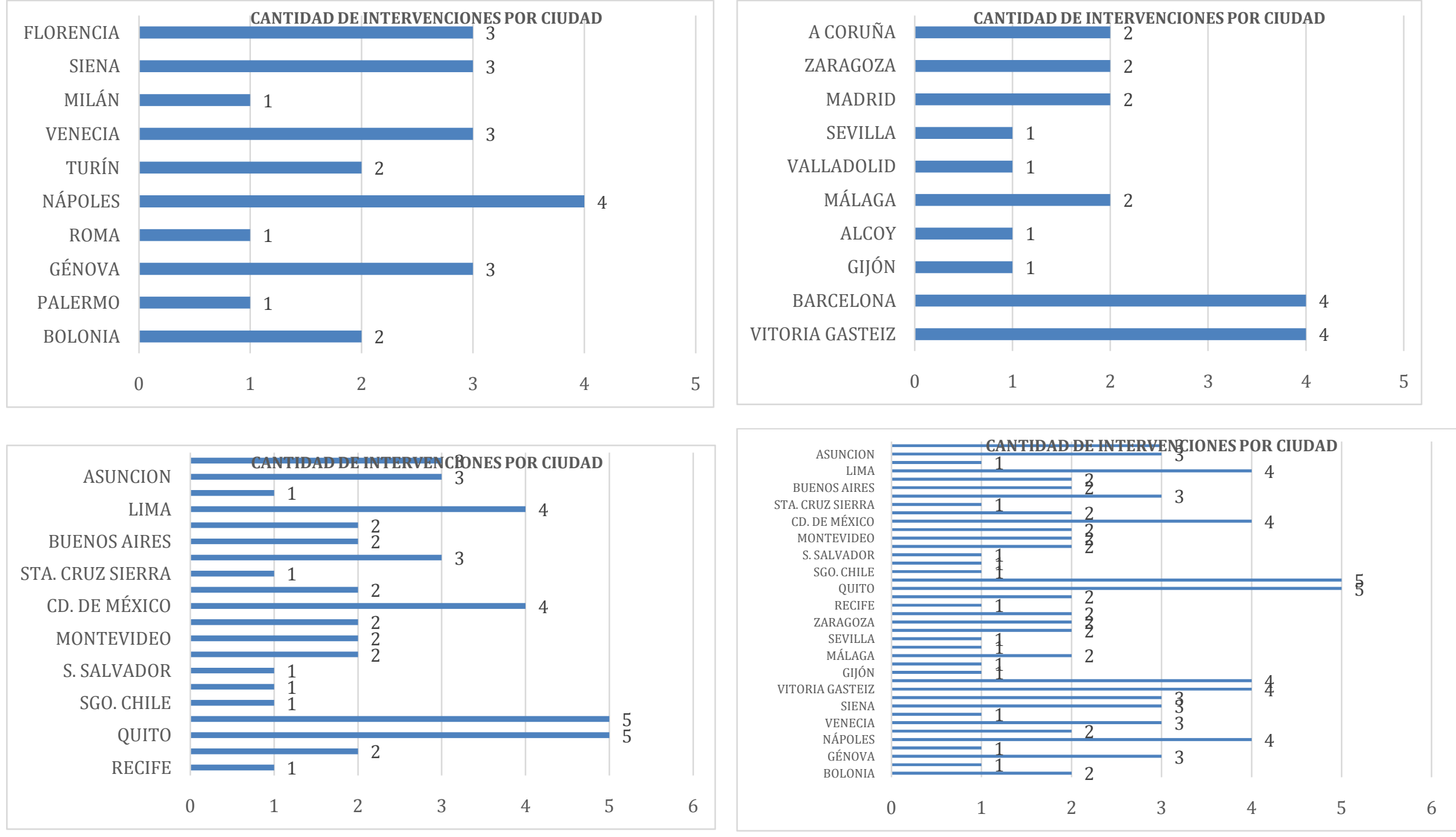


\section{ANÁLISIS CUANTITATIVO. INTERVENCIONES: DIMENSIÓN INSTITUCIONAL}

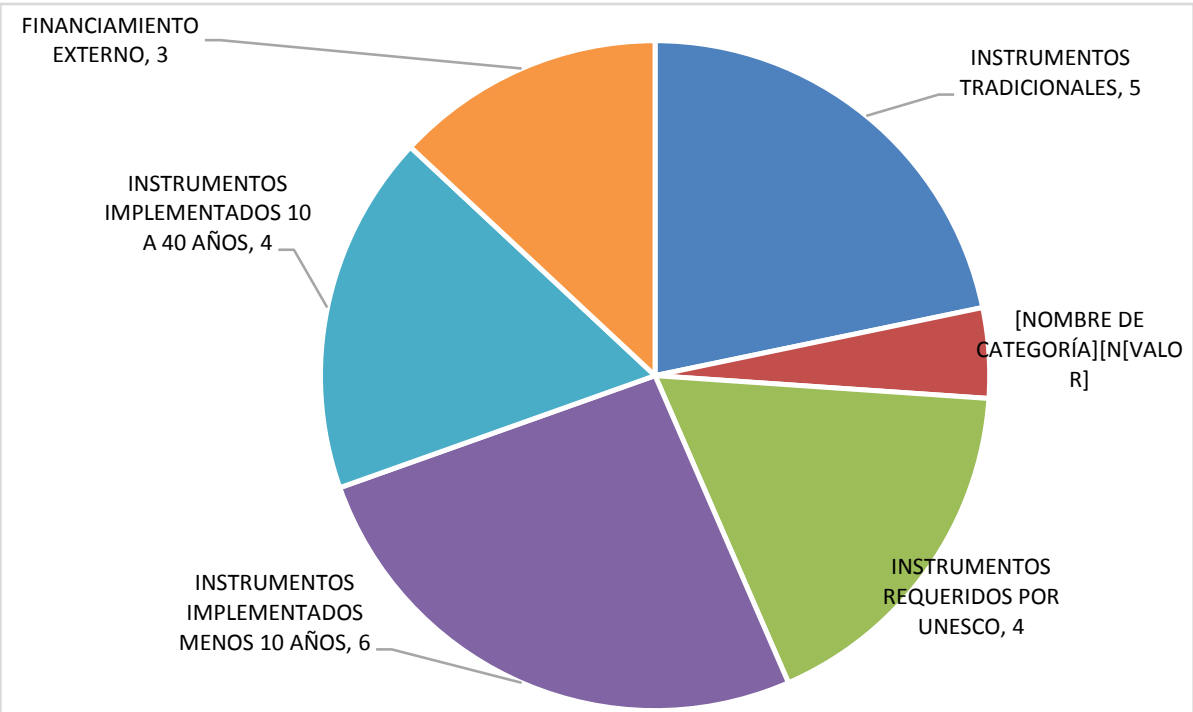

NANCIAMIENTO

EXTERNO, 3

INSTRUMENTOS
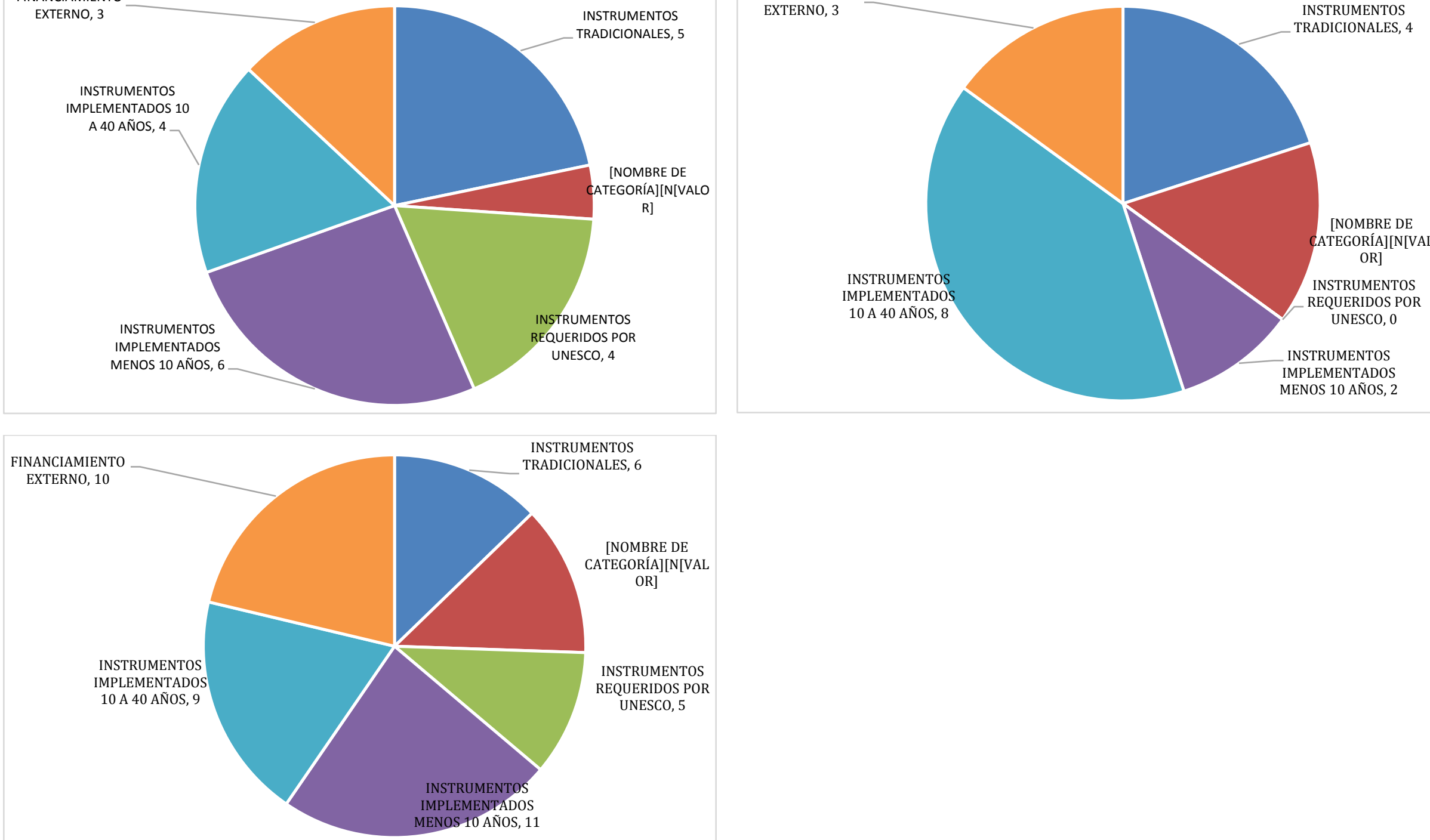


\section{ANÁLISIS CUANTITATIVO. INTERVENCIONES DE TODAS LAS DIMENSIONES}
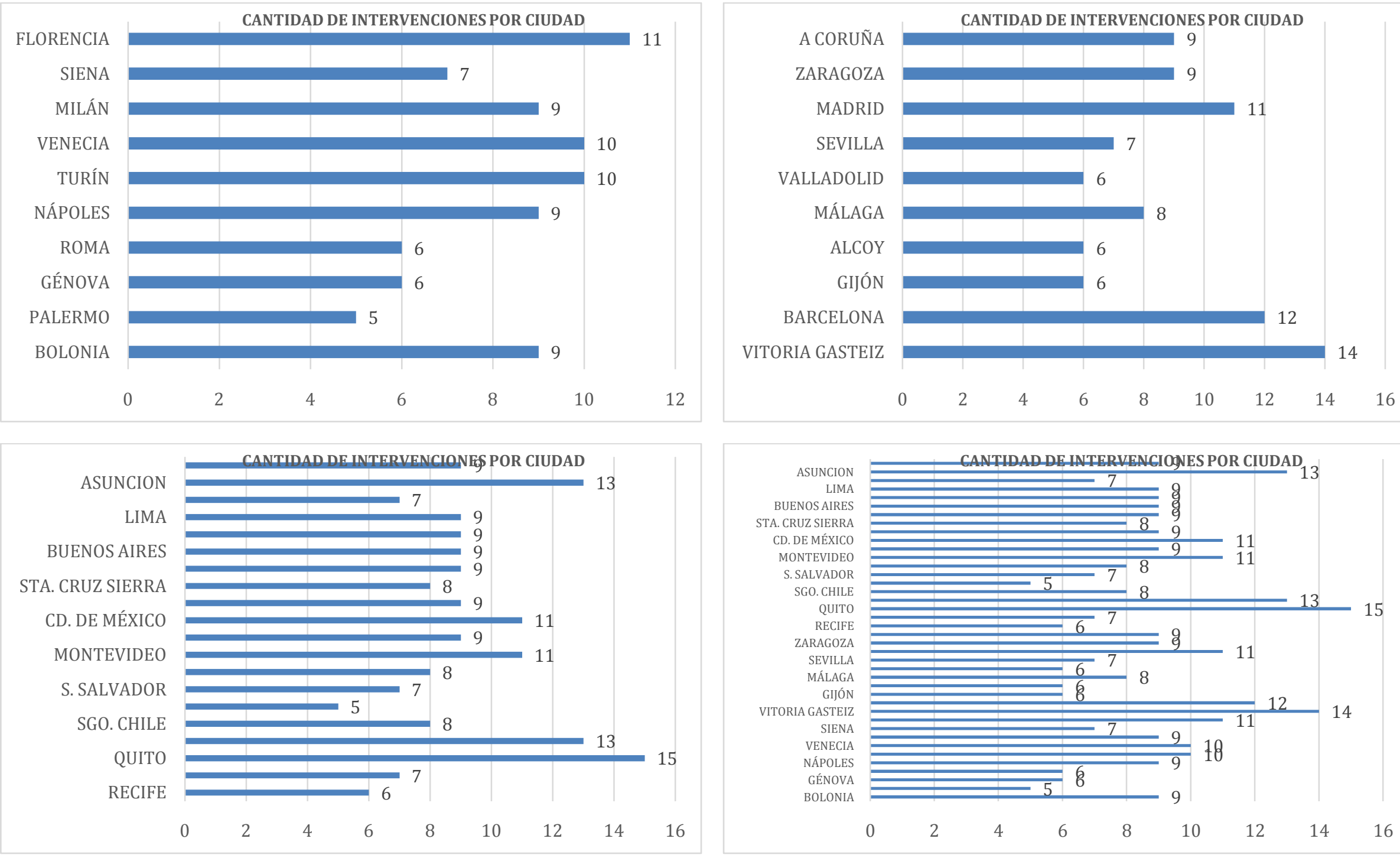
ANÁLISIS CUANTITATIVO. INTERVENCIONES DE TODAS LAS DIMENSIONES
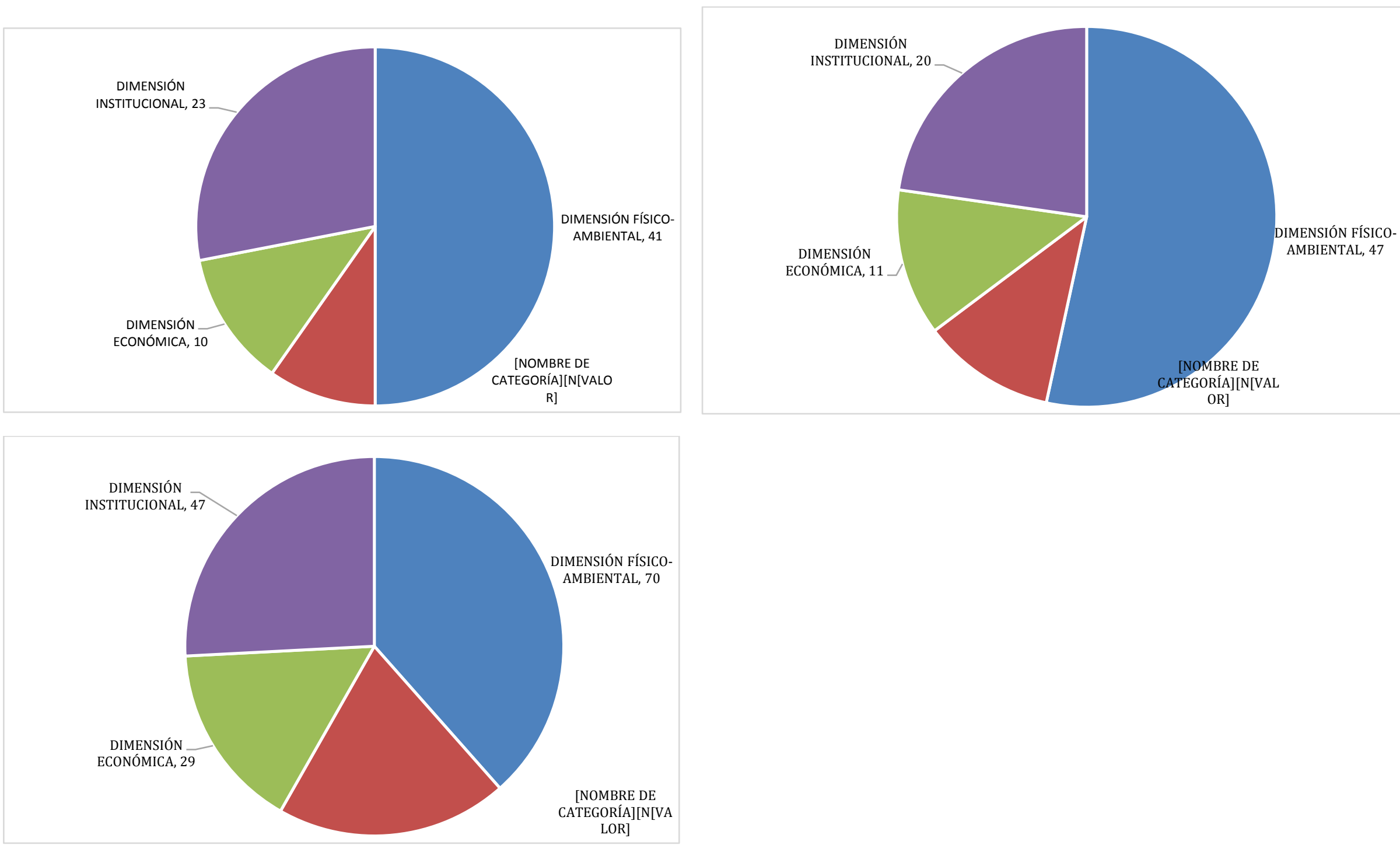


\section{BIBLIOGRAFÍA}




\section{BIBLIOGRAFÍA}

A continuación se expone la bibliografía citada y consultada para el abordaje teórico de cada una de las temáticas desarrolladas en la tesis, organizada de acuerdo al orden en que se fueron presentando en los capítulos, y asociados a los diversos sub-temas.

\section{B.1. CENTRO HISTÓRICO: CONCEPTO Y COMPONENTES}

\section{B.1.1 Origen y evolución del concepto centro histórico}

CARRION MENA, Fernando (2000); "Lugares o flujos centrales: los centros históricos urbanos" En División de Medio Ambiente y Asentamientos Humanos, Naciones Unidas, CEPAL, ECLAC.

CARRION MENA, Fernando (2006); "La recuperación de la ciudad. Centros históricos". Mesa de trabajo coordinada por Fernando Carrión en el I Encuentro sobre Arquitectura, Vivienda y Ciudad en Andalucía y América Latina. Hacia Cádiz 2012.

CARRION MENA, Fernando, (2009); "La centralidad histórica: entre el nacionalismo del pasado (monumento) y el sentido social de hoy (centro vivo)", En Revista Centro-h, Núm. 3, pp.7-12, Organización Latinoamericana y del Caribe de Centros Históricos, Ecuador. http://redalyc.uaemex.mx/src/inicio/ArtPdfRed.jsp?iCve=115112536001

CHATELOIN, Felicia (2008); "El centro histórico, ¿concepto o criterio en desarrollo?". En Arquitectura y Urbanismo, Vol. XXIX, pp. 10-23. Cuba.

CHOAY, Françoise (1992). L'allégorie du patrimoine, Éditions du Seuil, Paris.

CONTI, Alfredo (2008); "Paisajes históricos urbanos: nuevos paradigmas en conservación urbana", conferencia presentación. Disponible en: http://www.icomos.org.ar/wpcontent/uploads/2009/09/CONTI.pdf 
CONTI Alfredo (2011); "El espacio público en los cascos históricos“. V Jornadas Internacionales:

Experiencias de revitalización de cascos históricos, Buenos Aires, Argentina.

CONTI, Alfredo (2015); "La conservación y la gestión de las ciudades históricas desde la

perspectiva del Paisaje Urbano Histórico". Disponible en:

http://sedici.unlp.edu.ar/bitstream/handle/10915/50335/Documento completo.pdf-

PDFA.pdf?sequence $=3$

GAJA DIAZ, Fernando, 1992; "Teorías para la intervención urbanística en la ciudad preindustrial". Valencia, España, Editorial de la Universidad Politécnica de Valencia, Edición noviembre 2006.

GARCIA ESPINOSA, Salvador (2005); "Centros históricos. ¿herencia del pasado o construcción del presente? Agentes detonadores de un nuevo esquema de ciudad. En Scripta Nova, Revista Electrónica de Geografía y Ciencias Sociales, Universidad de Barcelona, Vol. IX, núm. 194 (39), 1 de agosto de 2005.

http://www.ub.es/geocrit/sn/sn-194-39.htm

GARCIA ESPINOSA, Salvador (2010): Centros urbanos o históricos, mas que una disyuntiva, um asunto de estructura urbana. En Topofilia, Revista de Arquitectura, Urbansimo y Ciências Sociales, Vol. Ii, num. 1, México.

GIOVANNONI, Gustavo (1932); Vecchie città ed edilizia nuova. Editorial Cittá studi, 1995. (Ventura, Choay, Cusmano).

HARDOY Jorge - GUTMAN Margarita (1982); Impacto de la urbanización en los centros históricos de Iberoamérica, tendencias y perspectivas. Madrid, Colección MAPFRE.

HARDOY Jorge (1982); Centros históricos americanos. Resistencia, Revista DANA No 13.

HIERNAUX, Nicolás Daniel (2012); "Los centros históricos y las nuevas dinámicas metropolitanas en América Latina", En www.rii.sei.ba.gov.br 
LALANA SOTO, Jose Luis (2011); "El paisaje urbano histórico, modas, paradigmas y olvidos". Ciudades, Revista del Instituto Universitario de urbanistica de la Universidad de Valladolid, núm. 14 $\mathrm{pp}$. 15-38. Disponible

http://www.academia.edu/3102539/E1_Paisaje_Urbano_Hist\%C3\%B3rico_modas_paradigmas_y_olvidos

MONTIEL ALVAREZ, Teresa (2014); John Ruskin vs Viollet le Duc. Conservación vs Restauración. En ArtyHum, Revista de Artes y Humanidades, Vol. 3, pp. 151-160,

http://www.academia.edu/7845080/John_Ruskin_vs_Viollet_le_Duc._Conservaci\%C3\%B3n_vs_Restauraci \% $3 \% \mathrm{~B} 3 \mathrm{n}$

MUTAL, Sylvio (2009); "El futuro de las ciudades históricas". En: Manejo y Gestión de centros históricos. Selección de conferencias de los Encuentros Internacionales IV, V, VI y VII, La Habana Vieja, 2005, 2006, 2007 y 2008. Ediciones Boloña, publicaciones de la Oficina del Historiador de la ciudad, colección ARCOS, La Habana, Cuba, 2009. 15-27.

NAJERA, José Luis, 2005; "Ciudades latinoamericanas, hacia una nueva lectura de la ciudad”. En http://www.buenastareas.com/ensayos/jos\%c3\%A9-luis-Lee-Najer

RODRIGUEZ ALOMA, Patricia, 2008; "El centros histórico: del concepto a la acción integral”, En Revista Centro-h, Núm. 1, pp.51-64, Organización Latinoamericana y del Caribe de Centros Históricos, Ecuador.

http://www.revistacentro-h.org/pdf/7.pdf

ROJAS, Eduardo, 2004; "Volver al centro: la recuperación de áreas urbanas centrales". Banco Interamericano de Desarrollo, Washington D.C., Estados Unidos de América. http://books.google.com/books?id=aWdncSnd078C\&printsec=frontcover\&hl=es\#v=onepage\&q\&f=false

RUSKIN, John (1989); Las siete lámparas de la arquitectura. Colegio Oficial de Aparejadores y Arquitectos de Murcia, Madrid, España.

SARASA, José Luis Andrés (2008); Posicionamiento de los centros históricos en un nuevo modelo de desarrollo. En Nimbus núm. 21-22, pp. 29-54, España.

SCOVAZZI, Emma (1996); Centros históricos y cultura urbana en América Latina. En Revista Ciudades, Núm. 3. Publicado por la Universidad de Valladolid, Instituto Universitario de Urbanística, 1996, España.

http://dialnet.unirioja.es/servlet/articulo;jsessionid=21F18E31C26902D810F797402EBCCBF8.dialnet01?co $\underline{\operatorname{dig}}=2241391$ 
SITTE, Camilo (1926); Construcción de ciudades según principios artísticos. Conocido también por su versión en español El arte de construir las ciudades.

WAISMAN Marina (1972); La estructura histórica del entorno, Buenos Aires, Ediciones Nueva Visión.

SANSUR, Juan Pablo (2009); Los centros históricos en América Latina. En OLACCHI, Organización Latinoamericana y del Caribe de Centros Históricos, Quito, Ecuador.

http://www.olacchi.org/contenidos.php?id=488\&idiom=1\&tipo=2

YORY, Carlos Mario (2002); Del monumento a la ciudad. El fin de la idea de monumento en el nuevo orden espacio-temporal de la ciudad. Centro Editorial Javeriano, Bogotá, Colombia. Disponible en: www.booksgoogle.com.ar

\section{Documentos Internacionales:}

CARTA DE ATENAS (1931);

Disponible

http://www.icomoscr.org/doc/teoria/VARIOS.1931.carta.atenas.restauracion.monumentos.historico $\underline{\text { s.pdf }}$

CARTA ITALIANA DEL RESTAURO (1931); Disponible en: https://riunet.upv.es/bitstream/handle/10251/28161/04.pdf?sequence $=6$

CARTA DE VENECIA (1964); Disponible en: https://www.icomos.org/charters/venice sp.pdf

NORMAS DE QUITO (1967); Disponible en: https://www.icomos.org/charters/quito.htm

CONVENCIÓN DE UNESCO (1972); Para la protección del Patrimonio Mundial, Cultural y Natural. Disponible en: http://whc.unesco.org/archive/convention-es.pdf

CARTA DE QUITO (1977); Disponible en: http://icomoschile.blogspot.com.ar/2007/09/carta-dequito-1977.html en: http://conservacion.inah.gob.mx/normativa/wp-content/uploads/Documento34.pdf

UNESCO (2011); Recomendación relativa a los paisajes urbanos históricos. 
UNESCO (2013); Nueva vida para las ciudades históricas. El planteamiento de los paisajes urbanos históricos.

\section{B.1.1.1 El Paisaje Urbano Histórico}

CONVENIO EUROPEO DE PAISAJE (2000); Consejo de Europa, Florencia. Disponible en: http://www.upv.es/contenidos/CAMUNISO/info/U0670786.pdf

RECOMENDACIÓN PARA LA APLICACIÓN DEL CONVENIO (2008). Disponible en:

https://www.asturias.es/medioambiente/articulos/ficheros/Recomendaciones\%20para\%20la\%20ap licaci\%C3\%B3n\%20del\%20Convenio\%20Europeo.pdf

MEMORANDUM DE VIENA (2005). Disponible en:

https://unesco.lt/uploads/file/failai VEIKLA/kultura/RA Vienna memorandum.pdf

RECOMENDACIÓN SOBRE LOS PAISAJES URBANOS HISTÓRICOS (2011). Disponible en: http://portal.unesco.org/es/ev.phpURL ID=48857\&URL DO=DO TOPIC\&URL SECTION=201.ht $\underline{\mathrm{ml}}$

SANTOS, Milton (1995); Metamorfosis del espacio habitado. Editorial Oikos Tau, Barcelona.

\section{B.1.2 El centro histórico como sistema en proceso continuo de transformación}

BORJA, Jordi, 2003; "Ciudad y planificación: la urbanística para las ciudades de América Latina". En "La ciudad inclusiva", Cuadernos de la CEPAL 88, publicación de las Naciones Unidas, CEPAL - Cooperazione italiana. Compiladores Balbo, jordán, Simioni. Pp. 81-104. Santiago de Chile, Noviembre de 20013. 
BRITO, Marcelo (2007); "Las ciudades históricas como Urbs: cuerpo y alma del Patrimonio Cultural Urbano". Ponencia presentada en la Mesa "La ciudad como patrimonio vivo" del Foro internacional de Arquitectura "Centros históricos, el corazón que late", Córdoba, 2004 y publicada por la Junta de Andalucía, Consejeria de Obras Publicas y Transportes. Dirección General de Arquitectura y Vivienda, Sevilla, España.

BRITO, Marcelo (2007); Las ciudades históricas como destinos patrimoniales: potencialidades y requisitos. Madrid: Universidad Complutense de Madrid. Facultad de Geografía e Historia, Departamento de Geografía Humana, Grupo de Investigación “Turismo, Patrimonio y Desarrollo”.

CARRION MENA, Fernando (2001); "Las nuevas tendencias de la urbanización en América Latina", En La ciudad construida. Urbanismo en América Latina. Quito, FLACSO - Junta de Andalucía - Municipio del Distrito Metropolitano de Quito, Ecuador.

CARRION, Fernando, (2005); "Los centros históricos en la era digital en América Latina". En Ciudades Translocales: Espacios, flujo, representación. Perspectivas desde las Américas, Primera Edición: Guadalajara, México. Editado por Rossana Reguillo y Marcial Godoy Anativia, ITESO / SSRC.

CARRION MENA, Fernando, (2009); "La centralidad histórica: entre el nacionalismo del pasado (monumento) y el sentido social de hoy (centro vivo)", En Revista Centro-h, Núm. 3, pp.7-12, Organización Latinoamericana y del Caribe de Centros Históricos, Ecuador. http://redalyc.uaemex.mx/src/inicio/ArtPdfRed.jsp?iCve=115112536001

RUIZ CABRERO, Gabriel (2007); "La ciudad como patrimonio vivo". Ponencia presentada en la Mesa "La ciudad como patrimonio vivo" del Foro internacional de Arquitectura "Centros históricos, el corazón que late", Córdoba, 2004 y publicada por la Junta de Andalucía, Consejeria de Obras Publicas y Transportes. Dirección General de Arquitectura y Vivienda, Sevilla, España.

\section{B.1.3 Componentes claves para un "Centro Histórico" vivo}

CARRION MENA, Fernando, 2003; "Ciudad y centros históricos: centros históricos y actores patrimoniales". En "La ciudad inclusiva", Cuadernos de la CEPAL 88, publicación de las Naciones Unidas, CEPAL - Cooperazione italiana. Compiladores Balbo, jordán, Simioni. Pp. 129-152. Santiago de Chile, Noviembre de 2003. 
CASADO GALVAN, Ignacio (2010); Apuntes para la delimitación y estudio del centro urbano. En Contribución a las Ciencias sociales, publicada por EUMEDNET, Universidad de Málaga, España: http://www.eumed.net/rev/cccss/07/icg.htm

PEREDA, Araceli (2007); "Cuando conservar no es conservador. El patrimonio cultural, parte esencial de nuestra calidad de vida". Ponencia presentada en el Foro internacional de Arquitectura "Centros históricos, el corazón que late", Córdoba, 2004 y publicada por la Junta de Andalucía, Consejería de Obras Publicas y Transportes. Dirección General de Arquitectura y Vivienda, Sevilla, España.

\section{Documentos Internacionales:}

CARTA DE QUITO (1977); ICOMOS (Consejo Internacional de Monumentos y Sitios). 2007. Carta Comité Chileno del Consejo Internacional de Monumentos y Sitios, Santiago de Chile, Chile. Disponible en: http://icomoschile.blogspot.com/2007/09/carta-de-quito-1977.html

\section{B.1.3.1 Patrimonio cultural, material e inmaterial}

ARÉVALO, Javier M. (2012); "El patrimonio como representación colectiva: la intangibilidad de los bienes culturales". En Revista Andes, vol. 23, núm. 2. Salta, Argentina. Disponible en: http://www.scielo.org.ar/scielo.php?script=sci arttext\&pid=S1668-80902012000200001

CARRION MENA, Fernando, 2003; "Ciudad y centros históricos: centros históricos y actores patrimoniales". En "La ciudad inclusiva”, Cuadernos de la CEPAL 88, publicación de las Naciones Unidas, CEPAL - Cooperazione italiana. Compiladores Balbo, jordán, Simioni. Pp. 129-152. Santiago de Chile, Noviembre de 2003.

CARRION MENA, Fernando, 2008; "Del olvido como memoria: la huella patrimonial", En Revista Centro-h, Núm. 1, pp.7-9, Organización Latinoamericana y del Caribe de Centros Históricos, Ecuador. http://redalyc.uaemex.mx/src/inicio/ArtPdfRed.jsp?iCve=115112534001

COULOMB, René, 2009; "Reduccionismo cultural y territorial del patrimonio urbano". En Revista Centro-h, Núm. 3, pp.79-90., Organización Latinoamericana y del Caribe de Centros Históricos, Ecuador. http://www.redalyc.org/pdf/1151/115112536007.pdf

CURY, Isabelle (2004); Cartas patrimoniais, $3^{\circ}$ edición, Edições do patrimônio, Instituto do Patrimônio Histórico e Artístico Nacional, Rio de Janeiro, Brasil. 
FERNANDEZ SALINAS, Victor (2007); "La ciudad que late". Ponencia presentada en el Foro internacional de Arquitectura "Centros históricos, el corazón que late", Córdoba, 2004 y publicada por la Junta de Andalucía, Consejeria de Obras Publicas y Transportes. Dirección General de Arquitectura y Vivienda, Sevilla, España.

http://www.juntadeandalucia.es/viviendayordenaciondelterritorio/centrosHistoricos/index.php?opcion=7\&su bopcion $=1$

KINGMAN, Eduardo - PRATS Llorenc, 2008; "El patrimonio, la construcción de las naciones y las políticas de exclusión. Diálogo sobre la cuestión de patrimonio". En Revista Centro-h, Núm. 1, pp.87-97, Organización Latinoamericana y del Caribe de Centros Históricos, Ecuador.

http://www.redalyc.org/pdf/1151/115112534008.pdf

MELÉ, Patrice (2006); "La producción del patrimonio urbano". Publicaciones de la casa chata, Centro de Investigaciones y Estudios Superiores en Antropología Social, México, DF.

https://books.google.com.ar/books?id=mKKk5XV7ABUC\&printsec=frontcover\&hl=es\&redir_esc $=\mathrm{y} \# \mathrm{v}=$ onepage $\& \mathrm{q} \& \mathrm{f}=$ false

PEREZ ESCOLANO, Víctor (2007); La ciudad como patrimonio vivo: conclusiones. Presentado en la Mesa 1 del Foro internacional de Arquitectura "Centros históricos, el corazón que late", Córdoba, 2004 y publicada por la Junta de Andalucía, Consejeria de Obras Publicas y Transportes. Dirección General de Arquitectura y Vivienda, Sevilla, España.

http://www.juntadeandalucia.es/viviendayordenaciondelterritorio/centrosHistoricos/index.php?opcion=7\&su $\underline{\text { bopcion }=1}$

SALMERÓN, Pedro (2007); La ciudad como patrimonio vivo. Los bienes de interés cultural. Ponencia presentada en el Foro internacional de Arquitectura "Centros históricos, el corazón que late", Córdoba, 2004 y publicada por la Junta de Andalucía, Consejeria de Obras Publicas y Transportes. Dirección General de Arquitectura y Vivienda, Sevilla, España.

SANCHEZ DEL REAL, Cristina (2011); Un proceso de remodelación radical del espacio funcional y social inducido por el nuevo régimen de acumulación. La destrucción de la memoria histórica y del patrimonio urbano. En Revista Ciudades, núm. 14, pp.81-110. Recuperación de centros históricos. Universidad de Valladolid, España.

\section{Documentos Internacionales:}


CARTA DE QUITO (1977); ICOMOS (Consejo Internacional de Monumentos y Sitios). 2007. Carta Comité Chileno del Consejo Internacional de Monumentos y Sitios, Santiago de Chile, Chile. Disponible en: http://icomoschile.blogspot.com/2007/09/carta-de-quito-1977.html

CARTAS, CONVENCIONES Y OTROS TEXTOS. En Portal Digital Todo patrimonio.com: http://www.todopatrimonio.com/cartas-convenciones-y-otros-textos

CARTAS Y RECOMENDACIONES INTERNACIONALES. En Revista America Patrimonio, Santiago, Chile: http://www.revistaamericapatrimonio.org/biblioteca_virtual_cartas.html

\section{B.1.3.1.1 Los límites de la intervención: las zonas de amortiguamiento}

GARZA MERODIO, Gustavo G. (2011); "Zonas de amortiguamiento y barrios antiguos en la consolidación y expansión de los entornos protegidos: el caso de Morelia, México". Naveg@mérica. Revista electrónica de la Asociación Española de Americanistas [en línea]. 2011, n. 7. Disponible en: <http://revistas.um.es/navegamerica>. [Consulta: Fecha de consulta]. ISSN 1989- 211X.

GUZMÁN, Paloma (2011); "Las zonas de amortiguamiento instrumentos para la conservación y gestión del patrimonio cultural mundial". En Hereditas: Revista de Dirección del Patrimonio Mundial del In2000stituto Nacional de Antropologñia e Historia (INAH), México.

LALANA SOTO José Luis (2010); "Las zonas de amortiguamiento". En Centro Ciudades Patrimonio Mundial, Documentos 01, Ávila, España.

\section{Documentos Internacionales:}

WHC (2009); “World Heritage and Buffer Zones”. World Heritage Paper 25, UNESCO, Paris.

\section{B.1.3.2 Espacio público}


ALTAHBE, Gerard. 2000. Seminario Aproximaciones Antropológicas a la Ciudad y los Urbano. Buenos Aires, junio 2000

ALTHABE, Gerard y Felix SCHUSTE. 1999. Antropología del Presente (Buenos Aires: Edicial)

AUGE, Marc. 1992. Non-lieux. Introduction à une anthropologie de la surmodernité (Paris: Seuil). Traduccion Española por Margarita N. Mizraji, Los No Lugares. Espacios del anonimato. Una antropología de la sobremodernidad (Barcelona: Gedisa, 1998)

BORJA, Jordi- MUXI, Zaida (2000); “El espacio público: ciudad y ciudadanía”. Barcelona, España.

BORJA, Jordi, 2009. "La ciudad es la calle. Espacio público y centros históricos como test de la ciudad democrática". Sesión Inaugural del Seminario Permanente Centro Histórico de la Ciudad de México, 5 de octubre de 2009.

http://www.puec.unam.mx/site/seminario_permanentech/jordi_borja_ponencia.pdf

BOSSIO, Silvia - STORCHI, Stefano et al. (2014); Dialoghi sullo spazio pubblico fra Europa e America Latina - Espacio público: diálogos entre Europa y América Latina. Publicación de la Associazione Nazionale Centro Storico-Artistici (ANCSA), Oficina del historiador de la Ciudad de La Habana, Cuba $(\mathrm{OHCH})$, y la Dirección General del Casco Histórico de la Ciudad de Buenos Aires, Argentina.

CAÑAVALE, José Luis (2004); "Espacio público y tiempo público en la ciudad histórica”, ponencia presentada en la mesa: El espacio público y el tiempo público. "CENTROS HISTORICOS: El corazón que late" (2004). Publicación del Foro Internacional de Arquitectura, Córdoba 2004, España. Junta de Andalucía. Consejería de Obras Públicas y Transportes. Dirección General de Arquitectura y Vivienda.

CARRIÓN MENA, Fernando (2008); "Centro histórico: la polisemia del espacio público". En Centro-h, Revista de la Organización Latinoamericana y del Caribe de Centros Históricos No. 2, diciembre 2008.

GEHL, Jan (2006); La humanización del espacio urbano: la vida social entre los edificios. Estudios Universitarios de Arquitectura 9, Editorial Reverté, Barcelona. En: 

mary_r\&cad $=0 \# \mathrm{v}=$ onepage $\& \mathrm{q} \& \mathrm{f}=$ false

GEHL, Jan (2011); "El arquitecto de las personas", entrevista a Jan Gehl, publicado en la Revista digital Yorokobu, febrero de 2011. www.yorokobu.es

HERCE VALLEJO, Manuel (2001); "Instrumentos de transformación del espacio urbano; presencia y operatividad en América Latina", En La ciudad construida. Editor: Fernando Carrión Mena. Urbanismo en América Latina. Quito, FLACSO - Junta de Andalucía - Municipio del Distrito Metropolitano de Quito, Ecuador.

Lineamiento de política: "Primero el Espacio Público", documento técnico de soporte Plan de Ordenamiento Territorial de Medellín, Departamento Administrativo de Planeación, Medellín.

MUXÍ, Zaida (2004); Ponencia presentada en la mesa: El espacio público y el tiempo público. "CENTROS HISTORICOS: El corazón que late" (2004). Publicación del Foro Internacional de Arquitectura, Córdoba 2004, España. Junta de Andalucía. Consejería de Obras Públicas y Transportes. Dirección General de Arquitectura y Vivienda.

ORTIZ GUITART, Anna (2006); "Regeneración urbana, espacio público y sentido de lugar. Un caso de estudio en la Ciudad de México. En Revista Provincia, núm. 15, enero-junio, 2006, Universidad de los Andes
http://www.redalyc.org/pdf/555/55501503.pdf

RUBIO GONZÁLEZ, Francisco José (2004); Ponencia presentada en la mesa: El espacio público y el tiempo público. "CENTROS HISTORICOS: El corazón que late" (2004). Publicación del Foro Internacional de Arquitectura, Córdoba 2004, España. Junta de Andalucía. Consejería de Obras Públicas y Transportes. Dirección General de Arquitectura y Vivienda.

SANTOS, Milton (1996); Metamorfosis del espacio habitado, Oikos Tau, Barcelona, España.

SEPÚLVEDA VOULLIÉME, Daniel (2004); "Espacio público y urbanidad", ponencia presentada en la mesa: El espacio público y el tiempo público. "CENTROS HISTORICOS: El corazón que late" (2004). Publicación del Foro Internacional de Arquitectura, Córdoba 2004, España. Junta de 
Andalucía. Consejería de Obras Públicas y Transportes. Dirección General de Arquitectura y Vivienda.

\section{B.1.3.3 Multifuncionalidad}

ALONSO VELASCO, Juan Manuel (2004); "El centro histórico como objeto de debate", ponencia presentada en la mesa: Cultura y equipamiento. "CENTROS HISTORICOS: El corazón que late" (2004). Publicación del Foro Internacional de Arquitectura, Córdoba 2004, España. Junta de Andalucía. Consejería de Obras Públicas y Transportes. Dirección General de Arquitectura y Vivienda.

BAYON, Félix (2004); "El centro histórico como objeto de debate", ponencia presentada en la mesa: La ciudad conectada y las nuevas tecnologías. "CENTROS HISTORICOS: El corazón que late" (2004). Publicación del Foro Internacional de Arquitectura, Córdoba 2004, España. Junta de Andalucía. Consejería de Obras Públicas y Transportes. Dirección General de Arquitectura y Vivienda.

BORJA, Jordi (2001); "La ciudad del deseo", En La ciudad construida. Urbanismo en América Latina. Quito, FLACSO - Junta de Andalucía - Municipio del Distrito Metropolitano de Quito, Ecuador.

CARRIÓN MENA, Fernando (2009); "La centralidad histórica: entre el nacionalismo del pasado (monumento) y el sentido social de hoy (centro vivo)", En Revista Centro-h, Núm. 3, pp.7-12, Organización Latinoamericana y del Caribe de Centros Históricos, Ecuador. http://redalyc.uaemex.mx/src/inicio/ArtPdfRed.jsp?iCve=115112536001

FERNÁNDEZ SALINAS, Víctor (1999): "La singularidad del centro histórico: multifuncionalidad y dinamismo. Sus procesos de cambio", en BERNAL SANTA OLALLA, B. (coord.): Revitalización Funcional del Centro Histórico. Un Reto de las Ciudades Históricas. II Jornadas de Geografía Urbana, Burgos, Universidad de Burgos, pp.17-27.

FERRER REGALES, Manuel 2000): "La integración de los cascos antiguos en la ciudad y la región", en Actas del I Congreso de Centros Históricos de la Comunidad Valenciana: Historia, Patrimonio y Arte, Valencia, ARCHIVAL, pp. 23-35. 
FLORIDA, Richard (2009); Las ciudades creativas: Por qué dónde vives puede ser la decisión más importante de tu vida. Barcelona. Paidós. (Título original Who`s your city?. Nueva Cork, Basic Books, 2008).

TROITIÑO VINUESA, Miguel Ángel 2000): "Multifuncionalidad e Innovación en la Gestión de las Ciudades Patrimonio de la Humanidad", en Actas del $5^{\circ}$ Coloquio Internacional de las Ciudades del Patrimonio Mundial. OCPM. pp. 20-32.

TROITIÑO VINUESA, Miguel Ángel (2003); "La protección, recuperación y revitalización funcional de los centros históricos". Colección mediterráneo económico "Ciudades, arquitectura y espacio urbano". Editado por CAJAMAR, Caja Rural intermediterránea, España.

VENTURINI, Edgardo (2006); "El uso turístico del patrimonio en los centros históricos urbanos". Ponencia presentada en el VIII Congreso Internacional de Rehabilitación del Patrimonio y Edificación, "La dimensión social del patrimonio", CICOP, Argentina.

\section{B.1.3.3.1 Residencialidad}

ARIZAGA GUZMÁN, Dora (2004); Mesa "La vivienda y la comunidad", en Congreso "CENTROS HISTORICOS: El corazón que late" (2004). Publicación del Foro Internacional de Arquitectura, Córdoba 2004, España. Junta de Andalucía. Consejería de Obras Públicas y Transportes. Dirección General de Arquitectura y Vivienda.

CARRION MENA, Fernando (2000); "Lugares o flujos centrales: los centros históricos urbanos" En División de Medio Ambiente y Asentamientos Humanos, Naciones Unidas, CEPAL, ECLAC.

GONZALEZ TAMARIT Luis (2001); El regreso a la ciudad construida. La recuperación de la ciudad. Disponible en:

http://www.flacsoandes.edu.ec/biblio/catalog/resGet.php?res/d=19145

GONZALEZ TAMARIT Luis (2003); Algunas reflexiones sobre la ciudad histórica y sobre los modos de intervenir en su recuperación. Tucumán, Seminario lberoamericano de políticas de vivienda.

HERNÁNDEZ PEZZI, Carlos (2004); Mesa "La vivienda y la comunidad", en Congreso 
"CENTROS HISTORICOS: El corazón que late" (2004). Publicación del Foro Internacional de Arquitectura, Córdoba 2004, España. Junta de Andalucía. Consejería de Obras Públicas y Transportes. Dirección General de Arquitectura y Vivienda.

LEAL MALDONADO, Jesús (2004); "La intervención sobre la vivienda en los centros históricos", ponencia presentada en la Mesa "La vivienda y la comunidad", Congreso "CENTROS HISTORICOS: El corazón que late" (2004). Publicación del Foro Internacional de Arquitectura, Córdoba 2004, España. Junta de Andalucía. Consejería de Obras Públicas y Transportes. Dirección General de Arquitectura y Vivienda.

MORENO GARCÍA, José R. (2001); "La vivienda en los centros históricos", En La ciudad construida. Urbanismo en América Latina. Quito, FLACSO - Junta de Andalucía - Municipio del Distrito Metropolitano de Quito, Ecuador.

\section{B.1.3.4 Identidad y participación ciudadana}

BOSSIO, Silvia N. (2006); Rehabilitar para mejorar la calidad de vida. Criterios y ejemplos de rehabilitación del patrimonio arquitectónico y urbano. Ponencia presentada en el VIII Congreso internacional de rehabilitación del patrimonio arquitectónico y edificación. La dimensión social del patrimonio. Cicop, Buenos Aires, Argentina.

CASTELLS, Manuel (1999); 0 Poder da Identidade. Sao Paulo: Paz e Terra.

COULOMB, René (2001); "Modelos de gestión en los centros históricos", En La ciudad construida. Urbanismo en América Latina. Quito, FLACSO - Junta de Andalucía - Municipio del Distrito Metropolitano de Quito, Ecuador.

GARCÍA CANCLINI, Néstor (1993); "Los usos sociales del patrimonio cultural”. En El Patrimonio Cultural de México, E. Florescano Comp. México.

GARCIA CANCLINI, Néstor (2007); Imaginarios urbanos. $3^{\circ}$ edición. EUDEBA, Publicación de la Universidad de Buenos Aires, Argentina.

MELÉ, Patrice (2006); "La producción del patrimonio urbano". Publicaciones de la casa chata, Centro de Investigaciones y Estudios Superiores en Antropología Social, México, DF. 
MENDOZA BARRAU, Heidi Jane (2011); Cultura ciudadana: espacio público, educación y participación ciudadana". En "Ciudades en transformación, disputas por el espacio apropiación de la ciudad y prácticas de ciudadanía". Plural editores, La paz, Bolivia.

ORMINDO DE AZEVEDO, Paulo (2001); "Los centros históricos latinoamericanos y la globalización", en Urbanismo final, FLACSO, Ecuador. Disponible en: http://www.flacso.org.ec/docs/sfccormindo.pdf

RAINIS, Liliana (1987). .Sobre el patrimonio ambiental., Cuadernos de la FAU/UNC núm. 1, Córdoba.

VENTURINI, Edgardo (2004); "Centros urbanos, patrimonio e identidad ciudadana en el mundo de la globalización". En Estudios, Núm. 15. Centro de Estudios avanzados de la Universidad Nacional de Córdoba, Argentina.

\section{Documentos internacionales:}

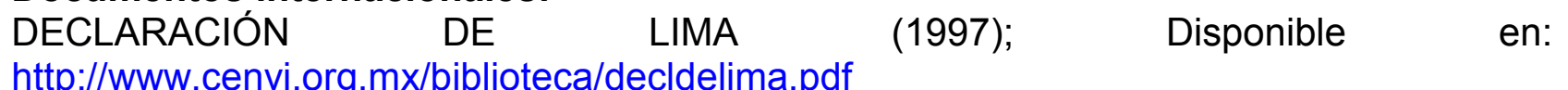

http://www.cenvi.org.mx/biblioteca/decldelima.pdf

B2.

B.2.1 Los cambios de enfoques en los Proyectos Urbanos y las estrategias de intervención y gestión implementadas

BOSSIO, Silvia N. (2006); Rehabilitar para mejorar la calidad de vida. Criterios y ejemplos de rehabilitación del patrimonio arquitectónico y urbano. Ponencia presentada en el VIII Congreso internacional de rehabilitación del patrimonio arquitectónico y edificación. La dimensión social del patrimonio. Cicop, Buenos Aires, Argentina.

BRAVO, José Maria (2012); Renovación urbana. En Diario el mundo.com:

http://www.elmundo.com/portal/opinion/columnistas/renovacion urbana.php\#.VLFcS9KG9dk 
CARRION, Fernando - HANLEY, Lisa, 2005, "Regeneración y revitalización urbana en las Américas: hacia un Estado estable". Primera edición. FLACSO, Facultad Latinoamericana de Ciencias Sociales Quito, Ecuador.

http://books.google.com/books?id=DY5Y2h4DuSsC\&printsec=frontcover\&hl=es\#v=onepage \&q\&f= false

CASTRILLO, María et al. (2014); ¿Regeneración urbana?, Deconstrucción y reconstrucción de un concepto incuestionado. En PAPELES de relaciones ecosociales y cambio global, núm. 126, pp. 129-139.

CEPROMUR y los Procesos de Renovación Urbana, una reflexión desde la práctica. Publicado por Cepromur (Centro de Promoción Urbana) y CORDAID Holanda. Diciembre de 2010. Lima, Perú.

CONSUEGRA F. Martín et al (2015); "La regeneración urbana integrada y la declaración de Toledo". En Informes de la construcción, Vol. 67, No. Extra-1. Disponible en: http://informesdelaconstruccion.revistas.csic.es/index.php/informesdelaconstruccion/article/view/4 099/4708

DEL VAL, Rubio (2011); Rehabilitación urbana en España (1989-2010). Barreras actuales y sugerencias para su eliminación. Informes de la construcción, Vol. 63, Extra, 5-20.

ENCAJES URBANOS (2011); "Revitalización". Arquitectura y urbanismo desde y para las personas. Disponible en: https://encajesurbanos.com/2011/12/12/revitalizacion-azoteascolectivas/

ETULAIN, Juan Carlos (2009); Gestión Urbanística y Proyecto Urbano. Modelos y estrategias de Intervención. Primera edición. Editorial Nobuko-FAU-UNLP. Buenos Aires. Argentina.

ETULAIN, Juan Carlos, GONZÁLEZ BIFFIS, Alejandra (2014); "La evolución del proyecto urbano. Intervenciones urbanas y cambios de paradigmas". En Revista Cuaderno Urbano, Espacio, cultura y sociedad. Vol. 17. Núm. 17. Nobuko EUDENE, Editorial de la Universidad Nacional del Nordeste.

GAJA DÍAZ, Fernando (2001); "Intervenciones en centros históricos de la Comunidad Valenciana", Consejo de Obras Públicas, Urbanismo y Transporte, Dirección General de Arquitectura y Vivienda, Universidad Politécnica de Valencia, Departamento de Urbanismo. 
GAJA I DIAZ, Fernando (2006); “Urbanismo y Sostenibilidad. ¿Una Contradicción en los términos?" En Revista I.T N 75. Madrid, España.

GIROLA MF, YACOVINO MP \& LABORDE S. 2011. Recentrando la centralidad: procesos de recualificación urbana y espacio publico en la ciudad de Buenos Aires desde una perspectiva etnográfica. Cuaderno Urbano, Cultura, Sociedad, Junio 2011, 10 (10): 9-29

GNEMMI, Horacio (2013); "Nuevo en lo viejo. Sobre el diseño, la calidad y la ética en relación con la pre-existencia". En "Reencuentro2", publicación de las V Jornadas Internacionales de Experiencias de Revitalización de Cascos Históricos 2011, Buenos Aires, Argentina.

HALL, Peter (1996); "Capitulo 11. La Ciudad de los Promotores". En Ciudades del mañana. Ediciones del Serval. Barcelona, España.

MARTINEZ DELGADO, María Eugenia, 2007; "El centro histórico: objeto de estudio e intervención". Editorial Pontificia Universidad Javeriana, Bogotá, Colombia http://books.google.com/books?id=92ve2SaI7DcC\&printsec=frontcover\&hl=es \#v=onepage \&q\&f=false

MONCLÚS, Francisco-Javier (2003); "El Modelo Barcelona, ¿Una fórmula original? De la "Reconstrucción" a los Proyectos Urbanos Estratégicos (1979-2004)". En Revista Perspectivas Urbanas N 3. España.

MONTERRUBIO, Anavel (2013); Renovación urbana y calidad de vida en el hábitat popular de los barrios históricos de la ciudad de México. Centro de Estudios sociales y de opinión publica, núm. 152, México, D.F.

MORIS, Roberto (2014); Regeneración urbana: consolidación y sustentabilidad de un mercado en desarrollo. Disponible en:

http://www.academia.edu/1762435/Regeneraci\%C3\%B3n Urbana Consolidaci\%C3\%B3n y sust entabilidad de un mercado en desarrollo 
PASUAL I ESTEVE, Joseph María (1999); La estrategia de las ciudades. Los planes estratégicos como instrumento: métodos, técnicas y buenas prácticas. Publicación de la Diputación de Barcelona y el Centro Iberoamericano de Desarrollo Estratégico Urbano, Barcelona, España.

POLLET, Andre y BAIN, Anne (1987); "Reglas de Urbanismo Operacional”. En Revistas Ciudad y Territorio № 72-73. Editada por el Colegio de Arquitectos de Madrid. Madrid, España.

PORTAS, Nuno (1996); "El Planeamiento Urbano como Proceso de Regulación Variable". En Revista Ciudades N 3. Valladolid, España.

PORTAS, Nuno (1998); “L'emergenza del progetto urbano”. En Urbanistica, 110.

PORTAS, Nuno (2003); “EI Surgimiento del Proyecto Urbano”. En Revista Perspectivas Urbanas N 3. España.

"Regeneración urbana integrada en Europa. Documento de Síntesis" (2010), Instituto universitario de Urbanística, universidad de Valladolid, Dirección General de Suelo y Políticas Urbanas del ministerio de vivienda en España.

Regeneración Urbana. Disponible en: http://es.scribd.com/doc/50018920/REGENERACIONURBANA\#scribd

Rehabilitación de ámbitos urbanos. Junta de Andalucía. Disponible en: http://www.juntadeandalucia.es/temas/vivienda-consumo/rehabilitacion/urbanos.html

RODRIGUEZ ALOMA, Patricia, 2008; "El centros histórico: del concepto a la acción integral”, En Revista Centro-h, Núm. 1, pp.51-64, Organización Latinoamericana y del Caribe de Centros Históricos, Ecuador. http://www.redalyc.org/pdf/1151/115112534005.pdf

RODRIGUEZ SUAREZ, Iván (2014); Rehabilitación, renovación y regeneración urbana en Bilbao La Vieja, San Francisco y Zabala. En Revista "Ciudad y Territorio: Estudios Territoriales", v. XLVI (n. 179); pp. 199-206, Madrid, España. 
SOLA-MORALES, Manuel (1987); “La segunda historia del proyecto urbano”. En Revista UR № 5. Laboratorio de Urbanismo de Barcelona. Barcelona, España.

TORO, Maria (2013); ¿Qué es la regeneración urbana integral?. En La Ciudad Viva: http://www.laciudadviva.org/blogs/?p=19123

YAGUE, José Maria (2010); Revitalización vs Rehabilitación. Ponencia presentada en el Congreso "Rehabilitación y Sostenibilidad, el futuro es posible", Barcelona, España.

\section{B.2.2 Los desafíos de la intervención y gestión: el Desarrollo Sostenible. Origen y dimensiones del DS}

BONAN, Georges (2011); "Construir la sustentabilidad de un casco histórico y/o la compatibilidad entre protección, modernización, revitalización y "mestizaje" social: El ejmplo de Montpellier". En "Reencuentro", publicación de las IV Jornadas Internacionales de Experiencias de Revitalización de Cascos Históricos 2009, Buenos Aires, Argentina.

GEHL (2010); Ciudades para la gente -Byer for Mennesker-. (Primera edición en español Buenos Aires, 2014. ONU Hábitat, Ediciones Infinito). Disponible en: http://cisav.mx/wpcontent/uploads/2017/03/M4T3.-Gehl-Jan-Ciudades-para-la-gente-cap.-1.pdf

RESTREPO MEJÍA, León (2011); "El difícil reto de la sostenibilidad en cascos históricos plenamente dinámicos. Reflexiones desde ciudades y poblaciones de la región Antioqueña, Colombia. En "Reencuentro", publicación de las IV Jornadas Internacionales de Experiencias de Revitalización de Cascos Históricos 2009, Buenos Aires, Argentina.

WANDEMBERG BOSCHETTI, Juan Carlos (2015); "Sostenible por diseño, Desarrollo económico, social y ambiental".

\section{Documentos internacionales:}

INFORME BRUNDTLNAD (1987); Disponible en:

http://www.un.org/es/comun/docs/?symbol=A/42/427 
DECLARACIÓN DE RÍO (1992); Disponible en:

http://www.un.org/spanish/esa/sustdev/agenda21/riodeclaration.htm

DOCUMENTO FINAL CUMBRE MUNDIAL ONU (2005); Disponible en:

http://www.un.org/spanish/summit2005/fact sheet.html

CARTA DE LA TIERRA (2000); Disponible en: http://cartadelatierra.org/descubra/la-carta-de-latierral

DECLARACIÓN UNIVERSAL SOBRE DIVERSIDAD CULTURAL, UNESCO (2001); Disponible

en:

http://portal.unesco.org/es/ev.php-

URL_ID=13179\&URL_DO=DO_TOPIC\&URL_SECTION=201.html

AGENDA 21 DE LA CULTURA (2004); Disponible en:

http://www.agenda21culture.net/sites/default/files/files/documents/multi/ag21 es ok.pdf

\section{B.2.2.1 El desafío de la Sostenibilidad Físico-ambiental:}

Vaciamiento Físico-funcional

CERLETTI, Andrea (2011); "Patrimonio y desarrollo: área Montserrat textil". En "Reencuentro", publicación de las IV Jornadas Internacionales de Experiencias de Revitalización de Cascos Históricos 2009, Buenos Aires, Argentina.

REENCUENTRO (2011); publicación de las IV Jornadas Internacionales de Experiencias de Revitalización de Cascos Históricos 2009, Buenos Aires, Argentina.

RESTREPO MEJÍA, León (2011); "El difícil reto de la sostenibilidad en cascos históricos plenamente dinámicos. Reflexiones desde ciudades y poblaciones de la región Antioqueña, Colombia. En "Reencuentro", publicación de las IV Jornadas Internacionales de Experiencias de Revitalización de Cascos Históricos 2009, Buenos Aires, Argentina.

TELLA, Guillermo - POTOCKO, Alejandra. (2009), "Historia + turismo: La fórmula para revertir la decadencia de los centros históricos". Buenos Aires: Diario El Cronista, Suplemento Proyectar y Construir; julio 23, pp. 10-11.

Articulación nuevo-antiguo 
CANNAROZZO, Teresa - LEONE, Manfredi (2013); "Palermo: el proceso de recuperación del centro histórico". En "Reencuentro2", publicación de las V Jornadas Internacionales de Experiencias de Revitalización de Cascos Históricos 2011, Buenos Aires, Argentina.

DEBENEDETTI, Walter (2011); "Patrimonio y sustentabilidad: los desafíos del siglo XXI". En "Reencuentro", publicación de las IV Jornadas Internacionales de Experiencias de Revitalización de Cascos Históricos 2009, Buenos Aires, Argentina.

GNEMMI, Horacio (2013); "Nuevo en lo viejo. Sobre el diseño, la calidad y la ética en relación con la pre-existencia". En "Reencuentro2", publicación de las V Jornadas Internacionales de Experiencias de Revitalización de Cascos Históricos 2011, Buenos Aires, Argentina.

GONZALEZ TAMARIT Luis (2001); El regreso a la ciudad construida. La recuperación de la ciudad. Disponible en:

http://www.flacsoandes.edu.ec/biblio/catalog/resGet.php?res/d=19145

\section{B.2.2.2. El desafío de la Sostenibilidad Socio-cultural:}

\section{Gentrificación}

ATKINSON R. \& BRIDGE, G. (2005). Gentrificación en un contexto global: el nuevo colonialismo urbano. Oxon: Routledge, 2005.

BURGESS, Rod (2003); "Ciudad y sostenibilidad: desarrollo urbano sostenible". En "La ciudad inclusiva", Cuadernos de la CEPAL 88, publicación de las Naciones Unidas, CEPAL Cooperazione italiana. Compiladores Balbo, jordán, Simioni. Pp. 81-104. Santiago de Chile, Noviembre de 20013.

CAMERON, Stuart (2003), "Gentrification, housing redifferentiation and urban regeneration: going for growth in Newcastle upon Tyne". Urban Studies, 12 (49).

CARRIÓN MENA, Fernando (2009); "La centralidad histórica: entre el nacionalismo del pasado (monumento) y el sentido social de hoy (centro vivo)", En Revista Centro-h, Núm. 3, pp.7-12, Organización Latinoamericana y del Caribe de Centros Históricos, Ecuador. http://redalyc.uaemex.mx/src/inicio/ArtPdfRed.jsp?iCve=115112536001 
CHECA ARTASU, Martín Manuel (2011); Gentrificación y cultura: algunas reflexiones. En Revista Biblio. 3W, Revista Bibliografíta de Geografía y Ciencias sociales, Vol. XVI, núm. 914, Universidad de Barcelona, marzo de 2011. http://www.ub.edu/geocrit/b3w-914.htm

DIAZ PARRA, Iban (2012); La gentrificación en su contexto: Aspectos esenciales del desarrollo de la gentrificación en el Estado español. http://isotropia.files.wordpress.com/2012/04/comunicacic3b3n-jornadas-miradas-glocalizadas.pdf

DIAZ PARRA, Ibán. -RABASCO POZUELO, Pablo (2013), ¿Revitalización sin gentrificación? En Cuadernos Geográficos 52 (2).

FOLCH, Ramón (2003); Parte I. Capítulo: Los conceptos sociológicos de partida. Serie Territorio y gobierno (Pp. 19 a 21). En El territorio como sistema. Conceptos u herramientas de ordenación. Visiones. Editado por Diputación de Barcelona, España.

FREEMAN, Lance (2008), "Comment on 'The Eviction of Critical Perspectives from Gentrification Research". International Journal of Urban and Regional Research, 32 (1).

GLASS, Ruth (1964); Introduction: aspects of change. In London: Aspects of Change, ed. Centre for Urban Studies, London: MacKibbon and Kee, xiii-xlii.

HAMNETT, Chris (2008), "The new Mikado? Tom Slater, gentrification and displacement", City. 5; (13).

JANOSCHKA, Michael - SEQUERA Jorge - SALINAS, Luis (2014); "Gentrificación en España y América Latina. Un diálogo critico”. En Revista de Geografía Norte Grande, núm. 58. Santiago de Chile.

JANOSCHKA, Michael, SEQUERA, Jorge (2014); Procesos de gentrificación y desplazamiento en América Latina, una perspectiva comparativista. En www.contestedcities.net

LEES, Loreta, Slater, Tom \& Wyly, Elvin (2009). Gentrification. London: Routledge, 2008, 310 p. Traducido al español por LOPEZ MORALES, Ernesto (2009), en Revista de Geografía Monte Grande, 44: 155 - 158 (2009)

LEFT HAND ROTATION. (2012). Gentrificación no es nombre de señora. Facultad de Bellas Artes, Universidad Complutense de Madrid, octubre 2012. 
MANZO, Lidia (2012); On people in changing neghborhoods. Gentrification and social mix: boundaries and resistance. En Revista Cidades, comunidades e Territòrios, pp. 1-29, junio 2012.

MUÑOZ CARRERA, Oscar (2011); Gentrificación y reestructuración del espacio social en Madrid. En Observatorio Metropolitano. Reflexión multidisciplinar sobre los fenómenos de transformación de

http://www.observatoriometropolitano.org/2011/03/25/gentrificacion-y-reestructuracion-del-espacio-socialen-madrid/

ORMINDO DE AZEVEDO, Paulo (2004); El Pelourinho de Bahia, cuatro décadas después. En Iconos, Revista de Ciencias Sociales, núm. 20, pp. 45-52, septiembre de 2004 http://www.redalyc.org/articulo.oa? id=50902005

PICCINATO, Giorgio (1983): "El problema del centro histórico", en CIARDINI, F. y FALINI, P. Los centros históricos. Política urbanística y programa de actuación. Gustavo Gili, Barcelona. pp. 1431.

SABATINI, Francisco, 2010; "Gentrificación sin expulsión", En Revista Arq. _ Arte _ Diseño Universidad Diego Portales, 180 / 24, Santiago de Chile.

SALINAS ARREORTUA, Luis Alberto (2013); Gentrificación en la ciudad latinoamericana: el caso de Buenos Aires y Ciudad de México. En Revista Digital Geographos, Vol. 4, núm. 44 file:///C:/Documents\%20and\%20Settings/Usuario/Escritorio/MAESTRIA\%20\%20DOCTORADO/MARCO $\% 20$ TEORICO/ENFOQUE\%20SISTEMICO-

\section{INTEGRAL/GENTRIFICACION/SALINAS\%20ARREORTUA.pdf}

SARGATAL, M. ALBA, (2001). Gentrificación e inmigración en los centros históricos: El caso del barrio del Raval en Barcelona. En Scrpta Nova, Revista Electrónica de geografía y Ciencias Sociales, agosto de 2001, Barcelona.

SLATER, Tom (2006), "The eviction of critical perspectives from gentrification research". International Journal of Urban and Regional Research, (30).

SLATER, Tom (2009), "Missing Marcuse. On gentrification and displacement”. City, 13 (2-3).

SMITH Neil, (1996), La nueva frontera urbana: gentrificación y ciudad revanchista. Nueva York: Routledge, 1996. 
VERGARA CONSTELA, Carlos (2013); Gentrificación y renovación urbana. Abordajes conceptuales y expresiones en América Latina. En Anales de Geografía, vol. 33, núm. 1, pp. 219-234.

WARD, Francisca (2012); Gentrificación latinoamericana: ¿una oportunidad para la inclusión?. En Revista Digital Plataforma Urbana, http://www.plataformaurbana.cl/archive/2012/10/19/gentrificacionlatinoamericana-\%C2\%BFuna-oportunidad-para-la-inclusion/

\section{Derecho a la ciudad}

BORJA, Jordi (2003); La ciudad conquistada, Alianza Editorial, Madrid..

HARVEY, David (2008); "El derecho a la ciudad". International Journal of Urban and Regional research, vol. 27, núm. 4. Disponible en: http://www.sinpermiso.info/textos/el-derecho-a-la-ciudad

HARVEY, David (2013); Ciudades rebeldes. Del derecho a la ciudad a la revolución urbana. Akal, pensamiento crítico, Madrid, España.

LEFEBVRE, Henri (1968); El derecho a la ciudad, versión en español de "Le droit a la ville".

\section{Documentos internacionales:}

CARTA MUNDIAL POR EL DERECHO A LA CIUDAD (2004), Quito.

Disponible en: http://www.ugr.es/ revpaz/documentacion/rpc n5 2012 doc1.pdf

Grupo de investigación de derecho a la ciudad, FLACSO, Ecuador:

https://derechoalaciudadflacso.wordpress.com/archivos-y-descargas/

\section{B.2.2.3 El desafío de la sostenibilidad económica: Turismo y comercio callejero}

CARRIÓN MENA, Fernando (2003); "La venta ambulante en el centro histórico", publicado en Diario Hoy. Disponible en: http://www.flacso.org.ec/docs/fc ventambulante.pdf

CARRION MENA, Fernando (2000); "Lugares o flujos centrales: los centros históricos urbanos" En División de Medio Ambiente y Asentamientos Humanos, Naciones Unidas, CEPAL, ECLAC. 
FERNANDEZ SALINAS, Víctor (2004); "La ciudad que late". ponencia presentada en la Mesa "La ciudad como patrimonio vivo", Congreso "CENTROS HISTORICOS: El corazón que late" (2004). Publicación del Foro Internacional de Arquitectura, Córdoba 2004, España. Junta de Andalucía. Consejería de Obras Públicas y Transportes. Dirección General de Arquitectura y Vivienda.

GIROLA, M. Florencia, YACOVINO, M. Paula \& LABORDE, Soledad (2011);. Recentrando la centralidad: procesos de recualificación urbana y espacio publico en la ciudad de Buenos Aires desde una perspectiva etnográfica. Cuaderno Urbano, Cultura, Sociedad, Junio 2011.

HANLEY, Lisa M. (2008); "Centros históricos: espacios de rehabilitación y disputa", En Revista Centro-h, Núm. 1, pp.78-84, Organización Latinoamericana y del Caribe de Centros Históricos, Ecuador.

PRATS, Llorenç (1997); Antropología y patrimonio. Grupo Planeta.

VENTURINI, Edgardo (2006); "El uso turístico del patrimonio en los centros históricos urbanos". Ponencia presentada en el VIII Congreso Internacional de Rehabilitación del Patrimonio y Edificación, "La dimensión social del patrimonio", CICOP, Argentina.

PRADILLA COBOS, Emilio (2012); Formas productivas, fracciones del capital y re-construcción urbana en América latina. Disponible

en www.rii.sei.ba.gov.br/.../formas\%20productivas $\% 20$ fracciones $\% 20$ del $\%$

\section{B.2.2.4 El desafío de la sostenibilidad institucional: Gestión}

BOSSIO, Silvia - STORCHI, Stefano (2009); Centri storici: gestire la trasformazione, ANCSA, Cremona.

CAMPOS VENUTI (1978); Urbanismo y austeridad. Editorial Siglo XXI de España Editores S.A., 1981.

CIARDINI - FALINI (1983); Los centros históricos: Política urbanística y programas de actuación. Barcelona, España. Editado por Editorial Gustavo Gili.

CARRION MENA, Fernando, 2003; "Ciudad y centros históricos: centros históricos y actores patrimoniales". En "La ciudad inclusiva", Cuadernos de la CEPAL 88, publicación de las Naciones 
Unidas, CEPAL - Cooperazione italiana. Compiladores Balbo, jordán, Simioni. Pp. 129-152. Santiago de Chile, Noviembre de 2003.

CARRION MENA, Fernando (2007); "El financiamiento de los centros históricos de América Latina y el Caribe". Primera edición. FLACSO, Facultad Latinoamericana de Ciencias Sociales, Quito, Ecuador.

CONTRUCCI, Pablo (1999); "Nuevos instrumentos y estrategias de gestión urbana", En Revista Distrito 2, número 40, Colegio de Arquitectos de la Provincia de Buenos Aires.

COULOMB, René (2001); "Modelos de gestión en los centros históricos", En La ciudad construida. Urbanismo en América Latina. Quito, FLACSO - Junta de Andalucía - Municipio del Distrito Metropolitano de Quito, Ecuador.

ETULAIN, Juan Carlos (2009); Gestión Urbanística y Proyecto Urbano. Modelos y estrategias de Intervención. Primera edición. Editorial Nobuko-FAU-UNLP. Buenos Aires. Argentina.

HERCE VALLEJO, Manuel (2001); "Instrumentos de transformación del espacio urbano; presencia y operatividad en América Latina", En La ciudad construida. Editor: Fernando Carrión Mena. Urbanismo en América Latina. Quito, FLACSO - Junta de Andalucía - Municipio del Distrito Metropolitano de Quito, Ecuador.

HIERNAUX, Daniel - GONZALEZ, Carmen Imelda, 2008; “¿Regulación o desregulación?: de las políticas sobre los centros históricos". En Revista Centro-h, Núm. 1, pp.40-50, Organización Latinoamericana y del Caribe de Centros Históricos, Ecuador.

http://redalyc.uaemex.mx/src/inicio/ArtPdfRed.jsp?iCve=115112534004

MANEJO Y GESTION DE CENTROS HISTORICOS (2009); Selección de conferencias de los Encuentros Internacionales IV, V, VI y VII, La Habana Vieja, 2005, 2006, 2007 y 2008. Ediciones Boloña, Publicaciones de la Oficina del Historiador, colección ARCOS, La Habana, Cuba, 2009.

MELÉ, Patrice (2006); "La producción del patrimonio urbano". Publicaciones de la casa chata, Centro de Investigaciones y Estudios Superiores en Antropología Social, México, DF. 
MORENO GARCÍA, José Ramón, (2001); "La vivienda en los centros históricos", en Carrión, Fernando (ed.) La ciudad construida. Urbanismo en América Latina, Quito, FLACSO.

SALGADO GOMEZ, Mireya, 2008; "El patrimonio cultural como narrativa totalizadora y técnica de gubernamentalidad". En Revista Centro-h, Núm. 1, pp.13-25, Organización Latinoamericana y del Caribe de Centros Históricos, Ecuador.

\section{Documentos internacionales:}

DECLARACIÓN DE MÉXICO (1979); Disponibe en:

http://www.unesco.org/education/pdf/MEXICO S.PDF

DECLARACIÓN DE LIMA (2014); Disponible en:
http://www.unesco.org/fileadmin/MULTIMEDIA/FIELD/Santiago/pdf/Declaracion-de-Lima31-10-2014-ESP.pdf

"Empresas de barrio, una nueva posibilidad para la regeneración urbana" (2014). En: http://www.laciudadviva.org/blogs/?p=20869

\section{B.3 EXPERIENCIAS DE INTERVENCIÓN Y GESTIÓN EN CENTROS HISTÓRICOS}

\section{B.3.1 Enfoques en el contexto europeo}

B.3.1.1 Intervención y gestión en Italia

BLASCO, José Antonio (2014); "Cuando el Plan de Bolonia era una referencia urbanística (y de izquierdas) para la intervención de los centros históricos de las ciudades”. En Urban Networks.

CAMPOS VENUTI, Giuseppe (1993): "Cincuenta años: tres generaciones ur- banísticas".

Cincuenta años de urbanismo en Italia, 1942-1992. BOE y Universidad Carlos III, Madrid.

CESARI, Carlo (1982): "Criterios de intervención en el Centro Histórico". Actas de las I Jornadas de Patrimonio Histórico-Artístico. Junta de Castilla y León, Burgos. 
CESARI, Carlo (1993); “El proceso de conservación y rehabilitación en Italia”. Revista Científica de ICOMOS, Núm. 2, Galicia, España.

CHAVES MARTÍN, Miguel Ángel (2013); "Criterios de intervención en el centro histórico de Ferrara: de las políticas de reconstrucción tras la guerra mundial al Plan de Rehabilitación Integral". Arte y Ciudad, Revista de investigación, Núm. 3.

LUCA, María Franchina (2010); La nuova questione dei centri storici in Italia. Una rocognizione: nella letteratura, nelle politiche urbanistiche, nei progetti. Politecnico di Milano, Facoltà di Architettura e Società, Corso di Laurea Magistrale in Pianificazione Urbana e Politiche Territoriali.

RIDOLFI, Mario (1952); en texto de CHAVES MARTíN, Miguel Ángel "Criterios de intervención en el centro histórico de Ferrara: de las políticas de reconstrucción tras la guerra mundial al Plan de Rehabilitación Integral". Arte y Ciudad, Revista de investigación, Núm. 3, 2013.

\section{Documentos internacionales:}

CARTA DE GUBBIO (1960); http://www.italianostra.org/wp-content/uploads/2010/04/Carta-diGubbio.pdf

\section{CARTA EUROPEA DE PATRIMONIO (1975); Disponible en:}

http://ipce.mecd.gob.es/dam/jcr:93713826-20c7-42a1-bb7f-bb09d201ed21/1975-cartaamsterdam.pdf

\section{B.3.1.2 Intervención y gestión en España}

GAJA DÍAZ, Fernando (2001); "Intervenciones en centros históricos de la Comunidad Valenciana", Consejo de Obras Públicas, Urbanismo y Transporte, Dirección General de Arquitectura y Vivienda, Universidad Politécnica de Valencia, Departamento de Urbanismo. 
GARCIA ANTON, José Ramón (2001); Presentación del libro "Intervenciones en Centros Históricos de la Comunidad Valenciana", Consejería de Obras Publicas, Urbanismo y Transporte. Dirección General de Arquitectura y Vivienda, Universidad Politecnica de Valencia, Departamento
de
Urbanismo.
Redactor:
Fernando
Gaja
Díaz.
Disponible
en:

http://personales.upv.es/fgaja/publicaciones/centroshistoricos.pdf

POL MÉNDEZ, Francisco (1993); “La recuperación de los centros históricos en España”. En

Dialnet:

https://dialnet.unirioja.es/descarga/articulo/2151411.pdf

SANTAMARÍA COMALLONGA, Joaquín (2013); “Centros históricos: análisis y perspectivas desde la geografía”. En GeoGraphos, Revista Digital para estudiantes de Geografía y Ciencias Sociales, Vol. 4. Alicante: Grupo interdisciplinario de estudios críticos y de América Latina de la Universidad de Alicante.

TOBALINA, LETICIA (2012); "La protección de la ciudad y los centros históricos". Patrimonio Histórico Artístico y Gestión de Bienes Culturales. Disponible en: https://es.scribd.com/document/169629916/Phagbic-Apuntes-Tema-11-Leticia

TROITIÑO VINUESA, Miguel Ángel (2003); "La protección, recuperación y revitalización funcional de los centros históricos". En Colección Mediterráneo Económico: "Ciudades, arquitectura y espacio urbano", núm. 3. Edita Caja Rural Intermediterránea, Instituto de Estudios Socioeconómicos Cajamar.

VALENZUELA RUBIO, Manuel (2000); "La regeneración de los cascos históricos en España. El programa URBAN, dinero comunitario para una estrategia global". En III Jornadas de Geografía Urbana: Oportunidades de desarrollo urbano sostenible para los conjuntos urbanos históricos. Publicación de la Universidad de Burgos, España.

\section{B.3.2 Enfoques en el contexto latinoamericano}

LUQUE AZCONA Emilio - SMITH Harry (2007); "Novedades y retos en la gestión de centros históricos de Europa, Latinoamérica y el Caribe (1980-2005)". En Revista Scripta Nova, Revista electrónica de geografía y ciencias sociales, Vol. XI, núm. 254, diciembre de 2007. 
RODRÍGUEZ ALOMÁ, Patricia (2008); "El centro histórico: del concepto a la acción integral". En Revista Centro-h, núm.1, OLACCHI, Quito.

RODRÍGUEZ ALOMÁ, Patricia (2013); "La gestión del desarrollo integral de los centros históricos en Latinoamérica". En Carajillo de la ciudad, Revista digital del Programa en gestión de la ciudad 'Café de las ciudades, núm.16.

\section{Documentos internacionales:}

CARTA DE QUITO, COLOQUIO DE QUITO (1977); Disponible en:

http://informesdelaconstruccion.revistas.csic.es/index.php/informesdelaconstruccion/article/viewFil e/1473/1639

CARTA DE MACHU PICCHU (1977); Disponible en:
http://www.cubaarqueologica.org/document/carta12.pdf

CARTA DE PETRÓPOLIS (1987); Disponible en:

http://portal.iphan.gov.br/uploads/ckfinder/arquivos/Carta\%20de\%20Petropolis\%201987.pdf

CARTA DE VERACRUZ (1992); Disponible en:

http://ipce.mecd.gob.es/dam/jcr:13ecce3e-7a22-4d26-a06c-74774556d55c/1992-carta-

veracruz.pdf

CARTA DE WASHINGTON (1987); Disponible en: https://www.icomos.org/charters/towns sp.pdf

B.3.3 Fichas de análisis de casos (según orden de numeración de fichas)

B.3.3.1 Italianos

NÁPOLES, PLAN DE ACCIÓN LOCAL (2011); “Plan de Gestión del Centro Histórico de Nápoles Patrimonio de la Humanidad".

Plan de Acción Local, URBACT, Unión Europea. http://urbact.eu/sites/default/files/lap naples.pdf

BOLONIA (2014); "Cuando el Plan de Bolonia era una referencia urbanística (y de izquierdas para la intervención de los centros históricos

de las ciudades (2.EI Plan). En: http://urban-networks.blogspot.com.ar/2014/08/cuando-el-plande-bolonia-era-una.html 
CERVELLATI, Pier Luigi, SCANNAVINI, Roberto (1973); BOLONIA: Política y metodología de la restauración de centros históricos. Gustavo Gili, Barcelona.

ROMA, PIANO REGOLATORE (2003); "Piano Regolatore Generale di Roma”, Comune di Roma: www.urbanistica.comune.roma.it/prg.html / http://www.urbanistica.comune.roma.it/prgracconto/prg-racconto-cittastorica.html

GÉNOVA, PIANO OPERATIVO (2002); "Il Piano Operativo per il Centro Storico" - Comune di genova: http://civis.comune.genova.it/piano operativo/ / (2014); "Il recupero del Centro Storico" - Urban Center - Comune di Genova: http://www.urbancenter.comune.genova.it/node/73

MIÁN: ARCIDIACONO A., GALUZZI P., POGLIANO L., ROTA G., SOLERO E., VITILLO E. (2013); "Il piano Urbanístico di Milano (PGT 2012)", TeknoeBook, Wolters Kluwer Italia s.r.I, Milano. Comune di Milano.

TURÍN (2011);“Urban Barriera”, Comune di Torino: http://www.comune.torino.it/urbanbarriera/progetto/index.shtml

PALERMO, PIANO PARTICOLAREGGIATO (1993); "Piano Particolareggiato Esecutivo del Centro Storico di Palermo", Comune di Palermo: http://ideam.altervista.org/files da pubblicare/Norme\%20Tecniche\%20Attuazione\%20Centro\%2 0Storico\%20di\%20Palermo\%20-\%20P.P.E..pdf / Cannarozzo T., Manfredi L. (2011); "Palermo: el proceso de recuperación del centro histórico". En Reencuentro2, Libro de las V Jornadas Internacionales de Experiencias de Revitalización de Cascos Históricos, Buenos Aires, Argentina.

FLORENCIA, PLAN DE EGSTIÓN (2016); "The Managemente Plan of the Historic Centre of Florence - UNESCO World Heritage", Comune di Firenze: http://www.firenzepatrimoniomondiale.it/en/piano-di-gestione/

http://www.firenzepatrimoniomondiale.it/wp-content/uploads/2015/12/nuovo-Piano-di-GestioneFirenze.pdf

SIENA, PLAN DE GESTIÓN (2015); "Piano di Gestione del Sito UNESCO Centro Storico di Siena", Comune di Siena: http://www.comune.siena.it/La-Citta/Territorio/Direzione-TerritorioSportello-Unico-e-Attivita-Economiche/Ufficio-Centro-Storico-e-Sito-Unesco/ll-nuovo-Piano-diGestione-2015-2018 
VENECIA, VARIANTE PLAN REGULADOR (2002); "Variante Piano Regolatore generale per il Centro Storico di Venezia, Cittá Antica", Comuni de Venezia: https://www.comune.venezia.it/archivio/48035 / http://www.veniceandlagoon.net/web/wpcontent/uploads/2014/12/MP volume low eng.pdf

\section{B.3.3.2 Españoles}

MÁLAGA: MARÍN Cots P.; OLIVA Pérez B.; BLANCO NIETO M. (2011); "El centro histórico en el siglo XXI como un proceso continuo de memoria cultural de la ciudad", En Reencuentro2, libro de $\mathrm{V}$ Jornadas Internacionales "Experiencias de revitalización de cascos históricos", Buenos Aires, Argentina. / http://avancepepricentro.malaga.eu/es/descargar-documento/\#.WH5IAyPhBOs http://www.malaga.eu/recursos/sociales/observatorio/descargas/mapa trabajo social/distrito1.pd f

SEVILLA: NUEVO PLAN GENERAL (2005); Nuevo Plan General de ordenación Urbanística Sevilla: http://www.sevilla.org/plandesevilla/adef/doc/AD I 13.pdf

DÍAZ PARRA I. (2008); "Plan Especial de Protección del Casco Histórico de Sevilla. ¿Plan de Protección o Plan de Reforma Interior?. En Espacio y Tiempo, Revista de Ciencias Humanas, No 22, pp. 67-84. En: https://dialnet.unirioja.es/descarga/articulo/2877032.pdf

ZARAGOZA: PLAN INTEGRAL (2013); Evaluación del Plan Integral del Casco Histórico 2005-2012. Diagnóstico del Barrio y Propuestas de futuro. Zaragoza, España. En: http://www.zaragoza.es/contenidos/sectores/pich/evaluacionpich.pdf /

http://www. aragondigital.es/noticia.asp?notid=25066\&secid $=9$

https://wearethecityheroes.wordpress.com/2013/01/31/zaragoza-plan-integral-del-casco-historico estonoesunsolar/

SEVILLA: POL MÉNDEZ F. (1993); “La recuperación de los centros históricos en España”, En: https://dialnet.unirioja.es/descarga/articulo/2151411.pdf

VALADOLID: POL MÉNDEZ F. (1993); “La recuperación de los centros históricos en España”, Disponible en:

https://dialnet.unirioja.es/descarga/articulo/2151411.pdf / Plan Especial Casco Histórico de Valladolid: www.itcvalladolid.es/.../PLAN\%20ESPECIAL\%20CASCO\%20HISTORICO\%20VAL... 
BARCELONA: CABRERA MASSANES P. (2002); "Ciutat Vella, Rehabilitación Integral en el Centro Histórico de Barcelona, España”. En: http://habitat.aq.upm.es/bpes/onu/bp259.html ; http://habitat.aq.upm.es/bpes/onu02/bp393.htm

AJUNTAMENT DE BARCELONA (1999); "Barcelona: Gobierno y Gestión de Ciudad, Una experiencia de modernización municipal.". Barcelona. Ediciones Díaz de Santos S. A., pág. 27; "Nuevos Instrumentos de Gestión.". Barcelona. Ediciones Díaz de Santos S. A.

MADIRD: HERRÁEZ S. (2000); "La Rehabilitación del centro Histórico de Madrid". En Informes de la Construcción Vol. 51 Núm. 465. I Plan para la Revitalización del centro urbano: www.madrid.es/UnidadesDescentralizadas/UrbanismoyVivienda/.../C02.pdf

ALCOY: GAJA DÍAZ, F. (2001); "Intervenciones en centros históricos de la Comunidad Valenciana", Consejo de Obras Públicas, Urbanismo y Transporte, Dirección Genreal de Arquitectura y vivienda, Universidad Politécnica de Valencia, Departamento de Urbanismo.

A CORUÑA: REVISIÓN Y ADAPTACIÓN DEL PEPRI (2012); Revisión y adaptación del Plan Especial de Protección y Reforma Interior de la Ciudad Vieja de A Coruña (PEPRI) http://www.coruna.es/urbanismo/es/modificacion-pepri/aprobacion-inicial

VITORIA GASTEIZ: ARROITA, G. (2011); "Los centros históricos que se quedaron atrás: La reactivación Integral en Vitoria Gasteiz", IV Jornadas Internacionales "Experiencias de revitalización de cascos históricos", Buenos Aires, Argentina. / Villapún Ansotegui, E; Vitoria Gasteiz, Geografía Urbana. AYUNTAMIENTO DE VITORIA GASTEIZ (1980); Plan Especial de Rehabilitación Integrada del Casco Medieval. Disponible en:http://www.vitoriagasteiz.org/we001/was/we001Action.do?aplicacion=wb021\&tabla=contenido\&idioma=e s\&uid=u1acfee53 13a67fbb9d6 7faa; (2006); Revisión Plan Especial de Rehabilitación Integrada del Casco Medieval. Disponible en:http://www.vitoriagasteiz.org/wb021/http/contenidosEstaticos/adjuntos/es/44/52/14452.pdf; (2008); Plan de Reactivación integral del Casco Histórico. Disponible en: https://www.vitoriagasteiz.org/docs/wb021/contenidosEstaticos/adjuntos/es/75/46/37546.p $\underline{\mathrm{df}}$

\section{B.3.3.3 Latinoamericanos}

BUENOS AIRES, PLAN DE MANEJO (2015); Plan de Manejo del Casco Histórico de Buenos Aires. 
FERNÁNDEZ WAGNER, R. (2006; EI casco histórico de Buenos Aires. Fuentes de financiamiento, programas y proyectos de intervención patrimonial.

SANTA CRUZ DE LA SIERRA: DINO MÉNDEZ, J. (2011); "Gestión Municipal comprometida con el Patrimonio Histórico de Santa Cruz de la Sierra, Bolivia”. En Reencuentro2, libro de las V Jornadas Internacionales de Experiencias de Revitalización de Cascos Históricos, Buenos Aires, Argentina / http://documentslide.com/art-photos/plan-de-revitalizacion-integral-del-centro-historico-santa-cruz-de-lasierra.html

http://arqa.com/arquitectura/el-centro-historico-santa-cruz-de-la-sierra.html

RECIFE: Informe Corporación de Desarrollo del Sur. UOCDS (1999); Buenos Aires, Argentina. LURDERMIR BERNARINO I.; Vivir en el centro histórico. La habitabilidad en el casco antiguo de la ciudad de Recife en Brasil, Universidad Federal de Pernambuco, Brasil.

SALVADOR DE BAHÍA: MARQUES BRAGA P., RIBEIRO DOS SANTOS, W.J. (2009); "Programa de Recuperaçao do Centro Histórico de Salvador: políticas públucas e participaçao social”. En Revista Risco, Revista de pesquisa en arquitectura e urbanismo. http://www.revistas.usp.br/risco/article/viewFile/44777/48408 / Luque Azcona E., Smith H. (2010); "Transformaciones, conflictos e identidades en el centro histórico de Salvador de Bahía". En Revista Complutense de Historia de América.

CARTAGENA DE INDIAS: RUZ ROJAS, G. (2011); "Revitalización del Centro Histórico de Cartagena: Por una ciudad para soñar". En Reencuentro, libro de las IV Jornadas Internacionales de Experiencias de Revitalización de Cascos Históricos, Buenos Aires, Argentina / Plan de Revitalización del Centro Histórico de Cartagena https://www.youtube.com/watch?v=eMbOpveOgtk

SAN JOSÉ DE COSTA RICA: https://www.laprensalibre.cr/Noticias/detalle/73431/municipalidadapoya-dar-nueva-cara-a-san-jose / Despoblamiento y repoblamiento de San José centro". En Revista Ambientico, Revista mensual sobre la actualidad ambiental, Costa Rica, 2013.. En: http://www.ambientico.una.ac.cr/pdfs/ambientico/234.pd

LA HABANA VIEJA: PEDI (2011); Avance PEDI Plan Especial de Desarrollo Integral, Plan Maestro para la Revitalización Integral de La Habana, Oficina del Historiador de la ciudad de La Habana, Cuba, 2011. http://www.planmaestro.ohc.cu/recursos/papel/libros/pedi.pdf

Planes La Habana Vieja: Disponibles en: http://www.planmaestro.ohc.cu/index.php/gestion-delplan/planes 
SANTIAGO DE CHILE: GREENE M., MORA R., BERRIOS E. (2009); "Los instrumentos de repoblamiento del centro de Santiago: SRU y SIT entre 1999 y 2005". En Ciudades para un futuro sostenible, Simposio Internacional Desarrollo, Ciudad y Sostenibilidad, La Serena. Chile.

http://habitat.aq.upm.es/boletin/n42/ab-rmor.html

QUITO: "La ciudad en el siglo XXI. Buenas practicas de gestión Urbana en América Latina y el Caribe". Ponencia Simposio, BID-SDS, Barcelona, 1997. http://es.slideshare.net/PatrimonioBogota/la-vivienda-en-el-centro-histrico-de-quito

ARREGUI, Edmundo; El programa de rehabilitación del Centro Histórico de Quito. Flacso, Andes.

SAN SALVADOR: ESPINOZA L.A.A. (2015); "El Centro Antiguo de San Salvador: problemas, esfuerzos y desafíos de las intervenciones", XXXIV Congreso Arquisur, La Plata, Argentina. I Barba J. - Córdoba A. (2001); "Gestión urbana: recuperación del centro de San Salvador, El Salvador. Proyecto Calle Arce. CEPAL, Santiago de Chile, 2001. En: http://repositorio.cepal.org/bitstream/handle/11362/5719/1/S01050371 es.pdf

ANTIGUA GUATEMALA: PLAN MAESTRO DE LA ANTIGUA GUATEMALA (2014); https://issuu.com/biblioteca-ulpgc/docs/plan maestro de la antigua guatemal

LÓPEZ J.S. (2009); "La Antigua Guatemala: Plan Maestro para su centro Histórico". En Manejo y gestión de centros históricos, selección de conferencias de encuentros internacionales en La $\begin{array}{lccc}\text { Habana } & \text { Vieja, } & \text { La } & \text { Habana, } \\ \text { http://www.planmaestro.ohc.cu/recursos/papel/libros/manejoygestion2.pdf }\end{array}$

COMAYAGUA: RUBI Pineda R.A. (2007); "La revitalización del centro histórico de Comayagua. El Plan como generador de desarrollo y redistribuidor de la riqueza urbana". En: http://desarrollourbanoyterritorial.duot.upc.edu/sites/default/files/R.Rubi MDUT\%202007.pdf /

Programa Comayagua Colonial, en: http://www.aecid.es/CentroDocumentacion/Documentos/Publicaciones\%20coeditadas\%20por\%20AECID/Estudio impacto P CCxver reducidax.pdf

CIUDAD DE MÉXICO: PLAN DE MANEJO (2011); Plan de Manejo Integral del Centro Histórico de la Ciudad de México, $2011 \quad$ - 2016. http://www.autoridadcentrohistorico.df.gob.mx/noticias/Plan integral de manejo espanol.pdf. TELLEZ CONTRERAS L.F. (2014); "La revitalización del Centro Histórico de la Ciudad de México: entre la voluntad de la élite y la realidad del pueblo". En: http://www.pacarinadelsur.com/home/mascaras-e-identidades/949-la-revitalizacion-del-centrohistorico-de-la-ciudad-de-mexico-entre-la-voluntad-de-la-elite-y-la-realidad-del-pueblo 
SANTIAGO DE QUERÉTARO, PLAN DE MANEJO (2008): Plan de Manejo y conservación de la zona de monumentos históricos de Santiago de Querétaro. En: http://ciudadespatrimonio.mx/descargables/biblioteca/plan de manejo y conservacion de la zo na de monumentos historicos de santiago de queretaro.pdf

PANAMÁ: PNUD (2009); Informe Final "Lineamientos para la consolidación de la integralidad e inclusión social en la implementación del Plan Maestro del Casco Antiguo de la ciudad de Panamá.

RODRÍGUEZ M. (2011); "La interinstitucionalidad en el manejo del Casco Antiguo de la ciudad de Panamá". En Reencuentro2, libro de las V Jornadas Internacionales de Experiencias de Revitalización de Cascos Históricos, Buenos Aires, Argentina.

ASUNCIÓN: PLAN CHA (2015); Plan CHA, Plan Maestro para la Revitalización del Centro histórico de Asunción (2015). http://plancha.gov.py/sinopsis-del-plan-cha-2/

LIMA, PLAN MAESTRO (2014); Plan Maestro del Centro Histórico de Lima. En: http://es.slideshare.net/PatriciaDiasVElarde/plan-maestro-centro-histrico-de-lima-al-2035 http://www.munlima.gob.pe/prolima

SANTO DOMINGO: PLAN ESTRATÉGICO (2006); Ordenanza del Plan Estratégico de Revitalización Integral de la Ciudad Colonial de Santo Domingo http://www.diariolibre.com/noticias/ciudad/realizan-investigacion-en-la-ciudad-colonial-en-buscadel-desarrollo-de-esta-zona-IJ17482

MONTEVIDEO: ARANA, M. (2011); "Manejo del Casco Histórico de Montevideo". En Reencuentro2, libro de las $\mathrm{V}$ Jornadas Internacionales de Experiencias de Revitalización de Cascos Históricos, Buenos Aires, Argentina.

Plan Especial de Ordenación, Protección y Mejora de la Ciudad Vieja - 18 de Julio. http://www.montevideo.gub.uy/institucional/politicas/ordenamiento-territorial/plan-especial-deordenacion-proteccion-y-mejora-de-ciudad-vieja-18-de-julio

MARACAIBO: PORTILLO R., FERNÁNDEZ NAVA L., USECHE M.C. (2013); "Incidencia de la arquitectura patrimonial en la formación de la imagen de la ciudad". En Revista Perspectiva, Revista electrónica científica, Universidad de Zulia Venezuela. 
FERRER, Mercedes; QUINTERO, Carolina; BARROSO, Helen (2002) Maracaibo, periferia y área central, hacia una política de consolidación sustentable en Venezuela, Revista Ciencias de Gobierno, año 6, volumen 6, número 011, pp. 51-74

\section{BIBLIOGRAFIA. B.5}

BENAVIDES CUETO, Leopoldo (2002); Recuperación de centros históricos. El reto de la sostenibilidad urbana. Propuesta de indicadores de desarrollo urbano sostenible. Síntesis. Tesis de Master en Medio Ambiente Urbano y sostenibilidad.

CAÑAS Ignacio (1995); Valoración del paisaje. Unicopia: Lugo.

JARAMILLO VALDIVIESO, lovana Lizbeth (2016); "Paisaje Histórico Urbano del Centro Histórico de Zaruma. Estudio, lineamientos y estrategias para la aconservación". Trabajo para obtener el título de Magister en Conservación y Gestión del patrimonio cultural edificado, Cuenca, Ecuador.

GÓMEZ VILLARINO, Miguel y Teresa - Gómez Orea, Domingo (2013); “El paisaje urbano: una aproximación a sus componentes básicos para su inserción en planes y proyectos". En Revista Revista Ciudad y territorio, Estudios territoriales, Núm. 175, España.

MARTIGNONI, Jimena (2009); "El paisaje como referente de diseño". En Revista 30, Cuadernos del Centro de Estudios en Diseño y Comunicación (Ensayos), año 10, número 30. Buenos Aires, Argentina.

MAZZONI, Elizabeth (2014); "Unidades de paisaje como base para la organización y gestión territorial”. En Estudios Socio-territoriales, Revista de Geografía Núm. 16.

MUÑOZ-PEDREROS, Andrés (2004); "La evaluación del paisaje: una herramienta de gestión ambiental". Revista Chilena de Historia Natural.

OJEDA LEAL, Carolina (2014); "Paisaje cultural y patrimonio. Fragilidad paisajística como propuesta de análisis de patrimonio y paisaje". En Revista Urbano núm. 30., Universidad del BíoBío, Chile. 
OTERO PASTOR et al. (2009); "Metodología de valoración de paisaje desde infraestructuras lineales". España.

PLAN DE ACCIÓN TERRITORIAL DE PROTECCIÓN DE LA HUERTA DE VALENCIA. "Estudio preliminar de paisaje. Valores y Objetivos de calidad paisajística".

PLAN ESPECIAL DE LA CIUDAD HISTÓRICA DE SANTIAGO DE COMPOSTELA. Estudio de Paisaje.

PLAN ESPECIAL DE PROTECCIÓN DEL CONJUNTO HISTÓRICO DE BURRIANA. Estudio de integración paisajística (2011).

PÉREZ CHACÓN-ESPINO, Emma (1999); “Unidades de paisaje. Aproximación científica y aplicaciones". III Congreso de Ciencia del Paisaje,

RAMÓN BUSTMANTE, Andrea Vanesa (2012); Valoración del paisaje urbano. Metodología para su consideración objetiva como criterio de Planificación Territorial. Tesis de grado, Universidad Católica de Loja, Ecuador.

SERRANO GINÉ, David (2012); "Consideraciones en torno al concepto de unidad de paisaje y sitematización de propuestas". En Revista Estudios Geográficos, Núm. 272.

ZOIDO NARANJO, Florencio (...); "Los paisajes como patrimonio natural y cultural”. Disponible en: $\quad$ http://paisajeyterritorio.es/assets/los-paisajes-como-patrimonio-natural-y-cultural.-zoido$\underline{\text { naranjo,-f..pdf }}$

\section{Documentos internacionales}

CONVENIO EUROPEO DE PAISAJE (2000); Consejo de Europa, Florencia. Disponible en: http://www.upv.es/contenidos/CAMUNISO/info/U0670786.pdf

RECOMENDACIÓN PARA LA APLICACIÓN DEL CONVENIO (2008). Disponible en:

https://www.asturias.es/medioambiente/articulos/ficheros/Recomendaciones\%20para\%20la\%20ap licaci\%C3\%B3n\%20del\%20Convenio\%20Europeo.pdf 
MEMORANDUM DE VIENA (2005). Disponible en:

https://unesco.It/uploads/file/failai VEIKLA/kultura/RA Vienna memorandum.pdf

RECOMENDACIÓN SOBRE LOS PAISAJES URBANOS HISTÓRICOS (2011). Disponible en:

http://portal.unesco.org/es/ev.phpURL_ID=48857\&URL_DO=DO_TOPIC\&URL_SECTION=201.ht $\mathrm{ml}$

UNESCO (2008); Historic districs for all. A social and human approach for sustainable revitalization. Brochure designed for local authorities.

UNESCO (2010); Managing Historic Cities. Gérer les villes historiques. World Heritage papaers. Paris, Francia.

UNESCO (2013); Nueva vida para las ciudades históricas. El planteamiento de los Paisajes Urbanos Históricos. Paris, Francia.

UNESCO (2013); El paisaje histórico urbano en las ciudades Patrimonio Mundial. Indicadores para su conservación y gestión II. Criterios, metodologías y estudios aplicados. Instituto Andaluz de Patrimonio Histórico, Centro de Patrimonio mundial.

\section{B.6 CIERRE Y APERTURA}

LERNER, Jaime (2010); “Cómo pensar una ciudad”. En: www.youtube.com/watch?v=|XGY0X-wdjl

RODRÍGUEZ ALOMÁ, Patricia (2009); "La innovación urbana en la recuperación de los centros históricos”. En Manejo y gestión de centros históricos, Editorial Boloña, La Habana, Cuba. 


\section{CENTROS DE DOCUMENTACION}

ORCALC (Oficina Regional de Cultura para América Latina y el Caribe)

http://www.unesco.org.cu/informacion/cdboletinpatrimonio.htm

SIRCHAL (Sitio Internacional sobre la revitalización de Centros Históricos de Ciudades de America Latina y el Caribe)

http://www.archi.fr/SIRCHAL

CEPAL (Comisión Económica para América Latina y el Caribe)

http://www.eclac.cl

Proyecto. "Instrumentos y estrategias de gestión urbana para el desarrollo sostenible en America latina y el Caribe (GUDS).

UNESCO (Organización de las Naciones Unidas para la Educación, la Ciencia y la Cultura) http://www.unesco.org/new/es/mexico/work-areas/culture/world-heritage/

Brasil. IPHAN

http://portal.iphan.gov.br/portal/montarPaginaInicial.do;jsessionid=82D3E724FEE7029E65F990F7B96BAE $\underline{17}$

\section{REVISTAS DIGITALES Y BLOGS}

Fernando Carrión http://works.bepress.com/fernando_carrion/

La Ciudad Viva (Consejería de Fomento y Vivienda de la Junta de Andalucía, España).

http://www.laciudadviva.org/blogs/?tag=regeneracion-urbana

Re-hab (Rehabilitación y Regeneración Urbana. Departamento de Urbanística y Ordenación del territorio, Universidad Politécnica de Madrid, España).

http://www2.aq.upm.es/Departamentos/Urbanismo/blogs/re-hab/

Revista digital del Área de Gestión de la ciudad y urbanismo. http://www.cafedelasciudades.com.ar/carajillo/

\section{B.7 Enfoque metodológico}

La investigación 
SAMAJA, Juan Alfonso (1993); Epistemología y metodología: elementos para una teoría de la investigación científica. $3^{\circ}$ ed., $4^{\circ}$ reimp., Editorial Universitaria de Buenos Aires, 2004.

SANTOS GRACIA, Miguel Ángel (2004); Kant y la lógica de la investigación científica. En Dialnet, Vol. XXIII/I-3, 2004, pp. 199-213.

BATTHYANY, K. y CABRERA, M. (Coord.) (2011); Metodología de la Investigación en Ciencias Sociales. Universidad de la República, Uruguay, 2011. Capítulo IX. Los métodos en las ciencias sociales. Abordaje cuantitativo y cualitativo de la investigación. Pp. 75 a 83

ECO, Umberto (1998); Como se Hace una Tesis. Técnicas y Procedimientos de Investigación, Estudio y Escritura. Edición 22. Editorial Gedisa. Barcelona. España. 11.6.1. La Elección del Tema. Que es la Cientificidad. Pp. 47 a 53

ETULAIN, Juan Carlos et al (2001); Ficha N 2. Acercamiento a la Problemática de la Investigación Científica. Apunte de Cátedra Metodología de la Investigación. Escuela de Turismo. UNLP. Pp. 1 a 18

ETULAIN, Juan Carlos et al (2001); Ficha N 9. Clases de Investigación. Apunte de Cátedra Metodología de la Investigación. Escuela de Turismo. UNLP. Pp. 1 a 3

Diseño y planificación de la investigación

ECO, Umberto (1998); Como se Hace una Tesis. Técnicas y Procedimientos de Investigación, Estudio y Escritura. Edición 22. Editorial Gedisa. Barcelona. España. Capitulo V. La Redacción. Pp. 188 a 219

EGUIA, A. y PIOVANI, J (2003); Metodología de Investigación. Algunas reflexiones y pautas para la elaboración de una tesis. Revista Tram(p)as de la Comunicación y la Cultura №17. Facultad de Periodismo y Comunicación Social, UNLP. Pp. 21 a 35

MARRADI, A., ARCHENTI, N. y PIOVANI, J (2007); Metodología de las Ciencias Sociales. Emecé, Buenos Aires. Capitulo 5: El diseño de la investigación. Pp. 71 a 86

GARZA MERCADO, Ario (1981); Manual de Técnicas de Investigación. 3ra. Edición. Editorial El Colegio de México. México. El Plan de Trabajo. 
MARRADI, A., ARCHENTI, N. y PIOVANI, J (2007); Metodología de las Ciencias Sociales. Emecé, Buenos Aires. Capitulo 14: Estudio de caso/s. Pp. 237 a 246

ROJAS SORIANO, Raúl (1996); Guía para realizar investigaciones sociales. Plaza y Valdés, México, 1996. Capítulo IV. Planteamiento del Problema. Pp. 49 a 60

WAINERMAN, C. y SAUTU, R (Comp.) (2011); La trastienda de la investigación. Edit. Manantial, Buenos Aires. Errores comunes en la formulación de investigaciones sociales. Págs. 8 a 12.

YIN, Robert K. (2003); Investigación sobre estudio de casos: Diseño y métodos. Segunda Edición. Applied social research methods series, volume 5. SAGE Publications, International Educational and Professional Publisher Thousand Oaks, London, New Delhi. 